\title{
ESTIMATIVA DA PRODUÇÃO PRIMÁRIA E BIOMASSA FITOPLANCTÔNICA ATRAVÉS DE SENSORIAMENTO REMOTO DA COR DO OCEANO E DADOS IN SITU NA COSTA SUDESTE BRASILEIRA
}

\begin{abstract}
Tese de doutorado apresentada ao Instituto Oceanográfico da Universidade de São Paulo, como parte dos requisitos para obtenção do título de Doutor em Ciências, área de Oceanografia Biológica
\end{abstract}

Orientador:

Prof. Dr. Salvador Airton Gaeta

Versão revisada

São Paulo 



\title{
UNIVERSIDADE DE SÃO PAULO INSTITUTO OCEANOGRÁFICO
}

\author{
ESTIMATIVA DA PRODUÇÃO PRIMÁRIA E BIOMASSA \\ FITOPLANCTÔNICA ATRAVÉS DE SENSORIAMENTO REMOTO DA COR \\ DO OCEANO E DADOS IN SITU NA COSTA SUDESTE BRASILEIRA
}

\author{
Milton Kampel
}

Dissertação apresentada ao Instituto Oceanográfico da Universidade de São Paulo, como parte dos requisitos para obtenção do título de Doutor em Ciências, área de Oceanografia Biológica.

APROVADA EM 12/11/2003 POR:

Dr Salvador A. Gaeta

Dr João A. Lorenzzetti

Dr Frederico P. Brandini

Dra Eliane Gonzalez-Rodriguez

Dra Rosane Gonçalves Ito 

"O céu, azul de luz quieta

As ondas brandas a quebrar,

Na praia lúcida e completa -

Pontos de dedos a brincar.

No piano anônimo da praia

Tocam nenhuma melodia

De cujo ritmo por fim seria

Todo o sentido deste dia.

Que bom, se isto satisfizesse!

Que certo, se eu pudesse crer

Que esse mar e essas ondas e esse

Céu tem vida e têm ser."

FERNANDO PESSOA

A todos aqueles que fizeram e vêm me fazendo crer que o mar, as ondas e o céu têm vida e têm ser... 

Aos meus maiores tesouros:

Silvana, Alexandre e André 



\section{AGRADECIMENTOS}

Ao Instituto Oceanográfico da Universidade de São Paulo, pela oportunidade de estudos e pela disponibilidade de suas instalações, embarcações, equipamentos, laboratórios e serviços essenciais ao desenvolvimento desta Tese.

Ao Instituto Nacional de Pesquisas Espaciais, pela oportunidade de me capacitar em nível de Doutorado.

Ao Prof. Dr. Salvador Airton Gaeta, pelo conhecimento passado, pela orientação, pelo estímulo, pelo apoio e pelos recursos colocados a minha disposição durante o período em que trabalhamos juntos.

Ao Dr. João Antônio Lorenzzetti, Dr Frederico P. Brandini, Dra Eliane GonzalezRodriguez e Dra. Rosane Gonçalves Ito, pelas sugestões apresentadas para a conclusão deste trabalho.

Ao International Ocean-Colour Coordination Group pela oportunidade em participar do curso Primary Production: Theory, Modelling and Estimation by Remote Sensing, em um momento importante do desenvolvimento deste trabalho. Aos professores deste curso, em especial ao Dr Trevor Platt e a Dr Shubba Stahyendranath, pelos ensinamentos passados e pelo novo incentivo dado ao meu desenvolvimento científico.

Aos professores do curso de Doutorado pelo conhecimento compartilhado.

Aos colegas de turma e de embarque, companheiros de IOUSP (pessoal do LIO - Luis Nonato e Wilsinho; pessoal do LADO - Ilson, Rafael, Leandro, Domingos e outros; pessoal do Mario K. - Caca, June e outros) e INPE (Eduardo, Felipe, Sydnea, João Carlos, Arcilan, Camilo, Olga, Márcia, Marcelo, Marinaldo, Paulino, Sergio, Evlyn, Epiphanio, Bernardo, Stech, Vianei, Gilberto, funcionários da gráfica, em especial ao Nicolau e outros), que sempre incentivaram o cumprimento das tarefas e etapas necessárias à conclusão deste trabalho. Em especial, aos colegas de "sala" mais chegados no IOUSP, Mayza, Lu, Mau, Tomás e Walter pelo apoio na realização deste trabalho e principalmente pelas pessoas especiais com quem convivi. Também não poderia deixar de agradecer ao Dr Ilson da Silveira, responsável pelo processamento dos dados hidrográficos utilizados neste trabalho.

Aos funcionários do Departamento de Oceanografia Biológica, do Navio Oceanográfico Prof. Besnard, da Biblioteca e da Administração do IOUSP (em especial ao Wilson Macedo) que, direta ou indiretamente, colaboraram durante o período de elaboração desta Tese.

Ao Conselho Nacional de Desenvolvimento Científico e Tecnológico - CNPq, pelo auxilio financeiro de três anos de bolsa de estudos. 
Ao Ministério da Ciência e Tecnologia, Programa de Núcleos de Excelência (proc. 368/96) pelo fomento ao projeto Dinâmica do Ecossistema de Plataforma da Região Oeste do Atlântico Sul (DEPROAS), no qual esta Tese está inserida.

Ao SeaWiFS Project, ao Distributed Active Archive Center do Goddard Space Flight Center, EUA e ao grupo de desenvolvimento do SeaDAS, pela disponibilização e distribuição de dados, publicações e software utilizados no processamento dos dados SeaWiFS. Estas atividades são financiadas pela NASA.

Aos meus amores Silvana, Alexandre e André.

Aos meus pais, irmãs e familiares por sempre acreditarem na importância do estudo.

Agradeço a todas as pessoas que me ajudaram a vencer mais esta etapa da vida. 


\title{
ESTIMATIVA DA PRODUÇÃO PRIMÁRIA E BIOMASSA FITOPLANCTÔNICA ATRAVÉS DE SENSORIAMENTO REMOTO DA COR DO OCEANO E DADOS IN SITU NA COSTA SUDESTE BRASILEIRA
}

\begin{abstract}
RESUMO
A biomassa e a produtividade primária fitoplanctônica da costa sudeste foram estimadas através de sensoriamento remoto da cor do oceano e dados in situ. Foram realizados quatro cruzeiros hidrográficos sazonais de mesoescala nas regiões de plataforma e talude continental durante os verões e invernos de 2001 e 2002. Com a descrição das características hidrográficas e distribuições de nutrientes inorgânicos dissolvidos, complementada pela análise de imagens orbitais (AVHRR e SeaWiFS), foi possível determinar os padrões de circulação da Corrente do Brasil, monitorar ressurgências costeiras e de quebra de plataforma, meandramentos e vórtices de mesoescala, assim como, a intrusão de águas frias, menos salinas e ricas em nutrientes vindas de sul sobre a plataforma continental, no inverno. A área de estudo foi dividida nos domínios de plataforma, talude-verão e talude-inverno, baseados em análises estatísticas da biomassa e produção primária fitoplanctônica integradas na zona eufótica. O domínio de plataforma não apresentou diferença sazonal devido ao processo de intrusão da ACAS sobre a plataforma. Este foi apontado como o principal processo de fertilização da zona eufótica nas águas de plataforma e talude tanto no verão como no inverno. Imagens da produtividade primária oceânica foram geradas pela primeira vez para a costa brasileira a partir de imagens da cor do oceano (SeaWiFS), utilizando-se um algoritmo semianalítico não espectral, verticalmente homogêneo e dados fotossintéticos in situ obtidos simultaneamente. $\mathrm{O}$ avanço científico decorrente do presente trabalho é significativo, pois as estimativas de biomassa e produtividade primária fitoplanctônica através de imagens da cor do oceano e dados in situ coletados simultaneamente, ainda não haviam sido realizados na Zona Econômica Exclusiva brasileira. Comparações entre temperaturas da superfície do mar obtidas pelo AVHRR e medidas in situ (CTD) mostraram diferenças menores que $0,5^{\circ} \mathrm{C}$. O algoritmo $\mathrm{OC} 4$ apresentou o melhor desempenho entre os algoritmos testados (OC2, GSM01 e NN) para estimar a concentração de clorofila $a$, a partir de dados SeaWiFS, em relação às medidas fluorimétricas in situ, subestimando as concentrações mais baixas e superestimando as mais altas. Os algoritmos semi-analíticos de produção primária por satélite testados concordaram com as estimativas in situ $\left({ }^{14} \mathrm{C}\right)$ por um fator de 2 , nos melhores casos. As análises de regressão múltipla mostraram uma relação linear entre a produção primária e a biomassa fitoplanctônica integradas na coluna d'água. Uma abordagem alternativa baseada em uma rede neural artificial multicamada perceptron (12-5-1) foi testada como um modelo não linear para estimar a produção primária integrada na coluna d'água. A produção primária média para o período 2001-2002 foi estimada a partir de dados SeaWiFS em $386 \mathrm{gC} \mathrm{m}^{-2} \mathrm{a}^{-1}$ e a produção primária potencial para a plataforma continental sudeste brasileira (PCSE) foi estimada em $0,06 \mathrm{Gt} \mathrm{C} \mathrm{a}{ }^{-1}$. O limite superior da produção pesqueira foi estimado considerando-se uma cadeia trófica com 2,8 níveis e uma eficiência trófica média de $10 \%$. O resultado obtido foi cerca de 90 vezes maior que a captura média entre 1991 e 2000 . Porém, se a produção pesqueira estimada for um limite superior que será reduzido a $10 \%$ ou $20 \%$ devido à acessibilidade ambiental, os recursos pesqueiros estariam limitados por alimento na PCSE.
\end{abstract}





\title{
PHYTOPLANKTON PRIMARY PRODUCTION AND BIOMASS ESTIMATE WITH OCEAN COLOUR REMOTE SENSING AND IN SITU DATA ALONG THE SOUTHEASTERN BRAZILIAN COAST
}

\begin{abstract}
The phytoplankton biomass and primary production of the Southeastern Brazilian coast are estimated using ocean color remote sensing and in situ data. This study is based on four seasonal hydrographic cruises carried out during the summer and winter of 2001 and 2002, along the continental shelf and slope waters. The hydrographic and dissolved inorganic nutrients in situ measurements were complemented by the sea surface temperature from the Advanced Very High Resolution Radiometer (AVHRR) sensor and chlorophyll $a$ estimates from the Sea-viewing Wide Field-of-view Sensor (SeaWiFS) sensor to identify relevant features of the Brazil Current (BC) circulation related to the biological dynamics of this oceanic region. Several meanders and vortices were observed throughout the period along the inshore frontal zone of the $\mathrm{BC}$ in association with break shelf upwelling. Coastal upwelling events were observed to encompass a region larger than normally indicated in the literature and anomalous upwelling events were observed during the winter. Cold, less saline, and nutrient rich waters were observed flowing northward over the shelf during the winter. Based on statistical analysis of water column integrated chlorophyll and primary production the study area was divided into 3 domains: shelf, summer-slope, and winter-slope. The shelf domain did not present a significant seasonal difference due to the intrusion of South Atlantic Central Water over the shelf. This intrusion is the main process for the euphotic zone productivity enhancement in the shelf and slope waters during the summer and winter. A non-spectral and vertically homogeneous semi-analytical algorithm was applied to the SeaWiFS ocean color data, which incorporate simultaneously measured in situ photosynthetic parameters. This is the first time that the phytoplankton primary production and biomass estimation over the Brazilian Economic Exclusive Zone were done through remote sensed ocean colour and simultaneously acquired in situ data. Comparisons between in situ measurements and AVHRR based estimates of sea surface temperature have shown differences lower than $0.5^{\circ} \mathrm{C}$. The $\mathrm{OC} 4$ algorithm performed better then other chlorophyll retrieval algorithms (OC2, GSM01 and NN) when compared with in situ fluorometric data. However, it overestimates chlorophyll $a$ at higher concentrations and underestimates at lower concentration. The best performing ocean colour remote sensing primary productivity algorithms tested agreed with the ${ }^{14} \mathrm{C}$ based estimates within a factor of 2. A multiple regression analysis showed linear relation between the water column integrated primary production and the integrated chlorophyll. An alternative approach based on a backpropagation multilayer perceptron artificial neural network (12-5-1) was tested to estimate the water column integrated primary production for non-linear phytoplankton production modeling. The mean primary production for the 2 year period in the South Brazilian Bight (SBB) estimated

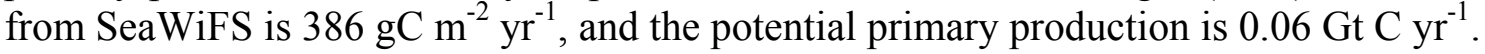
The upper bound for sustainable fish yield was estimated using a food chain of 2.8 links and an average trophic efficiency of $10 \%$. The result was $\sim 90$ times larger than the observed fish catch from 1991 through 2000. If this fish yield is an upper bound that will be decreased to $10 \%$ or $20 \%$ by environmental accessibility, the fishery resources in the SBB are likely to be food-limited.
\end{abstract}





\section{SUMÁRIO}

Pág.

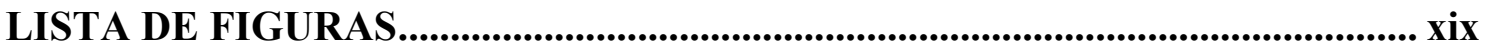

LISTA DE TABELAS ...................................................................................... $\mathrm{xxV}$

LISTA DE SÍMBOLOS ...........................................................................................

LISTA DE SIGLAS E ABREVIATURAS ................................................................. xxxi

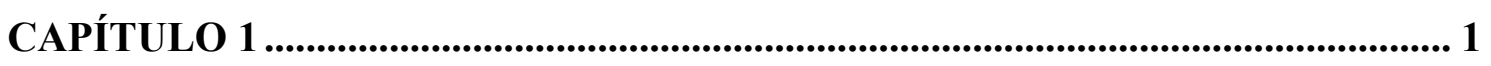

INTRODUÇÃ

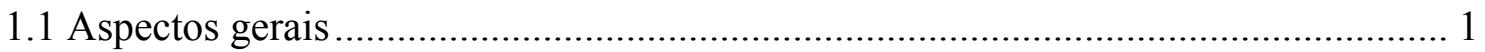

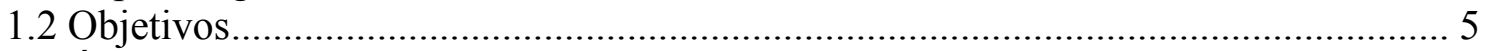

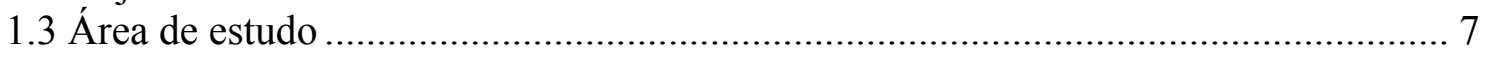

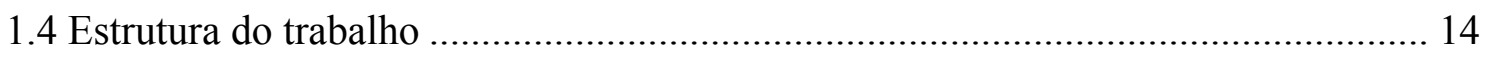

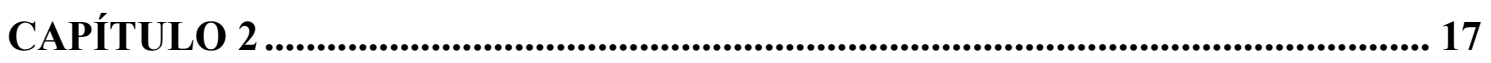

MATERIAL E MÉTODOS ................................................................................... 17

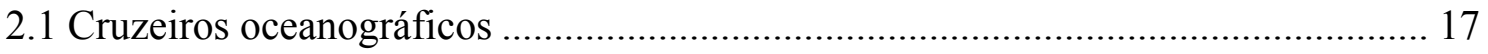

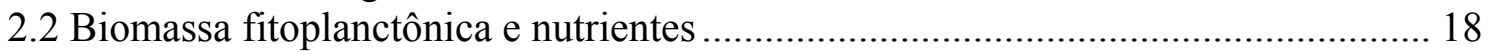

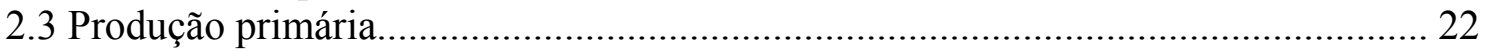

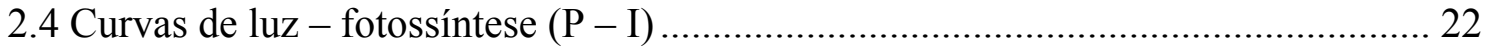

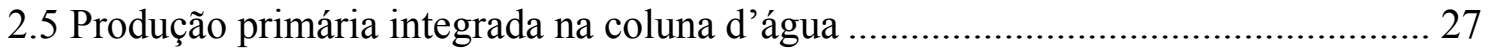

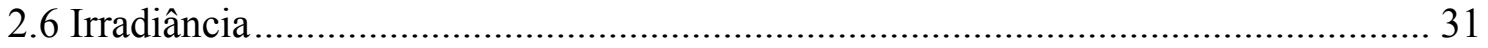

2.7 Imagens de Temperatura da Superfície do Mar (TSM)......................................... 33

2.8 Imagens da Concentração de Clorofila da Superfície do Mar (CSM)...................... 35

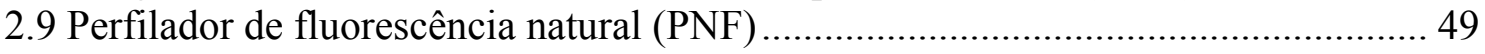

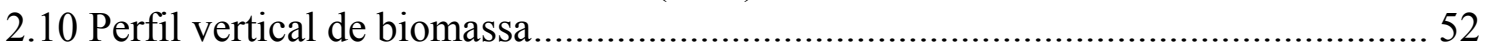

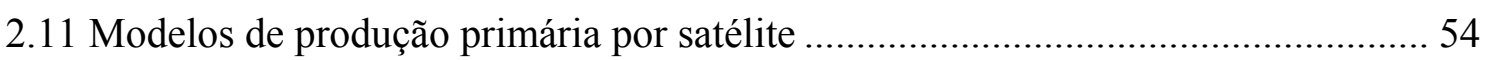

2.11.1 Modelo de produtividade de Bedford - Verticalmente homogêneo, não espectral -

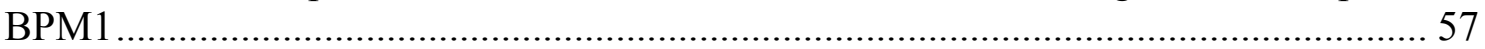

2.11.2 Modelo de produtividade de Bedford - Perfil vertical de biomassa não uniforme,

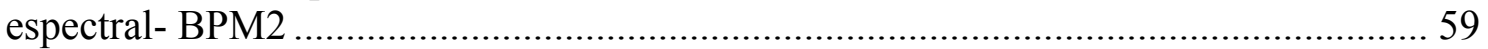

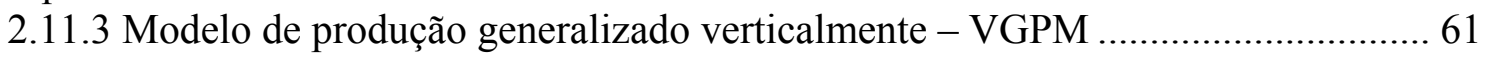

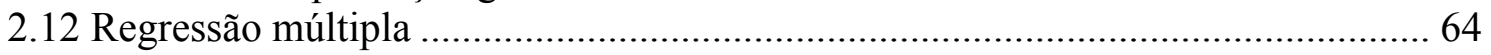

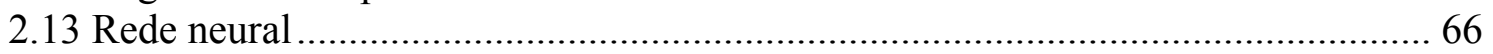

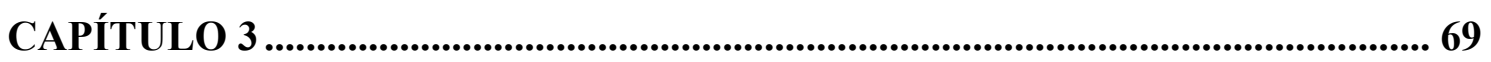

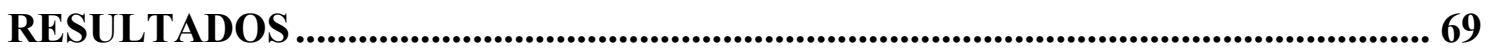

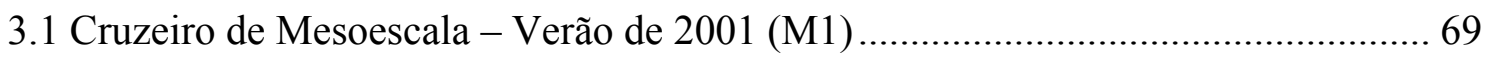

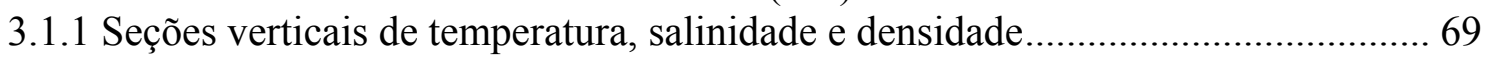

3.1.2 Seções verticais de clorofila- $a$, nitrato e produção primária ................................ 73

3.1.2.1 Curvas de luz - fotossíntese ........................................................................ 76

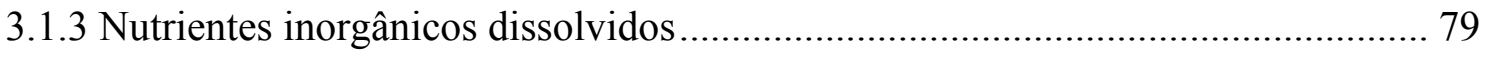


3.1.4 Imagens de Temperatura da Superfície do Mar.... 82

3.1.5 Imagens de Concentração de Clorofila da Superfície do Mar............................... 85

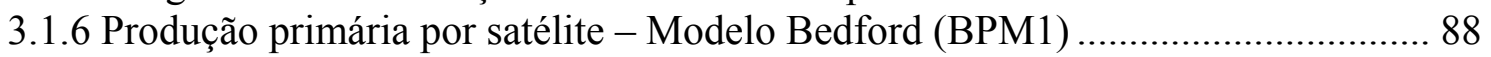

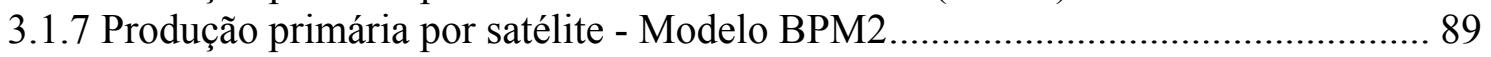

3.1.8 Produção primária por satélite - Modelo VGPM ............................................... 90

3.2 Cruzeiro de Mesoescala - Inverno de 2001 (M2) ..................................................... 91

3.2.1 Seções verticais de temperatura, salinidade e densidade...................................... 91

3.2.2 Seções verticais de clorofila- $a$, nitrato e produção primária ................................ 95

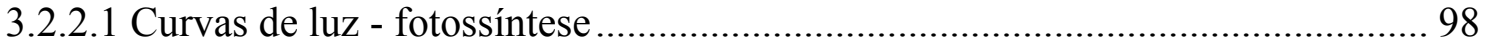

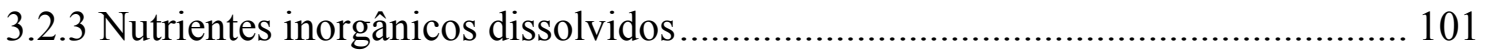

3.2.4 Imagens de Temperatura da Superfície do Mar.................................................... 104

3.2.5 Imagens de Concentração de Clorofila da Superfície do Mar............................. 107

3.2.6 Produção primária por satélite - Modelo Bedford (BPM1) ................................. 109

3.2.7 Produção primária por satélite - Modelo Bedford BPM2 ................................. 110

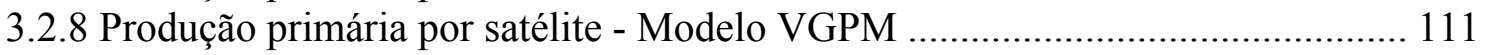

3.3 Cruzeiro de Mesoescala - Verão de 2002 (M3) ....................................................... 112

3.3.1 Distribuições horizontais de temperatura e salinidade ...................................... 112

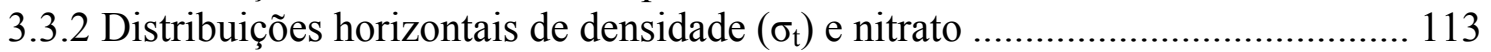

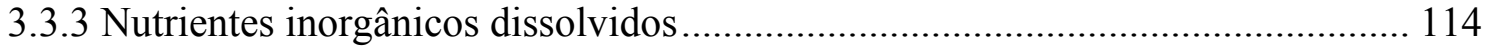

3.3.4 Distribuições horizontais de clorofila $a$ e produtividade primária ..................... 119

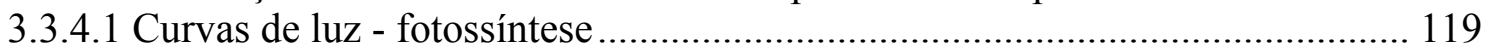

3.3.5 Imagens de Temperatura da Superfície do Mar.................................................. 123

3.3.6 Imagens de Concentração de Clorofila da Superfície do Mar............................. 126

3.3.7 Produção primária por satélite - Modelo Bedford (BPM1) ................................ 126

3.3.8 Produção primária por satélite - Modelo Bedford BPM2 …............................. 128

3.3.9 Produção primária por satélite - Modelo VGPM ................................................ 129

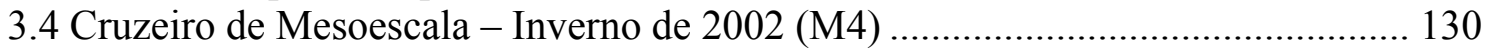

3.4.1 Distribuições horizontais de temperatura e salinidade .................................... 130

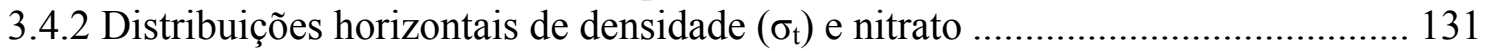

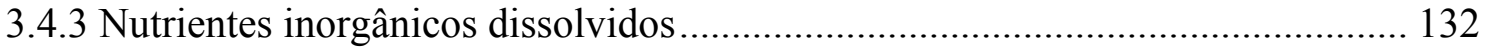

3.4.4 Distribuições horizontais de clorofila $a$ e produtividade primária ..................... 137

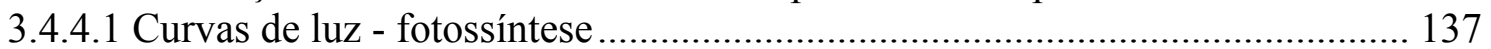

3.4.5 Imagens de Temperatura da Superfície do Mar.................................................... 140

3.4.6 Imagens de Concentração de Clorofila da Superfície do Mar.............................. 145

3.4.7 Produção primária por satélite - Modelo Bedford (BPM1) ................................. 149

3.4.8 Produção primária por satélite - Modelo Bedford BPM2 …............................... 151

3.4.9 Produção primária por satélite - Modelo VGPM .............................................. 152

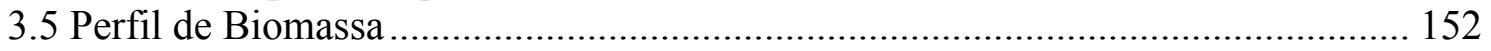

3.6 Comparação entre dados in situ e dados de satélites ............................................ 154

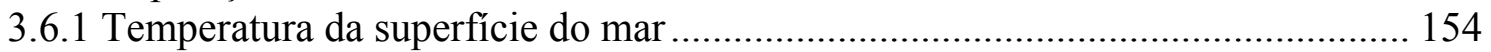

3.6.2 Concentração de Clorofila da Superfície do Mar ................................................ 157

3.7 Produção Primária Estimada pelo PNF ................................................................. 165

3.8 Testes estatísticos para agrupamento dos dados.................................................... 173

3.8.1 Teste de hipótese para agrupamento dos cruzeiros M1-M3 e M2-M4 ................. 173

3.8.2 Teste de hipótese para agrupamento verão-inverno ......................................... 175

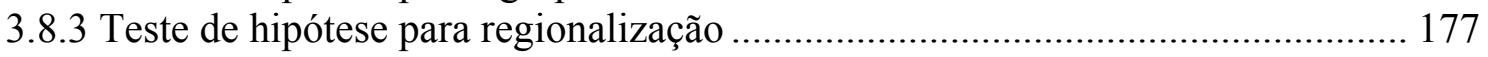




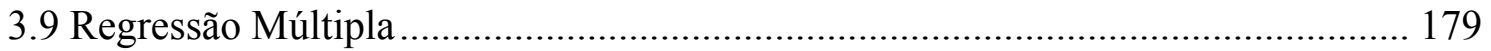

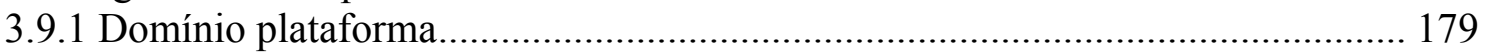

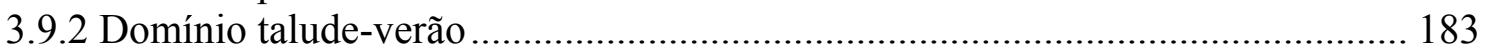

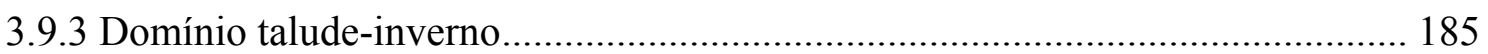

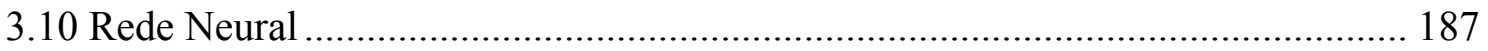

3.11 Comparações entre as estimativas da produção primária diária integrada ............ 190

3.11.1 Produção primária diária integrada in situ e Modelo Bedford 1 (BPM1) ......... 190

3.11.2 Produção primária diária integrada in situ e Modelo Bedford 2 (BPM2) ......... 192

3.11.3 Produção primária diária integrada in situ e Modelo VGPM ............................ 193

3.11.4 Produção primária diária integrada in situ a 100\% e 1\% de irradiância............. 195

3.12 Imagens da produtividade primária oceânica (PPO) ......................................... 197

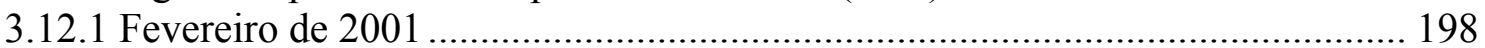

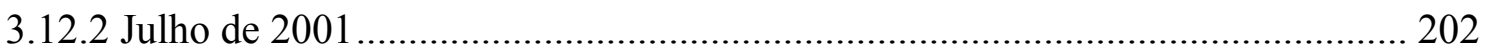

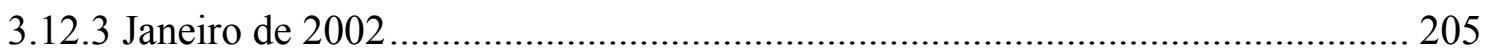

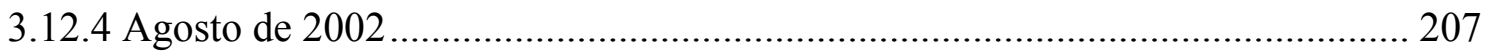

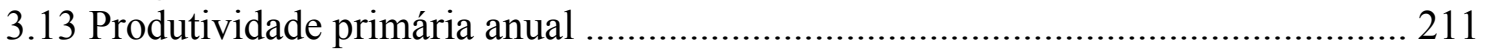

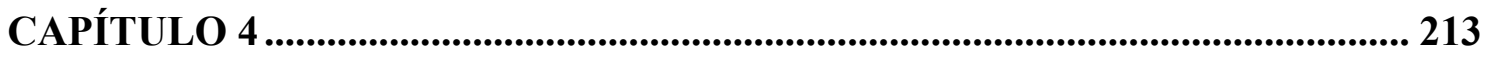

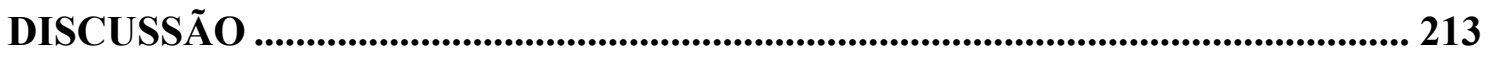

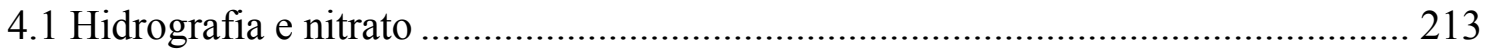

4.2 Biomassa e produtividade primária fitoplanctônica ............................................ 219

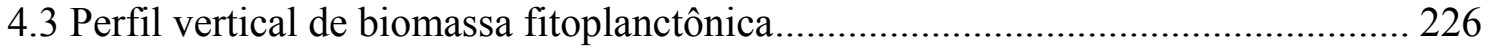

4.4 Comparação entre dados in situ e dados de satélites ............................................ 228

4.4.1 Temperatura da superfície do mar (TSM) ............................................................ 228

4.4.2 Concentração de clorofila da superfície do mar (CSM) ..................................... 230

4.5 PNF 233

4.6 Testes estatísticos para agrupamento de dados ................................................... 235

4.7 Regressão múltipla e Rede neural ................................................................. 238

4.8 Comparações entre as estimativas da produção primária diária integrada ............. 241

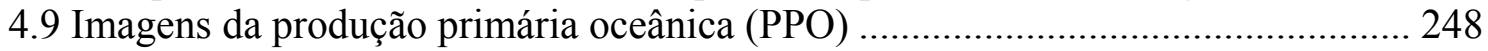

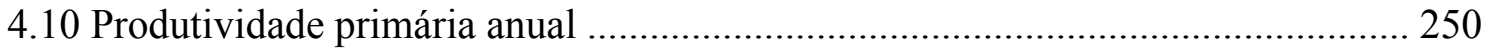

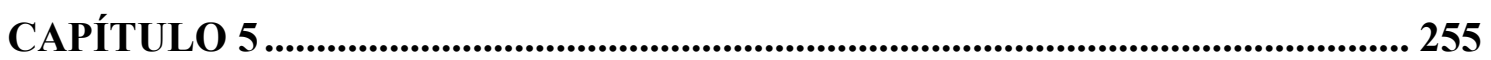

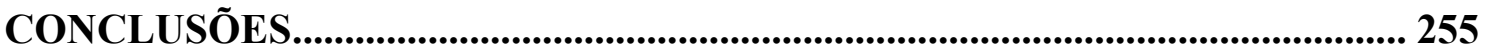

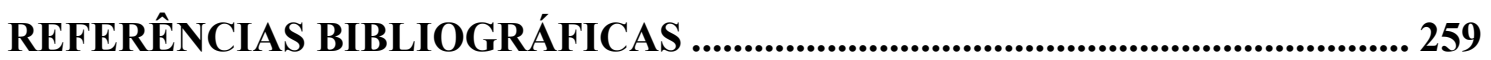




\section{LISTA DE FIGURAS}

Figura 1.1 - Batimetria da plataforma continental sudeste brasileira e área oceânica adjacente (valores em metros).

Figura 1.2 - Circulação superficial do Atlântico Sul (adaptado de Peterson e Stramma, 1991).

Figura 2.1 - Cruzeiro de mesoescala do projeto DEPROAS realizado entre 7/2/2001 e 13/2/2001 (M1). Experimentos de produção primária $\left({ }^{14} \mathrm{C}\right)$ em azul. Isóbatas de $100,200,500,1000$ e 2000 em metros.

Figura 2.2 - Cruzeiro de mesoescala do projeto DEPROAS realizado entre 12/7/2001 e 19/7/2001 (M2). Experimentos de produção primária $\left({ }^{14} \mathrm{C}\right)$ em azul. Isóbatas de $100,200,500,1000$ e 2000 em metros.

Figura 2.3 - Cruzeiro de mesoescala do projeto DEPROAS realizado entre 5/1/2002 e 24/1/2002 (M3). Experimentos de produção primária $\left({ }^{14} \mathrm{C}\right)$ em azul. Isóbatas de $100,200,500,1000$ e 2000 em metros.

Figura 2.4 - Cruzeiro de mesoescala do projeto DEPROAS realizado entre 3/8/2002 e 21/8/2002 (M4). Experimentos de produção primária $\left({ }^{14} \mathrm{C}\right)$ em azul. Isóbatas de $100,200,500,1000$ e 2000 em metros.

Figura 2.5 - Curva de luz - fotossíntese (linha contínua) ajustada a um conjunto idealizado de dados de produção primária normalizada pela biomassa (adaptado de Jassby e Platt, 1986).

Figura 2.6 - Fluxograma descrevendo os passos necessários no cálculo da produção primária a uma dada profundidade na coluna d'água.

Figura 2.7 - Fluxograma dos passos envolvidos no cálculo da produção primária diária integrada na coluna d'água (adaptado de Platt e Sathyendranath, 2002).............. 30

Figura 2.8 - Funções de ativação ou transferência mais utilizadas em redes neurais artificiais. (a) Função sigmóide; (b) Função tangente hipérbólica.

Figura 2.9 - Rede de Múltiplas Camadas (Adapatado de Haykin, 1994).

Figura 2.10 - Padrões linearmente separáveis: dados que caem em lados opostos do hiperplano e podem ser separados por uma linha reta. Os padrões que não pertencem à determinada classe, mas que foram a ela designadas, são minoria e representam uma porcentagem de erro admissível (Fonte: Bishop, 1995).....

Figura 2.11 - Padrões não linearmente separáveis: padrões que caem em determinadas posições do hiperplano que não podem ser separados por uma linha reta. Soluções não lineares, normalmente, apresentam percentuais de erro na classificação inferiores à soluções lineares para a grande maioria dos problemas ( Fonte: Bishop, 1995).

Figura 2.12 - Arquitetura Multicamadas Perceptron com duas camadas escondidas (Adapatada de Haykin, 1994).

Figura 2.13 - Modelo de curva de Gauss-deslocada para o perfil vertical de biomassa (adaptado de Platt et al., 1994)

Figura 2.14 - Um exemplo de perfil de biomassa (esquerda), o campo de luz submarina correspondente (centro) e o perfil de produção calculado com um modelo nãoespectral (adaptado de Platt e Sathyendranath, 2002). 
Figura 2.15 - Relação usada por Behrenfeld e Falkowski (1997a) para estimar $P_{\text {opt }}{ }^{B}$ a partir da temperatura da superfície do mar.

Figura 3.1 - Seções verticais de temperatura $\left({ }^{\circ} \mathrm{C}\right)$ radiais à costa em Cabo Frio, RJ, realizadas durante o verão de 2001 (M1).

Figura 3.2 - Seções verticais de salinidade radiais à costa em Cabo Frio, RJ, realizadas durante o verão de 2001 (M1).

Figura 3.3 - Seções verticais de $\sigma_{\mathrm{t}}\left(\mathrm{kg} . \mathrm{m}^{-3}\right)$ radiais à costa em Cabo Frio, RJ, realizadas durante o verão de 2001 (M1).

Figura 3.4 - Seções verticais de clorofila $\left(\mathrm{mg} . \mathrm{m}^{-3}\right)$ radiais à costa em Cabo Frio, RJ, realizadas durante o verão de 2001 (M1).

Figura 3.5 - Seções verticais de nitrato $(\mu \mathrm{M})$ radiais à costa em Cabo Frio, RJ, realizadas durante o verão de 2001 (M1).

Figura 3.6 - Seções verticais de produção primária $\left(\mathrm{mgC} \cdot \mathrm{m}^{-3} \cdot \mathrm{h}^{-1}\right)$ radiais à costa em Cabo Frio, RJ, realizadas durante o verão de 2001 (M1). Profundidade da camada de mistura indicada pela linha tracejada.

Figura 3.7 - Diagramas de dispersão dos nutrientes inorgânicos dissolvidos $(\mu \mathrm{M}) \mathrm{em}$ função de $\sigma_{\mathrm{t}}\left(\mathrm{kg} \cdot \mathrm{m}^{-3}\right)$, para o cruzeiro de verão de 2001 (M1). A linha tracejada indica o limite isopicnal inferior da Água Central do Atlântico Sul.

Figura 3.8 - Imagens da temperatura da superfície do mar referentes aos dias 01 (esquerda em cima), 12 (esquerda embaixo), 13 (direita em cima) e 14 (direita embaixo) de fevereiro de 2001. Isóbatas de 100, 200 e $1.000 \mathrm{~m}$ em preto.

Figura 3.9 - Imagens da temperatura da superfície do mar referentes aos dias 18 (esquerda em cima), 19 (esquerda embaixo), 20 (direita em cima) e 25 (direita embaixo) de fevereiro de 2001. Isóbatas de 100, 200 e $1.000 \mathrm{~m}$ em preto.

Figura 3.10 - Imagens da concentração de clorofila da superfície do mar referentes aos dias 1 (esquerda em cima), 8 (esquerda embaixo), 13 (direita em cima) e 14 (direita embaixo) de fevereiro de 2001. Isóbatas de 500, 1.000, 2.000, 3.000 e $4.000 \mathrm{~m} \mathrm{em}$ preto. Tabela de cores em escala logarítmica.

Figura 3.11 - Imagens da concentração de clorofila da superfície do mar referentes aos dias 15 (esquerda em cima), 17 (esquerda embaixo), 18 (direita em cima) e 19 (direita embaixo) de fevereiro de 2001. Isóbatas de 500, 1.000, 2.000, $3.000 \mathrm{e}$ $4.000 \mathrm{~m}$ em preto. Tabela de cores em escala logarítmica.

Figura 3.12 - Seções verticais de temperatura $\left({ }^{\circ} \mathrm{C}\right)$ radiais à costa em Cabo Frio, RJ, realizadas durante o inverno de 2001 (M2).

Figura 3.13 - Seções verticais de salinidade radiais à costa em Cabo Frio, RJ, realizadas durante o inverno de 2001 (M2).

Figura 3.14 - Seções verticais de $\sigma_{\mathrm{t}}\left(\mathrm{kg} . \mathrm{m}^{-3}\right)$ radiais à costa em Cabo Frio, RJ, realizadas durante o inverno de 2001 (M2).

Figura 3.15 - Seções verticais de clorofila $\left(\mathrm{mg} . \mathrm{m}^{-3}\right)$ radiais à costa em Cabo Frio, RJ, realizadas durante o inverno de 2001 (M2).

Figura 3.16 - Seções verticais de nitrato $(\mu \mathrm{M})$ radiais à costa em Cabo Frio, RJ, realizadas durante o inverno de 2001 (M2).

Figura 3.17 - Seções verticais de produção primária $\left(\mathrm{mgC} \cdot \mathrm{m}^{-3} \cdot \mathrm{h}^{-1}\right)$ radiais à costa em Cabo Frio, RJ, realizadas durante o inverno de 2001 (M2). Profundidade da camada de mistura indicada pela linha tracejada. 
Figura 3.18 - Diagramas de dispersão dos nutrientes inorgânicos dissolvidos $(\mu \mathrm{M}) \mathrm{em}$ função de $\sigma_{\mathrm{t}}\left(\mathrm{kg} \cdot \mathrm{m}^{-3}\right)$, para o cruzeiro de inverno de 2001 (M2). A linha tracejada indica o limite isopicnal inferior da Água Central do Atlântico Sul.

Figura 3.19 - Imagens da temperatura da superfície do mar referentes aos dias 8 (esquerda em cima), 10 (esquerda embaixo), 11 (direita em cima) e 17 (direita embaixo) de julho de 2001. Isóbatas de 100, 200 e $1.000 \mathrm{~m}$ em preto.

Figura 3.20 - Imagens da temperatura da superfície do mar referentes aos dias 18 (esquerda em cima), 19 (esquerda embaixo), 20 (direita em cima) e 25 (direita embaixo) de julho de 2001. Isóbatas de 100, 200 e $1.000 \mathrm{~m}$ em preto.

Figura 3.21 - Imagens da concentração de clorofila da superfície do mar referentes aos dias 7 (esquerda em cima), 8 (esquerda embaixo), 10 (direita em cima) e 15 (direita embaixo) de julho de 2001. Isóbatas de 500, 1.000, 2.000, 3.000 e $4.000 \mathrm{~m}$ em preto. Tabela de cores em escala logarítmica.

Figura 3.22 - Imagens da concentração de clorofila da superfície do mar referentes aos dias 16 (esquerda em cima), 17 (esquerda embaixo), 19 (direita em cima) e 21 (direita embaixo) de julho de 2001. Isóbatas de 500, 1.000, 2.000, 3.000 e $4.000 \mathrm{~m}$ em preto. Tabela de cores em escala logarítmica. 109

Figura 3.23 - Distribuições horizontais de temperatura $\left({ }^{\circ} \mathrm{C}\right)$ e salinidade a $0,25,50,75$ e $100 \mathrm{~m}$ de profundidade durante o cruzeiro de verão de 2002 (M3). 115

Figura 3.24 - Distribuições horizontais de densidade $\left(\mathrm{kg} \cdot \mathrm{m}^{-3}\right)$ e nitrato $(\mu \mathrm{M})$ a $0,25,50$, 75 e $100 \mathrm{~m}$ de profundidade durante o cruzeiro de verão de 2002 (M3). ............ 116

Figura 3.25 - Diagramas de dispersão dos nutrientes inorgânicos dissolvidos $(\mu \mathrm{M}) \mathrm{em}$ função de $\sigma_{\mathrm{t}}\left(\mathrm{kg} \cdot \mathrm{m}^{-3}\right)$, para o cruzeiro de verão de 2002 (M3). A linha tracejada indica o limite isopicnal inferior da Água Central do Atlântico Sul.

Figura 3.26 - Distribuições horizontais de clorofila $a$ superficial $\left(\mathrm{mg} \cdot \mathrm{m}^{-3}\right)$ e integrada na zona eufótica $\left(\mathrm{mg} . \mathrm{m}^{-2}\right)$, produtividade primária integrada na zona eufótica $\left(\mathrm{gC} . \mathrm{m}^{-}\right.$

$\left.{ }^{2} \cdot \mathrm{d}^{-1}\right)$ referente aos níveis de $100 \%$ e $1 \%$ de irradiância (M3).

Figura 3.27 - Imagens da temperatura da superfície do mar referentes aos dias 2 (esquerda em cima), 5 (esquerda embaixo), 9 (direita em cima) e 15 (direita embaixo) de janeiro de 2002. Isóbatas de 100, 200 e $1.000 \mathrm{~m}$ em preto.

Figura 3.28 - Imagens da temperatura da superfície do mar referentes aos dias 21 (esquerda em cima), 22 (esquerda embaixo), 26 (direita em cima) e 31 (direita embaixo) de janeiro de 2002. Isóbatas de 100, 200 e $1.000 \mathrm{~m}$ em preto.

Figura 3.29 - Imagens da concentração de clorofila da superfície do mar referentes aos dias 3 (esquerda em cima), 21 (esquerda embaixo), 27 (direita em cima) e 28 (direita embaixo) de janeiro de 2002. Isóbatas de 500, 1.000, 2.000, 3.000 e 4.000 $\mathrm{m}$ em preto. Tabela de cores em escala logarítmica.

Figura 3.30 - Distribuições horizontais de temperatura $\left({ }^{\circ} \mathrm{C}\right)$ e salinidade a $0,25,50,75$ e $100 \mathrm{~m}$ de profundidade durante o cruzeiro de inverno de 2002 (M4).

Figura 3.31 - Distribuições horizontais de densidade $\left(\mathrm{kg}^{-3} \mathrm{~m}^{-3}\right)$ e nitrato $(\mu \mathrm{M})$ a $0,25,50$, 75 e $100 \mathrm{~m}$ de profundidade durante o cruzeiro de inverno de 2002 (M4)......... 134

Figura 3.32 - Diagramas de dispersão dos nutrientes inorgânicos dissolvidos $(\mu \mathrm{M}) \mathrm{em}$ função de $\sigma_{\mathrm{t}}\left(\mathrm{kg} \cdot \mathrm{m}^{-3}\right)$, para o cruzeiro de inverno de 2002 (M4). A linha tracejada indica o limite isopicnal inferior da Água Central do Atlântico Sul. 
Figura 3.33 - Distribuições horizontais de clorofila $a$ superficial $\left(\mathrm{mg} \cdot \mathrm{m}^{-3}\right)$ e integrada na zona eufótica $\left(\mathrm{mg} . \mathrm{m}^{-2}\right)$, produtividade primária integrada na zona eufótica $\left(\mathrm{gC} . \mathrm{m}^{-}\right.$

$\left.{ }^{2} \cdot \mathrm{d}^{-1}\right)$ referente aos níveis de $100 \%$ e $1 \%$ de irradiância (M4).

Figura 3.34 - Imagens da temperatura da superfície do mar referentes aos dias 25 de julho (esquerda em cima), 7 (esquerda embaixo), 8 (direita em cima) e 12 (direita embaixo) de agosto de 2002. Isóbatas de 100, 200 e $1.000 \mathrm{~m}$ em preto.

Figura 3.35 - Imagens da temperatura da superfície do mar referentes aos dias 13 (esquerda em cima), 19 (esquerda embaixo), 20 (direita em cima) e 21 (direita embaixo) de agosto de 2002. Isóbatas de 100, 200 e $1.000 \mathrm{~m}$ em preto.

Figura 3.36 - Imagens da temperatura da superfície do mar referentes aos dias 24 (esquerda em cima), 25 (esquerda embaixo), 28 (direita em cima) e 29 (direita embaixo) de agosto de 2002. Isóbatas de 100, 200 e $1.000 \mathrm{~m}$ em preto.

Figura 3.37 - Imagens da concentração de clorofila da superfície do mar referentes aos dias 29 de julho (esquerda em cima), 8 (esquerda embaixo), 13 (direita em cima) e 14 (direita embaixo) de agosto de 2002. Isóbatas de 500, 1.000, 2.000, $3.000 \mathrm{e}$ $4.000 \mathrm{~m}$ em preto. Tabela de cores em escala logarítmica.

Figura 3.38 - Imagens da concentração de clorofila da superfície do mar referentes aos dias 17 (esquerda em cima), 19 (esquerda embaixo), 20 (direita em cima) e 21 (direita embaixo) de agosto de 2002. Isóbatas de 500, 1.000, 2.000, 3.000 e 4.000 $\mathrm{m}$ em preto. Tabela de cores em escala logarítmica.

Figura 3.39 - Imagens da concentração de clorofila da superfície do mar referentes aos dias 22 (esquerda em cima), 24 (esquerda embaixo), 25 (direita em cima) e 26 (direita embaixo) de agosto de 2002. Isóbatas de 500, 1.000, 2.000, 3.000 e 4.000 $\mathrm{m}$ em preto. Tabela de cores em escala logarítmica.

Figura 3.40 - Diagrama de dispersão das temperaturas obtidas por satélite

(AVHRR/NOAA) versus a temperatura da superfície do mar medida in situ, para o período de verão (em cima), inverno (meio) e verão + inverno (embaixo).

Figura 3.41 - Histograma da distribuição de freqüência dos valores de Log (clorofila $a$ ) do período de verão $(n=37)$.

Figura 3.42 - Diagrama de dispersão das clorofilas obtidas por satélite (SeaWiFS) versus a clorofila da superfície do mar medida in situ, para o período de verão (OC4 esquerda em cima, OC2 esquerda embaixo, GSM01 direita em cima, NN direita embaixo).

Figura 3.43 - Histograma da distribuição de freqüência dos valores de $\log ($ clorofila $a$ ) do período de verão $(n=80)$.

Figura 3.44 - Diagrama de dispersão das clorofilas obtidas por satélite (SeaWiFS) versus a clorofila da superfície do mar medida in situ, para o período de inverno (OC4 esquerda em cima, OC2 esquerda embaixo, GSM01 direita em cima, NN direita embaixo).

Figura 3.45 - Histograma da distribuição de freqüência dos valores de Log (clorofila $a$ ) do conjunto completo de dados $(n=118)$.

Figura 3.46 - Diagrama de dispersão das clorofilas obtidas por satélite (SeaWiFS) versus a clorofila da superfície do mar medida in situ, para o conjunto completo de dados (OC4 esquerda em cima, OC2 esquerda embaixo, GSM01 direita em cima, $\mathrm{NN}$ direita embaixo). 
Figura 3.47 - Perfis verticais de clorofila $\left(\mathrm{mg} \cdot \mathrm{m}^{-3}\right)$ e produção primária instantânea $\left(\mathrm{mgC} \cdot \mathrm{m}^{-3} \cdot \mathrm{h}^{-1}\right)$ medidos pelo PNF (linha tracejada) e in situ (linha contínua) nas estações 6901 (100\%, lado esquerdo) e 6892 (1\%, lado direito).

Figura 3.48 - Perfis verticais de clorofila $\left(\mathrm{mg} \cdot \mathrm{m}^{-3}\right)$ e produção primária instantânea $\left(\mathrm{mgC} \cdot \mathrm{m}^{-3} \cdot \mathrm{h}^{-1}\right)$ medidos pelo PNF (linha tracejada) e in situ (linha contínua) nas estações 7060 (100\%, lado esquerdo) e 7071 (1\%, lado direito).

Figura 3.49 - Perfis verticais de clorofila $\left(\mathrm{mg} . \mathrm{m}^{-3}\right)$ e produção primária instantânea $\left(\mathrm{mgC} \cdot \mathrm{m}^{-3} \cdot \mathrm{h}^{-1}\right)$ medidos pelo PNF (linha tracejada) e in situ (linha contínua) nas estações 7097 (100\%, lado esquerdo) e 7116 (1\%, lado direito).

Figura 3.50 - Perfis verticais de clorofila $\left(\mathrm{mg}^{-\mathrm{m}^{-3}}\right)$ e produção primária instantânea $\left(\mathrm{mgC} \cdot \mathrm{m}^{-3} \cdot \mathrm{h}^{-1}\right)$ medidos pelo PNF (linha tracejada) e in situ (linha contínua) nas estações 7300 (100\%, lado esquerdo) e 7301 (1\%, lado direito).

Figura 3.51 - Diagrama de dispersão dos coeficientes de atenuação vertical $\left(\mathrm{m}^{-1}\right)$ obtidos com o PNF $\left(\mathrm{K}_{\mathrm{PNF}}\right)$ versus os coeficientes estimados pelo disco de Secchi $\left(\mathrm{K}_{\text {Secchi }}\right)$, para o período de verão (em cima), verão + inverno (meio) e inverno (embaixo).

Figura 3.52 - Diagrama de dispersão das saídas da rede neural versus a produção primária integrada na zona eufótica para o modelo 12-5-1, utilizando o conjunto de dados para validação $(\mathrm{n}=22)$.

Figura 3.53 - Diagrama de dispersão das saídas da rede neural versus a produção primária integrada na zona eufótica medida in situ para o modelo 12-5-1, utilizando o conjunto total de pontos $(n=67)$.

Figura 3.54 - Diagramas de dispersão entre as produções primárias diárias integradas na coluna d'água in situ versus as estimativas do modelo BPM1, nos domínios de plataforma (lado esquerdo) e talude-inverno (lado direito), zona eufótica em cima e primeira profundidade óptica embaixo.

Figura 3.55 - Diagrama de dispersão entre a produção primária diária integrada na zona eufótica in situ versus as estimativas obtidas pelo modelo BPM1 para o conjunto completo de dados.

Figura 3.56 - Diagramas de dispersão entre as produções primárias diárias integradas na zona eufótica in situ versus as estimativas do modelo BPM2, nos domínios de plataforma (lado esquerdo em cima), talude-verão (lado esquerdo embaixo), talude-inverno (lado direito em cima) e conjunto completo (lado direito embaixo).

Figura 3.57 - Diagrama de dispersão entre a produção primária diária integrada na zona eufótica in situ versus estimativas do modelo VGPM, no domínio de plataforma.

Figura 3.58 - Diagrama de dispersão entre a profundidade da zona eufótica in situ ( $Z_{\text {EUSecchi }} \mathrm{m}$ ) e a estimada pelo modelo VGPM ( $\left.Z_{\text {EUVGPM }}\right)$ no domínio de plataforma.

Figura 3.59 - Diagramas de dispersão entre as produções primárias diárias integradas na zona eufótica para amostras dos níveis de 100\% $\left(\mathrm{PP}_{\mathrm{EU} 100}\right)$ e $1 \%\left(\mathrm{PP}_{\mathrm{Eu} 1}\right)$ de irradiância, nos domínios de plataforma (lado esquerdo em cima), talude-verão (lado esquerdo embaixo), talude-inverno (lado direito em cima) e conjunto completo (lado direito embaixo)....... 
Figura 3.60 - Imagens da produção primária oceânica $\left(\mathrm{gC} \cdot \mathrm{m}^{-2} \cdot \mathrm{d}^{-1}\right)$ da costa sudeste brasileira referentes aos dias 1 (esquerda em cima), 3 (esquerda embaixo), 13 (direita em cima) e 14 (direita embaixo) de fevereiro de 2001 (continente e nuvens em branco).

Figura 3.61 - Imagens da produção primária oceânica $\left(\mathrm{gC} \cdot \mathrm{m}^{-2} \cdot \mathrm{d}^{-1}\right)$ da costa sudeste brasileira referentes aos dias 15 (esquerda em cima), 16 (esquerda embaixo), 18 (direita em cima) e 19 (direita embaixo) de fevereiro de 2001 (continente e nuvens em branco). 200

Figura 3.62 - Imagem média da produtividade primária oceânica $\left(\mathrm{gC} \cdot \mathrm{m}^{-2} \cdot \mathrm{d}^{-1}\right)$ da costa sudeste brasileira durante o mês de fevereiro de 2001 (continente e nuvens em branco).

Figura 3.63 - Imagens da produção primária oceânica $\left(\mathrm{gC} \cdot \mathrm{m}^{-2} \cdot \mathrm{d}^{-1}\right)$ da costa sudeste brasileira referentes aos dias 7 (esquerda em cima), 8 (esquerda embaixo), 10 (direita em cima) e 15 (direita embaixo) de julho de 2001 (continente e nuvens em branco).

Figura 3.64 - Imagens da produção primária oceânica $\left(\mathrm{gC} \cdot \mathrm{m}^{-2} \cdot \mathrm{d}^{-1}\right)$ da costa sudeste brasileira referentes aos dias 16 (esquerda em cima), 17 (esquerda embaixo), 19 (direita em cima) e 21 (direita embaixo) de julho de 2001 (continente e nuvens em branco)

Figura 3.65 - Imagem média da produtividade primária oceânica $\left(\mathrm{gC} \cdot \mathrm{m}^{-2} \cdot \mathrm{d}^{-1}\right)$ da costa sudeste brasileira durante o mês de julho de 2001 (continente e nuvens em branco).

Figura 3.66 - Imagens da produção primária oceânica $\left(\mathrm{gC} \cdot \mathrm{m}^{-2} \cdot \mathrm{d}^{-1}\right)$ da costa sudeste brasileira referentes aos dias 3 (esquerda em cima), 4 (esquerda embaixo), 21 (direita em cima) e 28 (direita embaixo) de janeiro de 2002 (continente e nuvens em branco).

Figura 3.67 - Imagem média da produtividade primária oceânica $\left(\mathrm{gC} \cdot \mathrm{m}^{-2} \cdot \mathrm{d}^{-1}\right)$ da costa sudeste brasileira durante o mês de janeiro de 2002 (continente e nuvens em branco)

Figura 3.68 - Imagens da produção primária oceânica $\left(\mathrm{gC} \cdot \mathrm{m}^{-2} \cdot \mathrm{d}^{-1}\right)$ da costa sudeste brasileira referentes aos dias 29/7 (esquerda em cima), 31/7 (esquerda embaixo), 7/8 (direita em cima) e 12/8 (direita embaixo) de 2002 (continente e nuvens em branco)

Figura 3.69 - Imagens da produção primária oceânica $\left(\mathrm{gC} \cdot \mathrm{m}^{-2} \cdot \mathrm{d}^{-1}\right)$ da costa sudeste brasileira referentes aos dias 19 (esquerda em cima), 22 (esquerda embaixo), 24 (direita em cima) e 25 (direita embaixo) de agosto 2002 (continente e nuvens em branco)

Figura 3.70 - Imagem média da produtividade primária oceânica $\left(\mathrm{gC}^{-2} \mathrm{~m}^{-2} \cdot \mathrm{d}^{-1}\right)$ da costa sudeste brasileira durante o mês de agosto de 2002 (continente e nuvens em branco).

Figura 4.1 - Representação esquemática da troca e mistura (entrapment) entre águas de plataforma e águas da CB induzidas por meandro ciclônico (lado esquerdo: imagem SeaWiFS; lado direito: imagem AVHRR). 


\section{LISTA DE TABELAS}

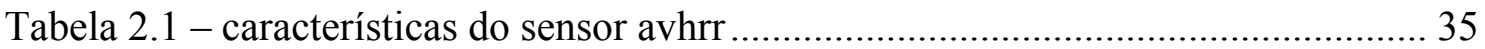

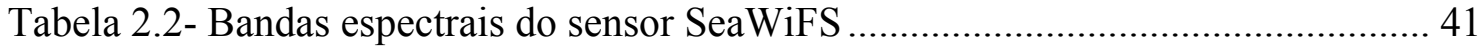

Tabela 2.3 - Características do sistemA SeaStar/SeaWiFS ......................................... 41

Tabela 2.4 - Sistema de classificação dos modelos de produtividade primária oceânica

(ppO) baseado nos níveis implícitos de integração ................................................56

Tabela 2.5 - Pesos $\Omega_{x}$ da aproximaçãopolinomial de $f\left(I_{*}^{m}\right)$ calculados para

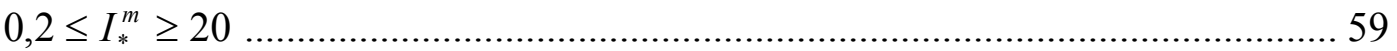

Tabela 2.6 - padrões de entrada e de saída da rede neural ............................................. 68

Tabela 3.1 - Concentrações médias de clorofila $\left(\mathrm{mg} \cdot \mathrm{m}^{-3}\right)$ durante o cruzeiro de verão de

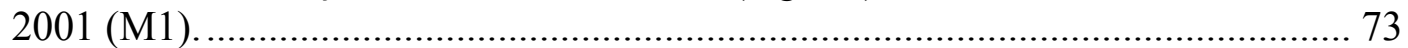

Tabela 3.2 - Parâmetros fotossintéticos das curvas de luz - fotossíntese durante o cruzeiro de verão de 2001 (M1) ...................................................................... 76

Tabela 3.3 - Produção primária durante o cruzeiro de verão de 2001 (M1).................. 77

Tabela 3.4 - Clorofila e produção primária integradas na zona eufótica sobre a plataforma e o talude durante o cruzeiro de verão de 2001 (M1)......................... 79

Tabela 3.5 - Concentração de nutrientes inorgânicos dissolvidos durante o cruzeiro de

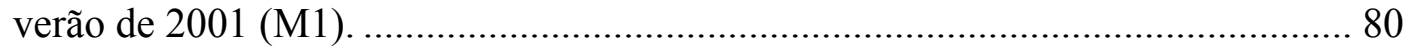

Tabela 3.6 - Médias das concentrações relativas dos compostos nitrogenados dissolvidos e da concentração absoluta do nitrogênio total durante o cruzeiro de verão de 2001 (M1).

Tabela 3.7 - Produções primárias integradas na zona eufótica, primeira profundidade óptica e camada de mistura pelo modelo BPM1 (M1)....

Tabela 3.8 - Produção primária integrada na zona eufótica calculada com o modelo BPM2 (M1).

Tabela 3.9 - Produção primária integrada na zona eufótica calculada com o modelo VGPM (M1).

Tabela 3.10 - Concentrações médias de clorofila $\left(\mathrm{mg} . \mathrm{m}^{-3}\right)$ durante o cruzeiro de inverno de 2001 (M2).

Tabela 3.11 - Parâmetros fotossintéticos das curvas de luz - fotossíntese durante o cruzeiro de Inverno de 2001 (M2).

Tabela 3.12 - Produção primária durante o cruzeiro de inverno de 2001 (M2)........... 100

Tabela 3.13 - Clorofila e produção primária integradas na zona eufótica sobre a plataforma e o talude durante o cruzeiro de inverno de 2001 (M2).

Tabela 3.14 - Concentração de nutrientes inorgânicos dissolvidos durante o cruzeiro de Inverno de 2001 (M2).

Tabela 3.15 - Médias das concentrações relativas dos compostos nitrogenados dissolvidos e da concentração absoluta do nitrogênio total durante o cruzeiro de inverno de 2001 (M2).

Tabela 3.16 - Produções primárias integradas na zona eufótica, primeira profundidade óptica e camada de mistura pelo modelo BPM1 (M2)...

Tabela 3.17 - Produção primária integrada na zona eufótica calculada com o modelo BPM2 (M2). 
Tabela 3.18 - Produção primária integrada na zona eufótica calculada com o modelo VGPM (M2).

Tabela 3.19 - Concentrações médias dos nutrientes inorgânicos dissolvidos durante o cruzeiro de verão de 2002 (M3).

Tabela 3.20 - Médias das concentrações relativas dos compostos nitrogenados dissolvidos e da concentração absoluta do nitrogênio total durante o cruzeiro de verão de 2002 (M3).

Tabela 3.21 - Parâmetros fotossintéticos das curvas de luz - fotossíntese durante o cruzeiro de verão de 2002 (M3).

Tabela 3.22 - Clorofila e produção primária integradas na zona eufótica sobre a plataforma e o talude durante o cruzeiro de verão de 2002 (M3).

Tabela 3.23 - Produções primárias integradas na zona eufótica, primeira profundidade óptica e camada de mistura pelo modelo BPM1 (M3).

Tabela 3.24 - Produção primária integrada na zona eufótica calculada com o modelo BPM2 (M3).

Tabela 3.25 - Produção primária integrada na zona eufótica calculada com o modelo VGPM (M3).

Tabela 3.26 - Concentraçôes médias dos nutrientes inorgânicos dissolvidos durante o cruzeiro de inverno de 2002 (M4).

Tabela 3.27 - Médias das concentrações relativas dos compostos nitrogenados dissolvidos e da concentração absoluta do nitrogênio total durante o cruzeiro de inverno de 2002 (M4).

Tabela 3.28 - Parâmetros fotossintéticos das curvas de luz - fotossíntese durante o cruzeiro de inverno de 2002 (M4).

Tabela 3.29 - Clorofila e produção primária integradas na zona eufótica sobre a plataforma e o talude durante o cruzeiro de inverno de 2002 (M4).

Tabela 3.30 - Produções primárias integradas na zona eufótica, primeira profundidade óptica e camada de mistura pelo modelo BPM1 (M4) ....................................... 150

Tabela 3.31 - Produção primária integrada na zona eufótica calculada com o modelo BPM2 (M4).

Tabela 3.32 - Produção primária integrada na zona eufótica calculada com o modelo VGPM (M4).

Tabela 3.33 - Parâmetros médios dos perfis verticais de biomassa (modelo gaussianodeslocado)

Tabela 3.34 - Análise de regressão linear entre as temperaturas in situ e obtidas por satélites (AVHRR).

Tabela 3.35 - Análise de regressão linear entre as clorofilas in situ e obtidas por satélite (SeaWiFS) no período de verão.

Tabela 3.36 - Análise de regressão linear entre as clorofilas in situ e obtidas por satélite (SeaWiFS) no período de inverno

Tabela 3.37 - Análise de regressão linear entre as clorofilas in situ e obtidas por satélite (SeaWiFS) para o conjunto completo de dados (verão + inverno).

Tabela 3.38 - Formulações dos algoritmos empíricos OC2 e OC4 locais.................... 164

Tabela 3.39 - Análise de regressão linear entre as clorofilas in situ e obtidas por satélite (SeaWiFS) para o conjunto completo de dados (verão + inverno). ..................... 164

Tabela 3.40 - Produção primária integrada na coluna d'água obtida com o PNF. ...... 170 
Tabela 3.41 - Coeficiente de atenuação vertical obtido com o PNF.

Tabela 3.42 - Análise de regressão linear entre oscoeficientes de atenuação vertical obtidos pelo PNF $\left(\mathrm{K}_{\mathrm{pnf}}\right)$ e pelo disco de Secchi $\left(\mathrm{K}_{\mathrm{s}}\right)$........................................ 171

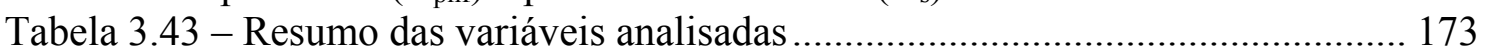

Tabela 3.44 - Variáveis físicas, químicas e biológicas calculadas para o domínio plataforma....

Tabela 3.45 - Análise de regressão múltipla para a variável dependente $\mathrm{PP}_{\mathrm{EU}}$ no domínio plataforma.

Tabela 3.46 - Análise de regressão múltipla para a variável dependente $\mathrm{C}_{\mathrm{EU}}$ no domínio plataforma.

Tabela 3.47 - Variáveis físicas, químicas e biológicas calculadas para o domínio taludeverão.

Tabela 3.48 - Análise de regressão múltipla para a variável dependente $\mathrm{PP}_{\mathrm{EU}}$ no domínio talude-verão.

Tabela 3.49 - Análise de regressão múltipla para a variável dependente $\mathrm{C}_{\mathrm{EU}}$ no domínio talude-verão.

Tabela 3.50 - Variáveis físicas, químicas e biológicas calculadas para o domínio taludeinverno.

Tabela 3.51 - Análise de regressão múltipla para a variável dependente $\mathrm{PP}_{\mathrm{EU}}$ no domínio talude-inverno.

Tabela 3.52 - Análise de regressão múltipla para a variável dependente $\mathrm{C}_{\mathrm{EU}}$ no domínio talude-inverno.

Tabela 3.53 - Análise de regressão linear entre as produções primárias diárias integradas na coluna d'água in situ e obtidas pelo modelo BPM1

Tabela 3.54 - Análise de regressão linEar entre as produções primárias diárias integradas na zona eufótica in situ e obtidas pelo modelo BPM2.

Tabela 3.55 - Análise de regressão linear entre as produções primárias diárias integradas na zona eufótica in situ e obtidas pelo modelo VGPM.

Tabela 3.56 - Análise de regressão linear entre as profundidades da zona eufótica in situ (disco de Secchi) e estimadas pelo modelo VGPM.

Tabela 3.57 - Análise de regressão linear entre as produções primárias diárias integradas na zona eufótica in situ com amostras de 100\% e 1\% de irradiância................... 196

Tabela 3.58 - Estimativas da produtividade primária anual para os domínios de plataforma e talude

Tabela 4.1 - Profundidades médias (m) da termoclina e da zona eufótica nos cruzeiros de verão e inverno.

Tabela 4.2 - Parâmetros médios e desvios padrão da curva de gauss-deslocada para os períodos de verão e inverno.

Tabela 4.3 - Análise de sensibilidade do cálculo da produção primária integrada e profundidade da zona eufótica pelo modelo bpm2 no verão.

Tabela 4.4 - Análise de sensiBILIDADE do cálculo da produção primária integrada e profundidade da zona eufótica pelo modelo bpm2 no inverno. 


\section{LISTA DE SÍMBOLOS}

$A_{E U} \quad$ - Amônia integrada na zona eufótica $\left(\mu \mathrm{M} \cdot \mathrm{m}^{-2}\right)$

$B \quad$ - Biomassa $\left(\mathrm{mg} \mathrm{m}^{-3}\right)$

$B(z)$ - Biomassa fotossinteticamente ativa, dependente da profundidade $\left(\mathrm{mg} \mathrm{m}^{-3}\right)$

$B_{0} \quad$ - Componente de fundo da curva de Gauss-deslocada $\left(\mathrm{mg} \mathrm{m}^{-3}\right)$

$C_{s a t} \quad$ - Concentração de clorofil $a$ medida pelo satélite $\left(\mathrm{mg} \mathrm{m}^{-3}\right)$

$C_{\text {insitu }}$ - Concentração de clorofila a medida in situ $\left(\mathrm{mg} \mathrm{m}^{-3}\right)$

$C(z) \quad$ - Clorofila $a$, dependente da profundidade $\left(\mathrm{mg} \mathrm{m}^{-3}\right)$

$C_{T O T}$ - Clorofila total na coluna d'água $\left(\mathrm{mg} \mathrm{m}^{-2}\right)$

$D \quad$ - Fotoperíodo (horas)

$E \quad$ - Irradiância $\left(\mathrm{W} \mathrm{m}^{-2} ; \mu \mathrm{E} \mathrm{m}^{-2} \mathrm{~h}^{-1} ; \mathrm{E} \mathrm{m}^{-2} \mathrm{~d}^{-1}\right)$

$E_{0} \quad$ - Irradiância escalar total $\left(E_{0 d}+E_{0 u}\right)\left(\mathrm{W} \mathrm{m}^{-2}\right)$

$E_{0}{ }^{m} \quad$ - Irradiância ao meio dia $\left(\mathrm{W} \mathrm{m}^{-2}\right)$

$E_{\text {opt }} \quad$ - Irradiância PAR diária total $\left(\mathrm{E} \mathrm{m}^{-2} \mathrm{~d}^{-1}\right)$

$E_{u} \quad$ - Irradiância ascendente $\left(\mathrm{W} \mathrm{m}^{-2}\right)$

$E_{d} \quad$ - Irradiância descendente $\left(\mathrm{W} \mathrm{m}^{-2}\right)$

E - Estabilidade da coluna d'água $\left(\mathrm{m}^{-1}\right)$

$\mathrm{g} \quad$ - Aceleração da gravidade $\left(\mathrm{m} \mathrm{s}^{-2}\right)$

$h$ - Parâmetro altura (amplitide) da curva de Gauss-deslocada ( $\mathrm{mg} \mathrm{m}^{-2}$ )

$I \quad$ - Irradiância na faixa PAR $\left(\mathrm{W} \mathrm{m}^{-2} ; \mu \mathrm{E} \mathrm{m}^{-2} \mathrm{~h}^{-1}\right)$

$I * \quad-\quad I / I_{k}$ (Adimensional)

$I_{0}(t) \quad$ - Irradiância superficial dependente do tempo $\left(\mathrm{W} \mathrm{m}^{-2} ; \mu \mathrm{E} \mathrm{m}^{-2} \mathrm{~h}^{-1}\right)$

$I_{c} \quad$ - Ponto de compensação ( $\mathrm{W} \mathrm{m}^{-2} ; \mu \mathrm{E} \mathrm{m}^{-2} \mathrm{~h}^{-1}$ )

$I_{0}^{m} \quad$ - Irradiância superficial máxima ao meio do dia $\left(\mathrm{W} . \mathrm{m}^{-2}\right)$

$I_{k} \quad$ - Parametro de fotoadaptação ( $\mathrm{W} \mathrm{m}^{-2} ; \mu \mathrm{E} \mathrm{m}_{-2}^{-2} \mathrm{~h}^{-1}$ )

$I_{T} \quad$ - Irradiância diária total na superfície $\left(\mathrm{W} \mathrm{m}^{-2} \mathrm{~d}^{-1}\right)$

$K \quad$ - Coeficiente vertical de atenuação da luz difusa $\left(\mathrm{m}^{-1}\right)$

$K_{d} \quad$ - Coeficiente de atenuação difusa $\left(\mathrm{m}^{-1}\right)$, da luz descendente

$K_{s} \quad$ - Coeficiente de atenuação difusa $\left(\mathrm{m}^{-1}\right)$, medido pelo disco de Secchi

$\mathrm{K}_{\mathrm{PNF}} \quad$ - Coeficiente de atenuação difusa $\left(\mathrm{m}^{-1}\right)$, medido pelo PNF

$L \quad$ - Radiância (W m ${ }^{-2} \mathrm{sr}^{-1}$ )

$L_{t} \quad$ - Radiância observada pelo satélite $\left(\mathrm{W} \mathrm{m}^{-2} \mathrm{sr}^{-1}\right)$

$L_{r} \quad$ - Radiância molecularmente espalhada pela atmosfera $\left(\mathrm{W} \mathrm{m}^{-2} \mathrm{sr}^{-1}\right)$

$L_{a} \quad$ - Radiância espalhada pelos aerossóis $\left(\mathrm{W} \mathrm{m}^{-2} \mathrm{sr}^{-1}\right)$

$L_{g} \quad$ - Radiância refletida espacularmente pela superfície da água ( $\mathrm{W} \mathrm{m}^{-2} \mathrm{sr}^{-1}$ )

$L_{w} \quad$ - Radiância ascendente da água $\left(\mathrm{W} \mathrm{m}^{-2} \mathrm{sr}^{-1}\right)$

$L_{u} \quad$ - Radiância ascendente $\left(\mathrm{W} \mathrm{m}^{-2} \mathrm{sr}^{-1}\right)$

$\mathrm{N}^{2} \quad$ - Frequência de Brünt-Väisälä $\left(\mathrm{s}^{-1}\right)$

$\mathrm{N}_{\mathrm{EU}} \quad$ - Nitrato integrado na zona eufótica $\left(\mu \mathrm{M} \cdot \mathrm{m}^{-2}\right)$

$P \quad$ - Taxa fotossintética $\left(\mathrm{mgC} \mathrm{m}^{-3} \mathrm{~h}^{-1}\right)$

$P^{B} \quad$ - Taxa de produção primária normalizada pela biomassa $\left(\mathrm{mgC} .(\mathrm{mgClo})^{-1} \cdot \mathrm{h}^{-1}\right)$

$P_{\max }^{B} \quad$ - Número de assimilação $\left(\mathrm{mgC}\left(\mathrm{mgClo}^{-1} \mathrm{~h}^{-1}\right)\right.$ 
$P P_{E U}$ - Produção primária diária integrada na zona eufótica $\left(\mathrm{gC} \mathrm{m}^{-2} \mathrm{~d}^{-1}\right)$

$P_{Z, T} \quad$ - Produção primária diária integrada na coluna d'água $\left(\mathrm{mgC} \mathrm{m}^{-2} \mathrm{~d}^{-1}\right)$

$P_{\text {opt }}^{B} \quad$ - Taxa fotossintética máxima específica da clorofila $\left(\mathrm{mgC}(\mathrm{mgClo})^{-1} \mathrm{~h}^{-1}\right)$

$R \quad$ - Respiração

$R(\lambda, z)$ - Reflectância (adimensional)

$R_{R S} \quad$ - Reflectância de sensoriamento remoto $\left(\mathrm{sr}^{-1}\right)$

$R_{25} \quad$ - Razão entre reflectâncias de sensoriamento remoto em 443 e $555 \mathrm{~nm}$ $\left(R_{R S}(443) / R_{R S}(555)\right)$

$R_{35} \quad$ - Razão entre reflectâncias de sensoriamento remoto em 490 e $555 \mathrm{~nm}$ $\left(R_{R S}(490) / R_{R S}(555)\right)$

$R_{45} \quad$ - Razão entre reflectâncias de sensoriamento remoto em 510 e 555 nm $\left(R_{R S}(510) / R_{R S}(555)\right)$

$R_{2 S} \quad-\quad \log _{10}\left(R_{35}\right)$

$R_{4 S} \quad-\quad \log _{10}\left(R_{25}>R_{35}>R_{45}\right)$, o mesmo que $R_{\max }$

$T \quad$ - Temperatura $\left({ }^{\circ} \mathrm{C} ; \mathrm{K}\right)$

$T A_{E U} \quad$ - Taxa de assimilação potencial diária $\mathrm{mgC} .(\mathrm{mgClo})^{-1} \cdot \mathrm{d}^{-1}$

TSM - Temperatura da superfície do $\operatorname{mar}\left({ }^{\circ} \mathrm{C}\right)$

$W_{\lambda} \quad$ - Excitância espectral

$Z_{E U} \quad$ - Profundidade da zona eufótica (metros), definida como 1\% da irradiância

$Z_{P} \quad$ - Profundidade da picnoclina (metros)

$Z_{T} \quad$ - Profundidade da termoclina (metros)

$Z_{M} \quad$ - Profundidade do máximo subsuperficial de clorofila (metros)

$z$ - Profundidade (metros)

$\alpha^{B} \quad$ - Inclinação inicial da curva P-I $\left(\mathrm{mgC}(\mathrm{mg} \mathrm{Clo})^{-1}\left(\mathrm{~W} \mathrm{~m}^{-2}\right)^{-1} \mathrm{~h}^{-1} ; \mathrm{mgC}(\mathrm{mg}\right.$ $\left.\mathrm{Clo})^{-1}\left(\mu \mathrm{E} \mathrm{m}^{-2}\right)^{-1} \mathrm{~h}^{-1}\right)$

$\beta$ - Parâmetro de fotoinibição

$\theta \quad$ - Ângulo zenital

$\lambda \quad$ - Comprimento de onda (nm)

$\phi \quad$ - Ângulo azimutal

$\sigma \quad$ - Parâmetro de escala da largura do pico subsupoerficial na curva de Gaussdeslocada (metros)

$\Phi \quad$ - Rendimento quântico específico da clorofila para a PAR absorvida

$\varphi \quad$ Rendimento quântico específico da clorofila para a PAR disponível 


\section{LISTA DE SIGLAS E ABREVIATURAS}

$\begin{array}{ll}\text { AC } & \text { Água Costeira } \\ \text { ACAS } & \text { Água Central do Atlântico Sul } \\ \text { AT } & \text { Água Tropical } \\ \text { AVHRR } & \text { Advanced Very High Resolution Radiometer } \\ \text { BPM1 } & \begin{array}{l}\text { Modelo de produtividade de Bedford 1, não espectral, verticalmente } \\ \text { homogêneo }\end{array} \\ \text { BPM2 } & \text { Modelo de produtividade de Bedford 2, espectral, perfil vertical de } \\ \text { biomassa não uniforme } & \text { Bermuda Atlantic Time Series } \\ \text { BPM2 } & \text { Modelo de produtividade de Bedford 2 } \\ \text { CB } & \text { Corrente do Brasil } \\ \text { CLO } & \text { Clorofila } a \\ \text { COROAS } & \text { Circulação Oeste da Região Oeste do Atlântico Sul } \\ \text { CSM } & \text { Concentração de clorofila } \text { a na superfícioe do mar } \\ \text { CTD } & \text { Conductivity, Temperature, Depth } \\ \text { CZCS } & \text { Coastal Zone Color Scanner } \\ \text { DEP3 } & \text { Algoritmo local 2-bandas para cálculo da clorofila a por satélite } \\ & \text { (SeaWiFS) } \\ \text { DEP4 } & \text { Algoritmo local 4-bandas para cálculo da clorofila a por satélite } \\ \text { (SeaWiFS) } & \text { Dinâmica do Ecossistema de Plataforma da Região Oeste do } \\ \text { DEPROAS } & \text { Atlântico Sul } \\ \text { DIM } & \text { Depth integrated models } \\ \text { FAO } & \text { Food and Agriculture Organization of the United Nations } \\ \text { GAC } & \text { Global Area Coverage } \\ \text { GSM01 } & \text { Garver, Siegel, Maritorena version 01 } \\ \text { HRPT } & \text { High Resolution Picture Transmission } \\ \text { IFOV } & \text { Instantaneous Field of View } \\ \text { IGBP } & \text { International Geosphere Biosphere Program (IGBP) Study } \\ \text { INPE } & \text { Instituto Nacional de Pesquisas Espaciais } \\ \text { IOUSP } & \text { Instituto Oceanográfico da Universidade da São Paulo } \\ \text { IV } & \text { Infravermelho } \\ \text { JGOFS } & \text { Joint Global Ocean Flux } \\ \text { LAC } & \text { Local Area Coverage } \\ \text { M1 } & \text { Cruzeiro de mesoescala do projeto DEPROAS no verão de 2001 } \\ \text { Cruzeiro de mesoescala do projeto DEPROAS no inverno de 2001 } \\ \text { Cruzeiro de mesoescala do projeto DEPROAS no verão de 2002 }\end{array}$


M4 Cruzeiro de mesoescala do projeto DEPROAS no inverno de 2002

MBR Razão de banda máxima

MODIS Moderate Resolution Imaging Spectroradiometer

NASA National Aeronautics and Space Administration

NN Neural Netwok - Redes neurais artificiais

NOAA National Oceanic and Atmospheric Administration

OC2 Ocean Chlorophyll 2-bands

OC4 Ocean Chlorophyll 4-bands

PAR Radiação fotossinteticamente ativa

PCSE Plataforma continental sudeste brasileira

P-I Luz - fotossíntese

PNF Perfilador de Fluorescência Natural

PPO Produtividade Primária Oceânica

$\mathrm{R}^{2} \quad$ Coeficiente de Determinação

SeaBAM SeaWiFS Bio-Optical Algorithm Mini-Workshop

SeaWiFS Sea-viewing Wide Field-of-view Sensor

SIMBIOS Sensor Intercomparison and Merger for Biological and Interdisciplinary Oceanic Studies

TIM Time integrated models

TSM Temperatura da superfície do mar

UNESCO United Nations Educational, Scientific and Cultural Organization

VGPM Vertically Generalized Production Model

WIM Wavelenght integrated models

WOCE World Ocean Circulation Experiment

WRM Wavelenght resolved models 


\section{CAPÍTULO 1}

\section{INTRODUÇÃO}

\subsection{Aspectos gerais}

A caracterização temporal e espacial da biomassa fitoplanctônica e produtividade primária tem sido um tópico de grande interesse da oceanografia há algumas décadas, já que a principal base trófica nos oceanos depende da fotossíntese realizada pelo fitoplâncton marinho. O fitoplâncton faz a ligação entre a energia solar e a produção de recursos biológicos do qual dependem todos os outros níveis tróficos (Clark e Sherman, 1986). Este tópico é importante em escalas regional e global, por suas aplicações comerciais e gerenciais dos recursos marinhos, e na análise do ciclo global do carbono. O ciclo do carbono é criticamente dependente da produção primária líquida, definida como a quantidade de carbono fixado fotossinteticamente e disponível para níveis tróficos superiores (Falkowski et al., 1998). Desta forma, diversos esforços para determinar a produtividade primária marinha têm sido feitos pela comunidade oceanográfica, enfatizados por programas internacionais tais como o International Geosphere Biosphere Program (IGBP) e um de seus componentes, o Joint Global Ocean Flux Study (JGOFS). Em escalas temporais de segundos a séculos, os processos biológicos oceânicos seqüestram grandes quantidades de carbono atmosférico, modulando as concentrações de $\mathrm{CO}_{2}$ na baixa atmosfera (IPCC, 2001).

Os objetivos do JGOFS são observar e compreender os ciclos biogeoquímicos no oceano, possibilitando a previsão das interações acopladas entre as componentes atmosfera, oceano e sedimentos no ciclo do carbono (JGOFS/SCOR, 1990). Em 1988, o entendimento sobre o ciclo do carbono oceânico era baseado em diferentes paradigmas (ver Karl et al., 2001). Primeiro considera-se que o fitoplâncton oceânico superficial assimile os nutrientes dissolvidos em proporções estequiométricas fixas, de modo a balancear as disponibilidades de carbono, nitrogênio e fósforo em camadas mais profundas (Copin-Montegut e Copin-Montegut,1983). Segundo a partir da idéia que o 
oceano é predominantemente limitado em nitrogênio (Carpenter e Capone, 1983), a produção primária pode ser dividida em duas categorias baseadas na assimilação de nitrogênio "novo" versus "regenerado", sendo denominadas como produção nova e regenerada, respectivamente (Dugdale e Goering, 1967). Terceiro, estima-se que o fluxo de afundamento do material orgânico particulado a partir da zona eufótica representa uma perda estequiométrica associada aos nutrientes, que deve ser balanceada pela entrada de nutriente novo (Dugdale, 1967). Por fim, acredita-se que as comunidades planctônicas dos oceanos subtropicais existam em um estado de "clímax", no qual a biomassa e estrutura de composição das espécies não apresentam tendências sazonais ou de longo período. Entretanto, esses paradigmas têm sido alterados significativamente, a partir de séries temporais de observações obtidas na última década (Lomas et al., 2002).

Para quantificar a produtividade primária dos oceanos e caracterizar sua variabilidade em escalas regional e global, são necessárias medições freqüentes, bem distribuídas e com grande cobertura espacial. Esta amostragem é praticamente impossível de ser conduzida somente por métodos tradicionais in situ, principalmente em regiões ao largo. A utilização do sensoriamento remoto a nível orbital permite que esta abordagem espacial global seja realizada se as medições radiométricas obtidas por satélites puderem ser interpretadas quantitativamente em termos da produtividade primária (Berthelot e Deschamps, 1994). A absorção seletiva dos comprimentos de onda nas faixas do azul e verde do espectro eletromagnético pelos pigmentos fotossintéticos (principalmente pela clorofila $a$ ), possibilita a quantificação da biomassa fitoplanctônica oceânica através de medidas da cor do oceano obtidas por satélite (Morel e Prieur, 1977; Gordon e Morel, 1983). As concentrações de clorofila e composição taxonômica de comunidades fitoplanctônicas dependem dos padrões de circulação oceânica e processos físicos de mesoescala, principalmente quando estes influenciam os fluxos de nutrientes essenciais desde camadas subsuperficiais até a zona eufótica (Falkowski et al., 1998). Nos grandes giros oceânicos, o fluxo de nutrientes das zonas mais profundas é relativamente pequeno, e as concentrações médias de clorofila na camada superior da zona eufótica são em torno de $0,2 \mathrm{mg} \cdot \mathrm{m}^{-3}$ (Yoder et al., 1983). Em regiões de ressurgência costeira e com feições de mesoescala indutoras de ressurgência (como 
meandros e vórtices), o fluxo vertical de nutrientes consegue suportar incrementos de biomassa superiores a $5 \mathrm{mg} . \mathrm{m}^{-3}$ (Falkowski et al., 1991; entre outros). Juntamente com outros dados ambientais tais como, a temperatura da superfície do mar e a irradiância solar incidente, por exemplo, os dados de concentração de clorofila a podem ser utilizados para estimar a produtividade primária marinha em qualquer região do oceano (Longhurst et al., 1995; Antoine et al., 1996; Behrenfeld e Falkowski, 1997a). Esforços para estimar a produtividade potencial do oceano mundial têm sido realizados desde que a disponibilidade de dados tornou-se adequada à obtenção de inferências em escala global (Koblentz-Mishke et al., 1970). Estimativas relativamente recentes obtidas através de dados in situ pelo método do ${ }^{14} \mathrm{C}$ (Berger et al., 1989), variaram entre 20 e 50 Gt.C (1Gt.C $\left.=10^{15} \mathrm{gC}\right)$. Mais recentemente, valores obtidos a partir de dados de satélite também oscilaram entre 27 e 50 Gt.C, a maioria excedendo 40 Gt.C (Behrenfeld e Falkowski, 1997a), ou seja, aproximadamente igual à produtividade terrestre (Field et al., 1998). Entretanto, este fluxo global de carbono é governado pela biomassa fitoplanctônica oceânica totalizada em cerca de 1 Gt.C, o que equivale aproximadamente, a $0,2 \%$ da biomassa de carbono fotossinteticamente ativa na Terra (Field et al., 1998). Conseqüentemente, a biomassa fitoplanctônica oceânica é reciclada em média, em escala semanal (Falkowski et al., 1998).

Mesmo que os algoritmos de produção primária baseados em dados de sensoriamento remoto ainda apresentem incertezas da ordem de um fator de 2 quando comparados a dados in situ (Balch et al., 1992; Balch e Byrne, 1994; Campbell et al., 2002), a cobertura espacial e temporal obtida através dos dados de satélites os tornam uma ferramenta de pesquisa inestimável (Carr, 2002). Por outro lado, ainda que as informações obtidas por satélites constituam uma base de dados consistente e significativa, o cálculo da produtividade primária através do sensoriamento remoto requer informações regionais acerca das características fotossintéticas do fitoplâncton, que por sua vez, permanecem bastante subamostradas (Longhurst et al, 1995). A fim de se obter uma síntese global sobre fluxos de carbono no oceano, deve se utilizar modelos matemáticos que considerem a temperatura, luz, nutrientes e concentrações de clorofila $a$ como variáveis de entrada. O que se pretende buscar não são informações sobre a 
fixação de carbono em pontos isolados do planeta, mas sim um conjunto de relações matemáticas entre as variáveis mencionadas acima e o fluxo de carbono fotossintético. O mais importante é determinar quais são os parâmetros das funções que relacionam as taxas de fixação do carbono fitoplanctônico à temperatura, irradiância e concentrações de clorofila $a$ ou absorção de luz (Laws et al., 2002).

Variações na concentração de fitoplâncton na camada superficial oceânica e conseqüentes variações na penetração submarina da luz visível têm impacto significativo nos processos biológicos, físicos e geoquímicos. O fitoplâncton utiliza a energia solar para converter matéria inorgânica em orgânica, sustentando a biodiversidade marinha e a produção pesqueira mundial. Em escala global, o fitoplâncton remove o carbono inorgânico da água, reduzindo a pressão parcial do dióxido de carbono nas camadas superficiais. Nos casos em que a pressão parcial é inferior a da atmosfera sobrejacente, ocorre um fluxo de dióxido de carbono da atmosfera para o oceano (Lewis, 1995). A irradiância solar absorvida pelo fitoplâncton também contribui para o aquecimento localizado de certas regiões oceânicas, influenciando o desenvolvimento da estrutura termal e dinâmica do oceano superior. Em condições de maior descarga de nutrientes no mar (esgoto doméstico, aportes terrígenos, runoff agrícola etc.), as concentrações fitoplanctônicas aumentam alterando a transparência e a qualidade da água. Segundo Morel et al. (1996), em todos os estudos voltados aos ciclos e fluxos biogeoquímicos, o elo essencial na cadeia é o processo biológico da produtividade primária pelos organismos fitoplanctônicos. Este processo tem duas conseqüências: a fixação do carbono inorgânico dissolvido, e a síntese de carbono orgânico particulado nas camadas superiores (sendo que uma parte é exportada para níveis mais profundos). Portanto, a utilização do sensoriamento orbital em estudos biogeoquímicos de grande e mesoescala baseia-se em duas considerações iniciais (Lewis, 1992): (i) o fitoplâncton pode ser quantificado em termos da concentração de clorofila $a$ na camada superficial e pode-se integrar este valor para a coluna d'água (Morel e Berthon, 1989); e (ii) modelos são capazes de transformar os campos de clorofila $a$ em mapas de produtividade primária. 
A partir das imagens disponibilizadas pelo sensor Coastal Zone Color Scanner (CZCS) entre 1978 e 1986, foi possível observar sinopticamente feições biológicas de sistemas dinâmicos como os grandes giros subtropicais, frentes oceânicas, ressurgências e vórtices de mesoescala (Peláez e McGowan, 1986; Biggs e Müller-Karger, 1994; Santamaria-del-Angel et al., 1994; Monger et al., 1997; entre outros). Estudos sobre o papel dos oceanos no ciclo global do carbono e nos níveis de $\mathrm{CO}_{2}$ atmosférico também foram realizados com a utilização de dados CZCS (Platt e Sathyendranath, 1991; McClain et al., 1992). Da mesma forma, Laurs e Brucks (1985) utilizaram mapas de clorofila para estudar a distribuição e a captura de tunídeos. Devido à natureza dinâmica do clima e do oceano mundial, e à importância do papel dos oceanos nas mudanças climáticas globais, ficou aparente à comunidade oceanográfica que novos sensores deveriam suceder o CZCS (Hooker et al., 1992). Desta forma, o Sea-viewing Wide Field-of-view Sensor (SeaWiFS) foi lançado em agosto de 1997. O propósito do Projeto SeaWiFS é fornecer dados quantitativos das propriedades bio-ópticas dos oceanos, examinando os fatores oceânicos que afetam as mudanças globais (McClain et al., 1992). O SeaWiFS superou o CZCS ao fornecer uma cobertura global a cada 24-48 horas, um esquema de correção atmosférica aperfeiçoado e uma determinação da concentração de clorofila a mais precisa (Falkowski et al., 1998). A velocidade com que a concentração de clorofila varia no tempo é chamada de produtividade primária (primária porque é a fase inicial e crítica da teia alimentar). Para entender a produtividade nos oceanos, inicialmente é preciso ser capaz de estimá-la. A utilização de algoritmos desenvolvidos para dados orbitais de cor do oceano permite a comparação dos produtos derivados (concentração de clorofila $a$, radiâncias e produtividade primária) através de medidas in situ.

\subsection{Objetivos}

Vários programas de pesquisa multi-institucionais têm sido conduzidos nos oceanos nos últimos anos. Dentre estes, cabe ressaltar para o Oceano Atlântico o World Ocean Circulation Experiment (WOCE), o IGBP e o JGOFS, entre outros. Estes programas têm alcançado resultados significativos, aperfeiçoando a descrição teórica e entendimento sobre os processos oceanográficos observados. O Projeto Dinâmica do 
Ecossistema de Plataforma da Região Oeste do Atlântico Sul (DEPROAS) foi concebido para estudar os mecanismos físicos que possibilitam a penetração sazonal da Água Central do Atlântico Sul (ACAS) na plataforma continental situada entre o Cabo de São Tomé, RJ e São Sebastião, SP e o impacto que essa penetração e a Corrente do Brasil (CB) tem sobre os processos biológicos do ecossistema da região. Neste projeto, nitidamente multidisciplinar, atuam especialistas de diversas áreas da Oceanografia, tais como físicos, biólogos, geólogos e engenheiros oriundos de diferentes instituições nacionais e internacionais. $\mathrm{O}$ projeto conta com o apoio institucional do Instituto Oceanográfico da Universidade de São Paulo e do Instituto Nacional de Pesquisas Espaciais.

O presente foi inserido no âmbito do projeto DEPROAS trabalho com o objetivo estimar a produção primária e a biomassa fitoplanctônica através de sensoriamento remoto da cor do oceano e dados in situ na costa sudeste brasileira. Para alcançar este objetivo, foram estabelecidos os seguintes objetivos específicos:

- Descrever, em escala sazonal, as distribuições termohalinas, de $\sigma_{\mathrm{t}}$ e nutrientes inorgânicos dissolvidos (com ênfase no nitrato);

- Descrever, em escala sazonal, as distribuições de biomassa fitoplanctônica indexada pela concentração de clorofila $a$;

- Descrever, em escala sazonal, as distribuições de produção primária fitoplanctônica;

- Adquirir, processar e analisar dados de satélites nas faixas do visível (SeaWiFS) e infravermelho termal (AVHRR), contribuindo para a determinação dos padrões de circulação da Corrente do Brasil, para o monitoramento de ressurgências e vórtices de mesoescala, e para a determinação da temperatura e concentração de clorofila $a$ na superfície do mar; 
- Aplicar modelos bio-ópticos para determinação da biomassa fitoplanctônica (concentração de clorofila $a$ ) e produtividade primária oceânica integrada na coluna d'água através do sensoriamento remoto da cor do oceano e dados in situ;

- Gerar imagens da produtividade primária oceânica a partir dos campos de clorofila $a$ obtidos por satélite (SeaWiFS);

- Caracterizar os domínios de plataforma e talude em termos da biomassa e produtividade primária fitoplanctônica integradas na zona eufótica;

- Identificar os processos físicos importantes para a variabilidade da produção primária fitoplanctônica na área de estudo;

- Analisar possíveis relações entre as variáveis físicas, químicas e biológicas determinantes das variabilidades da biomassa e produção primária fitoplanctônica integradas na coluna d'água.

\section{3 Área de estudo}

\section{Características gerais}

A área de estudo abrange a plataforma continental entre o Cabo de São Tomé $\left(22^{\circ} \mathrm{S}\right)$, RJ e a Ilha de São Sebastião (23050'S), SP. Representa a proção norte da plataforma continental sudeste brasileira (PCSE), aqui definida como a região da plataforma continental atlântica que se estende desde o Cabo de São Tomé $\left(22^{\circ} \mathrm{S}\right)$ no Rio de Janeiro até o Cabo de Santa Marta (28 40’S) em Santa Catarina (Figura 1.1). Possui características dinâmicas típicas de plataformas continentais de latitudes médias (Castro, 1996; Castro e Miranda, 1998).

A parte mais larga da PCSE, com $230 \mathrm{~km}$, está localizada em frente a Santos, e as partes mais estreitas nas proximidades de Cabo Frio, com 50 km, e Cabo de Santa Marta, com $70 \mathrm{~km}$. Seu comprimento é de aproximadamente $1110 \mathrm{~km}$ e, com exceção de algumas poucas ilhas grandes, geralmente situadas nas proximidades da costa, como Ilha Grande, Ilha de São Sebastião, Ilha de São Francisco e Ilha de Santa Catarina, e de muitas ilhas pequenas, situadas geralmente no interior de baías, a topografia da PCSE é suave, com as isóbatas dispondo-se paralelamente à linha de costa. A profundidade da quebra de 
plataforma continental varia entre $120 \mathrm{~m}$ e $180 \mathrm{~m}$, e a área total da PCSE é de cerca de $150.000 \mathrm{~km}^{2}$ (Zembruski, 1979). Na Figura 1.1 podemos observar a batimetria da área de estudo. Este mapa batimétrico foi gerado pela interpolação de 1.900 .000 valores de profundidade provenientes de diferentes fontes (Marinha do Brasil, Instituto Brasileiro de Geografia e Estatística, Projeto REMAC, Geophysical Data System, General Bathymetric Chart of the Oceans, PETROBRAS). A quantidade de água doce descarregada sazonalmente por rios na PCSE gira em torno de $1.000 \mathrm{~m}^{3} . \mathrm{s}$ (Ekau e Knoppers, 1999). Com relação a plumas estuarinas na PCSE, existem indicações da deriva de águas de baixas salinidades em direção nordeste nas proximidades do Canal de São Sebastião (Castro e Miranda, 1995) e a formação de uma Frente Subtropical de Plataforma associada à pluma do Rio da Prata (Piola et al., 2000). Ao largo da Baía da Ilha Grande foi observada também, uma frente salina marcante, devido à descarga de água doce da Baía de Sepetiba (Miranda et al., 1977).

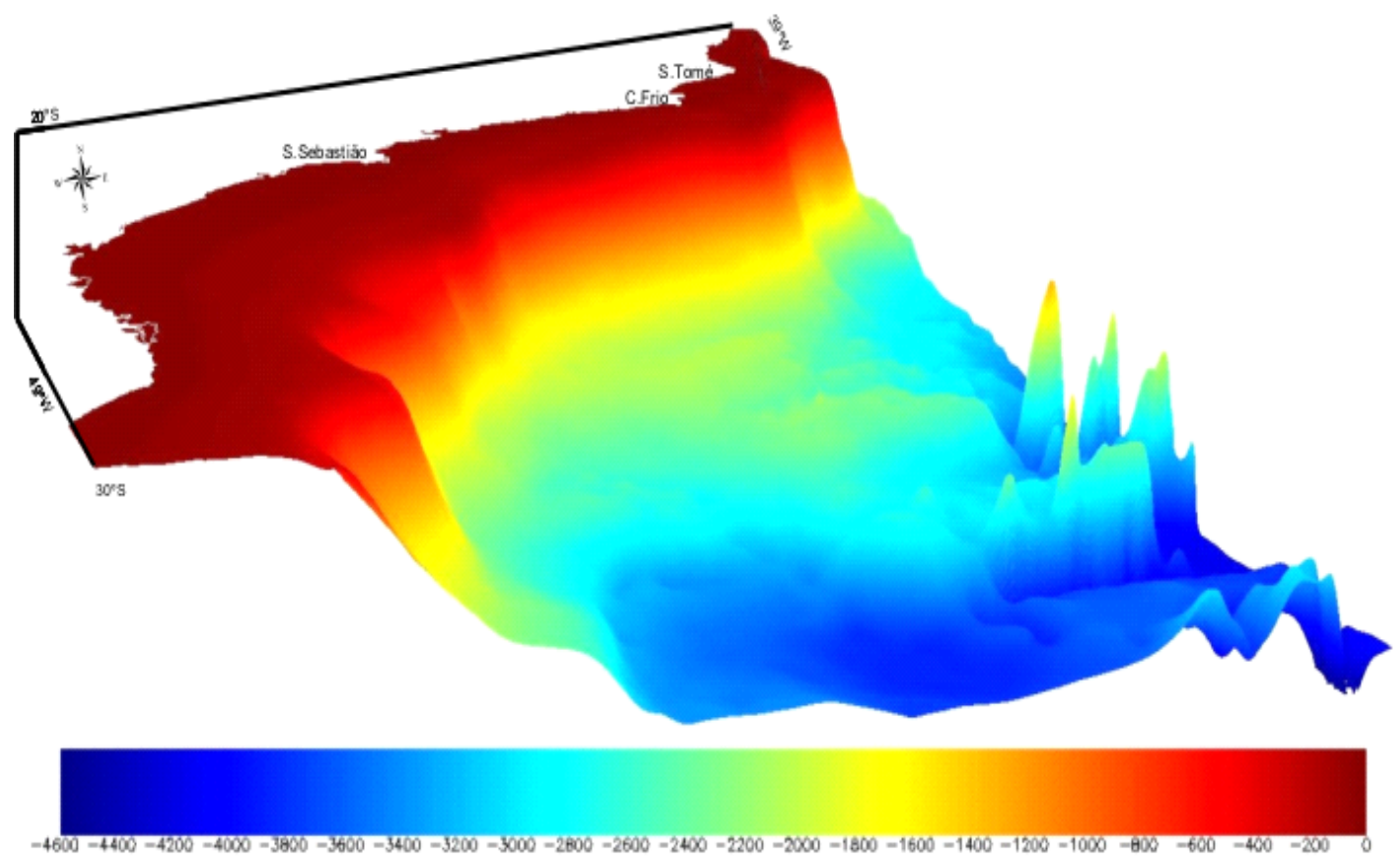

Figura 1.1 - Batimetria da plataforma continental sudeste brasileira e área oceânica adjacente (valores em metros).

Embora situada na região tropical, a PCSE está localizada suficientemente longe do equador para que a geostrofia seja dominante em movimentos com escalas de 
freqüência subinerciais (escalas temporais entre 2 e 15 dias) e sazonais (1 ano) (Castro, 1996).

\section{Corrente do Brasil (CB)}

A feição mais notável da circulação oceânica superficial do Atlântico Sudoeste é a Corrente do Brasil localizada na parte mais externa da PCSE (Figura 1.2 ). Sua origem se dá a partir da bifurcação da Corrente Sul Equatorial quando esta encontra o continente sul-americano, ao sul de $10^{\circ} \mathrm{S}$ (Strama, 1991; Silveira et al., 1994) . A CB representa a corrente de contorno oeste do giro subtropical do Atlântico Sul. A CB flui para sul mudando sua direção para sudoeste na altura de Cabo Frio $\left(23^{\circ} \mathrm{S}\right)$, devido à mudança de direção da linha de costa. Entre $33^{\circ}$ e $38^{\circ} \mathrm{S}$ a CB conflui com a corrente fria das Malvinas na região da Convergência Subtropical e se separa da costa (Olson et al., 1988; Silveira et al., 2000). Apesar de ser uma corrente superficial de contorno oeste, o transporte de volume da $\mathrm{CB}$ é menor que o das correntes de contorno oeste do Hemisfério Norte (Corrente do Golfo e Corrente de Kuroshio). Segundo Stommel (1957), o transporte da CB é menos intenso do que o teoricamente esperado devido ao efeito contrário da circulação termohalina, uma vez que esta e a circulação superficial gerada pelo vento têm sentidos opostos no Atlântico Sul. Segundo Stramma et al. (1990), o giro subtropical do Atlântico Sul não é um sistema fechado e a maior parte (80\%) do transporte da Corrente Sul Equatorial é desviada para o Hemisfério Norte pela Corrente Norte do Brasil. Próximo à região de Cabo Frio $\left(23^{\circ} \mathrm{S}\right)$, o transporte da $\mathrm{CB}$ aumenta significativamente provavelmente, devido a uma célula de recirculação do giro subtropical, cujas águas passam a dominar a CB em torno de $30^{\circ} \mathrm{S}$ (Reid, 1989). Nesta região, a $\mathrm{CB}$ tem menos que $200 \mathrm{~m}$ de profundidade e flui próxima à quebra de plataforma (Castro e Miranda, 1998). Imediatamente ao sul de Cabo Frio, ocorre uma abrupta mudança na direção da linha de costa de NE-SO para E-O. Por conservação de vorticidade potencial, a CB é forçada a girar ciclonicamente para oeste, atingindo a quebra de plataforma novamente em torno do paralelo $24^{\circ} \mathrm{S}$. A rotação ciclônica da CB ao sul de Cabo Frio foi observada através de dados hidrográficos (Signorini, 1978) e imagens termais orbitais (Campos, 1995; Kampel et al., 2000; entre outros). Este comportamento também foi modelado numericamente (Cirano, 1995). Após penetrar 
sobre a plataforma, cruzando a quebra de plataforma e as isóbatas na borda de plataforma quase perpendicularmente, a $\mathrm{CB}$ gira para $\mathrm{SO}$, meandrando próxima à quebra de plataforma ao longo da PCSE (Castro e Miranda, 1998). Silveira et al., (2000) apresentam uma compilação das informações disponíveis na literatura sobre a CB.

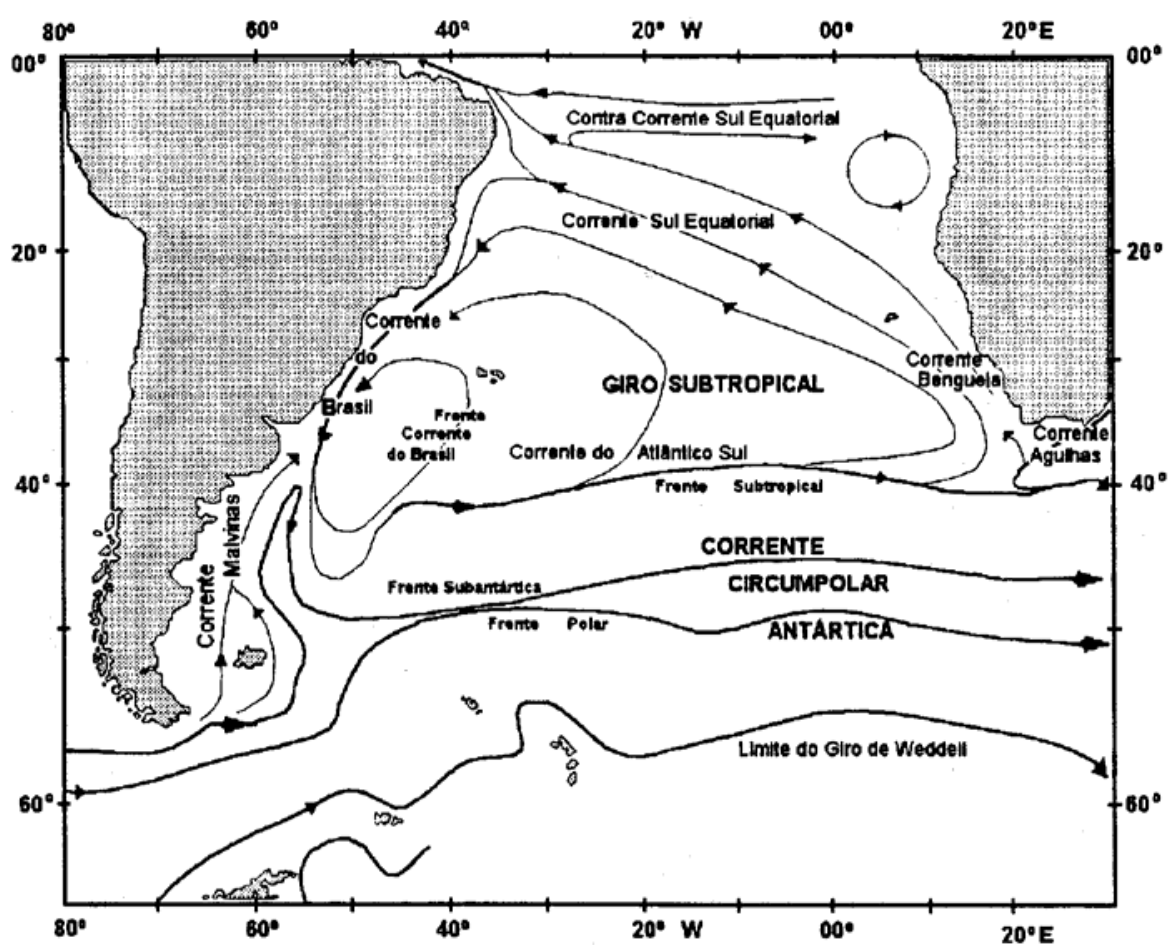

Figura 1.2 - Circulação superficial do Atlântico Sul (adaptado de Peterson e Stramma, 1991).

\section{Massas de água}

Conforme estabelecido por Emilsson (1961), e mais tarde detalhado por vários outros autores, em geral, as massas de água presentes na PCSE são resultado da mistura entre:

- Água Tropical (AT), quente e salina $\left(\mathrm{T}>20^{\circ} \mathrm{C}\right.$ e $\mathrm{S}>36,40$; Miranda, 1982) transportada para sul-sudoeste na camada superficial $(0-200 \mathrm{~m})$ da Corrente do Brasil (CB), sobre o talude continental, nas proximidades da quebra da plataforma continental;

- Água Central do Atlântico Sul (ACAS), relativamente fria $\left(\mathrm{T}<20^{\circ} \mathrm{C}\right.$ e $\mathrm{S}<$ 36,40; Miranda, 1982) transportada para sul-sudoeste ao longo do talude 
continental na camada inferior da CB $(200-500 \mathrm{~m})$, próximo à quebra da plataforma continental;

- Água Costeira (AC), resultante da mistura da descarga continental de água doce com as águas da plataforma continental, tendo a menor salinidade das águas da PCSE devido principalmente ao efeito combinado dos muitos rios pequenos e médios existentes na região.

A parte mais interna da plataforma continental é ocupada principalmente pela AC. Ao largo dessa faixa costeira, observa-se a presença de águas com influencia da AT e da ACAS, geralmente as primeiras próximas à superfície e as segundas próximas ao fundo, principalmente no entorno da quebra da plataforma continental. Durante o verão, a ACAS penetra na camada profunda em direção à costa, atingindo muitas vezes a parte mais interna da plataforma continental. Durante o inverno, por outro lado, essa massa d'água afasta-se em direção à quebra da plataforma continental, aumentando a largura da faixa costeira onde a AC é predominante (Castro et al., 1987).

\section{Ventos}

Uma característica marcante da dinâmica das plataformas continentais é a resposta de suas águas a ventos superficiais com escala temporal sazonal e sinóptica (Castro, 1996). Dependendo da combinação entre a largura e a topografia da plataforma continental, e a intensidade, a direção e a persistência da tensão de cisalhamento do vento, as correntes geradas podem ser as mais energéticas na PCSE. Essas correntes são, em geral, paralelas às isóbatas para manter o balanço geostrófico na direção normal à topografia.

A partir da climatologia elaborada por Samuels e Cox (1987), pode-se observar a influência do giro subtropical anticiclônico presente no Atlântico Sul em latitude médias (Alta Subtropical), sobre a área de interesse. Em geral, esse giro traz ventos provenientes de sudeste-nordeste para a costa situada entre $15^{\circ}$ e $25^{\circ} \mathrm{S}$, e leva ventos provenientes de sudoeste-noroeste para o largo entre as latitudes de $35^{\circ}$ e $40^{\circ} \mathrm{S}$. A posição da Alta Subtropical do Atlântico Sul varia sazonalmente, afetando diretamente a intensidade e direção dos ventos sobre a plataforma continental. Durante o verão, os 
ventos predominantes sobre a região costeira situada entre $15^{\circ}$ e $35^{\circ} \mathrm{S}$ sopram de lestenordeste. Durante o inverno, estes ventos ficam confinados entre as latitudes de $20^{\circ} \mathrm{e}$ $25^{\circ} \mathrm{S}$

Sistemas frontais (frentes frias) caracterizam-se como a perturbação meteorológica em escala sinóptica mais importante sobre a PCSE. Freqüentemente, os sistemas frontais são observados propagando-se ao longo da costa entre $40^{\circ}$ e $20^{\circ} \mathrm{S}$, embora possam atingir latitudes menores, especialmente durante o inverno (Kousky, 1979). Entre $20^{\circ} \mathrm{e}$ $34^{\circ} \mathrm{S}$, a ocorrência de sistemas frontais varia ao longo do ano entre 3 e 6 por mês, resultando em escalas de tempo entre 5 e 10 dias. Entre $20^{\circ}$ e $25^{\circ} \mathrm{S}$ a mínima ocorrência é em fevereiro, 3 por mês, e a máxima em outubro, 5 por mês, em média (Oliveira, 1986).

\section{Plâncton e hidrografia}

Revisões bibliográficas sobre o plâncton e a produção primária na costa sudeste brasileira foram sintetizadas por Valentin (1994) para o Estado do Rio de Janeiro e Gaeta (1994) para o Estado de São Paulo. Posteriormente, Brandini et al. (1997) fizeram um levantamento histórico sobre a planctonologia na plataforma continental brasileira. Recentemente, Gaeta (1999) e Gaeta e Brandini (2003) atualizaram estas revisões bibliográficas para a plataforma sul e sudeste do Brasil.

No Atlântico Sudoeste, entre a região equatorial e a Convergência Subtropical, o estoque de nutrientes inorgânicos dissolvidos mais próximo da zona eufótica encontrase nas camadas subsuperficiais da ACAS. Fertilizações em massa da zona eufótica não ocorrem devido à presença de uma termoclina permanente, como conseqüência da água quente superficial "empilhada" para o lado ocidental das bacias oceânicas. Qualquer processo oceanográfico que rompa a estrutura fisicamente estável da termoclina resulta em ressurgências de águas profundas, trazendo nutrientes para a zona eufótica (Brandini et al., 1997). Em regiões afastadas da costa, a fertilização em massa da zona eufótica ocorre apenas nas divergências equatoriais (Lalli e Parsons, 1993) ou em áreas de

quebra de plataforma (Brandini, 1990a). Próximo aos bancos submersos e ilhas oceânicas, a ACAS também pode ressurgir como conseqüência do regime de ventos e 
da circulação local, trazendo nutrientes para a zona eufótica e aumentando a produção primária dessas regiões (Takahashi e Barth, 1968). Em regiões costeiras, ocorrem fertilizações em massa nas regiões estuarinas ou nas ressurgências costeiras como em Cabo Frio (Valentin, 1989).

$\mathrm{Na}$ área de estudo, prevalece o sistema de produção regenerada (Metzler et al., 1997) no qual o nitrogênio inorgânico, normalmente limitante em ecossistemas marinhos (Ryther e Dunstan, 1971) está disponível sob a forma de compostos reduzidos (amônia, uréia, etc.), oriundos da excreção da comunidade planctônica e da regeneração bacteriana na coluna d'água. Sistemas de produção regenerada são pobres do ponto de vista pesqueiro, pois o acúmulo de biomassa é pequeno tendo em vista o grande número de níveis tróficos ao longo da teia alimentar pelágica (Lalli e Parsons, 1993). Eventualmente, este tipo de produção alterna-se com a produção nova, baseada em fontes externas de nitrogênio introduzido no sistema por ressurgências de água subsuperficial, aportes continentais e atmosféricos, difusão molecular na base da zona eufótica e ressuspensão de sedimentos em áreas rasas. Nessas condições, a produção fitoplanctônica aumenta, favorecendo o desenvolvimento larval, o recrutamento e o acúmulo de biomassa pesqueira pelágica, podendo também ser exportada sob a forma de matéria orgânica particulada para as comunidades bênticas (Brandini et al., 1997).

As características hidrográficas têm implicações imediatas sobre a composição e a biomassa da comunidade planctônica, antes de serem refletidas nos estoques biológicos da teia alimentar onde está incluída a maioria dos organismos de interesse comercial. O setor norte da área de estudo, entre o Cabo de São Tomé e a Baía de Guanabara, foi estudado por Signorini (1978), que descreveu a ocorrência da Água Tropical (AT) com temperaturas de $25^{\circ} \mathrm{C}$ e salinidades acima de 36 ao longo de uma camada superficial de mistura de aproximadamente $100 \mathrm{~m}$, acima da termoclina permanente. Na região oceânica, essa camada ocupada pela AT torna-se mais espessa à medida que a Corrente do Brasil desloca-se para S-SO, devido à perda de energia, à queda de temperatura e aumento da densidade associados e à turbulência causada por ventos da região sul. Do ponto de vista biológico, é importante identificar alguns processos oceanográficos em 
grande e mesoescala que influem sobre a estrutura e dinâmica do ecossistema pelágico na plataforma continental da área de estudo:

- As penetrações da ACAS pelo fundo da plataforma durante o verão, acentuando a termoclina, como conseqüência da incidência dominante de ventos de NE (Matsuura, 1986; Castro et al., 1987);

- A proximidade da Zona de Confluência Brasil/Malvinas, onde a água quente da Corrente do Brasil encontra as águas frias da Corrente das Malvinas. As mudanças climáticas sazonais causam deslocamentos latitudinais dessa zona de mistura, afetando a estrutura e a dinâmica da comunidade planctônica na plataforma e nas áreas costeiras da região (Brandini, 1990b);

- A penetração de águas frias vindas de sul sobre a plataforma da costa sul e sudeste brasileira, nos períodos de inverno (Silva Jr. e Kampel, 1996);

- As ressurgências de borda de plataforma (Mesquita et al., 1983) causadas por vórtices frontais ciclônicos da Corrente do Brasil (Matsuura, 1990), as quais fertilizam a base da zona eufótica com nutrientes inorgânicos, modificando provisoriamente o sistema de produção regenerada, típico das áreas oceânicas oligotróficas, para o sistema de produção nova em áreas sobre o talude continental;

- A ressurgência de Cabo Frio, fenômeno associado aos ventos de NE, ao transporte de Ekman das águas de superfície e à geomorfologia local, que fertiliza a zona eufótica (Valentin, 1989) com efeitos até $400 \mathrm{~km}$ a Sudoeste, sobre a plataforma de São Paulo (Lorenzzetti e Gaeta, 1996).

\subsection{Estrutura do trabalho}

Este trabalho foi estruturado da seguinte forma: no capítulo 1 foi feita uma introdução geral, foram mostrados os objetivos gerais e específicos além da caracterização física e geográfica da área de estudo. 
No capítulo 2, veremos a metodologia utilizada durante os levantamentos, processamentos e análises dos dados. Foram incluídos fundamentos físicos e biológicos, além de conceituações teóricas julgadas importantes.

No capítulo 3, os resultados encontrados serão apresentados, enquanto que no capítulo 4 , será feita a discussão desses resultados.

Finalmente, o capítulo 5 irá sumarizar os resultados e oferecer sugestões para trabalhos a serem desenvolvidos no futuro. 


\section{CAPÍTULO 2}

\section{MATERIAL E MÉTODOS}

\subsection{Cruzeiros oceanográficos}

Durante o projeto DEPROAS, visando atender aos objetivos propostos, foram adotadas duas estratégias de amostragem com apoio do N/Oc Prof. W. Besnard: uma radial ao largo de Cabo Frio (cruzeiros de verão - M1 e inverno - M2 de 2001) e uma rede de estações oceanográficas em mesoescala entre o Cabo de São Tomé, RJ e a Ilha de São Sebastião, SP (cruzeiros de verão - M3 e inverno - M4 de 2002). O planejamento dos cruzeiros M1 e M2 objetivou o levantamento das condições oceanográficas, em escalas de tempo subinerciais, ao largo de Cabo Frio. Uma mesma radial oceanográfica teve como extremidades as posições $22^{\circ} 58,4^{\prime} \mathrm{S}-42^{\circ} 03,2^{\prime} \mathrm{W}$ e $24^{\circ} 43,0^{\prime} \mathrm{S}-41^{\circ} 15,0^{\prime} \mathrm{W}$ e foi repetida quatro vezes durante os cruzeiros de 2001, totalizando 35 estações no verão e 27 no inverno. A rede de mesoescala foi organizada através de quatorze (M3) ou treze (M4) seções transversais aproximadamente perpendiculares à costa, cada uma delas estendendo-se mais ou menos da isóbata de $25 \mathrm{~m}$ até regiões oceânicas com profundidades superiores a $1.500 \mathrm{~m}$. A estrutura hidrográfica foi resolvida por um espaçamento de 20 milhas náuticas entre as radiais e as estações, num total de 76 estações no verão e 66 estações no inverno de 2002. Os cruzeiros foram realizados nos seguintes períodos: M1 - 7/2/2001 a 13/2/2001; M2 - 12/7/2001 a 19/07/2001; M3 5/1/2002 a 24/1/2002 e M4 - 3/8/2002 a 21/8/2002. Em cada estação foram anotados os horários, posição geográfica (GPS Furuno 1250, WGS-84), condições meteorológicas (pressão, velocidade e direção do vento, cobertura de nuvens) e profundidade. Em cada estação foram realizados perfis verticais contínuos de hidrografia (temperatura e salinidade) com equipamento Conductivity, Temperature, Depth - CTD (Falmouth Scientific Inc.) acoplado a um sistema coletor de amostras d'água do tipo rosette de garrafas sustentado por cabo eletromecânico, com aquisição de dados digitais em tempo real. Foram coletadas amostras d'água com o emprego de 12 garrafas de Niskin de 1,7 L 
cada, instaladas no sistema rosette e acionadas por mecanismo de controle a bordo programado para as profundidades padrão: $0,5,10,25,50,75,100,150$ e $200 \mathrm{~m}$, variando de acordo com a isóbata ocupada e dos picos máximos subsuperficiais observados. Estas amostras se destinaram às determinações das concentrações de clorofila $a$, nutrientes inorgânicos dissolvidos (nitrato, nitrito, amônia, fosfato e silicato) e taxas de produção primária. Em todas as estações ocupadas durante o fotoperíodo, foram realizados perfis verticais através da zona eufótica, preliminarmente estimada a partir de medidas com o disco de Secchi, empregando-se um Perfilador de Fluorescência Natural (PNF-300, Biospherical Instruments Inc.) com a finalidade de se obter o nível de radiação fotossinteticamente ativa (PAR, 400 - $700 \mathrm{~nm}$ ) incidente na superfície, a irradiância escalar ao longo da camada eufótica, a irradiância da coluna d'água através do espectro de emissão da clorofila centrado no comprimento de onda $683 \mathrm{~nm}$, o coeficiente de atenuação difusa $\left(\mathrm{K}_{\mathrm{PNF}}\right)$ e a estimativa da produção primária instantânea. As Figuras 2.1, 2.2, 2.3 e 2.4 mostram as posições geográficas das estações oceanográficas. Os dados hidrográficos foram reduzidos e editados de acordo com as recomendações da UNESCO (1988) pelo Laboratório de Dinâmica Oceânica do IOUSP. A salinidade é expressa em valores sem unidade. As massas d'água foram descritas com base em suas propriedades hidrográficas, campos de biomassa (clorofila $a$ ) e nutrientes.

\subsection{Biomassa fitoplanctônica e nutrientes}

A abundância fitoplanctônica foi estimada a partir de amostras de $250 \mathrm{~mL}$ filtradas por filtros Whatman GF/F. Os filtros foram mantidos em nitrogênio líquido e as concentrações de clorofila $a$ determinadas por fluorescência em fluorímetro Turner 10AU-005 após extração em $5 \mathrm{~mL}$ de acetona $90 \%$ a $-4{ }^{\circ} \mathrm{C}$ por 12 horas (Holm-Hansen et al., 1965; Shoaf e Lium, 1976; Stramski e Morel, 1990; Welschmeyer, 1994). As amostras para análise dos nutrientes foram transferidas diretamente das garrafas de coleta para frascos de polietileno e congeladas a $-20{ }^{\circ} \mathrm{C}$ para posterior análise no laboratório do Instituto Oceanográfico da Universidade de São Paulo. As concentrações dos nutrientes seguiram os seguintes métodos: nitrito (Grasshoff, 1983), nitrato (Strickland e Parsons, 1972), amônia (Paranhos, 1996), silicato (Koroleff, 1983) e fosfato (Koroleff, 1983). 


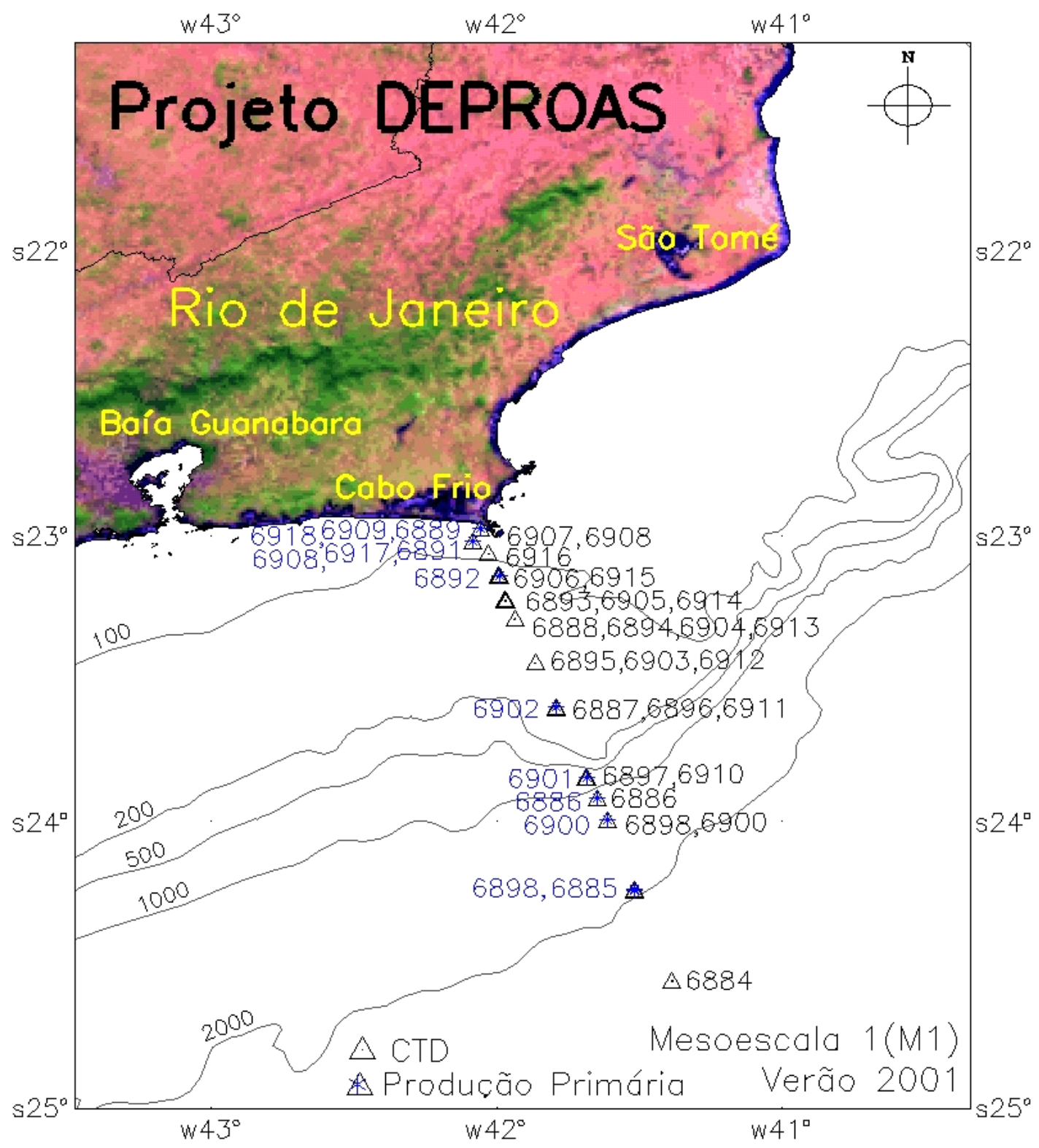

Figura 2.1 - Cruzeiro de mesoescala do projeto DEPROAS realizado entre 7/2/2001 e $13 / 2 / 2001$ (M1). Experimentos de produção primária $\left({ }^{14} \mathrm{C}\right)$ em azul. Isóbatas de 100, 200, 500, 1000 e 2000 em metros. 


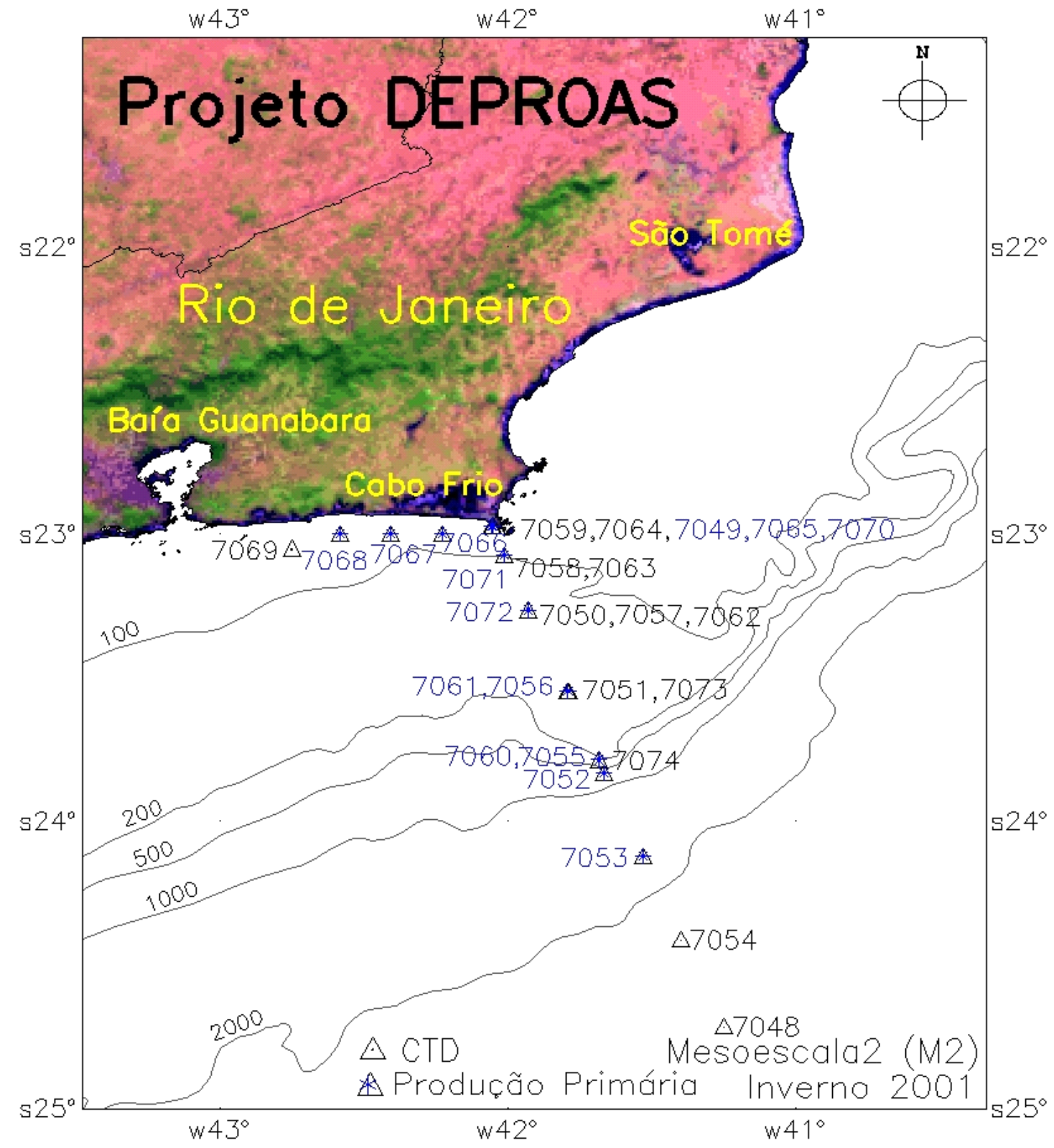

Figura 2.2 - Cruzeiro de mesoescala do projeto DEPROAS realizado entre 12/7/2001 e 19/7/2001 (M2). Experimentos de produção primária $\left({ }^{14} \mathrm{C}\right)$ em azul. Isóbatas de 100, 200, 500, 1000 e 2000 em metros. 


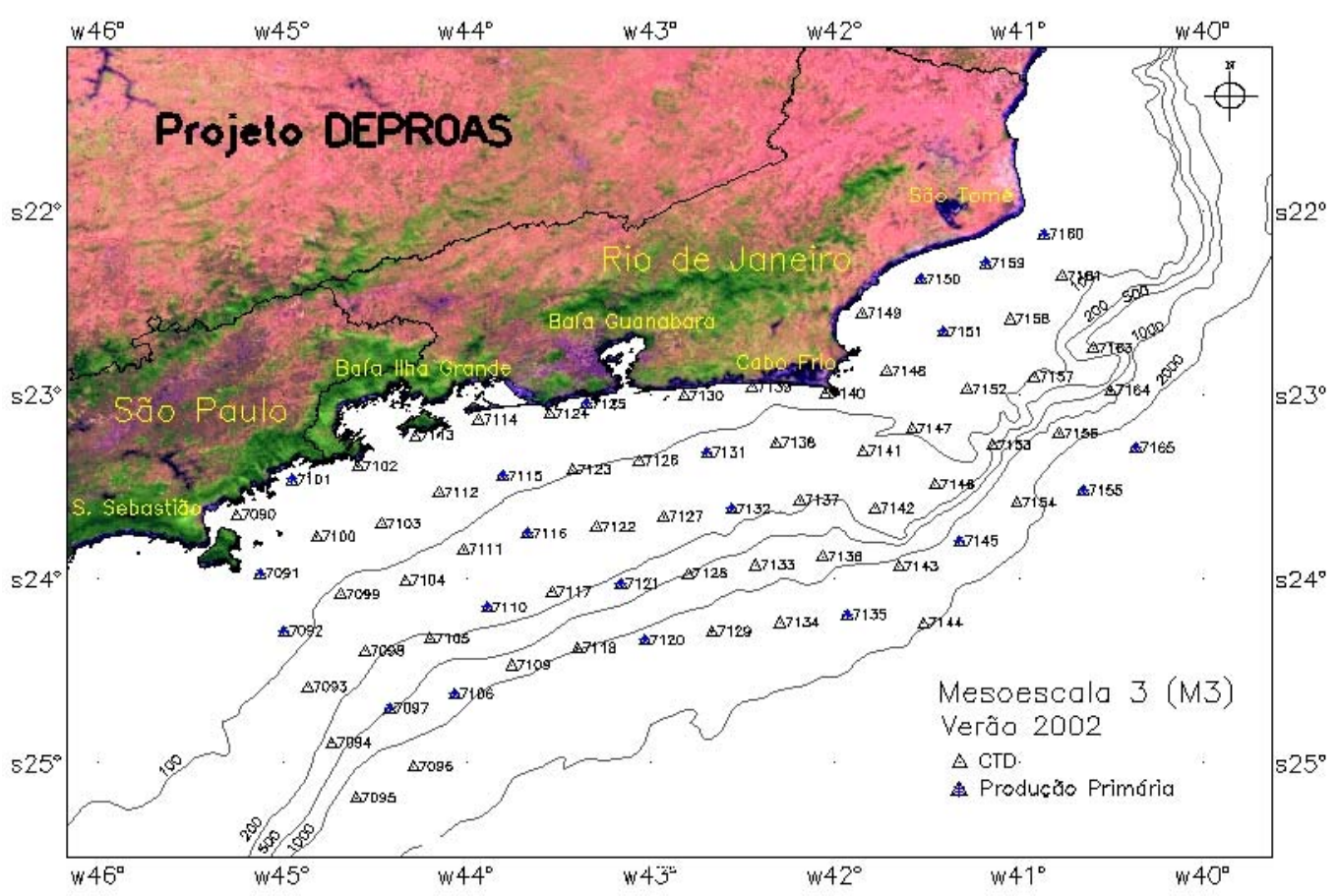

Figura 2.3 - Cruzeiro de mesoescala do projeto DEPROAS realizado entre 5/1/2002 e 24/1/2002 (M3). Experimentos de produção primária $\left({ }^{14} \mathrm{C}\right)$ em azul. Isóbatas de 100, 200, 500, 1000 e 2000 em metros.

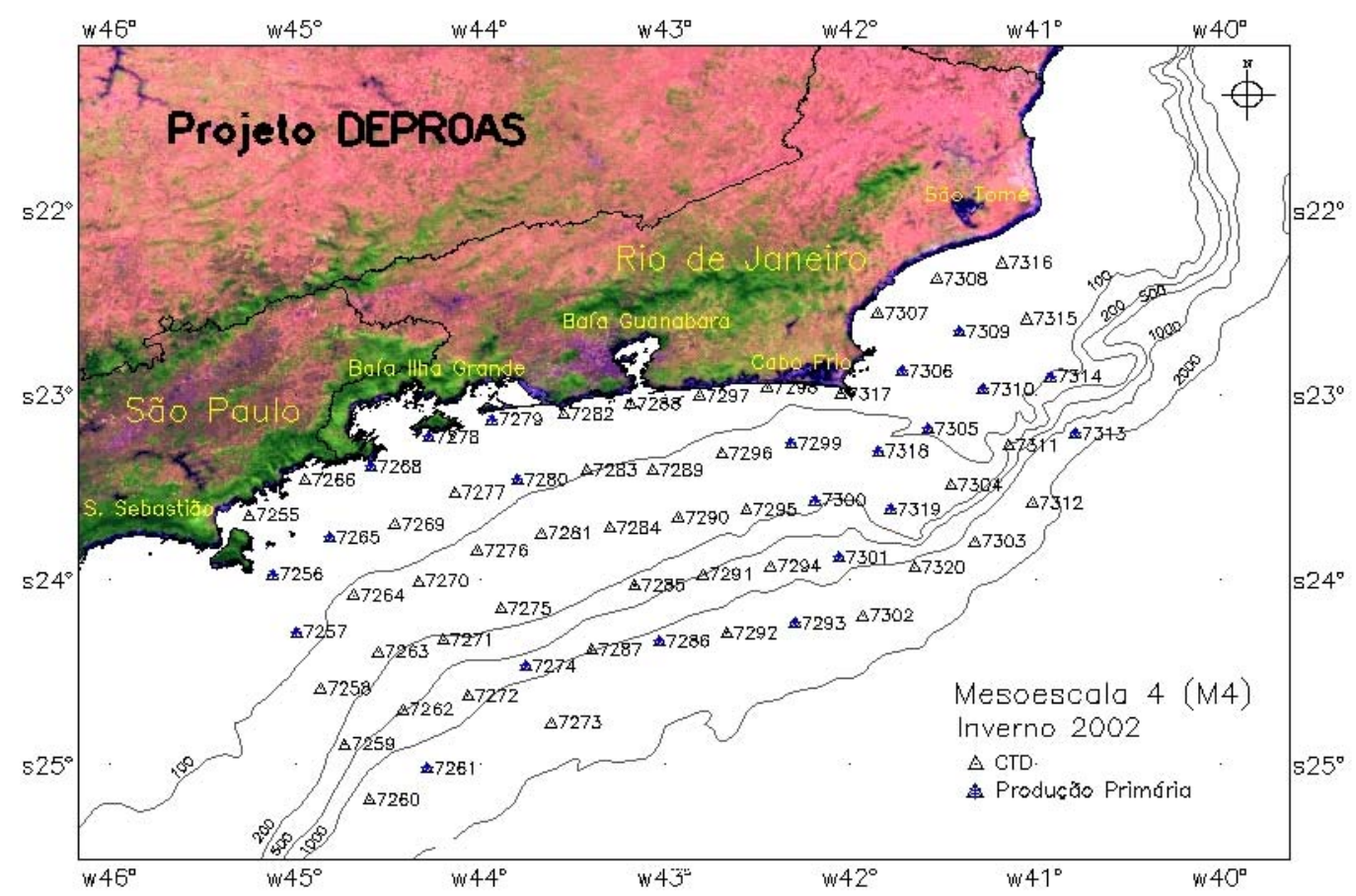

Figura 2.4 - Cruzeiro de mesoescala do projeto DEPROAS realizado entre 3/8/2002 e 21/8/2002 (M4). Experimentos de produção primária $\left({ }^{14} \mathrm{C}\right)$ em azul. Isóbatas de 100, 200, 500, 1000 e 2000 em metros. 


\subsection{Produção primária}

Experimentos de produção primária in situ-simulados pelo método do ${ }^{14} \mathrm{C}$ (SteemanNielsen,1952), foram realizados com amostras de duas profundidades selecionadas para corresponderem a 100\% (superfície) e 1\% (base da zona eufótica) da irradiância na superfície $\left(\mathrm{E}_{0}\right.$ ou $\left.\mathrm{I}_{0}\right)$. A base da zona eufótica foi determinada pela profundidade de desaparecimento do disco de Secchi (Poole e Atkins, 1929). As amostras foram incubadas em frascos de policarbonato NALGENE de $67 \mathrm{~mL}$ de volume, adicionandose 0,5 a $1,0 \mathrm{~mL}$ de $\mathrm{NaH}^{14} \mathrm{CO}_{3}$, cuja atividade nominal era de $20 \mu \mathrm{Ci}$, sob exposição solar com fluxo contínuo de água da superfície do mar e sob diferentes intensidades luminosas $(100,75,50,25,10$ e 1\%). O gradiente de luz foi simulado com o uso de tubos transparentes de acrílico revestidos internamente com filtros neutros constituídos de malhas e placas perfuradas de aço inoxidável com porosidade variável. As incubadoras de polietileno azul claro foram revestidas internamente com chapa de acrílico azul escuro e azul-violeta (Acriresinas $\mathrm{N}^{\mathrm{o}} \mathrm{B}-24$ e V-08) propiciando um clima qualitativo de radiância de fundo refletida, similar às condições da cor do oceano (Laws et al., 1990). Ao término da incubação, de 2 a 4 horas, as amostras foram filtradas em filtros Whatman GF/F que ficaram preservados em nitrogênio líquido até a análise em laboratório. A radioatividade dos filtros foi analisada em espectrômetro de cintilação líquida Packard Tri-Cab 1600CA, seguindo procedimento descrito em Aidar-Aragão et al., (1980). Os valores de produção primária foram calculados utilizando-se a equação descrita por Teixeira (1973) em primeira instância, e os resultados obtidos em peso de carbono fixado por volume e por tempo $\left(\mathrm{mgC} \cdot \mathrm{m}^{-3} \cdot \mathrm{h}^{-1}\right)$ foram posteriormente, recalculados para produções por área e por tempo $\left(\mathrm{gC} \cdot \mathrm{m}^{-2} \cdot \mathrm{d}^{-1}\right)$.

\subsection{Curvas de luz - fotossíntese $(P-I)$}

\section{Principais variáveis}

A fotossíntese envolve a conversão do carbono inorgânico (dióxido de carbono) em carbono orgânico (glicose) tendo a luz como fonte de energia. Em fisiologia vegetal, a taxa de conversão (ou fixação de carbono) é denominada taxa fotossintética. Para amostras aquáticas, é expressa em termos de massa de carbono convertido (fixado) por 
unidade de volume de água por unidade de tempo $(P)$. Existem várias alternativas para definição do índice de biomassa $B$ (massa de carbono, massa total, massa de pigmento), e nenhuma chega a ser a ideal. Ainda que haja uma grande diversidade de vegetais florescendo no planeta, a estrutura empregada para interceptar a energia solar é formada pelos cloropolastos com moléculas de pigmentos associados. O cloroplasto é, portanto, a interface física pela qual a biosfera é conectada à fonte luminosa (sol), estando ajustada para a faixa do espectro solar entre 400-700 nm, conhecida como radiação fotossinteticamente ativa PAR. Em vista do papel crítico dos cloroplastos, a escolha adotada para o índice de biomassa é pela massa de pigmento fotossintético, normalmente apresentado como concentração de clorofila $a$. De modo geral, $B$ pode ser usado tanto como biomassa fitoplanctônica, concentração de clorofila $a$ ou somente clorofila. Uma vantagem desta escolha para o índice de biomassa é que os campos de biomassa derivados de sensores orbitais da cor do oceano são expressos da mesma forma. Tanto $P$ como $B$ são variáveis ditas locais no sentido de que suas magnitudes podem variar em curta escala de tempo e espaço. Por vários motivos, é recomendável utilizar a propriedade normalizada $P / B$, ou seja, produção primária por unidade de clorofila, denotada por $P^{B}$, onde o sobrescrito $B$ indica a normalização pela biomassa. Uma vez que a variação da biomassa é a causa biogênica principal de variação na taxa fotossintética, a normalização pela biomassa produz uma propriedade $P^{B}$ de significado mais geral do que $P$ (sua variação espacial e sazonal pode ser analisada independentemente de possíveis flutuações da biomassa). Em outras palavras, $P^{B}$ é uma propriedade intrínseca da amostra, ou da estação do ano na qual foi obtida. Sua magnitude será estável em relação a variações locais da biomassa, de modo que seu valor em uma estação particular possa ser considerado mais representativo do domínio no qual a estação esteja embutida do que os valores de $P$ ou $B$ na mesma estação.

Outra variável básica importante é a irradiância $I$. Uma propriedade importante de um campo de irradiância é seu comprimento de onda $\lambda$. Uma vez que a resposta fotossintética à luz disponível é dependente do comprimento de onda e do estado fisiológico das células vegetais, devemos escrever $I(\lambda)$. Entretanto, nem em modelos mais simples, a dependência espectral pode ser suprimida. Similarmente, a distribuição 
angular do campo de irradiância também é importante em modelos mais complexos de produção primária, e a descrição mais completa seria $I(\lambda, \theta, \Phi)$, onde $\theta$ e $\Phi$ são, respectivamente, os ângulos azimutal e zenital do campo de luz.

A irradiância pode ser expressa tanto como fluxo de energia por unidade de área por unidade de tempo, ou como fluxo de fótons por unidade de área por unidade de tempo. Ambas as representações são úteis. Entretanto, é extremamente importante entender como fazer as devidas conversões quando necessário. Unidades típicas de $I$ são Watt. $\mathrm{m}^{-2}$, Joule. $\mathrm{m}^{-2} \cdot \mathrm{s}^{-1}$ ou Einstein. $\mathrm{m}^{-2} \cdot \mathrm{s}^{-1}$. No cálculo da produção primária, utilizamos a variável $P^{B}$. Como a fotossíntese envolve um processo fotoquímico, devemos escrever:

$$
P^{B}=P^{B}(I)
$$

\section{Cenário fenomenológico}

Uma descrição simples da fotossíntese como um processo químico pode ser escrito da seguinte forma:

$$
\mathrm{CO}_{2}+\mathrm{H}_{2} \mathrm{O} \stackrel{\operatorname{luz}}{\rightarrow} \mathrm{CH}_{2} \mathrm{O}+\mathrm{O}_{2}
$$

Onde o dióxido de carbono e a água combinam, sob influência da luz, para formar um açúcar simples, representado por $\mathrm{CH}_{2} \mathrm{O}$ e oxigênio. A taxa de fotossíntese, equivalente à produção primária, pode ser avaliada pela medição tanto da taxa de incorporação de carbono no açúcar como pela taxa de evolução do oxigênio. É importante notar que a reação é reversível. A reação de "volta", que não precisa do estímulo da luz, é chamada de respiração. Esta leva a liberação de dióxido de carbono. Durante o dia, ambas as reações podem ocorrer ao mesmo tempo.

A resposta funcional da fotossíntese fitoplanctônica à luz pode ser estudada com o uso de experimentos fotossíntese - luz (curvas P - I). Uma curva P - I idealizada é mostrada na Figura 2.5 Os círculos cheios representam os pontos de dados experimentais e a linha escura é uma curva ajustada aos dados (curva de saturação de luz ou curva P - I). 
A curva não passa necessariamente pela origem. O intercepto $R^{B}$ no eixo das ordenadas pode ser interpretado como uma medida da respiração no escuro pelo fitoplâncton (perda de carbono ao nível zero de luz, quando a fotossíntese é zero por definição). O ponto onde a curva corta o eixo das abcissas define o valor de irradiância $I_{c}$, denominado ponto de compensação e interpretado como a irradiância para a qual a fotossíntese somente balanceia a respiração no escuro.

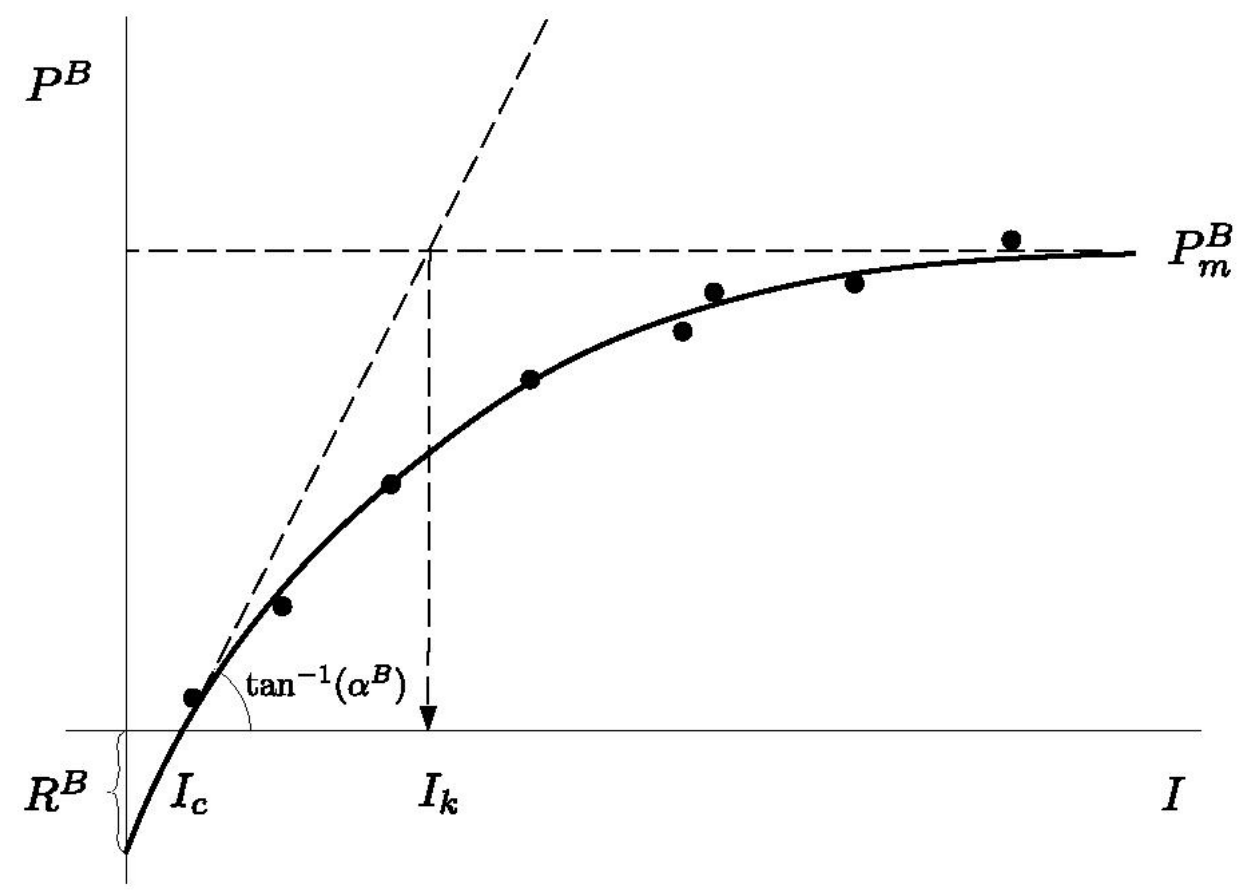

Figura 2.5 - Curva de luz - fotossíntese (linha contínua) ajustada a um conjunto idealizado de dados de produção primária normalizada pela biomassa (adaptado de Jassby e Platt, 1986).

Próximo do eixo das abcissas, a curva é quase linear e com a inclinação denotada por $\alpha^{B}$, também chamada de inclinação inicial. Caracteriza as reações fotoquímicas da fotossíntese. Para valores maiores de irradiância, a inclinação da curva decresce progressivamente até atingir um platô de amplitude $P^{B}{ }_{\max }$, chamado número de assimilação. Representa a taxa de fotossíntese específica no ótimo de intensidade de luz. A projeção da intersecção da inclinação inicial com o platô sobre o eixo das abcissas define a irradiância $I_{k}$, chamada de parâmetro de fotoadaptação. Da Figura 2.5 , podemos dizer que, quando $R^{B}=0$, temos $P^{B}{ }_{\max } / I_{k}=\alpha^{B}$, de onde se conclui que: 


$$
I_{k}=P_{\max }^{B} / \alpha^{B}
$$

Onde $I_{k}$ tem dimensões de irradiância. É geralmente usado como uma escala para normalizar a irradiância tornando-a adimensional. Desta forma:

$$
I_{*}=I / I_{k}=\alpha^{B} I / P_{\max }^{B}
$$

Onde $\mathrm{o}$ asterisco denota uma quantidade adimensional. $\mathrm{O}$ valor $I_{*}=1$, correspondendo a $I=I_{k}$, divide a curva mostrada na Figura 2.5 em dois regimes. Para $I * \leq 1$, a fotossíntese depende fortemente da irradiância. Para $I *>1$, a fotossíntese depende menos da irradiância, eventualmente ficando independente desta. $\mathrm{Na}$ prática, há um terceiro regime para altos níveis de intensidade de luz onde a fotossíntese realmente decresce com o aumento da irradiância. Este fenômeno é conhecido como fotoinibição, mas não será tratado no presente trabalho.

\section{Representação matemática}

Uma curva como a mostrada na Figura 2.5 precisa de dois ou três parâmetros para sua descrição completa, dependendo se passa ou não pela origem. Se passar pela origem $\left(R^{B}=0\right)$, somente dois parâmetros serão necessários. Convencionalmente, estes são escolhidos como sendo a inclinação inicial $\alpha^{B}$, e o número de assimilação $P_{\max }^{B}$. Nos casos em que $R^{B}$ não é zero, o terceiro parâmetro requerido é $R^{B}$ mesmo. Os casos em que $R^{B}=0$ ou $R^{B} \neq 0$ podem ser relacionados matematicamente por uma simples transformação linear. No presente trabalho, as curvas de luz - fotossíntese passam sempre pela origem (Platt et al., 1980). Unidades típicas de $\alpha^{B}$ podem ser $\operatorname{mgC} .(\mathrm{mgClo})^{-1}\left(\mathrm{~W} \cdot \mathrm{m}^{-2}\right)^{-1} \cdot \mathrm{h}^{-1}$ e para $P^{B}{ }_{\max }, \mathrm{mgC} \cdot(\mathrm{mgClo})^{-1} \cdot \mathrm{h}^{-1}$. No caso em que $R^{B}=0$, a curva $\mathrm{P}$ - I pode ser representada por uma função de uma variável (irradiância) e dois parâmetros $\left(\alpha^{B}\right.$ e $\left.P^{B}{ }_{\max }\right)$, da seguinte forma:

$$
P^{B}(I)=p^{B}\left(I ; \alpha^{B}, P_{\max }^{B}\right)
$$

O formalismo de $p^{B}\left(I ; \alpha^{B}, P^{B}{ }_{\max }\right)$ é uma representação genérica da curva de saturação de luz. Quando a equação (2.5) é utilizada com dados in situ para calcular a produção primária, o valor de $I$ deverá ser a irradiância a uma determinada profundidade $z$ na 
coluna d'água, em um dado tempo. Para cada valor de irradiância existe uma profundidade correspondente, dado que, em sistemas aquáticos, a irradiância é uma função de decaimento monotônico com a profundidade. Desta forma, a equação (2.5) permite estimar a produção primária a uma dada profundidade. A equação 2.5 pode então, ser escrita da seguinte forma:

$$
P^{B}(z)=p^{B}\left(I(z) ; \alpha^{B}, P_{\max }^{B}\right)
$$

A função utilizada no presente trabalho para especificar a função $p^{B}$ foi a sugerida por Platt et al., (1980) sem fotoinibição:

$$
p^{B}=P_{\max }^{B}\left(1-\exp \left(-\alpha^{B} I / P_{\max }^{B}\right)\right)
$$

A informação derivada de um experimento de curva $\mathrm{P}$ - I pode ser resumido por dois números: as magnitudes dos parâmetros $\left(\alpha^{B}, P^{B}{ }_{\max }\right)$ que melhor ajustam os dados experimentais. Inversamente, estes dois números são suficientes para reproduzir a curva que irá descrever a performance fotossintética da assembléia fitoplanctônica usada no experimento. Desta forma, os parâmetros fotossintéticos normalizados pela biomassa $\alpha^{B}$ e $P^{B}{ }_{\text {max }}$ fornecem um meio "econômico" de organizar dados de produção primária oceânica, sem perda de informação (Platt e Sathyendranath, 2002).

\subsection{Produção primária integrada na coluna d'água}

O fluxograma mostrado a seguir (Figura 2.6) fornece uma visão geral dos diferentes passos seguidos no cálculo da produção primária a uma dada profundidade. $\mathrm{O}$ primeiro passo é especificar o campo de luz superficial $I_{0}=I(z=0)$, onde $z$ é a profundidade (positiva para baixo). Pode ser especificado como uma função dependente do tempo $I_{0}(t)$, como uma integral diária ou uma série de integrais por períodos menores que 1 dia (Bird, 1984; Gregg e Carder, 1990). O passo seguinte é especificar o perfil vertical de biomassa $B(z)$. Isto é importante por duas razões: primeiro, porque determina como o fluxo de irradiância superficial será transmitido pela coluna d'água e segundo, porque determina, em qualquer profundidade, quanto da energia transmitida será absorvida pelo 
fitoplâncton. A distribuição vertical de $B$ pode ser especificada como uma curva padrão, tipo Gaussiana, por exemplo (Platt et al., 1988, 1994), ou pode ser especificada por uma série de valores discretos. No caso mais simples, $B(z)$ é tratada como uma constante.

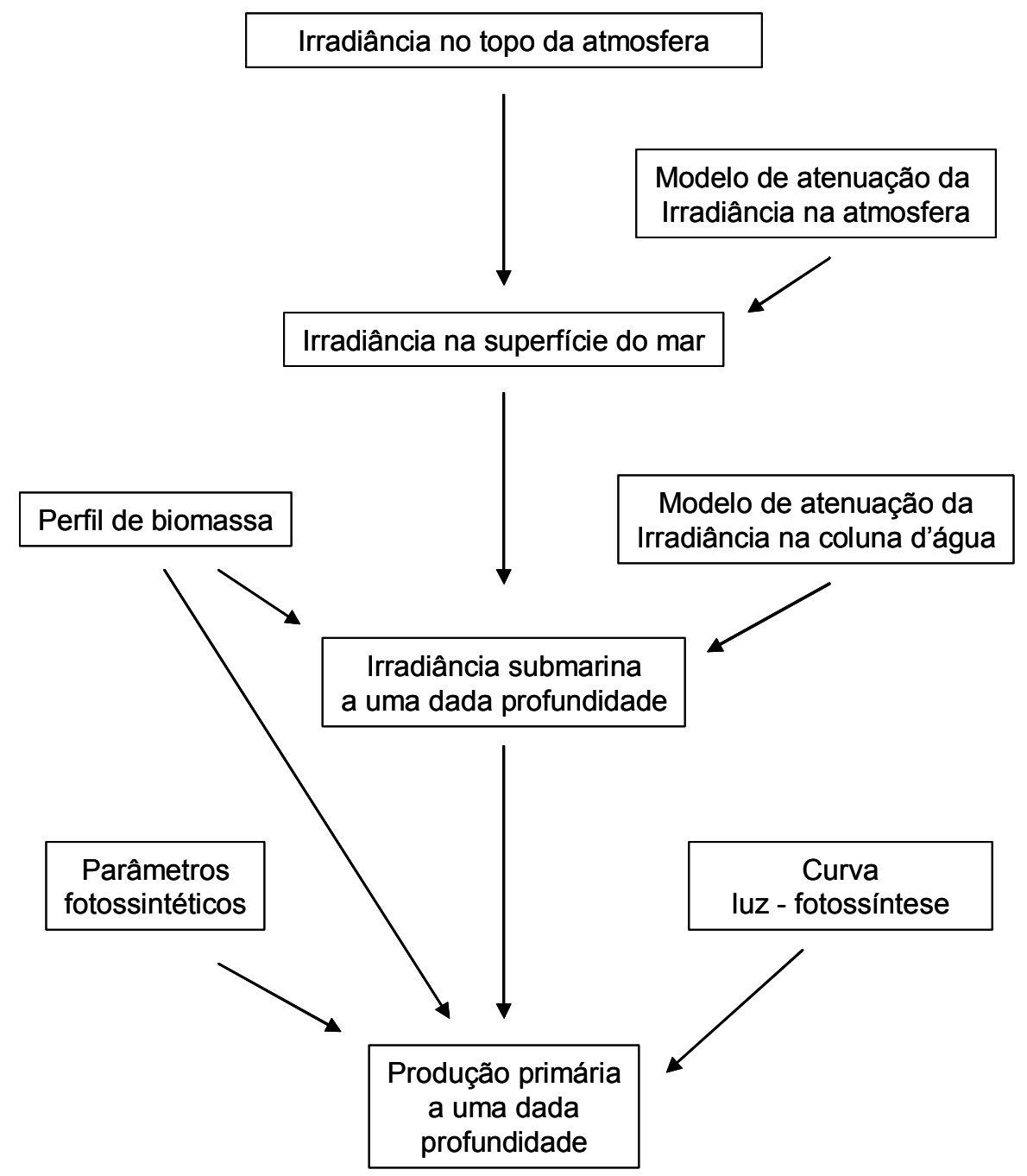

Figura 2.6 - Fluxograma descrevendo os passos necessários no cálculo da produção primária a uma dada profundidade na coluna d'água.

Dado $B(z)$, é preciso utilizar um modelo de atenuação da luz na coluna d'água para calcular a irradiância em função da profundidade (Sathyendranath e Platt, 1988). Uma vez que $B(z)$ e $I(z)$ são conhecidos, aplica-se o modelo escolhido para a função $p^{B}(I)$ (Platt et al., 1980). Como visto anteriormente (equação 2.5), a produção primária absoluta pode ser obtida simplesmente por:

$$
P=B \times P^{B}
$$


Como a biomassa normalmente depende da profundidade $z$, pode-se escrever que:

$$
P(z)=B(z) P^{B}(z)
$$

O cálculo da produção primária na coluna d'água $P_{Z}$ é computado pela integração da equação (2.9), ou seja:

$$
P_{z}=\int_{z} P(z) d z=\int_{0}^{1 \% I} B(z) P^{B}(z) d z
$$

Onde $z$ é positivo para baixo. O limite superior da integral foi considerado neste trabalho, como a base da zona eufótica $\left(1 \%\right.$ de $\left.I_{0}\right)$. O valor de $P(z)$ dado pela equação (2.9) é uma taxa instantânea. Como mostrado anteriormente (equação 2.5), I(z) é uma variável dependente do tempo, ou seja:

$$
P(z, t)=B(z, t) P^{B}(z, t)
$$

Da mesma forma, podemos escrever que:

$$
P^{B}(z)=p^{B}(I(z, t))
$$

Assim, a equação(2.10) pode ser escrita como segue:

$$
P_{z}(t)=\int_{z} P(z, t) d z=\int_{0}^{1 \% I} B(z, t) p^{B}(I(z, t)) d z .
$$

Ainda, é necessário integrar a taxa instantânea da coluna d'água no tempo, de modo a se calcular a produção primária diária integrada em profundidade $P_{Z, T}$ :

$$
P_{Z, T}=\int_{0}^{D} \int_{0}^{1 \% I} B(z, t) p^{B}(I(z, t)) d z d t
$$

Onde o tempo $t$ é medido desde o nascer do sol e $D$ é o fotoperíodo. Para a integração no tempo, é usual considerar que a mudança de biomassa durante o dia é 
suficientemente lenta para que seja desprezível (ou não significativa). Ou seja, suprimese a dependência de $B$ em relação a $t$ na equação (2.14) de modo que:

$$
P_{Z, T}=\int_{0}^{D} \int_{0}^{1 \% I} B(z) p^{B}(I(z, t)) d z d t
$$

A Figura 2.7 sumariza os passos envolvidos no cálculo de $P_{Z T}$.
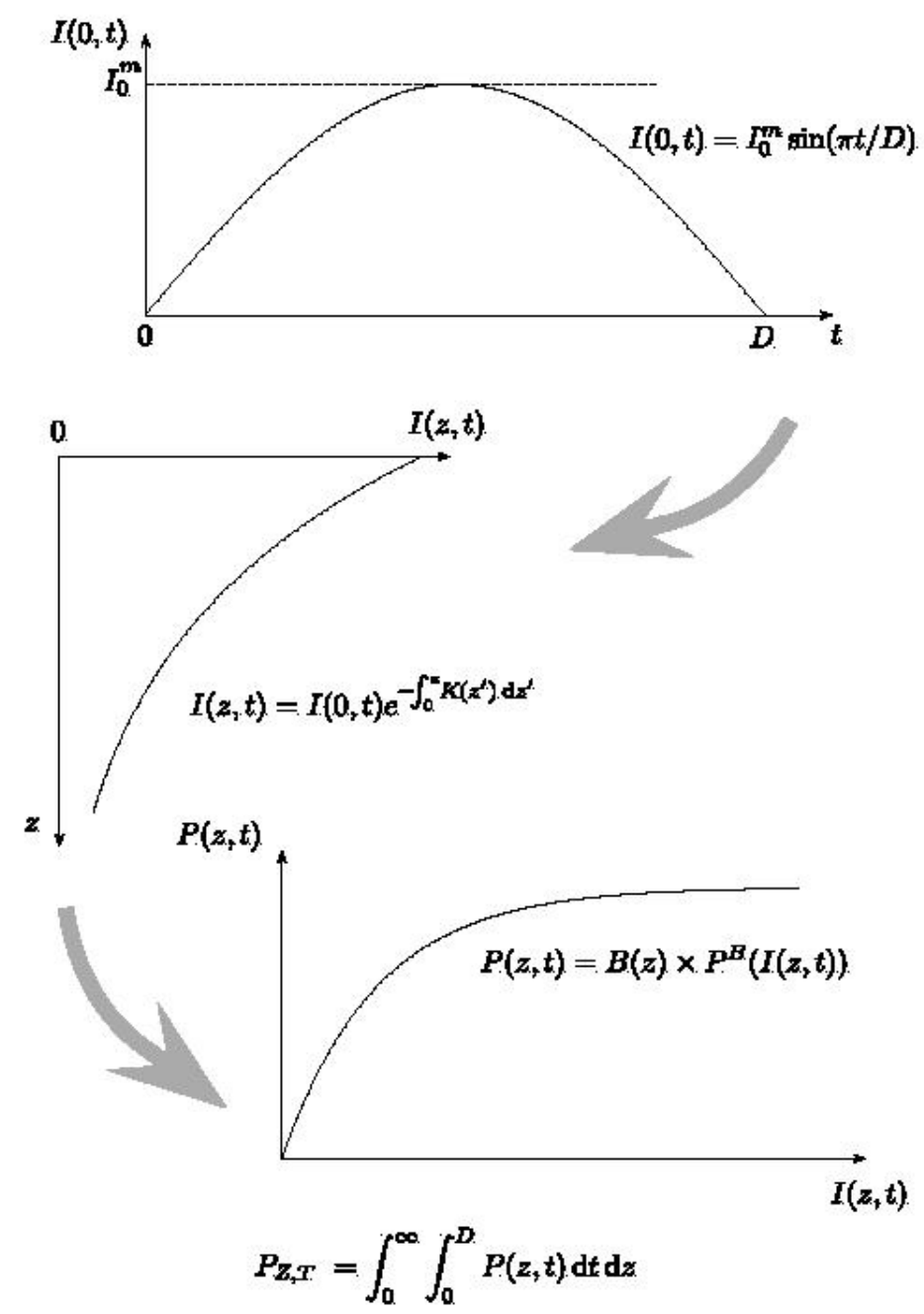

Figura 2.7 - Fluxograma dos passos envolvidos no cálculo da produção primária diária integrada na coluna d'água (adaptado de Platt e Sathyendranath, 2002).

No primeiro passo mostrado na Figura 2.7 (em cima), o campo de luz na superfície do oceano deve ser prescrito. No centro, a atenuação da luz na coluna d'água deve ser estimada. Embaixo, a produção instantânea numa dada profundidade é calculada, 
conhecendo-se o campo de luz e biomassa a uma dada profundidade e a resposta fotossintética do fitoplâncton à luz disponível. Finalmente, a produção primária diária integrada na coluna d'água é calculada pela integração das estimativas instantâneas em profundidade e no tempo.

\subsection{Irradiância}

Apesar da disponibilidade de um sensor de irradiância escalar de superfície (QSR-240 Biospherical Instruments Inc.) instalado a bordo no N/Oc. Prof. W. Besnard durante os cruzeiros oceanográficos, o equipamento apresentou sérios problemas técnicos de funcionamento, impossibilitando a utilização de grande parte dos dados coletados. Desta forma, foram utilizados modelos espectrais da irradiância para determinar as componentes difusa e direta da energia luminosa disponível na superfície do oceano. Bird (1984), Bird e Riordan (1986) e Gregg e Carder (1990) simplificaram modelos complexos que estimavam a atenuação da irradiância espectral pela atmosfera. $O$ trabalho desenvolvido por Gregg e Carder permite simular diferentes condições atmosféricas típicas de continentes ou áreas oceânicas, com alta resolução espectral, fornecendo uma estimativa da PAR disponível na superfície do mar, em função de variáveis meteorológicas e da reflexão na interface atmosfera - oceano. Ainda que as propriedades ópticas de diferentes corpos d'água possam variar significativamente, existe um padrão global que é diferente das propriedades ópticas da atmosfera (Mobley, 1994). O tamanho e o tipo de cobertura de nuvens interferem no fluxo solar que chega na superfície terrestre. Nuvens isoladas em céu claro sem obscurecer o sol, aumentam a quantidade de radiação difusa, mas não afetam a radiação solar direta. Entretanto, nuvens mais contínuas irão reduzir a irradiância. Se ao longo do dia houver cobertura de nuvens, porém de forma descontínua, o valor da radiação irá variar entre o total (céu claro) e cerca de 50\% do total (Kirk, 1994).

A irradiância total superficial foi calculada no presente trabalho usando-se o modelo espectral de céu claro de Bird (1984). Este modelo determina as componentes difusa e direta da irradiância descendente $I_{0}(t)\left(\right.$ Watts. $\left.\mathrm{m}^{-2}\right)$ na superfície em função do tempo $t$ (horas), para uma dada posição geográfica (latitude) e data. Ajustes para variações 
sazonais na irradiância solar extraterrestre e para a reflectância superficial foram incorporados, como descrito por Sathyendranath e Platt (1988). A duração do dia $D$ é função da latitude e data (dia juliano). Para um dado dia, o tempo $t$ é medido a partir do nascer do sol. Uma vez que a irradiância superficial é função do tempo, a irradiância diária total $I_{0}(t)$ é definida pela integral:

$$
I_{T}=\int_{o}^{D} I_{0}(t) d t
$$

A função $I_{0}(t)$ é considerada simétrica em torno do meio-dia $(t=D / 2)$, de modo que a integral possa ser expressa na seguinte forma:

$$
I_{T}=\int_{0}^{D / 2} I_{0}(t) d t+\int_{D / 2}^{D} I_{0}(t) d t=2 \times \int_{0}^{D / 2} I_{0}(t) d t
$$

O máximo $I_{0}^{m} \mathrm{de} I_{0}(t)$ ocorre ao meio-dia local, isto é, quando $I_{0}^{m}=I_{0}(D / 2)$. Um incremento é definido como $\Delta_{t}=D / 24$. O ângulo zenital é calculado 12 vezes $\left(1 \mathrm{x} \Delta_{\mathrm{t}}\right.$, $\left.2 \times \Delta_{\mathrm{t}}, \ldots, D / 2\right)$. A irradiância superficial total $I_{0}(t)\left(\mathrm{W} \cdot \mathrm{m}^{-2}\right)$, em função do tempo $t$ (h), é calculada nos casos onde o ângulo zenital é menor que $80^{\circ}$. A irradiância diária total é obtida, usando-se a regra do trapézio para fazer a integração mostrada na equação (2.17).

As fórmulas de Newton-Cotes são as mais comumente usadas em métodos de integração numérica, aproximando a integração de funções complexas (ou de dados tabulados) pela substituição da função por vários polinômios ao longo do intervalo da integral. A integração da função original pode ser obtida pela soma de todos os polinômios cujas "áreas" são calculadas pelos coeficientes ponderados e os valores da função nos pontos nodais. A regra trapezoidal, ou método dos trapézios é a primeira das fórmulas de Newton-Cotes, definida como:

$$
\int_{x_{1}}^{x_{n}} f(x) d x=\sum_{k=1}^{n-1} \int_{x_{k}}^{x_{k+1}} f(x) d x=\sum_{k=1}^{n-1} \frac{h}{2}\left[f\left(x_{k+1}\right)+f\left(x_{k}\right)\right]+O\left(h^{3} f^{\prime \prime}(x)\right)
$$

onde $h=x_{k+1}-x_{k}$. 
O método dos trapézios foi usado em diversas integrações realizadas no presente trabalho.

\subsection{Imagens de Temperatura da Superfície do Mar (TSM)}

\section{Princípios físicos}

A teoria de transferência radiativa geral pode ser utilizada para estimar a temperatura superficial de praticamente, qualquer corpo dada a sua radiação emitida. $\mathrm{Na}$ faixa de infravermelho termal do espectro eletromagnético, o oceano pode ser considerado como um corpo negro e sua radiação emitida, ou excitância, pode ser aproximada a do radiador de Planck:

$$
W_{\lambda}=\frac{C_{1} \lambda^{-5}}{e^{\frac{C_{2}}{\lambda T}}-1}
$$

Onde: $\mathrm{C}_{1}=2 \pi \mathrm{c}^{2} \mathrm{~h}=3,7416 \times 10^{-12} \mathrm{~W} \cdot \mathrm{cm}^{2} ; \mathrm{C}_{2}=\mathrm{ch} / \mathrm{k}=1,4389 \mathrm{~cm} . \mathrm{K} ; \operatorname{com} \lambda$ em cm e T em K $\left(={ }^{\circ} \mathrm{C}+273\right) ; \mathrm{c}=$ velocidade da luz; $\mathrm{h}=$ constante de Planck; $\mathrm{k}=$ constante de Boltzman. A temperatura do corpo em questão pode então ser estimada. No caso do sensoriamento remoto, em princípio, a TSM pode ser expressa em termos das estimativas de temperatura em dois comprimentos de onda, ou canais radiométricos (McMillin e Crosby, 1984) pela equação:

$$
\mathrm{TSM}=a T_{i}+\gamma\left(T_{i}-T_{j}\right)+c
$$

Onde $T_{i}$ e $T_{j}$ são as temperaturas de brilho medidas nos canais (bandas) $i$ e $j$; $c$ é uma constante e $a$ é normalmente igual a 1 . O termo de absorção diferencial $\gamma$ é definido como uma função da transmitância atmosférica $\tau$ para as respectivas bandas em questão, ou seja:

$$
\gamma=\left(1-\tau_{i}\right) /\left(\tau_{i}-\tau_{j}\right)
$$

A transmitância é dada por $\tau=e^{k u}$, onde $k$ é o coeficiente de absorção de massa e $u$ é o comprimento da trajetória. 


\section{Sensor Advanced Very High Resolution Radiometer (AVHRR)}

O sensor AVHRR está instalado a bordo dos satélites da série NOAA. As espaçonaves da National Oceanic and Atmosphere Administration (NOAA) são colocadas em órbitas heliossíncronas, circulares quase-polares, com altitude média de $850 \mathrm{~km}$. Duas altitudes nominais de $833 \mathrm{~km}$ e $870 \mathrm{~km}$ foram selecionadas para permitir a operação simultânea de dois satélites (Rao, 1990). O sensor AVHRR é um radiômetro imageador de varredura que detecta a energia nas faixas do visível e infravermelho do espectro eletromagnético. Este radiômetro possui atualmente (satélites NOAA 15, 16 e 17) seis canais espectrais que observam simultaneamente uma mesma superfície terrestre. Nas versões anteriores dos satélites $\operatorname{NOAA}(12,14)$ o instrumento possui apenas 5 canais espectrais. Cada canal do instrumento possui um campo de visada instantânea (IFOV) médio de 1,3 milirradianos proporcionando assim, uma resolução espacial de 1,1km no nadir. Um espelho elíptico de varredura em constante rotação possibilita a realização de varreduras transversais entre $\pm 55,4^{\circ}$ a partir do nadir. A varredura transversal (da direita para a esquerda) é executada por incrementos de IFOV, a uma taxa de 360 linhas por minuto. Os dados analógicos do sensor são digitalizados a bordo do satélite com resolução de 10 bits (0 a 1.023 níveis digitais), a uma taxa de 39.936 amostras por segundo, por canal. Nesta razão de amostragem, são obtidas 1,362 amostras por IFOV. Desta forma, um total de 2.048 amostras é obtido por canal, a cada linha. A faixa imageada obtida tem cerca de $2.250 \mathrm{~km}$ de largura. A Tabela 2.1 apresenta os canais do AVHRR e suas respectivas características espectrais, espaciais e termais (quando apropriado). Kampel (2003) fez uma revisão completa sobre o sensor AVHRR, bem como, sobre os satélites NOAA e seus respectivos instrumentos. 
TABELA 2.1 - CARACTERÍSTICAS DO SENSOR AVHRR

\begin{tabular}{|c|c|c|c|}
\hline CANAL & $\begin{array}{c}\text { BANDA } \\
\text { ESPECTRAL }(\mu \mathrm{m})\end{array}$ & $\begin{array}{c}\text { RESOLUÇÃO } \\
\text { ESPACIAL (km) }\end{array}$ & $\begin{array}{c}\text { RELAÇÃO S/N } \\
\text { ou NE } \Delta T\end{array}$ \\
\hline 1 (visível) & $0,58-0,68$ & 1,1 & $\geq 9: 1$ a $0,5 \%$ Albedo \\
\hline 2 (IV ${ }^{1}$-próximo) & $0,725-1,00$ & 1,1 & $\geq 9: 1$ a $0,5 \%$ Albedo \\
\hline 3A (IV ${ }^{1}$-próximo) & $1,58-1,64$ & 1,1 & $\geq 20: 1$ a $0,5 \%$ Albedo \\
\hline 3B (infravermelho) & $3,55-3,93$ & 1,1 & $\leq 0,12 \mathrm{~K}$ a $300 \mathrm{~K}$ \\
\hline 4 (infravermelho) & $10,3-11,3$ & 1,1 & $\leq 0,12 \mathrm{~K}$ a $300 \mathrm{~K}$ \\
\hline 5 (infravermelho) & $11,5-12,5$ & 1,1 & $\leq 0,12 \mathrm{~K}$ a $300 \mathrm{~K}$ \\
\hline
\end{tabular}

\section{Processamento digital}

As imagens do sensor Advanced Very High Resolution Radiometer (AVHRR) de alta resolução $(1 \mathrm{x} 1 \mathrm{~km})$, foram adquiridas em modo High Resolution Picture Transmission (HRPT) pela antena de recepção instalada no Instituto Nacional de Pesquisas Espaciais (INPE), em São José dos Campos, SP. Os dados brutos foram calibrados radiometricamente para gerar valores de albedo e temperatura de brilho referentes à superfície marinha imageada. As áreas com intensa nebulosidade ou com baixos ângulos de elevação do satélite $\left(37^{\circ}\right)$ foram descartadas. As imagens selecionadas foram recortadas de acordo com a área de interesse. Cada imagem passou por algoritmos de correção atmosférica antes do cálculo da TSM. Os valores de TSM foram calculados com a utilização dos algoritmos Multi-Channel Sea Surface Temperature (MCSST) divulgados pela National Oceans and Atmosphere Administration (NOAA) (Kidwell, 1995). Lorenzzetti e Araujo (2003) apresentam uma revisão dos princípios físicos envolvidos na obtenção da TSM pelo sensor AVHRR.

\subsection{Imagens da Concentração de Clorofila da Superfície do Mar (CSM)}

\section{Princípios físicos}

A cor intrínseca da superfície do mar é definida pelas variações espectrais de sua reflectância $R$ na superfície. Em qualquer profundidade $z, R$ é definida como:

$$
R(\lambda, z)=\frac{E_{u}(\lambda, z)}{E_{d}(\lambda, z)}
$$


onde, $E_{u}(\lambda, z)$ é a irradiância ascendente (fluxo por unidade de área superficial), no comprimento de onda $\lambda$ e profundidade $z$; e $E_{d}(\lambda, z)$ é a irradiância descendente, no mesmo comprimento de onda e profundidade. Estas irradiâncias medidas em superfícies planas (coletor co-seno plano) devem ser distinguidas da irradiância escalar, que é medida pelo fluxo recebido de todas as direções em um coletor esférico. A irradiância escalar normalmente recebe a notação $E_{0}$, tendo as mesmas dimensões que a irradiância. Também pode ser dividida em componentes descendente e ascendente ( $E_{0 d}$ e $E_{0 u}$, respectivamente).

A irradiância ascendente é uma medida de toda a luz que deixa a superfície do mar. Entretanto, um sensor remoto com um campo limitado de visada não consegue detectar todo o sinal que deixa a superfície, uma vez que a forma dos detectores e suas respectivas geometrias de visada restringem o sinal a uma pequena fração do fluxo original. Desta forma, uma descrição do campo luminoso estaria incompleta se não incluísse nenhuma informação sobre como os fluxos variam em função das direções. Esta descrição mais completa é fornecida pela medida de radiância, que mede o fluxo por unidade de área e por unidade de ângulo sólido. Se $L(\theta, \phi)$ for a radiância na direção definida pelo ângulo zenital $\theta$ e ângulo azimutal $\phi$, então as várias irradiâncias de interesse podem ser obtidas pela integração de $L$ nos ângulos apropriados. Por exemplo:

$$
E_{d}(\lambda, z)=\int_{\phi=0}^{2 \pi} \int_{\theta=0}^{\pi / 2} L(\lambda, z, \theta, \phi) \cos \theta \operatorname{sen} \theta d \theta d \phi
$$

e

$$
E_{0 d}(\lambda, z)=\int_{\phi=0}^{2 \pi} \int_{\theta=0}^{\pi / 2} L(\lambda, z, \theta, \phi) \operatorname{sen} \theta d \theta d \phi
$$

Aqui, a direção de visada vertical para baixo representa o ângulo zenital zero. As irradiâncias ascendentes $\left(E_{u}\right.$ e $\left.E_{d}\right)$ podem ser obtidas similarmente à distribuição de radiância, integrando-se em todos os ângulos zenitais entre $\pi / 2$ e $\pi$. No contexto do 
sensoriamento remoto, é comum usar a reflectância de sensoriamento remoto $\left(R_{R S}\right)$, que é fortemente correlacionada com a reflectância da superfície do mar $R$, mas que faz uso da radiância ascendente ao invés da irradiância, e é definida como:

$$
R_{R S}(\theta, \phi, \lambda, 0)=\frac{L(\theta, \phi, \lambda, 0)}{E_{d}(\lambda, 0)}
$$

Os argumentos $\theta$ e $\phi$ em $L$ indicam que a radiância que deixa o corpo d'água pode variar com o ângulo de visada (na superfície, $z=0$ ). $\mathrm{O}$ objetivo do sensoriamento remoto da cor do oceano é obter informações quantitativas sobre os tipos e concentrações de substâncias presentes em um corpo d'água, a partir de variações na forma espectral e na intensidade do sinal remoto na faixa do visível do espectro eletromagnético. Portanto, é desejável expressar a reflectância e reflectância de sensoriamento remoto como funções das concentrações das substâncias na coluna d'água que influenciam a cor do oceano. Entretanto, esta não é uma tarefa trivial.

\section{Propriedades ópticas}

A cor do oceano, assim como a reflectância de sensoriamento remoto, podem ser modificadas pela estrutura angular zenital do campo de luz incidente. Em outras palavras, são propriedades ópticas aparentes, como definidas por Preisendorfer, (1976). As propriedades ópticas aparentes são aquelas influenciadas pela distribuição angular do campo de luz, assim como pela natureza e quantidade de substâncias presentes no meio. Uma propriedade óptica aparente de interesse é o coeficiente de atenuação difusa da irradiância descendente, ou $K_{d}$, que define a taxa de diminuição da irradiância descendente com a profundidade. Tem-se por definição:

$$
\frac{d E_{d}(\lambda, z)}{E_{d}(\lambda, z)}=-K_{d}(\lambda) d z
$$

O coeficiente de atenuação $K_{d}$ é utilizado nos modelos para calcular a produção primária em função da luz disponível a uma dada profundidade. Também é usado como 
um índice de transparência da água, sendo uma das variáveis geofísicas que podem ser obtidas a partir de dados da cor do oceano.

\section{Questões relacionadas à correção atmosférica}

A cor do oceano em ambientes naturais é resultante da energia solar retroespalhada pela superfície e volume do corpo d'água. O azul escuro do oceano aberto e de águas oligotróficas é resultante da absorção e espalhamento seletivo da água pura, com baixa concentração (ou ausência) de fitoplâncton ou outras substâncias opticamente ativas. Com uma maior entrada de nutrientes no sistema aquático, geralmente próximo à costa, ocorre um desenvolvimento natural de maiores concentrações de fitoplâncton com conseqüente mudança da cor azul para a verde. Quanto maior for o aporte de sedimentos ou material dissolvido no ambiente aquático, a cor do oceano mudará para amarelo-marron, chegando a vermelha em certas circunstâncias. Estas cores percebidas pelo olho humano podem ser quantificadas por medidas da distribuição espectral da radiância ascendente através de sensores instalados a bordo de satélites. A radiância observada pelos satélites pode ser dividida em:

$$
L_{t}(\lambda)=L_{r}(\lambda)+L a(\lambda)+t(\lambda, \theta) L_{g}(\lambda)+\tau(\lambda, \theta) L_{w}(\lambda)
$$

onde $L_{t}$ é a radiância observada pelo satélite em um determinado comprimento de onda $\lambda, L_{r}$ é a radiância molecularmente espalhada (Rayleigh) pela atmosfera, $L_{a}$ é a radiância espalhada pelos aerossóis atmosféricos, $L_{g}$ é a parte refletida especularmente pela superfície da água e $L_{w}$ é a radiância ascendente ressurgida da coluna d'água (Gordon e Morel, 1983). As radiâncias resultantes da radiação refletida especularmente pela superfície do mar e emergente da subsuperfície, são atenuadas pela transmitância difusa ( $\tau$ ) através da atmosfera em direção ao satélite, segundo o ângulo de visada $\theta$ em relação à vertical. Os modelos dos processos atmosféricos empregados no desenvolvimento de algoritmos da cor do oceano geralmente incorporam um tratamento dos efeitos causados pelo espalhamento Rayleigh (molecular) e pelo espalhamento Mie (aerossóis). O espalhamento molecular é tipicamente responsável pelas maiores contribuições (Gordon, et al., 1988; Andre e Morel, 1989). Com relação ao termo referente ao 
espalhamento pelos aerossóis, é necessário considerar a distribuição vertical destes aerossóis, sua distribuição efetiva de tamanho e propriedades ópticas (Gordon e Castano, 1989).

Tipicamente, as técnicas de correção atmosférica para as águas do Caso 1 se baseiam no fato de que a radiância que deixa a água aproxima-se de zero no domínio do infravermelho próximo. O sinal que alcança o satélite nesta faixa espectral é analisado para inferir as propriedades ópticas da atmosfera nesta mesma região do espectro, e os resultados são extrapolados para o domínio do visível usando modelos de transferência radiativa na atmosfera (Gordon e Morel, 1983; Gordon, 1993; Stürm, 1993; Gordon e Wang, 1994; Gordon, 1997). Isto permite o cálculo da radiância que deixa a água na faixa do visível do espectro eletromagnético.

Por definição, as águas do Caso 1 são aquelas nas quais o fitoplâncton, e todo o material de origem biológica covariante com ele, é o principal agente responsável por variações nas propriedades ópticas da água. Por outro lado, as águas do Caso 2 são influenciadas não somente pelo fitoplâncton, mas também, por outras substâncias opticamente ativas, que variam independentemente, notadamente, as partículas inorgânicas em suspensão e as substâncias amarelas (Morel e Prieur, 1977; Gordon e Morel, 1983; Sathyendranath e Morel, 1983). Esta consideração de que a radiância que deixa a água seria nula na faixa do infravermelho próximo pode não ser verdadeira para as águas do Caso 2 (dominadas pelo material particulado em suspensão). Desta forma, temos que melhorar nossos conhecimentos sobre as propriedades ópticas inerentes dos constituintes da água na faixa do infravermelho próximo para poder também aperfeiçoar as técnicas de correção atmosférica.

\section{Algoritmos bio-ópticos}

Assumindo que a contribuição atmosférica ao sinal do satélite pode ser estimada, resta interpretar a radiância ascendente que emerge da água em termos das características ópticas das camadas superiores do corpo d'água (ou em termos das variações nas concentrações e tipos de material dissolvido e particulado que contribuem para variações nestas propriedades ópticas). As equações utilizadas nestes procedimentos são 
coletivamente referidas como algoritmos bio-ópticos (Smith e Baker, 1978; Clark, 1981). O termo "estado bio-óptico" serve para representar uma medida do efeito total dos processos biológicos sobre as propriedades ópticas das águas em ambientes naturais. Da irradiância que chega aos corpos d'água, 90\% retorna à atmosfera e é proveniente da primeira profundidade óptica, ou seja, da profundidade até onde a irradiância é reduzida a 37\% (1/e) do seu valor na superfície (Gordon e McCluney, 1975; Morel e Berthon, 1989). Por isso, a determinação da concentração de pigmentos através do sensoriamento remoto orbital é restrita a esta camada. A expressão mostrada a seguir foi demonstrada por Morel e Berthon (1989) e relaciona a concentração de clorofila $a$ detectada pelo satélite $\left(\mathrm{C}_{\mathrm{sat}}\right)$ e o perfil vertical de clorofila $\left(\mathrm{C}_{\mathrm{Z}}\right)$ :

$$
C_{\text {sat }}=\left[\int_{0}^{1 / K_{d}} C(z) \exp \left(-2 K_{d} Z\right) d Z\right] /\left[\int_{0}^{1 / K_{d}} \exp \left(-2 K_{d} Z\right) d z\right]
$$

A maioria dos algoritmos desenvolvidos para determinar a concentração de pigmentos a partir de $L_{w}(\lambda)$ relaciona a concentração de pigmentos com a razão entre $L_{w}$ em dois comprimentos de onda $\lambda$, geralmente azul e verde (Gordon e Clark, 1980; Clark, 1981; Morel e Prieur, 1977; Morel, 1980; O'Reilly, et al., 1998; O’Reilly et al., 2000). Esta relação é devida a alta absorção do fitoplâncton na região do azul do espectro eletromagnético em relação à baixa absorção no verde. Kampel e Novo (2003) fizeram uma revisão sobre alguns dos princípios físicos importantes para o sensoriamento remoto de corpos d'água.

\section{O sensor Sea-viewing Wide Filed-of-view Sensor (SeaWiFS)}

O sensor SeaWiFS foi lançado em agosto de 1997 para suceder o CZCS. O propósito do Projeto SeaWiFS é fornecer dados quantitativos das propriedades bio-ópticas dos oceanos, examinando os fatores oceânicos que afetam as mudanças globais. Faz parte dos objetivos da missão avaliar o papel dos oceanos no ciclo global do carbono, assim como em outros ciclos biogeoquímicos, através de programas de pesquisa abrangentes. Os dados do SeaWiFS são empregados para esclarecer a magnitude e variabilidade da concentração de clorofila e produtividade primária, e quantificar as relações entre a física dos oceanos e os padrões de produtividade em grande e mesoescala (McClain et 
al.,1992). O sensor SeaWiFS possui bandas espectrais com resoluções espacial e temporal similares às do AVHRR/NOAA (Tabela 2.2). Algumas características do sensor SeaWiFS estão na Tabela 2.3.

TABELA 2.2- BANDAS ESPECTRAIS DO SENSOR SeaWiFS

\begin{tabular}{c|c}
\hline Banda & $\lambda$ SeaWiFS (nm) \\
\hline $\mathbf{1}$ & $402-422$ \\
\hline $\mathbf{2}$ & $433-453$ \\
\hline $\mathbf{3}$ & $480-500$ \\
\hline $\mathbf{4}$ & $500-520$ \\
\hline $\mathbf{5}$ & $545-565$ \\
\hline $\mathbf{6}$ & $660-680$ \\
\hline $\mathbf{7}$ & $745-785$ \\
\hline $\mathbf{8}$ & $845-885$ \\
\hline
\end{tabular}

TABELA 2.3 - CARACTERÍSTICAS DO SISTEMA SEASTAR/SeaWiFS

\begin{tabular}{c|c}
\hline Resolução no nadir & $1,1 \mathrm{~km} \mathrm{LAC} ; 4,5 \mathrm{~km} \mathrm{GAC}$ \\
\hline Tipo de órbita & Heliossíncrona, $705 \mathrm{~km}$ \\
\hline Cruzamento com equador & $12: 00, \pm 20$ min., descendente \\
\hline Faixa imageada & $2800 \mathrm{~km} \mathrm{LAC}\left( \pm 58.3^{\circ}\right) ; 1505 \mathrm{~km} \mathrm{GAC}\left( \pm 45^{\circ}\right)$ \\
\hline Resolução radiométrica & $10 \mathrm{bits}$ \\
\hline
\end{tabular}

\section{Processamento digital de imagens}

As imagens do sensor SeaWiFS de alta resolução foram adquiridas em modo High Resolution Picture Transmission (HRPT) pela antena de recepção instalada no Instituto Nacional de Pesquisas Espaciais (INPE), em São José dos Campos, SP. Os dados SeaWiFS ficaram codificados por um período de tempo entre 15 e 30 dias até poderem ser decodificados, conforme determinação da National Aeronautics and Space Administration (NASA). O processamento das imagens SeaWiFS foi realizado em ambiente SeaDAS 4.3. Os dados brutos foram calibrados radiometricamente para gerar valores de radiâncias normalizadas referentes à superfície marinha. As imagens julgadas de interesse foram recortadas de acordo com a área de interesse. Cada imagem passou por algoritmos de correção atmosférica (Hooker e Firestone, 2003) antes do cálculo das concentrações de clorofila $a$. Foram utilizados os algoritmos empíricos Ocean 
Chlorophyll 4-bands - OC4 e Ocean Chlorophyll 2-bands - OC2 (O'Reilley et al., 2000), semi-analítico Garver, Siegel, Maritorena version 01 - GSM01 (Maritorena et al., 2002) e redes neurais artificiais $\mathrm{NN}$ (Gross et al., 2000) para estimar as concentrações de clorofila $a$ a partir dos dados SeaWiFS.

\section{Algoritmos empíricos}

A acurácia, precisão e utilidade dos algoritmos empíricos da cor do oceano para estimar a distribuição de clorofila $a$ superficial dependem das características desses algoritmos e das observações in situ usadas em seus respectivos desenvolvimentos. Os algoritmos empíricos para determinação de pigmentos e clorofila amplamente utilizados no processamento global de imagens CZCS foram desenvolvidos a partir de um conjunto de dados contendo apenas 60 radiâncias e concentrações de clorofila $a$ medidas in situ (Evans e Gordon, 1994). Desde a era CZCS, um número crescente de pesquisadores tem medido in situ a reflectância de sensoriamento remoto $\left(R_{R S}\right)$ e concentrações de clorofila $a\left(\mathrm{C}_{\text {insitu }}\right)$ em diferentes províncias oceânicas. Em 1997, o grupo SeaBAM (Firestone e Hooker, 1998) reuniu um conjunto maior de dados contendo 919 observações de $R_{R S}$ e $\mathrm{C}_{\text {insitu }}$. Esta base de dados serviu para avaliar o comportamento estatístico dos algoritmos de clorofila $a$ e para desenvolver os algoritmos de duas bandas - OC2 e de quatro bandas - OC4 (O’Reilley at al., 1998). O algoritmo OC2 estima a $C_{\text {insitu }}$ a partir da razão de bandas $R_{R S}(490) / R_{R S}(555)\left(R_{35}\right)$ utilizando uma função polinomial cúbica modificada (MCP). O algoritmo OC4 também relaciona razões de bandas com a clorofila $a$ através de uma única função polinomial, mas emprega a razão de banda máxima (MBR) determinada como a maior razão $\left(R_{\max }\right)$ entre os valores de $R_{R S}(443) / R_{R S}(555), \quad R_{R S}(490) / R_{R S}(555) \quad$ e $\quad R_{R S}(510) / R_{R S}(555) \quad\left(R_{25}, \quad R_{35} \quad\right.$ e $\quad R_{45}$, respectivamente). O algoritmo OC2 foi empregado como padrão pelo Projeto SeaWiFS após o lançamento do satélite em setembro de 1997. Ainda que as características estatísticas de OC4 fossem superiores às do OC2, o grupo SeaBAM recomendou a utilização da versão mais simples OC2 logo após o lançamento.

A fim de melhorar as estimativas globais em águas ricas em clorofila, o algoritmo OC2 foi revisado (versão 2) baseado em um conjunto de dados maior contendo 1.174 
observações (Maritorena e O’Reilly, 2000). A revisão 2 do OC2 foi aplicada pelo Projeto SeaWiFS no segundo reprocessamento da base de dados SeaWiFS (McClain et al., 2000). Dados in situ adicionais foram sendo disponibilizados como resultado de novos programas (por exemplo, SIMBIOS) e pela continuidade e expansão de campanhas de campo em operação. Esses dados mais novos ampliaram a variedade de províncias bio-ópticas representadas na base original de dados, preenchendo regiões nos domínios de $R_{R S}$ e $C_{i n s i t u}$ que não haviam sido representadas até então. O'Reilly et al., (2000) apresentaram uma revisão dos algoritmos OC2 e OC4 baseados em um conjunto de dados mais amplo e mais representativo de diferentes províncias biogeoquímicas, oligotróficas e eutróficas. Estas últimas versões dos algoritmos OC2 e OC4 foram utilizadas no presente trabalho para estimar as concentrações de clorofila $a$. $\mathrm{O}$ polinômio de quarta ordem para o algoritmo OC4 versão 4 é:

$$
C_{\text {insitu }}=10,0^{\left(0,366-3,067 R_{4 S}+1,930 R_{4 S}^{2}+0,649 R_{4 S}^{3}-1,532 R_{4 S}^{4}\right)}
$$

onde $R_{4 S}=\log _{10}\left(R_{25}>R_{35}>R_{45}\right)$, ou seja, o logaritmos do máximo entre os três valores. A equação polinomial cúbica modificada para o algoritmo OC2 versão 4 é:

$$
C_{\text {insitu }}=10,0^{\left(0,319-2,336 R_{2 S}+0,879 R_{2 S}^{2}-0,135 R_{2 S}^{3}\right)}-0,071
$$

onde $R_{2 S}=\log _{10}\left(R_{35}\right)$.

\section{Algoritmos semi-analíticos}

Os algoritmos semi-analíticos da cor do oceano têm como principal vantagem sobre os modelos empíricos de razão de bandas, a obtenção de várias propriedades ópticas simultaneamente a partir de um único espectro de radiâncias emergentes do oceano. Entretanto, a complexidade desses modelos semi-analíticos tem dificultado seu desenvolvimento e implementação operacional. Maritorena et al., (2000) apresentaram um procedimento para otimizar o modelo semi-analítico inicialmente proposto por Garver e Siegel (1997), para aplicações globais. O modelo GSM01 obtém simultaneamente, estimativas da concentração de clorofila $a$, coeficiente de absorção do 
material dissolvido e detritos $\left[a_{c d m}(443)\right]$ e o coeficiente de material retroespalhado [b $\left.b_{b p}(443)\right]$ a partir de medidas do espectro de radiâncias normalizadas ascendentes da água. A formulação completa do modelo pode ser expressa da seguinte forma:

$$
L_{W N}(\lambda)=\frac{t F_{0}(\lambda)}{n_{w}^{2}} \sum_{i=1}^{2} g_{i}\left\{\frac{b_{b w}(\lambda)+b_{b p}\left(\lambda_{0}\right)\left(\lambda / \lambda_{0}\right)^{-\eta}}{b_{b w}(\lambda)+b_{b p}\left(\lambda_{0}\right)\left(\lambda / \lambda_{0}\right)^{-\eta}+a_{w}(\lambda)+\operatorname{Cloa}_{p h}{ }^{*}(\lambda)+a_{c d m}\left(\lambda_{0}\right) \exp \left[-S\left(\lambda-\lambda_{0}\right)\right]}\right\}^{-i}
$$

onde $t$ é o fator de transmissão oceano-atmosfera; $F_{0}(\lambda)$ é a irradiância solar extraterrestre; $n_{w}$ é o índice de refração da água; $b_{b w}(\lambda)$ é o retroespalhamento da água; $a_{w}(\lambda)$ é a absorção pela água; $b_{b p}(\lambda)$ é o retroespalhamento por partículas; $a_{p h}{ }^{*}$ é o coeficiente de absorção específico da clorofila $a, S$ é o decaimento espectral constante para a absorção pelo material dissolvido e detritos $(c d m) ; \eta$ é o expoente da lei de potência para o coeficiente de retroespalhamento particulado; $\lambda_{0}$ é o comprimento de onda $443 \mathrm{~nm}$.

\section{Modelos de redes neurais}

Uma metodologia para aplicação de redes neurais artificiais (NN) a reflectâncias espectrais medidas pelo SeaWiFS, com fins de estimar a concentração de pigmento fitoplanctônico na superfície de águas do Caso 1, foi desenvolvida por Gross et al., (2000). As principais vantagens deste tipo de abordagem são a associação com complexidades não lineares, a sensibilidade reduzida a ruído e uma aparente filtragem mais eficiente de erros residuais da correção atmosférica. Como demonstrado previamente por Thiria et al., (1993), redes neurais artificiais constituem um bom candidato para a modelagem de funções inversas. Esta abordagem tem sido utilizada em diferentes aplicações geofísicas, porém, só recentemente foram feitas tentativas de se estimar variáveis oceânicas através de redes neurais (Schiller e Doerffer, 1998; Keiner e Brown, 1999). Redes neurais artificiais são sistemas paralelos distribuídos compostos por unidades de processamento simples (nodos ou neurônios) que computam determinadas funções matemáticas, normalmente não-lineares (Braga et al., 1998). Tais unidades são dispostas em uma ou mais camadas e interligadas por um grande número de conexões, geralmente unidirecionais. Na maioria dos modelos estas conexões estão 
associadas a pesos, os quais armazenam o conhecimento representado no modelo e servem para ponderar a entrada recebida por cada neurônio da rede. $\mathrm{O}$ funcionamento destas redes é inspirado em uma estrutura física concebida pela natureza: o cérebro humano.

Em NN's, o procedimento usual na solução de problemas passa inicialmente por uma fase de aprendizagem, onde um conjunto de exemplos é apresentado para a rede, a qual extrai automaticamente as características necessárias para representar a informação fornecida. Isto ocorre por meio de um processo iterativo de ajustes aplicado a seus pesos, o treinamento. As características extraídas são utilizadas posteriormente para gerar respostas para o problema (Braga et al., 1998). Os neurônios artificiais possuem uma estrutura e funcionamento similar aos neurônios biológicos. Pode-se dizer que o neurônio artificial é constituído basicamente de uma função de combinação e uma função de transferência (ativação). A função de combinação é responsável por compor a informação de entrada do neurônio. Se for linear passa a representar a somatória das entradas ponderadas pelos respectivos pesos. Os pesos das conexões denominados pesos sinápticos, análogos aos do neurônio biológico, representam matematicamente o peso de cada informação com relação a um dado neurônio. A função de ativação é responsável pela intensidade do sinal a ser transmitido pelas conexões para os neurônios das camadas adjacentes. Tipicamente, o intervalo de amplitude normalizada de saída de um neurônio está no intervalo unitário $(0,1)$ ou $(-1,1)$ (Galvão e Valença, 1999). As funções de ativação mais utilizadas são a sigmóide e tangente hiperbólica (Loesch e Sari, 1996; Kovacs, 1996). Esquemas dessas funções são mostrados na Figura 2.8.

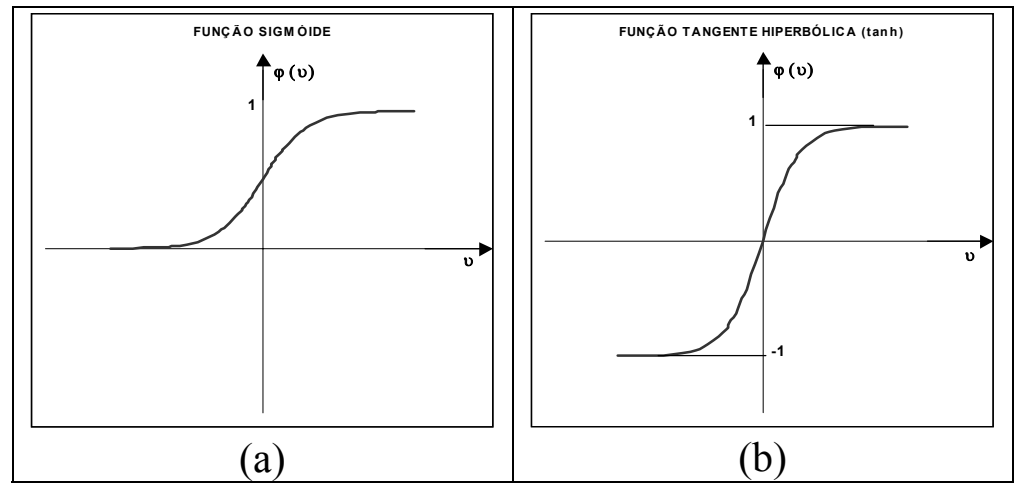

Figura 2.8 - Funções de ativação ou transferência mais utilizadas em redes neurais artificiais. (a) Função sigmóide; (b) Função tangente hipérbólica. 
Em redes de múltiplas camadas, existe mais de um neurônio entre uma entrada e uma saída da rede (Figura 2.9). A camada de entrada é responsável pela distribuição da informação para as camadas intermediárias ou ocultas, ou seja, onde os padrões são apresentados. A camada oculta é onde ocorre o processamento por meio das funções de combinação e ativação e através de conexões ponderadas. A camada de saída é responsável pela saída da rede, onde o resultado final é apresentado. O perceptorn é uma forma simples de NN para classificar um tipo especial de padrão denominado de linearmente separável (Figura 2.10), ou seja, padrões que ficam em lados opostos de um hiperplano (Bishop, 1995). Rumelhart et al., (1986) desenvolveram o algoritmo de treinamento backpropagation, demonstrando que era possível treinar com eficiência redes com camadas intermediárias. Isto resultou no modelo de $\mathrm{NN}$ mais utilizado atualmente, as redes perceptron multicamadas (MLP). Este tipo de rede é utilizado em reconhecimento de padrões, filtragem de sinais, compressão de dados e comparação de padrões heteroassociativos que associam um padrão a outro. As redes feedforward multicamadas possuem um melhor desempenho devido à passagem unidirecional do sinal pela rede (Bishop, 1995). Estas redes podem ser utilizadas para classificação de padrões não linearmente separáveis (Figura 2.11). A Figura 2.12 mostra uma rede neural feedforward típica. Neste exemplo, observa-se uma camada de entrada, duas ocultas e uma camada de saída. Desta maneira, os passos necessários para a aplicação de uma NN são: coleta de dados, separação dos conjuntos de treinamento e verificação, configuração da rede, treinamento, verificação e integração da rede. 


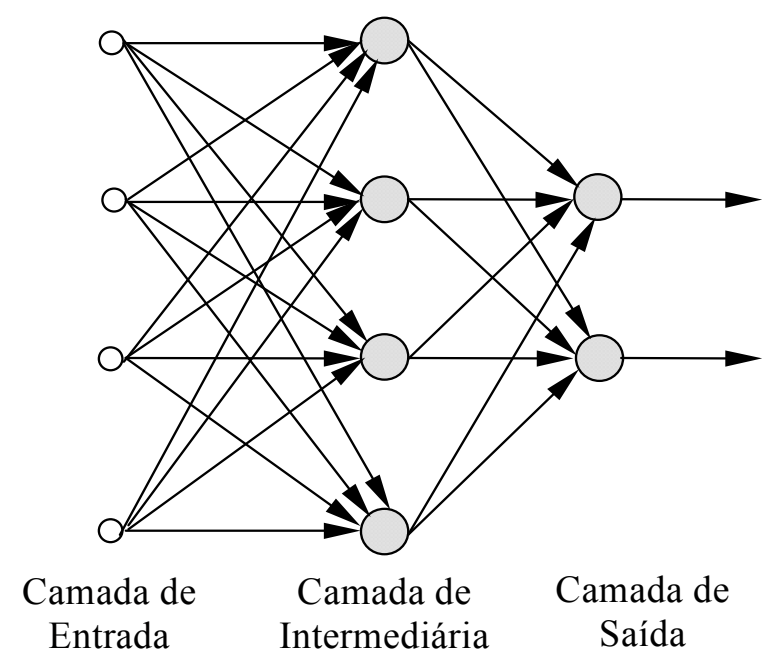

Figura 2.9 - Rede de Múltiplas Camadas (Adapatado de Haykin, 1994).

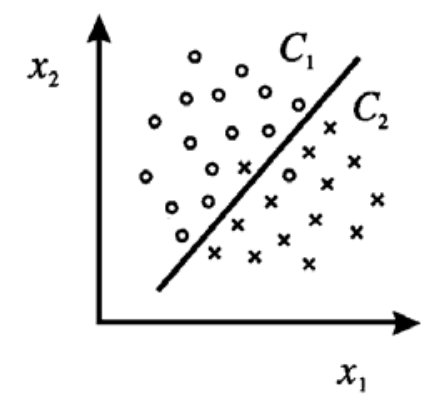

Figura 2.10 - Padrões linearmente separáveis: dados que caem em lados opostos do hiperplano e podem ser separados por uma linha reta. Os padrões que não pertencem à determinada classe, mas que foram a ela designadas, são minoria e representam uma porcentagem de erro admissível (Fonte: Bishop, 1995).

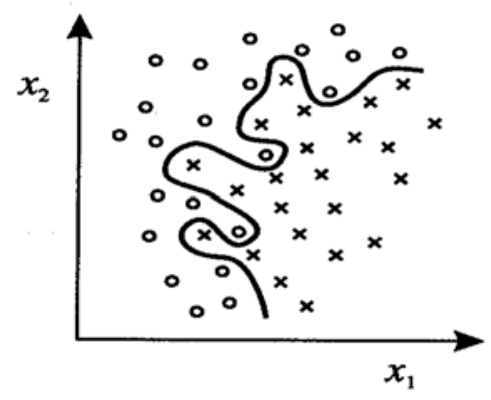

Figura 2.11 - Padrões não linearmente separáveis: padrões que caem em determinadas posições do hiperplano que não podem ser separados por uma linha reta. Soluções não lineares, normalmente, apresentam percentuais de erro na classificação inferiores à soluções lineares para a grande maioria dos problemas ( Fonte: Bishop, 1995). 


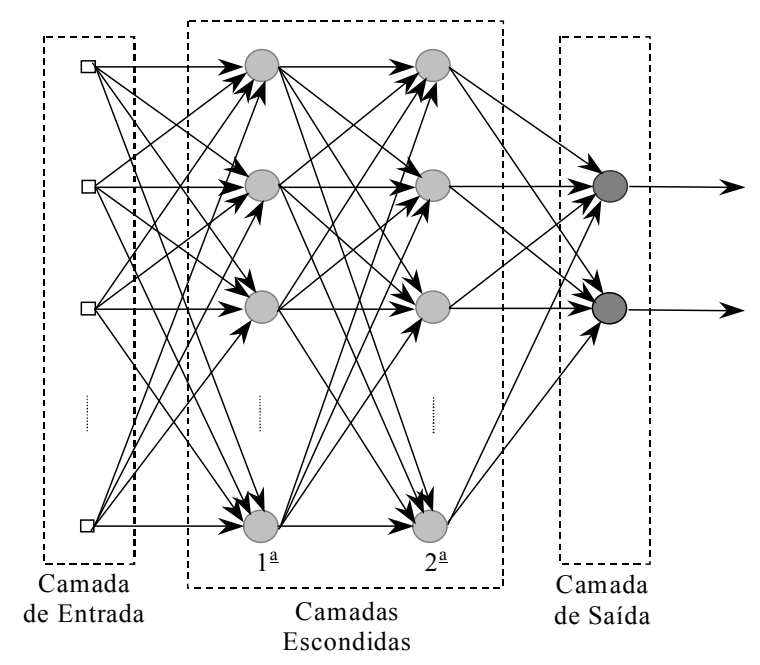

Figura 2.12 - Arquitetura Multicamadas Perceptron com duas camadas escondidas (Adapatada de Haykin, 1994).

No presente trabalho, foi utilizado o modelo NN de Gross et al., (2000), que propuseram a utilização de uma rede multicamada perceptron (MLP) para estimar a concentração de clorofila $a$ a partir das reflectâncias medidas pelo SeaWiFS.

\section{Comparações entre dados in situ e dados de satélites}

Comparações entre temperaturas da superfície do mar medidas in situ e estimadas por satélite (sensor AVHRR/NOAA) foram realizadas dentro de um período de \pm 1 dia, a partir da data da estação oceanográfica. Este intervalo de tempo não permite evitar os efeitos provocados pelo aquecimento diurno e resfriamento noturno das camadas superiores do oceano. Os pares de dados foram formados entre a TSM in situ e o valor mediano de uma janela de 5 x 5 pixels $(25 \mathrm{~km}$ x $25 \mathrm{~km})$ centrada na posição geográfica da estação oceanográfica na imagem equivalente.

As comparações entre as medidas de Clorofila a in situ $\left(\mathrm{C}_{\text {insitu }}\right)$ e estimadas por satélite (SeaWiFS) foram realizadas dentro de um período de \pm 1 dia, a partir da data da estação oceanográfica. Os pares de dados foram formados entre a $\mathrm{C}_{\text {insitu }}$ e o valor mediano de uma janela de 5 x 5 pixels ( $25 \mathrm{~km}$ x $25 \mathrm{~km}$ ) centrada na posição geográfica da estação oceanográfica na imagem SeaWiFS equivalente. 


\subsection{Perfilador de fluorescência natural (PNF)}

O equipamento PNF-300 (Biospherical Instruments Inc.) possibilitou a estimativa de perfis verticais de clorofila $a$, produção primária instantânea e coeficiente de atenuação vertical da luz. O sistema é composto de um instrumento que mede a radiância emergente (centrada no comprimento de onda de fluorescência máxima da clorofila $a$ ), uma referência da PAR superficial (QSR-240) e cabos. O instrumento é lançado a partir do navio até a profundidade máxima definida em função do comprimento de seu respectivo cabo $(100 \mathrm{~m})$. Em condições de fortes correntezas, essa profundidade fica reduzida em função da inclinação do equipamento. O PNF-300 também mede a radiação PAR submarina, pressão e temperatura da água. Constantes de calibração foram fornecidas pelo fabricante do equipamento, para conversão das voltagens em parâmetros de interesse.

\section{Princípios físicos}

A fluorescência natural no oceano é a emissão da clorofila $a$ estimulada pela luz do sol em uma banda estreita centrada em $683 \mathrm{~nm}$ (Chamberlin et al., 1990), resultante da absorção de luz natural pelo fitoplâncton. Esta emissão não deve ser confundida com a bioluminescência, que vem a ser a produção de luz a partir de energia bioquimicamente armazenada.Uma vez que a radiação na região do vermelho do espectro eletromagnético é fortemente absorvida pela água, a radiação solar nos comprimentos de onda de emissão da clorofila desaparece nos primeiros metros da coluna d'água. A radiância emergente restante no vermelho advém quase que totalmente do fitoplâncton. Desde sua identificação (Morel e Prieur,1977; Neville e Gower, 1977), a fluorescência natural tem sido utilizada para obtenção do perfil vertical de biomassa fitoplanctônica. Kiefer et al., (1989) e Chamberlin (1989) sugeriram a utilização de medidas da fluorescência natural para estimar a produção primária. Entretanto, existem problemas relacionados à interpretação da fluorescência natural no mar, como por exemplo: contaminação do sinal por feopigmentos; razão muito alta entre produção e fluorescência nas algas verdeazuladas; efeitos inibidores sobre a razão produção - fotossíntese devido ao esgotamento de nutrientes; reflexão de profundidades rasas ou problemas de 
espalhamento próximo à superfície, entre outros (Biospherical Instruments, 1996). A estimativa da concentração de clorofila $a$ e produção primária pelo PNF-300 resulta de medidas coincidentes da irradiância incidente, que governa a fotossíntese, e da radiância emergente no vermelho, resultante da fluorescência pelo fitoplâncton. A PAR medida pelo PNF-300 utiliza sensores com geometria esférica para medir a irradiância escalar $E_{0}\left(\mu \mathrm{E} \cdot \mathrm{m}^{-2} \cdot \mathrm{s}^{-1}\right)$. Sendo $L$ a radiância, $w$ o ângulo sólido de resposta do coletor $(4 \pi), \theta \mathrm{o}$ ângulo zenital e $\phi$ o ângulo azimutal do fluxo radiante, a irradiância escalar no intervalo PAR é definida como:

$$
E_{0}(P A R)=\int_{400}^{700} \int_{4 \pi} L(\theta, \phi) d w d \lambda
$$

Um fluorímetro natural é um sensor óptico cuja resposta espectral é projetada para medir a radiância emergente $L_{u(C l o)}\left(\mathrm{nE} \cdot \mathrm{m}^{-2} \cdot \mathrm{s}^{-1} \cdot \mathrm{sr}^{-1}\right)$ especificamente no espectro de emissão da clorofila $a$. Se $V$ (volts) for a saída do sensor com resposta $R(\lambda)$ (volts por $\left.\mathrm{nE} \cdot \mathrm{m}^{-2} \cdot \mathrm{s}^{-1} \cdot \mathrm{sr}^{-1}\right)$ para a radiância com características de emissão da clorofila, $L_{c}(l)\left(\mathrm{nE} \cdot \mathrm{m}^{-}\right.$ $\left.{ }^{2} \cdot \mathrm{s}^{-1} \cdot \mathrm{sr}^{-1}\right)$, então pode-se estimar a radiância a partir da fluorescência da clorofila:

$$
L_{u}(\operatorname{chl})=\frac{V \int_{\lambda=400}^{700} L_{c}(\lambda) d \lambda}{\int_{\lambda=400}^{700} R(\lambda) L_{c}(\lambda) d \lambda}
$$

Tipicamente, o espectro de emissão da clorofila $a$ tem máximo em $683 \mathrm{~nm}$ in vivo, e é importante distinguir entre as medidas de $L_{u}(683)$ e $L_{u(C l o)}$. A primeira, normalmente refere-se a uma medida da radiância emergente centrada espectralmente em $683 \mathrm{~nm}$, usando um sensor com $10 \mathrm{~nm}$ de largura de banda. Estes sensores são calibrados por uma fonte de banda mais larga, normalmente com unidades em mW. $\mathrm{cm}^{-2} \cdot \mathrm{sr}^{-1} \cdot \mathrm{nm}^{-1}$, que são diferentes das de $L_{u(C l o)}$. Para calcular a concentração de clorofila $a$ e taxas instantâneas de fotossíntese, são necessárias algumas variáveis intermediárias calculadas a partir da radiância e irradiância medidas. O fluxo de volume de fluorescência natural $F_{f}$, ou seja, a medida de luz por unidade de volume assumindo que 
a fonte seja a fluorescência da clorofila, pode ser calculado a partir de medidas de $L_{u(C l o)}$ e da taxa de atenuação da luz na coluna d'água:

$$
F_{f}=4 \pi(k(P A R)+a(C l o)) L_{u}(C l o)
$$

$\mathrm{Na}$ equação (2.34), o termo $4 \pi$ é uma constante geométrica com unidades de sterradianos $\left(\mathrm{sr}^{-1}\right)$ como mencionado por Chamberlin et al. (1990). O coeficiente de atenuação difusa da PAR, $K_{P N F}\left(\mathrm{~m}^{-1}\right)$, é calculado a partir das medidas de irradiância. $\mathrm{O}$ termo $a(\mathrm{Clo})$ é o coeficiente total de absorção da água considerado como constante $\left(0,48 \mathrm{~m}^{-1}\right)$. Estes termos são usados para converter as medidas de radiância $\left(\mu \mathrm{E} \cdot \mathrm{m}^{-2} \cdot \mathrm{s}^{-1} \cdot \mathrm{sr}^{-1}\right)$ em fluorescência volumétrica $\left(\mu \mathrm{E} \cdot \mathrm{m}^{-3} \cdot \mathrm{s}^{-1} \cdot \mathrm{sr}^{-1}\right)$. A concentração de clorofila $\left(\mathrm{mg} . \mathrm{m}^{-3}\right)$ pode ser calculada a partir de $F_{f}$, e da irradiância incidente (Equação 2.35). Há duas considerações importantes: ${ }^{o} a_{c}(P A R)$ é o coeficiente de absorção específico da clorofila (absorção normalizada pela concentração de clorofila) e $\Phi_{\mathrm{f}}$ é o rendimento quântico da fluorescência. Ambos os valores são tratados como constantes, com valores iguais a $0,04 \mathrm{~m}^{2} . \mathrm{mg}^{-1}$ e $0,045 \mathrm{mE}$ emitido por $\mathrm{mE}$ absorvido, respectivamente.

$$
C l o=\frac{F_{f}}{{ }^{o} a_{c}(P A R)^{*} \Phi_{f}{ }^{*} E_{0}(P A R)}
$$

A taxa de fotossíntese $F_{c}$ (ng.atmos.C. $\mathrm{m}^{-3} . \mathrm{s}^{-1}$ ) usa o termo de fluorescência volumétrica definido na Equação (2.34) e a irradiância incidente. Os valores empíricos $\Phi_{r \max }$ e $k_{\Phi}$ são o valor máximo da razão entre o rendimento quântico máximo da fluorescência e a irradiância na qual essa razão é metade do máximo. Um valor igual a 4 átomos de carbono por fóton é atribuído a $\Phi_{\text {rmax }} ; k_{\Phi}$ é considerado igual a $133 \mu \mathrm{E} \cdot \mathrm{m}^{-2} . \mathrm{s}^{-1}$ (Chamberlin et al., 1990). Assim, temos:

$$
F_{c}=F_{f} \frac{k_{\Phi} \Phi_{r \max }}{k_{\Phi}+E_{0}(P A R)}
$$


Para converter as unidades da produção primária instantânea estimada pelo PNF (ng.atmos.C. $\left.\mathrm{m}^{-3} \cdot \mathrm{s}^{-1}\right)$ em relação às medidas in situ $\left(\mathrm{mgC} \cdot \mathrm{m}^{-3} \cdot \mathrm{h}^{-1}\right)$, foi utilizada uma constante igual a 0,0432 .

Os dados de concentração de clorofila medidos com o PNF foram filtrados e interpolados de metro em metro, desde a superfície até a profundidade máxima amostrada. Sempre que possível estes dados foram aproveitados no ajuste dos perfis verticais de biomassa.

\subsection{Perfil vertical de biomassa}

Estimativas da produção primária diária integrada na coluna d'água usando dados de sensoriamento remoto da cor do oceano, segundo a abordagem proposta por Platt e Sathyendranath (1988), com modificações sugeridas por Sathyendranath et al., (1995), requerem quatro classes ou tipos de informação: cobertura de nuvens, clorofila superficial, parâmetros do perfil vertical de biomassa na coluna d'água e parâmetros fotossintéticos. A latitude e data (dia juliano) de uma determinada estação oceanográfica ditam o ângulo zenital do sol (Paltridge e Platt, 1976), que por sua vez, determina a irradiância superficial. Perfis verticais de biomassa fotossinteticamente ativa, $B_{(z)}$, e de biomassa $C_{(z)}$, são necessários (para uma distinção formal entre $B$ e $C$, ver Sathyendranath et al., 1989). Ambos podem ser obtidos in situ ou por modelo. No oceano aberto, a contribuição de feopigmentos em $C_{(z)}$ é desprezível (Longhurst et $a l ., 1995)$. Desta forma, pode-se usar $B_{(z)}$ para representar ambas as quantidades, e computar o coeficiente de atenuação vertical difuso a partir de $B_{(z)}$ como descrito em Sathyendranath e Platt (1988). Sabendo-se o coeficiente de atenuação e a irradiância de superfície, que pode requerer correções devido à cobertura de nuvens, a irradiância em cada profundidade da zona eufótica pode ser determinada. Com a irradiância em cada profundidade, somente os parâmetros de resposta fotossintética da biomassa clorofiliana para uma dada região e estação do ano, são necessários para calcular a produção primária em cada profundidade.

O perfil Gaussiano foi utilizado por Lewis et al., (1983) para descrever a distribuição vertical de biomassa fitoplanctônica no oceano. Posteriormente, Platt et al., (1988) 
introduziram o conceito da curva de Gauss-deslocada, que nada mais é do que uma curva de Gauss sobreposta a uma constante de fundo (background). Esta abordagem de Platt et al., (1988) mostrou-se como um modelo de perfil vertical de biomassa mais versátil (Platt et al., 1994). O perfil vertical de biomassa modelado pela curva de Gaussdeslocada pode ser descrito (usando uma entre diferentes formulações matemáticas equivalentes) pela equação:

$$
B(z)=f\left(z ; h, \sigma, B_{0}, Z_{M}\right)=B_{0}+\frac{h}{\sigma \sqrt{2 \pi}} e^{-\frac{\left(z-Z_{M}\right)^{2}}{2 \sigma^{2}}}
$$

onde $B_{(z)}$ é a biomassa $\left(\mathrm{mg} . \mathrm{m}^{-3}\right)$ em função da profundidade $z$ (metros, positiva para baixo); $B_{0}\left(\mathrm{mg} \cdot \mathrm{m}^{-3}\right)$ representa a concentração de fundo (background) sobre a qual a curva de Gauss, cujo pico é centrado na profundidade $Z_{M}$ (metros), é sobreposta (Figura 2.13); $h$ é o parâmetro de amplitude do máximo de clorofila $\left(\mathrm{mg}^{-2} \mathrm{~m}^{-2}\right)$; $\sigma$ é o parâmetro de escala da largura do pico de clorofila (metros). Em certos casos, formas alteradas do modelo podem ser apropriadas $\left(B_{0} \equiv 0\right.$ ou $\left.h \equiv 0\right)$. O modelo de Gauss-deslocado permite combinar os valores superficiais sem comprometer a estrutura do perfil vertical. Este perfil é o padrão adotado por diferentes autores (Morel e Berthon,1989; Sathyendranath e Platt,1989; Sathyendranath et al., 1989; André, 1992; Gordon, 1992). Foi demonstrado que a curva de Gauss-deslocada fornece uma descrição adequada para as distribuições verticais de clorofila, tanto para $B_{(\mathrm{z})} \operatorname{como} C_{(z)}$ (geralmente, são iguais), em diversos locais do oceano. A partir das observações in situ de clorofila a obtidas no presente trabalho, foram estimados os parâmetros médios da curva de Gauss-deslocada para os quatro cruzeiros de mesoescala. 

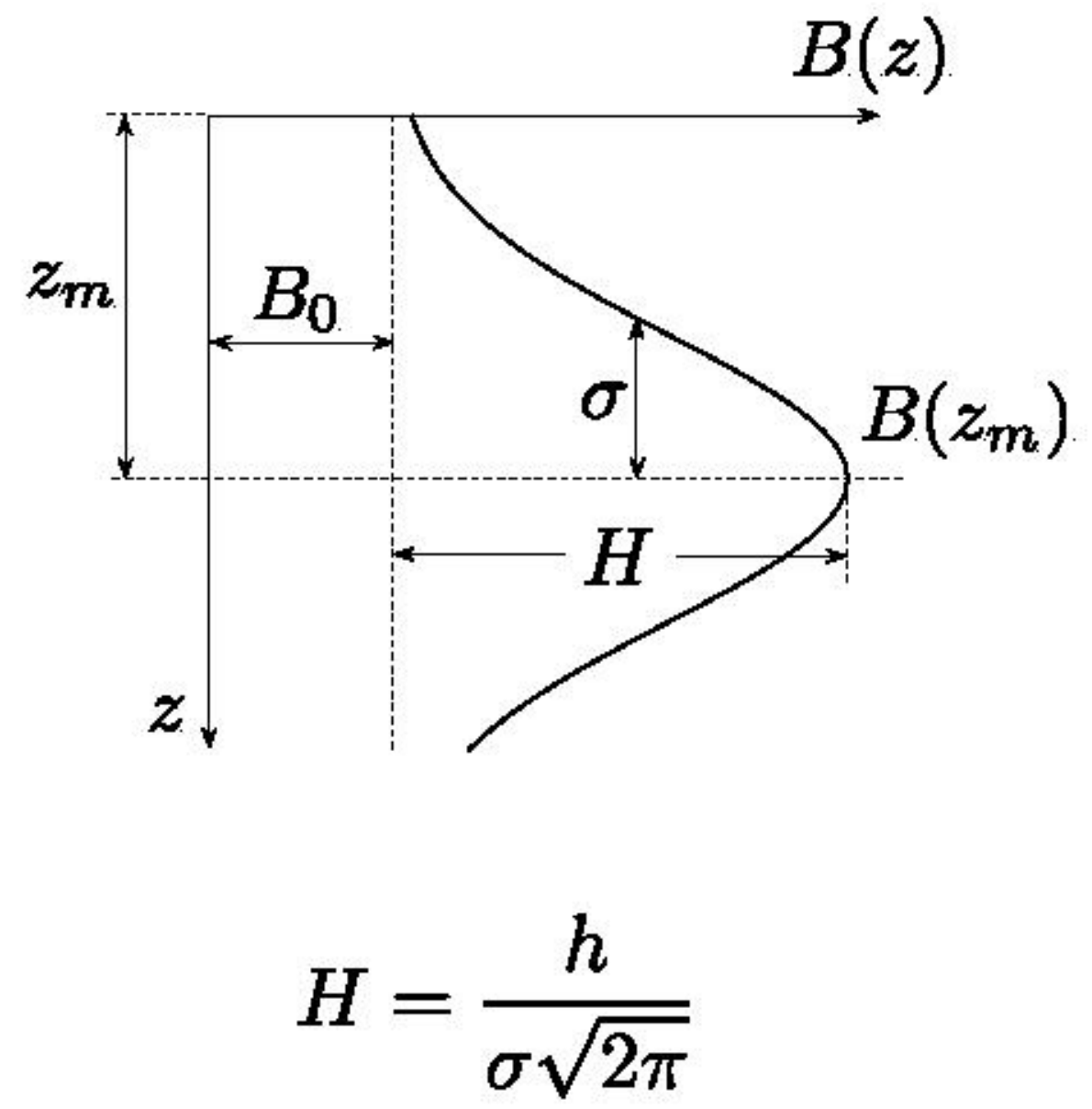

Figura 2.13 - Modelo de curva de Gauss-deslocada para o perfil vertical de biomassa (adaptado de Platt et al., 1994)

\subsection{Modelos de produção primária por satélite}

Mapas globais da concentração de clorofila na superfície do oceano são obtidos por sensores orbitais da cor do oceano. Esses sensores multiespectrais são capazes de mapear a concentração de clorofila, como indexador da biomassa fitoplanctônica, detectando variações espectrais da radiância emergente do mar. Quando as concentrações de clorofila aumentam, a luz azul é mais absorvida e menos retroespalhamento ocorre na direção do espaço. Ainda que uma cobertura global possa ser obtida nominalmente a cada 1 ou 2 dias, a resolução temporal real é reduzida a 5 10 dias devido à cobertura de nuvens. Entretanto, a cobertura fornecida pelo sensoriamento remoto orbital é muito maior que a possível de ser obtida por outros 
meios convencionais. Uma das principais aplicações de dados globais de clorofila é a estimativa da produção primária (Behrenfeld et al., 2001).

Os modelos matemáticos ou procedimentos para estimar a produção primária por satélite são conhecidos como algoritmos de produtividade primária (Campbell et al., 2002). Na era CZCS, relações estatísticas simples foram propostas para calcular a produção primária a partir da concentração de clorofila superficial (Smith e Baker, 1978; Eppley et al., 1985). Estes algoritmos derivados empiricamente ainda são considerados úteis quando aplicados a dados médios anuais (Iverson et al., 2000), porém, não são considerados suficientemente precisos para estimar a produção em escalas sazonais (Campbell et al., 2002). Os trabalhos de diferentes autores demonstraram, que a clorofila superficial só era capaz de explicar cerca de $30 \%$ da variância na produção primária em escala local, de uma estação oceanográfica (Balch et al., 1992; Campbell e O’Reilly, 1988). Nas últimas duas décadas, os pesquisadores pensaram em aperfeiçoar os algoritmos pela combinação de dados de clorofila obtidos por satélite com outros campos de dados também obtidos por sensoriamento remoto, tais como, a radiação fotossinteticamente ativa e temperatura da superfície do mar, por exemplo. Estes algoritmos incorporaram modelos da resposta fotossintética do fitoplâncton à luz, temperatura e outras variáveis ambientais. Alguns algoritmos também incorporaram modelos da distribuição vertical dessas propriedades na zona eufótica (Balch et al., 1989; Morel, 1991; Platt e Sathyendranath, 1993; Howard, 1995; Antoine e Morel, 1996a; Behrenfeld e Falkowski,1997a; Ondrusek et al., 2001). Os algoritmos foram utilizados para estimar a produção primária oceânica global a partir de dados CZCS (Antoine e Morel, 1996b; Longhurst et al., 1995; Behrenfeld e Falkowski, 1997a; Howard e Yoder, 1997), e mais recentemente, a partir de dados do SeaWiFS (Behrenfeld et al., 2001). Mapas globais da produção primária média semanal, mensal e anual estão sendo atualmente produzidos a partir do sensor Moderate Resolution Imaging Spectroradiometer (MODIS).

Enquanto que muitas das respostas fotossintéticas (à luz, temperatura, etc) sejam similarmente representadas em diferentes algoritmos, os tipos de modelos nos quais esses algoritmos se baseiam podem diferir com respeito às suas respectivas estruturas e 
complexidades computacionais. Behrenfeld e Falkowski (1997b) apresentam um esquema geral de classificação para os modelos de produtividade primária oceânica (Tabela 2.4). Cada categoria apresentada na Tabela 2.4 inclui um parâmetro fotoadaptativo $\left(\Phi, \varphi, P^{B}(z), P^{B}{ }_{o p t}\right)$ correspondente à resolução do campo de luz descrito. $\Phi$ e $\varphi$ são os rendimentos quânticos específicos da clorofila para a PAR absorvida ou disponível, respectivamente. Os modelos resolvidos espectralmente (Wavelenght resolved models - WRM) e espectralmente integrados (Wavelenght integrated models WIM) são parametrizados usando medições que os aproximam da fotossíntese líquida. Os modelos integrados no tempo (Time integrated models - TIM) e integrados em profundidade (Depth integrated models - DIM) são idealmente, parametrizados com medições conduzidas por $24 \mathrm{~h}$ o que os aproxima da produção líquida. $P^{B}(z)$ e $P^{B}{ }_{\text {opt }}$ são taxas fotossintéticas específicas da clorofila; o asterisco $\left(^{*}\right)$ denota normalização pela concentração de clorofila.

TABELA 2.4 - SISTEMA DE CLASSIFICAÇÃO DOS MODELOS DE PRODUTIVIDADE PRIMÁRIA OCEÂNICA (PPO) BASEADO NOS NÍVEIS IMPLÍCITOS DE INTEGRAÇ̃̃O

\begin{tabular}{c|c}
\hline Categoria & Estrutura Geral \\
\hline WRM & $P P_{E U}=\int_{\lambda=400}^{700} \int_{t=0}^{D} \int_{z=0}^{z_{e u}} \Phi(\lambda, t, z) P A R(\lambda, t, z) a^{*}(\lambda, z) C l o(z) d \lambda d t d z-R$ \\
\hline WIM & $P P_{E U}=\int_{t=0}^{D} \int_{z=0}^{z_{e u}} \varphi(t, z) P A R(t, z) C l o(z) d t d z-R$ \\
\hline TIM & $P P_{E U}=\int_{z=0}^{z_{e u}} P^{B}(z) P A R(z) D C l o(z) d z$ \\
\hline DIM & $P P_{E U}=P_{o p t}^{B} P A R(0) D C l o z$ \\
eu
\end{tabular}

Alguns modelos podem ser similares em estrutura, mas requerem diferentes parâmetros dependendo se descrevem a produção diária, horária ou instantânea, e mesmo quando esses aspectos são similares, os algoritmos muitas vezes geram resultados diferentes devido a diferenças nas parametrizações. Balch et al (1992) avaliaram diferentes algoritmos (tanto empíricos como baseados em modelos), usando medições in situ de produtividade disponíveis em uma base de dados globalmente distribuída, e encontraram que os algoritmos explicavam menos que 50\% da variância dos dados de 
produção primária. No presente trabalho, as produções primárias por satélite foram estimadas através de 3 modelos, sendo dois WIM e outro DIM.

\subsubsection{Modelo de produtividade de Bedford - Verticalmente homogêneo, não espectral - BPM1}

O modelo de produtividade de Bedford, na forma de um WIM, não espectral e verticalmente homogêneo (perfil vertical de biomassa constante), tem como representação formal a seguinte equação:

$$
\left.P P_{E U}=B P_{\max }^{B} \int_{t=0}^{D} \int_{z=0}^{z_{e u}}\left[1-\exp \left[-\alpha^{B} I_{0}^{m} \operatorname{sen}(\pi t / D) e^{-k z}\right) / P_{\max }^{B}\right]\right] d z d t
$$

onde $I_{0}{ }^{m}$ é a irradiância ao meio dia em unidades radiométricas (W.m ${ }^{-2}$ ), e a função senoidal no modelo descreve a distribuição de irradiância durante o dia. Platt et al. (1990) obtiveram uma solução analítica no caso do perfil vertical de biomassa ser considerado uniforme na coluna d'água (isto é, $B, K, \alpha^{B} e P_{\max }^{B}$ são constantes) e assumindo uma variação senoidal da irradiância ao longo do dia. Esta solução analítica foi utilizada no presente trabalho para estimar a produção primária diária integrada na zona eufótica $\left(P P_{E U}\right)$, tendo sido denominada como modelo de produtividade de Bedford - BPM1. O modelo padrão de referência é verticalmente homogêneo, não espectral. Este tem a seguinte solução para a produção diária da coluna d'água $P P_{E U}$ :

$$
P P_{E U}=\frac{B D P_{\max }^{B}}{K} f\left(I_{*}^{m}\right)
$$

onde $B$ é a biomassa $\left(\mathrm{mg} \cdot \mathrm{m}^{-3}\right), D$ é o fotoperíodo (h), $P_{\max }{ }^{B}$ é o número de assimilação $\left(\mathrm{mgC} .(\mathrm{mgClo})^{-1} \cdot \mathrm{h}^{-1}\right), K$ é o coeficiente vertical de atenuação difusa para a luz descendente $\left(\mathrm{m}^{-1}\right)$ e $f\left(I *^{m}\right)$ é a função da irradiância adimensional cuja forma é determinada uma vez que a representação matemática da curva de saturação de luz tenha sido selecionada. A quantidade $I_{*}{ }^{m}$ é dada por $I_{*}{ }^{m}=I_{0}{ }^{m} / I_{k}$, onde $I_{0}{ }^{m}$ é a irradiância local ao meio dia, e $I_{k}$ é o parâmetro de fotoadaptação. A equação (2.39) é denominada como forma canônica para a produção diária da coluna d'água (Platt et al., 
1990). Ela é robusta qualquer que seja a escolha da representação matemática escolhida para a curva de luz - fotossíntese. Pode ser escrita na forma compacta:

$$
P P_{E U}=A f\left(I_{*}^{m}\right)
$$

onde o fator de escala $A=B P_{\max }{ }^{B} D / K\left(\mathrm{mgC} \cdot \mathrm{m}^{-2}\right)$. Dada uma expressão para a função canônica $f$, a estimativa de $P P_{E U}$ é obtida pela seguinte equação (Platt e Sathyendranath, 1993):

$$
P P_{E U}=A \times\left[f\left(I_{*}^{m} e^{-z_{1} k}\right)-f\left(I_{*}^{m} e^{-z_{2} k}\right)\right]
$$

Por conveniência, pode-se substituir $f\left(I_{*}^{m}\right)$, por um polinômio de ordem relativamente baixa (Platt et al., 1990; Platt e Sathyendranath, 1993). Desta forma, temos:

$$
f\left(I_{*}^{m}\right)=\sum_{x=1}^{N} \Omega_{x}\left(I_{*}^{m}\right)^{x}
$$

onde os pesos $\Omega_{\mathrm{x}}$ são determinados por ajuste dos mínimos quadrados da solução numérica da equação (2.39). As magnitudes dos pesos irão depender do número de termos $N$ na série polinomial, e da amplitude de variação de $I_{*}{ }^{m}$ para a qual são computados. Normalmente, é suficiente considerar $N=5$, e considerar a variação $0<I^{m}{ }^{m}>20$. Os pesos só precisam ser determinados uma única vez. Seus respectivos valores encontram-se na Tabela 2.5 para o caso onde a curva de luz - fotossíntese ser representada por uma equação exponencial (Platt et al., 1980), ou seja:

$$
P^{B}(I)=P_{\max }^{B}\left(1-\exp \left(-\alpha^{B} I / P_{\max }^{B}\right)\right)
$$

onde $P^{B}$ é a produção normalizada pela biomassa , $I$ é a irradiância, $\alpha^{\mathrm{B}}$ é a inclinação inicial e $P_{\max }{ }^{B}$ é o número de assimilação. 
TABELA 2.5 - PESOS $\Omega_{x}$ DA APROXIMAÇÃOPOLINOMIAL DE

\begin{tabular}{cc}
\multicolumn{2}{c}{$f\left(I_{*}^{m}\right)$ CALCULADOS PARA $0,2 \leq I_{*}^{m} \geq 20$} \\
\hline $\mathbf{X}$ & $\Omega_{x}$ \\
\hline 1 & $6.1035 \times 10^{-1}$ \\
\hline 2 & $-8.9251 \times 10^{-2}$ \\
\hline 3 & $8.1477 \times 10^{-3}$ \\
\hline 4 & $-3.7427 \times 10^{-4}$ \\
\hline 5 & $6.6103 \times 10^{-6}$ \\
\hline
\end{tabular}

\subsubsection{Modelo de produtividade de Bedford - Perfil vertical de biomassa não uniforme, espectral- BPM2}

O modelo de produtividade de Bedford, na forma de um WIM, espectral e com perfil vertical de biomassa não homogêneo, foi denominado aqui como BPM2. A produção primária diária na coluna d'água é estimada por integração numérica de um modelo espectral. O perfil vertical de clorofila é modelado pela curva de Gauss-deslocada, como descrito em Platt et al. (1994). As componentes difusa e direta da irradiância de superfície são calculadas usando o modelo de irradiância espectral de Bird (1984), adaptado conforme sugestões de Sathyendranath e Platt (1988). É calculada a irradiância descendente $I_{0}(\lambda, t)\left(\mathrm{W} \cdot \mathrm{m}^{-2}\right)$ na superfície, para uma dada posição geográfica e dia juliano. A produção absoluta diária na coluna d'água é definida pela integral no tempo e profundidade:

$$
P P_{E U}=\int_{0}^{D} \int_{0}^{\infty} B(z) \int_{P A R} \Pi(z, \lambda, t) d \lambda d z d t
$$

onde $\Pi=P_{\max }^{B}\left(1-\exp \left(-\alpha^{B}(\lambda) I(z, \lambda, t) / P_{\max }^{B}\right.\right.$ é a taxa de fotossíntese $\left(\mathrm{mgC} \cdot(\mathrm{mgClo})^{-1} \cdot \mathrm{h}^{-}\right.$ ${ }^{1}$.(nm) $\left.)^{-1}\right)$ em função da profundidade $z(\mathrm{~m})$, comprimento de onda $\lambda(\mathrm{nm})$ e tempo $t(\mathrm{~h})$; $D$ é o fotoperíodo $(\mathrm{h}) ; B(z)$ é a biomassa $\left(\mathrm{mgClo}^{-3}\right) ; \alpha^{B}(\lambda)$ é o espectro de ação fotossintético (mgC. $\left.(\mathrm{mgClo})^{-1} \cdot\left(\mathrm{W} \cdot \mathrm{m}^{-2}\right)^{-1} \cdot \mathrm{nm}^{-1}\right) ; I_{0}(z, \lambda, t)$ é a luz disponível $\left(\mathrm{W} \cdot \mathrm{m}^{-2}\right) \mathrm{e}$ $P_{\max }{ }^{B}$ é o número de assimilação $\left(\mathrm{mgC} .(\mathrm{mgClo})^{-1} \cdot \mathrm{h}^{-1}\right)$. 
Como mostrado anteriormente, Platt et al. (1988) e Platt et al. (1994) demonstraram como um perfil não uniforme pode ser representado por uma curva Gaussianadeslocada:

$$
B(z)=B_{0}+\frac{h}{\sigma \sqrt{2 \pi}} \exp \left[-\frac{\left(z-Z_{m}\right)^{2}}{2 \sigma^{2}}\right]
$$

onde $B_{0}$ (constante de fundo), $h$ (biomassa total no pico), $Z_{m}$ (profundidade do máximo de clorofila) e $\sigma$ (medida da espessura ou escala vertical do pico) são parâmetros a serem determinados ou atribuídos para uma determinada estação para a qual se deseja calcular a produção primária. Cabe mencionar que $h /(\sigma \sqrt{2 \pi})$ é uma medida da altura do pico acima de $B_{0}$. Esta equação matemática (ou outra equivalente) forma a base da estrutura vertical da biomassa incorporada no cálculo da produção primária. $\mathrm{O}$ cálculo da produção primária baseado em um perfil de pigmento não uniforme não é facilmente tratável usando-se métodos analíticos, e nenhuma solução deste tipo foi ainda apresentada (Platt e Sathyendranath, 2002). Portanto, o desenvolvimento da solução envolveu métodos de integração numérica. A complexidade aumenta, quando se introduz a dependência espectral da fotossíntese na formulação. Os modelos não uniformes de biomassa devem considerar o fato de que a estrutura vertical da biomassa considera as variações da taxa exponencial de decaimento da luz com a profundidade (Figura 2.14). O perfil de produção correspondente será afetado pela estrutura vertical tanto no campo luminoso como no de biomassa. Dependendo da magnitude do pico subsuperficial, da profundidade onde este ocorre, da luz disponível nesta profundidade e dos valores dos parâmetros fotossintéticos, o perfil de produção resultante pode mostrar um pico subsuperficial proeminente, tipicamente em uma profundidade mais rasa do que a do pico de biomassa (Figura 2.14). Estes perfis de produção devem ser integrados no tempo e em profundidade para se obter a produção diária da coluna d'água $\left(P P_{E U}\right)$. Note-se que a produção geralmente decai exponencialmente até zero com o aumento da profundidade devido ao decaimento exponencial da luz com a profundidade, mesmo que o modelo de biomassa (Equação 2.45) mantenha um $B_{0}$ constante em todas as profundidades. 

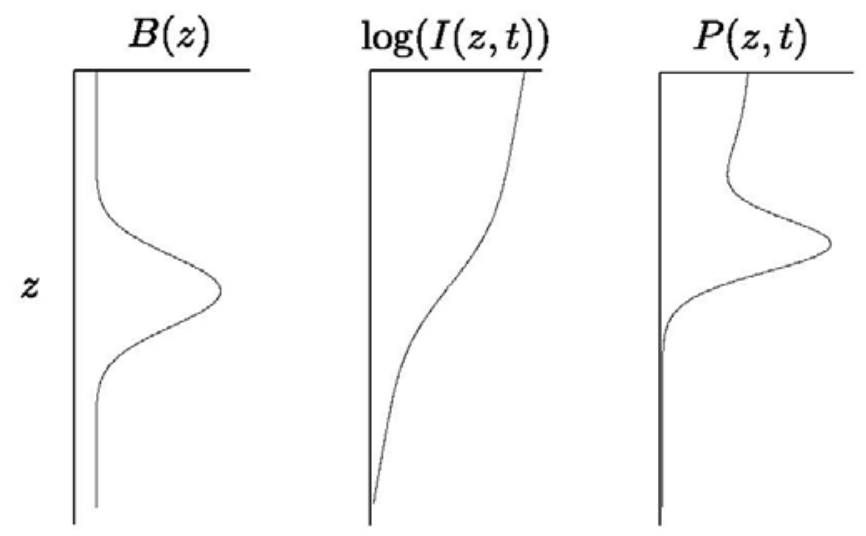

Figura 2.14 - Um exemplo de perfil de biomassa (esquerda), o campo de luz submarina correspondente (centro) e o perfil de produção calculado com um modelo não-espectral (adaptado de Platt e Sathyendranath, 2002).

\subsubsection{Modelo de produção generalizado verticalmente - VGPM}

O modelo desenvolvido por Behrenfeld e Falkowski (1997a), do tipo Vertically Generalized Production Model (VGPM), também foi utilizado no presente trabalho para estimar a produção primária diária integrada na zona eufótica. Este modelo fornece uma relação empírica derivada "semianaliticamente" para resolver a produção primária diária na zona eufótica. O VGPM é um modelo semianalítico no sentido que foi desenvolvido a partir de fatores que teoricamente afetam e controlam a fotossíntese marinha. Por outro lado, também é um modelo empírico uma vez que foi calibrado e simplificado em relação a dados in situ coletados em ambientes naturais. A simplificação do modelo VGPM incluiu o desenvolvimento de determinadas relações empíricas entre variáveis ambientais. O resultado final é um modelo relativamente simples em forma integral que pode ser resolvido com relativa facilidade. Pode ser considerado um modelo mais poderoso que outros modelos empíricos (Smith et al., 1982), porque inclui outros fatores controladores da produtividade marinha oceânica que não só a clorofila $a$. Porém é bem menos abrangente que outros modelos de maior resolução do tipo WRM (Morel, 1991). A versão formal do modelo VGPM é dada pela equação:

$$
P P_{E U}=P_{\max }^{B} \int_{t=0}^{D} \int_{z=0}^{z_{\text {eu }}} \frac{\left[1-e^{\left(-E(z) / E_{\max }\right)}\right] e^{\left(\beta_{d} E(z)\right)}}{\left[1-e^{\left.-E_{o p t} / E_{\max }\right)}\right] e^{\left(\beta_{d} E_{o p t}\right)}} d z d t
$$


onde $E$ é a irradiância superficial em unidades quânticas (Einsteins.m ${ }^{-2} \cdot \mathrm{d}^{-1}$ ), $E_{\max }$ é a irradiância no ponto de inflexão da curva de luz - fotossíntese, $E_{o p t}$ é a PAR diária total em $P_{\max }{ }^{B}$ e $\beta_{d}$ é o parâmetro de fotoinibição. No presente trabalho, foi utilizada uma versão simplificada do modelo VGPM, sem considerar a fotoinibição:

$$
P P_{E U}=0,66125 P_{o p t}^{B}\left[\frac{E_{0}}{E_{0}+4,1}\right] Z_{E U} \times C_{s a t} \times D
$$

onde $P_{o p t}^{B}$ é a taxa fotossintética máxima específica da clorofila, $E_{0}$ é a irradiância PAR superficial total (Einstein. $\left.\mathrm{m}^{-2} \cdot \mathrm{d}^{-1}\right) ; D$ é o fotoperíodo (h); $C_{\text {sat }}$ é a concentração de clorofila $a$ obtida pelo SeaWiFS $\left(\mathrm{mgClo} . \mathrm{m}^{-3}\right) ; Z_{E U}$ é a profundidade da zona eufótica calculada a partir de $C_{s a t}$, de acordo com Morel e Berton (1989). De certo modo distinto de outras parametrizações de modelos, esta relação foi desenvolvida pelo ajuste de dados in situ a um perfil de produção generalizado exibido por muitos corpos d'água (daí o nome verticalmente generalizado). Este perfil é normalizado pela profundidade óptica $\zeta\left(K_{d} Z\right)$ e pode ser expresso como uma função tangente hiperbólica:

$$
P^{B}(z)=P_{o p t}^{B} \tanh \left[E_{z} / E_{k}^{*}\right]
$$

$P_{o p t}{ }^{B}$ e $E_{k}{ }^{*}$ não devem ser confundidos com os parâmetros fotossintéticos $P_{\max }{ }^{B}$ e $I_{k}$. Ainda que teoricamente possam ser relacionados, ainda não se estabeleceu uma conversão entre estes parâmetros. Os resultados obtidos por Morel e Berthon (1989) foram adaptados para se obter um valor da zona eufótica a partir da concentração de clorofila a na coluna d'água. Outros autores (Kirk, 1994; Bukata et al., 1995) mostraram que em águas do Caso 1 , o regime de absorção de luz é dominado pela clorofila $a$ e pela própria água, de modo que $Z_{E U}$ pode ser expresso em função da clorofila total. Desta forma, $Z_{E U}$ foi calculado como a seguir:

$$
\begin{aligned}
& \mathrm{Z}_{\mathrm{eu}}=568,2<\mathrm{C}>_{\mathrm{TOT}^{-}}{ }^{-0.746} \text { quando }<\mathrm{C}>_{\mathrm{TOT}}<10 \mathrm{mg} \mathrm{m}^{-2} \\
& \mathrm{Z}_{\mathrm{eu}}=200,0<\mathrm{C}>_{\mathrm{TOT}^{-}}{ }^{-0.293} \text { quando }<\mathrm{C}>_{\mathrm{TOT}}>10 \mathrm{mg} \mathrm{m}^{-2}
\end{aligned}
$$

Por definição: 


$$
\langle C\rangle_{T O T}=\int_{0}^{Z_{E U}} C(z) d z
$$

Esta equação pode ser utilizada interativamente se o perfil de biomassa for dado. Morel e Berthon (1989) sugerem um esquema de interações onde a integral é resolvida pelo incremento de $z$ obtendo-se um novo valor de $Z_{E U}$ que decresce com as interações. Uma vez que $Z_{E U}$ se torne menor que $z$ o processo é interrompido e revertido, de modo que $<\mathrm{C}>_{\text {Tот }}$ e $Z_{E U}$ são gerados ao mesmo tempo. Para aplicação em sensoriamento remoto, $<\mathrm{C}>$ тот pode ser relacionado com $C_{\text {sat }}$ da seguinte forma (Morel e Berthon, 1989)

$$
\langle C\rangle_{\text {TOT }}=40,6 C_{\text {sat }}^{0,425}
$$

Para a estimativa de $P_{\text {opt }}{ }^{B}$, o modelo dependente da temperatura sugerido por Behrenfeld e Falkowski (1997a) foi implementado. Sua aplicabilidade foi justificada pelo fato que $P_{o p t}^{B}$ varia em função de $P_{\max }{ }^{B}$, que por sua vez, é regulado por atividade enzimática e por isso sofre influência da temperatura. Esta hipótese foi explorada por Ryther e Yentsch (1957), Eppley (1972), entre outros, e diferentes funções foram sugeridas para descrever esta relação para valores de temperatura entre $0^{\circ} \mathrm{C}$ e $29^{\circ} \mathrm{C}$. Para valores maiores que $29^{\circ} \mathrm{C}$ assume-se um valor de $P_{\text {opt }}{ }^{B}$ igual a 4 (Figura 2.15).

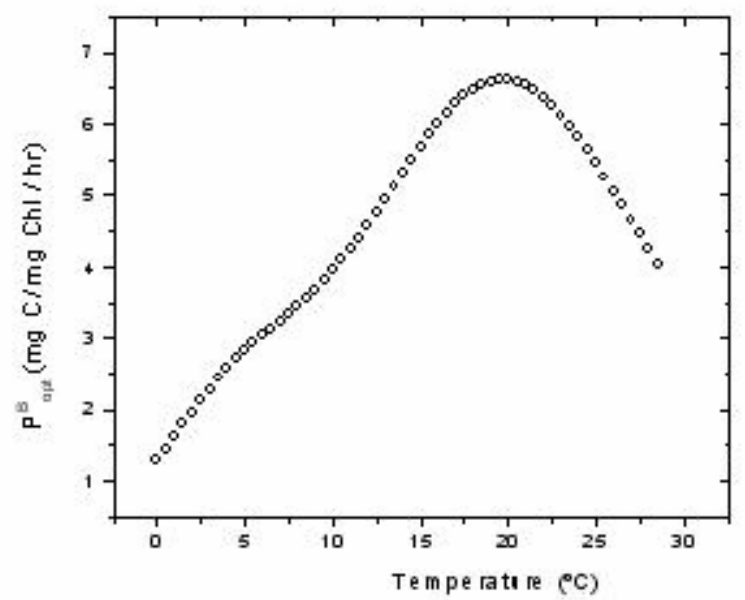

Figura 2.15 - Relação usada por Behrenfeld e Falkowski (1997a) para estimar $P_{\text {opt }}{ }^{B}$ a partir da temperatura da superfície do mar. 


$$
\begin{aligned}
& P_{o p t}^{B}=a T^{7}+b T^{6}-c T^{5}+d T^{4}-e T^{3}+f T^{2}+g T+h \\
& a=-3,27 \times 10^{-8} ; b=3,14132 \times 10^{-6} ; c=-1,348 \times 10^{-4} \\
& d=2,462 \times 10^{-3} ; e=-0,0205 ; f=0,0617 \\
& g=0,2749 ; h=1,2956
\end{aligned}
$$

Combinando-se as relações apresentadas, a produção primária diária integrada na zona eufótica foi calculada pelo modelo VGPM, de acordo com a equação (2.47), isto é, em função de variáveis ambientais: $C_{s a t}$, TSM e $E_{0}$.

\subsection{Regressão múltipla}

Foi aplicado o método de regressão múltipla passo-a-passo (Draper e Smith, 1966) para algumas variáveis físicas, químicas e biológicas calculadas e tomadas como variáveis independentes, e a produção primária diária e a clorofila $a$ integradas na zona eufótica como variáveis dependentes. A regressão múltipla é uma técnica adequada para investigar as relações das diversas variáveis com a produtividade primária e biomassa fitoplanctônica em razão de não ser necessário assumir prévios conhecimentos das interrelações entre quaisquer variáveis, exceto que, as variâncias das taxas de produção e biomassa constituem as respostas a outras variáveis. O nível de probabilidade para inclusão ou exclusão de um parâmetro nas regressões foi de $5 \%(\mathrm{p}<0,05)$. As variáveis físicas, químicas e biológicas da coluna d'água e superfície consideradas foram:

\section{Produção primária integrada na zona eufótica}

$\mathrm{PP}_{\mathrm{EU}} \mathrm{em} \mathrm{gC} \cdot \mathrm{m}^{-2} \cdot \mathrm{d}^{-1}$, estimada pela integração dos resultados derivados de experimentos de produção primária in situ-simulados, extrapolados para o fotoperíodo (ver item 2.5 neste capítulo).

\section{Concentração de clorofila $a$ integrada na zona eufótica}

$\mathrm{C}_{\mathrm{EU}}$ em mg.m ${ }^{-2}$, integrada pelo método dos trapézios.

\section{Profundidade}

Prof em metros, profundidade da estação oceanográfica. 


\section{Coeficiente vertical de atenuação difusa}

$\mathrm{K}_{\mathrm{s}}$ em m ${ }^{-1}$, estimado pela fórmula de Poole e Atkins (1929) com uso do disco de Secchi.

\section{Estabilidade}

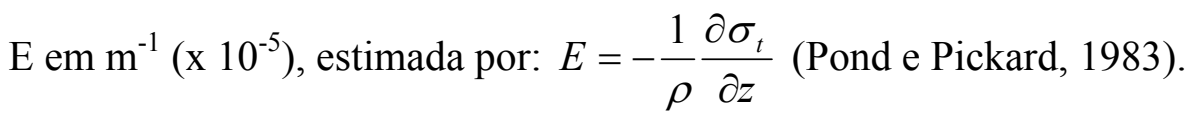

\section{Freqüência de Brünt-Väisäla}

$\mathrm{N}^{2}$ em s$^{-2}\left(\mathrm{x} 10^{-4}\right)$, estimada como: $N^{2}=g\left[-\frac{1}{\rho} \frac{\partial \sigma_{t}}{\partial z}\right]$ (Pond e Pickard, 1983), onde $\mathrm{g}=$ aceleração da gravidade $\left(9,8 \mathrm{~m} \cdot \mathrm{s}^{-2}\right)$.

\section{Profundidade da picnoclina}

$Z_{\mathrm{P}}$ em metros, estimada pela profundidade onde $\mathrm{N}^{2}$ é máxima (Pond e Pickard, 1983).

\section{Profundidade da termoclina}

$\mathrm{Z}_{\mathrm{T}}$ em metros, determinada como a profundidade com temperatura $1^{\circ} \mathrm{C}$ inferior a temperatura observada a $6 \mathrm{~m}$ de profundidade (Hastenrath e Merle, 1987).

\section{Profundidade do máximo subsuperficial de clorofila}

$\mathrm{Z}_{\mathrm{M}}$ em metros, obtido pelo ajuste do modelo da curva de Gauss-deslocada aos perfis verticais de biomassa (Platt et al., 1988; ver item 2.10 neste capítulo).

\section{Profundidade da zona eufótica}

$\mathrm{Z}_{\mathrm{EU}}$ em metros. A zona eufótica foi considerada em relação ao nível de $1 \%$ da irradiância superficial. Pela Lei de Beer, $E_{z}=E_{0} \exp \left(-K_{s} z\right)$, onde $E_{0}$ é a irradiância na superfície, $E_{z}$ é a irradiância na profundidade $z$ e $K_{s}$ é o coeficiente vertical de atenuação difusa. 


\section{Relação $\mathbf{Z}_{\mathbf{E U}} / \mathbf{Z}_{\mathbf{T}}$}

$\mathrm{Z}_{\mathrm{EU}} / \mathrm{Z}_{\mathrm{T}}$ adimensional, calculada pela razão entre a profundidade da zona eufótica e a profundidade da termoclina.

\section{Taxa de assimilação potencial diária na zona eufótica}

$\mathrm{TA}_{\mathrm{EU}} \mathrm{em} \operatorname{mgC} .(\mathrm{mgClo})^{-1} \cdot \mathrm{d}^{-1}$, estimada pela razão entre a produção primária diária e a clorofila integrada na zona eufótica.

\section{Nitrato integrado na zona eufótica}

$\mathrm{N}_{\mathrm{EU}}$ em $\mu \mathrm{M} \cdot \mathrm{m}^{-2}$, concentração de nitrato integrada na zona eufótica pelo método dos trapézios.

\section{Amônia integrada na zona eufótica}

$\mathrm{A}_{\mathrm{EU}} \mathrm{em} \mu \mathrm{M} . \mathrm{m}^{-2}$, concentração de amônia integrada na zona eufótica pelo método dos trapézios.

\section{Temperatura da superfície do mar}

$\mathrm{TSM}$ em ${ }^{\circ} \mathrm{C}$.

\subsection{Rede neural}

Foi utilizada uma rede neural artificial (NN) do tipo perceptron multicamada, com uma estrutura 12-5-1, ou seja, uma camada de entrada contendo 12 padrões, uma camada oculta com 5 neurônios e uma camada de saída contendo apenas 1 neurônio para estimar a produção primária oceânica integrada na zona eufótica. O modelo NN utilizado no presente trabalho foi desenvolvido em ambiente Stuttgart Neural Network Simulator (SNNS), distribuído pelo Institute for Parallel and Distributed High Performance Systems (IPVR), da Universidade de Stuttgart. $\mathrm{O}$ algoritmo de treinamento backpropagation foi utilizado em sua forma padrão, ou seja, com a taxa de aprendizagem ajustada ( $\eta$ a 0,05 mas sem variar durante o treinamento, e sem termo de 
momentum. A diferença máxima $d_{j}=t_{j}-o_{j}$ entre um valor de treinamento $t_{j}$ e um de saída (output) $o_{j}$ tolerada para uma unidade de saída foi ajustada para 0,00001. As redes neurais artificiais foram recentemente desenvolvidas como uma abordagem alternativa para estimar a produtividade primária oceânica (Scardi, 1996) e outros processos ecológicos complexos não-lineares (Lek et al., 1996). Uma das vantagens das redes neurais é sua capacidade de generalização. Isto é, uma rede treinada pode classificar dados da mesma classe dos dados de treinamento que nunca foram testados antes. $\mathrm{O}$ procedimento de treinamento foi baseado em um subconjunto de 30 padrões de entrada escolhidos aleatoriamente entre os 67 disponíveis. Um outro conjunto independente de 15 padrões foi utilizado para a validação da NN. Os 22 padrões restantes, que não foram utilizados no desenvolvimento da NN, serviram para comparar com resultados medidos in situ, independentemente. A estrutura escolhida para a $\mathrm{NN}$ foi baseada em testes empíricos e em outros trabalhos similares (Scardi, 1996; Scardi e Harding, 1999). A Tabela 2.6 a seguir apresenta os padrões de entrada utilizados na rede neural. Todas as variáveis foram normalizadas entre [0,1], da seguinte forma:

$$
x=\frac{\left(x_{i}-\min \right)}{(\max -\min )}
$$

onde min equivale ao valor mínimo observado para cada variável $x_{i}$, max equivale ao valor máximo observado de cada variável e $x$ é o padrão entre [0,1]. Tanto a produção primária integrada como a clorofila $a$ e integrada foram log-transformadas antes de serem normalizadas. Esta transformação foi efetuada em bases teóricas e empíricas. A base teórica refere-se ao fato que o erro médio quadrático da saída da rede poderia ficar tendencioso quando da utilização dos valores brutos (Scardi e Harding, 1999). Isto ocorre porque padrões de treinamento contendo altos valores de biomassa e produção primária e conseqüentemente, contendo maiores erros amostrais poderiam dominar os resultados. O teste empírico foi realizado comparando-se o desempenho da rede neural treinada com os dados transformados e brutos. Os resultados com os dados em escala $\log$ foram mais satisfatórios. O dia juliano foi transformado usando funções de seno e co-seno mapeando-os em um círculo (Scardi e Harding, 1999). Quando a profundidade 
da zona eufótica calculada fosse maior do que a profundidade da estação oceanográfica, esta era considerada como valor de $\mathrm{Z}_{\mathrm{EU}}$.

TABELA 2.6 - PADRÕES DE ENTRADA E DE SAÍDA DA REDE NEURAL

\begin{tabular}{|c|c|c|c|}
\hline Variável & \multirow{2}{*}{ Unidades } & \multirow{2}{*}{ Mínimo } & \multirow{2}{*}{ Máximo } \\
\hline Entrada & & & \\
\hline$\frac{1}{2}\left[\cos \left(\frac{2 \pi d i a}{365}\right)+1\right]$ & - & 0,01 & 0,29 \\
\hline$\frac{1}{2}\left[\operatorname{sen}\left(\frac{2 \pi d i a}{365}\right)+1\right]$ & - & 0,29 & 0,84 \\
\hline Latitude & graus & $-24,24$ & $-22,97$ \\
\hline Longitude & graus & $-45,12$ & $-40,37$ \\
\hline Profundidade & metros & 24 & 2522 \\
\hline TSM & ${ }^{\circ} \mathrm{C}$ & 14,7 & 27,6 \\
\hline Salinidade & PSU & 33,7 & 37,3 \\
\hline Clorofila superficial $\left(\log _{10}\right)$ & $\mathrm{mg} \cdot \mathrm{m}^{-3}$ & $-1,17$ & 0,77 \\
\hline Clorofila integrada $\left(\log _{10}\right)$ & $\mathrm{mg} \cdot \mathrm{m}^{-2}$ & 0,75 & 1,89 \\
\hline Irradiância superficial descendente & E. $\mathrm{m}^{-2} \cdot \mathrm{d}^{-1}$ & 30,25 & 62,7 \\
\hline Coeficiente de extinção de luz & $\mathrm{m}^{-1}$ & 0,06 & 0,34 \\
\hline Profundidade da zona eufótica & metros & 13,5 & 81,3 \\
\hline \multicolumn{4}{|l|}{ Saída } \\
\hline Produção primária integrada $\left(\log _{10}\right)$ & $\mathrm{mgC} \cdot \mathrm{m}^{-2} \cdot \mathrm{d}^{-1}$ & 2,05 & 3,69 \\
\hline
\end{tabular}

Unidades, mínimos e máximos usados para escalonar variáveis entre [0,1]. $\log _{10}$ indica que variáveis foram log-transformadas antes de serem normalizadas. 


\section{CAPÍTULO 3}

\section{RESULTADOS}

\subsection{Cruzeiro de Mesoescala - Verão de 2001 (M1)}

\subsubsection{Seções verticais de temperatura, salinidade e densidade}

As Figuras 3.1, 3.2 e 3.3 apresentam as seções verticais de temperatura, salinidade e $\sigma_{t}$, referentes às quatro radiais ocupadas durante o cruzeiro de verão de 2001, respectivamente. Em superfície, as temperaturas estão na maior parte das seções entre $25^{\circ}$ e $27^{\circ} \mathrm{C}$ (Figura 3.1). Entretanto, as temperaturas decrescem em direção à costa podendo-se notar um gradiente horizontal de temperatura normal à costa. Nas proximidades do fundo, as temperaturas apresentam valores menores do que $18^{\circ} \mathrm{C}$.

Valores de salinidades superficiais maiores do que 36,4 podem ser observados na maior parte das quatro seções realizadas. Ao largo pode-se notar a influência da AT. Valores menores são encontrados no espaço mais costeiro. Nas proximidades do fundo, os valores estão abaixo de 35,6. Foram notadas lentes subsuperficiais de águas mais salinas $(\mathrm{S}>36,8)$ em direção à costa, até próximo à quebra de plataforma (ver radiais 1 e 2 na Figura 3.2).

$\mathrm{Na}$ superfície, valores de densidade inferiores a 25,4 são observados na maior parte das seções (Figura 3.3). Valores maiores estão presentes nas proximidades da costa, associados à ressurgência da ACAS. A isopicnal de 24,0 encontra-se mais ao largo (ver radiais 1,2 e 3), indicando a presença da $\mathrm{CB}$.

A configuração das isotermas, isohalinas e isopicnais sugere o afloramento da termoclina e da ACAS com o estabelecimento de uma frente de ressurgência costeira, típica desta região, principalmente no período de verão. 

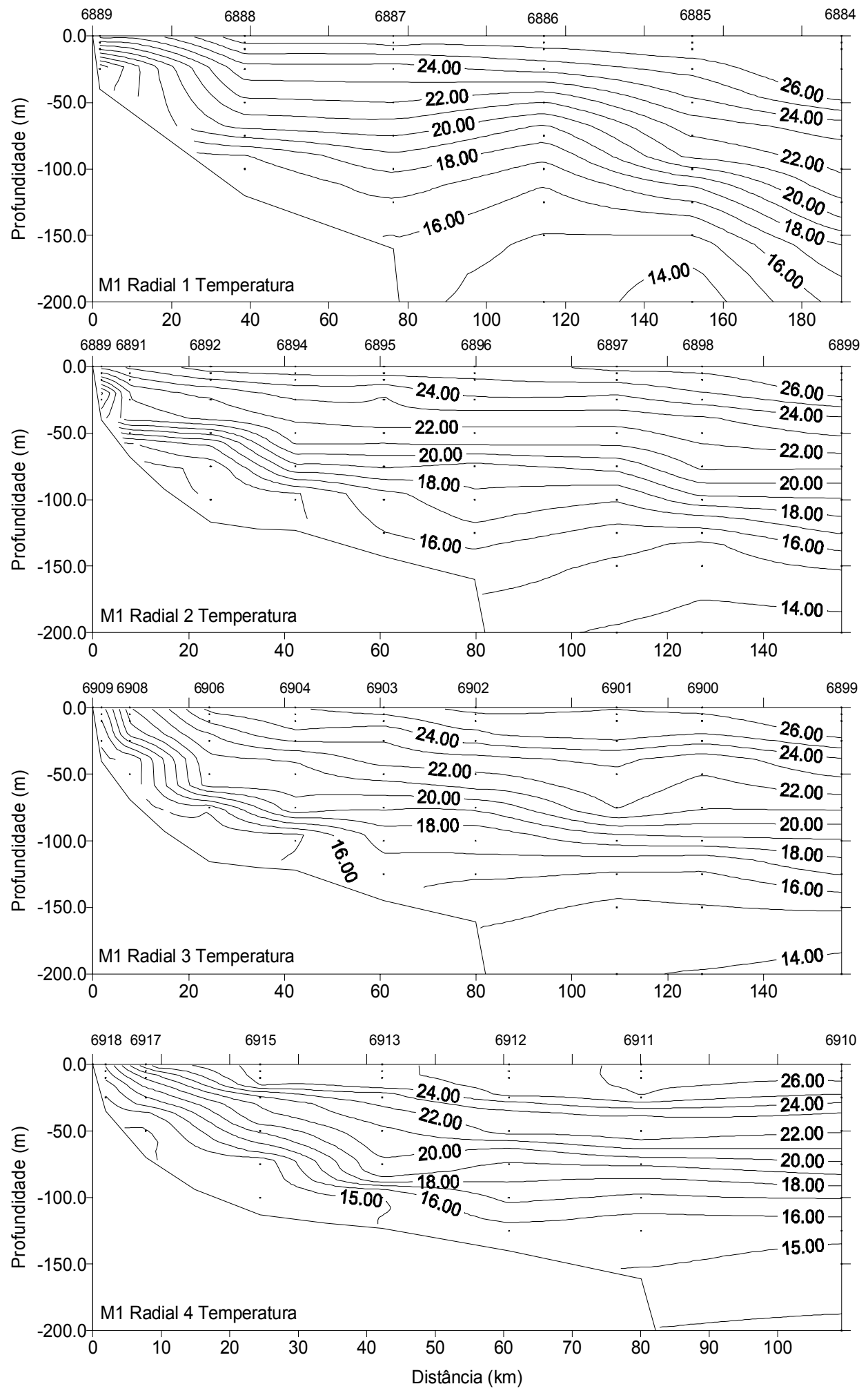

Figura 3.1 - Seções verticais de temperatura $\left({ }^{\circ} \mathrm{C}\right)$ radiais à costa em Cabo Frio, RJ, realizadas durante o verão de 2001 (M1). 

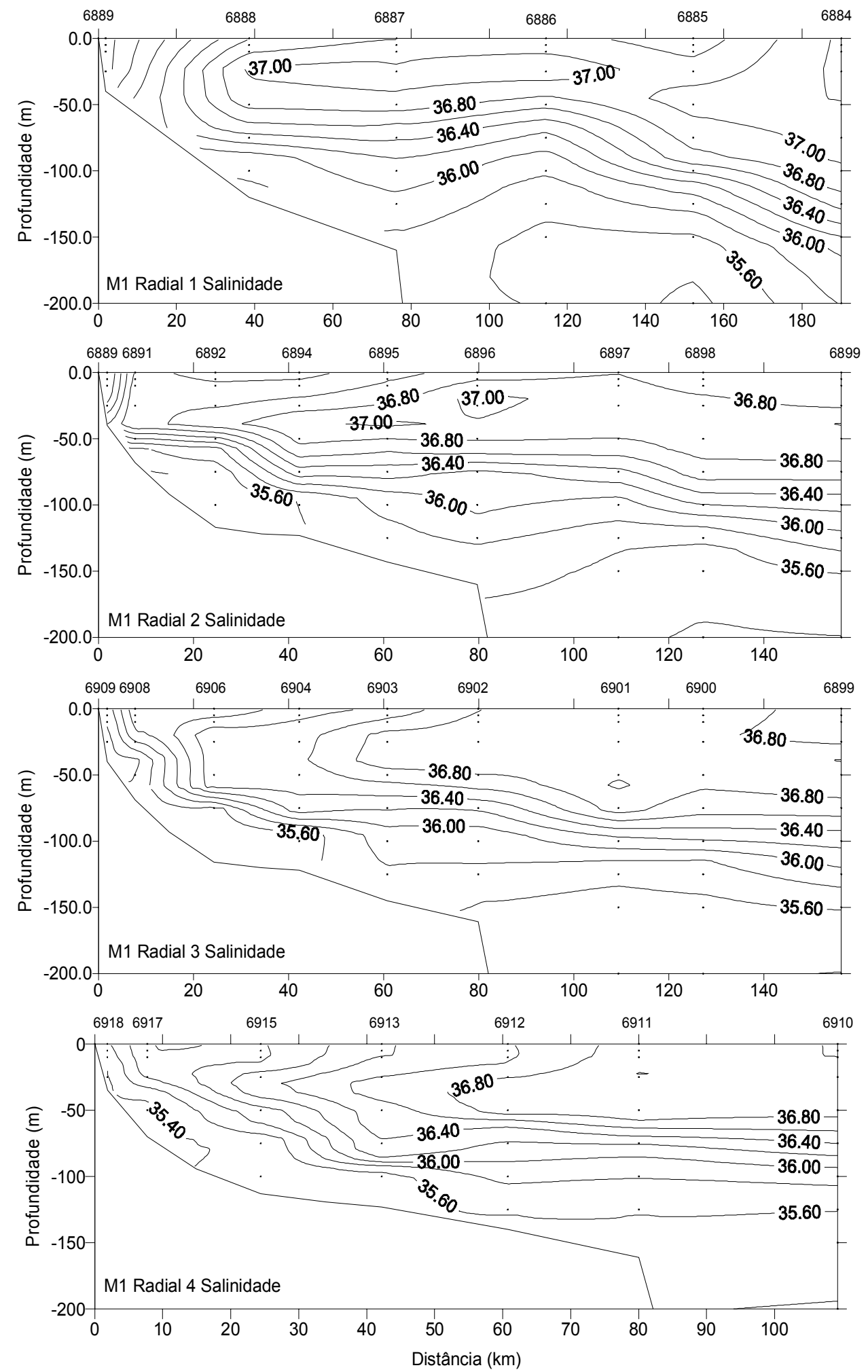

Figura 3.2 - Seções verticais de salinidade radiais à costa em Cabo Frio, RJ, realizadas durante o verão de 2001 (M1). 

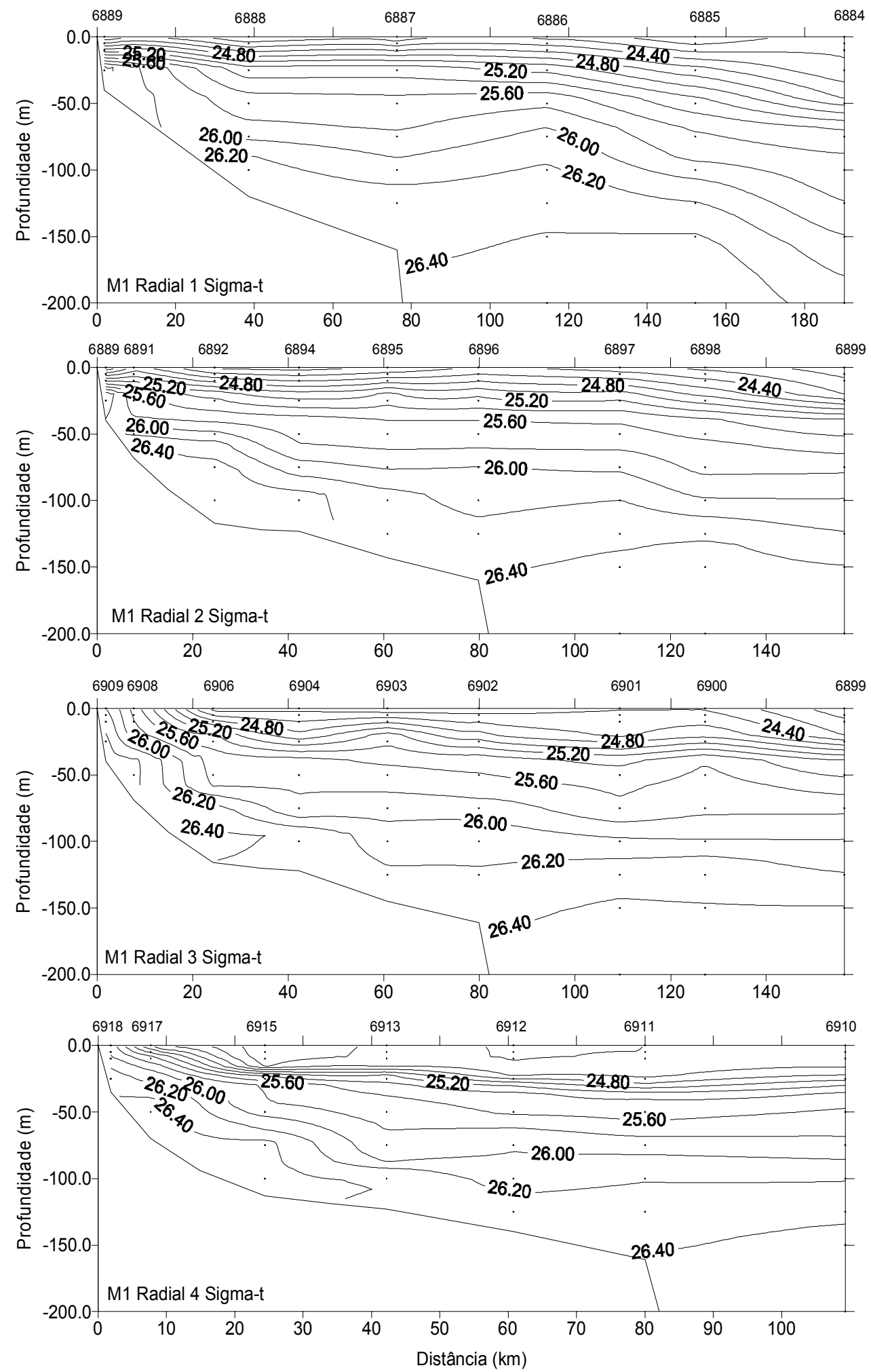

Figura 3.3 - Seções verticais de $\sigma_{\mathrm{t}}\left(\mathrm{kg} . \mathrm{m}^{-3}\right)$ radiais à costa em Cabo Frio, RJ, realizadas durante o verão de 2001 (M1). 


\subsubsection{Seções verticais de clorofila-a, nitrato e produção primária}

As Figuras 3.4 e 3.5 a seguir mostram as seções verticais de clorofila- $a$ e nitrato referentes às quatro radiais ocupadas durante o cruzeiro M1. Os valores de clorofila- $a$ variaram entre 0,001 e $0,96 \mathrm{mg} \cdot \mathrm{m}^{-3}$ (Tabela 3.1 ). Os maiores valores de clorofila- $a$ foram encontrados próximo ao continente, a não ser por máximos relativos em subsuperfície entre 25 e $100 \mathrm{~m}$ de profundidade. A concentração de clorofila- $a$ média sobre a plataforma (até $140 \mathrm{~m}$ de profundidade) foi de $0,46 \mathrm{mg} \cdot \mathrm{m}^{-3}\left( \pm 0,26 \mathrm{mg} \cdot \mathrm{m}^{-3}\right)$, enquanto que sobre o talude (profundidades maiores que $140 \mathrm{~m}$ ) foi de $0,13 \mathrm{mg} \cdot \mathrm{m}^{-3}$ $\left( \pm 0,11 \mathrm{mg} \cdot \mathrm{m}^{-3}\right)$.

\section{TABELA 3.1 - CONCENTRAÇÕES MÉDIAS DE CLOROFILA (mg.m-3) DURANTE O CRUZEIRO DE VERÃO DE 2001 (M1).

\begin{tabular}{c|c|c}
\hline M1 & Plataforma & Talude \\
\hline Média & 0,46 & 0,13 \\
\hline Máximo & 0,96 & 0,51 \\
\hline Mínimo & 0,01 & 0,001 \\
\hline Desvio Padrão & 0,26 & 0,11 \\
\hline $\begin{array}{c}\text { Coeficiente } \\
\text { Variação }\end{array}$ & $57 \%$ & $84 \%$ \\
\hline
\end{tabular}

Na Figura 3.5 , podem ser observados diversos núcleos subsuperficiais com valores altos de nitrato $(1,0$ a $5,0 \mu \mathrm{M})$ próximos à quebra de plataforma e ao largo. Próximo à costa, as concentrações também são maiores que 1,0 $\mu \mathrm{M}$. No restante da área, os valores de nitrato encontram-se abaixo de $0,5 \mu \mathrm{M}$.

Pode-se notar uma boa correlação espacial entre os núcleos de alta concentração de clorofila- $a$ e de nitrato, associados a inflexões das isotermas e isopicnais. Alguns núcleos de nitrato não têm correlação nos campos de clorofila- $a$ por estarem localizados em profundidades abaixo da zona eufótica. 

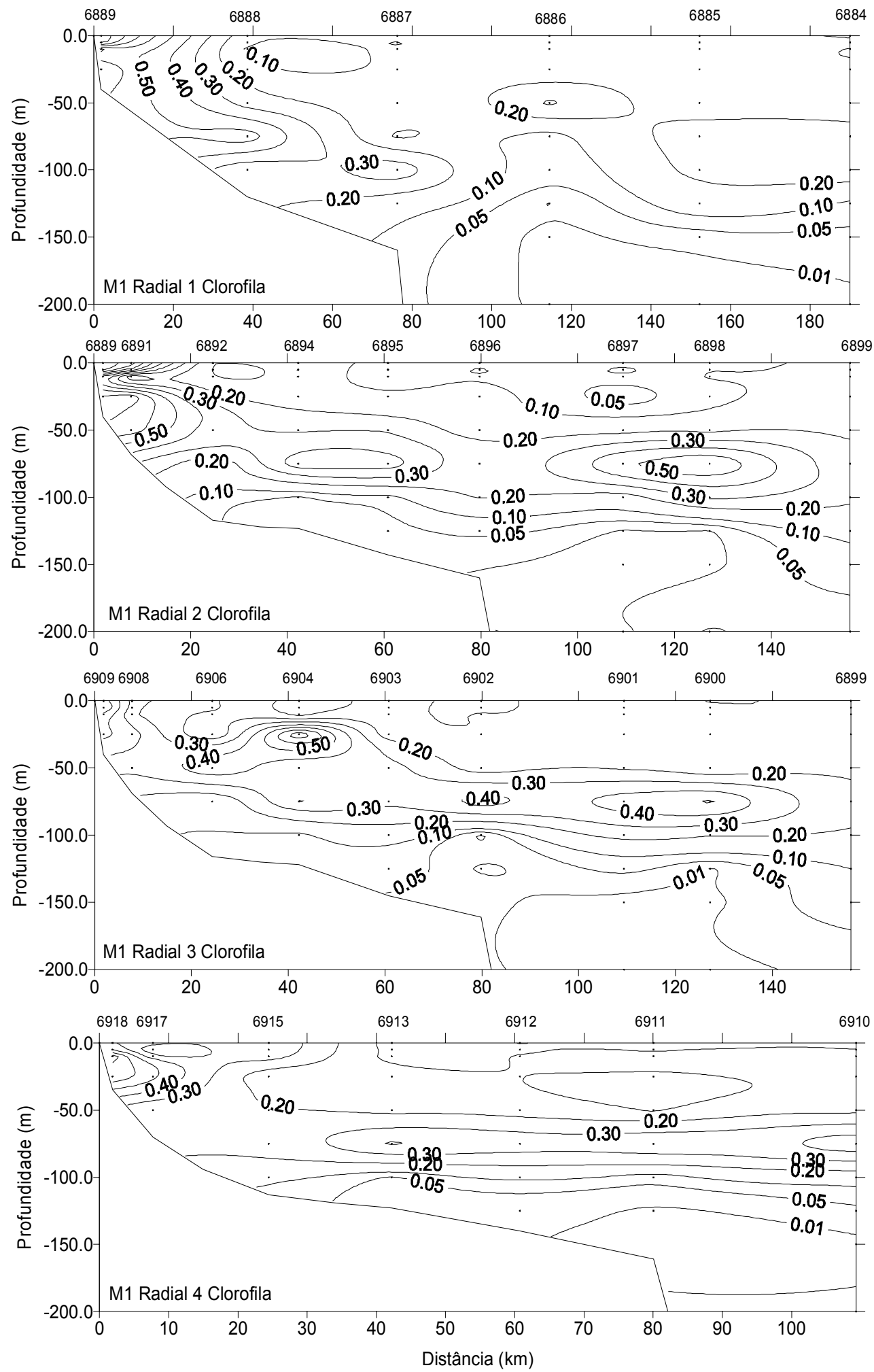

Figura 3.4 - Seções verticais de clorofila $\left(\mathrm{mg} \cdot \mathrm{m}^{-3}\right)$ radiais à costa em Cabo Frio, RJ, realizadas durante o verão de 2001 (M1). 

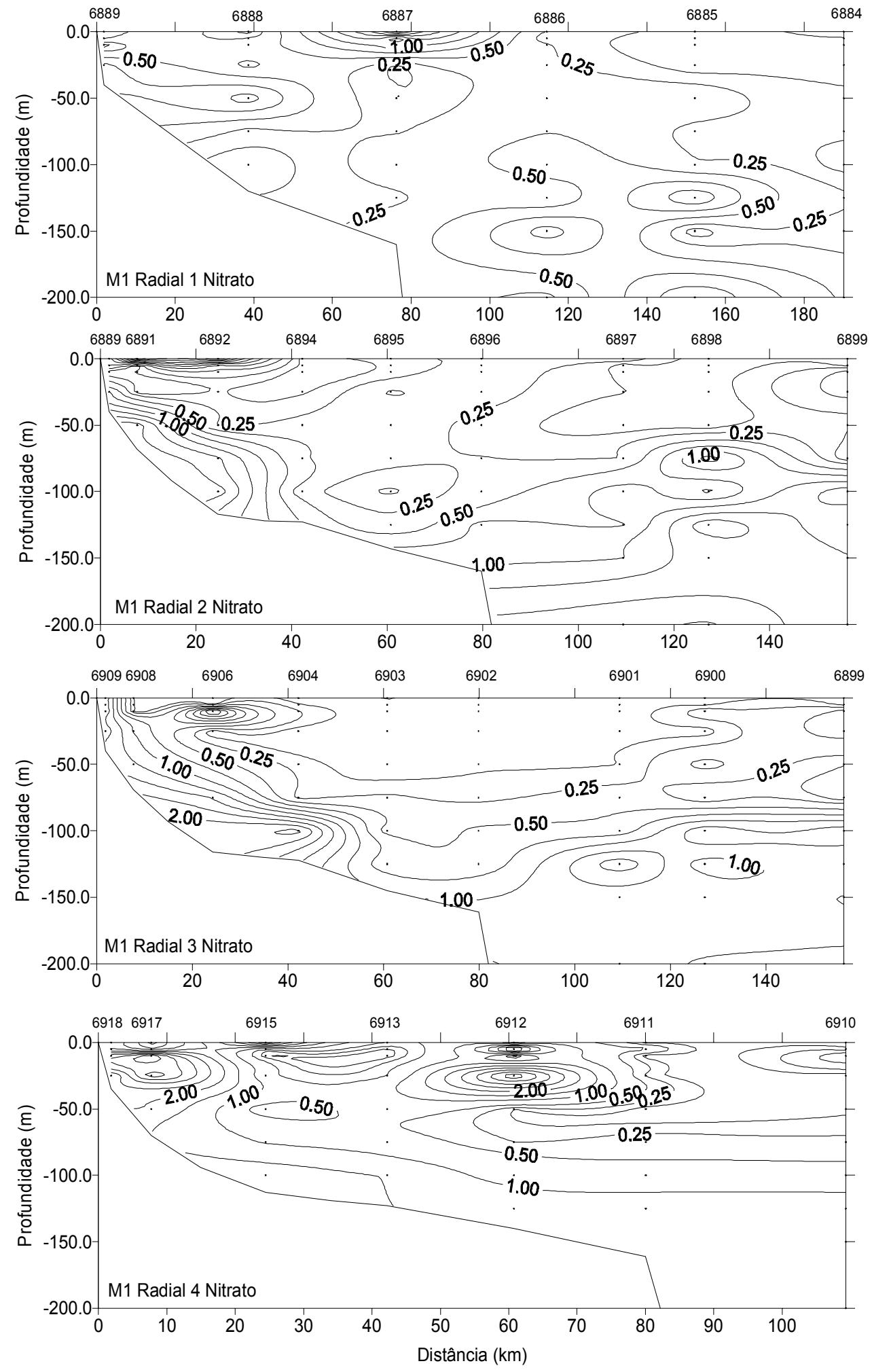

Figura 3.5 - Seções verticais de nitrato $(\mu \mathrm{M})$ radiais à costa em Cabo Frio, RJ, realizadas durante o verão de 2001 (M1). 


\subsubsection{Curvas de luz - fotossíntese}

$\mathrm{Na}$ Tabela 3.2 são apresentados os valores médios dos parâmetros fotossintéticos $\left(\mathrm{P}_{\max }{ }^{\mathrm{B}}\right.$ - número de assimilação e $\alpha^{B}$ - eficiência fotossintética) obtidos com o ajuste de modelos empíricos às amostras de produção primária. $\mathrm{O}$ parâmetro de adaptação $\mathrm{I}_{\mathrm{k}}$, ou constante de Talling, também é mostrado na Tabela 3.2 , para os experimentos com amostras das profundidades relativas a $100 \%$ e $1 \%$ de irradiância.

O número de assimilação $\left(\mathrm{P}_{\max }{ }^{\mathrm{B}}\right)$ das populações da camada de superfície variou de 2,79 a $9,90 \mathrm{mgC} \cdot\left(\mathrm{mgClo}^{-1}\right) \cdot \mathrm{h}^{-1}$, tendo sido a média igual a $5,58 \mathrm{mgC} \cdot\left(\mathrm{mgClo}^{-1}\right) \cdot \mathrm{h}^{-1}$. Para as populações localizadas na base da zona eufótica, esses valores foram iguais a 0,93, 4,58 e 2,44 $\mathrm{mgC} .\left(\mathrm{mgClo}^{-1}\right) \cdot \mathrm{h}^{-1}$, respectivamente. A eficiência fotossintética $\left(\alpha^{\mathrm{B}}\right)$ variou nas amostras coletadas em superfície de 0,01 a $0,61 \mathrm{mgC} \cdot\left(\mathrm{mgClo}^{-1}\right) \cdot \mathrm{h}^{-1} \cdot\left(\mathrm{W} \cdot \mathrm{m}^{-2}\right)^{-1}$, com média igual a $0,17 \mathrm{mgC} \cdot\left(\mathrm{mgClo}^{-1}\right) \cdot \mathrm{h}^{-1} \cdot\left(\mathrm{W} \cdot \mathrm{m}^{-2}\right)^{-1} \cdot \mathrm{O} \alpha^{\mathrm{B}}$ das amostras coletadas na base da zona eufótica apresentou valor médio igual a $0,93 \mathrm{mgC} \cdot\left(\mathrm{mgClo}^{-1}\right) \cdot \mathrm{h}^{-1} \cdot\left(\mathrm{W} \cdot \mathrm{m}^{-1}\right)^{-1}$ e uma amplitude de variação maior (Tabela 3.2 ). Em ambas as profundidades os desvios padrão foram altos em relação às médias, principalmente na profundidade de $1 \%$ de irradiância. Os valores médios de $I_{k}$ foram iguais a 22,18 e 5,55 W.m ${ }^{-2}$ na superfície $(100 \%)$ e no fundo (1\%), respectivamente. Em ambos os casos os desvios padrão também foram altos em relação às médias.

TABELA 3.2 - PARÂMETROS FOTOSSINTÉTICOS DAS CURVAS DE LUZ FOTOSSÍNTESE DURANTE O CRUZEIRO DE VERÃO DE 2001 (M1).

\begin{tabular}{c|c|c|c|c|c|c}
\hline \multirow{2}{*}{ M1 } & \multicolumn{3}{|c|}{$\mathbf{1 0 0 \%}$} & \multicolumn{3}{c}{$\mathbf{1 \%}$} \\
\cline { 2 - 7 } & $\mathbf{P}_{\mathbf{m a x}}^{\mathbf{B}}$ & $\alpha^{\mathbf{B}}$ & $\mathbf{I}_{\mathbf{k}}$ & $\mathbf{P}_{\mathbf{m a x}} \mathbf{B}$ & $\alpha^{\mathbf{B}}$ & $\mathbf{I}_{\mathbf{k}}$ \\
\hline Média & 5,58 & 0,17 & 22,18 & 2,44 & 0,93 & 5,55 \\
\hline Máximo & 9,90 & 0,61 & 80,05 & 4,58 & 5,60 & 29,12 \\
\hline Mínimo & 2,79 & 0,01 & 1,97 & 0,93 & 0,03 & 0,86 \\
\hline Desvio Padrão & 2,52 & 0,18 & 23,77 & 1,26 & 1,48 & 7,57 \\
\hline $\begin{array}{c}\text { Coeficiente } \\
\text { Variação }\end{array}$ & $45 \%$ & $102 \%$ & $107 \%$ & $52 \%$ & $158 \%$ & $136 \%$ \\
\hline${ }^{*} P_{\max }^{B}\left(m g C .\left(m g C l o^{-1}\right) \cdot h^{-1}\right), \alpha^{\beta}\left(\left(m g C .\left(m g C l o^{-1}\right) \cdot h^{-1} \cdot\left(W \cdot m^{-2}\right)^{-1}\right), I_{k}\left(W \cdot m^{-2}\right)\right.$
\end{tabular}


A Figura 3.6 apresenta as seções verticais de produção primária obtidas a partir dos experimentos in situ-simulados realizados em algumas das estações do cruzeiro de verão de 2001 (M1). Estão sendo apresentados os resultados referentes às amostras de superfície, ou seja, profundidade relativa à $100 \%$ de irradiância. Não foi possível interpolar a seção vertical referente à radial 4, uma vez que só foram realizados experimentos de incubação em duas estações costeiras (a menos de $10 \mathrm{~km}$ da costa). Os valores de produção primária variaram entre 0,25 e $5,10 \mathrm{mgC} \cdot \mathrm{m}^{-3} \cdot \mathrm{h}^{-1}$ (Tabela 3.3 ). Os maiores valores foram encontrados em regiões mais próximas do continente.

A produção primária média sobre a plataforma foi de $2,17 \mathrm{mgC} \cdot \mathrm{m}^{-3} \cdot \mathrm{h}^{-1}\left( \pm 1,24 \mathrm{mgC} \cdot \mathrm{m}^{-}\right.$ $\left.{ }^{3} \cdot \mathrm{h}^{-1}\right)$, enquanto que sobre o talude foi de $0,54 \mathrm{mgC} \cdot \mathrm{m}^{-3} \cdot \mathrm{h}^{-1}\left( \pm 0,19 \mathrm{mgC} \cdot \mathrm{m}^{-3} \cdot \mathrm{h}^{-1}\right)$. A produção primária média a $100 \%$ para todas as estações $\left(1,42 \pm 1,22 \mathrm{mgC} \cdot \mathrm{m}^{-3} \cdot \mathrm{h}^{-1}\right)$ foi maior do que a estimada para amostras da profundidade de $1 \%$ de irradiância $(0,87 \pm$ $\left.0,58 \mathrm{mgC} \cdot \mathrm{m}^{-3} \cdot \mathrm{h}^{-1}\right)$. Pode-se notar que a zona eufótica estimada esteve mais profunda do que a camada de mistura. $\mathrm{O}$ aquecimento sazonal do verão e o decréscimo da freqüência de tempestades permitem a formação da termoclina sazonal. A camada de mistura é rasa, elevando-se em direção à costa onde ocorre o afloramento da ACAS. Conseqüentemente, pode ocorrer aporte de nutrientes para dentro da zona eufótica, o que fortalece a produção primária.

TABELA 3.3 - PRODUÇÃO PRIMÁRIA DURANTE O CRUZEIRO DE VERÃO DE $2001(\mathrm{M} 1)$.

\begin{tabular}{c|c|c}
\hline M1 & $\begin{array}{c}\text { Plataforma } \\
\left(\mathbf{m g C} \cdot \mathbf{m}^{-\mathbf{3}} \cdot \mathbf{h}^{\mathbf{- 1}}\right)\end{array}$ & $\begin{array}{c}\text { Talude } \\
\left(\mathbf{m g C} \cdot \mathbf{m}^{-\mathbf{3}} \cdot \mathbf{h}^{\mathbf{- 1}}\right)\end{array}$ \\
\hline Média & 2,17 & 0,54 \\
\hline Máximo & 5,10 & 0,88 \\
\hline Mínimo & 0,42 & 0,25 \\
\hline Desvio Padrão & 1,24 & 0,19 \\
\hline $\begin{array}{c}\text { Coeficiente } \\
\text { Variação }\end{array}$ & $57 \%$ & $34 \%$ \\
\hline
\end{tabular}

A Tabela 3.4 apresenta os valores médios, amplitude de variação, desvio padrão e coeficiente de variação da clorofila- $a$ e produção primária integradas na zona eufótica $\left(\mathrm{mg} \cdot \mathrm{m}^{-2}\right.$ e $\mathrm{gC} \cdot \mathrm{m}^{-2} \cdot \mathrm{d}^{-1}$, respectivamente), para as regiões de plataforma e talude, referentes ao cruzeiro de verão de 2001 (M1). 

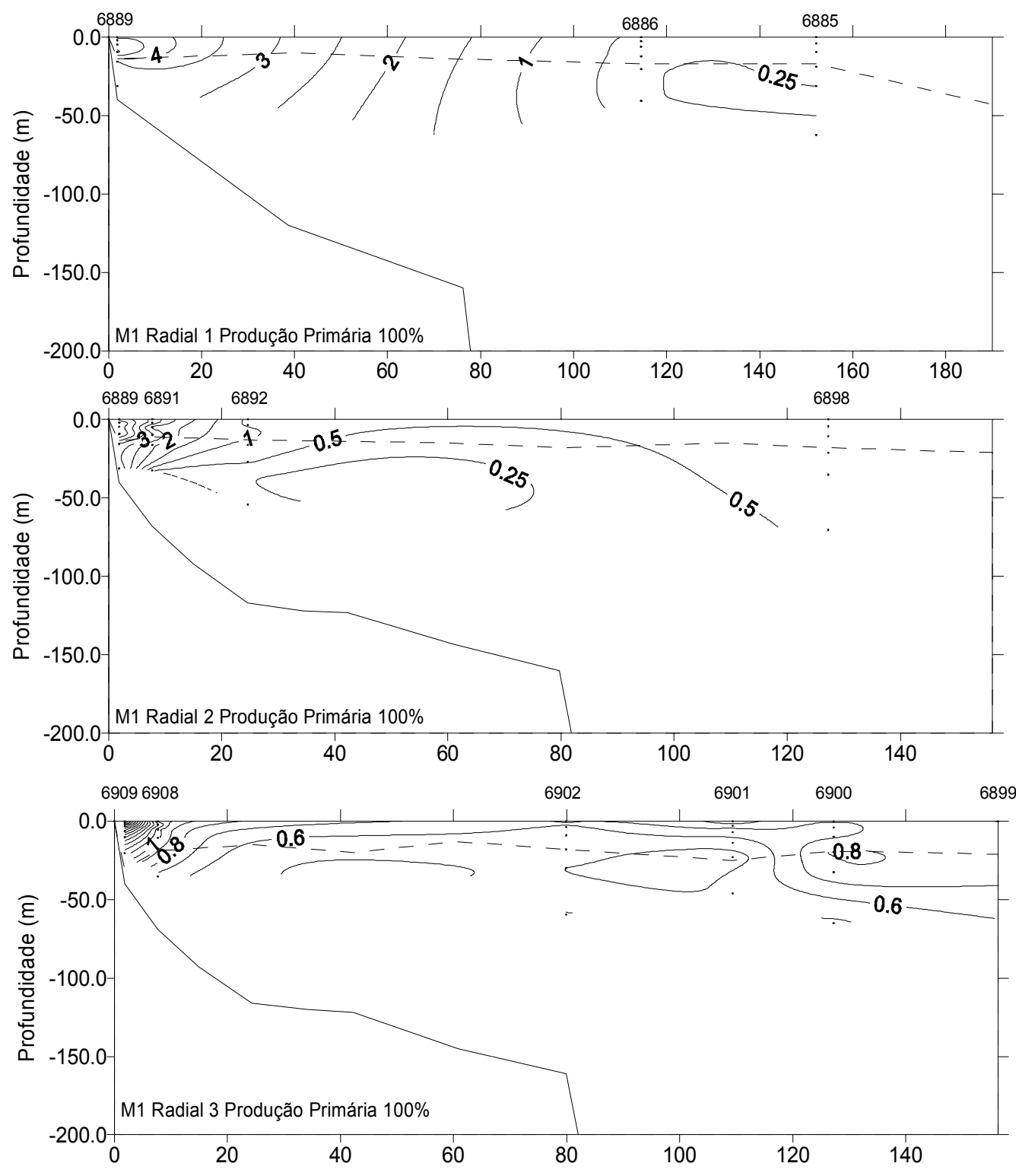

Figura 3.6 - Seções verticais de produção primária $\left(\mathrm{mgC} \cdot \mathrm{m}^{-3} \cdot \mathrm{h}^{-1}\right)$ radiais à costa em

Cabo Frio, RJ, realizadas durante o verão de 2001 (M1). Profundidade da camada de mistura indicada pela linha tracejada.

A clorofila- $a$ integrada na plataforma foi cerca de $45 \%$ maior $\left(14,05 \pm 4,43 \mathrm{mg} \cdot \mathrm{m}^{-2}\right)$ do que na região de talude $\left(9,18 \pm 3,68 \mathrm{mg} \cdot \mathrm{m}^{-2}\right)$. As estimativas de produção primária estão apresentadas em unidades de massa de carbono fixado, por área e por dia. Os valores da produção integrada para as amostras referentes a $100 \%$ de irradiância foram $45 \%$ superiores sobre a plataforma $\left(0,69 \pm 0,38 \mathrm{gC} \cdot \mathrm{m}^{-2} \cdot \mathrm{d}^{-1}\right)$ do que sobre o talude $(0,38 \pm$ 
$\left.0,18 \mathrm{gC} \cdot \mathrm{m}^{-2} \cdot \mathrm{d}^{-1}\right)$. O mesmo comportamento pode ser observado em relação às amostras de $1 \%$ de irradiância $\left(0,43 \pm 0,13 \mathrm{gC} \cdot \mathrm{m}^{-2} \cdot \mathrm{d}^{-1}\right.$ e $0,36 \pm 0,22 \mathrm{gC} \cdot \mathrm{m}^{-2} \cdot \mathrm{d}^{-1}$, respectivamente). Entretanto, comparando-se as produções integradas das amostras de 100\% em relação às de $1 \%$, observa-se uma diferença mais significativa somente entre as médias obtidas para a região de plataforma $\left(0,69\right.$ e $0,43 \mathrm{gC} \cdot \mathrm{m}^{-2} \cdot \mathrm{d}^{-1}$, respectivamente). As produções integradas médias sobre o talude são, aproximadamente, iguais para as amostras de $100 \%$ e $1 \%\left(0,38\right.$ e $0,36 \mathrm{gC} \cdot \mathrm{m}^{-2} \cdot \mathrm{d}^{-1}$, respectivamente).

\section{TABELA 3.4 - CLOROFILA E PRODUÇÃO PRIMÁRIA INTEGRADAS NA ZONA EUFÓTICA SOBRE A PLATAFORMA E O TALUDE DURANTE O CRUZEIRO DE VERÃO DE 2001 (M1).}

\begin{tabular}{c|c|c|c|c|c|c}
\hline \multirow{2}{*}{ M1 } & \multicolumn{3}{|c|}{ Plataforma } & \multicolumn{3}{c}{ Talude } \\
\cline { 2 - 7 } & $\mathbf{C}_{\text {EU }}$ & PP $_{\text {EU100 }}$ & PP $_{\text {EU1 }}$ & $\mathbf{C}_{\text {EU }}$ & PP $_{\text {EU100 }}$ & PP $_{\text {EU1 }}$ \\
\hline Média & 14,05 & 0,69 & 0,43 & 9,18 & 0,38 & 0,36 \\
\hline Máximo & 21,73 & 1,48 & 0,61 & 16,27 & 0,60 & 0,71 \\
\hline Mínimo & 9,07 & 0,39 & 0,23 & 5,68 & 0,16 & 0,15 \\
\hline $\begin{array}{c}\text { Desvio } \\
\text { Padrão }\end{array}$ & 4,43 & 0,38 & 0,13 & 3,68 & 0,18 & 0,22 \\
\hline $\begin{array}{c}\text { Coeficiente de } \\
\text { Variação }\end{array}$ & $32 \%$ & $56 \%$ & $30 \%$ & $40 \%$ & $47 \%$ & $61 \%$ \\
\hline
\end{tabular}

* $C_{E U}$ - Clorofila integrada na zona eufótica $\left(m g . m^{-2}\right) ; P P_{E U 100}$ - Produção primária integrada na zona eufótica das amostras de $100 \%\left(\mathrm{gC} . \mathrm{m}^{-2} . d^{-1}\right) ; P P_{E U 1}$ - Produção primária integrada na zona eufótica das amostras de $1 \%\left(g C . m^{-2} . d^{-1}\right)$.

\subsubsection{Nutrientes inorgânicos dissolvidos}

Durante o cruzeiro de verão de 2001 (M1) uma parte da plataforma continental amostrada apresentou-se estratificada, com a profundidade da termoclina sazonal variando de 8 a $20 \mathrm{~m}$. Esta estratificação também esteve relacionada a advecção de águas com densidades relativamente altas de origem oceânica (ACAS). Da mesma forma, esta estrutura foi alterada pela ressurgência na região mais próxima à costa.

Em diversas estações mais profundas, as concentrações de amônia estiveram abaixo do limite analítico de detecção. O valor máximo encontrado foi de $2,40 \mu \mathrm{M}$ próximo à costa na radial 1 (ver Tabela 3.5). A intrusão e ressurgência da ACAS resultaram em concentrações de nitrato relativamente elevadas, como mencionado anteriormente. $\mathrm{O}$ valor máximo encontrado foi de $4,46 \mu \mathrm{M}$ próximo à quebra de plataforma na radial 4 . A distribuição de fosfato seguiu a de nitrato com concentrações de até $1,83 \mu \mathrm{M}$, também 
próximo à quebra de plataforma, na radial 3. A maior concentração de silicato $(10,82$ $\mu \mathrm{M}$ ) foi observada nas estações mais profundas das radias 3 e 4 . Altas concentrações de silicato também foram estimadas na radial 4, próximas à costa.

TABELA 3.5 - CONCENTRAÇÃO DE NUTRIENTES INORGÂNICOS DISSOLVIDOS DURANTE O CRUZEIRO DE VERÃO DE 2001 (M1).

\begin{tabular}{c|c|c|c|c|c}
\hline $\mathbf{M 1}$ & $\begin{array}{c}\text { Nitrato } \\
(\boldsymbol{\mu M})\end{array}$ & $\begin{array}{c}\text { Nitrito } \\
(\boldsymbol{\mu M})\end{array}$ & $\begin{array}{c}\text { Amônia } \\
(\boldsymbol{\mu M})\end{array}$ & $\begin{array}{c}\text { Fosfato } \\
(\boldsymbol{\mu M})\end{array}$ & $\begin{array}{c}\text { Silicato } \\
(\boldsymbol{\mu M} \mathbf{M}\end{array}$ \\
\hline Média & 0,62 & 0,05 & 0,14 & 0,49 & 2,42 \\
\hline Máximo & 4,46 & 0,47 & 2,40 & 1,83 & 10,82 \\
\hline Mínimo & $<0,05$ & $<0,05$ & $<0,05$ & $<0,03$ & 0,23 \\
\hline Desvio padrão & 0,84 & 0,06 & 0,31 & 0,37 & 1,79 \\
\hline
\end{tabular}

Os diagramas de dispersão dos nutrientes inorgânicos dissolvidos em função de $\sigma_{t}$ podem ser vistos na Figura 3.7 mostrada a seguir. O limite isopicnal inferior da ACAS $\left(25,4 \mathrm{~kg} \cdot \mathrm{m}^{-3}\right)$ aparece indicado pela linha tracejada na Figura 3.7. Pode-se observar uma inflexão a partir da presença da ACAS. Interessante notar outro máximo relativo em torno de $24,5 \mathrm{~kg} \cdot \mathrm{m}^{-3}$.

Em termos de representação relativa de cada nutriente nitrogenado inorgânico, temos que tanto o nitrato, como o nitrito e a amônia contribuíram de 0 a $100 \%$ do nitrogênio total. Entretanto, se não considerarmos os casos em que as concentrações ficaram abaixo do limite analítico, teremos uma contribuição das concentrações de nitrato variando de 1,6 a $100 \%$. A amônia contribuiu de 0,9 a $100 \%$ e o nitrito de 0,1 a $100 \%$. Os valores médios de contribuições relativas e o valor absoluto do nitrogênio total são apresentados na Tabela 3.6. 

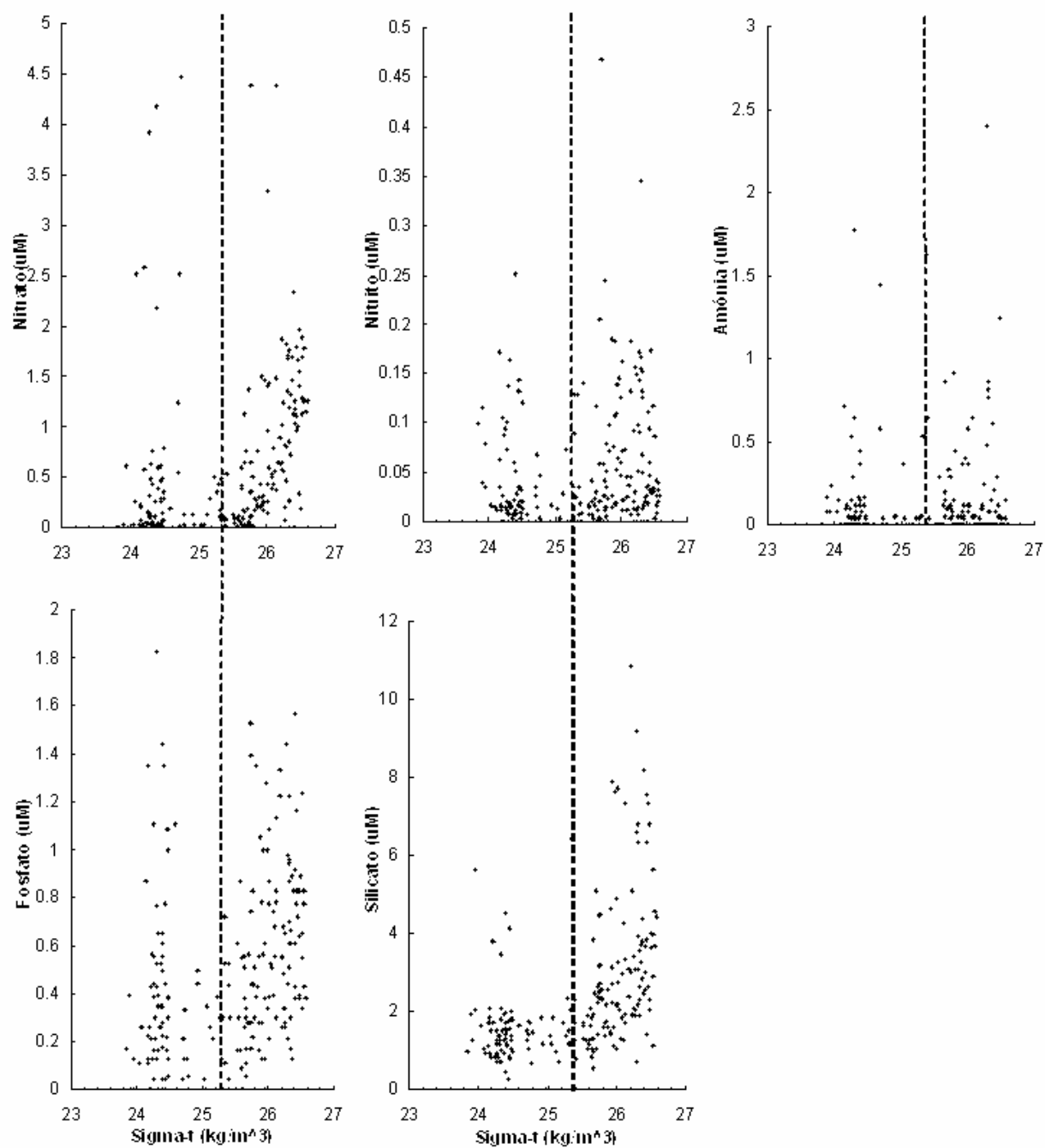

Figura 3.7 - Diagramas de dispersão dos nutrientes inorgânicos dissolvidos $(\mu \mathrm{M}) \mathrm{em}$ função de $\sigma_{\mathrm{t}}\left(\mathrm{kg} \cdot \mathrm{m}^{-3}\right)$, para o cruzeiro de verão de 2001 (M1). A linha tracejada indica o limite isopicnal inferior da Água Central do Atlântico Sul.

TABELA 3.6 - MÉDIAS DAS CONCENTRAÇÕES RELATIVAS DOS COMPOSTOS NITROGENADOS DISSOLVIDOS E DA CONCENTRAÇÃO ABSOLUTA DO NITROGÊNIO TOTAL DURANTE O CRUZEIRO DE VERÃO DE 2001 (M1).

\begin{tabular}{c|c|c|c|c}
\hline M1 & $\begin{array}{c}\text { Nitrato } \\
\mathbf{\%}\end{array}$ & $\begin{array}{c}\text { Nitrito } \\
\mathbf{\%}\end{array}$ & $\begin{array}{c}\text { Amônia } \\
\mathbf{\%}\end{array}$ & $\begin{array}{c}\text { Nitrogênio } \\
(\boldsymbol{\mu M})\end{array}$ \\
\hline Média & 70,25 & 17,34 & 41,24 & 0,81 \\
\hline Máximo & 100,00 & 100,00 & 100,00 & 4,57 \\
\hline Mínimo & 1,62 & 0,09 & 0,89 & 0,01 \\
\hline Desvio padrão & 28,75 & 23,19 & 30,30 & 0,92 \\
\hline
\end{tabular}




\subsubsection{Imagens de Temperatura da Superfície do Mar}

Apesar do cruzeiro de verão de 2001 ter sido realizado somente entre os dias 7 e 13 de fevereiro de 2001, serão incluídas imagens referentes a alguns dias anteriores e posteriores ao período de coletas in situ de modo a auxiliar na caracterização regional e sinóptica da região de interesse. A Figura 3.8 a seguir apresenta as imagens de temperatura da superfície do mar (TSM) obtidas para os dias 1, 12, 13 e 14 de fevereiro de 2001. As águas da $\mathrm{CB}$ em tons vermelhos, com temperaturas acima de $26,0^{\circ} \mathrm{C}$, aparecem nas imagens fluindo de NE para SE ao longo da quebra de plataforma. Em alguns trechos, como ao sul de Cabo Frio, a CB invade a plataforma, ultrapassando a isóbata de $200 \mathrm{~m}$. Nesta região, pode-se notar um meandramento ciclônico da CB com cerca de $120 \mathrm{~km}$ de extensão. Outro meandramento ciclônico menor, com cerca de 60 km de diâmetro médio pode ser observado ao largo de São Tomé. Interessante notar uma cunha de águas quentes $\left(\mathrm{T}>27,0^{\circ} \mathrm{C}\right)$ colada à costa, desde o litoral de São Paulo até quase Cabo Frio. As águas de plataforma apresentam valores entre 23, $0^{\circ}$ e $25,0^{\circ} \mathrm{C}$. Os tons ciano e azul claro indicam a presença de águas relativamente mais frias sobre a plataforma ao sul de Vitória $\left(\mathrm{T}<23,0^{\circ} \mathrm{C}\right)$, na região costeira ao sul de São Tomé $\left(\mathrm{T}<22,0^{\circ} \mathrm{C}\right)$ e a oeste de Cabo Frio $\left(\mathrm{T}<19,0^{\circ} \mathrm{C}\right)$. Nas imagens de 13 e 14/02/2002 é possível identificar um núcleo de águas frias em Búzios $\left(\mathrm{T}<21,5^{\circ} \mathrm{C}\right)$, ou seja, a norte de Cabo Frio.

A Figura 3.9 apresenta as imagens de TSM referentes aos dias 18, 19, 20 e 25 de fevereiro de 2001. Ainda que a disposição dos campos de temperatura superficial tenha permanecido similar à descrita com relação às imagens da Figura 3.8, é interessante notar o desenvolvimento da pluma de águas frias, associada à ressurgência costeira em Cabo Frio nas imagens que se seguem. 

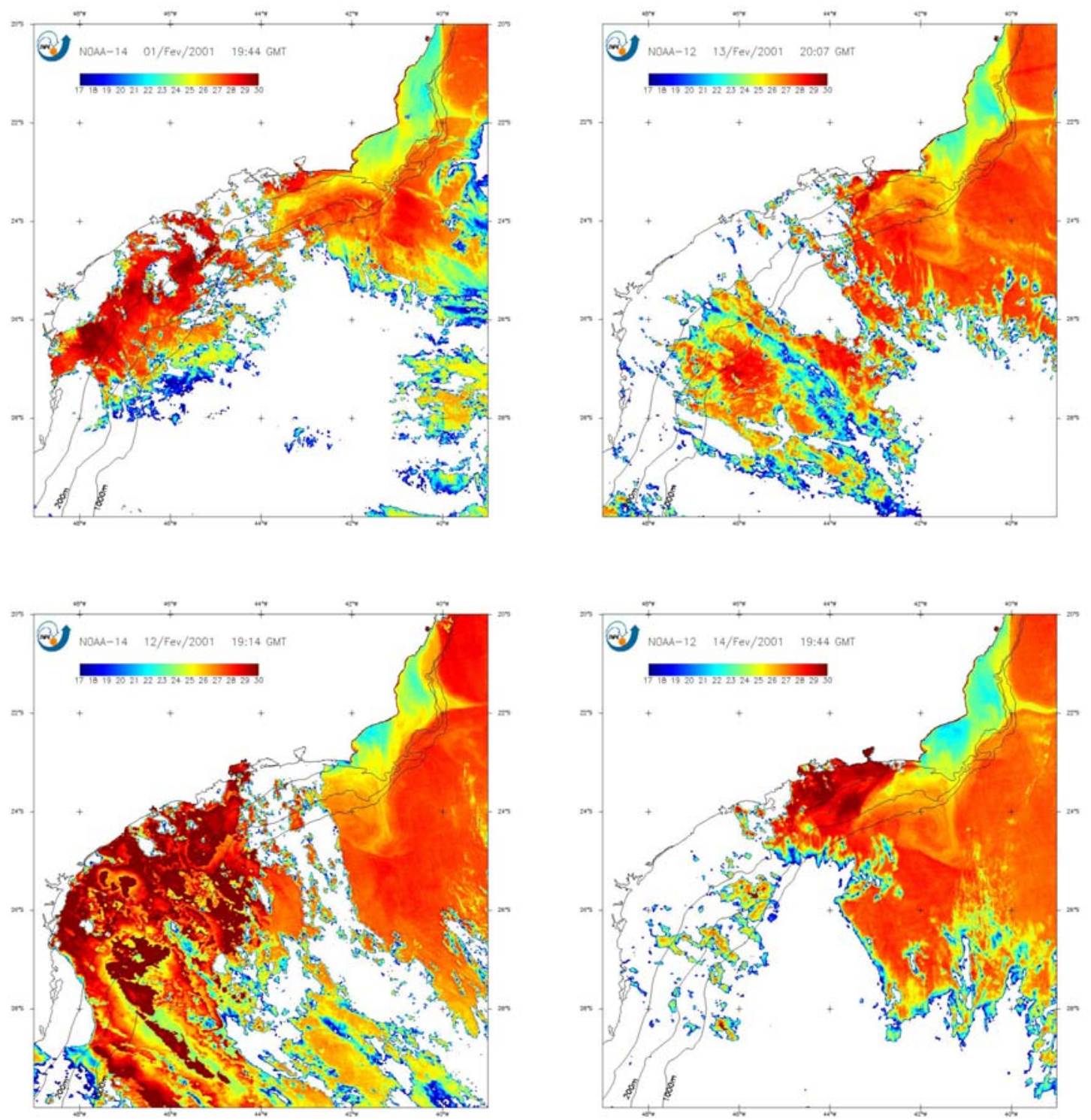

Figura 3.8 - Imagens da temperatura da superfície do mar referentes aos dias 01 (esquerda em cima), 12 (esquerda embaixo), 13 (direita em cima) e 14 (direita embaixo) de fevereiro de 2001. Isóbatas de 100, 200 e $1.000 \mathrm{~m}$ em preto.

No dia 18/02/2001 pode-se notar um pequeno núcleo de águas frias a oeste de Cabo Frio, com temperaturas menores que $21,5^{\circ} \mathrm{C}$. A sul de Búzios, também é possível observar outro pequeno núcleo com TSM abaixo de $21,5^{\circ} \mathrm{C}$. Colado à costa, entre Cabo Frio e São Tomé, ocorrem mínimos de $20,5^{\circ} \mathrm{C}$. 

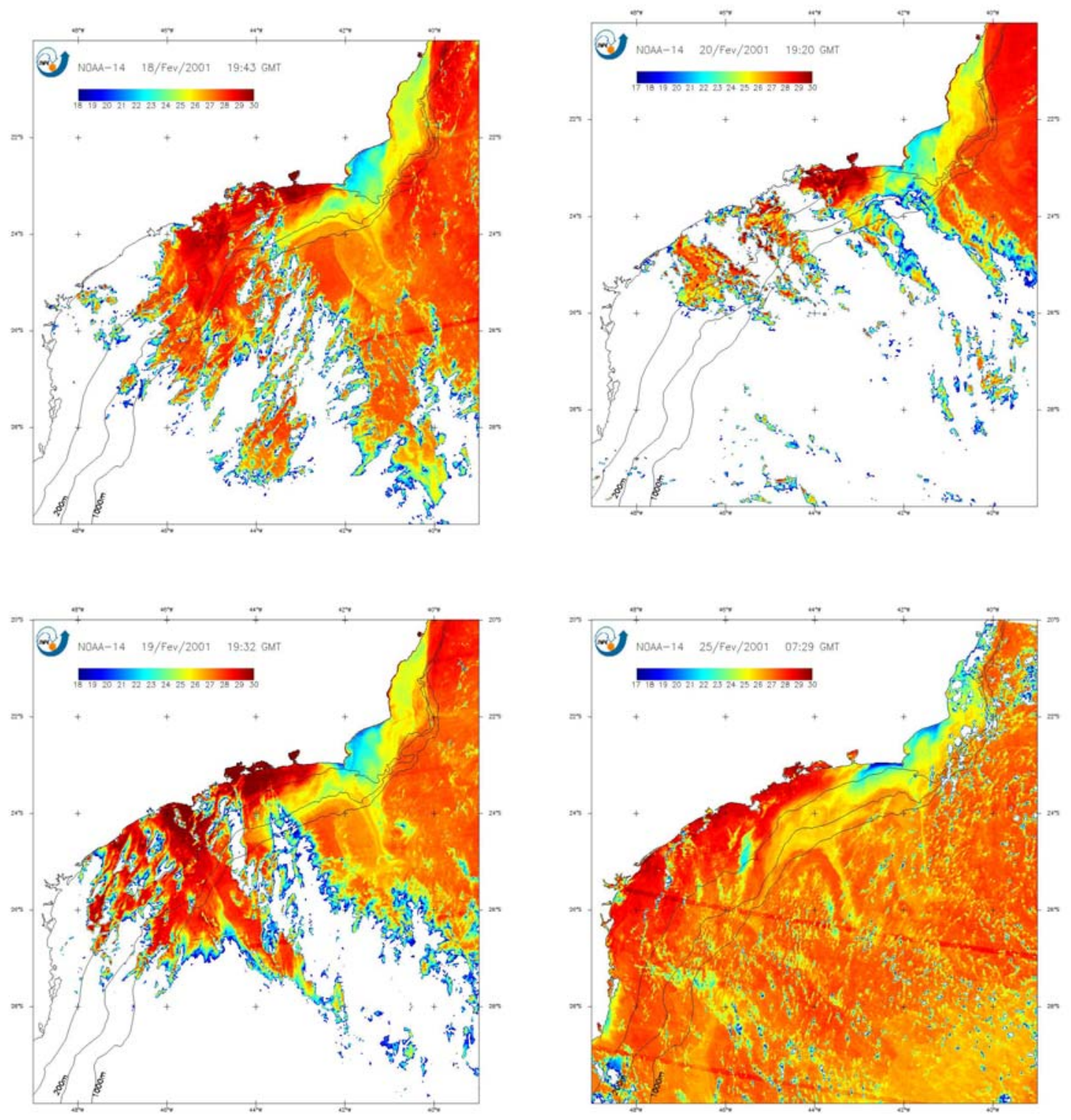

Figura 3.9 - Imagens da temperatura da superfície do mar referentes aos dias 18 (esquerda em cima), 19 (esquerda embaixo), 20 (direita em cima) e 25 (direita embaixo) de fevereiro de 2001. Isóbatas de 100, 200 e $1.000 \mathrm{~m}$ em preto.

Nas imagens que se seguem, as temperaturas mínimas observadas a oeste de Cabo Frio atingem valores abaixo de $20,0^{\circ} \mathrm{C}$. A pluma de ressurgência se desenvolveu na direção O-SO com extensão máxima de $100 \mathrm{~km}$ na imagem de 25/02/2002 (considerando a isoterma de $22,0^{\circ} \mathrm{C}$ como seu limite). Outra pluma de ressurgência costeira com origem a sul de São Tomé também é notada nas imagens com TSM abaixo de $20,5^{\circ} \mathrm{C}$. 


\subsubsection{Imagens de Concentração de Clorofila da Superfície do Mar}

Apesar da nebulosidade presente sobre a costa SE brasileira e do mascaramento de nuvens rigoroso aplicado no processamento digital das imagens SeaWiFS, é possível identificar algumas feições oceanográficas na área de interesse do projeto DEPROAS a partir da interpretação visual dessas imagens. A Figura 3.10 a seguir mostra as imagens de concentração de clorofila da superfície do mar (CSM) obtidas para os dias 1, 8, 13 e 14 de fevereiro de 2001. Pode-se observar a região costeira em tons vermelhos, indicando valores de biomassa fitoplanctônica acima de 5,0 mg. $\mathrm{m}^{-3}$. Os tons em azul mais escuro observados em regiões mais profundas estão associados às águas oligotróficas da $\mathrm{CB}$ fluindo ao largo na direção NE-SO. É possível notar um meandramento ciclônico da $\mathrm{CB}$ ao sul de Cabo Frio com a conseqüente intrusão de águas mais pobres sobre a plataforma, formando uma frente com intenso gradiente de biomassa. Uma extensa pluma com concentrações de clorofila relativamente mais altas $\left(>0,5 \mathrm{mg} \cdot \mathrm{m}^{-3}\right)$ pode ser observada sobre a quebra de plataforma, desde Cabo Frio até o litoral norte de São Paulo na imagem de 01/02/2001. Outras plumas de águas relativamente mais ricas em biomassa fitoplanctônica são observadas ao norte de Cabo Frio, entre Cabo Frio e a Baía de Guanabara. Outras manchas de biomassa fitoplanctônica acima de 5,0 mg.m ${ }^{-3}$ foram notadas a SO da Ilha de São Sebastião e próximo ao Cabo São Tomé. Interessante também notar uma extensa mancha com concentrações de clorofila de até $2,0 \mathrm{mg} \cdot \mathrm{m}^{-3}$ sobre a quebra de plataforma, desde a Ilha de São Sebastião, até o Cabo Santa Marta. Neste ponto, as manchas de alta biomassa costeira são indicativas de ressurgência no local. Feições de mesoescala da ordem de centenas de quilômetros também podem ser visualizadas na região mais meridional da área imageada, associadas à Convergência Subtropical. Um vórtice ciclônico na região frontal da CB foi observado ao largo de São Tomé. O vórtice de Vitória pode ser identificado em torno de $20,5^{\circ} \mathrm{S}-39,4^{\circ} \mathrm{W}$ na imagem de $13 / 02 / 2001$.

A Figura 3.11 apresenta as imagens SeaWiFS de concentração de clorofila da superfície do mar processadas para os dias 15, 17, 18 e 19 de fevereiro de 2001 . 


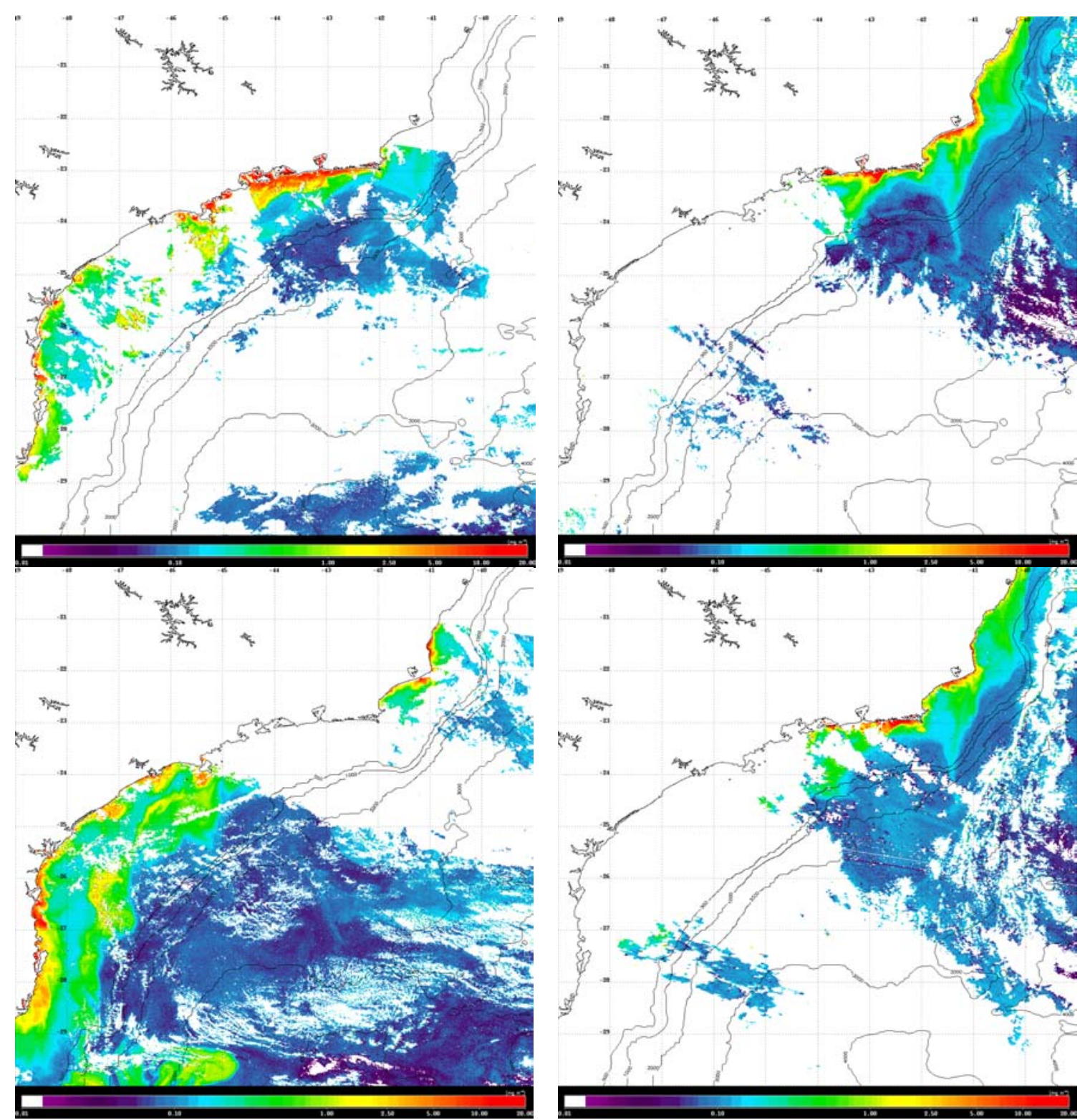

Figura 3.10 - Imagens da concentração de clorofila da superfície do mar referentes aos dias 1 (esquerda em cima), 8 (esquerda embaixo), 13 (direita em cima) e 14 (direita embaixo) de fevereiro de 2001. Isóbatas de 500, 1.000, 2.000, $3.000 \mathrm{e}$ $4.000 \mathrm{~m}$ em preto. Tabela de cores em escala logarítmica.

A imagem de 15/02/2001 exibe a área de estudo praticamente sem cobertura nuvens. A NE da Ilha de São Sebastião, nota-se uma pequena mancha com concentrações em torno de 2,0 mg.m $\mathrm{m}^{-3}$. Uma extensa pluma com valores de biomassa fitoplanctônica entre 0,5 e 3,0 mg. $\mathrm{m}^{-3}$ aparece desde Cabo Frio até a isóbata de $500 \mathrm{~m}$ no litoral norte de São Paulo. Uma pluma similar, porém muito mais estreita, também pode ser observada na direção N-S, cruzando o talude continental a SE de Cabo Frio até ser capturada pelo 
meandramento ciclônico da CB. Dois grandes meandros da $\mathrm{CB}$ foram observados a S-SO de Cabo Frio. Vórtices ciclônicos foram notados em Vitória, São Tomé e Cabo Frio. Plumas de alta biomassa fitoplanctônica aparecem fluindo ao sul de Vitória, São Tomé, Cabo Frio e Saquarema (>0,5 mg. $\left.\mathrm{m}^{-3}\right)$.

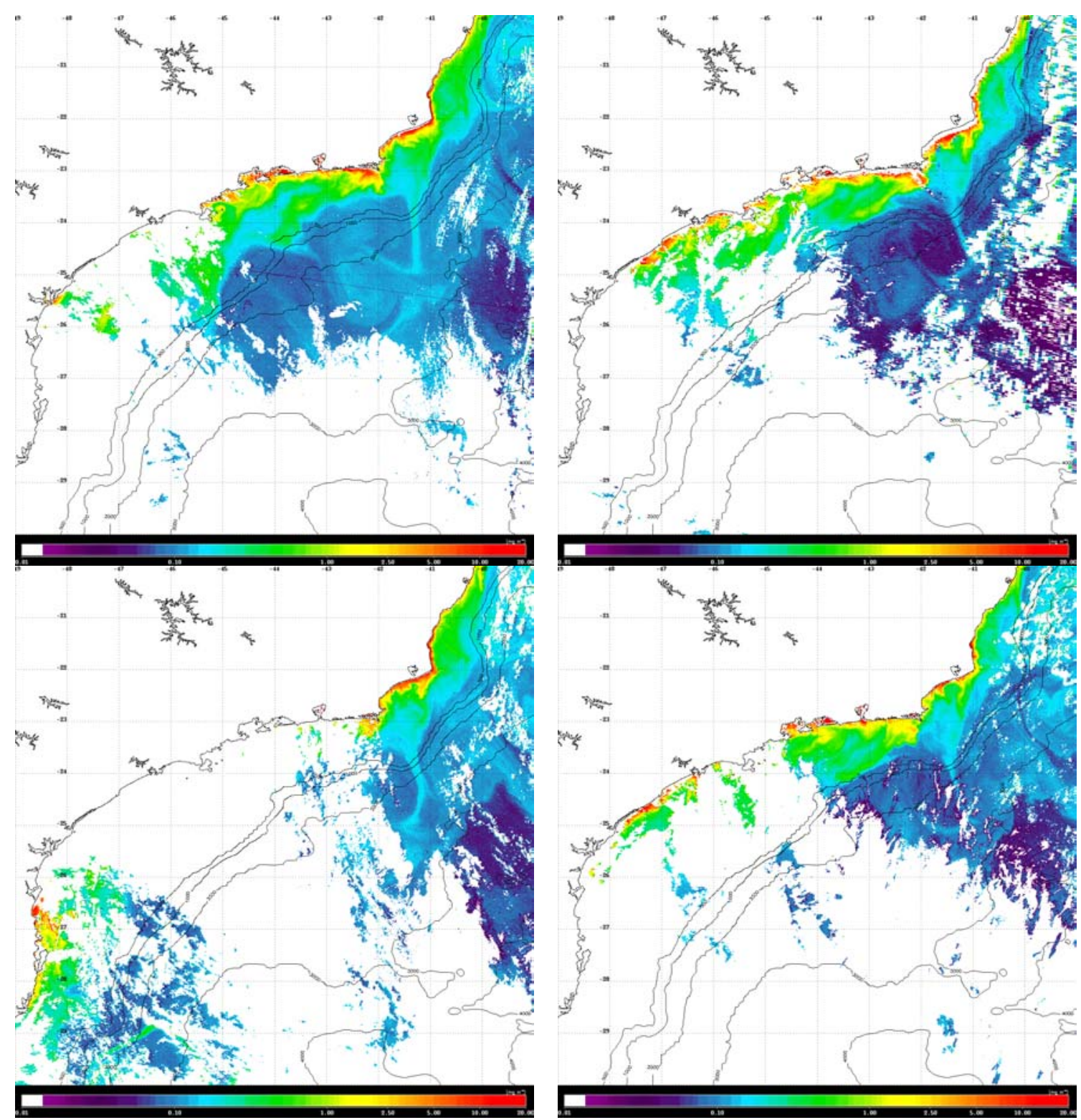

Figura 3.11 - Imagens da concentração de clorofila da superfície do mar referentes aos dias 15 (esquerda em cima), 17 (esquerda embaixo), 18 (direita em cima) e 19 (direita embaixo) de fevereiro de 2001. Isóbatas de 500, 1.000, 2.000, 3.000 e $4.000 \mathrm{~m}$ em preto. Tabela de cores em escala logarítmica. 


\subsubsection{Produção primária por satélite - Modelo Bedford (BPM1)}

Como foi mencionado anteriormente, o modelo aqui denominado BPM1 (não espectral, verticalmente homogêneo), estima a produção primária diária integrada na coluna d'água $\left(\mathrm{mgC} \cdot \mathrm{m}^{-2} \cdot \mathrm{d}^{-1}\right)$, de acordo com a solução analítica, não espectral, derivada por (Platt et al., 1990) e adaptada por Platt e Sathyendranath (1993). Este modelo também assume um perfil vertical homogêneo de biomassa fitoplanctônica.

Apesar de terem sido realizados experimentos de produção primária in situ simulada em 13 estações durante o cruzeiro de verão de 2001, só foram obtidas estimativas com o modelo de BPM1 em 3 estações $(6909,6917$ e 6918). Toda vez que a irradiância adimensional, calculada para o meio dia como $I_{*}^{m}=I_{0}^{m} / I_{k}$, for maior que 20 , a produção é considerada igual a 0,0 (nula), critério utilizado também por Fee (1990). A Tabela 3.7 apresenta as produções primárias integradas na zona eufótica $\left(\mathrm{gC} \cdot \mathrm{m}^{-2} \cdot \mathrm{d}^{-1}\right)$ estimadas com o modelo BPM1 durante o cruzeiro M1. São também mostrados os valores integrados na primeira profundidade óptica e na camada de mistura. Foram utilizados os parâmetros fotossintéticos relativos aos níveis de $100 \%$ e $1 \%$ de irradiância.

Os valores de produção primária integrada na estação 6909 foram menores que os estimados nas duas outras estações (6017 e 6918), tanto na zona eufótica, como na primeira profundidade óptica e na camada de mistura, apesar de ocuparem posições próximas da costa. Por outro lado, só foi possível estimar a produção primária integrada com os parâmetros fotossintéticos referentes ao nível de $1 \%$ naquela estação. $\mathrm{O}$ valor calculado para a camada de mistura foi muito próximo ao estimado na zona eufótica, na estação 6909 , tanto a $100 \%$ como a 1\%. Este comportamento também foi observado na estação 6918, para o nível de $100 \%$. Já na estação 6917 , a produção integrada na zona eufótica foi quase o dobro da calculada para a camada de mistura. 
TABELA 3.7 - PRODUÇÕES PRIMÁRIAS INTEGRADAS NA ZONA EUFÓTICA, PRIMEIRA PROFUNDIDADE ÓPTICA E CAMADA DE MISTURA PELO MODELO BPM1 (M1)

\begin{tabular}{|c|c|c|c|c|c|c|}
\hline & \multicolumn{3}{|c|}{$100 \%$} & \multicolumn{3}{|c|}{$1 \%$} \\
\hline Estação & BPM1 $_{\text {EU }}$ & BPM1 $_{\text {OP }}$ & BPM1 $_{\mathrm{CM}}$ & BPM1 $_{\mathrm{EU}}$ & BPM1 $_{\text {OP }}$ & BPM1 $_{\mathrm{CM}}$ \\
\hline 6909 & 0,455 & 0,184 & 0,466 & 0,182 & 0,085 & 0,185 \\
\hline 6917 & 0,966 & 0,332 & 0,492 & s.d. & s.d. & s.d. \\
\hline 6918 & 0,947 & 0,336 & 0,847 & s.d. & s.d. & s.d. \\
\hline
\end{tabular}

\subsubsection{Produção primária por satélite - Modelo BPM2}

No cálculo da produção primária diária integrada na zona eufótica pelo modelo BPM2 (espectral, não homogêneo), o perfil vertical de biomassa fitoplanctônica é representado por uma curva Gaussiana-deslocada, como descrito em Platt et al. (1994). As componentes direta e difusa da irradiância superficial são estimadas através do modelo de irradiância espectral de Bird (1984), adaptado por Sathyendranath e Platt (1988) de modo a fornecer a irradiância descendente $I_{0}(\lambda, t)$ na superfície em uma dada posição geográfica e ângulo zenital.

Com uso desse modelo, foram estimadas as produções primárias diárias integradas na zona eufótica nas 13 estações onde as produções foram determinadas in situ. A Tabela 3.8 apresenta os valores médios, amplitudes de variação e desvios padrão das produções integradas na zona eufótica $\left(\mathrm{gC} \cdot \mathrm{m}^{-2} \cdot \mathrm{d}^{-1}\right)$ calculadas com o modelo BPM2, para os domínios de plataforma e talude, em relação aos níveis de $100 \%$ e 1\%.

TABELA 3.8 - PRODUÇÃO PRIMÁRIA INTEGRADA NA ZONA EUFÓTICA CALCULADA COM O MODELO BPM2 (M1).

\begin{tabular}{|c|c|c|c|c|}
\hline \multirow{2}{*}{ M1 } & \multicolumn{2}{|c|}{ Plataforma } & \multicolumn{2}{|c|}{ Talude } \\
\hline & BPM2 ${ }_{100 \%}$ & BPM2 $1 \%$ & BPM2 $100 \%$ & BPM2 $1 \%$ \\
\hline Média & 1,02 & 0,56 & 0,72 & 0,42 \\
\hline Máximo & 1,59 & 0,96 & 1,26 & 0,78 \\
\hline Mínimo & 0,60 & 0,24 & 0,30 & 0,15 \\
\hline $\begin{array}{l}\text { Desvio } \\
\text { padrão }\end{array}$ & 0,35 & 0,25 & 0,39 & 0,27 \\
\hline $\begin{array}{l}\text { Coeficiente } \\
\text { variacão }\end{array}$ & $35 \%$ & $45 \%$ & $54 \%$ & $64 \%$ \\
\hline $\mathbf{n}$ & 7 & 7 & 6 & 6 \\
\hline
\end{tabular}


Os valores médios calculados sobre a plataforma foram maiores que sobre o talude, tanto para o nível de superfície como para as amostras a 1\%. Nos dois domínios, de plataforma e talude, a produção primária integrada na zona eufótica calculada pelo modelo BPM2 em relação a 100\% foi maior do que em relação ao nível mais profundo.

\subsubsection{Produção primária por satélite - Modelo VGPM}

O outro modelo também aplicado foi uma versão simplificada do VGPM desenvolvido por Beherenfeld e Falkowski (1997). Este modelo fornece uma relação semianalítica derivada empiricamente para resolver a produção primária integrada na zona eufótica. Com uso desse modelo, foram estimadas as produções primárias diárias integradas na zona eufótica em 7 estações onde as produções foram determinadas in situ, sendo 5 sobre a plataforma e somente duas no talude. Na falta das concentrações de clorofila $a$ estimadas por satélite, devido à cobertura de nuvens presente em alguns dias do cruzeiro $\mathrm{M}$, não foi possível estimar os parâmetros $\mathrm{C}_{\text {tot }}$ (concentração de clorofila $a$ média na zona eufótica) e $Z_{\mathrm{eu}}$ (profundidade da zona eufótica), necessários para a realização do cálculo da produção integrada. A Tabela 3.9 apresenta os valores médios, amplitudes de variação e desvios padrão das produções integradas na zona eufótica $\left(\mathrm{gC} \cdot \mathrm{m}^{-2} \cdot \mathrm{d}^{-1}\right)$ calculadas com o modelo VGPM, para os domínios de plataforma e talude, em relação ao nível de $100 \%$. Também são mostradas as profundidades calculadas para $\mathrm{Z}_{\mathrm{EU}}$.

TABELA 3.9 - PRODUÇÃO PRIMÁRIA INTEGRADA NA ZONA EUFÓTICA CALCULADA COM O MODELO VGPM (M1).

\begin{tabular}{c|c|c|c|c}
\hline \multirow{2}{*}{ M1 } & \multicolumn{2}{|c|}{ Plataforma } & \multicolumn{2}{c}{ Talude } \\
\cline { 2 - 5 } Média & VGPM $_{\mathbf{1 0 0} \%}$ & $\mathbf{Z}_{\mathbf{E U}}$ & $\mathbf{V G P M}_{\mathbf{1 0 0} \%}$ & $\mathbf{Z}_{\mathbf{E U}}$ \\
\hline Máximo & 1,91 & 0,06 & 0,31 & 0,09 \\
\hline Mínimo & 2,38 & 0,08 & 0,31 & 0,09 \\
\hline $\begin{array}{c}\text { Desvio } \\
\text { padrão }\end{array}$ & 1,05 & 0,04 & 0,30 & 0,09 \\
\hline $\begin{array}{c}\text { Coeficiente } \\
\text { variação }\end{array}$ & $27 \%$ & 0,53 & 0,009 & 0,0 \\
\hline $\mathbf{n}$ & 5 & $33 \%$ & $3 \%$ & $0,2 \%$ \\
\hline \multicolumn{7}{|c|}{} & * unidades $\left(g C . m^{-2} \cdot d^{-1}\right) ; n=$ número de observações
\end{tabular}




\subsection{Cruzeiro de Mesoescala - Inverno de 2001 (M2)}

\subsubsection{Seções verticais de temperatura, salinidade e densidade}

As Figuras 3.12, 3.13 e 3.14 apresentam as seções verticais de temperatura, salinidade e $\sigma_{t}$, referentes às quatro radiais ocupadas durante o cruzeiro de inverno de 2001, respectivamente. Em superfície, as temperaturas variam entre $22^{\circ}$ e $23{ }^{\circ} \mathrm{C}$, sendo mais homogêneas do que no verão, devido à não ocorrência de ressurgência costeira durante o período amostrado (Figura 3.12). Entretanto, nas proximidades do fundo, as temperaturas estão abaixo $18{ }^{\circ} \mathrm{C}$, de forma similar ao observado no período de verão do mesmo ano.

A influência da AT, com valores de salinidade maiores que 36,4 , pode ser observada nas parte mais externa da plataforma continental e ao largo. Nas proximidades do fundo, os valores estão abaixo de 35,6 sem grandes variações sazonais. Interessante notar a presença de lentes subsuperficiais de águas mais salinas $(\mathrm{S}>36,4)$ em direção à costa, em todas as radiais (Figura 3.13).

Valores superficiais de densidade inferiores a 25,4 são observados em toda a área amostrada (Figura 3.14). Densidades menores estão presentes nas proximidades da costa. As intrusões de AT não possuem assinatura na distribuição de densidade devido a compensações entre os valores associados de temperatura e de salinidade.

A configuração das isotermas e isohalinas indica a presença da ACAS sobre a plataforma, entre 50 e $100 \mathrm{~m}$ de profundidade. Embora a influência da ACAS não chegue à superfície do mar, o aumento da concentração de sais nutrientes na base da zona eufótica também pode incrementar a produção primária total (Metzler et al., 1997). Estruturas na forma de vórtices ciclônicos, na borda da plataforma continental na região sudeste, também são capazes de induzir movimentos ascendentes e transportar a ACAS para regiões da plataforma (Campos, 1995; Campos et al., 2000). 

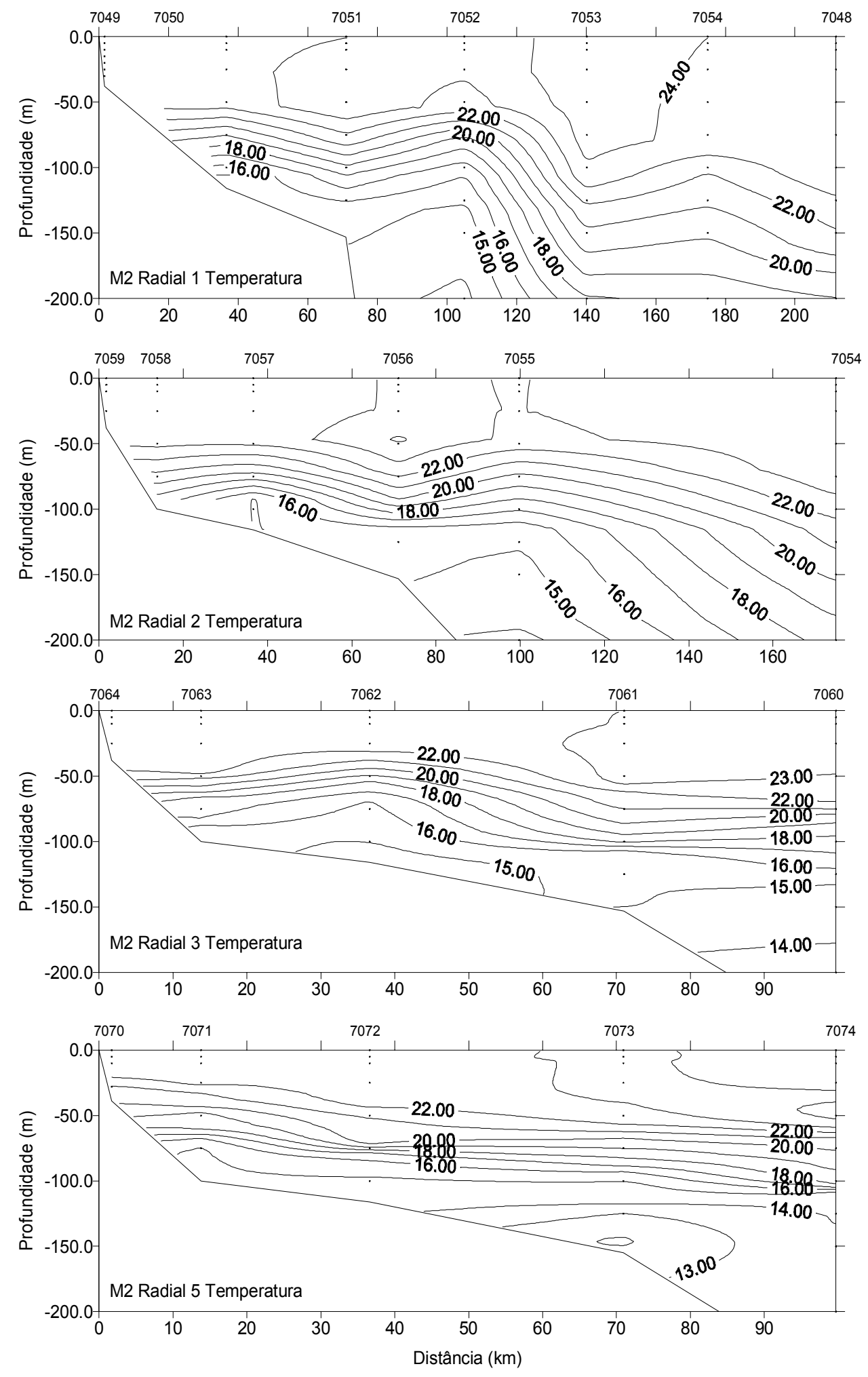

Figura 3.12 - Seções verticais de temperatura $\left({ }^{\circ} \mathrm{C}\right)$ radiais à costa em Cabo Frio, RJ, realizadas durante o inverno de 2001 (M2). 

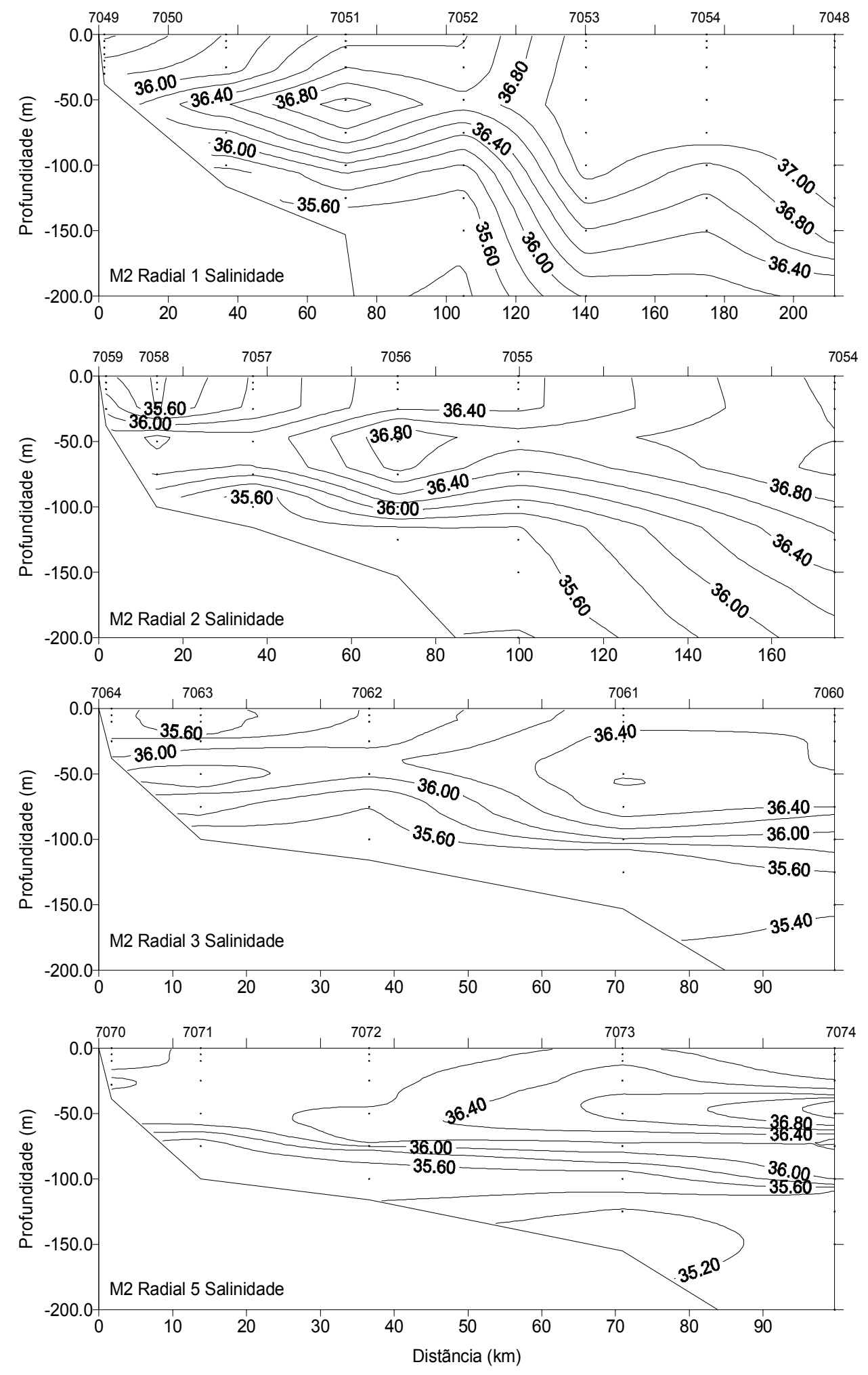

Figura 3.13 - Seções verticais de salinidade radiais à costa em Cabo Frio, RJ, realizadas durante o inverno de 2001 (M2). 

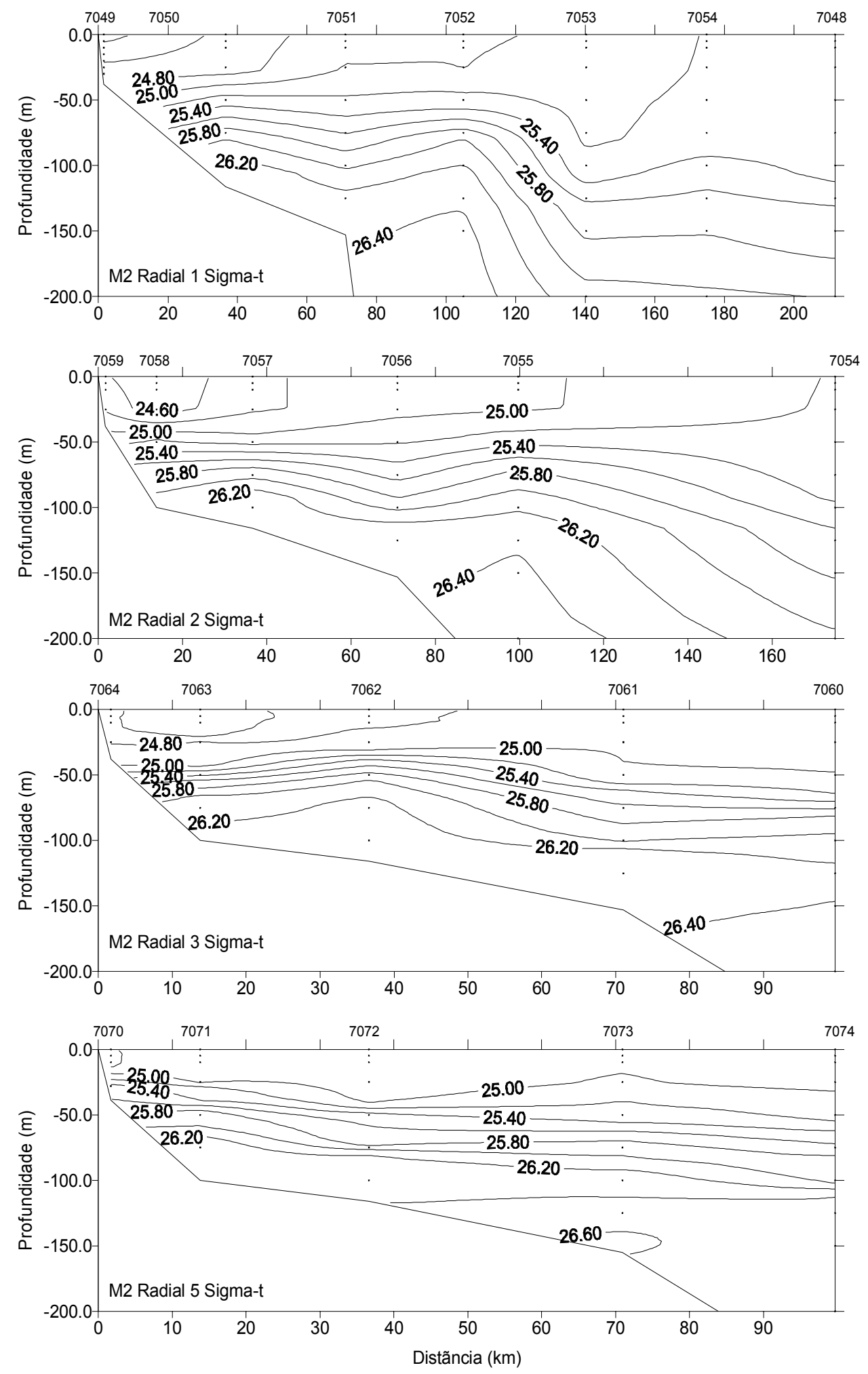

Figura 3.14 - Seções verticais de $\sigma_{\mathrm{t}}\left(\mathrm{kg} \cdot \mathrm{m}^{-3}\right)$ radiais à costa em Cabo Frio, RJ, realizadas durante o inverno de 2001 (M2). 


\subsubsection{Seções verticais de clorofila-a, nitrato e produção primária}

As Figuras 3.15 e 3.16 a seguir mostram as seções verticais de clorofila- $a$ e nitrato referentes às quatro radiais ocupadas durante o cruzeiro M2. A concentração de clorofila- $a$ variou entre 0,01 e $2,14 \mathrm{mg} \cdot \mathrm{m}^{-3}$ (Tabela 3.10), com máximos próximos ao continente, em profundidades entre 5 e $25 \mathrm{~m}$. Máximos relativos subsuperficiais também foram observados entre 25 e $75 \mathrm{~m}$ de profundidade próximos à quebra de plataforma (Figura 3.15). A concentração média sobre a plataforma foi de 0,96 $\pm 0,55$ $\mathrm{mg} \cdot \mathrm{m}^{-3}$, portanto maior do que a média observada durante o verão do mesmo ano. Sobre o talude, o valor médio de clorofila- $a$ estimado foi de $0,23 \pm 0,16 \mathrm{mg} . \mathrm{m}^{-3}$, sem grande variação sazonal.

TABELA 3.10 - CONCENTRAÇÕES MÉDIAS DE CLOROFILA (mg.m $\left.\mathbf{m}^{-3}\right)$
DURANTE O CRUZEIRO DE INVERNO DE 2001 (M2).
\begin{tabular}{c|c|c} 
M2 & $\begin{array}{c}\text { Plataforma } \\
\left(\mathbf{m g . m}^{-3}\right)\end{array}$ & $\begin{array}{c}\text { Talude } \\
\left(\mathbf{m g . m ^ { - 3 }}\right)\end{array}$ \\
\hline Média & 0,96 & 0,23 \\
\hline Máximo & 2,15 & 0,61 \\
\hline Mínimo & 0,09 & 0,01 \\
\hline Desvio Padrão & 0,55 & 0,16 \\
\hline $\begin{array}{c}\text { Coeficiente } \\
\text { Variação }\end{array}$ & $57 \%$ & $69 \%$ \\
\hline
\end{tabular}

Nas Figuras 3.12 e 3.14, pode-se observar que a região amostrada apresentou-se estratificada, com uma termoclina variando de 21 a $46 \mathrm{~m}$ na plataforma e de 54 a $106 \mathrm{~m}$ no talude. A camada de mistura mostrou-se pobre em nitrato $\left(\mathrm{NO}_{3}{ }^{-}<0,1 \mu \mathrm{M}\right)$. Entretanto, na última radial realizada (radial 5 na Figura 3.16 ), a camada de mistura aparece mais misturada com a presença de núcleos com alta concentração de nitrato $\left(\mathrm{NO}_{3}{ }^{-}>1,0 \mu \mathrm{M}\right)$ mais próximos da superfície.

De modo geral, pode-se notar uma boa correlação espacial entre os núcleos de alta concentração de clorofila- $a$ e de nitrato, associados a inflexões das isotermas e isohalinas. 

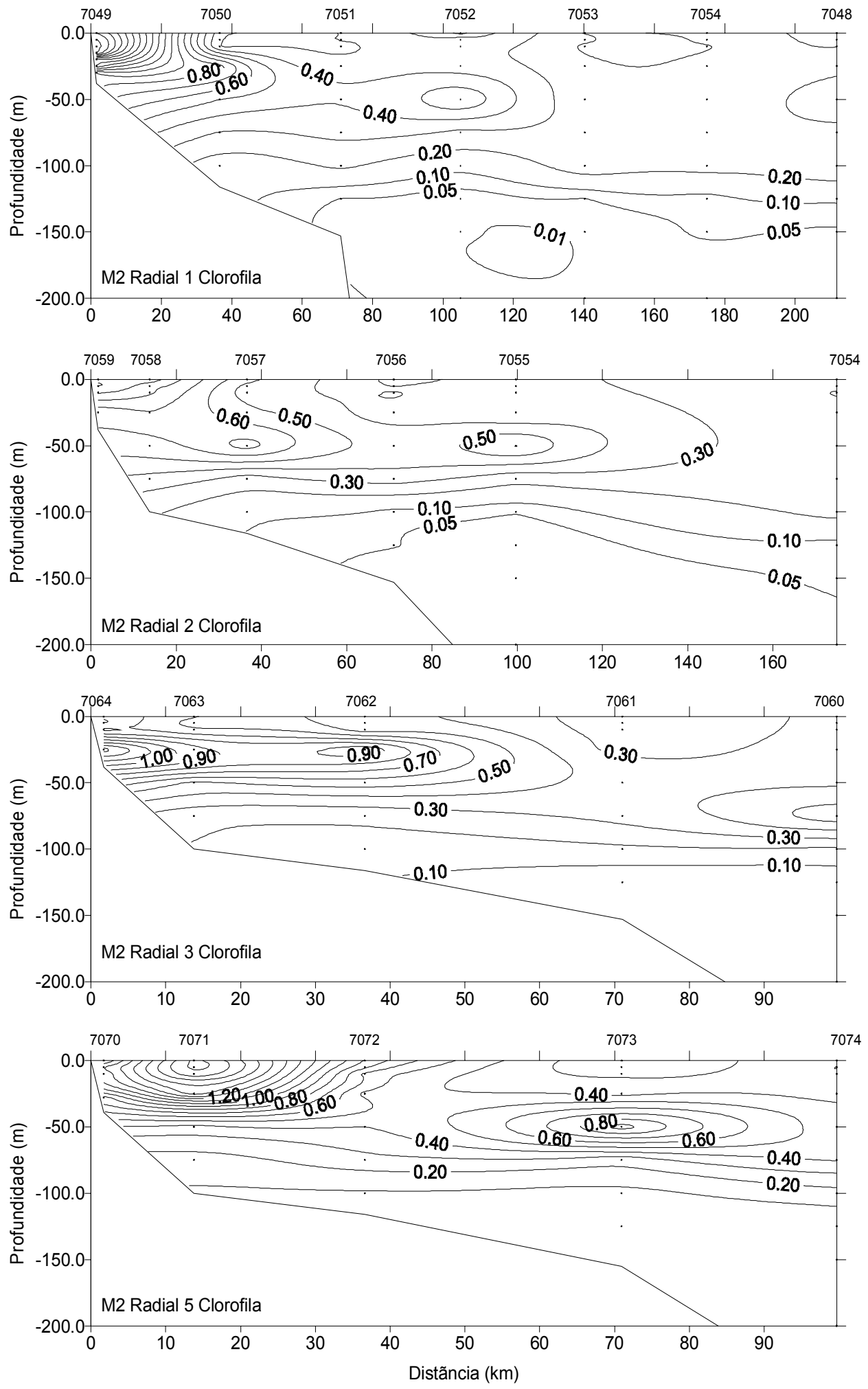

Figura 3.15 - Seções verticais de clorofila $\left(\mathrm{mg} \cdot \mathrm{m}^{-3}\right)$ radiais à costa em Cabo Frio, RJ, realizadas durante o inverno de 2001 (M2). 

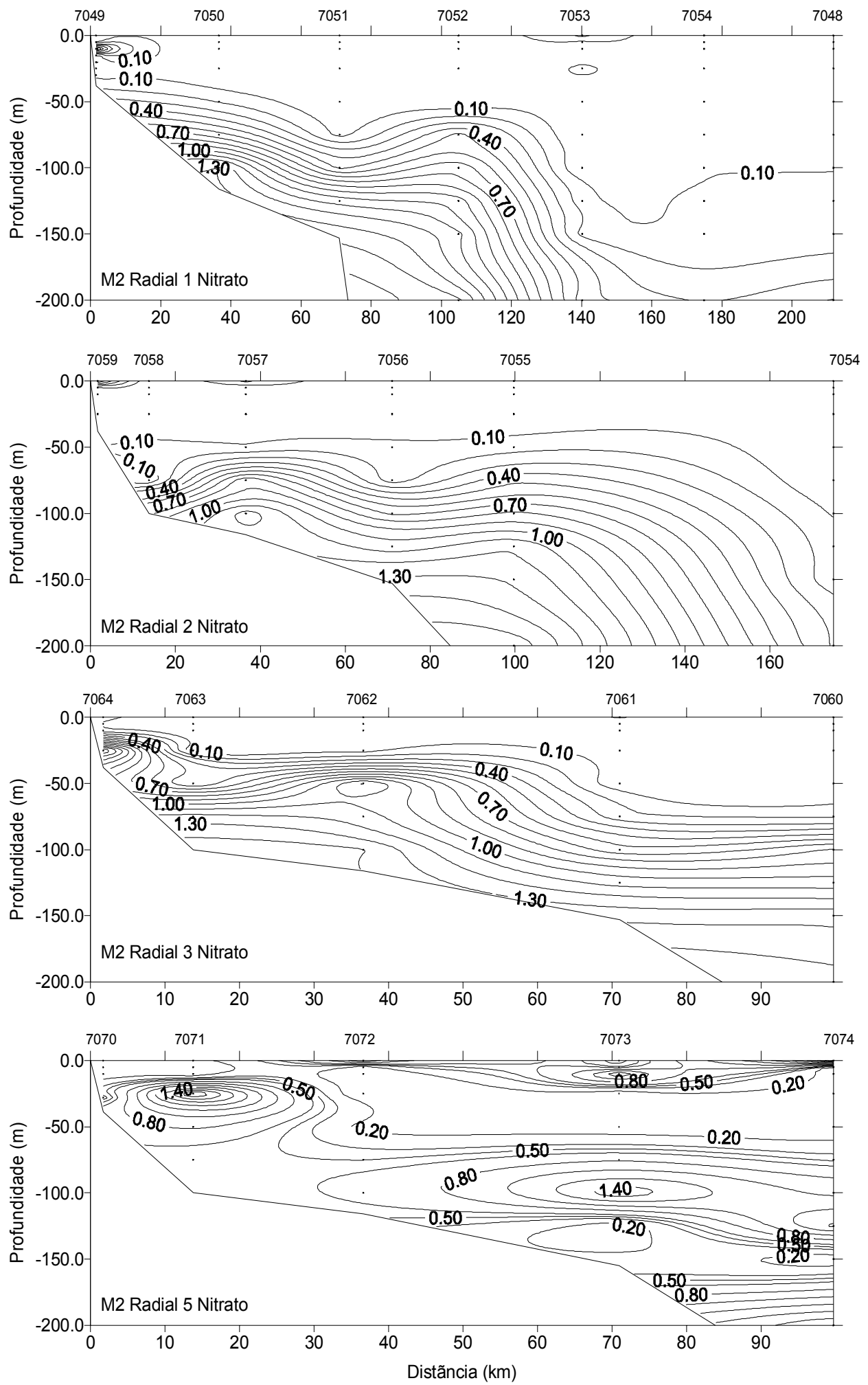

Figura 3.16 - Seções verticais de nitrato $(\mu \mathrm{M})$ radiais à costa em Cabo Frio, RJ, realizadas durante o inverno de 2001 (M2). 


\subsubsection{Curvas de luz - fotossíntese}

Na Tabela 3.11 são apresentados os valores médios dos parâmetros fotossintéticos $\left(\mathrm{P}_{\max }{ }^{\mathrm{B}}\right.$ - número de assimilação e $\alpha^{\mathrm{B}}$ - eficiência fotossintética) obtidos com o ajuste de modelos empíricos às amostras de produção primária. $\mathrm{O}$ parâmetro de adaptação $\mathrm{I}_{\mathrm{k}}$, ou constante de Talling, também é mostrado na Tabela 3.11, para os experimentos com amostras das profundidades relativas a $100 \%$ e 1\% de irradiância.

De forma geral, os números de assimilação médios encontrados durante o inverno de 2001 não foram muito diferentes aos obtidos no verão do mesmo ano. O parâmetro $\mathrm{P}_{\max }{ }^{\mathrm{B}}$ das populações da camada de superfície variou de 1,22 a 10,10 $\mathrm{mgC} .\left(\mathrm{mgClo}^{-1}\right) \cdot \mathrm{h}^{-1}$, tendo sido a média igual a $4,95 \mathrm{mgC} \cdot\left(\mathrm{mgClo}^{-1}\right) \cdot \mathrm{h}^{-1}$. Para as populações localizadas na base da zona eufótica, esses valores foram iguais a 1,08, 4,03 e 2,35 mgC. $\left(\mathrm{mgClo}^{-1}\right) \cdot \mathrm{h}^{-1}$, respectivamente. A eficiência fotossintética $\left(\alpha^{\mathrm{B}}\right)$ variou nas amostras coletadas em superfície de 0,01 a $0,20 \mathrm{mgC} \cdot\left(\mathrm{mgClo}^{-1}\right) \cdot \mathrm{h}^{-1} \cdot\left(\mathrm{W} \cdot \mathrm{m}^{-2}\right)^{-1}$, com média igual a $0,06 \mathrm{mgC} .\left(\mathrm{mgClo}{ }^{-1}\right) \cdot \mathrm{h}^{-1} \cdot\left(\mathrm{W} \cdot \mathrm{m}^{-2}\right)^{-1}$, portanto, mais baixa que a estimada durante o verão. $\mathrm{O} \alpha^{\mathrm{B}}$ das amostras coletadas na base da zona eufótica apresentou valor médio igual a $0,35 \mathrm{mgC} \cdot\left(\mathrm{mgClo}{ }^{-1}\right) \cdot \mathrm{h}^{-1} \cdot\left(\mathrm{W} \cdot \mathrm{m}^{-2}\right)^{-1}$ e uma amplitude de variação entre 0,04 e $1,25 \mathrm{mgC} \cdot\left(\mathrm{mgClo}^{-1}\right) \cdot \mathrm{h}^{-1} \cdot\left(\mathrm{W} \cdot \mathrm{m}^{-2}\right)^{-1}$. No inverno de 2001 , somente o desvio padrão das amostras referentes ao nível de $1 \%$ de irradiância foi alto. Os valores médios de $\mathrm{I}_{\mathrm{k}}$ foram iguais a 27,68 e $10,35 \mathrm{~W} \cdot \mathrm{m}^{-2}$ na superfície $(100 \%)$ e no fundo $(1 \%)$, respectivamente. Somente o valor do nível mais profundo apresentou diferença significativa em relação ao período de verão de 2001.

A Figura 3.17 apresenta as seções verticais de produção primária obtidas a partir dos experimentos in situ simulados realizados nas radiais 1 e 5 durante o cruzeiro de inverno de 2001 (M2). Estão sendo apresentados os resultados referentes às amostras de superfície, ou seja, profundidade relativa a $100 \%$ de irradiância. Não foi possível interpolar as seções verticais referentes às radiais 2 e 3 , uma vez que só foram realizados experimentos de incubação em apenas duas estações. 
TABELA 3.11 - PARÂMETROS FOTOSSINTÉTICOS DAS CURVAS DE LUZ FOTOSSÍNTESE DURANTE O CRUZEIRO DE INVERNO DE 2001

(M2).

\begin{tabular}{c|c|c|c|c|c|c}
\hline \multirow{2}{*}{ M2 } & \multicolumn{3}{|c|}{$\mathbf{1 0 0 \%}$} & \multicolumn{3}{c}{$\mathbf{1 \%}$} \\
\cline { 2 - 7 } & $\mathbf{P}_{\mathbf{m a x}}^{\mathbf{B}}$ & $\alpha^{\mathbf{B}}$ & $\mathbf{I}_{\mathbf{k}}$ & $\mathbf{P}_{\mathbf{m a x}} \mathbf{B}$ & $\alpha^{\mathbf{B}}$ & $\mathbf{I}_{\mathbf{k}}$ \\
\hline Média & 4,95 & 0,06 & 27,68 & 2,35 & 0,35 & 10,35 \\
\hline Máximo & 10,10 & 0,20 & 74,05 & 4,03 & 1,25 & 22,68 \\
\hline Mínimo & 1,22 & 0,01 & 4,89 & 1,08 & 0,04 & 2,33 \\
\hline Desvio Padrão & 3,28 & 0,05 & 17,68 & 0,90 & 1,48 & 6,82 \\
\hline $\begin{array}{c}\text { Coeficiente } \\
\text { Variação }\end{array}$ & $66 \%$ & $82 \%$ & $63 \%$ & $38 \%$ & $104 \%$ & $65 \%$ \\
\hline${ }^{*} P_{\max }^{B}\left(m g C .\left(m g C l o^{-1}\right) \cdot h^{-1}\right), \alpha^{\beta}\left(m g C .\left(m g C l o^{-1}\right) \cdot h^{-1} \cdot\left(W \cdot m^{-2}\right)^{-1}\right), I_{k}\left(W \cdot m^{-2}\right)$
\end{tabular}
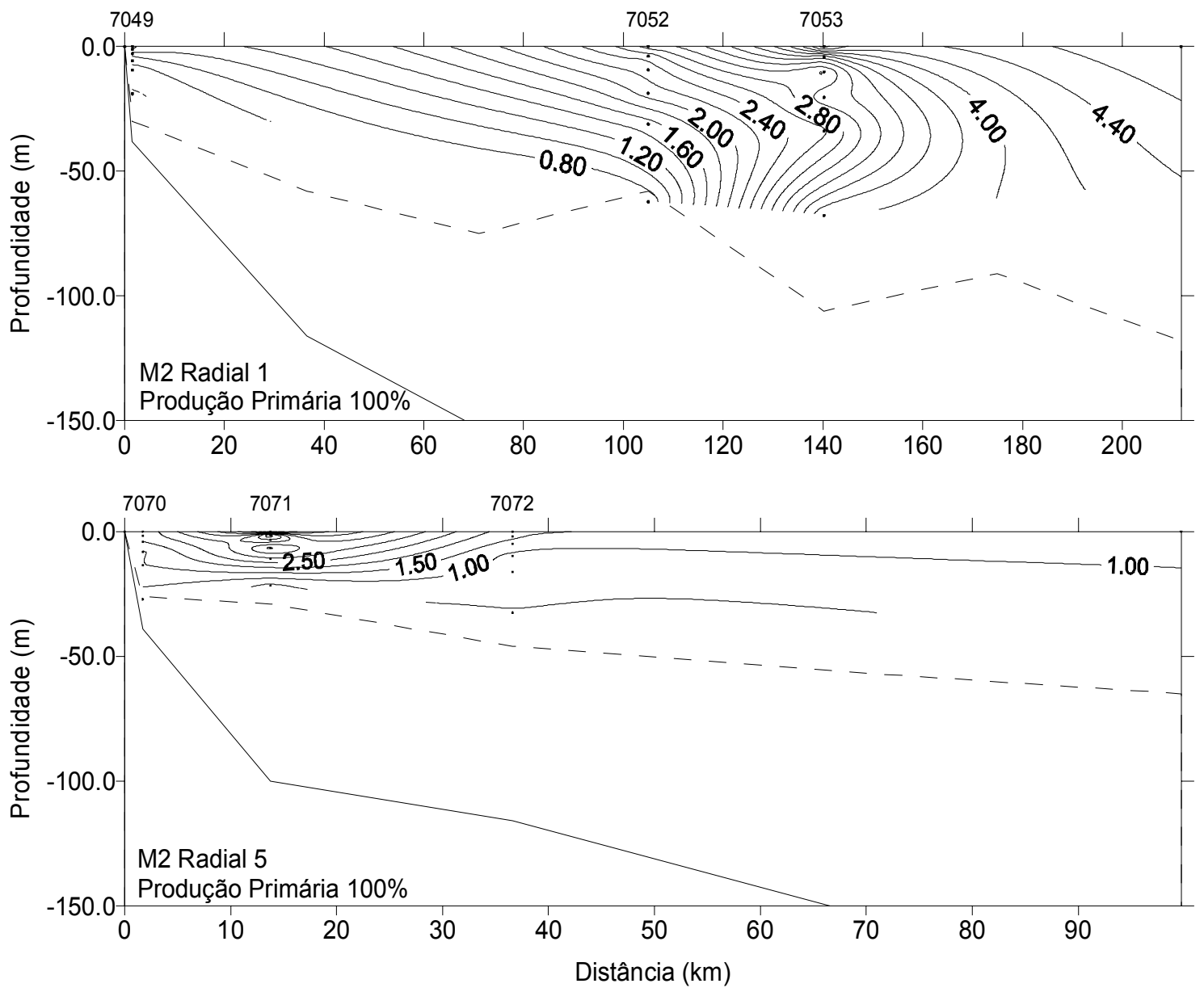

Figura 3.17 - Seções verticais de produção primária $\left(\mathrm{mgC} \cdot \mathrm{m}^{-3} \cdot \mathrm{h}^{-1}\right)$ radiais à costa em Cabo Frio, RJ, realizadas durante o inverno de 2001 (M2). Profundidade da camada de mistura indicada pela linha tracejada. 
Os valores de produção primária a $100 \%$ de irradiância incidente variaram entre 0,37 e 10,50 mgC. $\mathrm{m}^{-3} \cdot \mathrm{h}^{-1}$ (Tabela 3.12). De modo geral, os valores médios foram maiores do que aqueles obtidos no verão do mesmo ano, principalmente no domínio do talude. Cabe mencionar que também foram considerados para fins de cálculos, os experimentos de produção primária realizados em um transecto paralelo à costa.

\section{TABELA 3.12 - PRODUÇÃO PRIMÁRIA DURANTE O CRUZEIRO DE INVERNO} DE 2001 (M2).

\begin{tabular}{c|c|c}
\hline $\mathbf{M} 2$ & $\begin{array}{c}\text { Plataforma } \\
\left(\mathbf{m g C} \cdot \mathbf{m}^{-\mathbf{3}} \cdot \mathbf{h}^{-\mathbf{1}}\right)\end{array}$ & $\begin{array}{c}\text { Talude } \\
\left(\mathbf{m g C} \cdot \mathbf{m}^{-\mathbf{3}} \cdot \mathbf{h}^{\mathbf{- 1}}\right)\end{array}$ \\
\hline Média & 3,55 & 4,18 \\
\hline Máximo & 10,50 & 10,44 \\
\hline Mínimo & 0,37 & 0,64 \\
\hline Desvio Padrão & 3,47 & 2,40 \\
\hline $\begin{array}{c}\text { Coeficiente } \\
\text { Variação }\end{array}$ & $98 \%$ & $57 \%$ \\
\hline
\end{tabular}

A produção primária média sobre a plataforma foi de $3,55 \mathrm{mgC} \cdot \mathrm{m}^{-3} \cdot \mathrm{h}^{-1}$ $\left( \pm 3,47 \mathrm{mgC} \cdot \mathrm{m}^{-3} \cdot \mathrm{h}^{-1}\right)$, enquanto que sobre o talude foi de $4,18 \mathrm{mgC} \cdot \mathrm{m}^{-3} \cdot \mathrm{h}^{-1}$ $\left( \pm 2,40 \mathrm{mgC} \cdot \mathrm{m}^{-3} \cdot \mathrm{h}^{-1}\right)$. A produção primária média a $100 \%$ considerando-se todas as estações $\left(3,82 \pm 3,05 \mathrm{mgC} \cdot \mathrm{m}^{-3} \cdot \mathrm{h}^{-1}\right)$ foi maior do que a estimada para amostras da profundidade de $1 \%$ de irradiância $\left(2,15 \pm 1,19 \mathrm{mgC} \cdot \mathrm{m}^{-3} \cdot \mathrm{h}^{-1}\right)$. Pode-se notar que a zona eufótica estimada esteve mais rasa do que a camada de mistura.

A Tabela 3.13 apresenta os valores médios, amplitude de variação, desvio padrão e coeficiente de variação da clorofila-a e produção primária integradas na zona eufótica $\left(\mathrm{mg} \cdot \mathrm{m}^{-2}\right.$ e $\mathrm{gC} \cdot \mathrm{m}^{-2} \cdot \mathrm{d}^{-1}$, respectivamente), para as regiões de plataforma e talude, referentes ao cruzeiro de inverno de 2001 (M2).

No inverno de 2001, a clorofila- $a$ integrada na plataforma foi cerca de $20 \%$ maior $\left(27,29 \pm 7,89 \mathrm{mg} \cdot \mathrm{m}^{-2}\right)$ do que na região de talude $\left(21,40 \pm 4,72 \mathrm{mg} \cdot \mathrm{m}^{-2}\right)$, ou seja, apresentando um comportamento similar ao período de verão, ainda que com uma diferença percentual menor. As estimativas de produção primária estão apresentadas em unidades de massa de carbono fixado, por área e por dia. Os valores da produção integrada para as amostras referentes a $100 \%$ de irradiância foram $70 \%$ superiores sobre o talude $\left(2,17 \pm 0,87 \mathrm{gC} \cdot \mathrm{m}^{-2} \cdot \mathrm{d}^{-1}\right)$ do que sobre a plataforma $\left(0,81 \pm 0,71 \mathrm{gC} \cdot \mathrm{m}^{-2} \cdot \mathrm{d}^{-1}\right) . \mathrm{O}$ 
mesmo comportamento pode ser observado em relação às amostras de $1 \%$ de irradiância $\left(1,81 \pm 0,43 \mathrm{gC} \cdot \mathrm{m}^{-2} \cdot \mathrm{d}^{-1}\right.$ e $0,34 \pm 0,23 \mathrm{gC} \cdot \mathrm{m}^{-2} \cdot \mathrm{d}^{-1}$, para o talude e plataforma, respectivamente). Este padrão foi diferente do observado durante o verão de 2001 quando as produções integradas mostraram-se mais altas na plataforma do que no talude. Os valores obtidos a partir das amostras de 100\% também se apresentaram significativamente maiores do que os obtidos a partir das amostras de $1 \%$, tanto sobre o talude como na plataforma (ver Tabela 3.13 ).

TABELA 3.13 - CLOROFILA E PRODUÇÃO PRIMÁRIA INTEGRADAS NA ZONA EUFÓTICA SOBRE A PLATAFORMA E O TALUDE DURANTE O CRUZEIRO DE INVERNO DE 2001 (M2).

\begin{tabular}{c|c|c|c|c|c|c}
\hline \multirow{2}{*}{ M2 } & \multicolumn{3}{|c|}{ Plataforma } & \multicolumn{3}{c}{ Talude } \\
\cline { 2 - 7 } Média & $\mathbf{C}_{\text {EU }}$ & PP $_{\text {EU100 }}$ & PP $_{\text {EU1 }}$ & $\mathbf{C}_{\text {EU }}$ & PP $_{\text {EU100 }}$ & PP $_{\text {EU1 }}$ \\
\hline Máximo & 27,29 & 0,81 & 0,34 & 21,40 & 2,17 & 1,81 \\
\hline Mínimo & 18,46 & 1,91 & 0,68 & 27,19 & 3,60 & 2,21 \\
\hline $\begin{array}{c}\text { Desvio } \\
\text { Padrão }\end{array}$ & 7,89 & 0,11 & 0,18 & 15,20 & 1,01 & 1,27 \\
\hline $\begin{array}{c}\text { Coeficiente de } \\
\text { Variação }\end{array}$ & $29 \%$ & $87 \%$ & $67 \%$ & $22 \%$ & $40 \%$ & $24 \%$ \\
\hline
\end{tabular}

* $C_{E U}$ - Clorofila integrada na zona eufótica $\left(m g . m^{-2}\right) ; P P_{E U I 00}$ - Produção primária integrada na zona eufótica das amostras de $100 \%\left(\mathrm{gC} . \mathrm{m}^{-2} \cdot \mathrm{d}^{-1}\right) ; P P_{E U 1}$ - Produção primária integrada na zona eufótica das amostras de $1 \%\left(g C . m^{-2} . d^{-1}\right)$.

\subsubsection{Nutrientes inorgânicos dissolvidos}

Durante o cruzeiro de inverno de 2001 (M2) grande parte da plataforma continental amostrada apresentou-se estratificada, com a profundidade da termoclina variando de 21 a 46 m. São observadas intrusões de domos da AT em direção à costa e a presença da ACAS no fundo da plataforma. A disposição geral das isotermas e isohalinas também sugere a presença de um vórtice ciclônico atuando na região.

Na camada de mistura, as concentrações de nitrato mostraram-se baixas $(<0,1 \mu \mathrm{M})$, nas radiais 1 e 2 . A partir da radial 3 e principalmente na radial 5, as concentrações de nitrato acima da termoclina apresentaram-se mais elevadas, com núcleos de até $2,4 \mu \mathrm{M}$, próximo da costa e 1,4 $\mu \mathrm{M}$ na quebra de plataforma. De modo geral a concentração de $1,0 \mu \mathrm{M}$ acompanhou o deslocamento da termoclina. 
O valor máximo de amônia encontrado foi de $1,87 \mu \mathrm{M}$ na superfície sobre a plataforma continental da radial 3 (ver Tabela 3.14). Outros núcleos de máximos relativos de amônia $(>1,0 \mu \mathrm{M})$ foram observados em profundidades rasas, dentro da camada de mistura. $\mathrm{O}$ valor máximo de fosfato $(2,36 \mu \mathrm{M})$ foi observado ao largo da radial $3 \mathrm{e}$ abaixo da termoclina. Ainda que a distribuição de silicato tenha sido variável, as concentrações de silicato mais altas foram observadas próximo à costa e sobre a quebra de plataforma na radial 2.

TABELA 3.14 - CONCENTRAÇÃO DE NUTRIENTES INORGÂNICOS DISSOLVIDOS DURANTE O CRUZEIRO DE INVERNO DE 2001 (M2).

\begin{tabular}{c|c|c|c|c|c}
\hline $\mathbf{M} 2$ & $\begin{array}{c}\text { Nitrato } \\
(\boldsymbol{\mu M})\end{array}$ & $\begin{array}{c}\text { Nitrito } \\
(\boldsymbol{\mu M})\end{array}$ & $\begin{array}{c}\text { Amônia } \\
(\boldsymbol{\mu M})\end{array}$ & $\begin{array}{c}\text { Fosfato } \\
(\boldsymbol{\mu M})\end{array}$ & $\begin{array}{c}\text { Silicato } \\
(\boldsymbol{\mu M})\end{array}$ \\
\hline Média & 0,36 & 0,02 & 0,53 & 0,76 & 2,92 \\
\hline Máximo & 2,90 & 0,13 & 1,87 & 2,36 & 15,25 \\
\hline Mínimo & $<0,05$ & $<0,05$ & $<0,05$ & $<0,03$ & 0,15 \\
\hline Desvio padrão & 0,53 & 0,02 & 0,40 & 0,55 & 2,48 \\
\hline
\end{tabular}

Os diagramas de dispersão dos nutrientes inorgânicos dissolvidos em função de $\sigma_{t}$ podem ser vistos na Figura 3.18 mostrada a seguir. O limite isopicnal inferior da ACAS $\left(25,4 \mathrm{~kg} \cdot \mathrm{m}^{-3}\right)$ aparece indicado pela linha tracejada na mesma figura. Pode-se observar uma inflexão a partir da presença da ACAS para o nitrato. O fosfato, silicato e amônia apresentam uma dispersão relativamente maior.

Em termos de representação relativa de cada nutriente nitrogenado inorgânico, temos que o nitrato contribuiu entre 0,71 e $100 \%$. A amônia contribuiu de 1,61 a $100 \%$ e o nitrito, de 0,18 a 100\%. Os valores médios de contribuições relativas de cada composto nitrogenado e do nitrogênio total absoluto estão na Tabela 3.15 . 

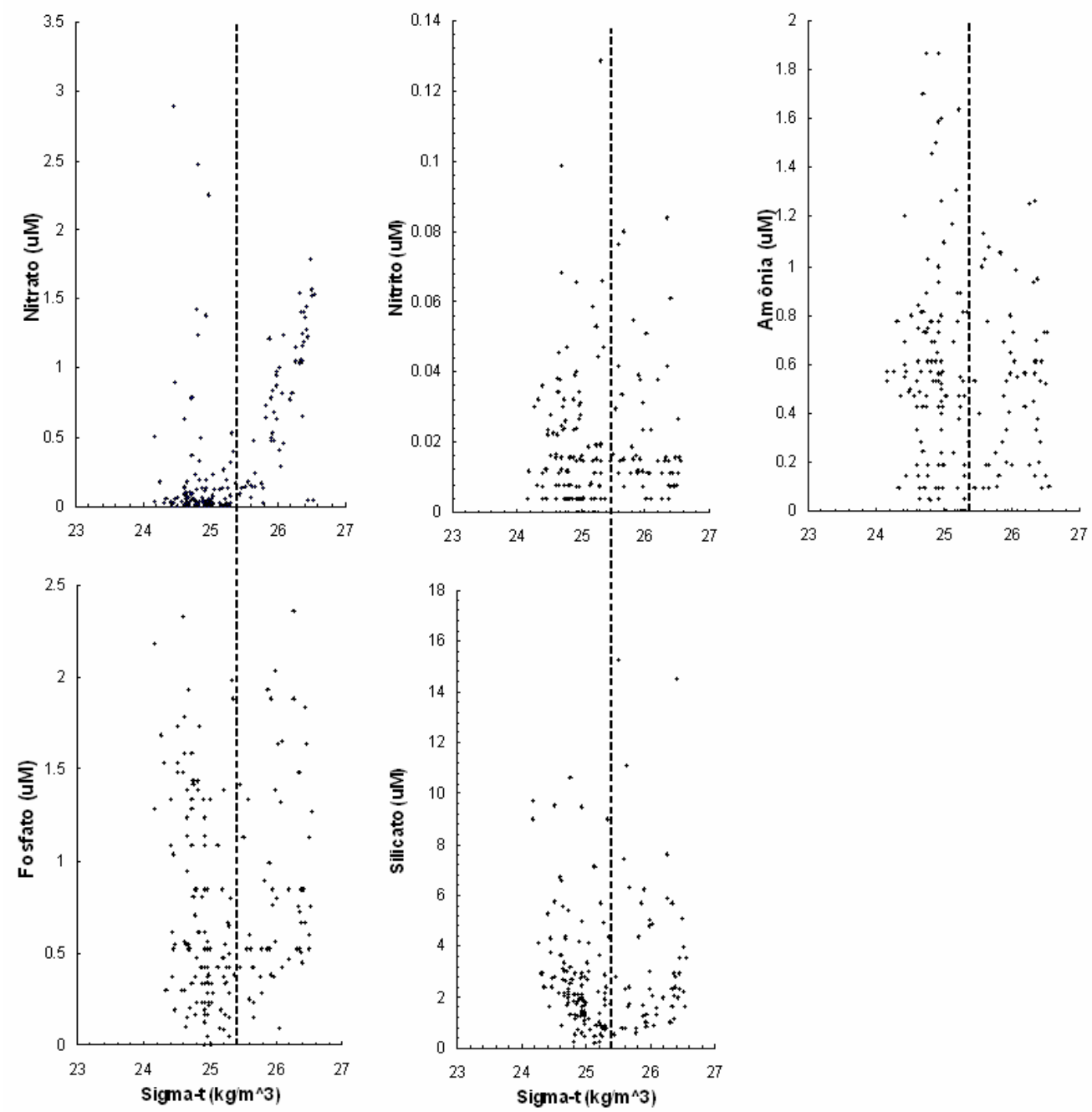

Figura 3.18 - Diagramas de dispersão dos nutrientes inorgânicos dissolvidos $(\mu \mathrm{M}) \mathrm{em}$ função de $\sigma_{\mathrm{t}}\left(\mathrm{kg} \cdot \mathrm{m}^{-3}\right)$, para o cruzeiro de inverno de 2001 (M2). A linha tracejada indica o limite isopicnal inferior da Água Central do Atlântico Sul.

TABELA 3.15 - MÉDIAS DAS CONCENTRAÇÕES RELATIVAS DOS COMPOSTOS NITROGENADOS DISSOLVIDOS E DA CONCENTRAÇÃO ABSOLUTA DO NITROGÊNIO TOTAL DURANTE O CRUZEIRO DE INVERNO DE 2001 (M2).

\begin{tabular}{c|c|c|c|c}
\hline $\mathbf{M} 2$ & $\begin{array}{c}\text { Nitrato } \\
\mathbf{\%}\end{array}$ & $\begin{array}{c}\text { Nitrito } \\
\mathbf{\%}\end{array}$ & $\begin{array}{c}\text { Amônia } \\
\mathbf{\%}\end{array}$ & $\begin{array}{c}\text { Nitrogênio } \\
(\boldsymbol{\mu M})\end{array}$ \\
\hline Média & 36,34 & 6,25 & 70,26 & 0,89 \\
\hline Máximo & 100,00 & 100,00 & 100,00 & 3,48 \\
\hline Mínimo & 0,71 & 0,18 & 1,61 & Não detectável \\
\hline Desvio padrão & 30,76 & 14,51 & 28,27 & 0,65 \\
\hline
\end{tabular}




\subsubsection{Imagens de Temperatura da Superfície do Mar}

Apesar do cruzeiro de inverno de 2001 ter sido realizado somente entre os dias 12 e 19 de julho de 2001, serão incluídas imagens referentes a alguns dias anteriores e posteriores ao período de coletas in situ de modo a auxiliar na caracterização regional e sinóptica da região de interesse. A Figura 3.19 a seguir apresenta as imagens de temperatura da superfície do mar (TSM) obtidas para os dias 8, 10, 11 e 17 de julho de 2001. As águas quentes da $\mathrm{CB}$, em tons vermelhos nas imagens, aparecem com temperaturas acima de $24,0{ }^{\circ} \mathrm{C}$. Ao largo de São Tomé, foi possível identificar um vórtice ciclônico na borda interna da $\mathrm{CB}$, com diâmetro médio em torno de $50 \mathrm{~km}$. Ao passar por Cabo Frio, a CB exibe outro meandramento ciclônico de maior amplitude (100 km). A intrusão de águas frias e pouco salinas vindas de sul sobre a plataforma pode ser observada nesta seqüência de imagens até o litoral do Rio de Janeiro. Temperaturas de $17,0^{\circ} \mathrm{C}$ são encontradas nessa massa de água próxima ao Cabo Santa Marta. Ao passar pela Ilha de São Sebastião, a TSM é de $21,0^{\circ} \mathrm{C}$. A extensão deste fluxo alcançou a divisa entre os estados de São Paulo e Rio de Janeiro. Na borda interna da CB foi possível notar diversos meandros ao longo de toda a plataforma continental sudeste. Outro vórtice foi identificado em torno de $23,2^{\circ} \mathrm{S}-41,4^{\circ} \mathrm{W}$ e com $70 \mathrm{~km}$ de diâmetro. Núcleos de águas mais frias foram observados em Cabo Frio (TSM mínima de $\left.20,0^{\circ} \mathrm{C}\right)$ e São Tomé $\left(\mathrm{T}<20,5^{\circ} \mathrm{C}\right)$. Uma pluma de águas frias, associada a um evento atípico de ressurgência, foi observada junto à costa oeste de Cabo Frio, com cerca de $60 \mathrm{~km}$ de extensão, considerando-se a isoterma de $22,0{ }^{\circ} \mathrm{C}$ como seu limite. Similarmente, outra pluma com TSM abaixo de $20,5^{\circ} \mathrm{C}$ foi encontrada a sul de São Tomé, com extensão de $40 \mathrm{~km}$. 

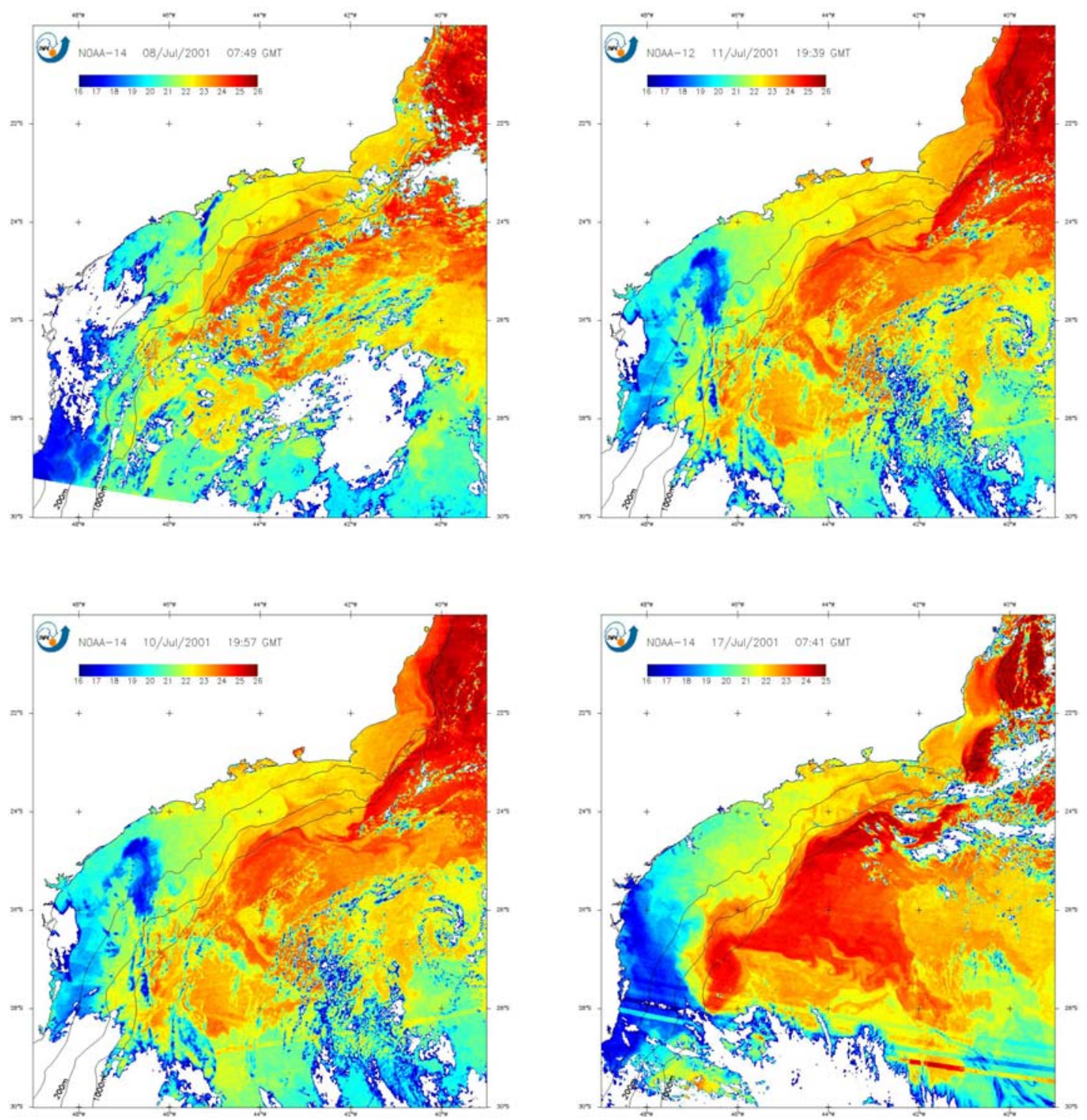

Figura 3.19 - Imagens da temperatura da superfície do mar referentes aos dias 8 (esquerda em cima), 10 (esquerda embaixo), 11 (direita em cima) e 17 (direita embaixo) de julho de 2001. Isóbatas de 100, 200 e $1.000 \mathrm{~m}$ em preto.

A Figura 3.20 mostra as imagens de TSM processadas para os dias 18, 19, 20 e 25 de julho de 2001. O cenário observado nesta seqüência de imagens é parecido ao descrito anteriormente. As águas frias e pouco salinas vindas de sul sobre a plataforma aparecem nas imagens ultrapassando a Ilha de São Sebastião. Um filamento com TSM de $22,0{ }^{\circ} \mathrm{C}$ parece ter sido advectado para o interior do meandramento ciclônico da CB ao sul de Cabo Frio (18/07/2001). A pluma de ressurgência ao sul de São Tomé apresentou TSM 
de $20,5^{\circ} \mathrm{C}$ e extensão de $80 \mathrm{~km}$. O vórtice em São Tomé apareceu centrado em torno de $22,7^{\circ} \mathrm{S}-40,4^{\circ} \mathrm{W}$, e com diâmetro médio aproximadamente igual a $70 \mathrm{~km}$. Manchas de águas relativamente frias $\left(<22,0^{\circ} \mathrm{C}\right)$ foram observadas entre São Tomé e Cabo Frio, delimitando uma região frontal sobre a plataforma.
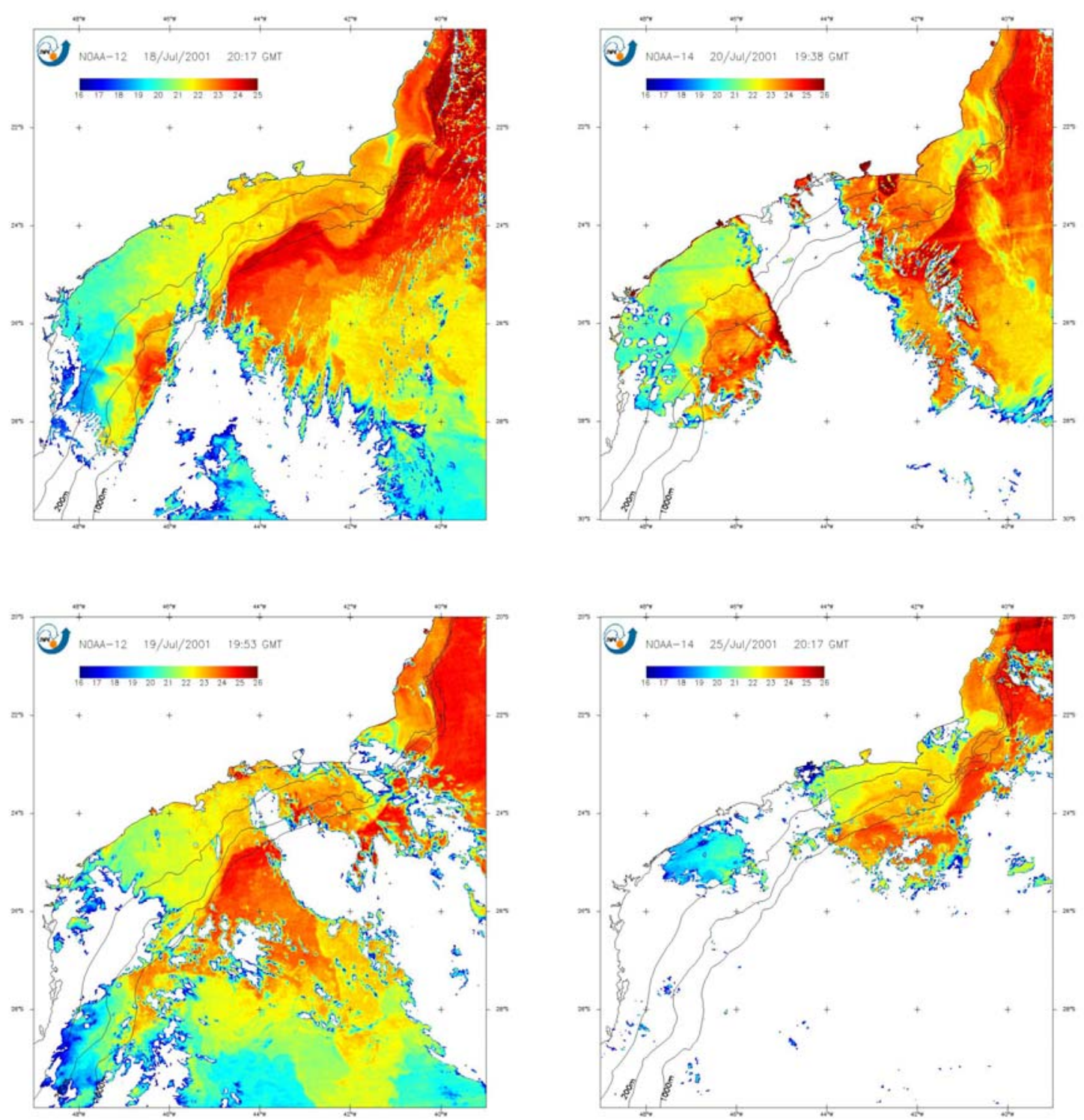

Figura 3.20 - Imagens da temperatura da superfície do mar referentes aos dias 18 (esquerda em cima), 19 (esquerda embaixo), 20 (direita em cima) e 25 (direita embaixo) de julho de 2001. Isóbatas de 100, 200 e $1.000 \mathrm{~m}$ em preto. 


\subsubsection{Imagens de Concentração de Clorofila da Superfície do Mar}

A Figura 3.21 apresenta as imagens de concentração de clorofila da superfície do mar (CSM) processadas nos dias 7, 8, 10 e 15 de julho de 2001. As águas pobres da CB aparecem ao largo, sobre o talude em tons azul claro. Meandramentos ciclônicos da CB foram observados na borda interna da corrente, ao largo de São Tomé (50 km) e a sul de Cabo Frio, com trocas entre águas de plataforma mais ricas em clorofila e águas oceânicas mais pobres. A CB exibiu ainda outros meandramentos a medida em que fluía para SO. A intrusão de águas vindas de sul, mais ricas em nutrientes e biomassa fitoplanctônica, foi observada nestas imagens atingindo a Ilha de São Sebastião $\left(>2,0 \mathrm{mg} \cdot \mathrm{m}^{-3}\right)$ e a Baía de Ilha Grande $\left(>1,5 \mathrm{mg} \cdot \mathrm{m}^{-3}\right)$. Altas concentrações de CSM $\left(>2,5 \mathrm{mg} \cdot \mathrm{m}^{-3}\right.$ ) foram encontradas nas regiões costeiras adjacentes a Saquarema (entre Cabo Frio e Baía de Guanabara), São Tomé e sul de Vitória. Manchas com valores altos de CSM (2,0 mg. $\mathrm{m}^{-3}$ ) também foram observadas em Cabo Frio e litoral norte de São Paulo. Na imagem de 15/07/2001, pode-se notar uma estrutura com forma de vórtice, centrada em torno de $22,8^{\circ} \mathrm{S}-41,5^{\circ} \mathrm{W}$ a leste de Cabo Frio.

A Figura 3.22 mostra as imagens SeaWiFS processadas nos dias 16, 17, 19 e 21 de julho de 2001. A intrusão de águas vindas de sul pela costa pode ser observada com concentrações de clorofila acima de 2,0 mg. $\mathrm{m}^{-3}$ em torno da Ilha de São Sebastião. O vórtice em São Tomé foi identificado entre as latitudes $22,5^{\circ}-22,8^{\circ} \mathrm{S}$ e as longitudes $40,5^{\circ}-41,5^{\circ} \mathrm{W}$, com diâmetro médio variando de 65 a $75 \mathrm{~km}$. Águas mais ricas $\left(\mathrm{CSM}>2,0 \mathrm{mg} \cdot \mathrm{m}^{-3}\right)$ de plataforma aparecem sendo advectadas para o interior do vórtice. Outro vórtice foi observado em torno de $23,3^{\circ} \mathrm{S}-41,5^{\circ} \mathrm{W}$ e diâmetro de $75 \mathrm{~km}$ sobre a quebra de plataforma. Estruturas semelhantes, porém de dimensões menores, foram notadas sobre a plataforma, entre São Tomé e Cabo Frio, com CSM entre 2,0 e 2,7 mg.m ${ }^{-3}$. Uma mancha de biomassa fitoplanctônica derivando para sul desde São Tomé, parece ter sido capturada pelo meandramento da CB em Cabo Frio. Outras manchas de alta biomassa fitoplanctônica $\left(\mathrm{CSM}>2,0 \mathrm{mg} \cdot \mathrm{m}^{-3}\right)$ foram encontradas na zona costeira desde Cabo Frio até Vitória. 

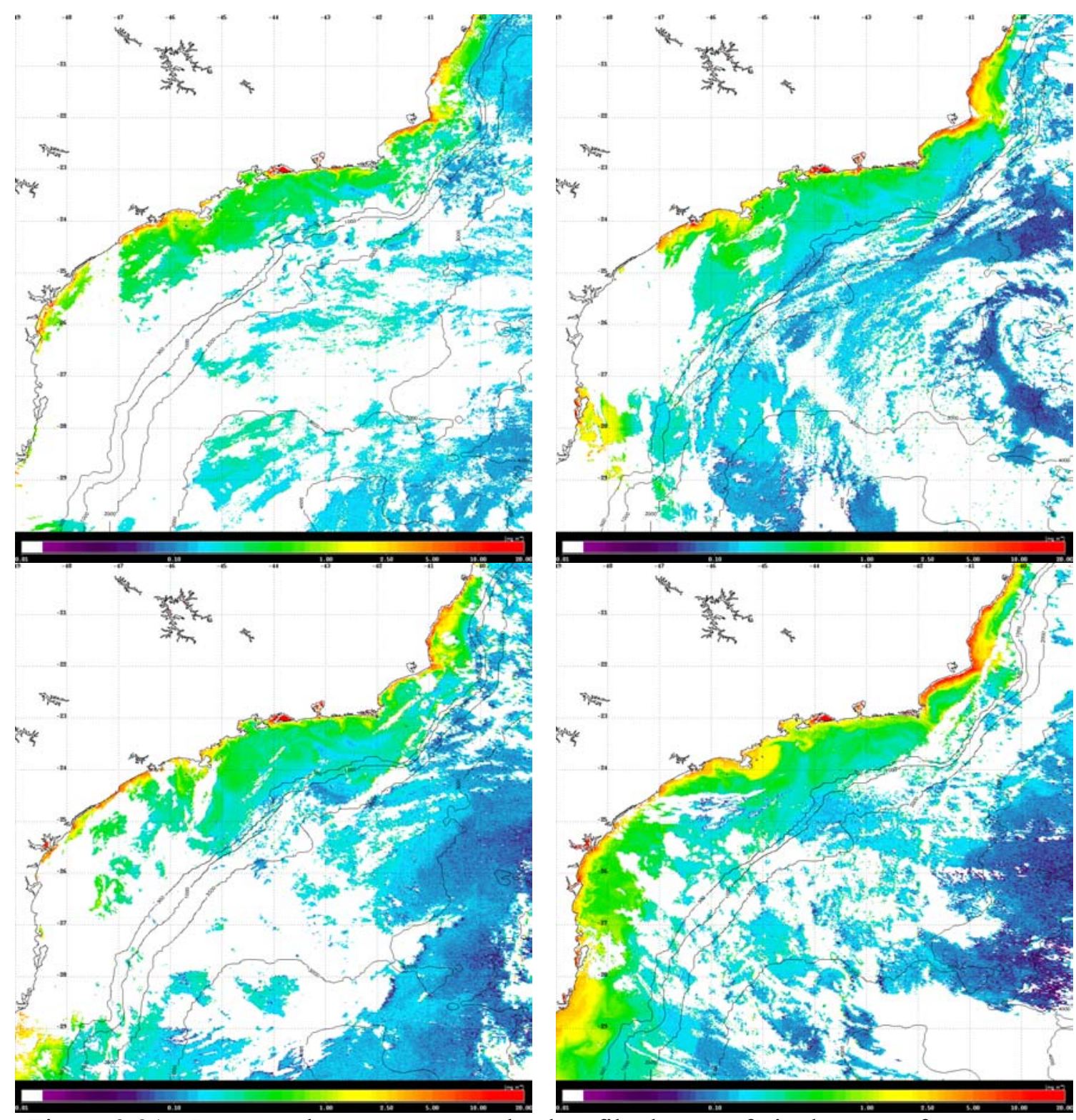

Figura 3.21 - Imagens da concentração de clorofila da superfície do mar referentes aos dias 7 (esquerda em cima), 8 (esquerda embaixo), 10 (direita em cima) e 15 (direita embaixo) de julho de 2001. Isóbatas de 500, 1.000, 2.000, $3.000 \mathrm{e}$ $4.000 \mathrm{~m}$ em preto. Tabela de cores em escala logarítmica. 


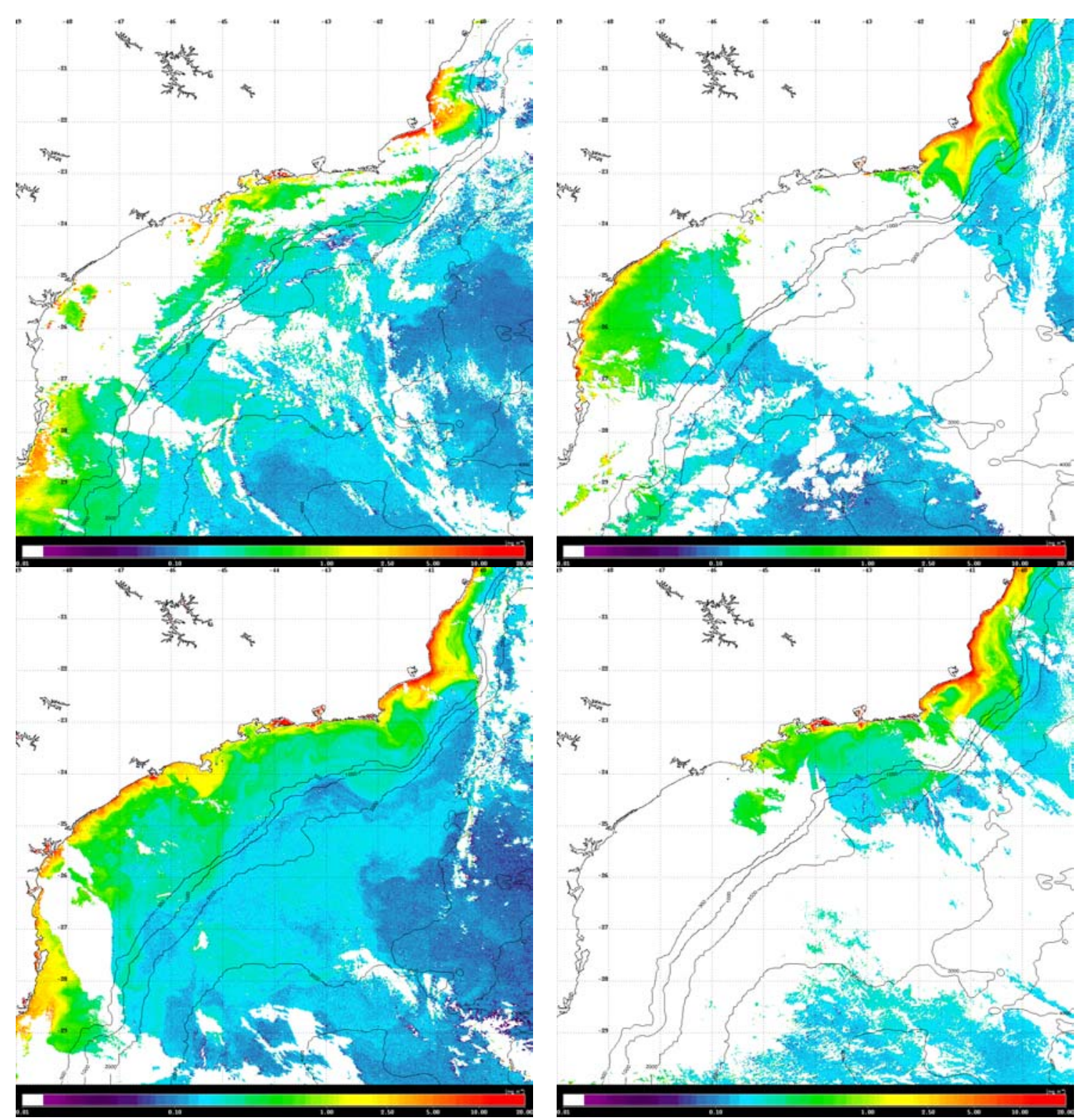

Figura 3.22 - Imagens da concentração de clorofila da superfície do mar referentes aos dias 16 (esquerda em cima), 17 (esquerda embaixo), 19 (direita em cima) e 21 (direita embaixo) de julho de 2001. Isóbatas de 500, 1.000, 2.000, $3.000 \mathrm{e}$ $4.000 \mathrm{~m}$ em preto. Tabela de cores em escala logarítmica.

\subsubsection{Produção primária por satélite - Modelo Bedford (BPM1)}

Durante o cruzeiro de mesoescala de inverno de 2001 foram realizados 14 experimentos de produção primária in situ simulado com amostras coletadas em superfície e 10 experimentos com amostras do fundo da zona eufótica. Com a aplicação do modelo BPM1 foi possível obter 13 estimativas para a produção primária integrada na coluna d'água, considerando as amostras de $100 \%$, e 5 estimativas para $1 \%$. Como mencionado 
anteriormente, toda vez que $I_{*}^{m}>20$, a produção é considerada igual a zero. A Tabela 3.16 apresenta os valores médios, amplitudes de variação e desvios padrão das produções integradas na zona eufótica $\left(\mathrm{gC} \cdot \mathrm{m}^{-2} \cdot \mathrm{d}^{-1}\right)$ calculadas com o modelo BPM1, para os domínios de plataforma e talude, em relação aos níveis de $100 \%$ e 1\%, durante o cruzeiro M2. São também mostrados os valores integrados na primeira profundidade óptica e na camada de mistura.

As produções primárias integradas na zona eufótica com o modelo BPM1 foram muito similares às estimadas para a camada de mistura (ver Tabela 3.16), sendo que, a termoclina esteve próxima da base da zona eufótica durante o cruzeiro M2. De modo geral, os valores obtidos para o domínio de plataforma foram maiores que os encontrados no talude, tanto para experimentos com amostras de superfície, como para as mais profundas. Da mesma forma, os resultados obtidos para o nível de superfície foram maiores que os calculados para $1 \%$, tanto sobre a plataforma, como no talude.

TABELA 3.16 - PRODUÇÕES PRIMÁRIAS INTEGRADAS NA ZONA EUFÓTICA, PRIMEIRA PROFUNDIDADE ÓPTICA E CAMADA DE MISTURA PELO MODELO BPM1 (M2)

\begin{tabular}{|c|c|c|c|c|c|c|c|c|c|c|c|c|}
\hline \multirow{3}{*}{ M2 } & \multicolumn{6}{|c|}{ Plataforma } & \multicolumn{6}{|c|}{ Talude } \\
\hline & \multicolumn{3}{|c|}{ BPM1 $_{100 \%}$} & \multicolumn{3}{|c|}{ BPM1 $_{1 \%}$} & \multicolumn{3}{|c|}{ BPM1 $_{100 \%}$} & \multicolumn{3}{|c|}{ BPM1 $_{1 \%}$} \\
\hline & EU & OP & $\mathbf{C M}$ & $\mathbf{E U}$ & OP & $\mathbf{C M}$ & $\mathbf{E U}$ & OP & $\mathbf{C M}$ & $\mathbf{E U}$ & $\mathbf{O P}$ & $\mathbf{C M}$ \\
\hline Média & 0,60 & 0,25 & 0,61 & 0,22 & 0,08 & 0,23 & 0,35 & 0,14 & 0,35 & 0,21 & 0,08 & 0,21 \\
\hline Máximo & 1,16 & 0,51 & 1,18 & 0,28 & 0,10 & 0,29 & 0,65 & 0,24 & 0,66 & 0,24 & 0,10 & 0,24 \\
\hline Mínimo & 0,07 & 0,03 & 0,07 & 0,16 & 0,05 & 0,16 & 0,19 & 0,08 & 0,19 & 0,17 & 0,06 & 0,18 \\
\hline dp & 0,47 & 0,20 & 0,47 & 0,06 & 0,03 & 0,06 & 0,18 & 0,06 & 0,18 & 0,04 & 0,03 & 0,04 \\
\hline cv \% & 77 & 79 & 77 & 28 & 32 & 28 & 51 & 43 & 52 & 21 & 36 & 21 \\
\hline $\mathbf{n}$ & 7 & 7 & 7 & 3 & 3 & 3 & 6 & 6 & 6 & 2 & 2 & 2 \\
\hline
\end{tabular}

* EU-zona eufótica; OP - primeira profundidade óptica; $C M$ - camada de mistura; unidades $\left(g C . m^{-2} \cdot d^{-1}\right) ; d p$-desvio padrão; $c v$ - coeficiente variação(\%).

\subsubsection{Produção primária por satélite - Modelo Bedford BPM2}

Com o uso do modelo BPM2 durante o cruzeiro M2, foram obtidas estimativas da produção primária diária integrada na zona eufótica nas 14 estações onde as produções foram determinadas in situ, considerando-se o nível de 100\% de irradiância. Em relação ao nível mais profundo (1\%), foram obtidas 10 estimativas. A Tabela 3.17 apresenta os 
valores médios, amplitudes de variação e desvios padrão das produções integradas na zona eufótica $\left(\mathrm{gC} \cdot \mathrm{m}^{-2} \cdot \mathrm{d}^{-1}\right)$, calculadas com o modelo BPM2 para os domínios de plataforma e talude, em relação aos níveis de $100 \%$ e $1 \%$ de irradiância.

TABELA 3.17 - PRODUÇÃO PRIMÁRIA INTEGRADA NA ZONA EUFÓTICA CALCULADA COM O MODELO BPM2 (M2).

\begin{tabular}{|c|c|c|c|c|}
\hline \multirow{2}{*}{ M2 } & \multicolumn{2}{|c|}{ Plataforma } & \multicolumn{2}{|c|}{ Talude } \\
\hline & BPM2 $_{100 \%}$ & BPM2 $1 \%$ & BPM2 $100 \%$ & BPM2 $_{1 \%}$ \\
\hline Média & 1,05 & 1,27 & 0,63 & 0,44 \\
\hline Máximo & 1,88 & 3,80 & 1,18 & 0,60 \\
\hline Mínimo & 0,29 & 0,30 & 0,29 & 0,33 \\
\hline Desvio padrão & 0,61 & 1,68 & 0,39 & 0,10 \\
\hline $\begin{array}{c}\text { Coeficiente } \\
\text { variação }\end{array}$ & $58 \%$ & $132 \%$ & $62 \%$ & $23 \%$ \\
\hline $\mathbf{n}$ & 8 & 4 & 6 & 6 \\
\hline
\end{tabular}

O valor médio da produção primária diária integrada na zona eufótica estimado sobre a plataforma para as amostras de $1 \%\left(1,27 \pm 1,68 \mathrm{gC} \cdot \mathrm{m}^{-2} \cdot \mathrm{d}^{-1}, \mathrm{n}=4\right)$ foi maior que $\mathrm{o}$ obtido para as amostras de $100 \%\left(1,05 \pm 0,61 \mathrm{gC} \cdot \mathrm{m}^{-2} \cdot \mathrm{d}^{-1}, \mathrm{n}=8\right)$. Este comportamento se mostra diferente do que tem sido observado em praticamente todos os outros resultados obtidos este trabalho. A razão para que o valor médio encontrado ao nível de $1 \%$ tenha sido relativamente alto foi a existência de um máximo absoluto calculado na estação $7072\left(3,80 \mathrm{gC} \cdot \mathrm{m}^{-2} \cdot \mathrm{d}^{-1}\right)$, durante o cruzeiro M2. No domínio do talude, o valor médio referente à $100 \%$ de irradiância $\left(0,63 \pm 0,39 \mathrm{gC} \cdot \mathrm{m}^{-2} \cdot \mathrm{d}^{-1}\right)$ foi maior que o encontrado em relação a $1 \%\left(0,44 \pm 0,10 \mathrm{gC} \cdot \mathrm{m}^{-2} \cdot \mathrm{d}^{-1}\right)$.

\subsubsection{Produção primária por satélite - Modelo VGPM}

Com o uso do modelo VGPM, foram obtidas estimativas da produção primária diária integrada na zona eufótica em todas as 14 estações onde foram realizados experimentos in situ simulados, durante o cruzeiro M2. A Tabela 3.18 apresenta os valores médios, amplitudes de variação e desvios padrão das produções integradas na zona eufótica $\left(\mathrm{gC} . \mathrm{m}^{-2} \cdot \mathrm{d}^{-1}\right)$ calculadas com o modelo VGPM, para os domínios de plataforma e talude, em relação aos níveis de $100 \%$ e 1\%, durante o cruzeiro M2. 
TABELA 3.18 - PRODUÇÃO PRIMÁRIA INTEGRADA NA ZONA EUFÓTICA CALCULADA COM O MODELO VGPM (M2).

\begin{tabular}{c|c|c}
\hline M2 & Plataforma & Talude \\
\hline Média & 1,91 & 0,64 \\
\hline Máximo & 3,78 & 0,79 \\
\hline Mínimo & 0,88 & 0,50 \\
\hline Desvio padrão & 0,84 & 0,11 \\
\hline Coeficiente variação & $44 \%$ & $17 \%$ \\
\hline n & 8 & 6 \\
\hline \multicolumn{2}{c}{ * unidades $\left(\mathrm{gC} \cdot \mathrm{m}^{-2} \cdot \mathrm{d}^{-1}\right)$}
\end{tabular}

O valor médio da produção primária diária integrada na zona eufótica sobre a plataforma foi igual a $1,91 \pm 0,84 \mathrm{gC} \cdot \mathrm{m}^{-2} \cdot \mathrm{d}^{-1}$, portanto maior do que o estimado para $\mathrm{o}$ talude $\left(0,64 \pm 0,11 \mathrm{gC} \cdot \mathrm{m}^{-2} \cdot \mathrm{d}^{-1}\right)$, durante o cruzeiro M2. Em relação aos valores calculados durante o verão do mesmo ano (M1, ver Tabela 3.9), houve diferença no domínio de talude (M2>M1).

\subsection{Cruzeiro de Mesoescala - Verão de 2002 (M3)}

\subsubsection{Distribuições horizontais de temperatura e salinidade}

A Figura 3.23 apresenta as distribuições horizontais de temperatura e salinidade na superfície e nas profundidades 25, 50, 75 e 100 m, observadas durante o cruzeiro de verão de 2002 (M3). Em superfície, grande parte da área amostrada apresenta temperaturas entre $24,0^{\circ}$ e $27,0^{\circ} \mathrm{C}$. Entretanto, as temperaturas decrescem em direção à costa podendo-se notar um gradiente horizontal de temperatura acentuado nas regiões do Cabo de São Tomé, Cabo Frio e Baía de Guanabara. Interessante notar uma intrusão de águas quentes em direção à costa $\left(\mathrm{T}>24,0^{\circ} \mathrm{C}\right)$, entre São Tomé e Cabo Frio, associada a um meandramento da CB. A distribuição de salinidade em superfície separa as águas mais salinas da CB ao largo, com salinidades acima de 37,0 (AT) e águas de salinidades mais baixas sobre a plataforma, em torno de 35,0. Em frente à Baía da Ilha Grande é possível observar a presença de águas costeiras, com salinidades mais baixas $(\mathrm{S}<34,8)$ e temperaturas elevadas $\left(\mathrm{T}>26,0^{\circ} \mathrm{C}\right)$. Inflexões acentuadas das isohalinas também são notadas entre o Cabo de São Tomé e Cabo Frio, no mesmo local do meandramento da CB. 
A $25 \mathrm{~m}$ de profundidade, as temperaturas aparecem mais baixas $\left(\mathrm{T}<18,0^{\circ} \mathrm{C}\right)$ e as salinidades entre 34,6 e 36,4 sobre a plataforma continental, indicando a presença da ACAS. Mais ao largo, pode-se notar a influência da AT com temperaturas e salinidades mais altas. A pluma de águas costeiras em frente à Baía da Ilha Grande não apresenta mais assinatura nos campos de temperatura ou salinidade nessa profundidade. Por outro lado, as intrusões de águas quentes e salinas da CB ainda podem ser notadas entre São Tomé e Cabo Frio. A 50 e $75 \mathrm{~m}$, o mesmo cenário é observado, porém, com temperaturas ainda mais baixas sobre a plataforma $\left(\mathrm{T}<14,0{ }^{\circ} \mathrm{C}\right)$. A assinatura do meandramento da CB ainda pode ser visto no comportamento das isotermas e isohalinas entre São Tomé e Cabo Frio. A 100 m, a disposição geral das isotermas e isohalinas permanece pouco alterada, podendo-se ainda perceber as assinaturas do meandramento da CB pelas inflexões das isotermas e isohalinas. A mudança de direção das isotermas e isohalinas deixando de seguir uma orientação paralela às isobatimétricas e assumindo direções perpendiculares às mesmas, denotam um comportamento baroclínico da CB.

\subsubsection{Distribuições horizontais de densidade $\left(\sigma_{t}\right)$ e nitrato}

As distribuições horizontais de $\sigma_{t}$ e nitrato são apresentadas na Figura 3.24. Na superfície, é possível notar a presença da ACAS $\left(\sigma_{\mathrm{t}}>25,4 \mathrm{~kg} \cdot \mathrm{m}^{-3}\right)$ em núcleos de água localizados em São Tomé, Cabo Frio e próximo a entrada da Baía de Guanabara. Em frente à Baía da Ilha Grande, pode-se observar uma pluma de águas menos densas $\left(\sigma_{\mathrm{t}}<23,4 \mathrm{~kg} . \mathrm{m}^{-3}\right)$ avançando em direção à quebra de plataforma. Valores abaixo de $24,0 \mathrm{~kg} \cdot \mathrm{m}^{-3}$ estão associados à presença da CB mais ao largo. A área em torno de Cabo Frio aparece com baixas concentrações de nitrato $(<0,25 \mu \mathrm{M})$. Plumas com concentrações relativamente mais altas $(>1,0 \mu \mathrm{M})$ podem ser observadas a S-SO da Baía da Ilha Grande e Baía de Guanabara. Núcleos com máximos relativos de nitrato $(1,5-2,0 \mu \mathrm{M})$ são notados sobre a quebra de plataforma, na direção da pluma proveniente da Baía de Guanabara e ao largo, em frente ao Cabo de São Tomé.

A $25 \mathrm{~m}$, é possível notar a presença da ACAS sobre toda a plataforma mais interna, com valores de $\sigma_{\mathrm{t}}$ maiores que $25,4 \mathrm{~kg} \cdot \mathrm{m}^{-3}$. Não se observa mais a presença de águas costeiras e menos densas em frente a Baía da Ilha Grande. Ao largo, pode-se notar a 
presença da Água Tropical, com densidades relativamente mais baixas. Concentrações mais altas de nitrato $(1,0 \mu \mathrm{M})$ são observadas próximo à costa, entre as Baías de Ilha Grande e da Guanabara, e entre Cabo Frio e Cabo São Tomé. A 50 m, a maior parte da região amostrada apresenta-se dominada pela ACAS. Ao largo, ainda se nota a presença da Água Tropical e o meandramento da CB entre Cabo Frio e São Tomé. Em Cabo Frio, pode-se observar um núcleo de nitrato com concentrações mais elevadas $(>1,0 \mu \mathrm{M})$, da mesma forma que em frente a Baía da Ilha Grande. Máximos relativos podem ser notados a SO da área de estudo. A $100 \mathrm{~m}$ de profundidade, o cenário é parecido, a não ser pela ausência da Água Tropical ao largo. Ainda é possível notar o meandramento da CB entre Cabo Frio e São Tomé pelas inflexões das isopicnais. Um núcleo de alta concentração de nitrato pode ser observado sobre a quebra de plataforma, em frente à Baía da Ilha Grande $(>1,5 \mu \mathrm{M})$.

\subsubsection{Nutrientes inorgânicos dissolvidos}

Durante o cruzeiro de verão de 2002 (M3), a plataforma continental apresentou-se estratificada, com uma termoclina sazonal bem estabelecida variando entre 7,0 e 67,0 m de profundidade, com valor médio igual a 26,5 $\pm 14,7 \mathrm{~m}$. Por outro lado, a zona eufótica esteve mais profunda, variando entre 13,5 e 89,4 $\mathrm{m}$, com profundidade média de $55,2 \pm 19,5 \mathrm{~m}$. As concentrações médias de nitrato (Tabela 3.19) foram relativamente baixas em toda a coluna d'água amostrada $(<0,50 \mu \mathrm{M})$, sendo que o maior valor médio foi encontrado a $200 \mathrm{~m}$ de profundidade. As concentrações de nitrato variaram de forma inversa às de clorofila. Todos os outros nutrientes analisados apresentaram maior valor médio em torno de $25 \mathrm{~m}$ de profundidade, coincidindo com a base da camada de mistura. 


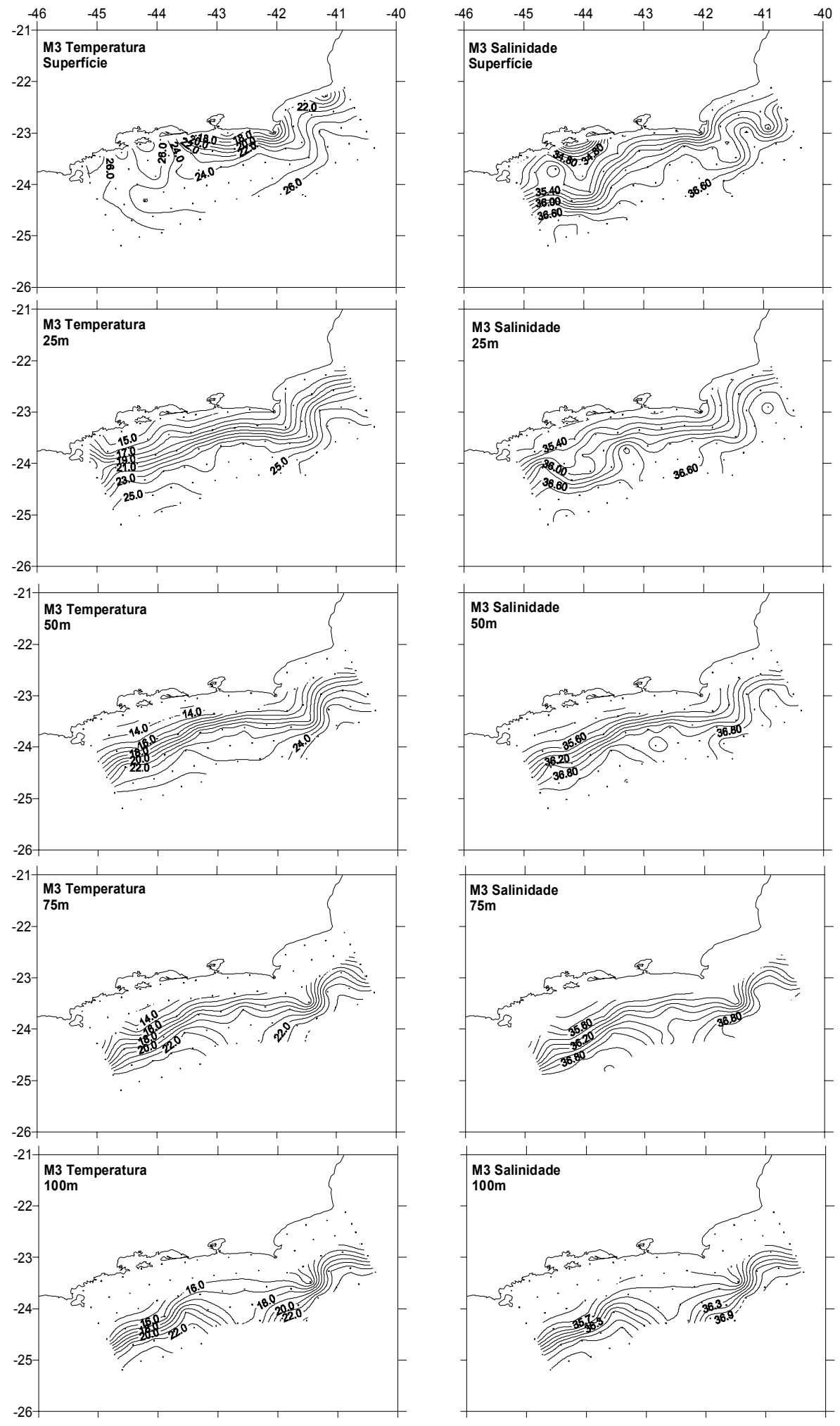

Figura 3.23 - Distribuições horizontais de temperatura $\left({ }^{\circ} \mathrm{C}\right)$ e salinidade a $0,25,50,75$ e $100 \mathrm{~m}$ de profundidade durante o cruzeiro de verão de 2002 (M3). 


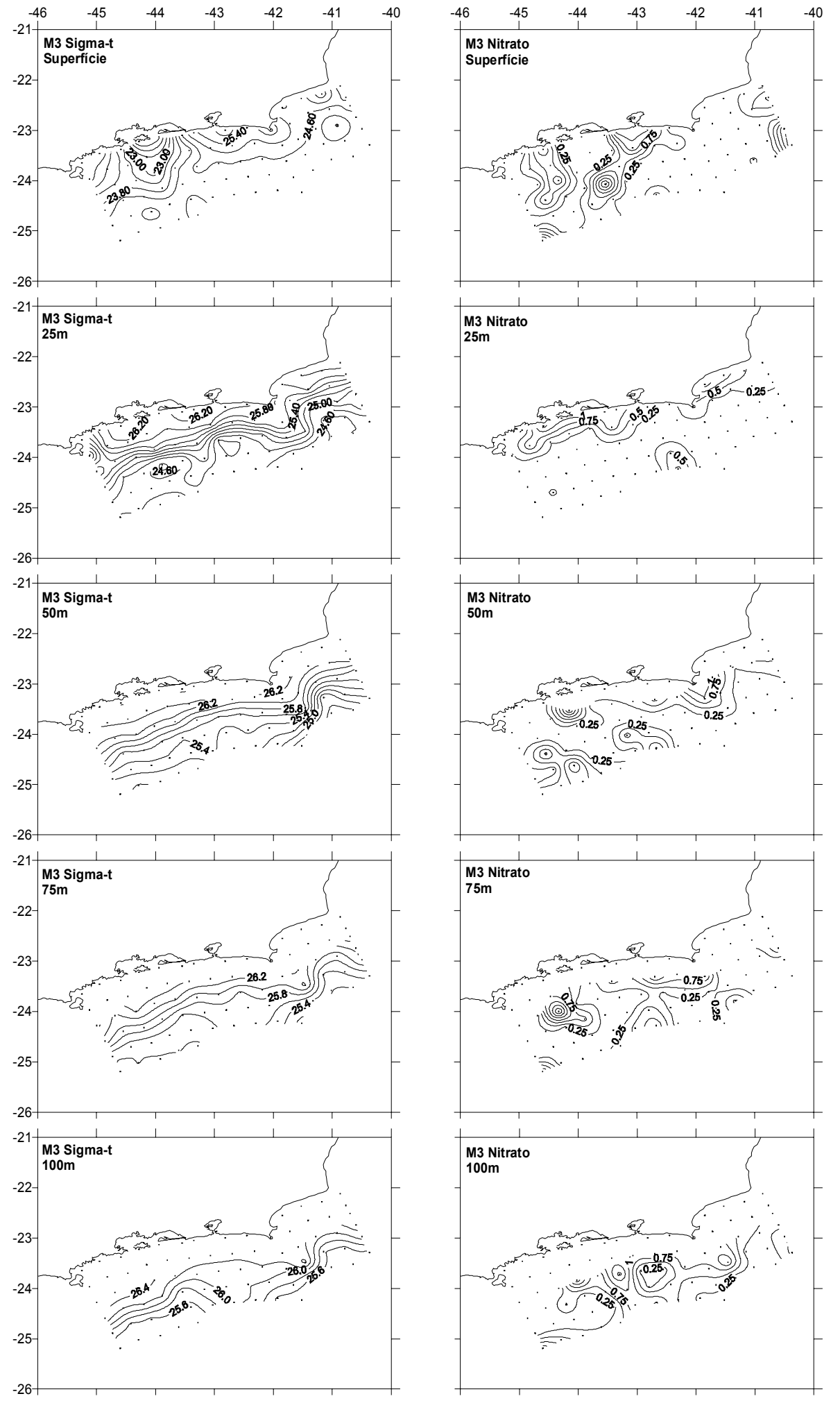

Figura 3.24 - Distribuições horizontais de densidade $\left(\mathrm{kg} \cdot \mathrm{m}^{-3}\right)$ e nitrato $(\mu \mathrm{M})$ a $0,25,50$, 75 e 100 m de profundidade durante o cruzeiro de verão de 2002 (M3). 
TABELA 3.19 - CONCENTRAÇÕES MÉDIAS DOS NUTRIENTES INORGÂNICOS DISSOLVIDOS DURANTE O CRUZEIRO DE VERÃO DE 2002 (M3).

\begin{tabular}{c|c|c|c|c|c}
\hline $\begin{array}{c}\text { Profundidade } \\
(\mathbf{m})\end{array}$ & $\begin{array}{c}\text { Nitrato } \\
(\boldsymbol{\mu M})\end{array}$ & $\begin{array}{c}\text { Amônia } \\
(\boldsymbol{\mu M})\end{array}$ & $\begin{array}{c}\text { Fosfato } \\
(\boldsymbol{\mu M})\end{array}$ & $\begin{array}{c}\text { Silicato } \\
(\boldsymbol{\mu M})\end{array}$ & $\begin{array}{c}\text { Clorofila } \\
\left(\mathbf{m g . m}^{-\mathbf{3}}\right)\end{array}$ \\
\hline \multirow{2}{*}{ Superfície } & $0,33(0,47)$ & $0,39(0,35)$ & $0,15(0,15)$ & $3,81(0,47)$ & $0,79(2,05)$ \\
& $0,0-1,88$ & $0,0-1,80$ & $0,0-1,14$ & $0,47-17,46$ & $0,06-11,19$ \\
\hline \multirow{2}{*}{$\mathbf{2 5}$} & $0,28(0,33)$ & $0,61(0,70)$ & $0,32(0,35)$ & $4,82(5,07)$ & $1,13(2,15)$ \\
& $0,0-1,35$ & $0,0-3,15$ & $0,0-1,35$ & $1,32-25,29$ & $0,07-11,35$ \\
\hline \multirow{5}{50}{} & $0,33(0,41)$ & $0,47(0,41)$ & $0,28(0,27)$ & $5,31(6,55)$ & $0,59(0,83)$ \\
& $0,0-1,79$ & $0,0-1,70$ & $0,0-1,14$ & $1,04-36,52$ & $0,11-5,62$ \\
\hline \multirow{2}{*}{$\mathbf{1 0 0}$} & $0,47(0,43)$ & $0,36(0,29)$ & $0,33(0,25)$ & $3,80(2,14)$ & $0,29(0,12)$ \\
& $0,01-1,61$ & $0,0-1,25$ & $0,0-0,99$ & $1,51-11,14$ & $0,04-0,56$ \\
\hline \multirow{2}{*}{$\mathbf{2 0 0}$} & $0,61(0,53)$ & $0,43(0,33)$ & $0,33(0,22)$ & $4,53(5,34)$ & $0,03(0,04)$ \\
& $0,05-1,62$ & $0,0-1,10$ & $0,05-0,78$ & $1,70-27,74$ & $0,003-0,19$ \\
\hline
\end{tabular}

* Em cima - Média e desvio padrão (entre parênteses); Embaixo - Amplitude de variação

A Figura 3.25 apresenta os diagramas de dispersão dos nutrientes inorgânicos dissolvidos em função da densidade $\left(\sigma_{t}\right)$. A linha tracejada sobreposta na Figura 3.25 indica o limite isopicnal inferior da ACAS $\left(25,4 \mathrm{~kg} \cdot \mathrm{m}^{-3}\right)$. Pode-se notar uma inflexão a partir da presença da ACAS, com concentrações mais altas dos nutrientes.

Em termos de representação relativa de cada nutriente nitrogenado inorgânico, temos que o nitrato contribuiu com cerca de $60 \%$ a 200 m, enquanto que a amônia e o nitrito contribuíram com $40 \%$ e menos que $2 \%$, respectivamente, na mesma profundidade (Tabela 3.20). A amônia contribuiu com 56\% em superfície, enquanto que o nitrato e o nitrito contribuíram com 39\% e 4\%, respectivamente. A 25 m, a contribuição do nitrito foi maior do que a do nitrato (31\% e 27\%, respectivamente). Nessa mesma profundidade, a contribuição da amônia foi de $42 \%$. A $50 \mathrm{~m}$, houve um equilíbrio entre as contribuições de nitrato e da amônia ( $45 \%$ e $49 \%$, respectivamente), enquanto que o nitrito contribuiu com $6 \%$. 

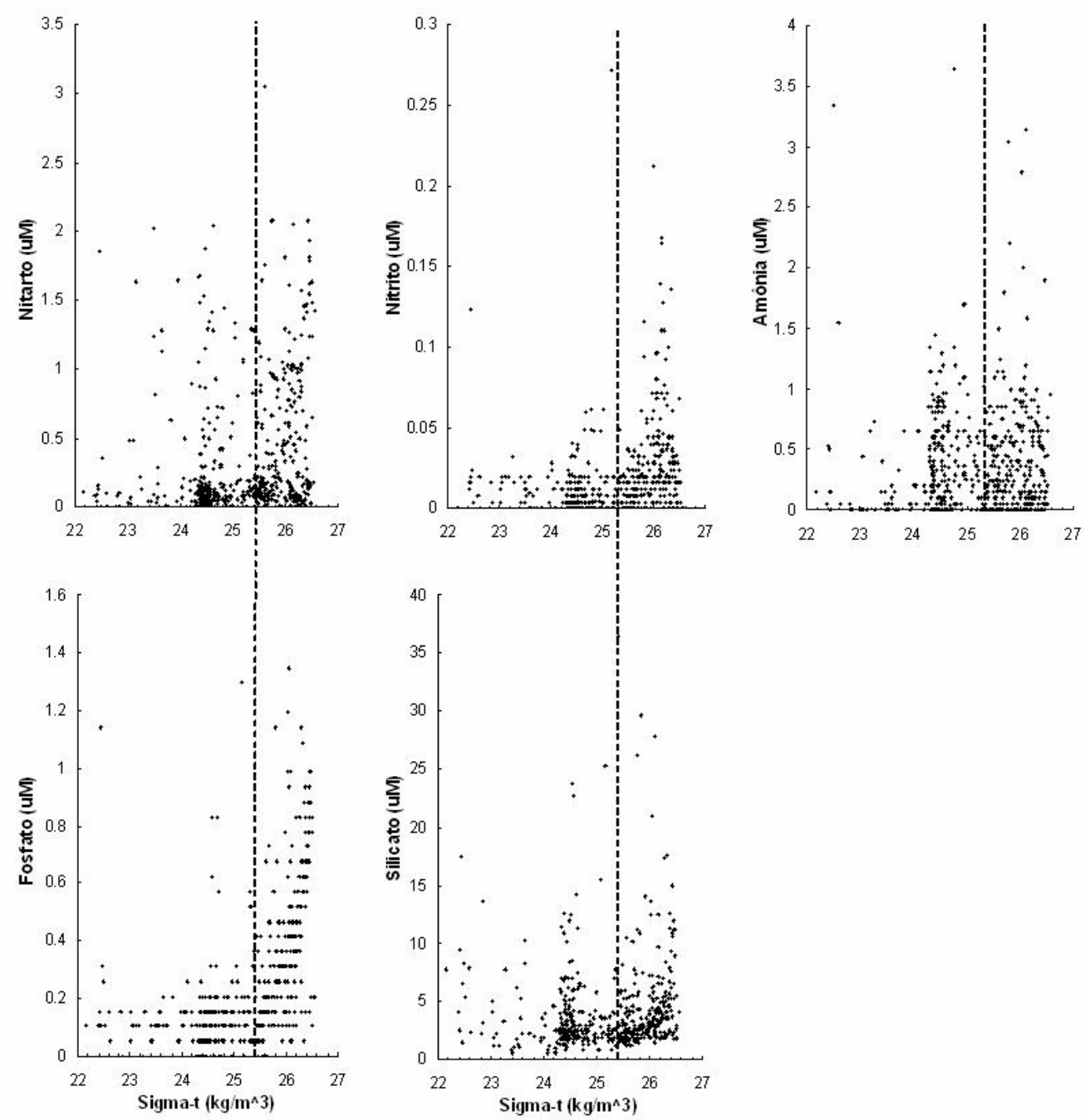

Figura 3.25 - Diagramas de dispersão dos nutrientes inorgânicos dissolvidos $(\mu \mathrm{M}) \mathrm{em}$ função de $\sigma_{\mathrm{t}}\left(\mathrm{kg} \cdot \mathrm{m}^{-3}\right)$, para o cruzeiro de verão de 2002 (M3). A linha tracejada indica o limite isopicnal inferior da Água Central do Atlântico Sul.

TABELA 3.20 - MÉDIAS DAS CONCENTRAÇÕES RELATIVAS DOS COMPOSTOS NITROGENADOS DISSOLVIDOS E DA CONCENTRAÇÃO ABSOLUTA DO NITROGÊNIO TOTAL DURANTE O CRUZEIRO DE VERÃO DE 2002 (M3).

\begin{tabular}{c|c|c|c|c}
\hline $\begin{array}{c}\text { Profundidade } \\
(\mathbf{m})\end{array}$ & $\begin{array}{c}\text { Nitrato } \\
\mathbf{\%}\end{array}$ & $\begin{array}{c}\text { Nitrito } \\
\mathbf{\%}\end{array}$ & $\begin{array}{c}\text { Amônia } \\
\mathbf{\%}\end{array}$ & $\begin{array}{c}\text { Nitrogênio } \\
(\boldsymbol{\mu M})\end{array}$ \\
\hline Superfície & $38,60(32,26)$ & $3,71(7,49)$ & $56,29(33,88)$ & $0,85(1,19)$ \\
\hline $\mathbf{2 5}$ & $26,85(23,51)$ & $31,04(29,07)$ & $42,12(30,03)$ & $1,21(1,03)$ \\
\hline $\mathbf{5 0}$ & $45,15(34,48)$ & $6,32(11,16)$ & $48,53(35,84)$ & $0,73(0,57)$ \\
\hline $\mathbf{1 0 0}$ & $46,56(28,95)$ & $6,23(13,30)$ & $47,20(30,08)$ & $0,83(0,52)$ \\
\hline $\mathbf{2 0 0}$ & $57,94(29,42)$ & $1,61(1,65)$ & $40,45(29,24)$ & $1,02(0,63)$ \\
\hline \multicolumn{5}{c}{ * Desvio padrão entre parênteses }
\end{tabular}




\subsubsection{Distribuições horizontais de clorofila $a$ e produtividade primária}

\subsubsection{Curvas de luz - fotossíntese}

Na Tabela 3.21 são apresentados os valores médios dos parâmetros fotossintéticos $\left(\mathrm{P}_{\max }{ }^{\mathrm{B}}\right.$ - número de assimilação e $\alpha^{\mathrm{B}}$ - eficiência fotossintética) obtidos com o ajuste de modelos empíricos às amostras de produção primária. $\mathrm{O}$ parâmetro de adaptação $\mathrm{I}_{\mathrm{k}}$ também é mostrado na Tabela 3.21, para os experimentos com amostras das profundidades relativas a $100 \%$ e $1 \%$ de irradiância.

TABELA 3.21 - PARÂMETROS FOTOSSINTÉTICOS DAS CURVAS DE LUZ FOTOSSÍNTESE DURANTE O CRUZEIRO DE VERÃO DE 2002 (M3).

\begin{tabular}{c|c|c|c|c|c|c}
\hline \multirow{2}{*}{ M3 } & \multicolumn{3}{|c|}{$\mathbf{1 0 0 \%}$} & \multicolumn{3}{c}{$\mathbf{1 \%}$} \\
\cline { 2 - 7 } Média & $\mathbf{P}_{\mathbf{m a x}}^{\mathbf{B}}$ & $\alpha^{\mathbf{B}}$ & $\mathbf{I}_{\mathbf{k}}$ & $\mathbf{P}_{\mathbf{m a x}} \mathbf{B}$ & $\alpha^{\mathbf{B}}$ & $\mathbf{I}_{\mathbf{k}}$ \\
\hline Máximo & 15,02 & 0,09 & 34,42 & 3,00 & 0,26 & 20,38 \\
\hline Mínimo & 0,79 & 0,98 & 78,08 & 9,25 & 0,87 & 113,52 \\
\hline Desvio Padrão & 3,67 & 0,20 & 21,60 & 2,55 & 0,23 & 25,93 \\
\hline $\begin{array}{c}\text { Coeficiente } \\
\text { Variação }\end{array}$ & $52 \%$ & $230 \%$ & $63 \%$ & $85 \%$ & $88 \%$ & $127 \%$ \\
\hline$* P_{\max }^{B}\left(m g C .\left(m g C l o^{-1}\right) \cdot h^{-1}\right), \alpha^{B}\left(m g C .\left(m g C l o^{-1}\right) \cdot h^{-1} .\left(W \cdot m^{-2}\right)^{-1}\right), I_{k}\left(W \cdot m^{-2}\right)$
\end{tabular}

De modo geral, os números de assimilação médios encontrados durante o verão de 2002 foram mais altos aos obtidos no verão do ano anterior (Tabela 3.2). O parâmetro $\mathrm{P}_{\max }{ }^{\mathrm{B}}$ das populações da camada superficial variou de 0,79 a $15,10 \mathrm{mgC} \cdot\left(\mathrm{mgClo}^{-1}\right) \cdot \mathrm{h}^{-1}$, tendo sido a média igual a 7,02 $\mathrm{mgC} \cdot\left(\mathrm{mgClo}^{-1}\right) \cdot \mathrm{h}^{-1}$. Para as populações localizadas na base da zona eufótica, esses valores foram iguais a 0,52, 9,25 e 3,00 mgC. $\left(\mathrm{mgClo}^{-1}\right) \cdot \mathrm{h}^{-1}$, respectivamente. A eficiência fotossintética $\left(\alpha^{\mathrm{B}}\right)$ variou nas amostras coletadas em superfície de 0,01 a $0,98 \mathrm{mgC} \cdot\left(\mathrm{mgClo}^{-1}\right) \cdot \mathrm{h}^{-1} \cdot\left(\mathrm{W} \cdot \mathrm{m}^{-2}\right)^{-1}$, com média igual a $0,09 \mathrm{mgC} .\left(\mathrm{mgClo}^{-1}\right) \cdot \mathrm{h}^{-1} \cdot\left(\mathrm{W} \cdot \mathrm{m}^{-2}\right)^{-1}$, portanto, mais baixa que a estimada durante o verão de 2001. O $\alpha^{\mathrm{B}}$ das amostras coletadas na base da zona eufótica apresentou valor médio igual $0,26 \mathrm{mgC} \cdot\left(\mathrm{mgClo}^{-1}\right) \cdot \mathrm{h}^{-1} \cdot\left(\mathrm{W} \cdot \mathrm{m}^{-2}\right)^{-1}$ e uma amplitude de variação entre $0,02 \mathrm{e}$ $0,87 \mathrm{mgC} \cdot\left(\mathrm{mgClo}^{-1}\right) \cdot \mathrm{h}^{-1} \cdot\left(\mathrm{W} \cdot \mathrm{m}^{-2}\right)^{-1} \cdot$ Em ambas as profundidades, os desvios padrão foram altos em relação às médias. Os valores médios de $\mathrm{I}_{\mathrm{k}}$ foram iguais a 34,42 e $20,38 \mathrm{~W} . \mathrm{m}^{-2}$ na superfície $(100 \%)$ e no fundo (1\%), respectivamente. Esses valores são mais altos do que os encontrados no verão de 2001 (Tabela 3.2). 
As distribuições horizontais de clorofila $a$ superficial e clorofila $a$ integrada na zona eufótica podem ser apreciadas na Figura 3.26 (lado esquerdo). Para a biomassa fitoplanctônica superficial, uma grande área costeira pode ser observada desde Macaé até a Ilha Grande, com aproximadamente $240 \mathrm{~km}$ de extensão e $50 \mathrm{~km}$ de largura máxima. Esta mancha é limitada por concentrações de $1,0 \mathrm{mg} \cdot \mathrm{m}^{-3}$, havendo um núcleo em Cabo Frio com concentrações maiores que $8,0 \mathrm{mg} \cdot \mathrm{m}^{-3}$. Estes valores altos de pigmento estão associados a um evento de ressurgência costeira. Comparando-se esta feição com a distribuição de nitrato (Figura 3.24), pode-se constatar o esgotamento de nitrato em superfície e a $25 \mathrm{~m}$ na região de Cabo Frio. A $50 \mathrm{~m}$ de profundidade, as concentrações de nitrato encontram-se mais altos $(\geq 1,0 \mu \mathrm{M})$ em razão desta profundidade estar abaixo da zona eufótica. Um pouco mais ao norte, em São Tomé, ocorre um outro máximo relativo, com concentrações maiores que $1,0 \mathrm{mg} \cdot \mathrm{m}^{-3}$, associado a outro evento fraco de ressurgência costeira no local.

Por outro lado, a clorofila $a$ integrada na zona eufótica também exibe uma extensa mancha de biomassa fitoplanctônica delimitada pela concentração de $45 \mathrm{mg} \cdot \mathrm{m}^{-2}$, coincidindo com aquela observada em superfície. Ainda, é possível notar uma continuidade desta mancha de biomassa até o litoral norte de São Paulo. Outro máximo relativo de biomassa integrada pode ser encontrado próximo a São Tomé, com concentrações maiores que $30 \mathrm{mg} \cdot \mathrm{m}^{-2}$. 


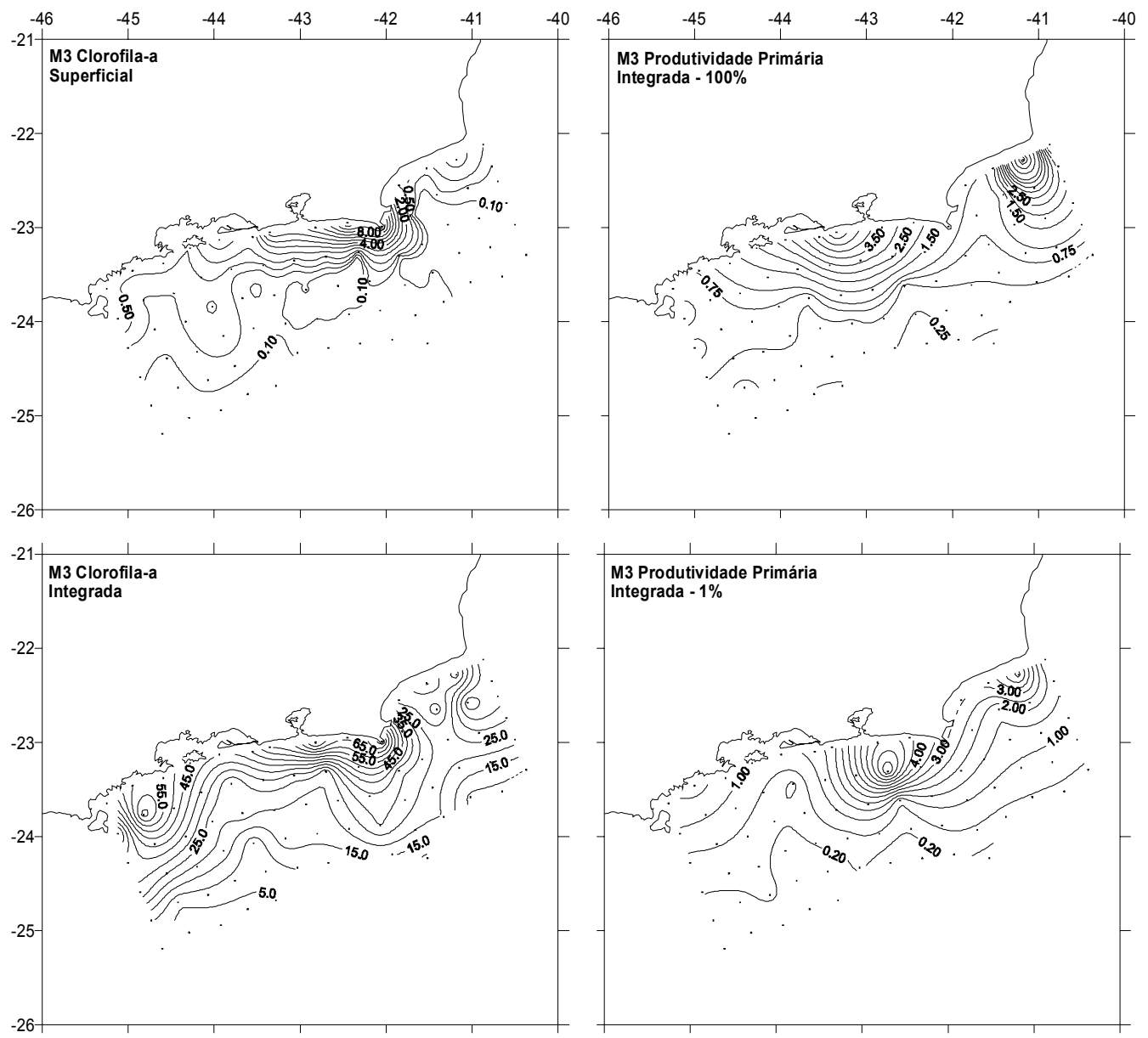

Figura 3.26 - Distribuições horizontais de clorofila $a$ superficial $\left(\mathrm{mg} \cdot \mathrm{m}^{-3}\right)$ e integrada na zona eufótica $\left(\mathrm{mg} \cdot \mathrm{m}^{-2}\right)$, produtividade primária integrada na zona eufótica $\left(\mathrm{gC} \cdot \mathrm{m}^{-2} \cdot \mathrm{d}^{-1}\right)$ referente aos níveis de $100 \%$ e $1 \%$ de irradiância (M3).

No lado direito da Figura 3.26, se encontram as distribuições horizontais da produtividade primária integrada na zona eufótica para as amostras referentes ao nível de 100\% (em cima) e 1\% (embaixo) de irradiância. A distribuição de produtividade primária integrada referente ao nível de superfície, apresenta uma mancha delimitada pela isolinha de $1,0 \mathrm{gC} \cdot \mathrm{m}^{-2} \cdot \mathrm{d}^{-1}$, que coincide aproximadamente, com as manchas observadas nas distribuições de clorofila, desde Cabo Frio até o litoral norte de São Paulo. Interessante notar uma mancha de alta produtividade próxima ao Cabo São Tomé, com valores superiores a $1,0 \mathrm{gC} \cdot \mathrm{m}^{-2} \cdot \mathrm{d}^{-1}$.

A distribuição horizontal da produtividade primária integrada na zona eufótica referente ao nível mais profundo, mostra um padrão similar ao observado para as amostras de superfície, porém, com valores maiores que $2,0 \mathrm{gC} \cdot \mathrm{m}^{-2} \cdot \mathrm{d}^{-1}$. 
A Tabela 3.22 apresenta os valores médios, amplitude de variação, desvio padrão e coeficiente de variação da clorofila- $a$ e produção primária integradas na zona eufótica $\left(\mathrm{mg} . \mathrm{m}^{-2}\right.$ e $\mathrm{gC} \cdot \mathrm{m}^{-2} \cdot \mathrm{d}^{-1}$, respectivamente), para as regiões de plataforma e talude, referentes ao cruzeiro de verão de 2002 (M3).

\section{TABELA 3.22 - CLOROFILA E PRODUÇÃO PRIMÁRIA INTEGRADAS NA ZONA EUFÓTICA SOBRE A PLATAFORMA E O TALUDE DURANTE O CRUZEIRO DE VERÃO DE 2002 (M3).}

\begin{tabular}{c|c|c|c|c|c|c}
\hline \multirow{2}{*}{ M3 } & \multicolumn{3}{|c|}{ Plataforma } & \multicolumn{3}{c}{ Talude } \\
\cline { 2 - 7 } & $\mathbf{C}_{\text {EU }}$ & PP $_{\text {EU100 }}$ & PP $_{\text {EU1 }}$ & $\mathbf{C}_{\text {EU }}$ & PP $_{\text {EU100 }}$ & PP $_{\text {EU1 }}$ \\
\hline Média & 29,78 & 1,56 & 1,92 & 12,66 & 0,38 & 0,28 \\
\hline Máximo & 77,78 & 4,93 & 6,53 & 19,73 & 0,55 & 0,42 \\
\hline Mínimo & 12,12 & 0,33 & 0,14 & 5,89 & 0,15 & 0,14 \\
\hline Desvio padrão & 19,44 & 1,53 & 1,96 & 5,23 & 0,12 & 0,10 \\
\hline $\begin{array}{c}\text { Coeficiente de } \\
\text { variação }\end{array}$ & $65 \%$ & $98 \%$ & $102 \%$ & $41 \%$ & $30 \%$ & $34 \%$ \\
\hline
\end{tabular}

* $C_{E U}$ - Clorofila integrada na zona eufótica $\left(m g . m^{-2}\right) ; P P_{E U 100}$ - Produção primária integrada na zona eufótica das amostras de $100 \%\left(g C . m^{-2} . d^{-1}\right) ; P P_{E U I}$ - Produção primária integrada na zona eufótica das amostras de $1 \%\left(g C . m^{-2} \cdot d^{-1}\right)$.

No verão de 2002, a clorofila- $a$ integrada na plataforma foi mais de $50 \%$ maior $\left(29,78 \pm 19,44 \mathrm{mg} \cdot \mathrm{m}^{-2}\right)$ do que na região de talude $\left(12,66 \pm 5,23 \mathrm{mg} \cdot \mathrm{m}^{-2}\right)$, ou seja, apresentando um comportamento similar ao verão de 2001, ainda que com valores e diferença percentual maiores. As estimativas de produção primária estão apresentadas em unidades de massa de carbono fixado, por área e por dia. Os valores da produção integrada para as amostras referentes a $100 \%$ de irradiância foram $75 \%$ superiores sobre a plataforma $\left(1,56 \pm 1,53 \mathrm{gC} \cdot \mathrm{m}^{-2} \cdot \mathrm{d}^{-1}\right)$ do que sobre o talude $\left(0,38 \pm 0,12 \mathrm{gC} \cdot \mathrm{m}^{-2} \cdot \mathrm{d}^{-1}\right) \cdot \mathrm{O}$ mesmo comportamento pode ser observado em relação às amostras de $1 \%$ de irradiância $\left(1,92 \pm 1,96 \mathrm{gC} \cdot \mathrm{m}^{-2} \cdot \mathrm{d}^{-1}\right.$ e $0,28 \pm 0,10 \mathrm{gC} \cdot \mathrm{m}^{-2} \cdot \mathrm{d}^{-1}$, para a plataforma e o talude, respectivamente). Este padrão foi similar ao observado durante o verão de 2001, ainda que com valores absolutos e diferenças percentuais maiores. Os valores obtidos a partir das amostras de 100\% não se mostraram significativamente diferentes daqueles obtidos a partir das amostras de $1 \%$, tanto sobre o talude como na plataforma. 


\subsubsection{Imagens de Temperatura da Superfície do Mar}

A Figura 3.27 mostra as imagens termais orbitais referentes aos dias 2, 5, 9 e 15 de janeiro de 2002. Apesar da nebulosidade normalmente presente sobre a costa SE brasileira nos períodos de verão, foi possível observar algumas feições oceanográficas de interesse nestas imagens. As águas quentes da $\mathrm{CB}$ aparecem nas imagens com temperaturas acima de $25,0^{\circ} \mathrm{C}$. Uma frente termal é formada na sua borda interna em contato com águas de plataforma com TSM entre $22,0^{\circ}$ e $24,0^{\circ} \mathrm{C}$. Vórtices ciclônicos da CB foram observados ao largo de São Tomé e a sul de Cabo Frio. O vórtice de São Tomé esteve centrado em torno de $22,6^{\circ} \mathrm{S}-40,4^{\circ} \mathrm{W}$ e com diâmetro médio igual a $75 \mathrm{~km}$. O outro vórtice em Cabo Frio mostrou-se centrado em torno de $24,2^{\circ} \mathrm{S}-42,2^{\circ} \mathrm{W}$ e com diâmetro máximo igual a $100 \mathrm{~km}$. Da mesma forma que no verão de 2001, águas quentes $\left(\mathrm{TSM}>26,0^{\circ} \mathrm{C}\right)$ são observadas na zona costeira, desde o litoral norte de São Paulo até quase Cabo Frio. Apesar da cobertura de nuvens, foi possível identificar um núcleo de águas frias em Cabo Frio.

A Figura 3.28 apresenta as imagens de temperatura da superfície do mar referentes aos dias 21, 22, 26 e 31 de janeiro de 2002. O vórtice de São Tomé foi encontrado em torno de $22,5^{\circ} \mathrm{S}-40,5^{\circ} \mathrm{W}$, com cerca de $70 \mathrm{~km}$ de diâmetro. O núcleo frio a oeste de Cabo Frio apresentou temperaturas abaixo de $20,0^{\circ} \mathrm{C}$. O litoral norte de São Paulo esteve dominado por águas quentes (acima de $26,0^{\circ} \mathrm{C}$ ) desde a costa até o talude. Uma pluma de águas relativamente frias e afastadas da costa pode ser notada entre Vitória e São Tomé, com aproximadamente $70 \mathrm{~km}$ de extensão, e temperaturas abaixo de $22,0{ }^{\circ} \mathrm{C}$. Um núcleo costeiro a sul de São Tomé apresentou TSM mínima de 20,0 ${ }^{\circ} \mathrm{C}$. Uma pluma costeira em Cabo Frio exibiu temperaturas abaixo de $22,5^{\circ} \mathrm{C}$. 

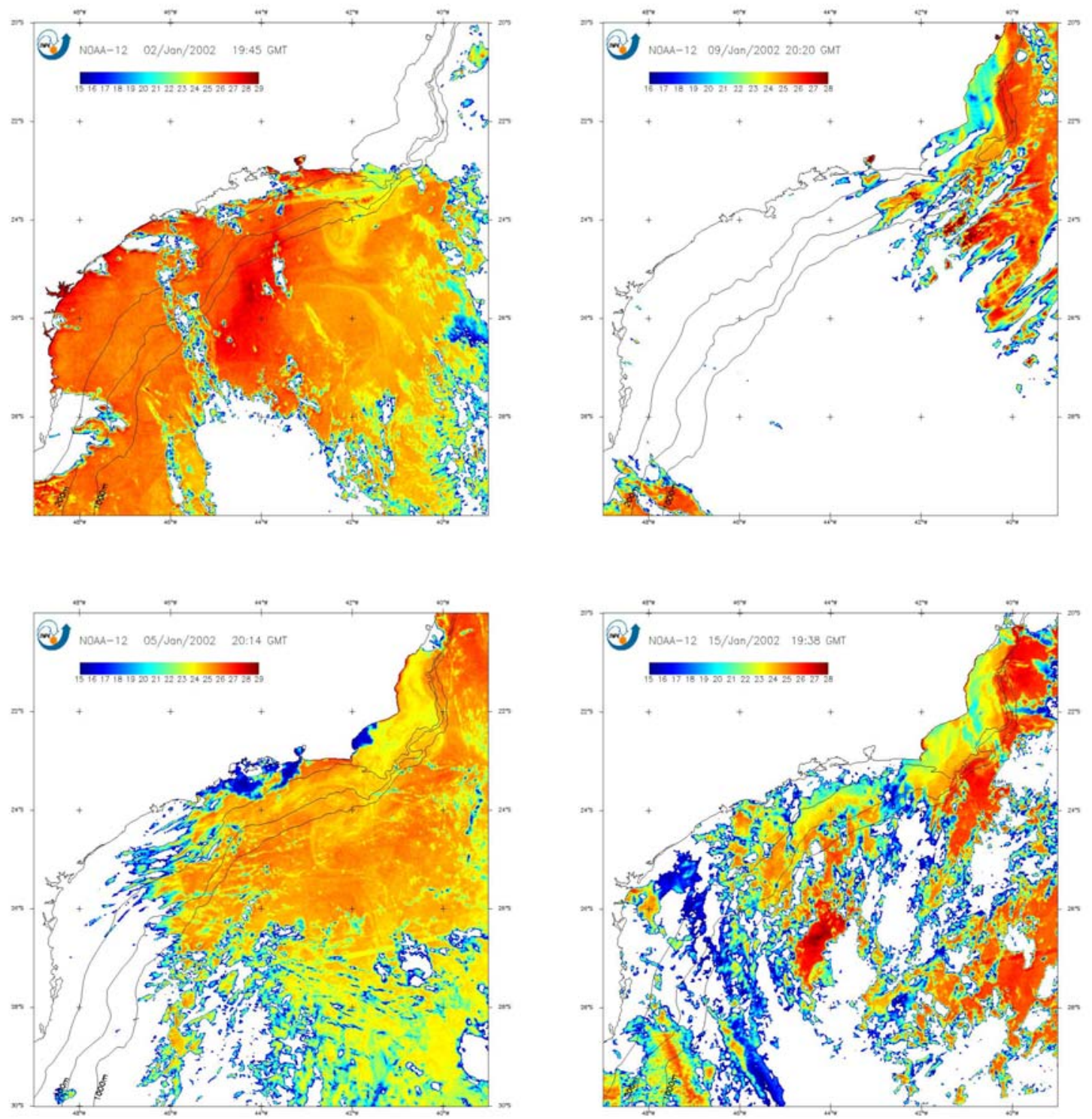

Figura 3.27 - Imagens da temperatura da superfície do mar referentes aos dias 2 (esquerda em cima), 5 (esquerda embaixo), 9 (direita em cima) e 15 (direita embaixo) de janeiro de 2002. Isóbatas de 100, 200 e 1.000 m em preto. 

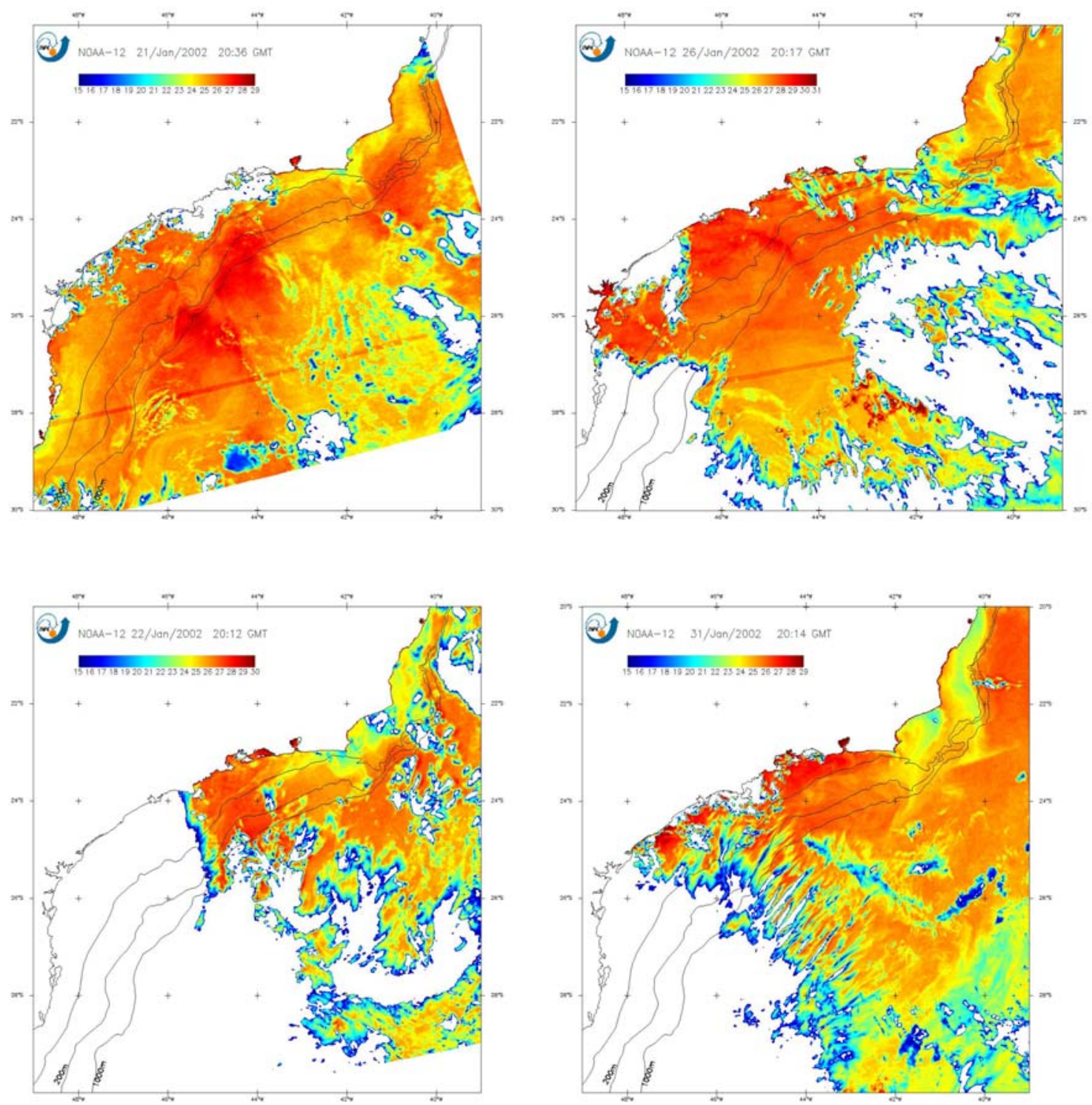

Figura 3.28 - Imagens da temperatura da superfície do mar referentes aos dias 21 (esquerda em cima), 22 (esquerda embaixo), 26 (direita em cima) e 31 (direita embaixo) de janeiro de 2002. Isóbatas de 100, 200 e $1.000 \mathrm{~m}$ em preto. 


\subsubsection{Imagens de Concentração de Clorofila da Superfície do Mar}

A Figura 3.29 apresenta as imagens de concentração de clorofila da superfície do mar processadas nos dias 3, 21, 27 e 28 de janeiro de 2002. As águas oligotróficas da CB aparecem em tom azul escuro, contrastando com as águas de plataforma mais ricas em biomassa fitoplanctônica em tons verde - amarelo $\left(0,5-2,0 \mathrm{mg} \cdot \mathrm{m}^{-3}\right)$. Meandramentos ciclônicos da CB foram notados em São Tomé e ao sul de Cabo Frio. As imagens SeaWiFS de 03/01/2002 e 28/01/2002 exibiram o vórtice ciclônico de São Tomé, centrado aproximadamente em $22,4^{\circ} \mathrm{S}-40,4^{\circ} \mathrm{W}$ e com diâmetro médio em torno de $57 \mathrm{~km}$. Plumas com concentrações relativamente altas de clorofila foram observadas sobre a plataforma a SE de Vitória $\left(0,5-2,0 \mathrm{mg} \cdot \mathrm{m}^{-3}\right)$, sul de São Tomé $\left(>3,0 \mathrm{mg} \cdot \mathrm{m}^{-3}\right)$, SO de Cabo Frio $\left(0,5-1,0 \mathrm{mg} \cdot \mathrm{m}^{-3}\right)$ e S-SO da Ilha de São Sebastião $\left(0,5 \mathrm{mg} \cdot \mathrm{m}^{-3}\right)$. As zonas costeiras entre Vitória e São Tomé, assim como a entrada da Baía de Guanabara, apresentaram concentrações de clorofila acima de 3,0 mg.m $\mathrm{m}^{-3}$.

\subsubsection{Produção primária por satélite - Modelo Bedford (BPM1)}

Durante o cruzeiro de mesoescala de verão de 2002 foram realizados 21 experimentos de produção primária in situ simulado. Com a aplicação do modelo BPM1, foi possível obter 14 estimativas para a produção primária diária integrada na coluna d'água, considerando as amostras de $100 \%$ de irradiância e 6 estimativas para as amostras mais profundas (1\%). Como mencionado anteriormente, toda vez que $I_{*}^{m}>20$, a produção é considerada igual a zero. A Tabela 3.23 apresenta os valores médios, amplitudes de variação e desvios padrão das produções integradas na zona eufótica $\left(\mathrm{gC} \cdot \mathrm{m}^{-2} \cdot \mathrm{d}^{-1}\right)$ calculadas com o modelo BPM1, para os domínios de plataforma e talude, em relação aos níveis de $100 \%$ e $1 \%$, durante o cruzeiro M3. São também mostrados os valores integrados na primeira profundidade óptica e na camada de mistura. 


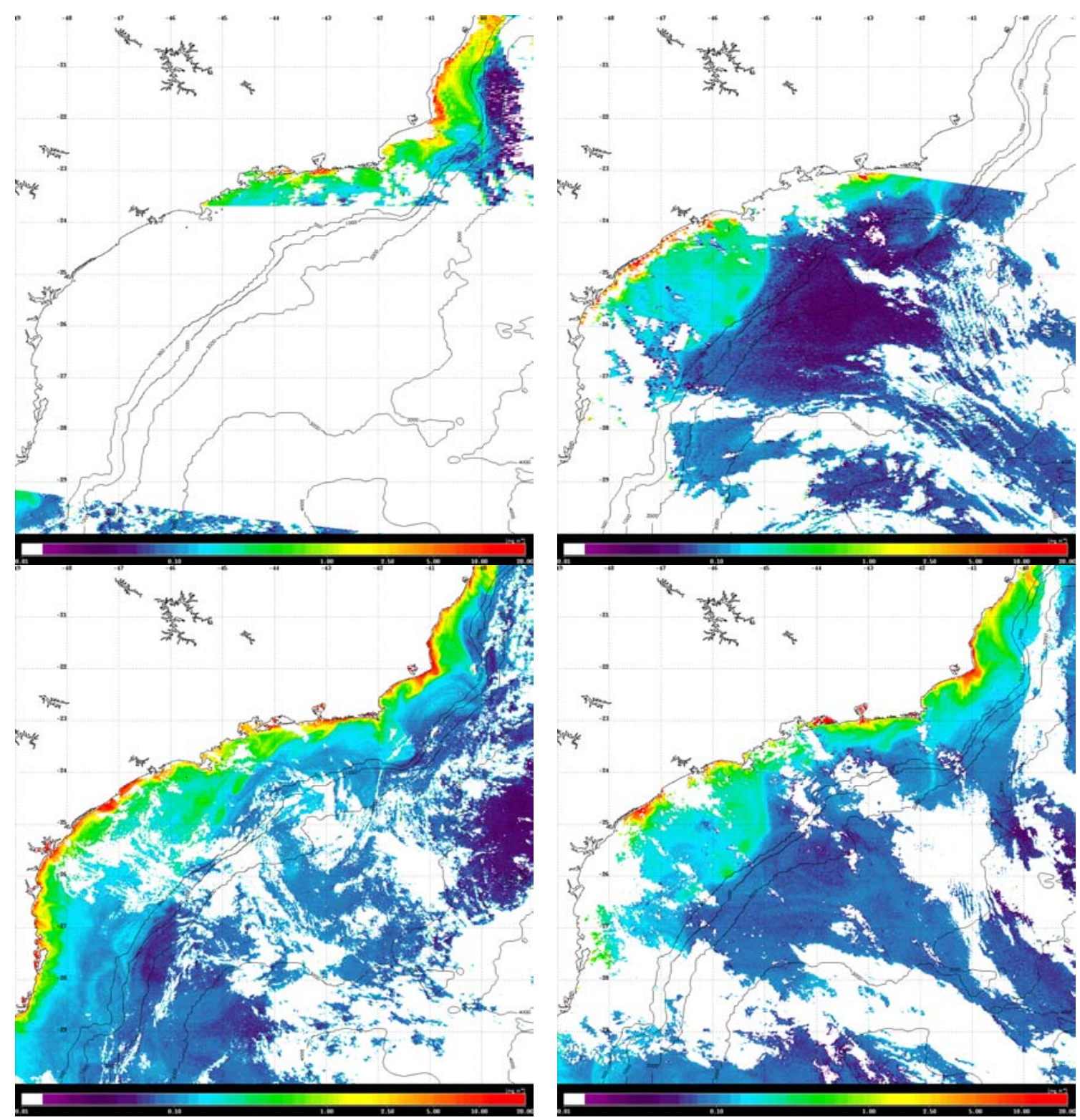

Figura 3.29 - Imagens da concentração de clorofila da superfície do mar referentes aos dias 3 (esquerda em cima), 21 (esquerda embaixo), 27 (direita em cima) e 28 (direita embaixo) de janeiro de 2002. Isóbatas de 500, 1.000, 2.000, $3.000 \mathrm{e}$ $4.000 \mathrm{~m}$ em preto. Tabela de cores em escala logarítmica. 
TABELA 3.23 - PRODUÇÕES PRIMÁRIAS INTEGRADAS NA ZONA EUFÓTICA, PRIMEIRA PROFUNDIDADE ÓPTICA E CAMADA DE MISTURA PELO MODELO BPM1 (M3)

\begin{tabular}{|c|c|c|c|c|c|c|c|c|c|c|c|c|}
\hline \multirow{3}{*}{ M3 } & \multicolumn{6}{|c|}{ Plataforma } & \multicolumn{6}{|c|}{ Talude } \\
\hline & \multicolumn{3}{|c|}{ BPM1 $_{100 \%}$} & \multicolumn{3}{|c|}{ BPM1 $1 \%$} & \multicolumn{3}{|c|}{ BPM1 $_{100 \%}$} & \multicolumn{3}{|c|}{ BPM1 $_{1 \%}$} \\
\hline & $\mathbf{E U}$ & OP & CM & $\mathbf{E U}$ & OP & $\mathbf{C M}$ & $\mathbf{E U}$ & OP & CM & $\mathbf{E U}$ & OP & $\mathbf{C M}$ \\
\hline Média & 0,79 & 0,32 & 0,49 & 0,43 & 0,18 & 0,30 & 0,23 & 0,10 & 0,20 & s.d. & s.d. & s.d. \\
\hline Máximo & 1,57 & 0,59 & 1,06 & 0,66 & 0,26 & 0,49 & 0,30 & 0,13 & 0,26 & s.d. & s.d. & s.d. \\
\hline Mínimo & 0,30 & 0,13 & 0,12 & 0,06 & 0,02 & 0,03 & 0,10 & 0,05 & 0,10 & s.d. & s.d. & s.d. \\
\hline dp & 0,46 & 0,17 & 0,28 & 0,22 & 0,09 & 0,16 & 0,09 & 0,04 & 0,07 & s.d. & s.d. & s.d. \\
\hline cv \% & 58 & 55 & 57 & 50 & 50 & 53 & 39 & 38 & 35 & s.d. & s.d. & s.d. \\
\hline $\mathbf{n}$ & 10 & 10 & 10 & 6 & 6 & 6 & 4 & 4 & 4 & s.d. & s.d. & s.d. \\
\hline
\end{tabular}

* EU-zona eufótica; OP - primeira profundidade óptica; $C M$ - camada de mistura; unidades $\left(g C . m^{-2} . d^{-1}\right) ; d p$ - desvio padrão; $c v$ - coeficiente variação(\%); s.d. - sem dados.

De modo geral, a produção primária diária integrada na coluna d'água através do modelo BPM1 para o domínio de plataforma foi maior que no domínio de talude. Na plataforma $(\mathrm{n}=10)$, o valor de $\mathrm{BPM} 1_{100 \%}$ estimado para a zona eufótica $\left(0,79 \pm 0,46 \mathrm{gC} \cdot \mathrm{m}^{-2} \cdot \mathrm{d}^{-1}\right)$ foi superior ao calculado para a camada de mistura $\left(0,49 \pm 0,28 \mathrm{gC} \cdot \mathrm{m}^{-2} \cdot \mathrm{d}^{-1}\right)$. Entretanto, sobre o talude $(\mathrm{n}=4)$, esta diferença não foi tão significativa $\quad\left(0,23 \pm 0,09 \mathrm{gC} \cdot \mathrm{m}^{-2} \cdot \mathrm{d}^{-1} \quad\right.$ e $\quad 0,20 \pm 0,07 \mathrm{gC} \cdot \mathrm{m}^{-2} \cdot \mathrm{d}^{-1}, \quad$ respectivamente $)$. Seguindo um comportamento médio geral observado até agora, as produções integradas sobre a plataforma foram maiores que sobre o talude durante M3 (ver Tabela 3.23 ).

\subsubsection{Produção primária por satélite - Modelo Bedford BPM2}

Com o uso do modelo BPM2 durante o cruzeiro M3, foram obtidas estimativas da produção primária diária integrada na zona eufótica nas 21 estações onde as produções foram determinadas in situ, nos dois níveis de irradiância amostrados. A Tabela 3.24 apresenta os valores médios, amplitudes de variação e desvios padrão das produções integradas na zona eufótica $\left(\mathrm{gC} \cdot \mathrm{m}^{-2} \cdot \mathrm{d}^{-1}\right)$, calculadas com o modelo BPM2 para os domínios de plataforma e talude, em relação aos níveis de $100 \%$ e 1\% de irradiância, durante o cruzeiro de verão de 2002. 
TABELA 3.24 - PRODUÇÃO PRIMÁRIA INTEGRADA NA ZONA EUFÓTICA CALCULADA COM O MODELO BPM2 (M3).

\begin{tabular}{|c|c|c|c|c|}
\hline \multirow{2}{*}{ M3 } & \multicolumn{2}{|c|}{ Plataforma } & \multicolumn{2}{|c|}{ Talude } \\
\hline & BPM2 $_{100 \%}$ & BPM2 $1 \%$ & BPM2 $_{100 \%}$ & BPM2 $1 \%$ \\
\hline Média & 1,84 & 1,09 & 0,58 & 0,23 \\
\hline Máximo & 4,02 & 3,48 & 0,80 & 0,42 \\
\hline Mínimo & 0,21 & 0,06 & 0,42 & 0,06 \\
\hline Desvio padrão & 1,41 & 1,01 & 0,12 & 0,13 \\
\hline $\begin{array}{c}\text { Coeficiente } \\
\text { variação }\end{array}$ & $76 \%$ & $92 \%$ & $20 \%$ & $54 \%$ \\
\hline n & 12 & 12 & 9 & 9 \\
\hline
\end{tabular}

Os valores médios calculados para BPM2 foram maiores sobre a plataforma do que sobre o talude, tanto para as amostras de superfície como para a base da zona eufótica (ver Tabela 3.24 ). Da mesma forma, os valores médios de BPM2 estimados com as amostras de $100 \%$ de irradiância também foram maiores que os valores referentes ao nível mais profundo. Com relação ao verão do ano anterior (M1), os valores médios de BPM2 foram maiores sobre a plataforma em M3 e maiores sobre o talude em M2 (ver Tabela 3.17).

\subsubsection{Produção primária por satélite - Modelo VGPM}

Aplicando-se o modelo VGPM aos dados do cruzeiro de verão de 2002 (M3), foram obtidas estimativas da produção primária diária integrada na zona eufótica em 15 estações de um total de 21 estações em que foram realizados experimentos in situ simulados. Das 15 estações onde se obteve com sucesso as estimativas para VGPM, onze eram sobre a plataforma e 4 sobre o talude. A Tabela 3.25 apresenta os valores médios, amplitudes de variação e desvios padrão das produções integradas na zona eufótica $\left(\mathrm{gC} \cdot \mathrm{m}^{-2} \cdot \mathrm{d}^{-1}\right)$ calculadas com o modelo VGPM, para os domínios de plataforma e talude, em relação ao nível de $100 \%$, durante o cruzeiro M3. 
TABELA 3.25 - PRODUÇÃO PRIMÁRIA INTEGRADA NA ZONA EUFÓTICA CALCULADA COM O MODELO VGPM (M3).

\begin{tabular}{c|c|c}
\hline M3 & Plataforma & Talude \\
\hline Média & 1,06 & 0,33 \\
\hline Máximo & 2,61 & 0,60 \\
\hline Mínimo & 0,28 & 0,25 \\
\hline Desvio padrão & 0,69 & 0,15 \\
\hline $\begin{array}{c}\text { Coeficiente } \\
\text { variação }\end{array}$ & $65 \%$ & $44 \%$ \\
\hline n & 11 & 4 \\
\hline \multicolumn{2}{c}{$*$ unidades $\left(g C \cdot m^{-2} \cdot d^{-1}\right)$}
\end{tabular}

O valor médio de VGPM calculado sobre a plataforma $\left(1,06 \pm 0,69 \mathrm{gC} \cdot \mathrm{m}^{-2} \cdot \mathrm{d}^{-1}\right)$ foi maior que o valor estimado para o domínio de talude $\left(0,33 \pm 0,15 \mathrm{gC} \cdot \mathrm{m}^{-2} \cdot \mathrm{d}^{-1}\right)$. Em relação ao verão do ano anterior (M1, ver Tabela 3.9 ), o VGPM de M3 foi cerca de $44 \%$ menor. Sobre o talude, os valores médios foram aproximadamente os mesmos $\left(0,31\right.$ e $0,33 \mathrm{gC} \cdot \mathrm{m}^{-2} \cdot \mathrm{d}^{-1}$ em M1 e M3, respectivamente).

\subsection{Cruzeiro de Mesoescala - Inverno de 2002 (M4)}

\subsubsection{Distribuições horizontais de temperatura e salinidade}

A Figura 3.30 apresenta as distribuições horizontais de temperatura e salinidade na superfície e nas profundidades 25,50,75 e $100 \mathrm{~m}$, observadas durante o cruzeiro de inverno de 2002 (M4). Em superfície, grande parte da área amostrada apresenta temperaturas entre 22,0 e $23,0^{\circ} \mathrm{C}$. Entretanto, as temperaturas decrescem em direção à costa podendo-se notar um gradiente horizontal de temperatura acentuado na região de Cabo Frio, onde ocorre um núcleo com temperaturas menores que $17,0^{\circ} \mathrm{C}$. Interessante notar uma intrusão de águas relativamente mais frias $\left(\mathrm{T}<21,0{ }^{\circ} \mathrm{C}\right)$ vindas de sul, pela costa, até a Baía da Ilha Grande. A distribuição de salinidade em superfície indica a presença de águas mais salinas da CB ao largo, com salinidades acima de 36,4 (AT) e águas de salinidades mais baixas sobre a plataforma, diminuindo em direção à costa com mínimos entre 34,6 e 34,0 (em frente às Baías da Ilha Grande e da Guanabara). A intrusão de águas vindas de sul pela costa apresenta assinatura na distribuição de salinidade superficial com valores de 34,6 até menores que 34,2. Em frente a Búzios e 
Cabo Frio pode-se observar uma inflexão das isohalinas de 35,4 e 35,6 em direção ao largo.

A $25 \mathrm{~m}$ de profundidade, o cenário é praticamente o mesmo, com águas mais quentes da $\mathrm{CB}$ ao largo $\left(\mathrm{T}>23,0^{\circ} \mathrm{C}\right)$, um núcleo frio de ressurgência em Cabo Frio $\left(\mathrm{T}=15,0^{\circ} \mathrm{C}\right)$, e a intrusão de águas relativamente frias vindas de sul, ao longo da costa, com temperaturas de $20,0^{\circ} \mathrm{C}$. Na distribuição de salinidade é possível notar a AT com salinidades de 37,0, a inflexão das isohalinas de 35,6 e 36,0 em direção ao largo, em frente a Búzios, e a intrusão de águas menos salinas vindas de sul pela costa, com valores abaixo de 34,0. A $50 \mathrm{~m}$, ainda nota-se um gradiente termal em Cabo Frio, associado à ressurgência costeira e as águas da $\mathrm{CB}$ mais quentes ao largo. Núcleos de águas mais frias $\left(\mathrm{T}<19,0^{\circ} \mathrm{C}\right)$ podem ser notados a SO da Baía da Ilha Grande e a SO de São Tomé. A distribuição de salinidade indica ainda um meandramento entre Cabo Frio e São Tomé, além do gradiente associado ao núcleo de ressurgência em Cabo Frio e a entrada de águas menos salinas vindas de sul.

A 75 e $100 \mathrm{~m}$, tem-se a presença da ACAS sobre a plataforma indicada pela isoterma de $18,0^{\circ} \mathrm{C}$ e salinidades entre 36,4 e 35,6 . As inflexões das isotermas e isohalinas observadas ao largo são associadas a meandramentos da CB.

\subsubsection{Distribuições horizontais de densidade $\left(\sigma_{t}\right)$ e nitrato}

As distribuições horizontais de $\sigma_{t}$ e nitrato são apresentadas na Figura 3.31. Em superfície, a plataforma interna é dominada por águas menos densas $\left(\sigma_{\mathrm{t}}<23,8 \mathrm{~kg} \cdot \mathrm{m}^{-3}\right)$. Em Cabo Frio é possível encontrar águas com densidades elevadas, acima de 25,4, típicas da ACAS. Um núcleo com concentrações altas de nitrato $\left(\mathrm{NO}_{3}{ }^{-}>1,0 \mu \mathrm{M}\right)$ também está presente em Cabo Frio. Outro máximo relativo de nitrato é encontrado próximo a São Tomé. Pode-se notar a entrada de águas menos densas vindas de sul pela $\operatorname{costa}\left(\sigma_{\mathrm{t}}=23,4 \mathrm{~kg} \cdot \mathrm{m}^{-3}\right)$ pela inflexão das isopicnais a NE da Ilha de São Sebastião.

A $25 \mathrm{~m}$, o cenário é parecido com o de superfície. O núcleo de ressurgência em Cabo Frio aparece com sua área um pouco expandida, com densidades acima de 26,0 kg.m $\mathrm{m}^{-3}$. O núcleo de nitrato não está mais presente em Cabo Frio, permanecendo apenas aquele 
notado em São Tomé $\left(\mathrm{NO}_{3}{ }^{-}>1,0 \mu \mathrm{M}\right)$. A intrusão de águas vindas de sul continua sendo vista no campo de densidades, mas sem assinatura nas distribuições de nitrato. A $50 \mathrm{~m}$ de profundidade, a entrada de águas vindas de sul ainda causa inflexão das isopicnais, com densidades mínimas de $24,2 \mathrm{~kg} \cdot \mathrm{m}^{-3}$. As concentrações de nitrato aparecem mais altas em quase toda a região amostrada, principalmente sobre a plataforma, aumentando em direção à costa $\left(\mathrm{NO}_{3}{ }^{-}>1,0 \mu \mathrm{M}\right.$.). A 75 e $100 \mathrm{~m}$, as concentrações de nitrato apresentam-se acima de $0,7 \mu \mathrm{M}$ sobre a quebra de plataforma, diminuindo em direção ao largo. A distribuição de densidade nessas profundidades ainda indica uma inflexão das isopicnais a SE da Ilha de São Sebastião.

\subsubsection{Nutrientes inorgânicos dissolvidos}

Durante o cruzeiro de inverno de 2002 (M4), a termoclina variou entre 7,0 e 141,0 m de profundidade, com valor médio igual 56,6 \pm 30,5 m.. Por outro lado, a zona eufótica variou entre 9,5 e 121,3 m, com valor médio igual a 50,0 $\pm 50,8 \mathrm{~m}$. Desta forma, a zona eufótica e a camada de mistura apresentaram-se muito próximas durante este cruzeiro (M4). As concentrações máximas dos nutrientes foram observadas na base da zona eufótica (Tabela 3.26). Em termos dos valores médios, podemos observar que o nitrato e o fosfato apresentaram comportamento parecido, com as concentrações aumentando em direção ao fundo (até $200 \mathrm{~m}$ ). A amônia apresentou maior valor médio em superfície. De modo geral, as concentrações de nitrato variaram de forma inversa às de clorofila. Esta apresentou concentração máxima na superfície, porém, com maior valor médio na base da zona eufótica $(50 \mathrm{~m})$. 


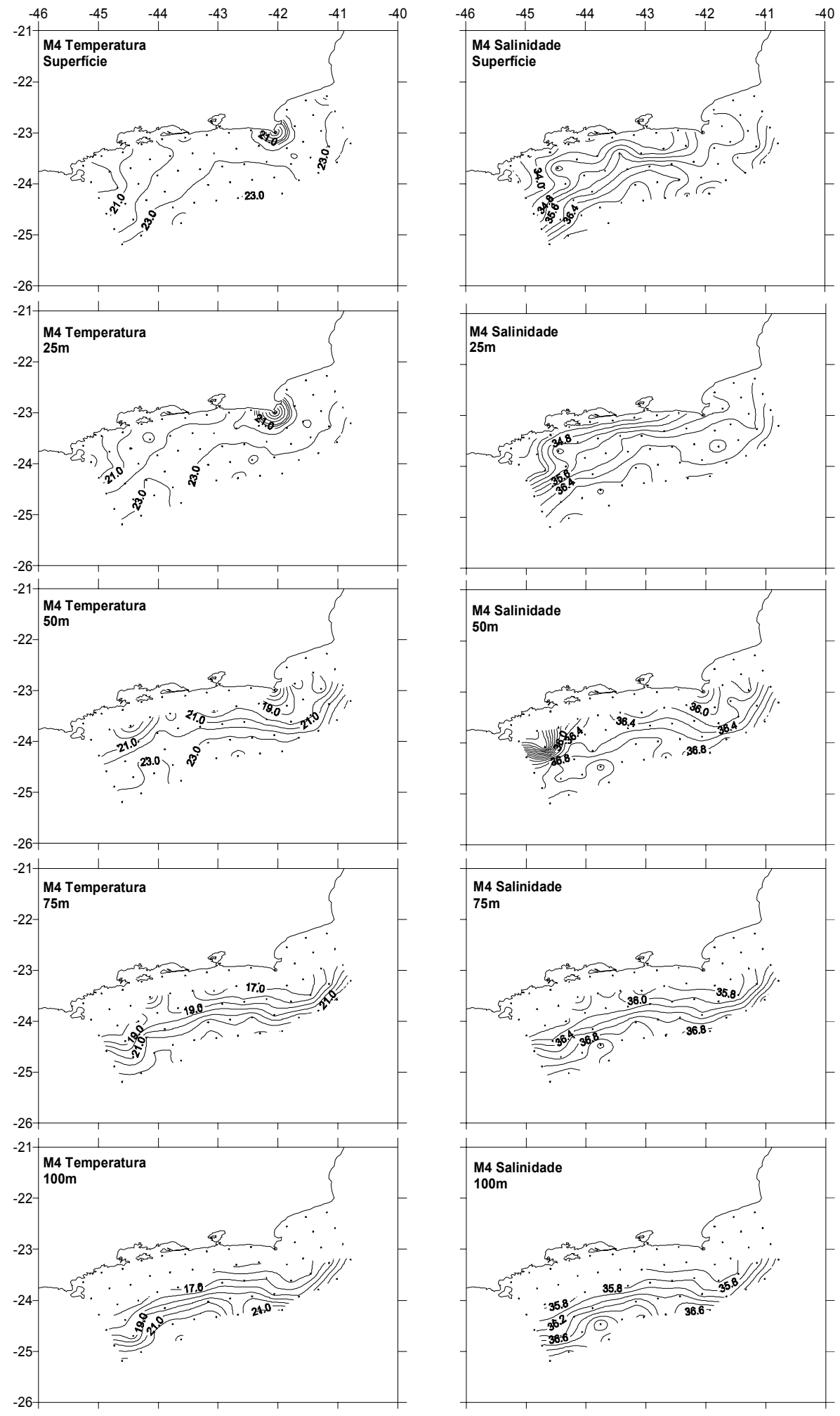

Figura 3.30 - Distribuições horizontais de temperatura $\left({ }^{\circ} \mathrm{C}\right)$ e salinidade a $0,25,50,75$ e $100 \mathrm{~m}$ de profundidade durante o cruzeiro de inverno de 2002 (M4). 

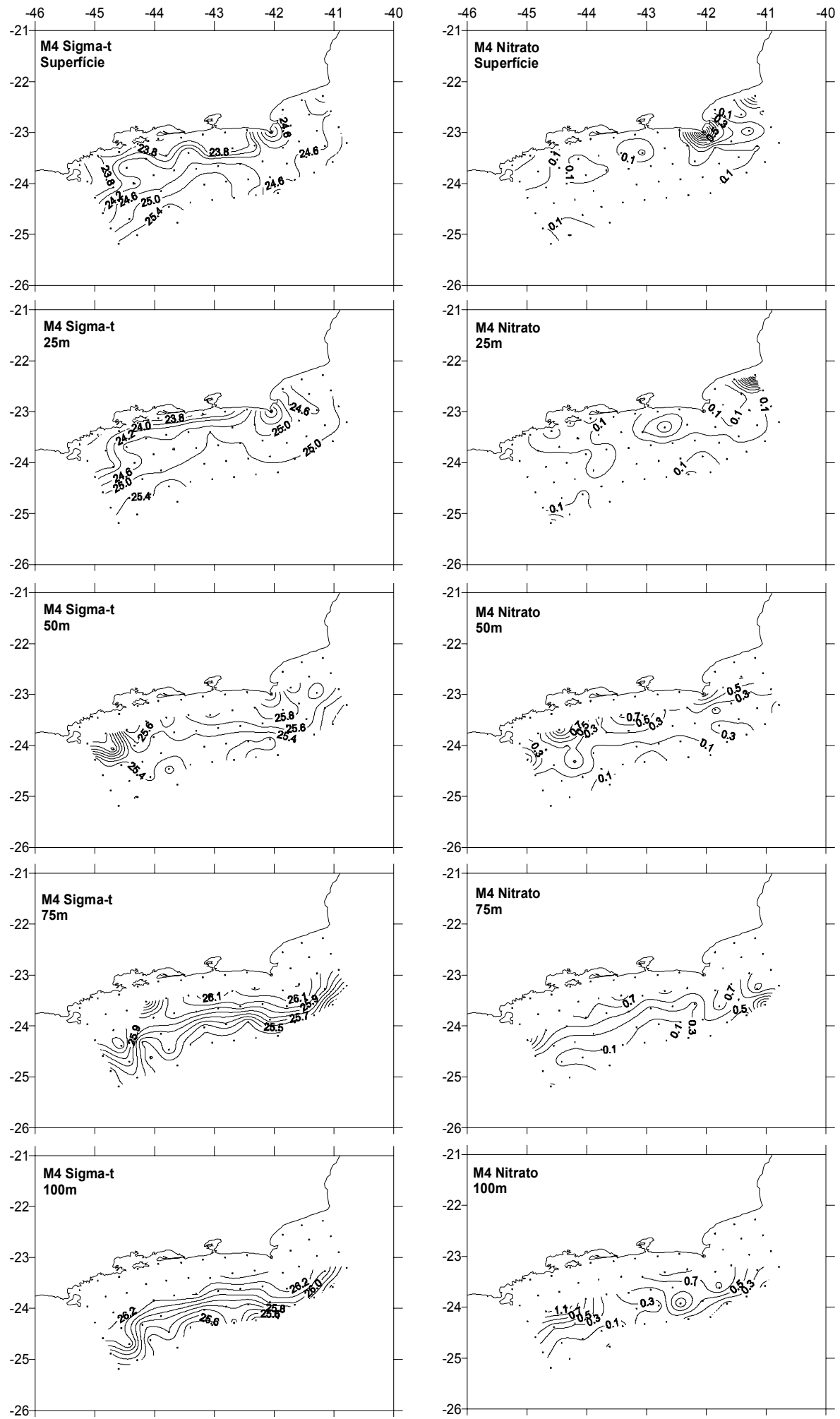

Figura 3.31 - Distribuições horizontais de densidade $\left(\mathrm{kg} \cdot \mathrm{m}^{-3}\right)$ e nitrato $(\mu \mathrm{M})$ a $0,25,50$, 75 e $100 \mathrm{~m}$ de profundidade durante o cruzeiro de inverno de 2002 (M4). 


\section{TABELA 3.26 - CONCENTRAÇÔES MÉDIAS DOS NUTRIENTES INORGÂNICOS DISSOLVIDOS DURANTE O CRUZEIRO DE INVERNO DE 2002 (M4).}

\begin{tabular}{|c|c|c|c|c|c|}
\hline $\begin{array}{c}\text { Profundidade } \\
(\mathrm{m})\end{array}$ & $\begin{array}{c}\text { Nitrato } \\
(\mu \mathrm{M})\end{array}$ & $\begin{array}{c}\text { Amônia } \\
(\mu \mathrm{M})\end{array}$ & $\begin{array}{c}\text { Fosfato } \\
(\mu \mathrm{M})\end{array}$ & $\begin{array}{c}\text { Silicato } \\
(\mu \mathrm{M})\end{array}$ & $\begin{array}{c}\text { Clorofila } \\
\left(\mathrm{mg}^{-m^{-3}}\right)\end{array}$ \\
\hline \multirow{2}{*}{ Superfície } & $0,12(0,17)$ & $0,31(0,24)$ & $0,36(0,16)$ & $6,06(6,08)$ & $0,49(0,45)$ \\
\hline & $0,0-1$ & & $0,0-0,88$ & $0,19-2$ & $0,14-2,53$ \\
\hline \multirow{2}{*}{25} & $0,13($ & $0,20($ & $0,32($ & 5,92 & ,38) \\
\hline & $0,0-1,4$ & $0,0-$ & $0,0-0,98$ & $0,28-20,29$ & $0,12-2,30$ \\
\hline \multirow{2}{*}{50} & 0,29 & 0,23 & $0,37(0$ & $5,45(6,10)$ & $0,55(0,29)$ \\
\hline & 0,0 & & 0,0 & 0,09 & 1,41 \\
\hline \multirow{2}{*}{100} & $0,42(0,36)$ & $0,22(0,27)$ & $0,40(0,23)$ & $5,12(24,06)$ & $0,20(0,14)$ \\
\hline & $0,0-1,25$ & $0,0-1,58$ & $0,0-0,93$ & $0,47-24,06$ & $0,02-0,54$ \\
\hline \multirow{2}{*}{200} & $0,66(0,23)$ & $0,17(0,11)$ & $0,59(0,13)$ & $6,11(5,94)$ & $0,03(0,06)$ \\
\hline & $0,35-1,25$ & $0,0-0,51$ & $0,36-0,79$ & $0,57-22,84$ & $0,001-0,29$ \\
\hline
\end{tabular}

* Em cima - Média e desvio padrão (entre parênteses); Embaixo - Amplitude de variação

A Figura 3.32 apresenta os diagramas de dispersão dos nutrientes inorgânicos dissolvidos em função da densidade $\left(\sigma_{t}\right)$. A linha tracejada sobreposta na Figura 3.32 indica o limite isopicnal inferior da ACAS $\left(25,4 \mathrm{~kg} \cdot \mathrm{m}^{-3}\right)$. Pode-se notar uma inflexão a partir da presença da ACAS, com concentrações mais altas de nitrato. Outro máximo relativo de nutrientes pode ser notado em torno de $24,0 \mathrm{~kg} \cdot \mathrm{m}^{-3}$.

Os valores médios de contribuições relativas de cada composto nitrogenado e do nitrogênio total absoluto estão na Tabela 3.27. A contribuição média da amônia foi a mais importante na camada de mistura, com $73 \%$ em superfície, $58 \%$ a $25 \mathrm{~m}$ e $47 \%$ a $50 \mathrm{~m}$. Na base da zona eufótica, as contribuições de nitrato e amônia foram praticamente as mesmas (48,5\% e 47,2\%, respectivamente). A partir daí, em direção ao fundo, temos um aumento gradativo das contribuições de nitrato, com máximo a $200 \mathrm{~m}$ de profundidade (78\%) e uma diminuição das contribuições de amônia com mínimo na mesma profundidade $(21 \%)$. As concentrações de nitrogênio total também aumentaram da base da zona eufótica em direção ao fundo. 

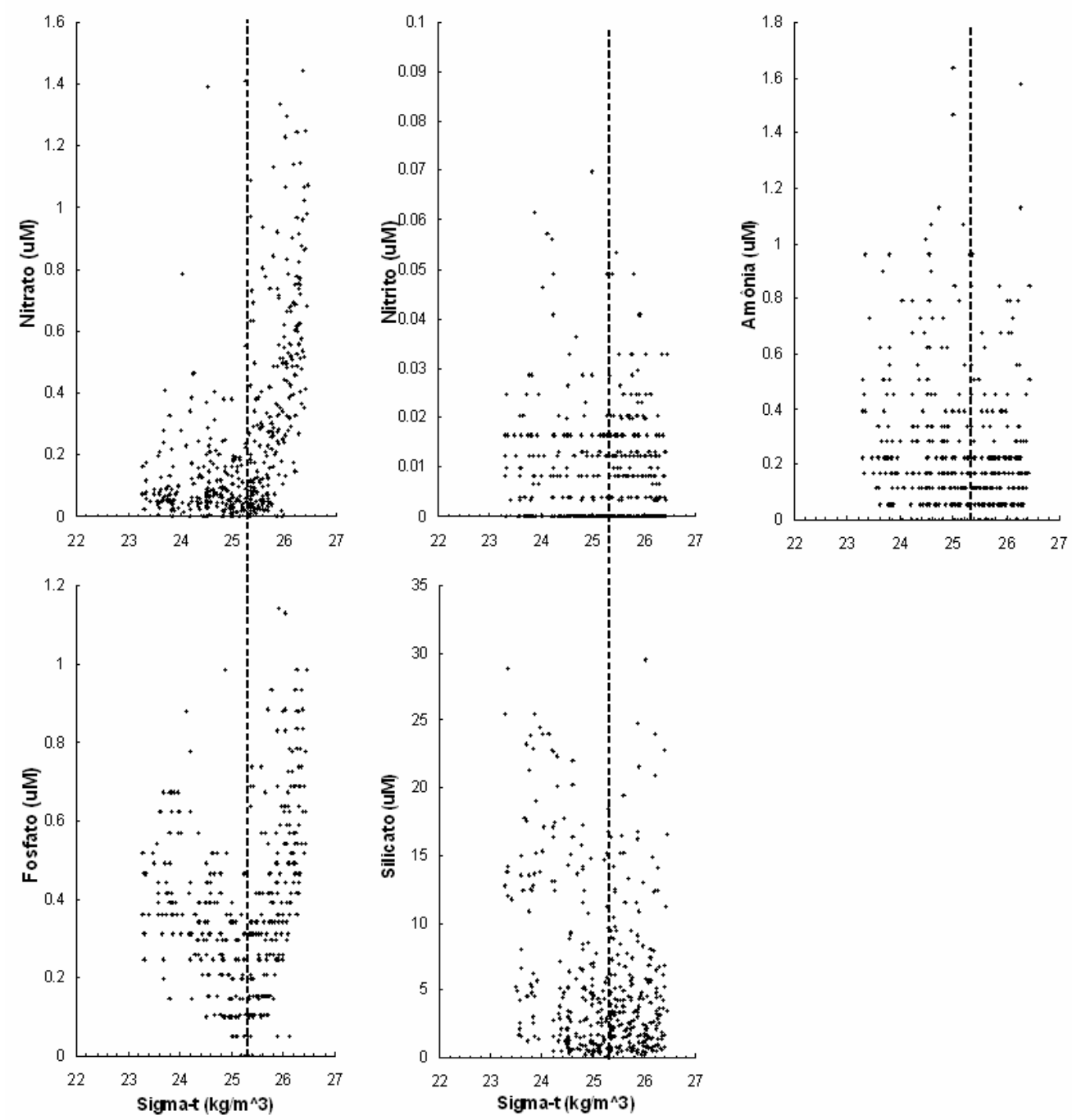

Figura 3.32 - Diagramas de dispersão dos nutrientes inorgânicos dissolvidos $(\mu \mathrm{M})$ em função de $\sigma_{\mathrm{t}}\left(\mathrm{kg} \cdot \mathrm{m}^{-3}\right)$, para o cruzeiro de inverno de 2002 (M4). A linha tracejada indica o limite isopicnal inferior da Água Central do Atlântico Sul.

TABELA 3.27 - MÉDIAS DAS CONCENTRAÇÕES RELATIVAS DOS COMPOSTOS NITROGENADOS DISSOLVIDOS E DA CONCENTRAÇÃO ABSOLUTA DO NITROGÊNIO TOTAL DURANTE O CRUZEIRO DE INVERNO DE 2002 (M4).

\begin{tabular}{c|c|c|c|c}
\hline $\begin{array}{c}\text { Profundidade } \\
(\mathbf{m})\end{array}$ & $\begin{array}{c}\text { Nitrato } \\
\mathbf{\%}\end{array}$ & $\begin{array}{c}\text { Nitrito } \\
\mathbf{\%}\end{array}$ & $\begin{array}{c}\text { Amônia } \\
\mathbf{\%}\end{array}$ & $\begin{array}{c}\text { Nitrogênio } \\
(\boldsymbol{\mu M})\end{array}$ \\
\hline Superfície & $25,62(20,46)$ & $1,54(2,37)$ & $72,84(20,19)$ & $0,43(0,29)$ \\
\hline $\mathbf{2 5}$ & $38,88(28,27)$ & $3,37(6,18)$ & $57,75(30,34)$ & $0,33(0,28)$ \\
\hline $\mathbf{5 0}$ & $48,50(28,75)$ & $4,30(5,32)$ & $47,20(28,43)$ & $0,53(0,42)$ \\
\hline $\mathbf{1 0 0}$ & $59,20(29,15)$ & $2,94(5,48)$ & $37,86(26,74)$ & $0,65(0,48)$ \\
\hline $\mathbf{2 0 0}$ & $78,41(11,74)$ & $0,37(0,46)$ & $21,22(11,99)$ & $0,84(0,26)$ \\
\hline \multicolumn{5}{c}{$*$ desvio padrão entre parênteses. }
\end{tabular}




\subsubsection{Distribuições horizontais de clorofila $a$ e produtividade primária}

\subsubsection{Curvas de luz - fotossíntese}

Na Tabela 3.28 são mostrados os valores médios dos parâmetros fotossintéticos $\left(\mathrm{P}_{\max }{ }^{\mathrm{B}}-\right.$ número de assimilação e $\alpha^{\mathrm{B}}$ - eficiência fotossintética) obtidos com o ajuste de modelos empíricos às amostras de produção primária. $\mathrm{O}$ parâmetro de adaptação $\mathrm{I}_{\mathrm{k}}$ também é mostrado na Tabela 3.28, para os experimentos realizados com amostras de superfície (100\% de irradiância) e da base da zona eufótica (1\% de irradiância).

\section{TABELA 3.28 - PARÂMETROS FOTOSSINTÉTICOS DAS CURVAS DE LUZ -} FOTOSSÍNTESE DURANTE O CRUZEIRO DE INVERNO DE 2002

(M4).

\begin{tabular}{c|c|c|c|c|c|c}
\hline \multirow{2}{*}{ M4 } & \multicolumn{3}{|c|}{$\mathbf{1 0 0 \%}$} & \multicolumn{3}{c}{$\mathbf{1 \%}$} \\
\cline { 2 - 7 } & $\mathbf{P}_{\max } \mathbf{B}$ & $\alpha^{\mathbf{B}}$ & $\mathbf{I}_{\mathbf{k}}$ & $\mathbf{P}_{\mathbf{m a x}} \mathbf{B}^{\mathbf{B}}$ & $\alpha^{\mathbf{B}}$ & $\mathbf{I}_{\mathbf{k}}$ \\
\hline Média & 6,44 & 0,05 & 58,58 & 2,98 & 0,16 & 13,08 \\
\hline Máximo & 16,62 & 0,31 & 312,58 & 13,80 & 0,44 & 46,49 \\
\hline Mínimo & 1,57 & 0,001 & 3,16 & 0,82 & 0,02 & 0,79 \\
\hline Desvio Padrão & 6,25 & 0,07 & 63,81 & 3,28 & 0,13 & 13,13 \\
\hline $\begin{array}{c}\text { Coeficiente } \\
\text { Variação }\end{array}$ & $103 \%$ & $71 \%$ & $92 \%$ & $91 \%$ & $133 \%$ & $99 \%$ \\
\hline$* P_{\max }^{B}\left(m g C .\left(m g C l o^{-1}\right) \cdot h^{-1}\right), \alpha^{B}\left(m g C .\left(m g C l o^{-1}\right) \cdot h^{-1} \cdot\left(W \cdot m^{-2}\right)^{-1}\right), I_{k}\left(W \cdot m^{-2}\right)$
\end{tabular}

$\mathrm{O}$ parâmetro $\mathrm{P}_{\max }{ }^{\mathrm{B}}$ das populações da camada superficial variou de $1,57 \mathrm{a}$ 16,62 mgC. $\left(\mathrm{mgClo}^{-1}\right) \cdot \mathrm{h}^{-1}$, com valor médio igual a $6,44 \mathrm{mgC} \cdot\left(\mathrm{mgClo}^{-1}\right) \cdot \mathrm{h}^{-1}$. Para as populações localizadas na base da zona eufótica, o parâmetro $\mathrm{P}_{\max }{ }^{\mathrm{B}}$ variou de 0,82 a 13,80 com valor médio igual $2,98 \mathrm{mgC} \cdot\left(\mathrm{mgClo}^{-1}\right) \cdot \mathrm{h}^{-1}$, respectivamente. Em ambas as profundidades, os desvios padrão foram altos em relação às médias. De modo geral, os números de assimilação médios encontrados durante o inverno de 2002 foram mais altos do que os obtidos no inverno do ano anterior (Tabela 3.11) e da mesma ordem que os estimados para o verão do mesmo ano (Tabela 3.21). A eficiência fotossintética $\left(\alpha^{\mathrm{B}}\right)$ ao nível de $100 \%$ variou de 0,001 a $0,31 \mathrm{mgC} \cdot\left(\mathrm{mgClo}^{-1}\right) \cdot \mathrm{h}^{-1}\left(\mathrm{~W} \cdot \mathrm{m}^{-2}\right)^{-1}$, com média igual a $0,05 \mathrm{mgC} \cdot\left(\mathrm{mgClo}^{-1}\right) \cdot \mathrm{h}^{-1} \cdot\left(\mathrm{W} \cdot \mathrm{m}^{-2}\right)^{-1} \cdot \mathrm{O} \alpha^{\mathrm{B}}$ das amostras coletadas na base da zona eufótica apresentou valor médio igual $0,16 \mathrm{mgC} \cdot\left(\mathrm{mgClo}^{-1}\right) \cdot \mathrm{h}^{-1} \cdot\left(\mathrm{W}^{-\mathrm{m}^{-2}}\right)^{-1} \mathrm{e}$ uma amplitude de variação entre 0,02 e $0,44 \mathrm{mgC} \cdot\left(\mathrm{mgClo}^{-1}\right) \cdot \mathrm{h}^{-1} \cdot\left(\mathrm{W} \cdot \mathrm{m}^{-2}\right)^{-1}$. Os valores médios de $\mathrm{I}_{\mathrm{k}}$ foram iguais a 58,58 e $13,08 \mathrm{~W} \cdot \mathrm{m}^{-2}$ na superfície $(100 \%)$ e no fundo (1\%), 
respectivamente. Esses valores são mais altos do que os encontrados no inverno de 2001 (Tabela 3.11).

As distribuições horizontais de clorofila $a$ superficial e clorofila $a$ integrada na zona eufótica podem ser apreciadas na Figura 3.33 (lado esquerdo). Um máximo de até 2,4 $\mathrm{mg} \cdot \mathrm{m}^{-3}$ em superfície é observado na área próxima à Ilha de São Sebastião. Esta feição está associada à penetração de águas vindas de sul pela costa também observada nos campos superficiais de temperatura, salinidade e densidade. Concentrações de clorofila $a$ maiores que $1,0 \mathrm{mg} \cdot \mathrm{m}^{-3}$ são encontradas em frente às Baías da Ilha Grande e da Guanabara. Próximo ao Cabo São Tomé também se observa uma mancha de clorofila superficial com concentrações de até $1,0 \mathrm{mg} \cdot \mathrm{m}^{-3}$.

Por outro lado, a biomassa fitoplanctônica integrada na zona eufótica exibe duas manchas delimitadas pela concentração de $25 \mathrm{mg} \cdot \mathrm{m}^{-2}$. A maior destas, com cerca de 170 km de extensão, e $100 \mathrm{~km}$ de largura máxima está localizada em torno de Cabo Frio e apresenta valores acima de 30,0 e 35,0 mg. $\mathrm{m}^{-2}$ (a SO). A outra mancha, com cerca de $110 \mathrm{~km}$ de diâmetro localiza-se sobre a quebra de plataforma a sul da Baía da Ilha Grande.

À direita, na Figura 3.33, são mostradas as distribuições horizontais da produtividade primária integrada na zona eufótica para as amostras coletadas em superfície $(100 \%$, em cima) e na base da zona eufótica (1\%, embaixo). A produtividade primária integrada referente ao nível de $100 \%$ de irradiância apresenta manchas com altos valores $(>1,8$ $\left.\mathrm{gC} \cdot \mathrm{m}^{-2} \cdot \mathrm{d}^{-1}\right)$ coincidindo com as manchas de biomassa superficial observadas próximas à Ilha de São Sebastião e em frente à baía da Ilha Grande. A sul da Baía de Guanabara e ao largo, pode-se observar um máximo relativo com valores acima de $1,0 \mathrm{gC} \cdot \mathrm{m}^{-2} \cdot \mathrm{d}^{-1}$. Valores de até $1,0 \mathrm{gC} \cdot \mathrm{m}^{-2} \cdot \mathrm{d}^{-1}$ também são encontrados próximo à costa, entre Cabo Frio e São Tomé. 


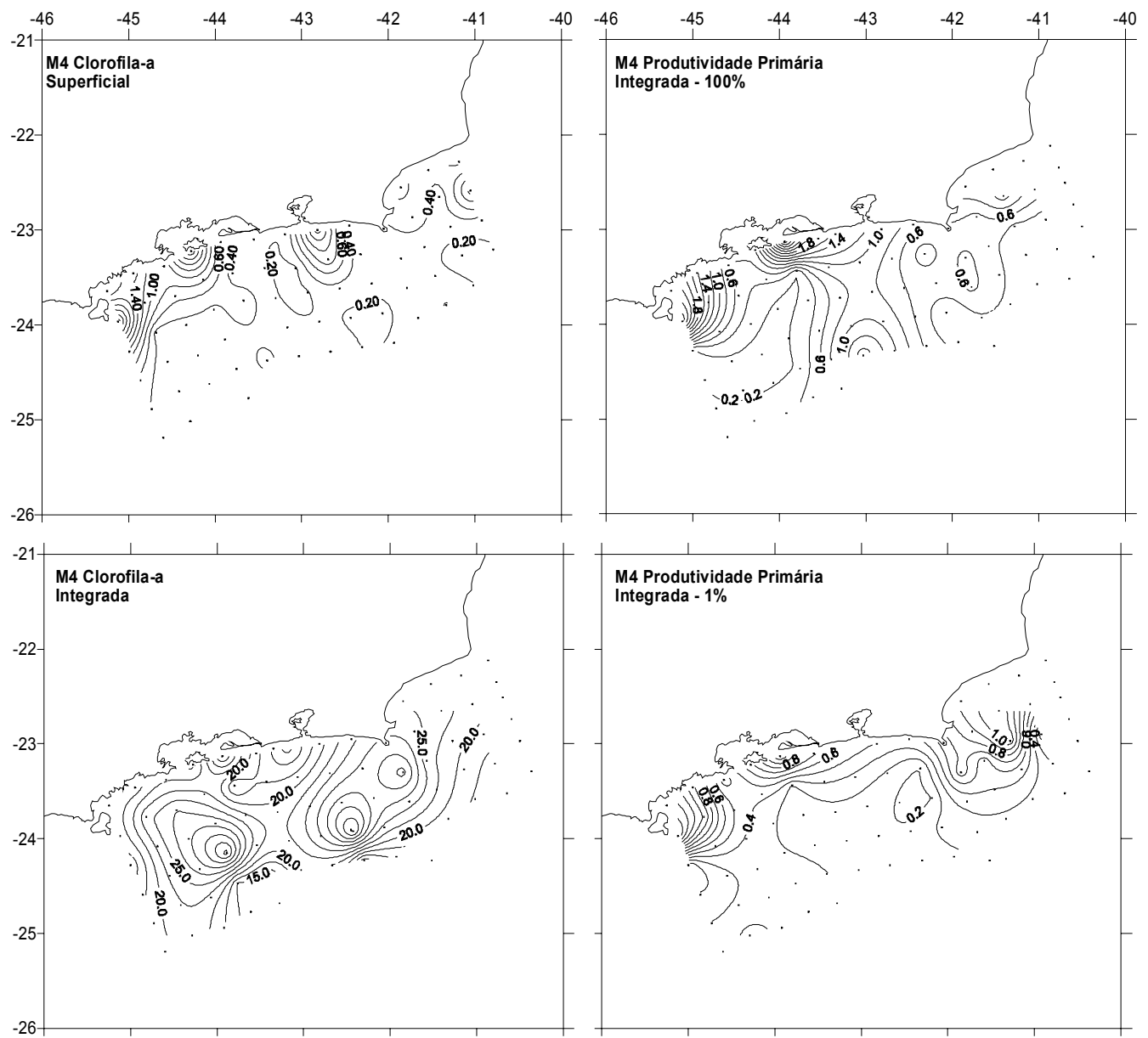

Figura 3.33 - Distribuições horizontais de clorofila $a$ superficial $\left(\mathrm{mg} . \mathrm{m}^{-3}\right)$ e integrada na zona eufótica $\left(\mathrm{mg} \cdot \mathrm{m}^{-2}\right)$, produtividade primária integrada na zona eufótica $\left(\mathrm{gC} \cdot \mathrm{m}^{-2} \cdot \mathrm{d}^{-1}\right)$ referente aos níveis de $100 \%$ e $1 \%$ de irradiância (M4).

A produtividade primária integrada na zona eufótica referente ao nível de $1 \%$ de irradiância, exibe uma distribuição espacial similar à observada para as amostras de superfície. Porém, as magnitudes são menores em torno da Ilha de São Sebastião (máximo de 1,8 gC.m $\mathrm{m}^{-2} \cdot \mathrm{d}^{-1}$ ), e em frente á Baía da Ilha Grande (até 1,0 gC.m $\mathrm{m}^{-2} \cdot \mathrm{d}^{-1}$ ).

A Tabela 3.29 apresenta os valores médios, amplitude de variação, desvio padrão e coeficiente de variação da clorofila- $a$ e produção primária integradas na zona eufótica $\left(\mathrm{mg} . \mathrm{m}^{-2}\right.$ e $\mathrm{gC} \cdot \mathrm{m}^{-2} \cdot \mathrm{d}^{-1}$, respectivamente), para as regiões de plataforma e talude, referentes ao cruzeiro de inverno de 2002 (M4). 
TABELA 3.29 - CLOROFILA E PRODUÇÃO PRIMÁRIA INTEGRADAS NA ZONA EUFÓTICA SOBRE A PLATAFORMA E O TALUDE DURANTE O CRUZEIRO DE INVERNO DE 2002 (M4).

\begin{tabular}{c|c|c|c|c|c|c}
\hline \multirow{2}{*}{ M4 } & \multicolumn{3}{|c|}{ Plataforma } & \multicolumn{3}{c}{ Talude } \\
\cline { 2 - 7 } & $\mathbf{C}_{\mathbf{E U}}$ & $\mathbf{P P}_{\mathbf{E U 1 0 0}}$ & $\mathbf{P P}_{\text {EU1 }}$ & $\mathbf{C}_{\mathbf{E U}}$ & $\mathbf{P P}_{\mathbf{E U 1 0 0}}$ & $\mathbf{P P}_{\text {EU1 }}$ \\
\hline Média & 22,19 & 0,81 & 0,68 & 20,32 & 0,52 & 0,32 \\
\hline Máximo & 33,50 & 2,75 & 1,41 & 28,62 & 1,50 & 0,43 \\
\hline Mínimo & 13,06 & 0,16 & 0,11 & 10,64 & 0,17 & 0,20 \\
\hline Desvio padrão & 6,05 & 0,80 & 0,42 & 6,14 & 0,43 & 0,09 \\
\hline $\begin{array}{c}\text { Coeficiente de } \\
\text { variação }\end{array}$ & $27 \%$ & $98 \%$ & $62 \%$ & $30 \%$ & $83 \%$ & $28 \%$ \\
\hline
\end{tabular}

$* \overline{\mathrm{C}_{\mathrm{EU}}-\text { Clorofila integrada na zona eufótica }\left(m g . \mathrm{m}^{-2}\right) ; P P_{E U 100}-\text { Produção primária integrada }}$ na zona eufótica das amostras de $100 \%\left(\mathrm{gC} \cdot \mathrm{m}^{-2} . \mathrm{d}^{-1}\right) ; P P_{E U 1}$ - Produção primária integrada na zona eufótica das amostras de $1 \%\left(g C . m^{-2} . d^{-1}\right)$.

No inverno de 2002, a clorofila- $a$ integrada sobre a plataforma apresentou um valor médio $\left(22,19 \pm 6,05 \mathrm{mg} \cdot \mathrm{m}^{-2}\right)$ apenas $10 \%$ maior ao calculado para a região de talude $\left(20,32 \pm 6,14 \mathrm{mg} \cdot \mathrm{m}^{-2}\right)$. A estimativa média da produção primária integrada para as amostras referentes a $100 \%$ de irradiância, foi cerca de $45 \%$ maior sobre a plataforma $\left(0,81 \pm 0,80 \mathrm{gC} \cdot \mathrm{m}^{-2} \cdot \mathrm{d}^{-1}\right)$ do que sobre o talude $\left(0,52 \pm 0,18 \mathrm{gC} \cdot \mathrm{m}^{-2} \cdot \mathrm{d}^{-1}\right) . \mathrm{O}$ mesmo comportamento foi observado em relação às amostras de $1 \%$ de irradiância $\left(0,68 \pm 0,42 \mathrm{gC} \cdot \mathrm{m}^{-2} \cdot \mathrm{d}^{-1}\right.$ e $0,32 \pm 0,09 \mathrm{gC} \cdot \mathrm{m}^{-2} \cdot \mathrm{d}^{-1}$, para a plataforma e talude, respectivamente). Os valores de produção integrada referentes às amostras de superfície foram maiores do que os estimados para as amostras do nível mais profundo. Em comparação ao inverno de 2001 (Tabela 3.13), os valores calculados são similares sobre a região de plataforma. Porém, sobre o talude, o comportamento é diferente, principalmente com relação às produções integradas.

\subsubsection{Imagens de Temperatura da Superfície do Mar}

A Figura 3.34 apresenta as imagens de temperatura da superfície do mar processadas nos dias 25 de julho, 7, 8 e 12 de agosto de 2002. A imagem do dia 25/07/2002, anterior ao início do cruzeiro de inverno de 2002, exibe toda a área de estudo com contrastes termais superficiais interessantes. As águas frias vindas de sul pela costa atingem Santos com temperaturas de $18.0^{\circ} \mathrm{C}$. Um pequeno filamento desta feição pode ser visto na Ilha de São Sebastião, com valores em torno de $19,3{ }^{\circ} \mathrm{C}$. As águas da $\mathrm{CB}$ apresentam temperaturas acima de $24,0^{\circ} \mathrm{C}$. Dois meandramentos ciclônicos da $\mathrm{CB}$, um a sul de 
Cabo Frio e outro a sul da Baía de Guanabara, aparecem centrados em torno de $24,1^{\circ} \mathrm{S}$ $41,4^{\circ} \mathrm{W}$ e $25,0^{\circ} \mathrm{S}-42,6^{\circ} \mathrm{W}$, respectivamente. Ambos possuem extensões médias de cerca de $85 \mathrm{~km}$. Outro meandramento ciclônico da CB pode ser notado ao largo de São Tomé, com manchas de águas relativamente frias $\left(\mathrm{T}<21,5^{\circ} \mathrm{C}\right)$ sobre a quebra de plataforma. Em torno do Cabo São Tomé, águas com TSM $<21,0{ }^{\circ} \mathrm{C}$ dominam a plataforma. Em Cabo Frio, ocorre um pequeno núcleo de águas frias $\left(\mathrm{T}<19,0{ }^{\circ} \mathrm{C}\right.$ ) desprendido da costa. Entre Cabo Frio e Baía de Guanabara ocorre outro núcleo de águas frias $\left(\mathrm{T}<19.0^{\circ} \mathrm{C}\right)$, também desprendido da costa.

Nas imagens seguintes, as águas frias vindas de sul, com temperaturas abaixo de $18,0^{\circ} \mathrm{C}$ alcançaram a Ilha de São Sebastião. Uma pluma de águas relativamente frias $\left(\mathrm{T}<21,0^{\circ} \mathrm{C}\right)$ quase alcançou Cabo Frio, onde se observou um pequeno núcleo de ressurgência com TSM mínima de $19,0^{\circ} \mathrm{C}$. Os meandramentos ciclônicos da $\mathrm{CB}$ a SE e $\mathrm{SO}$ de Cabo Frio, mostraram-se centrados em torno de $24,6^{\circ} \mathrm{S}-40,9^{\circ} \mathrm{W}$ e $25,6^{\circ} \mathrm{S}-$ $43,2^{\circ} \mathrm{W}$, respectivamente.

A Figura 3.35 mostra as imagens termais orbitais processadas nos dias 13, 19, 20 e 21 de agosto de 2002. As águas vindas de sul alcançaram a Ilha de São Sebastião com temperaturas abaixo de $20,0^{\circ} \mathrm{C}$. Após atingir Cabo Frio em 13/08/2002 com TSM abaixo de $21,0{ }^{\circ} \mathrm{C}$, as águas vindas de sul se retraíram um pouco em 19/08/2002. A pluma de ressurgência observada em Cabo Frio apresentou uma temperatura mínima de $14,0^{\circ} \mathrm{C}$ em seu núcleo e uma extensão de $120 \mathrm{~km}$ na direção O-SO no dia 21/08/2002 (considerando a isoterma de $20,0{ }^{\circ} \mathrm{C}$ como seu limite). 

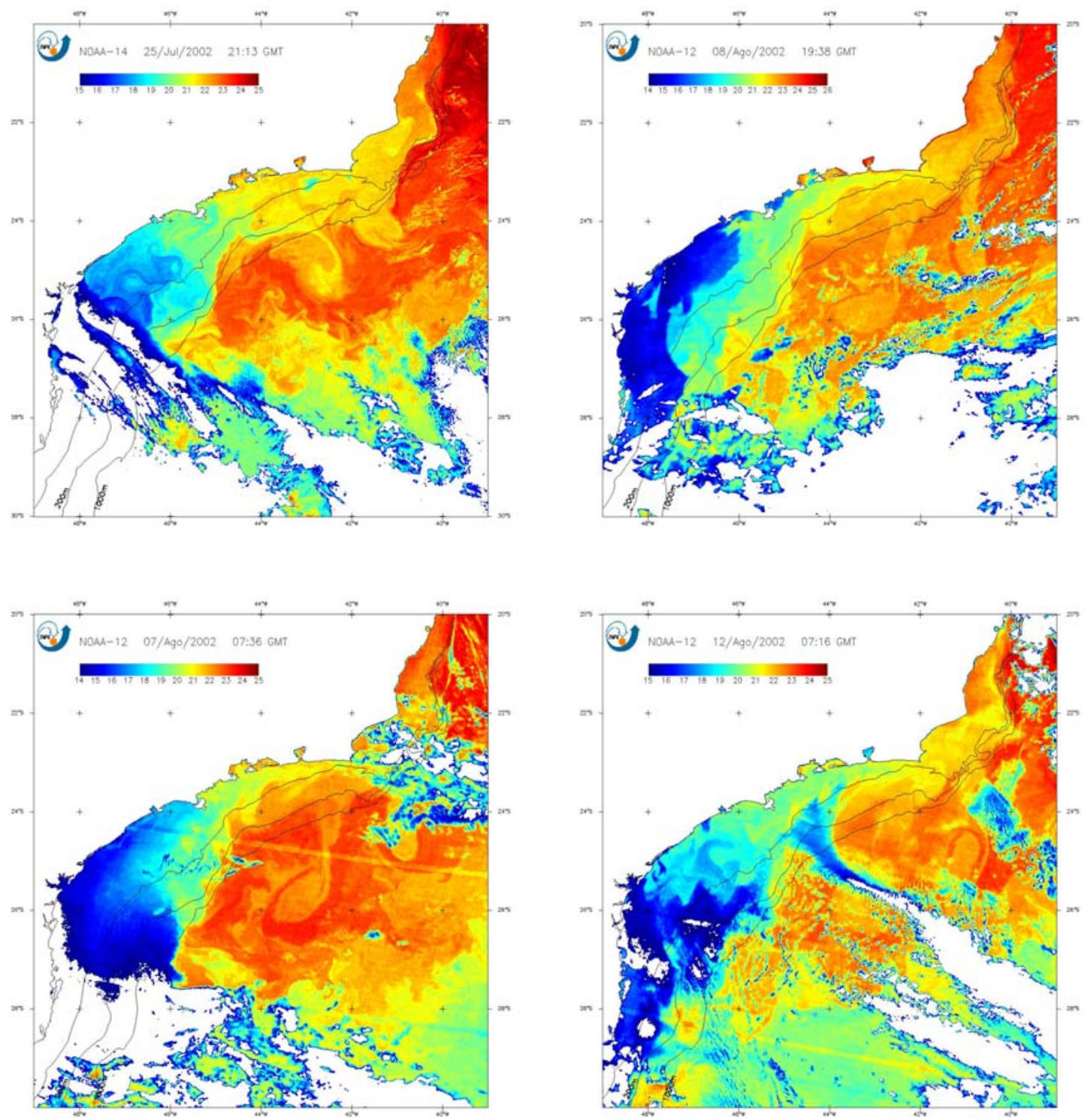

Figura 3.34 - Imagens da temperatura da superfície do mar referentes aos dias 25 de julho (esquerda em cima), 7 (esquerda embaixo), 8 (direita em cima) e 12 (direita embaixo) de agosto de 2002. Isóbatas de 100, 200 e $1.000 \mathrm{~m}$ em preto.

O meandramento ciclônico ao largo de São Tomé mostrou águas relativamente frias $\left(21,0^{\circ} \mathrm{C}\right)$ na sua borda setentrional em contato com a CB. Entre Vitória e São Tomé, uma pluma de águas relativamente frias, com temperaturas abaixo de $20,5^{\circ} \mathrm{C}$, pode ser notada sobre a plataforma continental, desprendida da costa. As águas da CB exibiram $\mathrm{TSM}>23,0^{\circ} \mathrm{C}$. 

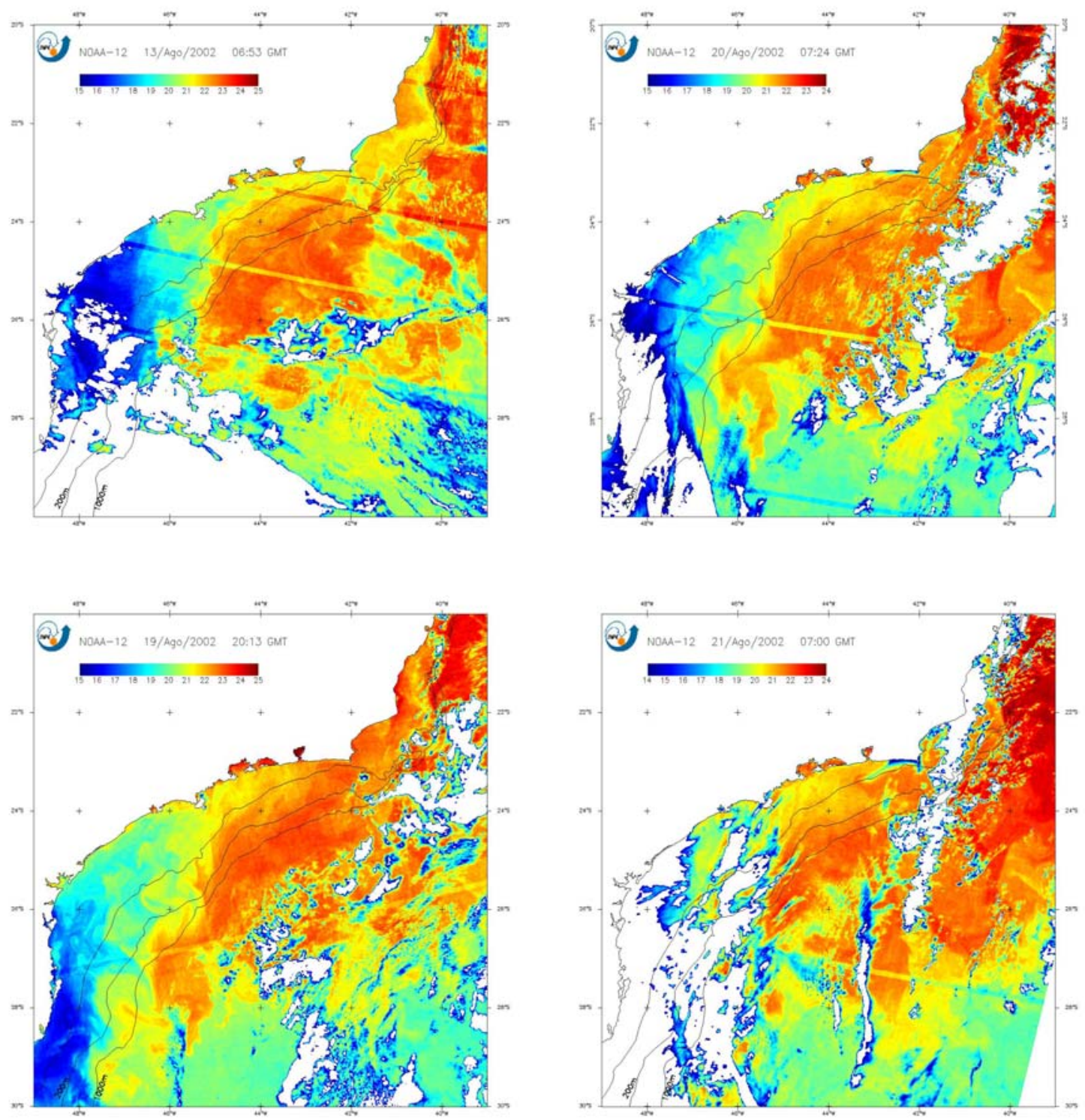

Figura 3.35 - Imagens da temperatura da superfície do mar referentes aos dias 13 (esquerda em cima), 19 (esquerda embaixo), 20 (direita em cima) e 21 (direita embaixo) de agosto de 2002. Isóbatas de 100, 200 e $1.000 \mathrm{~m}$ em preto.

A Figura 3.36 apresenta as imagens termais dos dias 24, 25, 28 e 29 de julho de 2002, em período posterior ao cruzeiro M4. Interessante notar nesta seqüência de imagens o desenvolvimento da pluma de ressurgência em Cabo Frio. 

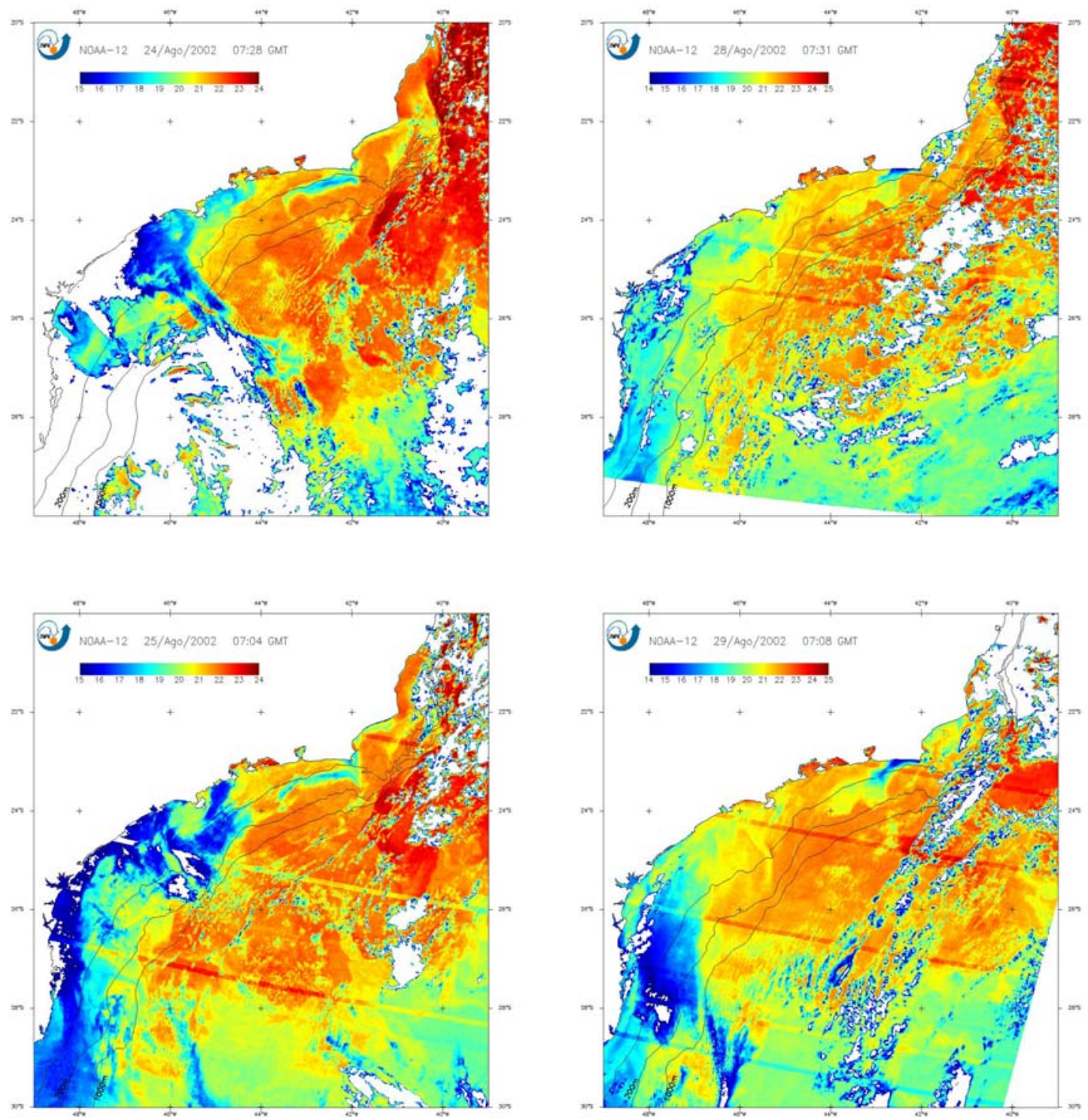

Figura 3.36 - Imagens da temperatura da superfície do mar referentes aos dias 24

(esquerda em cima), 25 (esquerda embaixo), 28 (direita em cima) e 29 (direita embaixo) de agosto de 2002. Isóbatas de 100, 200 e $1.000 \mathrm{~m}$ em preto.

$\mathrm{Na}$ imagem de $24 / 08 / 2002$, a pluma de águas frias, delimitada pela isoterma de $20,0{ }^{\circ} \mathrm{C}$, atingiu $160 \mathrm{~km}$ de extensão na direção O-SO. A temperatura mínima observada nesta pluma foi de $17,2^{\circ} \mathrm{C}$. Outros pequenos núcleos secundários foram encontrados colados à costa em Cabo Frio e a sul de Búzios $\left(\mathrm{T}<19,0^{\circ} \mathrm{C}\right)$. Na imagem do dia 25/08/2002, os núcleos mais costeiros de Cabo Frio e Búzios se desenvolveram, quase se unindo à pluma fria que se estendeu na direção O-SO. Uma pequena mancha com temperaturas 
abaixo de $19,5^{\circ} \mathrm{C}$ também pode ser notada a sul de São Tomé. Já na imagem de 28/08/2002, a pluma de águas frias apareceu colada à costa, estendendo-se na direção O-SO, com cerca de $100 \mathrm{~km}$ de extensão e TSM mínima de $16,0^{\circ} \mathrm{C}$. Na última imagem desta série (29/08/2002), a pluma de águas frias em Cabo Frio estendeu-se pela costa na direção O-SO e delimitada pela isoterma de $20,0{ }^{\circ} \mathrm{C}$, atingiu $120 \mathrm{~km}$ de extensão. A TSM mínima observada foi de $15,0{ }^{\circ} \mathrm{C}$.

\subsubsection{Imagens de Concentração de Clorofila da Superfície do Mar}

A Figura 3.37 apresenta as imagens SeaWiFS de concentração de clorofila da superfície do mar referentes aos dias 29 de julho, 8, 13 e 14 de agosto de 2002. A imagem de 29/07/2002, anterior ao cruzeiro M4, exibe as águas vindas de sul sobre a plataforma, com concentrações de biomassa fitoplanctônica acima de 2,0 mg. $\mathrm{m}^{-3}$. Contrapondo-se a este fluxo, observa-se a CB fluindo na direção NE-SO, com águas pobres em clorofila $\left(<0,2 \mathrm{mg} \cdot \mathrm{m}^{-3}\right)$. Entre esses dois fluxos, configuram-se vórtices ciclônicos e anticiclônicos que correspondem aos vales e cristas dos meandros da CB. Observa-se um vórtice ciclônico em Santa Marta, centrado em torno de $28,8^{\circ} \mathrm{S}-47,6^{\circ} \mathrm{W}$ com diâmetro médio igual a $75 \mathrm{~km}$. Em Cabo Frio, manchas de biomassa fitoplanctônica apresentam concentrações acima de $2,0 \mathrm{mg} \cdot \mathrm{m}^{-3}$.

Nas imagens seguintes, foram observadas manchas de CSM acima de 2,0 mg. $\mathrm{m}^{-3}$ a sul da Ilha de São Sebastião. Em São Tomé, manchas de alta CSM apresentaram valores acima de 2,5 mg.m ${ }^{-3}$. Uma pluma com alta concentração de clorofila também foi notada a sul de Vitória, com cerca de $80 \mathrm{~km}$ de extensão. O vórtice de São Tomé foi observado em torno de $22,4^{\circ} \mathrm{S}-40,3^{\circ} \mathrm{W}$ e com diâmetro médio igual a $75 \mathrm{~km}$. Águas relativamente ricas de plataforma $\left(2,0 \mathrm{mg} . \mathrm{m}^{-3}\right)$ foram advectadas para o interior deste vórtice. Outro vórtice ciclônico a SE de Cabo Frio, também foi observado aproximadamente em $25,0^{\circ} \mathrm{S}-40,8^{\circ} \mathrm{W}$ e com diâmetro em torno de $95 \mathrm{~km}$. As concentrações de clorofila em seu núcleo apresentaram-se acima de $0,5 \mathrm{mg} \cdot \mathrm{m}^{-3}$. A plataforma continental entre São Tomé e Cabo Frio apresentou-se intercalada de manchas com alta e baixa biomassa fitoplanctônica, demonstrando o padrão espacial complexo dessas estruturas. 

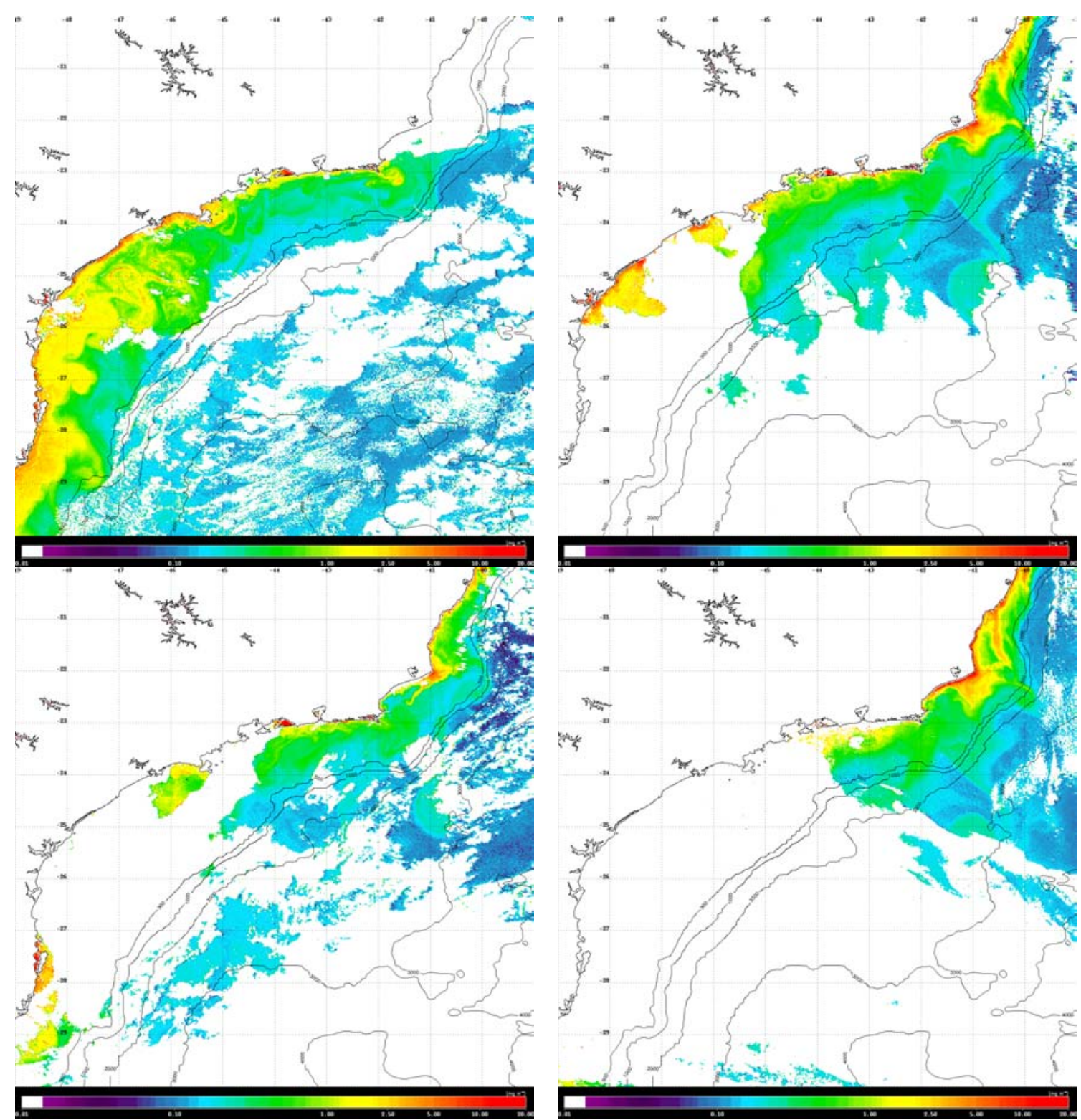

Figura 3.37 - Imagens da concentração de clorofila da superfície do mar referentes aos dias 29 de julho (esquerda em cima), 8 (esquerda embaixo), 13 (direita em cima) e 14 (direita embaixo) de agosto de 2002. Isóbatas de 500, 1.000, $2.000,3.000$ e $4.000 \mathrm{~m}$ em preto. Tabela de cores em escala logarítmica.

A Figura 3.38 apresenta as imagens SeaWiFS referentes aos dias 17, 19, 20 e 21 de agosto de 2003. Diferentes feições oceanográficas podem ser destacadas desta série de imagens. Altas concentrações de biomassa fitoplanctônica $\left(>3,0 \mathrm{mg} \cdot \mathrm{m}^{-3}\right)$ são encontradas no Cabo de Santa Marta onde também ocorre ressurgência costeira. As águas mais frias e relativamente mais ricas em biomassa vindas de sul pela plataforma, alcançam a Ilha de São Sebastião onde são observadas concentrações de clorofila acima 
de 2,0 mg.m ${ }^{-3}$. As águas oligotróficas da CB aparecem ao largo, fluindo para SO. Na frente formada entre as águas pobres da $\mathrm{CB}$ e as águas sobre a plataforma, surgem meandros ciclônicos e anticiclônicos, cabendo destacar nessas imagens, um vórtice ciclônico em frente a Cananéia, em torno de $25,5^{\circ} \mathrm{S}-46,2^{\circ} \mathrm{W}$. Outros meandramentos da CB também são notados a SE e a SO de Cabo Frio. O vórtice ciclônico em São Tomé aparece nas imagens, com centro em torno de $22,5^{\circ} \mathrm{S}-40,2^{\circ} \mathrm{W}$ e diâmetro médio de $60 \mathrm{~km}$. Águas de plataforma mais ricas parecem ser advectadas para o interior deste vórtice. Outro vórtice ciclônico no interior da $\mathrm{CB}$, em águas profundas, aparece centrado em torno de $25,7^{\circ} \mathrm{S}-41,5^{\circ} \mathrm{W}$ e com diâmetro médio igual a $60 \mathrm{~km}$. Ainda que as concentrações de clorofila em seu núcleo sejam de até $0,5 \mathrm{mg} \cdot \mathrm{m}^{-3}$, o contraste com as águas oligotróficas da $\mathrm{CB}$ ao seu redor é notável nas imagens. Manchas costeiras com concentrações de biomassa fitoplanctônica acima de $2,0 \mathrm{mg} \cdot \mathrm{m}^{-3}$ são observadas em diferentes pontos da costa, como em São Tomé, Cabo Frio, Baía de Guanabara e Baía de Sepetiba.

A Figura 3.39 a seguir, apresenta as imagens SeaWiFS dos dias 22, 24, 25 e 26 de agosto de 2002. Apesar deste período ser posterior à realização do cruzeiro M4, julgouse interessante observar o desenvolvimento de uma pluma de ressurgência em Cabo Frio iniciada durante o cruzeiro de inverno, através de imagens de satélite da cor do oceano.

Uma pequena mancha de biomassa fitoplanctônica foi observada na região costeira a leste da Baía de Guanabara, em 17/08/2002. Nas imagens que se seguiram, foi possível acompanhar o incremento nas concentrações de clorofila associado à mancha, a migração espacial da mesma bem como o aumento de sua extensão. $\mathrm{Na}$ imagem de 22/08/2002, é possível observar uma mancha com concentrações de clorofila acima de 2,0 mg.m $\mathrm{m}^{-3}$ estendendo-se cerca de $100 \mathrm{~km}$ na direção SO, a partir de Saquarema. Na imagem do dia 24/08/2002, a mancha de biomassa fitoplanctônica delimitada pela isolinha de 2,0 mg.m $\mathrm{m}^{-3}$ e estendendo-se para O-SO a partir de Cabo Frio, apresenta uma extensão de 160 km. Nas imagens seguintes, de 25 e 26/08/2002, ocorre uma regressão progressiva desta mancha de clorofila. Cabe mencionar a presença do vórtice ciclônico a SE de São Tomé e uma mancha costeira com alta biomassa fitoplanctônica $\left(>2,5 \mathrm{mg} \cdot \mathrm{m}^{-3}\right)$ persistente em torno deste mesmo Cabo. 


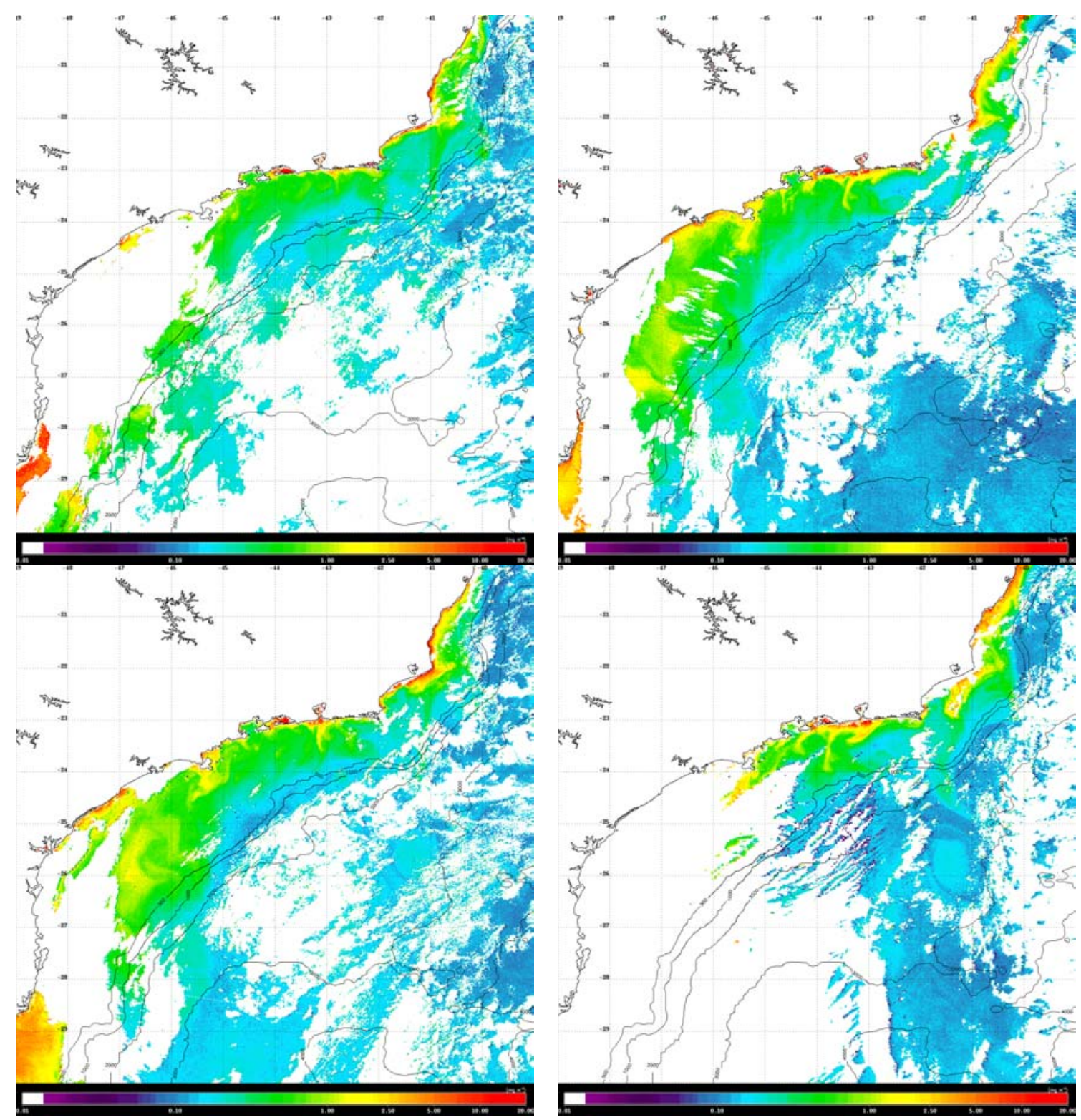

Figura 3.38 - Imagens da concentração de clorofila da superfície do mar referentes aos dias 17 (esquerda em cima), 19 (esquerda embaixo), 20 (direita em cima) e 21 (direita embaixo) de agosto de 2002. Isóbatas de 500, 1.000, 2.000, 3.000 e $4.000 \mathrm{~m}$ em preto. Tabela de cores em escala logarítmica. 

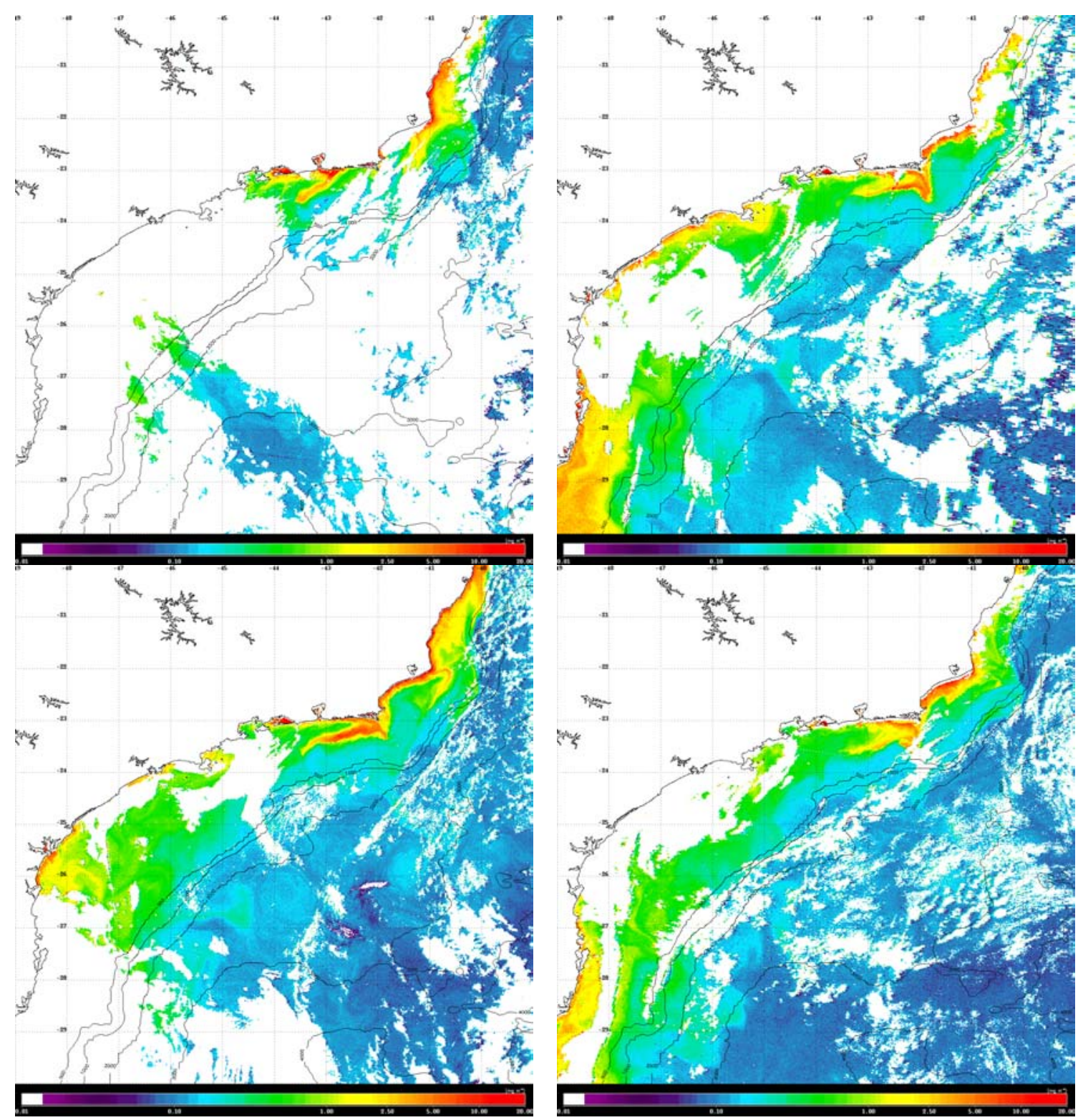

Figura 3.39 - Imagens da concentração de clorofila da superfície do mar referentes aos dias 22 (esquerda em cima), 24 (esquerda embaixo), 25 (direita em cima) e 26 (direita embaixo) de agosto de 2002. Isóbatas de 500, 1.000, 2.000, $3.000 \mathrm{e}$ $4.000 \mathrm{~m}$ em preto. Tabela de cores em escala logarítmica.

\subsubsection{Produção primária por satélite - Modelo Bedford (BPM1)}

Durante o cruzeiro de mesoescala de inverno de 2002 foram realizados 22 experimentos de produção primária in situ simulado. Com a aplicação do modelo BPM1, foi possível obter 18 estimativas para a produção primária diária integrada na coluna d'água, considerando as amostras de $100 \%$ de irradiância (12 sobre a plataforma e 6 sobre o talude) e 6 estimativas para as amostras mais profundas (4 sobre a plataforma e duas 
sobre o talude). Como mencionado anteriormente, toda vez que $I_{*}^{m}>20$, a produção é considerada igual a zero. A Tabela 3.30 apresenta os valores médios, amplitudes de variação, desvios padrão e $\mathrm{n}^{0}$ de observações das produções integradas na zona eufótica $\left(\mathrm{gC} \cdot \mathrm{m}^{-2} \cdot \mathrm{d}^{-1}\right)$ calculadas com o modelo BPM1, para os domínios de plataforma e talude, em relação aos níveis de $100 \%$ e 1\%, durante o cruzeiro M4. São também mostrados os valores integrados na primeira profundidade óptica e na camada de mistura.

TABELA 3.30 - PRODUÇÕES PRIMÁRIAS INTEGRADAS NA ZONA EUFÓTICA, PRIMEIRA PROFUNDIDADE ÓPTICA E CAMADA DE MISTURA PELO MODELO BPM1 (M4)

\begin{tabular}{|c|c|c|c|c|c|c|c|c|c|c|c|c|}
\hline \multirow{3}{*}{ M4 } & \multicolumn{6}{|c|}{ Plataforma } & \multicolumn{6}{|c|}{ Talude } \\
\hline & \multicolumn{3}{|c|}{ BPM1 $_{100 \%}$} & \multicolumn{3}{|c|}{ BPM1 $_{1 \%}$} & \multicolumn{3}{|c|}{ BPM1 $_{100 \%}$} & \multicolumn{3}{|c|}{ BPM1 $_{1 \%}$} \\
\hline & $\mathbf{E U}$ & OP & $\mathbf{C M}$ & $\mathbf{E U}$ & OP & $\mathbf{C M}$ & $\mathbf{E U}$ & OP & $\mathrm{CM}$ & $\mathbf{E U}$ & OP & $\mathbf{C M}$ \\
\hline Média & 0,88 & 0,38 & 0,87 & 1,07 & 0,40 & 1,09 & 0,26 & 0,11 & 0,25 & 0,14 & 0,07 & 0,15 \\
\hline Máximo & 4,85 & 2,26 & 4,95 & 1,53 & 0,55 & 1,52 & 0,57 & 0,21 & 0,59 & 0,22 & 0,12 & 0,23 \\
\hline Mínimo & 0,15 & 0,06 & 0,15 & 0,11 & 0,05 & 0,12 & 0,08 & 0,04 & 0,08 & 0,06 & 0,02 & 0,06 \\
\hline dp & 1,20 & 0,59 & 1,32 & 0,58 & 0,21 & 0,59 & 0,20 & 0,07 & 0,20 & 0,11 & 0,06 & 0,11 \\
\hline cv \% & 146 & 155 & 152 & 54 & 51 & 54 & 77 & 66 & 80 & 77 & 93 & 78 \\
\hline $\mathbf{n}$ & 12 & 12 & 12 & 4 & 4 & 4 & 6 & 6 & 6 & 2 & 2 & 2 \\
\hline
\end{tabular}

* $\overline{\text { EU-zona eufótica; } O P \text { - primeira profundidade óptica; } C M \text { - camada de mistura; unidades }}$ $\left(g C \cdot m^{-2} \cdot d^{-1}\right) ; d p$ - desvio padrão; cv-coeficiente variação(\%).

As produções primárias integradas na zona eufótica com o modelo BPM1 foram muito similares às estimadas para a camada de mistura (ver Tabela 3.30), tanto no domínio de plataforma como no talude. Cabe mencionar que, durante a realização dos experimentos in situ simulados de produção primária no cruzeiro M4, as profundidades médias da termoclina e da base da zona eufótica, no domínio de plataforma, foram iguais a 39,6 m e 39,2 m, respectivamente, e 60,1 m e 62,6 m, respectivamente, na região do talude. De modo geral, os valores obtidos para o domínio de plataforma foram maiores que os encontrados no talude, tanto para experimentos com amostras de superfície, como para as mais profundas. Interessante notar, que os valores médios de $\mathrm{BPM}_{1 \%}$ integrados na zona eufótica e camada de mistura, para o nível de $1 \%$ de irradiância, sobre a plataforma $\left(1,07 \pm 0,58\right.$ e $1,09 \pm 0,59 \mathrm{gC} \cdot \mathrm{m}^{-2} \cdot \mathrm{d}^{-1}$, respectivamente), foram maiores que as estimativas feitas para o nível de $100 \%\left(0,88 \pm 1,20\right.$ e $0,87 \pm 1,32 \mathrm{gC} \cdot \mathrm{m}^{-2} \cdot \mathrm{d}^{-1}$, respectivamente). Com relação ao inverno do ano anterior (M2), temos que a produção 
primária diária integrada na coluna d'água pelo modelo BPM1, foi maior sobre a plataforma em M4 (ver Tabela 3.30) e maior sobre o talude durante M2 (ver Tabela 3.16), para amostras de $100 \%$.

\subsubsection{Produção primária por satélite - Modelo Bedford BPM2}

Com o uso do modelo BPM2 durante o cruzeiro de inverno de 2002, foram obtidas estimativas da produção primária diária integrada na zona eufótica em 13 estações no domínio de plataforma e 8 estações no domínio de talude, tanto para as amostras correspondentes ao nível de $100 \%$ de irradiância como para o nível de 1\%, respectivamente. A Tabela 3.31 apresenta os valores médios, amplitudes de variação e desvios padrão das produções diárias integradas na zona eufótica $\left(\mathrm{gC}^{-\mathrm{m}^{-2}} \cdot \mathrm{d}^{-1}\right)$, calculadas com o modelo BPM2 para os domínios de plataforma e talude, em relação aos níveis de $100 \%$ e $1 \%$ de irradiância, referentes ao cruzeiro M4.

De modo geral, a produção primária diária integrada média na zona eufótica pelo modelo BPM2 durante o cruzeiro M4, foi maior sobre a plataforma que no talude (ver Tabela 3.31). Da mesma forma, os valores médios obtidos para o nível de $100 \%$ foram maiores que os referentes ao nível mais profundo. Em relação o mesmo período do ano anterior (cruzeiro M2, inverno de 2001, ver Tabela 3.17), os valores médios encontrados em M4 foram cerca de $15 \%$ e $60 \%$ menores sobre a plataforma (níveis de 100\% e 1\%, respectivamente), e cerca de $40 \%$ menores sobre o talude (em relação aos níveis $100 \%$ e $1 \%)$.

TABELA 3.31 - PRODUÇÃO PRIMÁRIA INTEGRADA NA ZONA EUFÓTICA CALCULADA COM O MODELO BPM2 (M4).

\begin{tabular}{|c|c|c|c|c|}
\hline \multirow{2}{*}{ M4 } & \multicolumn{2}{|c|}{ Plataforma } & \multicolumn{2}{|c|}{ Talude } \\
\hline & BPM2 $_{100 \%}$ & BPM2 ${ }_{1 \%}$ & BPM2 $2_{100 \%}$ & BPM2 $_{1 \%}$ \\
\hline Média & 0,90 & 0,52 & 0,38 & 0,26 \\
\hline Máximo & 3,87 & 1,92 & 1,10 & 0,38 \\
\hline Mínimo & 0,20 & 0,22 & 0,15 & 0,13 \\
\hline Desvio padrão & 1,02 & 0,51 & 0,30 & 0,07 \\
\hline $\begin{array}{c}\text { Coeficiente } \\
\text { variação }\end{array}$ & 112 & 97 & 78 & 28 \\
\hline $\mathbf{n}$ & 13 & 13 & 8 & 8 \\
\hline
\end{tabular}




\subsubsection{Produção primária por satélite - Modelo VGPM}

Com o uso do modelo VGPM, foram obtidas estimativas da produção primária diária integrada na zona eufótica em 21 de um total de 22 estações onde foram realizados experimentos in situ simulados, durante o cruzeiro M4, sendo que 13 foram sobre a plataforma e 8 no talude. A Tabela 3.32 apresenta os valores médios, amplitudes de variação e desvios padrão das produções integradas na zona eufótica $\left(\mathrm{gC} \cdot \mathrm{m}^{-2} \cdot \mathrm{d}^{-1}\right)$ calculadas com o modelo VGPM, para os domínios de plataforma e talude, em relação aos níveis de $100 \%$ e $1 \%$, durante o cruzeiro M4.

\section{TABELA 3.32 - PRODUÇÃO PRIMÁRIA INTEGRADA NA ZONA EUFÓTICA CALCULADA COM O MODELO VGPM (M4).

\begin{tabular}{|c|c|c|}
\hline M4 & Plataforma & Talude \\
\hline Média & 1,83 & 0,61 \\
\hline Máximo & 4,57 & 0,89 \\
\hline Mínimo & 0,50 & 0,32 \\
\hline Desvio padrão & 1,55 & 0,21 \\
\hline $\begin{array}{c}\text { Coeficiente } \\
\text { variação }\end{array}$ & $85 \%$ & $34 \%$ \\
\hline $\mathbf{n}$ & 13 & 8 \\
\hline
\end{tabular}

O valor médio de VGPM sobre a plataforma $\left(1,83 \pm 1,55 \mathrm{gC} \cdot \mathrm{m}^{-2} \cdot \mathrm{d}^{-1}\right)$ foi maior que no talude $\left(0,61 \pm 0,21 \mathrm{gC} \cdot \mathrm{m}^{-2} \cdot \mathrm{d}^{-1}\right)$ no cruzeiro M4. Em relação ao cruzeiro M2 (inverno de 2001), as diferenças entre os valores médios foram menores que 5\%, tanto para a plataforma como talude (ver Tabela 3.18).

\subsection{Perfil de Biomassa}

Os parâmetros médios dos perfis verticais de biomassa ajustados segundo o modelo Gaussiano, para cada região (plataforma e talude) e cada cruzeiro, são apresentados na Tabela 3.33 a seguir. As estações que apresentaram perfil vertical de biomassa homogêneo não foram consideradas. Da mesma forma, perfis verticais que apresentaram mais de um pico subsuperficial também não entraram nos cálculos. Só foram aproveitados perfis que continham um mínimo de seis profundidades amostradas. Quando possível, os perfis foram interpolados e ajustados com o perfil obtido pelo equipamento PNF. 
De modo geral, a profundidade média do máximo de clorofila subsuperficial esteve mais rasa no domínio de plataforma $(\mathrm{M} 1=39,37 \pm 26,43 \mathrm{~m}$; $\mathrm{M} 2=17,22 \pm 12,94 \mathrm{~m}$; $\mathrm{M} 3=49,68 \pm 31,51 \mathrm{~m} ; \mathrm{M} 4=32,94 \pm 18,76 \mathrm{~m})$ do que no talude $(\mathrm{M} 1=75,79 \pm$ $13,77 \mathrm{~m} ; \mathrm{M} 2=42,74 \pm 16,71 \mathrm{~m} ; \mathrm{M} 3=84,88 \pm 15,78 \mathrm{~m} ; \mathrm{M} 4=59,31 \pm 18,35 \mathrm{~m})$, durante os quatro cruzeiros, respectivamente. Sazonalmente, $\mathrm{Z}_{\mathrm{m}}$ esteve mais raso no inverno, tanto na plataforma como no talude $(27,86 \pm 18,47 \mathrm{~m}$ e $53,79 \pm 19,23 \mathrm{~m}$, respectivamente; $46,87 \pm 30,27 \mathrm{~m}$ e $81,41 \pm 15,53 \mathrm{~m}$, respectivamente no verão). $\mathrm{O}$ parâmetro de fundo $\mathrm{B}_{0}$ mostrou valores médios maiores na plataforma quando comparados ao talude ao longo dos cruzeiros de mesoescala (ver Tabela 3.33). Os valores médios de $\mathrm{B}_{0}$ no inverno foram maiores que os de verão, tanto na plataforma quanto no talude. O comportamento médio de h (altura Gaussiana) variou entre os cruzeiros e entre os domínios considerados. Entretanto, as médias sazonais indicaram valores mais altos e maior amplitude de variação sobre a plataforma. O parâmetro $\sigma$ (escala Gaussiana) mostrou-se mais alto, em média, no domínio de talude, durante todos os cruzeiros. Entretanto, os valores médios calculados para os períodos de verão e inverno não diferiram significativamente. 
TABELA 3.33 - PARÂMETROS MÉDIOS DOS PERFIS VERTICAIS DE BIOMASSA (MODELO GAUSSIANO-DESLOCADO)

\begin{tabular}{|c|c|c|c|c|c|}
\hline Cruzeiro & Domínio & $\mathbf{Z}_{\mathbf{m}}$ & $\mathbf{B}_{\mathbf{0}}$ & h & $\sigma$ \\
\hline \multirow{3}{*}{ M1 } & Plataforma & $\begin{array}{c}39,37(26,43) \\
242-75,00\end{array}$ & $\begin{array}{l}0,26(0,22) \\
0,04-065\end{array}$ & $\begin{array}{l}12,23(11,21) \\
121-4016\end{array}$ & $\begin{array}{l}11,01(6,24) \\
207-25,00\end{array}$ \\
\hline & \multirow{2}{*}{ Talude } & $75,79(13,77)$ & $0,06(0,04)$ & $17,18(8,16)$ & $24,60(15,27)$ \\
\hline & & $43,33-100,0$ & $0,0-0,11$ & $6,73-32,77$ & $7,83-59,24$ \\
\hline \multirow{4}{*}{ M2 } & \multirow{2}{*}{ Plataforma } & $17,22(12,94)$ & $0,38(0,29)$ & $33,74(33,45)$ & $16,10(8,27)$ \\
\hline & & $2,49-35,90$ & $0,0-0,91$ & $2,04-128,70$ & $7,70-35,66$ \\
\hline & \multirow{2}{*}{ Talude } & $42,74(16,71)$ & $0,12(0,14)$ & $28,12(20,43)$ & $29,38(20,24)$ \\
\hline & & $2,50-59,79$ & $0,0-0,35$ & $0,74-53,13$ & $2,96-54,42$ \\
\hline \multirow{4}{*}{ M3 } & \multirow{2}{*}{ Plataforma } & $49,68(31,51)$ & $0,30(0,43)$ & $35,95(25,85)$ & $12,06(5,33)$ \\
\hline & & $1,0-128,52$ & $0,05-2,5$ & $4,35-100,16$ & $3,0-24,45$ \\
\hline & \multirow{2}{*}{ Talude } & $84,88(15,78)$ & $0,09(0,07)$ & $23,63(11,81)$ & $26,33(16,09)$ \\
\hline & & $51,27-114,29$ & $0,0-0,37$ & $8,98-46,27$ & $5,77-66,62$ \\
\hline \multirow{4}{*}{ M4 } & \multirow{2}{*}{ Plataforma } & $32,94(18,76)$ & $0,35(0,33)$ & $22,52(15,09)$ & $12,75(10,60)$ \\
\hline & & $2,57-57,42$ & $0,0-1,51$ & $1,63-75,15$ & $0,63-54,33$ \\
\hline & \multirow{2}{*}{ Talude } & $59,31(18,36)$ & $0,07(0,08)$ & $36,62(13,47)$ & $34,19(18,79)$ \\
\hline & & $32,33-100,0$ & $0,0-0,28$ & $15,02-61,27$ & $12,61-68,38$ \\
\hline \multirow{4}{*}{$\begin{array}{c}\text { Verão } \\
(\mathrm{M} 1+\mathrm{M3}) \\
\mathbf{n}=\mathbf{4 4}\end{array}$} & \multirow{2}{*}{ Plataforma } & $46,87(30,27)$ & $0,29(0,38)$ & $29,48(25,06)$ & $11,77(5,37)$ \\
\hline & & $1,0-128,52$ & $0,04-2,50$ & $1,21-100,16$ & $2,07-25,00$ \\
\hline & \multirow{2}{*}{ Talude } & $81,41(15,53)$ & $0,08(0,07)$ & $21,18(10,93)$ & $25,67(15,62)$ \\
\hline & & $43,33-114,29$ & $0,0-0,37$ & $6,73-46,27$ & $5,77-66,62$ \\
\hline \multirow{4}{*}{$\begin{array}{c}\text { Inverno } \\
(\mathrm{M} 2+\mathrm{M} 4) \\
\mathrm{n}=42\end{array}$} & \multirow{2}{*}{ Plataforma } & $27,86(18,47)$ & $0,38(0,29)$ & $33,74(32,72)$ & $16,10(8,09)$ \\
\hline & & $2,49-57,42$ & $0,0-0,91$ & $2,04-128,70$ & $7,70-35,66$ \\
\hline & \multirow{2}{*}{ Talude } & $53,79(19,23)$ & $0,12(0,14)$ & $28,12(19,82)$ & $29,38(19,63)$ \\
\hline & & $2,50-100,00$ & $0,0-0,35$ & $0,74-53,13$ & $2,96-54,42$ \\
\hline
\end{tabular}

\subsection{Comparação entre dados in situ e dados de satélites}

\subsubsection{Temperatura da superfície do mar}

Neste capítulo foram apresentadas imagens orbitais de infravermelho termal processadas de modo a fornecer informações sobre o campo de temperaturas da superfície do mar. Diversas feições oceanográficas de interesse foram descritas a partir do conjunto de imagens disponível. A seguir, será apresentada uma comparação entre os dados obtidos através das imagens termais e dados in situ coletados durante os cruzeiros de mesoescala com o equipamento CTD.

As comparações entre as temperaturas da superfície do mar medidas in situ e estimadas por satélite foram realizadas dentro de um período de \pm 1 dia, a partir da data da estação 
oceanográfica. Este intervalo de tempo não permite evitar os efeitos provocados pelo aquecimento diurno e resfriamento noturno das camadas superiores do oceano. Os pares de dados foram formados entre a TSM in situ e o valor mediano de uma janela de 5 x 5 pixels $(25 \mathrm{~km} \times 25 \mathrm{~km})$ centrada na posição geográfica da estação oceanográfica na imagem equivalente.

A Tabela 3.34 apresenta os coeficientes encontrados nas regressões lineares e as diferenças médias $(\Delta \mathrm{T})$ entre as temperaturas in situ e os dados de satélite, para os períodos de verão, inverno e para o conjunto completo de dados.

TABELA 3.34 - ANÁLISE DE REGRESSÃO LINEAR ENTRE AS TEMPERATURAS IN SITU E OBTIDAS POR SATÉLITES (AVHRR).

\begin{tabular}{|c|c|c|c|c|c|c|c|}
\hline \multirow{2}{*}{ Período } & \multicolumn{5}{|c|}{$\mathbf{T}_{\text {in situ }}=a \mathbf{T}_{\text {sat }}+\boldsymbol{b}$} & \multicolumn{2}{|c|}{$\Delta T=T_{\text {in situ }}-T_{\text {sat }}$} \\
\hline & $a$ & $b$ & $\mathbf{n}$ & $\mathbf{R}^{2}$ & $\mathbf{r m s}$ & média & dp \\
\hline Verão & 0,622 & 9,701 & 42 & 0,47 & 1,10 & $-0,32$ & 1,26 \\
\hline Inverno & 0,844 & 3,045 & 115 & 0,50 & 0,88 & 0,47 & 0,89 \\
\hline Verão+Inverno & 0,980 & 0,215 & 157 & 0,68 & 1,00 & 0,26 & 1,06 \\
\hline
\end{tabular}

Os coeficientes de determinação $\left(\mathrm{R}^{2}\right)$ ficaram entre 0,47 e 0,68 sendo que, o ajuste para o conjunto completo de dados (verão + inverno) foi melhor do que para cada período separadamente. $O$ número de observações foi $\mathrm{n}=42$ para o verão, $\mathrm{n}=115$ para $\mathrm{o}$ inverno e $n=157$ para o conjunto completo. A Figura 3.40 mostra os diagramas de dispersão dos conjuntos de dados referentes aos períodos de verão, inverno e completo. 

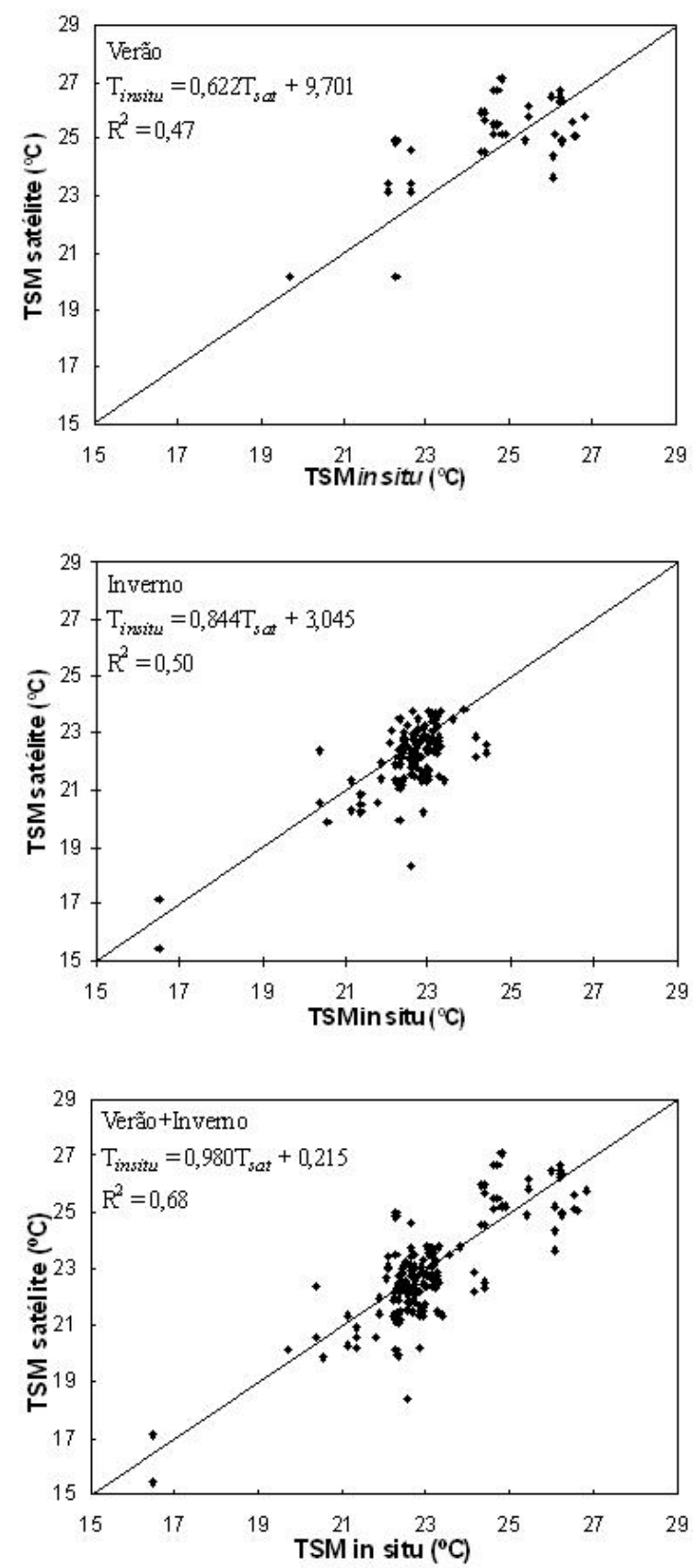

Figura 3.40 - Diagrama de dispersão das temperaturas obtidas por satélite

(AVHRR/NOAA) versus a temperatura da superfície do mar medida in situ, para o período de verão (em cima), inverno (meio) e verão + inverno

(embaixo).

Mesmo com o número de pontos tendo sido maior no inverno que no verão $(\mathrm{n}=115 \mathrm{e}$ 42, respectivamente), pode-se notar que, de modo geral, o algoritmo por satélite subestimou as temperaturas in situ no inverno e superestimou no verão. 


\subsubsection{Concentração de Clorofila da Superfície do Mar}

Neste capítulo foram apresentadas imagens orbitais da cor do oceano processadas de modo a fornecer informações sobre o campo de concentração de clorofila da superfície do mar. Diversas feições oceanográficas de interesse foram descritas a partir do conjunto de imagens disponível. A seguir, será apresentada uma comparação entre os dados obtidos através das imagens da cor do oceano e dados in situ coletados durante os cruzeiros de mesoescala.

Além dos algoritmos empíricos (OC2 e OC4), diversas outras abordagens também têm sido propostas para estimar $\mathrm{C}_{\text {insitu }}$ a partir de dados de satélite. Como mencionado anteriormente também foi aplicado o algoritmo semi-analítico - GSM01 (Maritorena et al., 2002), e o algoritmo de rede neural - NN (Gross et al., 2000) às imagens SeaWiFS. Foram estimados quatro valores de clorofila $a$ para cada pixel válido nas imagens referentes aos algoritmos $\mathrm{OC} 4, \mathrm{OC} 2, \mathrm{GSM} 01$ e $\mathrm{NN}$, respectivamente.

As comparações entre as medidas de Clorofila $a$ in situ e estimadas por satélite $\left(\mathrm{C}_{\text {sat }}\right)$ foram realizadas dentro de um período de \pm 1 dia, a partir da data da estação oceanográfica. Os pares de dados foram formados entre a $\mathrm{C}_{\text {insitu }}$ e o valor mediano de uma janela de $5 \times 5$ pixels $(25 \mathrm{~km} \times 25 \mathrm{~km})$ centrada na posição geográfica da estação oceanográfica na imagem SeaWiFS equivalente.

A Figura 3.41 mostra a distribuição de freqüência das concentrações de clorofila $a$ referentes ao período de verão.

A Tabela 3.35 apresenta os coeficientes encontrados nas regressões lineares entre as concentrações de clorofila $a$ in situ e as estimativas feitas por satélite, para o período de verão. A Figura 3.42 mostra os diagramas de dispersão dos quatro algoritmos de clorofila por satélite testados para o período de verão. 


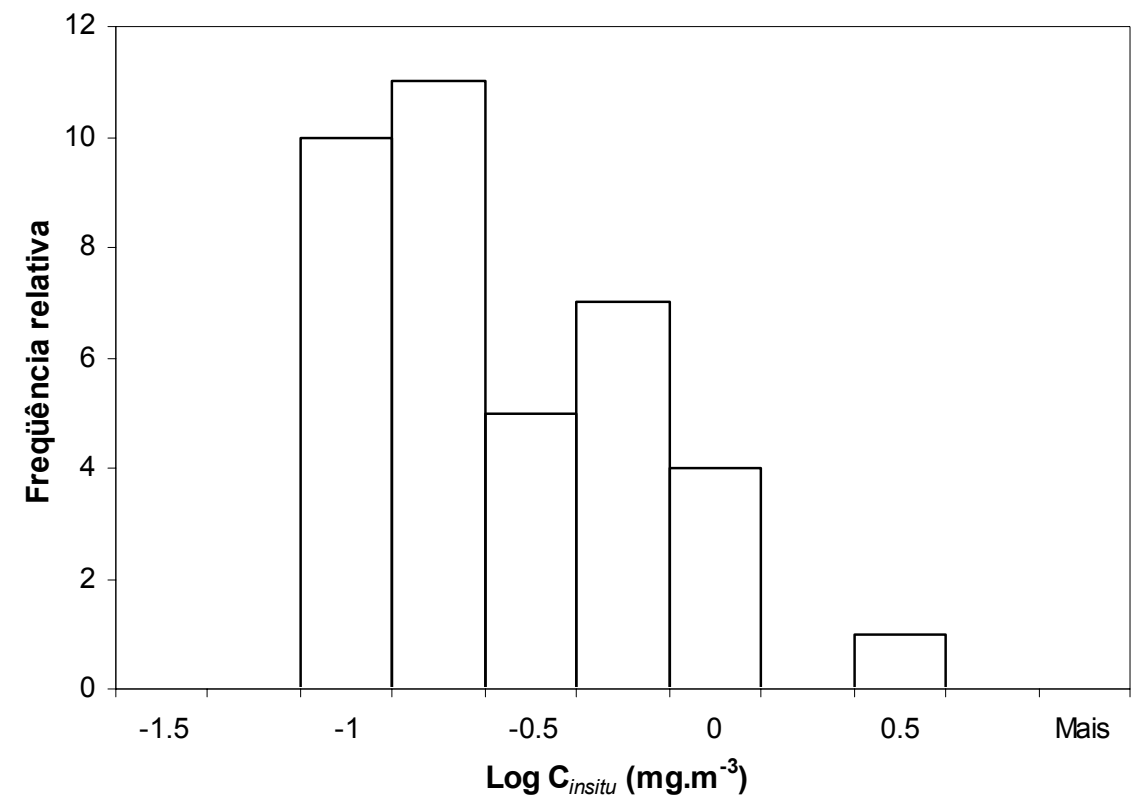

Figura 3.41 - Histograma da distribuição de freqüência dos valores de Log (clorofila $a$ ) do período de verão $(\mathrm{n}=37)$.

TABELA 3.35 - ANÁLISE DE REGRESSÃO LINEAR ENTRE AS CLOROFILAS IN SITU E OBTIDAS POR SATÉLITE (SeaWiFS) NO PERÍODO DE VERÃO.

\begin{tabular}{c|c|c|c|c|c}
\hline \multirow{2}{*}{$\mathbf{C}_{\text {sat }}$} & \multicolumn{5}{c}{$\mathbf{C}_{\text {insitu }}=\boldsymbol{a} \mathbf{C}_{\text {sat }}+\boldsymbol{b}$} \\
\cline { 2 - 6 } OC4 & $\boldsymbol{a}$ & $\boldsymbol{b}$ & $\mathbf{n}$ & $\mathbf{R}^{\mathbf{2}}$ & $\mathbf{r m s}$ \\
\hline OC2 & 0,130 & 0,015 & 37 & 0,87 & 0,22 \\
\hline GSM01 & 0,469 & 0,068 & 37 & 0,85 & 0,20 \\
\hline NN $^{*}$ & 1,35 & 0,064 & 38 & 0,80 & 0,12 \\
\hline \multicolumn{6}{c}{ * log-transformada; $n$ = número observações } \\
\hline
\end{tabular}

O algoritmo OC4 apresentou o maior coeficiente de determinação $(0,87)$, ainda que OC2 tenha tido valor muito próximo $\left(\mathrm{R}^{2}=0,85\right)$. Os outros dois algoritmos testados, GSM01 e NN, também tiveram bom desempenho explicando $80 \%$ e $69 \%$ da variância dos dados, respectivamente. O algoritmo GSM01 teve o menor valor rms $(0,12)$. 

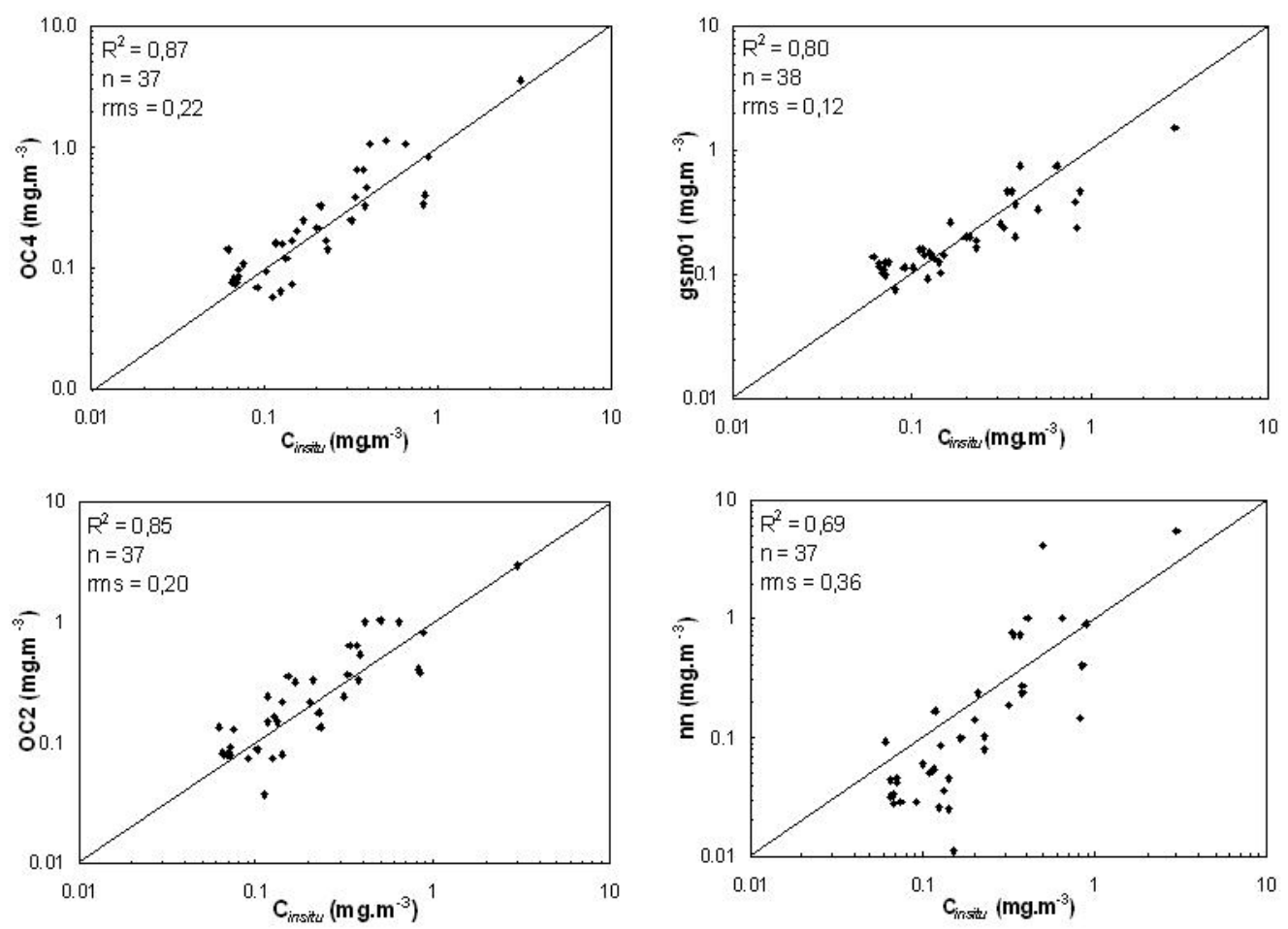

Figura 3.42 - Diagrama de dispersão das clorofilas obtidas por satélite (SeaWiFS) versus a clorofila da superfície do mar medida in situ, para o período de verão (OC4 esquerda em cima, OC2 esquerda embaixo, GSM01 direita em cima, $\mathrm{NN}$ direita embaixo).

De modo geral, o algoritmo semianalítico GSM01 subestimou a clorofila $a$ em concentrações mais altas e superestimou em concentrações baixas. Já o algoritmo NN exibiu um comportamento contrário, ou seja, superestimando a biomassa fitoplanctônica em concentrações altas e subestimando em baixas concentrações. Os algoritmos empíricos OC4 e OC2 exibiram um mesmo padrão para concentrações de clorofila $a$ baixas e altas.

A Figura 3.43 apresenta a distribuição de freqüência das concentrações de clorofila $a$ referentes ao período de inverno. A Tabela 3.36 mostra os coeficientes encontrados nas regressões lineares entre as concentrações de clorofila $a$ in situ e as estimativas feitas por satélite, para o período de inverno. A Figura 3.44 apresenta os diagramas de dispersão dos quatro algoritmos de clorofila por satélite testados para o período de inverno. 


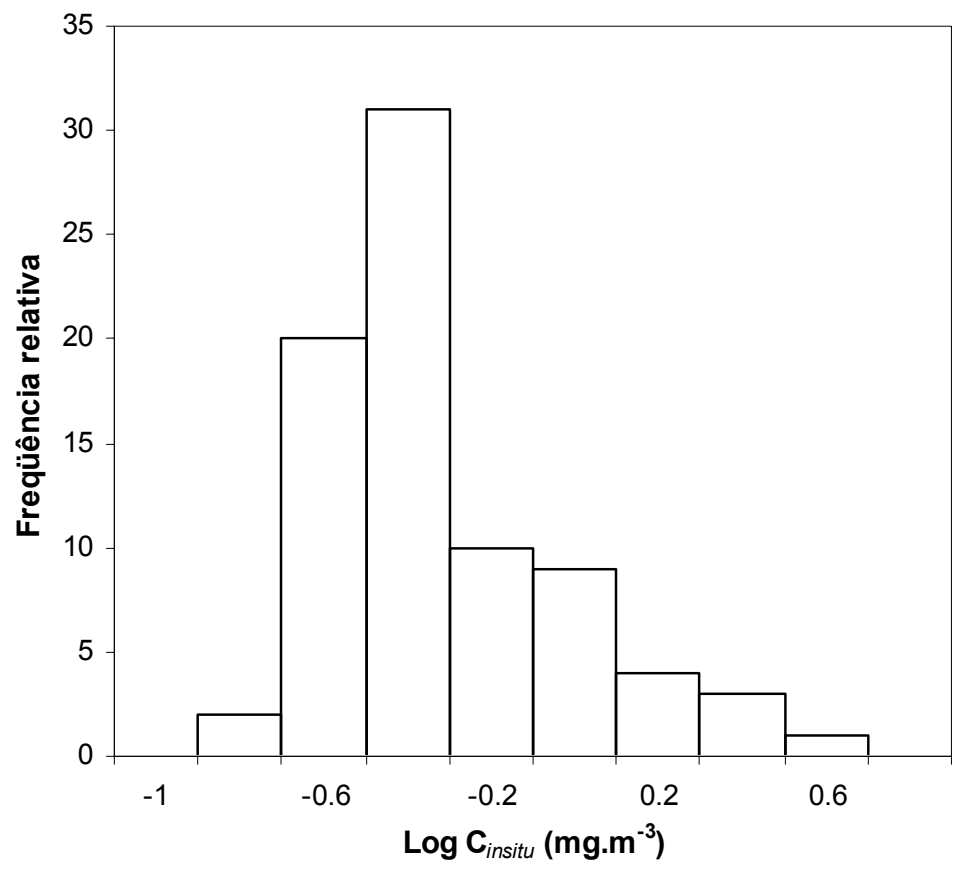

Figura 3.43 - Histograma da distribuição de freqüência dos valores de $\log ($ clorofila $a$ ) do período de verão $(\mathrm{n}=80)$.

TABELA 3.36 - ANÁLISE DE REGRESSÃO LINEAR ENTRE AS CLOROFILAS IN SITU E OBTIDAS POR SATÉLITE (SeaWiFS) NO PERÍODO DE INVERNO

\begin{tabular}{c|c|c|c|c|c}
\hline \multirow{2}{*}{$\mathbf{C}_{\text {sat }}$} & \multicolumn{5}{c}{$\mathbf{C}_{\text {insitu }}=\boldsymbol{a} \mathbf{C}_{\boldsymbol{s a t}}+\boldsymbol{b}$} \\
\cline { 2 - 6 } & $\boldsymbol{a}$ & $\boldsymbol{b}$ & $\mathbf{n}$ & $\mathbf{R}^{\mathbf{2}}$ & $\mathbf{r m s}$ \\
\hline OC4* $^{*}$ & 1,024 & $-0,031$ & 80 & 0,65 & 0,22 \\
\hline OC2 $^{*}$ & 0,993 & $-0,049$ & 80 & 0,60 & 0,24 \\
\hline GSM01 $^{*}$ & 0,811 & $-0,425$ & 73 & 0,29 & 0,36 \\
\hline $\mathbf{N N}$ & 1,288 & $-0,085$ & 79 & 0,50 & 0,61 \\
\hline \multicolumn{7}{|c}{} & $*$ log-transformada; $n=$ número observações
\end{tabular}

O algoritmo OC4 apresentou o maior coeficiente de determinação $(0,65)$ e o menor valor rms $(0,22)$, ainda que com desempenho pior do que o observado no período de verão. O outro algoritmo empírico OC2 explicou $60 \%$ da variância dos dados, e também teve desempenho pior do que no verão. $\mathrm{O}$ algoritmo $\mathrm{NN}$ obteve um coeficiente de determinação maior do que GSM01 no inverno (0,50 e 0,29, respectivamente), ao contrário do que ocorreu no período de verão. Por outro lado, o valor rms de GSM01 foi menor em comparação ao de $\mathrm{NN}(0,36$ e 0,61 , respectivamente). 
De modo geral, os algoritmos OC4, OC2 e NN superestimaram as concentrações mais altas de clorofila e subestimaram as mais baixas. O algoritmo GSM01 subestimou as concentrações de clorofila $a$.
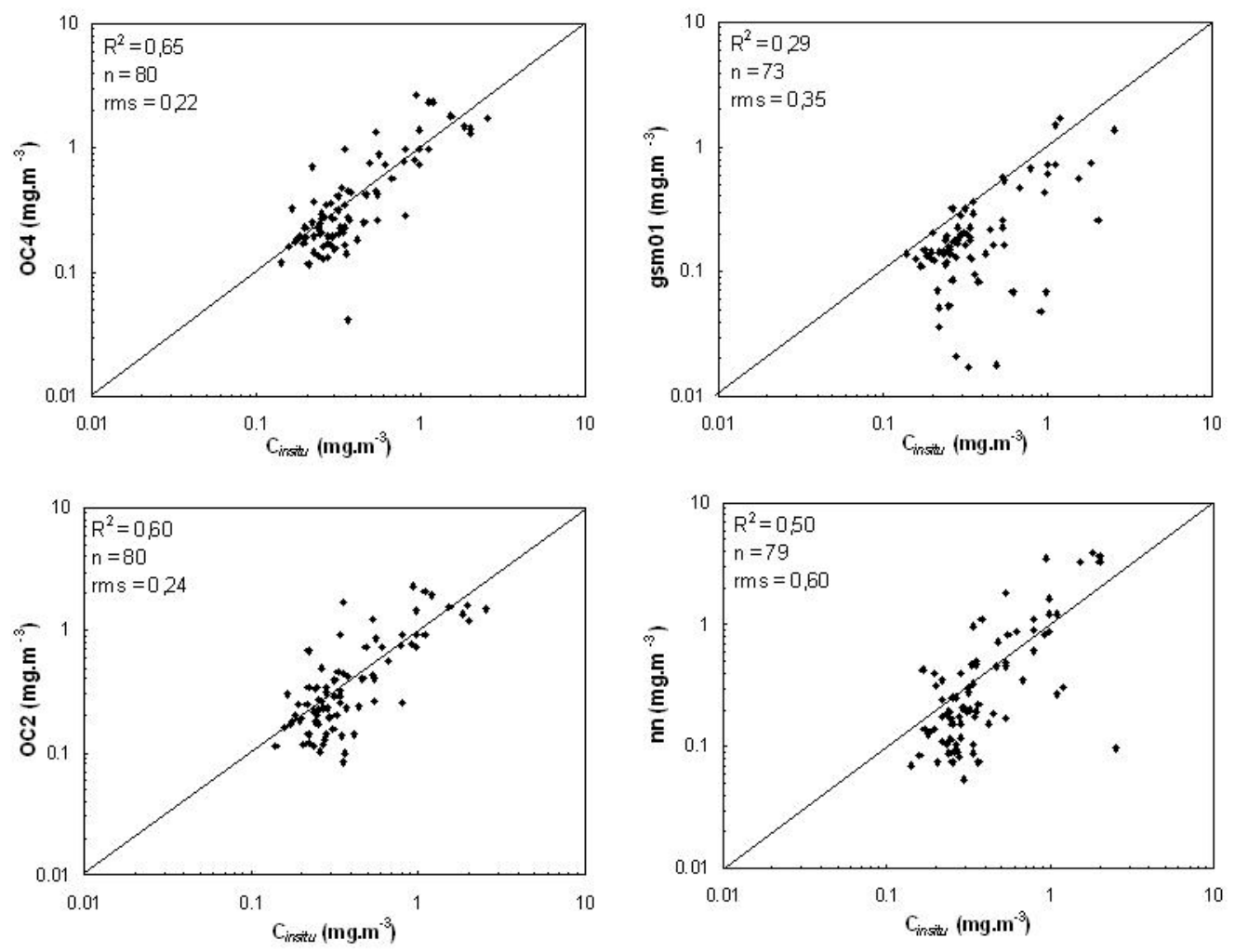

Figura 3.44 - Diagrama de dispersão das clorofilas obtidas por satélite (SeaWiFS) versus a clorofila da superfície do mar medida in situ, para o período de inverno (OC4 esquerda em cima, OC2 esquerda embaixo, GSM01 direita em cima, $\mathrm{NN}$ direita embaixo).

A Figura 3.45 apresenta a distribuição de freqüência das concentrações de clorofila $a$ referentes ao conjunto completo de dados. A Tabela 3.37 apresenta os coeficientes encontrados nas regressões lineares entre $C_{i n s i t u}$ e $C_{s a t}$, para o conjunto completo de dados (verão + inverno). A Figura 3.46 mostra os diagramas de dispersão dos quatro algoritmos de clorofila por satélite testados para o conjunto completo.

O algoritmo OC4 obteve o melhor desempenho para o conjunto completo de dados, explicando $71 \%$ da variância dos dados $(\mathrm{rms}=0,22)$. O outro algoritmo empírico OC2 também mostrou boa performance com $\mathrm{R}^{2}=0,67$ e $\mathrm{rms}=0,23$. O algoritmo de rede neural NN exibiu um coeficiente de determinação maior do que o algoritmo 
semianalítico GSM01 (0,62 e 0,55, respectivamente), ainda que seu rms tenha sido maior $(0,34$ e 0,20 , respectivamente).

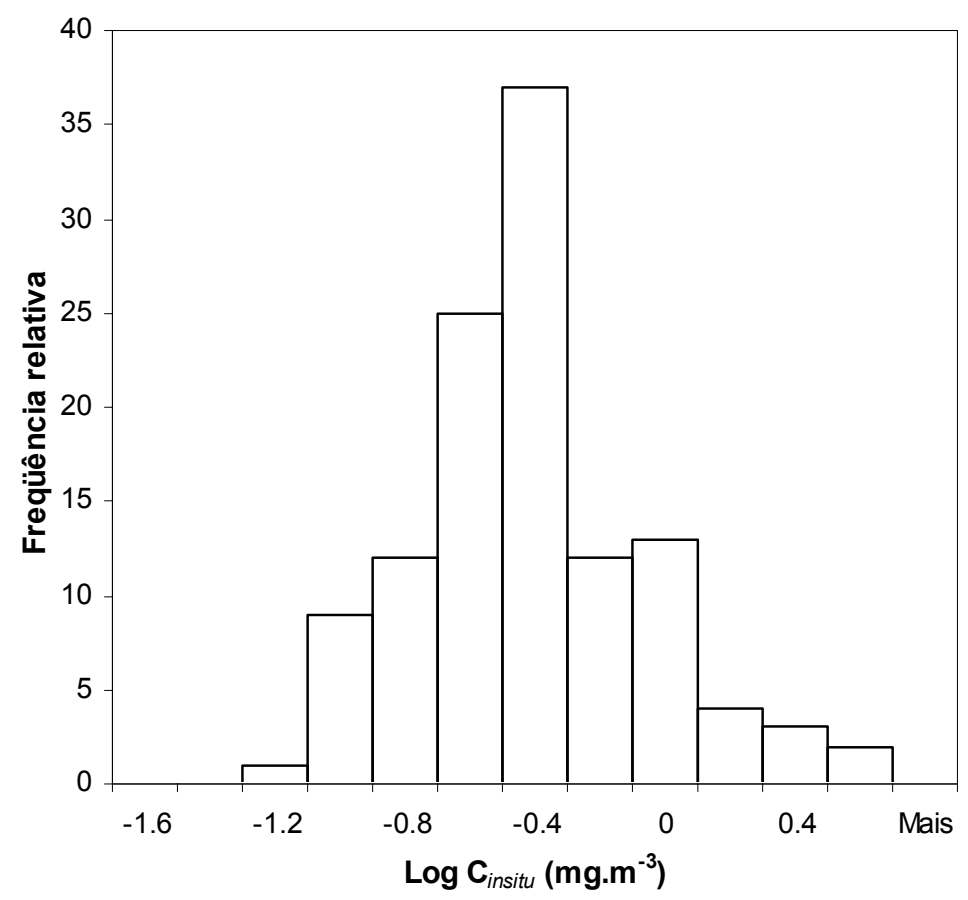

Figura 3.45 - Histograma da distribuição de freqüência dos valores de Log (clorofila $a$ ) do conjunto completo de dados $(\mathrm{n}=118)$.

TABELA 3.37 - ANÁLISE DE REGRESSÃO LINEAR ENTRE AS CLOROFILAS IN SITU E OBTIDAS POR SATÉLITE (SeaWiFS) PARA O CONJUNTO COMPLETO DE DADOS (VERÃO + INVERNO).

\begin{tabular}{c|c|c|c|c|c}
\hline \multirow{2}{*}{$\mathbf{C}_{\text {sat }}$} & \multicolumn{5}{c}{$\mathbf{C}_{\text {insitu }}=\boldsymbol{a} \mathbf{C}_{\text {sat }}+\boldsymbol{b}$} \\
\cline { 2 - 6 } & $\boldsymbol{a}$ & $\boldsymbol{b}$ & $\mathbf{n}$ & $\mathbf{R}^{\mathbf{2}}$ & $\mathbf{r m s}$ \\
\hline OC4 $^{*}$ & 0,953 & $-0,040$ & 117 & 0,71 & 0,22 \\
\hline OC2 $^{*}$ & 0,915 & $-0,056$ & 117 & 0,67 & 0,23 \\
\hline GSM01 $^{*}$ & 0,466 & 0,064 & 111 & 0,55 & 0,20 \\
\hline $\mathbf{N N}^{*}$ & 1,22 & $-0,030$ & 116 & 0,62 & 0,34 \\
\hline \multicolumn{6}{l}{ * log-transformada; $n=$ número observações }
\end{tabular}

De modo geral, os algoritmos $\mathrm{NN}$, OC4 e OC2 subestimaram as concentrações de clorofila mais baixas e superestimaram as mais altas. Já o GSM01, superestimou somente as menores concentrações de clorofila $a$, mas subestimou grande parte das demais. 

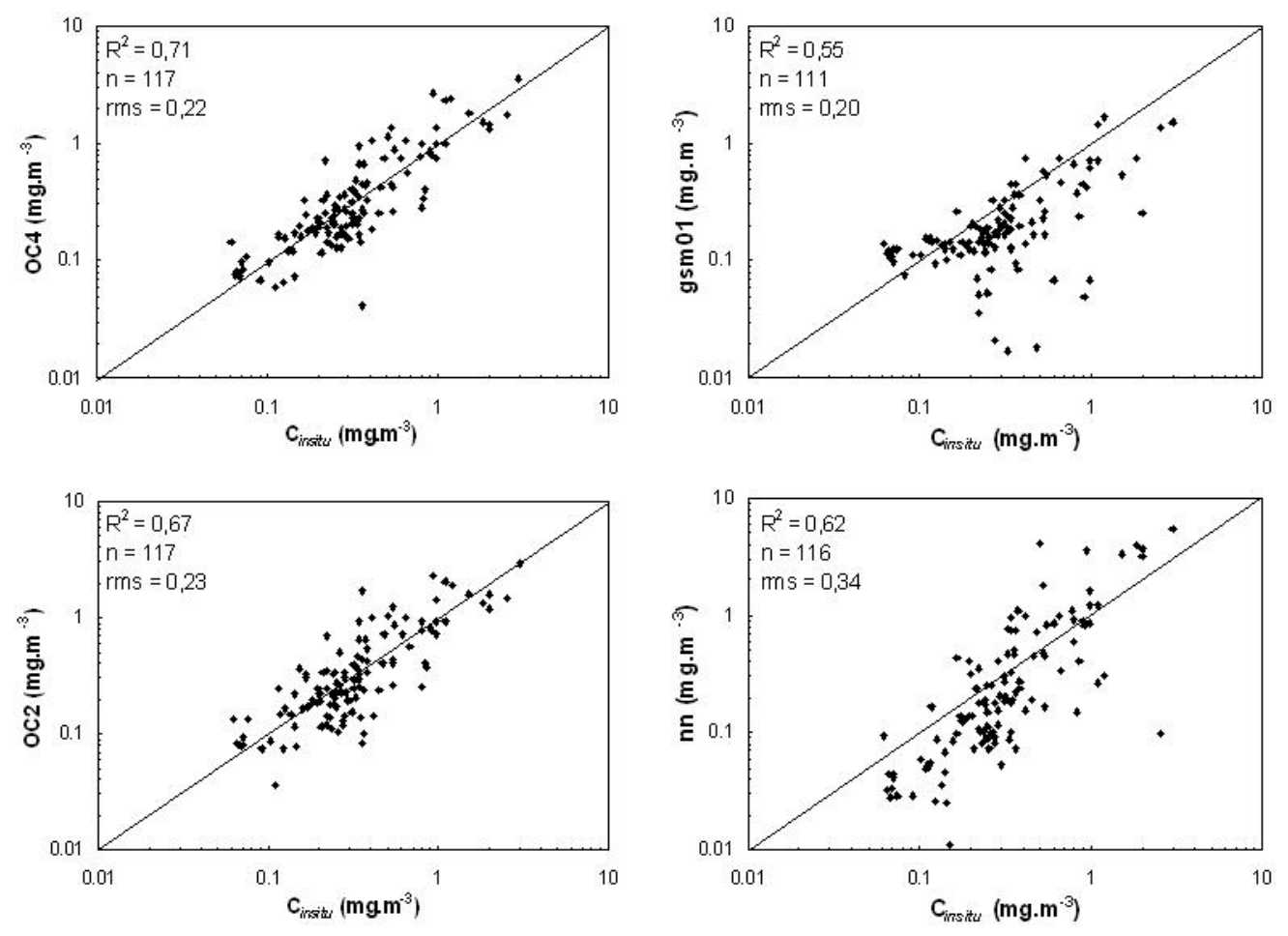

Figura 3.46 - Diagrama de dispersão das clorofilas obtidas por satélite (SeaWiFS) versus a clorofila da superfície do mar medida in situ, para o conjunto completo de dados (OC4 esquerda em cima, OC2 esquerda embaixo, GSM01 direita em cima, $\mathrm{NN}$ direita embaixo).

A seguir, foram feitas tentativas para derivação de relações empíricas entre as radiâncias espectrais normalizadas $\left(L_{W N}\right)$ em 412, 443, 490 e $555 \mathrm{~nm}$ obtidas pelo processamento das imagens SeaWiFS (canais 1, 2, 3 e 5, respectivamente) e as concentrações superficiais de clorofila $a$.

Do conjunto completo de dados $(\mathrm{n}=117)$, foram selecionados aleatoriamente 87 pontos para o ajuste regional dos coeficientes dos algoritmos DEP3 e DEP4. Os 30 pontos restantes foram utilizados para verificação e teste dos algoritmos regionais assim formulados. A Tabela 3.38 apresenta as formulações obtidas para os algoritmos DEP3 e DEP4 locais. Foram mantidos as formas e graus originais dos polinômios propostos pela NASA, ou seja, uma função polinomial cúbica para DEP3 (similar ao de OC2) e um polinômio do quarto grau para DEP4 (similar ao de OC4). 
TABELA 3.38 - FORMULAÇÕES DOS ALGORITMOS EMPÍRICOS OC2 E OC4 LOCAIS.

\begin{tabular}{c|c|c}
\hline Algoritmo & Tipo & Equação e coeficientes $(\boldsymbol{a})$ \\
\hline \multirow{2}{*}{ DEP3 } & Polinomial & $C_{\text {sat }}=10^{\left(a_{0}+a_{1} R_{35}+a_{2} R_{35}^{2}+a_{3} R_{35}^{3}\right)}$ \\
\cline { 3 - 4 } & $3^{\text {o grau }}$ & $a_{0}=0,172 ; a_{1}=-2,626 ; a_{2}=2,657 ; a_{3}=-2,068$ \\
\hline \multirow{2}{*}{ DEP4 } & Polinômio & $C_{\text {sat }}=10^{\left(a_{0}+a_{1} R_{\max }+a_{2} R_{\max }^{2}+a_{3} R_{\max }^{3}+a_{4} R_{\max }^{4}\right)}$ \\
\cline { 3 - 4 } & $4^{\text {o grau }}$ & $a_{0}=0,358 ; a_{1}=-5,241 ; a_{2}=15,425 ; a_{3}=-24,477 ; a_{4}=13,328$ \\
\cline { 3 - 4 } & $\left.\left.* R_{35}=\log \left(\frac{L_{W N 490}}{L_{W N 555}}\right) ; R_{\max }=\log \left(\frac{L_{W N 443}}{L_{W N 555}}\right\rangle \frac{L_{W N 490}}{L_{W N 555}}\right\rangle \frac{L_{W N 510}}{L_{W N 555}}\right)$
\end{tabular}

Para uma verificação preliminar da utilidade destes algoritmos, fez-se um teste de aplicação com o conjunto de 30 pontos selecionados aleatoriamente para este fim. Para fins de comparação, as equações dos algoritmos OC2 e OC4 também foram aplicadas ao mesmo conjunto de dados. A Tabela 3.39 mostra os resultados das regressões lineares efetuadas entre as concentrações de clorofila $a$ superficial in situ e as estimativas obtidas com a aplicação das equações referentes à DEP4, DEP3, OC4 e OC2.

TABELA 3.39 - ANÁLISE DE REGRESSÃO LINEAR ENTRE AS CLOROFILAS IN SITU E OBTIDAS POR SATÉLITE (SeaWiFS) PARA O CONJUNTO COMPLETO DE DADOS (VERÃO + INVERNO).

\begin{tabular}{c|c|c|c|c|c}
\hline \multirow{2}{*}{$\mathbf{C}_{\text {sat }}$} & \multicolumn{5}{|c}{$\mathbf{C}_{\text {insitu }}=\boldsymbol{a} \mathbf{C}_{\boldsymbol{s} \boldsymbol{a t}}+\boldsymbol{b}$} \\
\cline { 2 - 6 } & $\boldsymbol{a}$ & $\boldsymbol{b}$ & $\mathbf{n}$ & $\mathbf{R}^{\mathbf{2}}$ & $\mathbf{r m s}$ \\
\hline DEP4 & 0,796 & $-0,111$ & 30 & 0,51 & 0,21 \\
\hline DEP3 & 0,634 & $-0,222$ & 30 & 0,42 & 0,20 \\
\hline OC4eq. & 0,859 & $-0,123$ & 30 & 0,39 & 0,29 \\
\hline OC2eq. & 0,852 & $-0,116$ & 30 & 0,42 & 0,27 \\
\hline
\end{tabular}

* log-transformada; eq. - respectivas equações aplicadas a $R_{\max }(O C 4)$ e $R_{35}(O C 2)$.

O algoritmo DEP4, aplicado às radiâncias emergentes normalizadas estimadas pelo satélite SeaWiFS, tendo-se aplicado as técnicas de correção atmosférica sugeridas pela NASA, explicou $51 \%$ da variância de um conjunto de 30 pontos de dados escolhidos aleatoriamente. O algoritmo DEP3 teve um coeficiente de determinação igual a 0,42 , exatamente o mesmo obtido para OC2eq, porém, com rms menor $(0,20$ e 0,27, 
respectivamente). A aplicação da equação referente ao algoritmo $\mathrm{OC4}$ à $\mathrm{R}_{\max }$ resultou em que $39 \%$ da variância dos dados testados fosse explicada, com rms igual a 0,27.

\subsection{Produção Primária Estimada pelo PNF}

O equipamento PNF possibilitou a estimativa de perfis verticais de clorofila, produção primária instantânea e coeficiente de atenuação vertical da luz. Os dados de concentração de clorofila medidos com o PNF foram utilizados no ajuste dos perfis verticais de biomassa.

A Figura 3.47 apresenta exemplos de perfis verticais de clorofila $\left(\mathrm{mg} . \mathrm{m}^{-3}\right)$ e produção primária instantânea $\left(\mathrm{mgC} \cdot \mathrm{m}^{-3} \cdot \mathrm{h}^{-1}\right)$ adquiridos com o PNF durante o cruzeiro M1. No lado esquerdo em cima da Figura 3.47 , são mostrados os perfis de clorofila obtidos com o PNF (linha tracejada) e o perfil in situ ajustado (linha contínua) na estação 6901. No meio do lado esquerdo, aparece o perfil de produção primária in situ interpolado de metro em metro, referente às amostras de $100 \%$ de irradiância. Abaixo deste, estão os perfis de produção primária instantânea in situ interpolado e o perfil medido pelo PNF. No lado direito da Figura 3.47, são mostrados os gráficos referentes à estação 6892 e às amostras de $1 \%$.

Similarmente, na Figura 3.48 são mostrados exemplos de perfis de biomassa fitoplanctônica $\left(\mathrm{mg} \cdot \mathrm{m}^{-3}\right)$ e produção primária instantânea $\left(\mathrm{mgC} \cdot \mathrm{m}^{-3} \cdot \mathrm{h}^{-1}\right)$ adquiridos durante o cruzeiro M2. No lado esquerdo da Figura 3.48, estão os dados referentes à estação 7060 (100\%) e no lado direito, os dados da estação 7071 (1\%).

A Figura 3.49 exibe os exemplos de perfis verticais de concentrações de clorofila $\left(\mathrm{mg} . \mathrm{m}^{-3}\right)$ e produção primária $\left(\mathrm{mgC} \cdot \mathrm{m}^{-3} \cdot \mathrm{h}^{-1}\right)$ referentes às estações $7097(100 \%$, lado esquerdo) e 7116 (1\%, lado direito) realizadas no cruzeiro M3.

Da mesma forma, a Figura 3.50 mostra os exemplos de perfis verticais de clorofila $\left(\mathrm{mg} \cdot \mathrm{m}^{-3}\right)$ e produção primária $\left(\mathrm{mgC} \cdot \mathrm{m}^{-3} \cdot \mathrm{h}^{-1}\right)$ obtidos nas estações $7300(100 \%$, lado esquerdo) e 7301 ( $1 \%$, lado direito) durante o cruzeiro M4. 

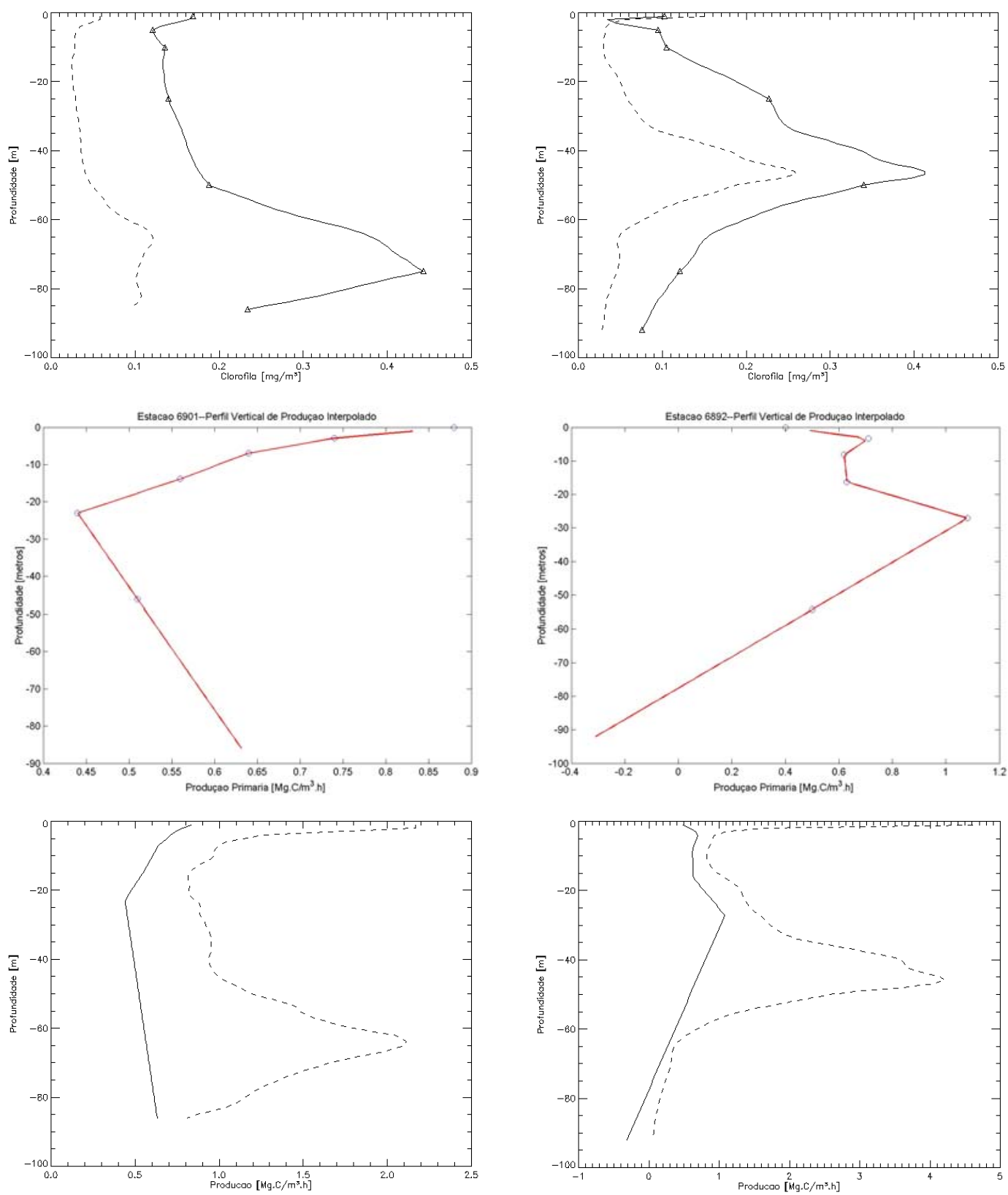

Figura 3.47 - Perfis verticais de clorofila $\left(\mathrm{mg} \cdot \mathrm{m}^{-3}\right)$ e produção primária instantânea $\left(\mathrm{mgC} \cdot \mathrm{m}^{-3} \cdot \mathrm{h}^{-1}\right)$ medidos pelo PNF (linha tracejada) e in situ (linha contínua) nas estações 6901 (100\%, lado esquerdo) e 6892 (1\%, lado direito). 

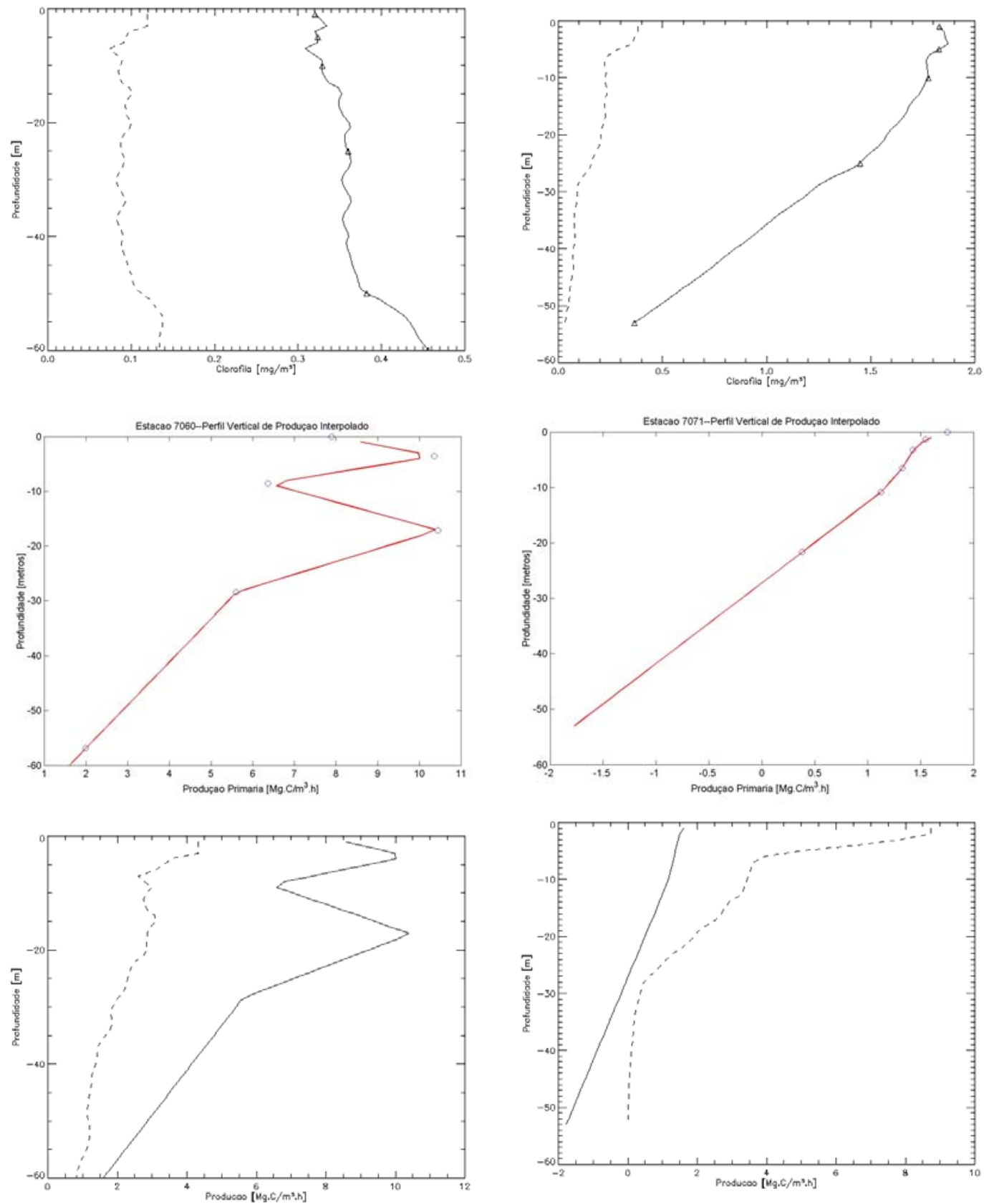

Figura 3.48 - Perfis verticais de clorofila $\left(\mathrm{mg} \cdot \mathrm{m}^{-3}\right)$ e produção primária instantânea (mgC. $\left.\mathrm{m}^{-3} \cdot \mathrm{h}^{-1}\right)$ medidos pelo PNF (linha tracejada) e in situ (linha contínua) nas estações 7060 (100\%, lado esquerdo) e 7071 (1\%, lado direito). 

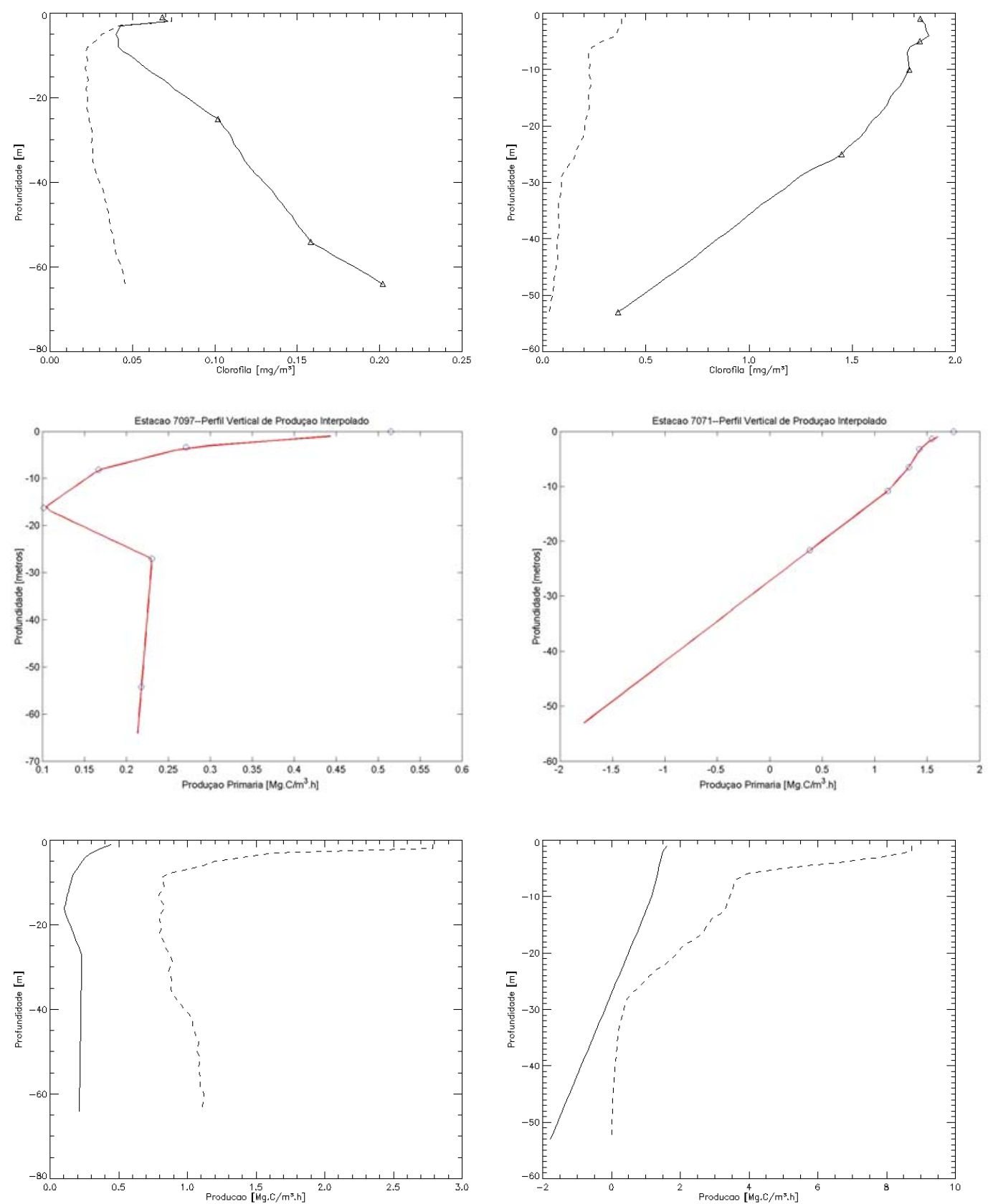

Figura 3.49 - Perfis verticais de clorofila $\left(\mathrm{mg} \cdot \mathrm{m}^{-3}\right)$ e produção primária instantânea $\left(\mathrm{mgC} \cdot \mathrm{m}^{-3} \cdot \mathrm{h}^{-1}\right)$ medidos pelo PNF (linha tracejada) e in situ (linha contínua) nas estações 7097 (100\%, lado esquerdo) e 7116 (1\%, lado direito). 

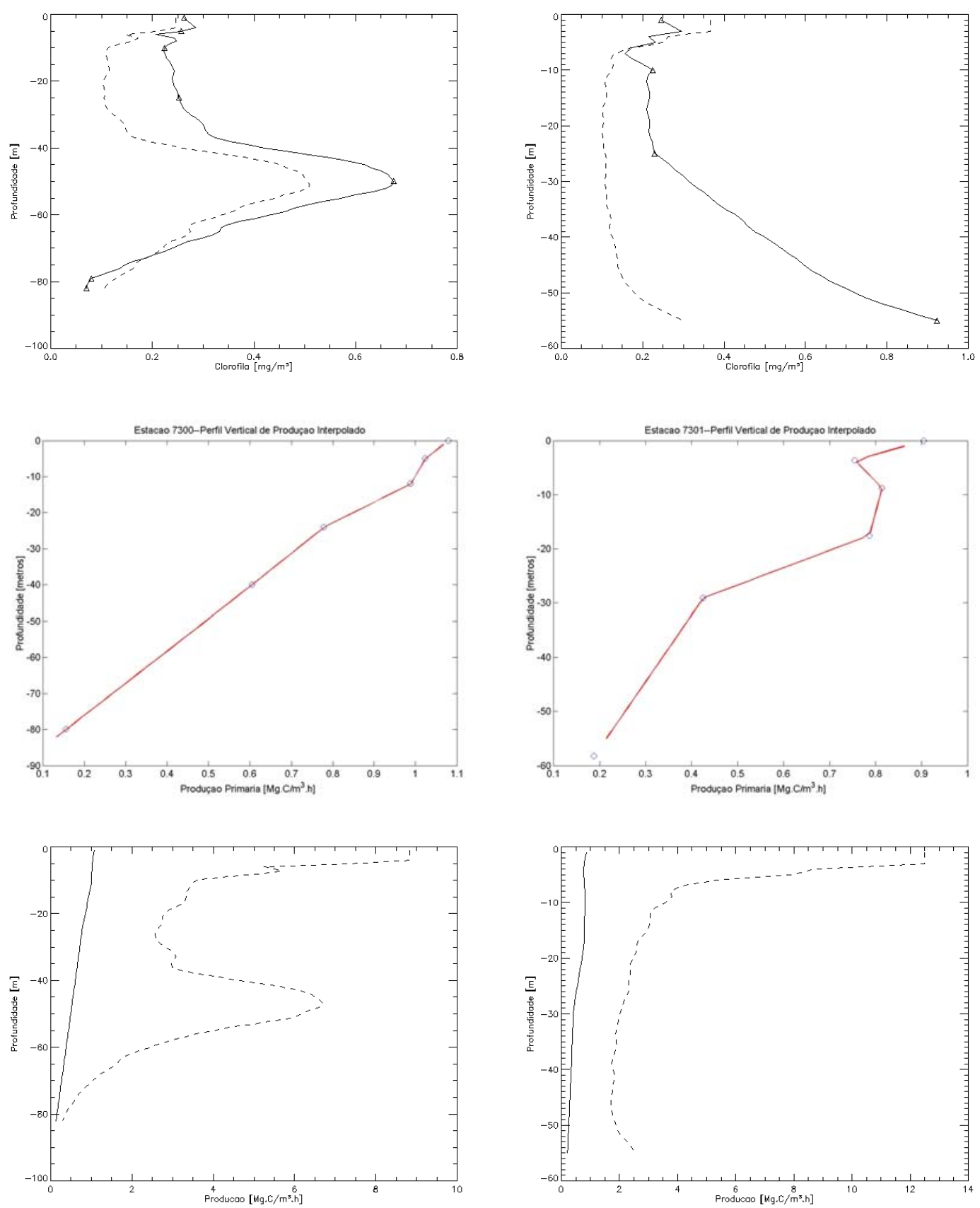

Figura 3.50 - Perfis verticais de clorofila $\left(\mathrm{mg} \cdot \mathrm{m}^{-3}\right)$ e produção primária instantânea $\left(\mathrm{mgC} \cdot \mathrm{m}^{-3} \cdot \mathrm{h}^{-1}\right)$ medidos pelo PNF (linha tracejada) e in situ (linha contínua) nas estações 7300 (100\%, lado esquerdo) e 7301 (1\%, lado direito).

$\mathrm{Na}$ Tabela 3.40, as estimativas médias de produção primária integradas na coluna d'água $\left(\mathrm{gC} \cdot \mathrm{m}^{-2} \cdot \mathrm{d}^{-1}\right)$ obtidas com o PNF para os quatro cruzeiros de mesoescala são apresentadas junto com suas respectivas amplitudes de variação, desvios padrão e coeficientes de variação. Em alguns casos, a profundidade amostrada pelo PNF foi 
inferior à da base da zona eufótica, devido ao curto comprimento do cabo do equipamento. Nestes casos, a integração foi calculada até a profundidade máxima amostrada.

\section{TABELA 3.40 - PRODUÇÃO PRIMÁRIA INTEGRADA NA COLUNA D’ÁGUA} OBTIDA COM O PNF.

\begin{tabular}{c|c|c|c|c}
\hline & M1 & M2 & M3 & M4 \\
\hline Média & 0,70 & 1,03 & 1,36 & 1,90 \\
\hline Máximo & 1,36 & 1,59 & 2,46 & 3,49 \\
\hline Mínimo & 0,06 & 0,59 & 0,37 & 0,60 \\
\hline Desvio Padrão & 0,43 & 0,26 & 0,69 & 0,84 \\
\hline $\begin{array}{c}\text { Coeficiente } \\
\text { variação }\end{array}$ & $61 \%$ & $25 \%$ & $51 \%$ & $45 \%$ \\
\hline \multicolumn{4}{c}{$*$ Produção primária integrada $\left(\mathrm{gC}^{-m^{-2}} \cdot \mathrm{d}^{-1}\right)$}
\end{tabular}

Em média, o cruzeiro de inverno de 2002 apresentou o maior valor de produção primária integrada $\left(1,90 \pm 0,84 \mathrm{gC} \cdot \mathrm{m}^{-2} \cdot \mathrm{d}^{-1}\right)$ de acordo com as estimativas feitas pelo PNF. O valor médio calculado para o verão de $2002\left(1,36 \pm 0,69 \mathrm{gC} \cdot \mathrm{m}^{-2} \cdot \mathrm{d}^{-1}\right)$ foi praticamente o dobro do estimado para o verão de $2001\left(0,70 \pm 0,43 \mathrm{gC} \cdot \mathrm{m}^{-2} \cdot \mathrm{d}^{-1}\right)$.

$\mathrm{O}$ coeficiente de atenuação difusa para a radiação fotossinteticamente ativa $\left(\mathrm{K}_{\mathrm{PNF}}\right)$ também é uma medida fornecida pelo equipamento PNF. Foram extraídos os valores medianos de cada perfil vertical interpolado de metro em metro. $\mathrm{O} \mathrm{K}_{\mathrm{PNF}}$ variou entre 0,03 e $0,18 \mathrm{~m}^{-1}$ durante o verão $(\mathrm{M} 1+\mathrm{M} 3)$, com valor médio igual a $0,08 \pm 0,04 \mathrm{~m}^{-1}$. Durante o inverno (M2 + M4), o coeficiente de atenuação vertical médio foi de 0,10 \pm $0,07 \mathrm{~m}^{-1}$, com mínimo de $0,03 \mathrm{~m}^{-1}$ e máximo de $0,35 \mathrm{~m}^{-1}$. Os valores médios, amplitudes de variação, desvios padrão e coeficientes de variação relativos ao $\mathrm{K}_{\mathrm{PNF}}$ obtidos no verão e no inverno estão na Tabela 3.41, junto com os valores de $\mathrm{K}_{\mathrm{s}}$, ou seja, estimados pelo disco de Secchi $\left(\mathrm{m}^{-1}\right)$. As diferenças percentuais entre $\mathrm{K}_{\mathrm{PNF}}$ e $\mathrm{K}_{\mathrm{s}}$ também são mostradas. A Tabela 3.42 apresenta os coeficientes encontrados nas regressões lineares entre os coeficientes de atenuação $\left(\mathrm{m}^{-1}\right)$ obtidos pelo PNF $\left(\mathrm{K}_{\mathrm{PNF}}\right)$ e pelo disco de Secchi $\left(K_{s}\right)$. 
TABELA 3.41 - COEFICIENTE DE ATENUAÇÃO VERTICAL OBTIDO COM O PNF.

\begin{tabular}{|c|c|c|c|c|c|c|}
\hline & \multicolumn{2}{|c|}{ Verão } & \multicolumn{2}{|c|}{ Inverno } & \multicolumn{2}{|c|}{ Verão+Inverno } \\
\hline & $\mathbf{K}_{\mathrm{PNF}}$ & $\mathbf{K}_{\mathrm{s}}$ & $\mathbf{K}_{\mathrm{PNF}}$ & $\mathbf{K}_{\mathrm{s}}$ & $\mathbf{K}_{\mathrm{PNF}}$ & $\mathbf{K}_{\mathbf{s}}$ \\
\hline Média & 0,08 & 0,11 & 0,10 & 0,14 & 0,08 & 0,12 \\
\hline Máximo & 0,18 & 0,34 & 0,35 & 0,49 & 0,35 & 0,49 \\
\hline Mínimo & 0,03 & 0,06 & 0,03 & 0,05 & 0,03 & 0,05 \\
\hline Desvio Padrão & 0,04 & 0,06 & 0,07 & 0,10 & 0,06 & 0,08 \\
\hline $\begin{array}{c}\text { Coeficiente } \\
\text { variação }\end{array}$ & $57 \%$ & $55 \%$ & $74 \%$ & $72 \%$ & $69 \%$ & $66 \%$ \\
\hline$\Delta$ Relativa & \multicolumn{2}{|c|}{$-27 \%$} & \multicolumn{2}{|c|}{$-23 \%$} & \multicolumn{2}{|c|}{$-25 \%$} \\
\hline
\end{tabular}

TABELA 3.42 - ANÁLISE DE REGRESSÃO LINEAR ENTRE OSCOEFICIENTES DE ATENUAÇÃO VERTICAL OBTIDOS PELO PNF $\left(\mathrm{K}_{\mathrm{PNF}}\right)$ E PELO DISCO DE SECCHI $\left(\mathrm{K}_{\mathrm{S}}\right)$.

\begin{tabular}{c|c|c|c|c|c}
\hline \multirow{2}{*}{ Período } & \multicolumn{5}{|c}{$\mathbf{K}_{\mathbf{P N F}}=\boldsymbol{a} \mathbf{K}_{\mathbf{s}}+\boldsymbol{b}$} \\
\cline { 2 - 6 } & $\boldsymbol{a}$ & $\boldsymbol{b}$ & $\mathbf{n}$ & $\mathbf{R}^{\mathbf{2}}$ & $\mathbf{r m s}$ \\
\hline Verão & 0,569 & 0,015 & 51 & 0,58 & 0,03 \\
\hline Inverno & 0,644 & 0,011 & 40 & 0,74 & 0,04 \\
\hline Verão+Inverno & 0,625 & 0,011 & 91 & 0,69 & 0,03 \\
\hline
\end{tabular}

Os coeficientes de determinação $\left(\mathrm{R}^{2}\right)$ ficaram entre 0,58 e 0,74 sendo que, o ajuste para o inverno foi melhor ainda que com rms um pouco maior. O número de observações foi $\mathrm{n}=51$ para o verão, $\mathrm{n}=40$ para o inverno e $\mathrm{n}=91$ para o conjunto completo (verão + inverno).

A Figura 3.51 mostra os diagramas de dispersão dos conjuntos de dados referentes aos períodos de verão, inverno e completo. Nos três diagramas apresentados é possível notar que os valores obtidos com o PNF subestimam os coeficientes de atenuação estimados pelo disco de Secchi. 

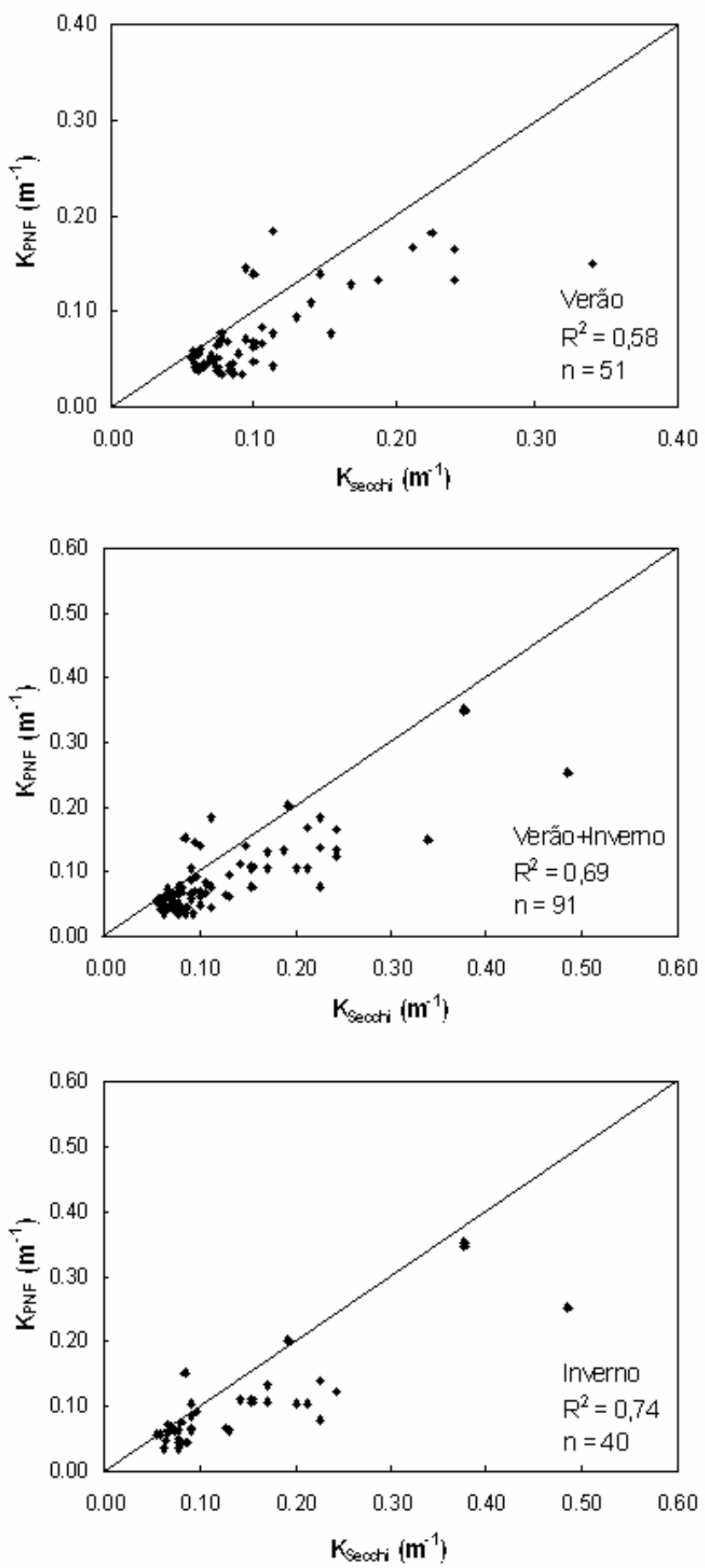

Figura 3.51 - Diagrama de dispersão dos coeficientes de atenuação vertical $\left(\mathrm{m}^{-1}\right)$ obtidos com o PNF ( $\left.\mathrm{K}_{\mathrm{PNF}}\right)$ versus os coeficientes estimados pelo disco de Secchi ( $\left.\mathrm{K}_{\text {Secchi }}\right)$, para o período de verão (em cima), verão + inverno (meio) e inverno (embaixo). 


\subsection{Testes estatísticos para agrupamento dos dados}

\subsubsection{Teste de hipótese para agrupamento dos cruzeiros M1-M3 e M2-M4}

Uma vez que foram realizados dois cruzeiros de verão (2001 e 2002) e dois cruzeiros de inverno (2001 e 2002), decidiu-se avaliar se os resultados obtidos em cada estação do ano e em anos diferentes poderiam ser estatisticamente considerados como pertencentes à mesma população, baseados nas estimativas da produção primária integrada na zona eufótica referente às amostras de superfície $\left(\mathrm{gC} \cdot \mathrm{m}^{-2} \cdot \mathrm{d}^{-1}\right)$ e da clorofila integrada na zona eufótica (mg.m $\mathrm{m}^{-2}$ ). A biomassa fitoplanctônica, indexada pela concentração de clorofila$a$, é a variável estimada por sensoriamento remoto da cor do oceano. Da mesma forma, a produtividade primária integrada na zona eufótica é alvo de estudo, cujas magnitudes pretende-se estimar a partir dos campos superficiais de clorofila- $a$ estimados por satélite. A Tabela 3.43 apresenta os resultados da análise geral dos cruzeiros amostrados quanto às variáveis selecionadas nesta análise.

TABELA 3.43 - RESUMO DAS VARIÁVEIS ANALISADAS

\begin{tabular}{|c|c|c|c|c|}
\hline CRUZEIRO & \multicolumn{2}{|c|}{ 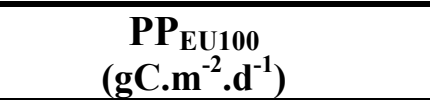 } & \multicolumn{2}{|c|}{$\underset{\left(\mathrm{mg} \cdot \mathrm{m}^{-2}\right)}{\mathrm{C}_{\mathrm{EU}}}$} \\
\hline & Média & Variância & Média & Variância \\
\hline M1 & 0,54 & 0,11 & 11,80 & 21,85 \\
\hline M2 & 1,39 & 1,05 & 24,77 & 51,25 \\
\hline M3 & 1,05 & 1,65 & 22,44 & 94,16 \\
\hline M4 & 0,71 & 0,49 & 21,51 & 36,06 \\
\hline
\end{tabular}

Os cruzeiros M1 e M3 referem-se ao período de verão, enquanto que os cruzeiros M2 e M4, referem-se ao período de inverno. O cruzeiro M2 apresentou valores superiores tanto para a produção primária integrada como para a clorofila integrada. Em 2001, o período de inverno apresentou valores superiores aos do verão $(\mathrm{M} 2>\mathrm{M} 1)$, mas em 2002, o padrão foi o oposto (M3 > M4). Deseja-se saber se os cruzeiros M1 e M3 podem ser considerados amostras de uma mesma população (verão), idem para os cruzeiros M2 e M4 (inverno). Contudo, não se sabe quais as características da população, ou seja, não se conhecem os valores de média e variância da população, apenas obteve-se a média e variância das amostras. O teste t de hipóteses foi aplicado para comparar os valores de média entre as amostras considerando-se a aleatoriedade 
das amostras e distribuição normal das populações. O teste f foi utilizado para testar se a igualdade das variâncias populacionais.

\section{Teste f para variância}

Para testar a igualdade das variâncias de M1 e M3 formulou-se a hipótese $\mathrm{H}_{0}$ : variância M1 = variância M3. Como resultado, obteve-se um F crítico igual a $0,39(5 \%$ de confiança, 12 e 20 graus de liberdade) e um F calculado igual a 0,07, para a produção primária integrada. Como $\mathrm{F}$ crítico foi maior que $\mathrm{F}$ calculado, não se pode rejeitar $\mathrm{H}_{0}$, logo, as variâncias são equivalentes.

Para a clorofila integrada, obteve-se um F crítico igual a 0,39 (5\% de confiança, 12 e 20 graus de liberdade) e um $\mathrm{F}$ calculado igual a 0,07 . Como $\mathrm{F}$ crítico foi maior do que $\mathrm{F}$ calculado, as variâncias são equivalentes.

Para testar a igualdade entre as variâncias de M2 e M4, procedeu-se da mesma forma. Como resultado, obteve-se um F crítico igual a 2,22 (5\% de confiança, 13 e 21 graus de liberdade) e um $\mathrm{F}$ calculado igual 2,16, para a produção primária integrada. Como $\mathrm{F}$ crítico foi maior do que o F calculado, conclui-se que as variâncias são equivalentes.

Para a clorofila integrada, obteve-se um F crítico igual a 2,22 (5\% de confiança, 13 e 21 graus de liberdade) e um F calculado igual a 1,42. Como $F$ crítico foi maior do que $F$ calculado, concluiu-se que as variâncias são equivalentes.

\section{Teste t para médias}

Uma vez que as variâncias não foram consideradas diferentes, seguiu-se com um teste $\mathrm{t}$ para comparar as médias. Foi formulada a hipótese $\mathrm{H}_{0}$ : média $\mathrm{M} 1$ = média M3. Como resultado, obteve-se um t crítico igual a 0,17 (bicaudal, $5 \%$ de confiança e 32 graus de liberdade) e um t calculado igual a 1,41 para a produção primária integrada. Como o $\mathrm{t}$ calculado está contido no intervalo $\pm 1,41$, não se pode rejeitar $\mathrm{H}_{0}, \log$, as médias são equivalentes. 
Para a clorofila integrada, obteve-se um t crítico igual a 2,74 (bicaudal, 1\% de confiança e 32 graus de liberdade) e um t calculado igual a -2,17. Como t calculado está contido no intervalo $\pm 2,74$, concluiu-se que as médias são equivalentes.

Para testar a igualdade entre as médias de M2 e M4, procedeu-se da mesma forma. Como resultado obteve-se um t crítico igual a 2,73 (bicaudal, 1\% de confiança, 34 graus de liberdade) e um t calculado igual a 2,38. Como t calculado está contido no intervalo $\pm 2,73$, não se pode rejeitar $\mathrm{H}_{0}$, logo as médias são equivalentes.

Para a clorofila integrada, obteve-se um t crítico igual a 2,03 (bicaudal, 5\% de confiança, 34 graus de liberdade) e um t calculado igual a 1,47. Como t calculado está contido no intervalo $\pm 2,03$, concluiu-se que as médias são equivalentes.

Os resultados obtidos a partir dos testes de hipóteses indicaram que tanto a produção primária como a clorofila $a$ integradas na zona eufótica apresentaram valores de variância que podem ser considerados equivalentes, permitindo assim a realização do teste t presumindo variâncias equivalentes para comparar suas respectivas médias. $\mathrm{O}$ teste $\mathrm{t}$ de hipóteses indicou que os cruzeiros M1 e M3, assim como M2 e M4, podem ser agrupados como verão e inverno, respectivamente.

Uma opção alternativa de análise dos dados, evitando os pressupostos de normalidade da população, seria possível através da aplicação de um teste não paramétrico, como teste de Mann-Whitney. Este teste pode ser utilizado em substituição ao teste t para avaliar se duas amostragens de tamanhos diferentes advêm da mesma população (Davis, 1973). Porém, este teste não foi realizado por não se dispor da tabela de valores críticos que considerasse amostras maiores que 20.

\subsubsection{Teste de hipótese para agrupamento verão-inverno}

Uma vez unidos os cruzeiros M1 e M3 que passaram a ser designados como "verão", e os cruzeiros M2 e M4, que passaram a ser designados como "inverno", caberia questionar se estes dois conjuntos podem ser considerados equivalentes ou não, baseando-se nas variáveis produção primária e clorofila $a$ integradas na zona eufótica. 
Neste ponto, seria possível proceder com uma análise de variância, mas como apenas duas variáveis estavam sendo consideradas, optou-se pelo uso do teste t novamente para comparar as médias populacionais, precedido pelo teste f para avaliar se as variâncias poderiam ser consideradas equivalentes.

\section{Teste f para variância}

Para testar a igualdade das variâncias de verão e inverno formulou-se a hipótese $\mathrm{H}_{0}$ : variância verão = variância inverno. Como resultado, obteve-se um F crítico igual a 1,77 (5\% de confiança, 33 de 35 graus de liberdade) e um F calculado igual a 1,39 para a produção primária integrada. Como $\mathrm{F}$ crítico é maior que $\mathrm{F}$ calculado, $\mathrm{H}_{0}$ não pode ser rejeitada, e as variâncias são equivalentes.

Para a clorofila integrada, obteve-se um F crítico igual a 1,77 (5\% de confiança, 33 e 35 graus de liberdade) e um $\mathrm{F}$ calculado igual a 4,94. Como $\mathrm{F}$ crítico foi menor que $\mathrm{F}$ calculado, as variâncias não são equivalentes.

\section{Teste t para médias}

Uma vez que a variância não foi considerada diferente par a variável produção primária integrada, seguiu-se com um teste t para comparar as médias. Foi formulada a hipótese $\mathrm{H}_{0}$ : média verão = média inverno. Como resultado, obteve-se um $\mathrm{t}$ crítico igual a 1,99 (bicaudal, 5\% de confiança e 68 graus de liberdade) e um t calculado igual a -0,50. Como o t calculado está contido no intervalo $\pm 1,99$, não se pode rejeitar $\mathrm{H}_{0}, \operatorname{logo}$, as médias são equivalentes.

Para a clorofila, procedeu-se com um teste $\mathrm{t}$ para comparar as médias entre duas amostras presumindo variâncias diferentes. Foi formulada a hipótese $\mathrm{H}_{0}$ : média verão média inverno, onde se obteve um F crítico igual a 2,01 (bicaudal, 5\% de confiança, 45 graus de liberdade) e $\mathrm{F}$ calculado igual a -1,61. Como $\mathrm{F}$ calculado está contido no intervalo $\pm 2,01$, concluiu-se que as médias são equivalentes. 
A partir destes resultados concluiu-se que os períodos de verão e de inverno não puderam ser diferenciados quanto às variáveis produção primária e clorofila $a$ integradas na zona eufótica.

\subsubsection{Teste de hipótese para regionalização}

Diversos trabalhos realizados na área de estudo sugeriram divisões para a plataforma continental sudeste brasileira. Os critérios adotados foram baseados em dados hidrográficos e correntometria (Castro, 1996), heterogeneidade nos gradientes horizontais de distribuição de biomassa fitoplanctônica (Gaeta, 1999), imagens CZCS de concentração de pigmentos (Gonzalez, 2001), entre outros. Uma análise preliminar dos resultados deste trabalho permitiu a identificação de uma heterogeneidade entre as regiões de plataforma e talude. Desta forma, o conjunto de dados foi dividido entre os domínios de plataforma (definida aqui até a profundidade de $140 \mathrm{~m}$, inclusive) e talude (profundidades maiores que $140 \mathrm{~m}$ ), preservando-se ainda a separação entre os períodos de verão e inverno. A seguir, optou-se pelo uso do teste t novamente para comparar as médias populacionais, precedido pelo teste $\mathrm{f}$ para avaliar se as variâncias poderiam ser consideradas equivalentes entre os domínios de "plataforma-verão" x "plataformainverno" e entre os domínio "talude-verão" x "talude-inverno".

\section{Teste f para variância}

Para testar a igualdade das variâncias de talude-verão e talude-inverno formulou-se a hipótese $\mathrm{H}_{0}$ : variância talude-verão = variância talude-inverno. Como resultado, obtevese um F crítico igual a 0,40 (5\% de confiança, 14 e 13 graus de liberdade) e um F calculado igual a 0,02 , para a produção primária integrada. Como $\mathrm{F}$ crítico foi maior que $\mathrm{F}$ calculado, não se pode rejeitar $\mathrm{H}_{0}$, logo, as variâncias são equivalentes.

Para a clorofila integrada, obteve-se um F crítico igual a 0,40 (5\% de confiança, 14 e 13 graus de liberdade) e um $\mathrm{F}$ calculado igual a 0,81. Como $\mathrm{F}$ crítico foi menor que $\mathrm{F}$ calculado, as variâncias não são equivalentes. 
Para testar a igualdade das variâncias de plataforma-verão e plataforma-inverno formulou-se a hipótese $\mathrm{H}_{0}$ : variância plataforma-verão = variância plataforma-inverno. Como resultado, obteve-se um F crítico igual a 2,12 (5\% de confiança, 18 e 21 graus de liberdade) e um $\mathrm{F}$ calculado igual a 2,94, para a produção primária integrada. Como $\mathrm{F}$ crítico foi menor que $\mathrm{F}$ calculado, rejeita-se $\mathrm{H}_{0}$, logo, as variâncias não são equivalentes.

Para a clorofila integrada, obteve-se um F crítico igual a 2,12 (5\% de confiança, 18 e 21 graus de liberdade) e um $\mathrm{F}$ calculado igual a 6,00. Como $\mathrm{F}$ crítico foi menor que $\mathrm{F}$ calculado, as variâncias não são equivalentes.

\section{Teste t para médias}

Uma vez que a variância da produção primária integrada não foi considerada diferente entre talude-verão e talude-inverno, seguiu-se com um teste t para comparar as médias. Foi formulada a hipótese $\mathrm{H}_{0}$ : média talude-verão = média talude-inverno. Como resultado, obteve-se um t crítico igual a 2,05 (bicaudal, 5\% de confiança e 27 graus de liberdade) e um t calculado igual a $-3,08$. Como o t calculado não está contido no intervalo $\pm 2,05$, rejeita-se $\mathrm{H}_{0}$. Logo, as médias não são equivalentes (resultado igual é obtido considerando $1 \%$ de confiança).

Para a clorofila, procedeu-se com um teste $\mathrm{t}$ para comparar as médias entre duas amostras presumindo variâncias diferentes. Foi formulada a hipótese $\mathrm{H}_{0}$ : média taludeverão $=$ média talude-inverno, onde se obteve um F crítico igual a 2,06 (bicaudal, 5\% de confiança, 26 graus de liberdade) e F calculado igual a -4,98. Como F calculado não está contido no intervalo $\pm 2,06$, concluiu-se que as médias não são equivalentes (resultado igual é obtido considerando $1 \%$ de confiança).

Para testar a igualdade entre as médias de plataforma-verão e plataforma-inverno, procedeu-se da mesma forma. Como resultado obteve-se um t crítico igual a 2,05 (bicaudal, 5\% de confiança, 28 graus de liberdade) e um $\mathrm{t}$ calculado igual a 1,25. Como t calculado está contido no intervalo $\pm 2,05$, não se pode rejeitar $\mathrm{H}_{0}$. Logo, as médias são equivalentes. 
Para a clorofila integrada, obteve-se um t crítico igual a 2,07 (bicaudal, 5\% de confiança, 23 graus de liberdade) e um t calculado igual a -0,02. Como t calculado está contido no intervalo $\pm 2,07$, concluiu-se que as médias são equivalentes.

Os resultados obtidos a partir destes testes de hipóteses, tanto para a produção primária integrada como para a clorofila $a$ integrada na zona eufótica, indicaram que o domínio de plataforma-verão não pode ser diferenciado do domínio plataforma-inverno, podendo ser agrupados em um único conjunto de dados.

Com relação aos domínios de talude-verão e talude-inverno, os testes de hipóteses indicaram que esses domínios podem ser diferenciados quanto à produção primária e clorofila $a$ integradas na zona eufótica.

Baseando-se nos resultados aqui obtidos, os dados foram agrupados em três conjuntos: plataforma, talude-verão e talude-inverno. Estes "domínios" foram adotados para a realização de diferentes análises cujos resultados são apresentados a seguir.

\subsection{Regressão Múltipla}

\subsubsection{Domínio plataforma}

A Tabela 3.44 apresenta as variáveis físicas, químicas e biológicas da coluna d'água e superfície calculados para o domínio de plataforma (Est - estação oceanográfica; $\mathrm{PP}_{\mathrm{EU}}-$ produção primária potencial integrada na zona eufótica em $\mathrm{gC} \cdot \mathrm{m}^{-2} \cdot \mathrm{d}^{-1} ; \mathrm{C}_{\mathrm{EU}}-$ clorofila $a$ integrada na zona eufótica em $\mathrm{mg} \cdot \mathrm{m}^{-2}$; Prof - profundidade em metros; $\mathrm{K}_{\mathrm{s}}$ - coeficiente

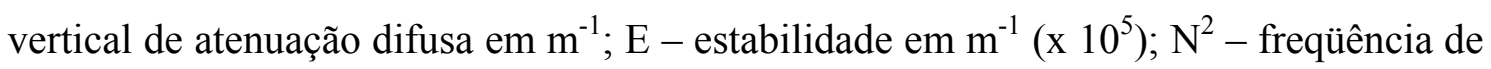
Brünt-Väisälä em s ${ }^{-2}\left(\begin{array}{ll}x & 10^{4}\end{array}\right) ; Z_{\mathrm{P}}$ - profundidade da picnoclina em metros; $Z_{\mathrm{T}}$ profundidade da termoclina em metros; $\mathrm{Z}_{\mathrm{M}}$ - profundidade do máximo de clorofila subsuperficial em metros; $Z_{\mathrm{EU}}$ - profundidade da zona eufótica em metros; $Z_{\mathrm{EU}} / Z_{\mathrm{T}}-$ adimensional; TAEU - taxa de assimilação potencial diária na zona eufótica em $\mathrm{mgC} .(\mathrm{mgClo})^{-1} \cdot \mathrm{d}^{-1} ; \mathrm{N}_{\mathrm{EU}}$ - nitrato integrado na zona eufótica em $\mu \mathrm{M} \cdot \mathrm{m}^{-2}$; TSM temperatura da superfície do mar em graus Celsius; $A_{E U}$ - amônia integrada na zona eufótica em $\mu \mathrm{M} \cdot \mathrm{m}^{-2}$. Apesar da produção primária integrada na zona eufótica aparecer 
na Tabela 3.44 expressa em gC.m ${ }^{-2} \cdot \mathrm{d}^{-1}$, de fato, foi utilizada a unidade em mgC.m $\mathrm{m}^{-2} \cdot \mathrm{d}^{-1}$ na análise por regressão múltipla.

No domínio plataforma, considerando-se os quatro cruzeiros conjuntamente, a $\mathrm{PP}_{\mathrm{EU}}$ variou entre 0,11 e 4,93 gC.m $\mathrm{m}^{-2} \cdot \mathrm{d}^{-1}$, com valor médio igual a $0,95 \pm 1,01 \mathrm{gC} \cdot \mathrm{m}^{-2} \cdot \mathrm{d}^{-1}$. A clorofila $a$ integrada na zona eufótica teve valor médio de $24,34 \pm 12,93 \mathrm{mg} \cdot \mathrm{m}^{-2}$, com variação entre 9,07 e 77,78 mg.m ${ }^{-2}$. Ambos os máximos foram estimados durante o cruzeiro de verão de 2002 (M3), em estações próximas à entrada da Baía de Guanabara (7125 e 7131, respectivamente). O maior valor de $\mathrm{K}_{\mathrm{s}}\left(0,34 \mathrm{~m}^{-1}\right)$ também foi encontrado na mesma estação em que se obteve a $\mathrm{PP}_{\mathrm{EU}}$ máxima (7125), próximo à isóbata de $40 \mathrm{~m}$. $\mathrm{O}$ comportamento de $\mathrm{E}$ e $\mathrm{N}^{2}$ foi muito correlacionado, como era de se esperar, e seus respectivos desvios padrão foram altos em relação às suas médias $(15,33 \pm 15,45$ $\mathrm{x} 10^{5} \mathrm{~m}^{-1}$ e $15,02 \pm 15,14 \times 10^{4} \mathrm{~s}^{-2}$ ). O mesmo comportamento correlacionado também foi observado para $Z_{P}$ e $Z_{T}$, com médias iguais a $24,1 \pm 15,5 \mathrm{~m}$ e $26,0 \pm 13,2 \mathrm{~m}$, respectivamente. Já $Z_{\mathrm{EU}}$ mostrou-se relativamente mais profunda que $Z_{\mathrm{P}}$ e $Z_{\mathrm{T}}$, com média igual a $37,3 \pm 17,1 \mathrm{~m}$. Isto pode ser comprovado pela relação $Z_{\mathrm{EU}} / \mathrm{Z}_{\mathrm{T}}$ quase sempre maior que 1,0 (média de 1,8 $\pm 1,2$ ). Interessante notar que o valor médio de $Z_{M}$ $(27,1 \pm 19,6 \mathrm{~m})$ se aproximou mais de $Z_{\mathrm{P}}$ e $\mathrm{Z}_{\mathrm{T}}$ do que de $\mathrm{Z}_{\mathrm{M}}$. A TA $\mathrm{A}_{\mathrm{EU}}$ variou entre 44,92 e 361,39 mgC. $(\mathrm{mgClo})^{-1} \cdot \mathrm{d}^{-1}$, com média igual a 44,92 $\pm 58,15 \mathrm{mgC} .(\mathrm{mgClo})^{-1} \cdot \mathrm{d}^{-1}$. O máximo de $\mathrm{TA}_{\mathrm{EU}}$ foi estimado na estação 7159 realizada durante o cruzeiro M3, próxima a São Tomé, na isóbata de $24 \mathrm{~m}$. O valor máximo de $\mathrm{A}_{\mathrm{EU}}$ foi observado neste mesmo cruzeiro, na estação 7151 (adjacente à 7159), próxima à isóbata de $50 \mathrm{~m}$. Já o valor máximo de $\mathrm{N}_{\mathrm{EU}}\left(108,37 \mu \mathrm{M}_{\mathrm{m}}{ }^{-2}\right)$, foi encontrado durante o verão de 2001 (M1) a cerca de $10 \mathrm{~km}$ da costa de Cabo Frio (6917). A TSM mostrou uma grande amplitude de variação $\left(14,69^{\circ}\right.$ a $\left.27,63^{\circ} \mathrm{C}\right)$, com valor médio igual a $22,37 \pm 2,59^{\circ} \mathrm{C}$. 
TABELA 3.44 - VARIÁVEIS FÍSICAS, QUÍMICAS E BIOLÓGICAS CALCULADAS PARA O DOMÍNIO PLATAFORMA

\begin{tabular}{|c|c|c|c|c|c|c|c|c|c|c|c|c|c|c|c|}
\hline Est & $\mathbf{P P}_{\mathbf{E U}}$ & $\mathbf{C}_{\mathrm{EU}}$ & rof & $\mathbf{K}_{\mathbf{S}}$ & $\mathbf{E}$ & $\mathbf{N}^{2}$ & $\mathbf{Z}_{\mathbf{P}}$ & $\mathbf{Z}_{T}$ & $\mathbf{Z}_{\mathbf{M}}$ & $\mathbf{Z}_{\mathbf{E U}}$ & $\begin{array}{c}\mathbf{Z}_{\mathbf{E U}} / \\
\mathbf{Z}_{\mathrm{T}}\end{array}$ & $\mathbf{T} \mathbf{A}_{\mathrm{EU}}$ & $\mathbf{N}_{\mathbf{E U}}$ & $\mathbf{S M}$ & $\mathbf{A}_{\mathbf{E U}}$ \\
\hline 889 & & 21.73 & & 0.15 & & & 5.0 & 14.0 & 3.1 & & & & 0.58 & & \\
\hline 91 & & 24 & & 14 & & & 0.0 & .0 & & & 0 & & & .11 & \\
\hline 892 & 46 & 10.57 & 7.0 & 0.09 & & & 4.0 & 13.0 & & & 4.2 & & & 25.49 & \\
\hline 08 & 39 & 38 & .0 & 0.13 & .33 & .10 & 3.0 & 9.0 & & & & & & 73 & 38 \\
\hline & & .28 & & 23 & & & & .0 & & & 0 & & & 69 & \\
\hline 6917 & & 9.07 & .0 & 0.19 & & & 4.0 & 8.0 & & & 3.0 & & & 22.28 & 1.14 \\
\hline 1 & 54 & 13.06 & 5.0 & 0.21 & & & 13.0 & 15.0 & & & & & & 06 & \\
\hline & & .46 & & 0.24 & & & & 30.0 & & & & & & .56 & \\
\hline 7065 & & 1.53 & .0 & 0.17 & & & 3.0 & 21.0 & & & .3 & & & .31 & 4.74 \\
\hline 16 & 91 & .58 & 7.0 & 0.14 & & & 18 & 35.0 & & & & & & .38 & \\
\hline & & .80 & & & & & & & & & & & & & \\
\hline 7068 & 29 & 23.29 & .0 & 0.15 & & & & 39.0 & & & 8 & & & .72 & 29.58 \\
\hline 7 & 40 & 3.18 & & 0.17 & & & & 26.0 & & & & & & 2.41 & .56 \\
\hline & & .90 & & & & & & & & & & & & & \\
\hline 707 & & 18.61 & 0 & 0. & & & & 46.0 & & & & & & .71 & .35 \\
\hline 7 & 33 & 16.88 & .0 & 0.10 & & & 0.0 & 14.0 & & & & & & .04 & 25 \\
\hline & & .46 & & & & & & .0 & & & & & & & \\
\hline 7 & & .30 & & & & & & 13.0 & & & & & & 27.63 & 00 \\
\hline 7 & & .05 & & 0.10 & & & & 12.0 & & & & & & & 4.41 \\
\hline & & .12 & & & & & & 16 & & & & & & & .38 \\
\hline & & .12 & & 0.34 & & & & 8.0 & & & & & & 53 & .99 \\
\hline & & 7.78 & & & & & & 25.0 & & & & & & & \\
\hline & & .23 & & & & & & 30.0 & & & & & & 62 & .1 \\
\hline 7. & & 26.17 & & 0.11 & & & & 9.0 & & & & & & .31 & 3.88 \\
\hline & & 12.20 & & & & & & 18.0 & & & & & & .76 & $\begin{array}{l}7.52 \\
\end{array}$ \\
\hline 7 & & .12 & & 0.24 & & & & 16.0 & & & & & & 48 & .5 \\
\hline 716 & & 39.88 & 6.0 & 0.24 & & & & 20.0 & & & & & & .41 & 19.93 \\
\hline & & 24.34 & & 0.1 & & & & 50 & & & & & & .44 & 06 \\
\hline 7268 & & 9.80 & & 0.17 & & & & 40.0 & & & & & & .56 & 10.09 \\
\hline 7278 & & 16.62 & & 0.23 & & & 24.0 & 28.0 & & & & & & 37 & 6.08 \\
\hline 7281 & 0 & 15.03 & & 0.19 & & & 9.0 & 59.0 & & & & & & .89 & 33 \\
\hline 7299 & & 28.00 & 0.0 & 0.10 & & & & 27.0 & & & & & & 2.40 & 11.0 \\
\hline 7305 & & 23.70 & & 0.09 & & & 37 & 38.0 & & & 4 & & & 2.78 & 12.67 \\
\hline 7306 & 0.4 & 25.85 & & 0.07 & & & 2.0 & 42.0 & & & & & & 22.69 & 22.48 \\
\hline 730 & 1 & 23.83 & & 0.09 & & & & 29.0 & & & & & & 22.69 & 17.75 \\
\hline & & 21.03 & 74.0 & 0.08 & & & & 40.0 & & & & & & 2.86 & 2.43 \\
\hline 731 & 27 & 19.30 & & 0.06 & & & 45.0 & 47.0 & & & 5 & 14.14 & .11 & 23.37 & 16.41 \\
\hline & 0 & 33.51 & 128.0 & 0.09 & & & & 29.0 & & & & .04 & & 22.87 & 7.45 \\
\hline Méd & & 24.34 & & 0.15 & & & & 26.0 & & 37.3 & & & & 22.37 & 12.68 \\
\hline Máz & 93 & 77.78 & 130.0 & 0.34 & 72.86 & 1.40 & 75.0 & 59.0 & 68.0 & 78.6 & 6.5 & 361.39 & 108.37 & 27.63 & 64.52 \\
\hline & & & & & & & & 8. & & & & & & 14.65 & 0.78 \\
\hline dp & 1.01 & 12.93 & 51.0 & 0.06 & $10.4 \mathrm{~J}$ & 15.14 & 15.5 & $\mid 13.2$ & 19.6 & 17.1 & 1.2 & & & 2.59 & 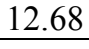 \\
\hline
\end{tabular}


Para verificar quais dessas variáveis seriam necessárias para a previsão de $\mathrm{PP}_{\mathrm{EU}}$ e $\mathrm{C}_{\mathrm{EU}}$ foram realizadas análises de regressão múltipla passo-a-passo, considerando-se $\mathrm{PP}_{\mathrm{EU}} \mathrm{e}$ $\mathrm{C}_{\mathrm{EU}}$ como varáveis dependentes (separadamente), e as demais variáveis físicas, químicas e biológicas mostradas na Tabela 3.44 como variáveis independentes. A Tabela 3.45 apresenta o resultado das análises de regressão múltipla realizadas para a variável dependente $\mathrm{PP}_{\mathrm{EU}}$ no domínio plataforma.

TABELA 3.45 - ANÁLISE DE REGRESSÃO MÚLTIPLA PARA A VARIÁVEL DEPENDENTE PP ${ }_{E U}$ NO DOMÍNIO PLATAFORMA.

\begin{tabular}{l|l|l|l|l}
\hline Variável & $\mathbf{R}$ & $\mathbf{R}^{2}$ & $\mathbf{F}$ & \% Explicação \\
\hline $\mathbf{T A}_{\mathbf{E U}}$ & 0,747 & 0,558 & 44,12 & 55,8 \\
\hline $\mathbf{C}_{\mathbf{E U}}$ & 0,893 & 0,797 & 66,56 & 23,9 \\
\hline $\mathbf{K s}$ & 0,901 & 0,813 & 47,69 & 1,6 \\
\hline $\mathbf{Z}_{\mathbf{E U}} / \mathbf{Z}_{\mathbf{T}}$ & 0,908 & 0,825 & 37,65 & 1,2 \\
\hline Total & & & & $82,5(\mathrm{gl} 4,32 \mathrm{p}<0,00000)$ \\
\hline
\end{tabular}

Equação: $\mathrm{PP}_{\mathrm{EU}}=-1216,35+13,52 \mathrm{TA}_{\mathrm{EU}}+36,38 \mathrm{C}_{\mathrm{EU}}+3249,33 \mathrm{~K}_{\mathrm{s}}+105,72 \mathrm{Z}_{\mathrm{EU}} / \mathrm{Z}_{\mathrm{T}}$

A Tabela 3.46 a seguir mostra o resultado das análises de regressão múltipla realizadas para a variável dependente $\mathrm{C}_{\mathrm{EU}}$ no domínio plataforma.

TABELA 3.46 - ANÁLISE DE REGRESSÃO MÚLTIPLA PARA A VARIÁVEL DEPENDENTE $\mathrm{C}_{\mathrm{EU}}$ NO DOMÍNIO PLATAFORMA.

\begin{tabular}{l|l|l|l|l}
\hline Variável & $\mathbf{R}$ & $\mathbf{R}^{\mathbf{2}}$ & $\mathbf{F}$ & \% Explicação \\
\hline $\mathbf{N}_{\mathbf{E U}}$ & 0,413 & 0,170 & 7,19 & 17,0 \\
\hline $\mathbf{T} \mathbf{A}_{\mathrm{EU}}$ & 0,498 & 0,248 & 5,60 & 7,8 \\
\hline $\mathbf{K}_{\mathbf{s}}$ & 0,524 & 0,275 & 4,17 & 2,7 \\
\hline Prof & 0,572 & 0,328 & 3,90 & 5,3 \\
\hline $\mathbf{N}^{2}$ & 0,616 & 0,379 & 3,78 & 5,1 \\
\hline Total & & & \multicolumn{5}{c}{$37,9(\mathrm{gl} 5,31 \mathrm{p}<0,00086)$} \\
\hline Equação: $\log \left(\mathrm{C}_{\mathrm{EU}}\right)=1,10-0,01 \mathrm{~N}_{\mathrm{EU}}-0,001 \mathrm{TA} \mathrm{A}_{\mathrm{EU}}+1,13 \mathrm{~K}_{\mathrm{s}}+0,002$ Prof $+0,0003 \mathrm{~N}^{2}$ \\
\hline
\end{tabular}

No domínio plataforma, a produção primária integrada na zona eufótica $\left(\mathrm{PP}_{\mathrm{EU}}\right)$ apresentou $56 \%$ de sua variância explicada por $\mathrm{TA}_{\mathrm{EU}}, 24 \%$ por $\mathrm{C}_{\mathrm{EU}}, 2 \%$ por $\mathrm{K}_{\mathrm{s}}$ e $1 \%$ por $\mathrm{Z}_{\mathrm{EU}} / \mathrm{Z}_{\mathrm{T}}$, às quais esteve diretamente correlacionada. A biomassa fitoplanctônica integrada na zona eufótica $\left(\mathrm{C}_{\mathrm{EU}}\right)$ esteve correlacionada a diversas variáveis, sendo que, $25 \%$ de explicação de sua variância foram atribuídas às variáveis $\mathrm{N}_{\mathrm{EU}}$ e TA $\mathrm{E}_{\mathrm{EU}}$ (inversamente correlacionadas) e $13 \%$ foram explicados por $\mathrm{K}_{\mathrm{s}}$, Prof e $\mathrm{N}^{2}$ (diretamente correlacionadas). 


\subsubsection{Domínio talude-verão}

A Tabela 3.47 apresenta as variáveis físicas, químicas e biológicas da coluna d'água e superfície calculados para o domínio talude-verão.

TABELA 3.47 - VARIÁVEIS FÍSICAS, QUÍMICAS E BIOLÓGICAS CALCULADAS PARA O DOMÍNIO TALUDE-VERÃO.

\begin{tabular}{|c|c|c|c|c|c|c|c|c|c|c|c|c|c|c|c|}
\hline Est & $\mathbf{P P}_{\mathbf{E U}}$ & $\mathbf{C}_{\mathbf{E U}}$ & Prof & $\mathbf{K}_{\mathrm{s}}$ & $\mathbf{E}$ & $\mathbf{N}^{2}$ & $\mathbf{Z}_{\mathbf{P}}$ & $\mathbf{Z}_{\mathrm{T}}$ & $\mathbf{Z}_{M}$ & $\mathbf{Z}_{\mathbf{E U}}$ & $\begin{array}{c}\mathbf{Z}_{\mathbf{E U}} / \\
\mathbf{Z}_{\mathbf{T}}\end{array}$ & $A_{-}$ & $\mathbf{N}_{\mathbf{E U}}$ & TSM & $\mathbf{A}_{\mathbf{E U}}$ \\
\hline 6885 & 23 & 8.66 & 60.0 & $|0.07|$ & 58.37 & 57.20 & 18.0 & 17.0 & 85.6 & 62.3 & 3.7 & 26.33 & 9.94 & 7.51 & 9.94 \\
\hline 86 & 16 & 68 & & & 63 & & .0 & 7.0 & .3 & 0.6 & 2.4 & 3.73 & & & \\
\hline 6898 & 60 & 7 & & & & & 19.0 & & & 70.4 & 3.9 & .71 & .45 & & 1 \\
\hline 6900 & 57 & 9.21 & 1323.0 & 0. & .97 & 67.60 & 23.0 & 19.0 & 77.7 & 65.0 & 3.4 & 61.58 & 08 & & 19.0 \\
\hline 901 & 31 & 52 & & 0.10 & .72 & 49.71 & .0 & 25.0 & 7.7 & 46.1 & 1.8 & 40.91 & 49 & & \\
\hline $\mathbf{6}$ & & & & & 12 & 1 & 17 & 8.0 & & .6 & 3 & 3.47 & & & 48 \\
\hline 7097 & 15 & 5.89 & 462.0 & \begin{tabular}{|l|}
0.09 \\
\end{tabular} & & 43.70 & 37.0 & 29.0 & \begin{tabular}{|l|}
97.9 \\
\end{tabular} & 54.2 & 1.9 & 24.74 & .92 & 6.10 & 13.03 \\
\hline 106 & 0 & 09 & & 0.0 & & & 36.0 & 39.0 & 104.4 & 55.5 & 4 & 49.15 & 1.92 & & \\
\hline 10 & & .93 & 5.0 & 0.11 & 80.16 & 176.56 & 30.0 & 29.0 & 71.7 & 43.3 & 1.5 & 30.65 & .22 & .74 & 33 \\
\hline 7120 & 46 & .41 & 1121.0 & \begin{tabular}{|l|}
0.07 \\
\end{tabular} & 55.03 & 53.93 & 32.0 & 35.0 & 95.2 & \begin{tabular}{|l|}
70.4 \\
\end{tabular} & 2.0 & 43.96 & 19.72 & 4.81 & 8.55 \\
\hline 7121 & 0. & .44 & 280.0 & 0.0 & & 78.33 & 20.0 & 23.0 & 73 & 81.3 & 3. & 19.91 & 32.98 & 5.01 & 24.9 \\
\hline 135 & 0. & 46 & 334.0 & 0.07 & 51.29 & 50.27 & 51.0 & 27.0 & 81.4 & 65.0 & 2.4 & 18.56 & \begin{tabular}{|l|}
1.35 \\
\end{tabular} & 6.06 & 4.88 \\
\hline 7145 & 39 & .73 & 1026.0 & 0.09 & 38.57 & 37.80 & 52.0 & 49.0 & 87.3 & \begin{tabular}{|l|}
50.1 \\
\end{tabular} & 1.0 & 19.63 & 87 & 6.49 & 28.80 \\
\hline 7155 & 0. & 8.27 & 2491.0 & 0.0 & 29.9 & 29.30 & 63.0 & 60.0 & 11 & 75.8 & 1. & 48.65 & 20 & 6.25 & 28.5 \\
\hline 7165 & \begin{tabular}{|l|}
0.47 \\
\end{tabular} & 70 & 2522.0 & 0.06 & 38.88 & 38.10 & 51.0 & 46.0 & 101.1 & \begin{tabular}{|l|}
78.6 \\
\end{tabular} & 1.7 & 48.06 & 10.93 & 6.38 & 74.98 \\
\hline Méd & 0.38 & 1.27 & 1133.7 & 0.08 & 64.11 & 62.83 & 32.5 & 30.1 & 83.5 & 61.2 & 2.4 & 36.74 & 15.50 & 6.02 & 20.03 \\
\hline Má & 0.60 & .73 & 2522.0 & 0.11 & 30.16 & 176.56 & 63 & 60.0 & 114.3 & 81.3 & 3.9 & 61.58 & 68.04 & 7.51 & 74.9 \\
\hline Mín & 0.15 & .68 & 155.0 & 0.06 & 29.90 & 29.30 & 13.0 & 17.0 & 43.3 & \begin{tabular}{|l|}
40.6 \\
\end{tabular} & 1.0 & 18.56 & \begin{tabular}{|l|}
1.35 \\
\end{tabular} & 24.74 & 1.00 \\
\hline dp & 0.14 & 4.86 & 761.3 & \begin{tabular}{|l|}
0.02 \\
\end{tabular} & 37.80 & 37.04 & 15.4 & 13.2 & 17.6 & $\mid 12.8$ & 1.0 & 13.76 & 17.06 & \begin{tabular}{|l|}
0.77 \\
\end{tabular} & 22.9 \\
\hline
\end{tabular}

No domínio talude-verão, considerando-se apenas os cruzeiros de verão (M1 e M3), a $\mathrm{PP}_{\mathrm{EU}}$ variou entre 0,15 e $0,60 \mathrm{gC} \cdot \mathrm{m}^{-2} \cdot \mathrm{d}^{-1}$, com valor médio igual a $0,38 \pm 0,14 \mathrm{gC} \cdot \mathrm{m}^{-2} \cdot \mathrm{d}^{-}$ ${ }^{1}$, portanto bem menor do que no domínio plataforma. A Clorofila $a$ integrada na zona eufótica teve valor médio de 19,73 \pm 4,86 mg.m ${ }^{-2}$, com variação entre 5,68 e 19,73 $\mathrm{mg} \cdot \mathrm{m}^{-2}$, e também mostrou uma magnitude inferior a observada no domínio plataforma. A amplitude de variação de $\mathrm{K}_{\mathrm{s}}$ foi baixa, entre 0,06 e $0,08 \mathrm{~m}^{-1}$, como pode ser comprovado pelo desvio padrão obtido para a média $\left(0,08 \pm 0,02 \mathrm{~m}^{-1}\right)$. Tanto $\mathrm{E}$ como $\mathrm{N}^{2}$ apresentaram valor máximo $\left(180,16 \times 10^{5} \mathrm{~m}^{-1}\right.$ e $\left.176,56 \times 10^{4} \mathrm{~s}^{-2}\right)$ na mesma estação oceanográfica (7110), realizada durante o cruzeiro M3. As profundidades médias de $Z_{\mathrm{P}}$ e $\mathrm{Z}_{\mathrm{T}}$ foram similares $\left(32,5 \pm 15,4 \mathrm{~m}\right.$ e $30,1 \pm 13,2 \mathrm{~m}$, respectivamente). Já $\mathrm{Z}_{\mathrm{EU}}$ mostrou- 
se mais profundo, com valor médio igual $61,22 \pm 12,8 \mathrm{~m}$. Este comportamento pode ser confirmado pela relação $Z_{\mathrm{EU}} / \mathrm{Z}_{\mathrm{T}}$ sempre maior que 1,0 (média igual a 2,4 $\pm 1,0$ ). Cabe mencionar que os valores apresentados para $\mathrm{Z}_{\mathrm{M}}$ foram calculados através da modelagem Gaussiana do perfil vertical de biomassa. Por isso o valor médio encontrado nesta análise $(83,54 \pm 17,6 \mathrm{~m})$ foi superior ao valor médio de $Z_{\mathrm{EU}}$. Entretanto, pode-se inferir que $Z_{M}$ se aproximou mais de $Z_{E U}$ do que de $Z_{P}$ ou $Z_{T}$. A TA $A_{E U}$ variou entre 18,56 e $61,58 \mathrm{mgC} .(\mathrm{mgClo})^{-1} \cdot \mathrm{d}^{-1}$, com média igual a $36,74 \pm 13,76 \mathrm{mgC} \cdot(\mathrm{mgClo})^{-1} \cdot \mathrm{d}^{-1}$, ou seja, com valores inferiores aos observados no domínio de plataforma. Tanto $\mathrm{N}_{\mathrm{EU}}$ como $\mathrm{A}_{\mathrm{EU}}$ apresentaram grande amplitude de variação $\left(1,35\right.$ a 68,04 e 1,00 a 74,98 $\mu \mathrm{M} . \mathrm{m}^{-2}$, respectivamente). A TSM por sua vez, mostrou uma pequena variação, entre $24,74^{\circ} \mathrm{e}$ $27,51^{\circ} \mathrm{C}$, com valor médio igual a $26,02 \pm 0,77^{\circ} \mathrm{C}$.

A Tabela 3.48 apresenta o resultado das análises de regressão múltipla realizadas para a variável dependente $\mathrm{PP}_{\mathrm{EU}}$ no domínio talude-verão.

TABELA 3.48 - ANÁLISE DE REGRESSÃO MÚLTIPLA PARA A VARIÁVEL DEPENDENTE PP ${ }_{\text {EU }}$ NO DOMÍNIO TALUDE-VERÃO.

\begin{tabular}{l|l|l|l|l}
\hline Variável & $\mathbf{R}$ & $\mathbf{R}^{\mathbf{2}}$ & $\mathbf{F}$ & \% Explicação \\
\hline $\mathbf{T A}_{\mathbf{E U}}$ & 0,512 & 0,263 & 4,63 & 26,3 \\
\hline $\mathbf{C}_{\mathbf{E U}}$ & 0,984 & 0,969 & 185,80 & 70,6 \\
\hline Prof & 0,986 & 0,972 & 126,81 & 0,3 \\
\hline $\mathbf{A}_{\mathbf{E U}}$ & 0,988 & 0,976 & 102,30 & 0,4 \\
\hline $\mathbf{T S M}$ & 0,990 & 0,979 & 85,57 & 0,3 \\
\hline $\mathbf{Z}_{\mathbf{P}}$ & 0,993 & 0,986 & 92,79 & 0,7 \\
\hline $\mathbf{Z}_{\mathbf{E U}} / \mathbf{Z}_{\mathbf{T}}$ & 0,995 & 0,989 & 90,28 & 0,3 \\
\hline $\mathbf{N}_{\mathbf{E U}}$ & 0,997 & 0,995 & 145,77 & 0,6 \\
\hline Total & & \multicolumn{3}{c}{$99,5(\mathrm{gl} 8,6 \mathrm{p}<0,00000)$} \\
\hline Equação: $\log \left(\mathrm{PP}_{\mathrm{EU}}\right)$ & $=2,94+0,12 \mathrm{TA} \mathrm{A}_{\mathrm{EU}}+0,04 \mathrm{C}_{\mathrm{EU}}+0,00008 \mathrm{Prof}-0,000112 \mathrm{~A}_{\mathrm{EU}}-$ \\
\multicolumn{5}{c}{$0,04 \mathrm{TSM}-0,004 \mathrm{Z}_{\mathrm{P}}-0,03 \mathrm{Z}_{\mathrm{EU}} / \mathrm{Z}_{\mathrm{T}}-0,002 \mathrm{~N}_{\mathrm{EU}}$} \\
\hline
\end{tabular}

No domínio talude-verão, a produção primária integrada na zona eufótica $\left(\mathrm{PP}_{\mathrm{EU}}\right)$ esteve correlacionada a diversas variáveis, mas $97 \%$ de explicação de sua variância foram atribuídas a $\mathrm{TA}_{\mathrm{EU}}, \mathrm{C}_{\mathrm{EU}}$ e Prof (diretamente correlacionadas). A biomassa fitoplanctônica integrada na zona eufótica $\left(\mathrm{C}_{\mathrm{EU}}\right)$ apresentou $46 \%$ de sua variância explicada por $\mathrm{TA}_{\mathrm{EU}}$, $\mathrm{TSM} \mathrm{e} \mathrm{K}_{\mathrm{s}}$, às quais esteve inversamente correlacionada, e $9 \%$ atribuída a $\mathrm{N}^{2}$ à qual esteve diretamente correlacionada. 
A Tabela 3.49 a seguir mostra o resultado das análises de regressão múltipla realizadas para a variável dependente $\mathrm{C}_{\mathrm{EU}}$ no domínio plataforma.

TABELA 3.49 - ANÁLISE DE REGRESSÃO MÚLTIPLA PARA A VARIÁVEL DEPENDENTE $\mathrm{C}_{\mathrm{EU}}$ NO DOMÍNIO TALUDE-VERÃO.

\begin{tabular}{l|l|l|l|l}
\hline Variável & $\mathbf{R}$ & $\mathbf{R}^{\mathbf{2}}$ & $\mathbf{F}$ & \% Explicação \\
\hline TA $\mathbf{A}_{\mathbf{E U}}$ & 0,503 & 0,253 & 4,42 & 25,3 \\
\hline TSM & 0,635 & 0,403 & 4,05 & 15,0 \\
\hline $\mathbf{K}_{\mathbf{s}}$ & 0,677 & 0,458 & 3,10 & 5,5 \\
\hline $\mathbf{N}^{2}$ & 0,738 & 0,545 & 2,99 & 8,7 \\
\hline Total & & & & $54,5(\mathrm{gl} \mathrm{4,10} \mathrm{p}<0,00072)$ \\
\hline
\end{tabular}

Equação: $\mathrm{C}_{\mathrm{EU}}=59,68-0,21 \mathrm{TA}_{\mathrm{EU}}-1,37 \mathrm{TSM}-100,46 \mathrm{~K}_{\mathrm{s}}+0,05 \mathrm{~N}^{2}$

\subsubsection{Domínio talude-inverno}

A Tabela 3.50 apresenta as variáveis físicas, químicas e biológicas da coluna d'água e superfície calculados para o domínio talude-inverno. No domínio talude-inverno, considerando-se apenas os cruzeiros $\mathrm{M} 2$ e $\mathrm{M} 4$, a $\mathrm{PP}_{\mathrm{EU}}$ variou entre 0,18 e 3,60 gC.m $2 . \mathrm{d}^{-1}$, com valor médio igual a $1,23 \pm 1,05 \mathrm{gC} \cdot \mathrm{m}^{-2} \cdot \mathrm{d}^{-1}$, portanto maior do que no domínio talude-verão. A variável $\mathrm{TA}_{\mathrm{EU}}$ também apresentou valor máximo $(175,35$ mgC.(mgClo $\left.)^{-1} \cdot \mathrm{d}^{-1}\right)$ na mesma estação que $\mathrm{PP}_{\mathrm{EU}}(7060)$. $\mathrm{O}$ valor médio de $\mathrm{TA} \mathrm{EU}_{\mathrm{EU}}$ foi igual a $61,52 \pm 7,25 \mathrm{mgC} \cdot(\mathrm{mgClo})^{-1} \cdot \mathrm{d}^{-1}$. A Clorofila $a$ integrada na zona eufótica teve valor médio de 20,78 $\pm 5,40 \mathrm{mg} \cdot \mathrm{m}^{-2}$, com variação entre 10,64 e 28,62 mg.m ${ }^{-2}$, mostrando uma amplitude de variação maior que a observada no domínio talude-verão. O comportamento de $\mathrm{K}_{\mathrm{s}}$ foi similar ao observado no domínio talude-verão, ou seja, com pequena amplitude de variação $\left(0,06\right.$ a $\left.0,09 \mathrm{~m}^{-1}\right)$. Os valores máximos de $\mathrm{E}$ e $\mathrm{N}^{2}$ $\left(94,93 \times 10^{5} \mathrm{~m}^{-1}\right.$ e $93,03 \times 10^{4} \mathrm{~s}^{-2}$, respectivamente) foram encontrados na mesma estação (7293) realizada durante o cruzeiro $M 4$, em que $Z_{M}$ também foi máximo (100,0 m). O valor médio de $Z_{M}$ foi igual a $52,4 \pm 15,4 \mathrm{~m}$, portanto mais raso do que os valores médios de $\mathrm{K}_{\mathrm{T}}(64,7 \pm 28,3 \mathrm{~m}), \mathrm{K}_{\mathrm{P}}(68,7 \pm 40,4 \mathrm{~m})$ e $\mathrm{Z}_{\mathrm{EU}}(62,5 \pm 8,16 \mathrm{~m})$. O valor médio da relação $Z_{\mathrm{EU}} / \mathrm{Z}_{\mathrm{T}}$ foi igual a $1,3 \pm 0,96 \mathrm{~m}$, com variação entre 0,5 e 4,3 m. $\mathrm{O}$ valor máximo de $\mathrm{A}_{\mathrm{EU}}$ foi encontrado na mesma estação em que $\mathrm{C}_{\mathrm{EU}}$ também foi máximo

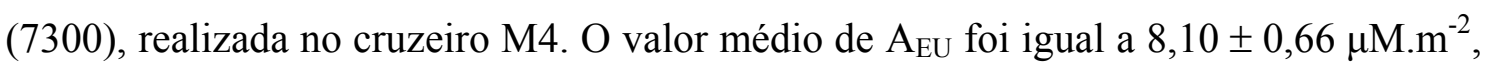
ou seja, maior que a média de $\mathrm{N}_{\mathrm{EU}}(6,27 \pm 0,66 \mu \mathrm{M})$. A TSM mostrou pequena 
amplitude de variação (de 22,74 a $24,72{ }^{\circ} \mathrm{C}$ ), um pouco menor que no domínio taludeverão.

TABELA 3.50 - VARIÁVEIS FÍSICAS, QUÍMICAS E BIOLÓGICAS CALCULADAS PARA O DOMÍNIO TALUDE-INVERNO.

\begin{tabular}{|c|c|c|c|c|c|c|c|c|c|c|c|c|c|c|c|}
\hline Est & $P_{\mathbf{E U}}$ & $\mathbf{C}_{\mathbf{E U}}$ & Prof & $\mathbf{K}_{\mathbf{S}}$ & $\mathbf{E}$ & $\mathbf{N}$ & $\mathbf{Z}_{\mathbf{P}}$ & $\mathbf{Z}_{\mathrm{T}}$ & $\mathbf{Z}_{\mathrm{M}}$ & $\mathbf{Z}_{\mathbf{E U}}$ & $\mid \begin{array}{c}\mathbf{Z}_{\mathrm{EU}} / \\
\mathbf{Z}_{\mathrm{T}}\end{array}$ & $\mathbf{T} \mathbf{A}_{\mathrm{EU}}$ & $\mathbf{N}_{\mathrm{EU}}$ & SM & \\
\hline & & & & & & & & & & & & & & & \\
\hline & & & & & & & & & & & 6 & & & & \\
\hline & & & & & & & & & & & & & & & \\
\hline & & & & & & & & & & & & & & & \\
\hline & & & & & & & & & & & 8 & & & & \\
\hline & & & & & & & & & & & 0 & & & & \\
\hline & & & & & & & & & & & & & & & \\
\hline & & & & & & & & & & & 5 & & 47 & .1 & \\
\hline & & & & & & & & & & & & & & & \\
\hline & & & & & & & & & & & & & & & \\
\hline & & & & & & & & & & & 9 & & .25 & 2.93 & \\
\hline & & & & & & & & & & & & & & 14 & \\
\hline & & & & & & & & & & & & & & & \\
\hline & & & & & & & & & & & & & & & \\
\hline & & & & & & 42.98 & & & & & 3 & & & 23.2 & \\
\hline & & & & & & & & & & & & & & .72 & \\
\hline & & & & & & & & & & & 0.5 & & & 2.74 & \\
\hline dp & 1.05 & 5.40 & 593.3 & 0.01 & 25.56 & 25.05 & 40.4 & 28.3 & 15.4 & \begin{tabular}{|l|}
8.2 \\
\end{tabular} & 1.0 & 52.76 & 5.55 & 0.57 & 6.4 \\
\hline
\end{tabular}

A Tabela 3.51 apresenta o resultado das análises de regressão múltipla realizadas para a variável dependente $\mathrm{PP}_{\mathrm{EU}}$ no domínio talude-inverno. A Tabela 3.52 apresenta $\mathrm{o}$ resultado das análises de regressão múltipla realizadas para a variável dependente $\mathrm{C}_{\mathrm{EU}}$ no domínio talude-inverno.

No domínio talude-inverno, a produção primária integrada na zona eufótica $\left(\mathrm{PP}_{\mathrm{EU}}\right)$ esteve correlacionada diretamente com $\mathrm{TA}_{\mathrm{EU}}$ e $\mathrm{C}_{\mathrm{EU}}$, que explicaram 97,9\% de sua variância, e inversamente correlacionada com $\mathrm{N}_{\mathrm{EU}}$, Prof e $Z_{\mathrm{P}}$, que explicaram $0,6 \%$ da variância. A biomassa fitoplanctônica integrada na zona eufótica $\left(\mathrm{C}_{\mathrm{EU}}\right)$ teve $45 \%$ de sua variância explicada diretamente por Ter e apresentou correlação inversa a Prof, $\mathrm{K}_{\mathrm{s}}$, TA $A_{\mathrm{EU}}, Z_{\mathrm{M}}, Z_{\mathrm{P}}$, TSM, $Z_{\mathrm{EU}}$ e $\mathrm{Z}_{\mathrm{EU}} / \mathrm{Z}_{\mathrm{T}}$ que explicaram 50 \% de sua variância. 
TABELA 3.51 - ANÁLISE DE REGRESSÃO MÚLTIPLA PARA A VARIÁVEL DEPENDENTE PP ${ }_{\mathrm{EU}}$ NO DOMÍNIO TALUDE-INVERNO.

\begin{tabular}{l|l|l|l|l}
\hline Variável & $\mathbf{R}$ & $\mathbf{R}^{\mathbf{2}}$ & $\mathbf{F}$ & \% Explicação \\
\hline TA $_{\mathbf{E U}}$ & 0,965 & 0,931 & 162,29 & 93,1 \\
\hline $\mathbf{C}_{\mathbf{E U}}$ & 0,989 & 0,079 & 256,53 & 4,8 \\
\hline $\mathbf{N}_{\mathbf{E U}}$ & 0,990 & 0,981 & 172,73 & 0,2 \\
\hline Prof & 0,992 & 0,983 & 131,04 & 0,2 \\
\hline $\mathbf{Z}_{\mathbf{P}}$ & 0,993 & 0,985 & 108,51 & 0,2 \\
\hline \multicolumn{7}{l}{ Total } & \multicolumn{5}{l}{} & $98,5(\mathrm{gl} 5,8 \mathrm{p}<0,00000)$ \\
\hline Equação: $\mathrm{PP}_{\mathrm{EU}}=-546,07+19,06 \mathrm{TA} \mathrm{EU}_{\mathrm{EU}}+33,83 \mathrm{C}_{\mathrm{EU}}-9,53 \mathrm{~N}_{\mathrm{EU}}-0,18 \operatorname{Prof}+1,40 \mathrm{Z}_{\mathrm{P}}$ \\
\hline
\end{tabular}

TABELA 3.52 - ANÁLISE DE REGRESSÃO MÚLTIPLA PARA A VARIÁVEL DEPENDENTE $\mathrm{C}_{\mathrm{EU}}$ NO DOMÍNIO TALUDE-INVERNO.

\begin{tabular}{l|l|l|l|l}
\hline Variável & $\mathbf{R}$ & $\mathbf{R}^{\mathbf{2}}$ & $\mathbf{F}$ & \% Explicação \\
\hline $\mathbf{Z}_{\mathbf{T}}$ & 0,668 & 0,447 & 9,69 & 44,7 \\
\hline Prof & 0,810 & 0,657 & 10,51 & 21,0 \\
\hline $\mathbf{K}_{\mathbf{s}}$ & 0,870 & 0,757 & 10,36 & 10,0 \\
\hline $\mathbf{T A}_{\mathbf{E U}}$ & 0,888 & 0,789 & 8,41 & 3,2 \\
\hline $\mathbf{Z}_{\mathbf{M}}$ & 0,913 & 0,834 & 8,01 & 4,5 \\
\hline $\mathbf{Z}_{\mathbf{P}}$ & 0,928 & 0,862 & 7,29 & 2,8 \\
\hline $\mathbf{T S M}$ & 0,945 & 0,893 & 7,15 & 3,1 \\
\hline $\mathbf{Z}_{\mathbf{E U}}$ & 0,958 & 0,919 & 7,05 & 2,6 \\
\hline $\mathbf{Z}_{\mathbf{E U}} / \mathbf{Z}_{\mathbf{T}}$ & 0,972 & 0,945 & 7,69 & 2,6 \\
\hline Total & & & & $94,5(\mathrm{gl} \mathrm{9,4} \mathrm{p}<0,00032)$ \\
\hline
\end{tabular}

Equação: $\mathrm{C}_{\mathrm{EU}}=267,69+0,08 \mathrm{Z}_{\mathrm{T}}-0,004$ Prof $-1144,02 \mathrm{~K}_{\mathrm{s}}-0,01 \mathrm{TA}_{\mathrm{EU}}-0,28 \mathrm{Z}_{\mathrm{M}}-$ $0,08 \mathrm{Z}_{\mathrm{P}}-3,73 \mathrm{TSM}-1,00 \mathrm{Z}_{\mathrm{EU}}+2,88 \mathrm{Z}_{\mathrm{EU}} / \mathrm{Z}_{\mathrm{T}}$

\subsection{Rede Neural}

A aplicação da rede neural neste trabalho deve ser considerada como uma tentativa inicial de se utilizar uma ferramenta poderosa que se bem explorada, poderá trazer significativos benefícios para os oceanógrafos interessados em modelar e prever a produção primária. Inicialmente, tentou-se fazer uma abordagem bem simples, com uma rede neural 3-5-1, utilizando a irradiância superficial, concentração de clorofila superficial e profundidade da zona eufótica como padrões de entrada (inputs). Entretanto, a rede neural 3-5-1 não foi capaz de reproduzir os valores de produção primária integrada na zona eufótica obtidos in situ $\left(\mathrm{R}^{2}\right.$ não significativo; $\left.\mathrm{p}>0,05\right)$.

Baseando-se nos resultados obtidos neste trabalho, e por outros autores que analisaram a produção primária na região sudoeste do Atlântico Sul, optou-se por incorporar outras 
variáveis ambientais como padrões de entrada de modo a melhorar o desempenho da rede neural. Foram realizados diferentes testes empíricos, tendo sempre a produção primária integrada na zona eufótica como padrão de saída. Todas as redes neurais testadas como modelos empíricos foram do tipo perceptron multicamada, com uma única camada oculta e com um único neurônio de saída. Segundo Scardi e Harding (1999) este é um tipo comum e flexível de rede neural e apresenta bom desempenho em diversas aplicações.

O modelo de rede neural usando uma estrutura 12-5-1, ou seja, com um conjunto mais amplo de variáveis preditivas, apresentou resultados mais satisfatórios (Figura 3.52). Os padrões de entrada utilizados foram: dia do ano, latitude, longitude, profundidade, temperatura da água, salinidade, concentração de clorofila $a$, clorofila $a$ integrada na zona eufótica, irradiância na superfície, coeficiente vertical de atenuação difusa e profundidade da zona eufótica. Os padrões produção primária integrada e clorofila $a$ superficial e integrada na zona eufótica foram transformados em base logarítmica decimal. Esta transformação foi baseada em resultados obtidos em outros trabalhos (Scardi, 1996, Scardi e Harding 1999), em testes empíricos e considerações teóricas.

Foram utilizados 45 pontos para treinamento da rede neural e 22 para validação. $O$ modelo final obtido conseguiu explicar $53 \%$ da variância dos dados usados para validação $(\mathrm{n}=22 ; \mathrm{rms}=0,13)$. Ao se aplicar a rede neural ao conjunto total de pontos $(\mathrm{n}=67)$, obteve-se um resultado um pouco pior $\left(\mathrm{R}^{2}=0,43 ; \mathrm{rms}=0,14\right)$. A Figura 3.53 mostra o diagrama de dispersão do conjunto total de pontos. 


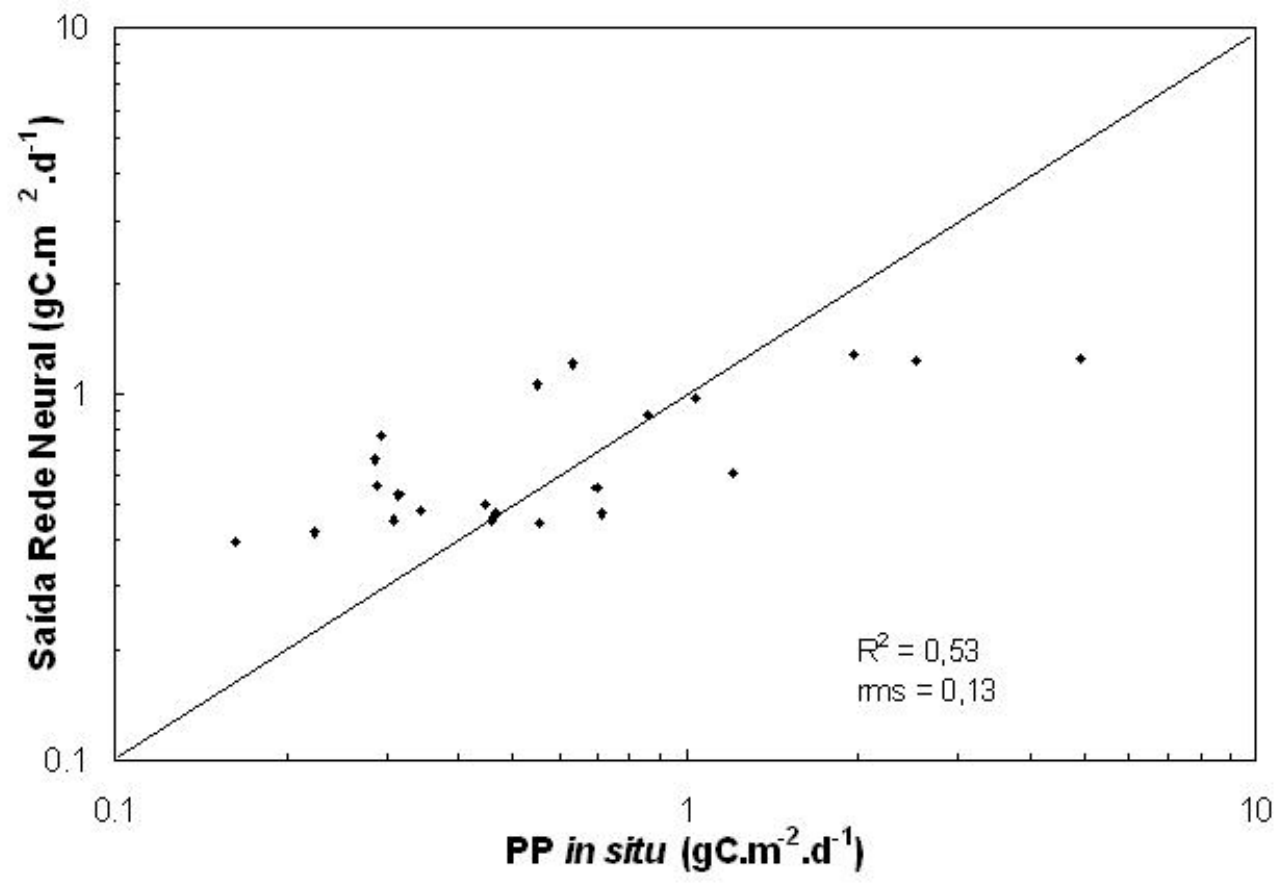

Figura 3.52 - Diagrama de dispersão das saídas da rede neural versus a produção primária integrada na zona eufótica para o modelo 12-5-1, utilizando o conjunto de dados para validação $(n=22)$.

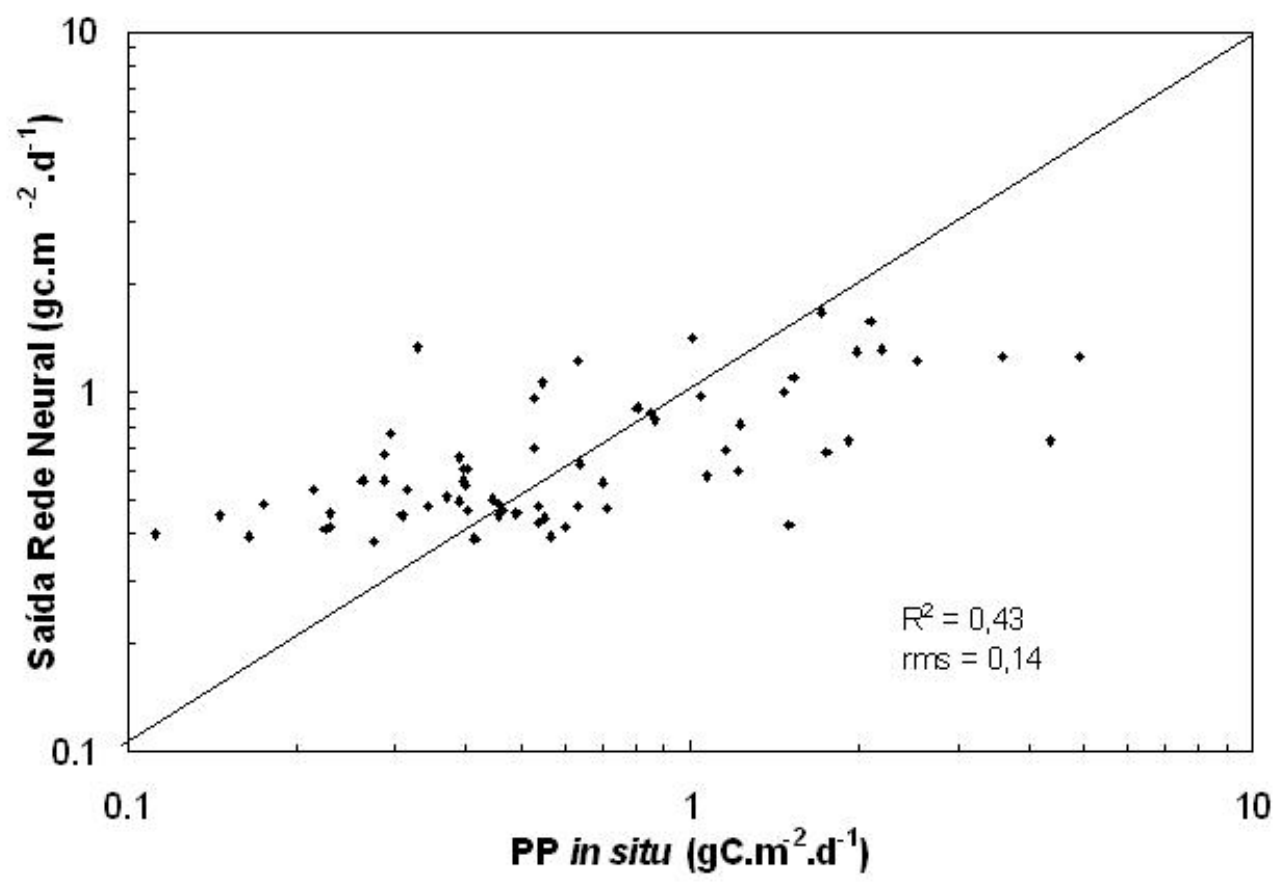

Figura 3.53 - Diagrama de dispersão das saídas da rede neural versus a produção primária integrada na zona eufótica medida in situ para o modelo 12-5-1, utilizando o conjunto total de pontos $(\mathrm{n}=67)$. 


\subsection{Comparações entre as estimativas da produção primária diária integrada}

A seguir, será apresentada uma comparação entre as estimativas das produções primárias diárias integradas na coluna d'água $\left(\mathrm{gC} \cdot \mathrm{m}^{-2} \cdot \mathrm{d}^{-1}\right)$ através de diferentes modelos (BPM1, BPM2, VGPM) utilizando dados de satélite da cor do oceano e estimativas in situ obtidas a partir de experimentos com ${ }^{14} \mathrm{C}\left(\mathrm{gC} \cdot \mathrm{m}^{-2} \cdot \mathrm{d}^{-1}\right)$. Será considerada como valor in situ, a produção primária diária integrada na coluna d'água obtida a partir das amostras referentes ao nível de superfície, ou seja, $100 \%$ de irradiância. As comparações serão realizadas para os domínios definidos como plataforma, taludeverão, talude-inverno e para o conjunto completo de dados.

\subsubsection{Produção primária diária integrada in situ e Modelo Bedford 1 (BPM1)}

A Tabela 3.53 apresenta os coeficientes encontrados nas regressões lineares entre as produções primárias diárias integradas na coluna d'água obtidas pelo método do ${ }^{14} \mathrm{C} \mathrm{e}$ as estimativas feitas com o modelo BPM1 para os domínios de plataforma, taludeinverno e conjunto completo de dados. O domínio talude-verão só apresentou 4 pontos válidos, impossibilitando sua respectiva análise estatística. Foram efetuadas comparações entre integrações na zona eufótica e na primeira profundidade óptica.

Os coeficientes de determinação $\left(\mathrm{R}^{2}\right)$ variaram entre 0,34 e 0,53 , sendo que, os ajustes para o domínio de talude-inverno foram os que explicaram a maior parte da variância dos dados (53\% tanto para a zona eufótica como para a primeira profundidade óptica, ainda que o rms desta última tenha sido menor, ver Tabela 3.53). O número de observações utilizadas em cada regressão foi $n=33$ e $n=31$ para o domínio de plataforma, profundidades da zona eufótica e primeira profundidade óptica, respectivamente, e $\mathrm{n}=12$ para o domínio talude-inverno. A Figura 3.54 mostra os diagramas de dispersão entre as produções primárias diárias integradas na zona eufótica e primeira profundidade óptica $\left(\mathrm{gC} \cdot \mathrm{m}^{-2} \cdot \mathrm{d}^{-1}\right)$ obtidas in situ $\left({ }^{14} \mathrm{C}\right)$ e as estimativas calculadas com o modelo BPM1, nos domínios de plataforma e talude-inverno, respectivamente. 
TABELA 3.53 - ANÁLISE DE REGRESSÃO LINEAR ENTRE AS PRODUÇÕES PRIMÁRIAS DIÁRIAS INTEGRADAS NA COLUNA D'ÁGUA IN SITU E OBTIDAS PELO MODELO BPM1.

\begin{tabular}{c|c|c|c|c|c|c}
\hline & & \multicolumn{5}{|c}{$\mathbf{P P}_{\mathbf{1 0 0}}=\boldsymbol{a}$ BPM1 $+\boldsymbol{b}$} \\
\hline Domínio & Profundidade & $\boldsymbol{a}$ & $\boldsymbol{b}$ & $\mathbf{n}$ & $\mathbf{R}^{\mathbf{2}}$ & $\mathbf{r m s}$ \\
\hline Plataforma & EU $^{*}$ & 0,692 & 0,048 & 33 & 0,49 & 0,28 \\
\hline Plataforma & OP $^{*}$ & 0,542 & $-0,280$ & 31 & 0,34 & 0,35 \\
\hline Talude - Inverno & EU $^{*}$ & 1,022 & 0,635 & 12 & 0,53 & 0,30 \\
\hline Talude - Inverno & OP $^{*}$ & 1,128 & 0,551 & 12 & 0,53 & 0,27 \\
\hline Completo & EU $^{*}$ & 0,582 & 0,103 & 48 & 0,43 & 0,32 \\
\hline
\end{tabular}

* Log - transformada; $E U=$ zona eufótica; $O P=$ primeira profundidade óptica.
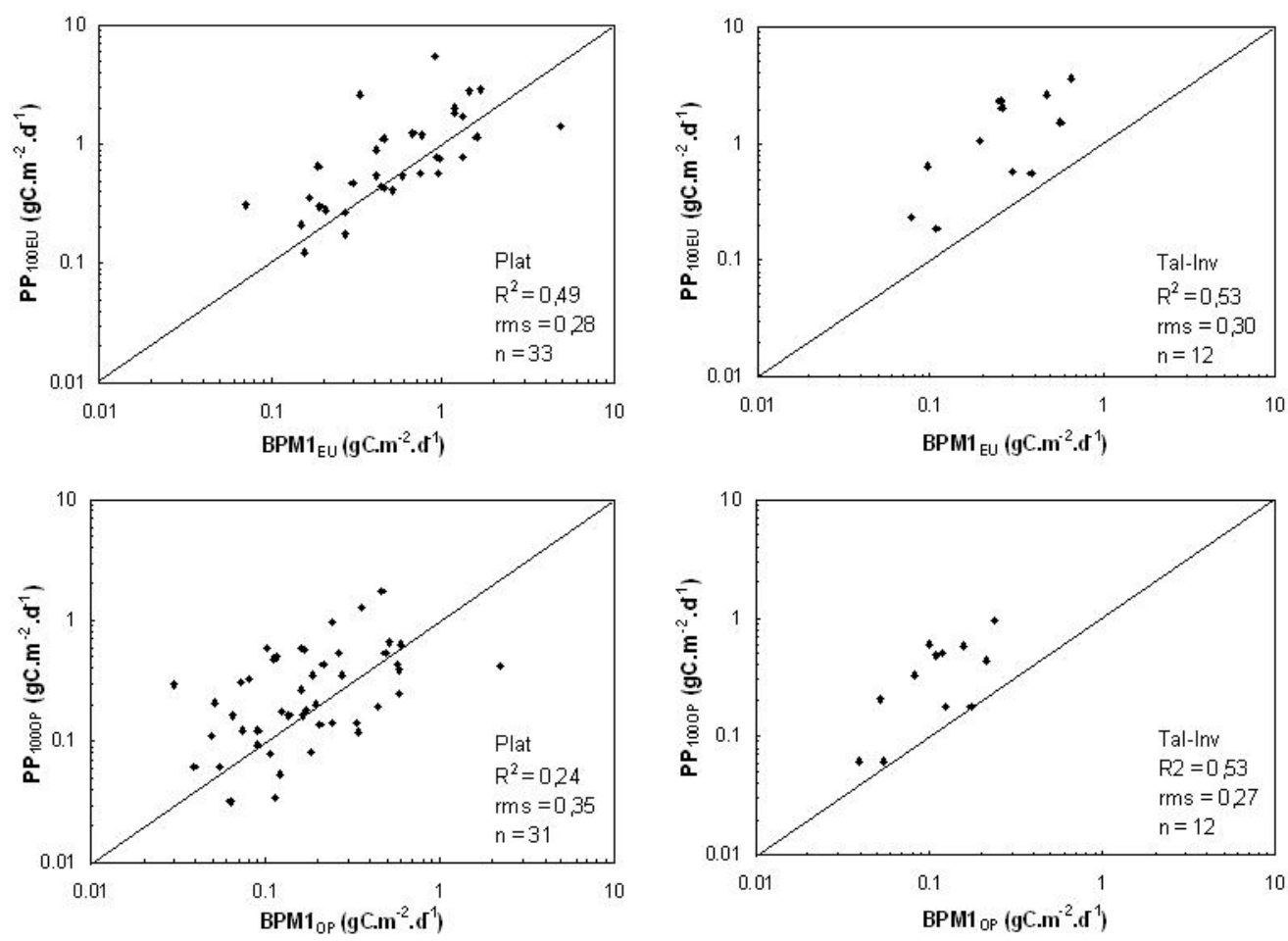

Figura 3.54 - Diagramas de dispersão entre as produções primárias diárias integradas na coluna d'água in situ versus as estimativas do modelo BPM1, nos domínios de plataforma (lado esquerdo) e talude-inverno (lado direito), zona eufótica em cima e primeira profundidade óptica embaixo.

De modo geral, as estimativas obtidas com o modelo BPM1 subestimaram as produções primárias diárias integradas na coluna d'água, tanto na plataforma como no taludeinverno. Isto também pode ser observado na Figura 3.55 que mostra o diagrama de dispersão entre a produção primária diária integrada na zona eufótica in situ e as estimativas obtidas pelo modelo BPM1 $\left(\mathrm{gC} \cdot \mathrm{m}^{-2} \cdot \mathrm{d}^{-1}\right)$ para o conjunto completo de dados. 


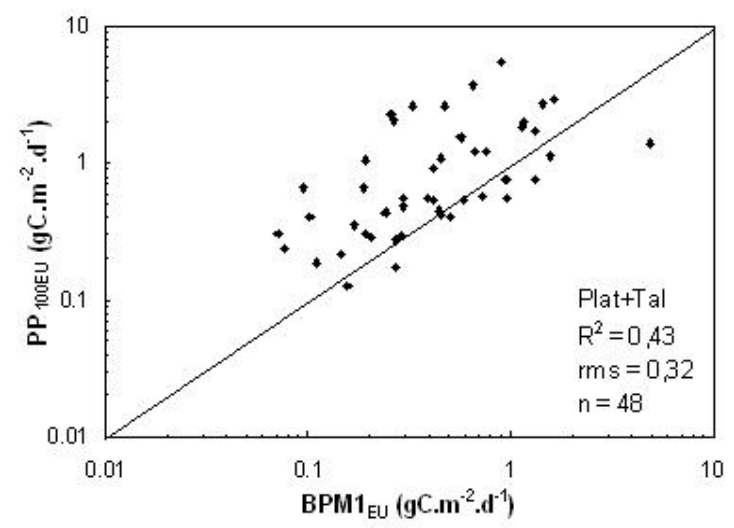

Figura 3.55 - Diagrama de dispersão entre a produção primária diária integrada na zona eufótica in situ versus as estimativas obtidas pelo modelo BPM1 para o conjunto completo de dados.

\subsubsection{Produção primária diária integrada in situ e Modelo Bedford 2 (BPM2)}

A Tabela 3.54 apresenta os coeficientes encontrados nas regressões lineares entre as produções primárias diárias integradas na zona eufótica obtidas pelo método do ${ }^{14} \mathrm{C}$ e as estimativas feitas com o modelo BPM2 para os domínios de plataforma, talude-verão, talude inverno e conjunto completo de dados, respectivamente.

\section{TABELA 3.54 - ANÁLISE DE REGRESSÃO LINEAR ENTRE AS PRODUÇÕES PRIMÁRIAS DIÁRIAS INTEGRADAS NA ZONA EUFÓTICA IN SITU E OBTIDAS PELO MODELO BPM2.}

\begin{tabular}{c|c|c|c|c|c}
\hline & \multicolumn{5}{|c}{$\mathbf{P P}_{\mathbf{E U}}=\boldsymbol{a}$ BPM2 $+\boldsymbol{b}$} \\
\hline Domínio & $\boldsymbol{a}$ & $\boldsymbol{b}$ & $\mathbf{n}$ & $\mathbf{R}^{\mathbf{2}}$ & $\mathbf{r m s}$ \\
\hline Plataforma $^{*}$ & 0,839 & $-0,105$ & 41 & 0,59 & 0,25 \\
\hline Talude - Verão & 0,279 & 0,217 & 15 & 0,26 & 0,13 \\
\hline Talude - Inverno $^{*}$ & 1,210 & 0,412 & 14 & 0,57 & 0,30 \\
\hline Completo * $^{7}$ & 0,730 & $-0,078$ & 69 & 0,41 & 0,30 \\
\hline \multicolumn{6}{c}{ *og - transformada. }
\end{tabular}

Os coeficientes de determinação $\left(\mathrm{R}^{2}\right)$ variaram entre 0,26 e 0,59 (nível de confiança de 95\%). O modelo BPM2 explicou 59\% da variância dos dados no domínio de plataforma ( $\mathrm{n}=41)$ e $57 \%$ no domínio de talude-inverno $(\mathrm{n}=14)$, ou seja, com desempenho melhor que BPM1 para a zona eufótica (49\% e 53\%, respectivamente, ver Tabela 3.53). O conjunto completo de dados (plataforma, talude-inverno e talude-verão) teve $41 \%$ de sua variância explicada por BPM2, isto é, menos do que por BPM1 (44\%, ver 
Tabela 3.53). A Figura 3.56 mostra os diagramas de dispersão entre as produções

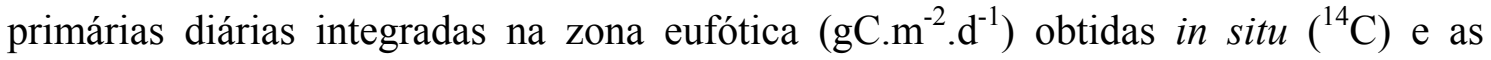
estimativas calculadas com o modelo BPM2, nos domínios de plataforma, talude-verão, talude-inverno e conjunto completo de dados, respectivamente.
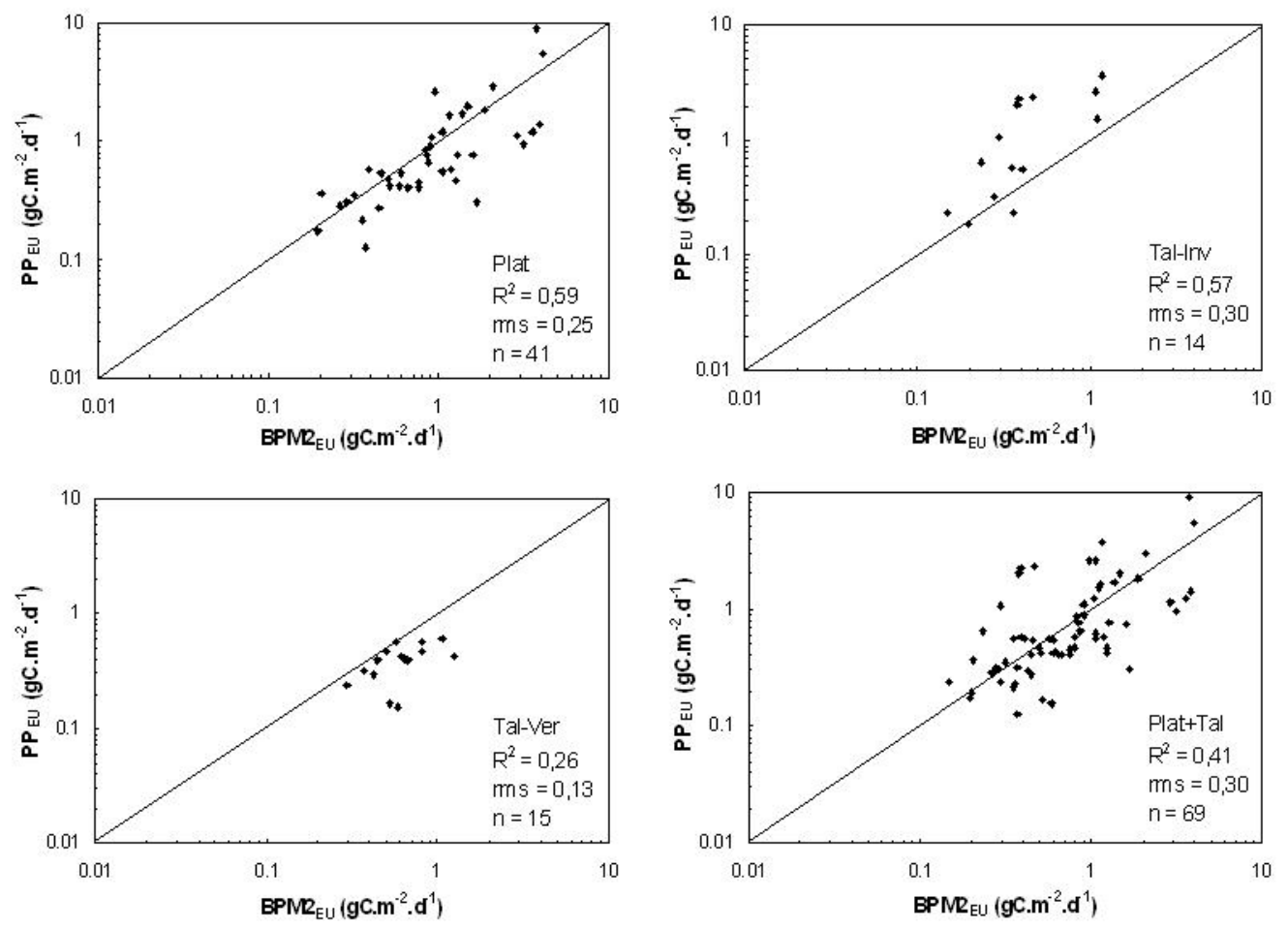

Figura 3.56 - Diagramas de dispersão entre as produções primárias diárias integradas na zona eufótica in situ versus as estimativas do modelo BPM2, nos domínios de plataforma (lado esquerdo em cima), talude-verão (lado esquerdo embaixo), talude-inverno (lado direito em cima) e conjunto completo (lado direito embaixo).

De modo geral, o modelo BPM2 superestimou as produções primárias diárias integradas na zona eufótica $\left(\mathrm{gC} \cdot \mathrm{m}^{-2} \cdot \mathrm{d}^{-1}\right)$ nos domínios de plataforma e talude-verão, e subestimou no domínio de talude-inverno.

\subsubsection{Produção primária diária integrada in situ e Modelo VGPM}

A Tabela 3.55 apresenta os coeficientes encontrados na regressão linear entre as produções primárias diárias integradas na zona eufótica obtidas pelo método do ${ }^{14} \mathrm{C}$ e as estimativas feitas com o modelo VGPM para o domínio de plataforma. O domínio 
talude-verão apresentou somente 7 pontos válidos, e o domínio talude-inverno não obteve resultado significativo (nível de confiança de 95\%). O coeficiente de determinação $\left(\mathrm{R}^{2}\right)$ obtido para a regressão linear entre a produção primária diária integrada na zona eufótica in situ e a estimativa obtida pelo VGPM, para o domínio de plataforma, foi igual a $0,17(\mathrm{n}=35, \mathrm{rms}=1,00)$. A Figura 3.57 mostra o diagrama de dispersão referente à esta regressão. De modo geral, o modelo VGPM superestimou as produções primárias diárias integradas na zona eufótica sobre a plataforma.

\section{TABELA 3.55 - ANÁLISE DE REGRESSÃO LINEAR ENTRE AS PRODUÇÕES PRIMÁRIAS DIÁRIAS INTEGRADAS NA ZONA EUFÓTICA IN SITU E OBTIDAS PELO MODELO VGPM.

\begin{tabular}{c|c|c|c|c|c}
\hline & \multicolumn{5}{|c}{$\mathbf{P P}_{\mathrm{EU}}=\boldsymbol{a}$ VGPM $+\boldsymbol{b}$} \\
\hline Domínio & $\boldsymbol{a}$ & $\boldsymbol{b}$ & $\mathbf{n}$ & $\mathbf{R}^{\mathbf{2}}$ & $\mathbf{r m s}$ \\
\hline Plataforma & 0,434 & 0,371 & 35 & 0,17 & 1,00 \\
\hline
\end{tabular}

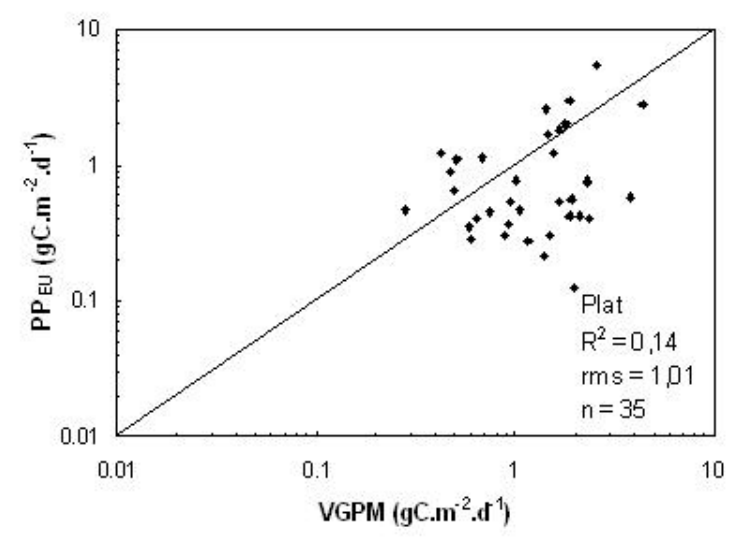

Figura 3.57 - Diagrama de dispersão entre a produção primária diária integrada na zona eufótica in situ versus estimativas do modelo VGPM, no domínio de plataforma.

Em relação ao modelo VGPM, foi feita uma comparação entre a profundidade da zona eufótica (metros) estimada por este modelo e a estimada a partir de medidas com o disco de Secchi. A profundidade da zona eufótica obtida pelo disco de Secchi foi utilizada nos cálculos da produção primária diária integrada in situ.

A Tabela 3.56 apresenta os coeficientes encontrados na regressão linear entre a profundidade zona eufótica estimada pelo modelo VGPM ( $Z_{\text {EUVGPM }} \mathrm{m}$ ) e com o disco de Secchi $\left(Z_{\text {EUSecchi }} \mathrm{m}\right)$ no domínio de plataforma. $\mathrm{O}$ coeficiente de determinação $\left(\mathrm{R}^{2}\right)$ 
no domínio talude-inverno não foi significativo ao nível de confiança de $95 \%$ e o domínio talude-verão não apresentou número de pontos válidos suficientes para efetuar a regressão $(n=7)$. A Figura 3.58 mostra o diagrama de dispersão entre a profundidade da zona eufótica in situ (m) e a estimada pelo modelo VGPM.

TABELA 3.56 - ANÁLISE DE REGRESSÃO LINEAR ENTRE AS
PROFUNDIDADES DA ZONA EUFÓTICA IN SITU (DISCO DE
SECCHI) E ESTIMADAS PELO MODELO VGPM.
\begin{tabular}{c|c|c|c|c|c}
\hline \multicolumn{6}{|c}{$\mathbf{Z}_{\text {EUSechi }}=\boldsymbol{a} \mathbf{Z}_{\text {EUVGM }}+\boldsymbol{b}$} \\
\hline Domínio & $\boldsymbol{a}$ & $\boldsymbol{b}$ & $\mathbf{n}$ & $\mathbf{R}^{\mathbf{2}}$ & $\mathbf{r m s}$ \\
\hline Plataforma & 0,681 & $-2,842$ & 39 & 0,47 & 1,4 \\
\hline
\end{tabular}

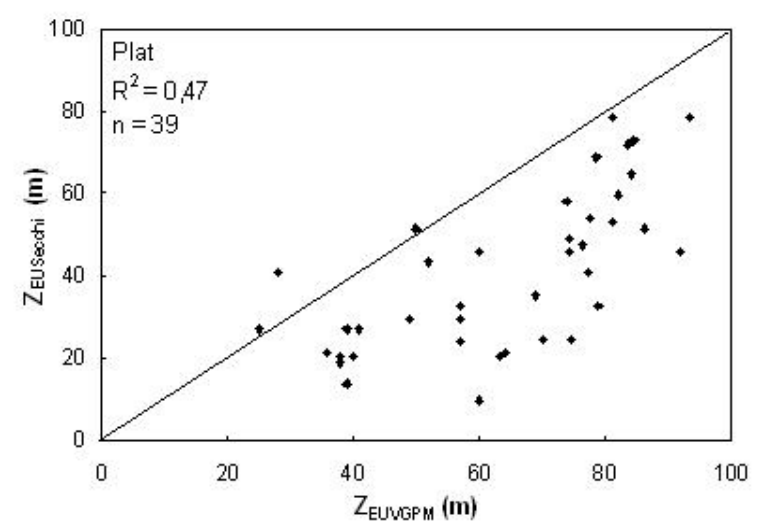

Figura 3.58 - Diagrama de dispersão entre a profundidade da zona eufótica in situ ( $Z_{\text {EUSecchi }} \mathrm{m}$ ) e a estimada pelo modelo VGPM ( $\left.Z_{\text {EUVGPM }}\right)$ no domínio de plataforma.

De modo geral, a profundidade da zona eufótica estimada pelo modelo VGPM superestimou o valor in situ.

\subsubsection{Produção primária diária integrada in situ a 100\% e 1\% de irradiância}

A Tabela 3.57 apresenta os coeficientes encontrados nas regressões lineares entre as produções primárias diárias integradas na zona eufótica obtidas pelo método do ${ }^{14} \mathrm{C}$ com amostras do nível de $100 \%$ e $1 \%$ de irradiância $\left(\mathrm{gC}^{-2} \mathrm{~m}^{-2} \cdot \mathrm{d}^{-1}\right)$, para os domínios de plataforma, talude-verão, talude inverno e conjunto completo de dados, respectivamente. 
TABELA 3.57 - ANÁLISE DE REGRESSÃO LINEAR ENTRE AS PRODUÇÕES PRIMÁRIAS DIÁRIAS INTEGRADAS NA ZONA EUFÓTICA IN SITU COM AMOSTRAS DE 100\% E 1\% DE IRRADIÂNCIA.

\begin{tabular}{c|c|c|c|c|c}
\hline & \multicolumn{5}{|c}{$\mathbf{P P}_{\mathrm{EU100}}=\boldsymbol{a} \mathbf{P P}_{\mathrm{EU1}}+\boldsymbol{b}$} \\
\hline Domínio & $\boldsymbol{a}$ & $\boldsymbol{b}$ & $\mathbf{N}$ & $\mathbf{R}^{\mathbf{2}}$ & $\mathbf{r m s}$ \\
\hline Plataforma $^{*}$ & 0,650 & $-0,002$ & 38 & 0,46 & 0,25 \\
\hline Talude - Verão $^{*}$ & 0,565 & 0,216 & 15 & 0,41 & 0,11 \\
\hline Talude - Inverno $^{*}$ & 1,058 & 0,289 & 14 & 0,60 & 0,28 \\
\hline Completo $^{*}$ & 0,719 & 0,013 & 66 & 0,54 & 0,26 \\
\hline
\end{tabular}

Os coeficientes de determinação $\left(\mathrm{R}^{2}\right)$ variaram entre 0,41 e 0,60 , sendo que, o domínio talude-inverno foi o que apresentou a melhor relação entre as produções primárias diárias integradas na zona eufótica referentes aos níveis de $100 \%$ e $1 \%$ de irradiância. Ainda que o $\mathrm{R}^{2}$ encontrado para o domínio talude-verão $(0,41)$,foi também onde se observou o menor rms $(0,11)$. O número de observações foi $\mathrm{n}=38$ para o domínio plataforma, $n=15$ para talude-verão, $n=14$ para talude-inverno e $n=66$ considerando o conjunto completo de dados. A Figura 3.59 mostra os diagramas de dispersão entre as produções primárias diárias integradas na zona eufótica $\left(\mathrm{gC} \cdot \mathrm{m}^{-2} \cdot \mathrm{d}^{-1}\right)$ referentes aos níveis de $100 \%$ e $1 \%$ de irradiâncias, nos domínios plataforma, talude-verão, taludeinverno e conjunto completo de dados, respectivamente.

De modo geral, as produções primárias diárias integradas na zona eufótica referentes ao nível de $100 \%$ de irradiância foram maiores que às referentes ao nível de $1 \%$, em todos os domínios considerados. 

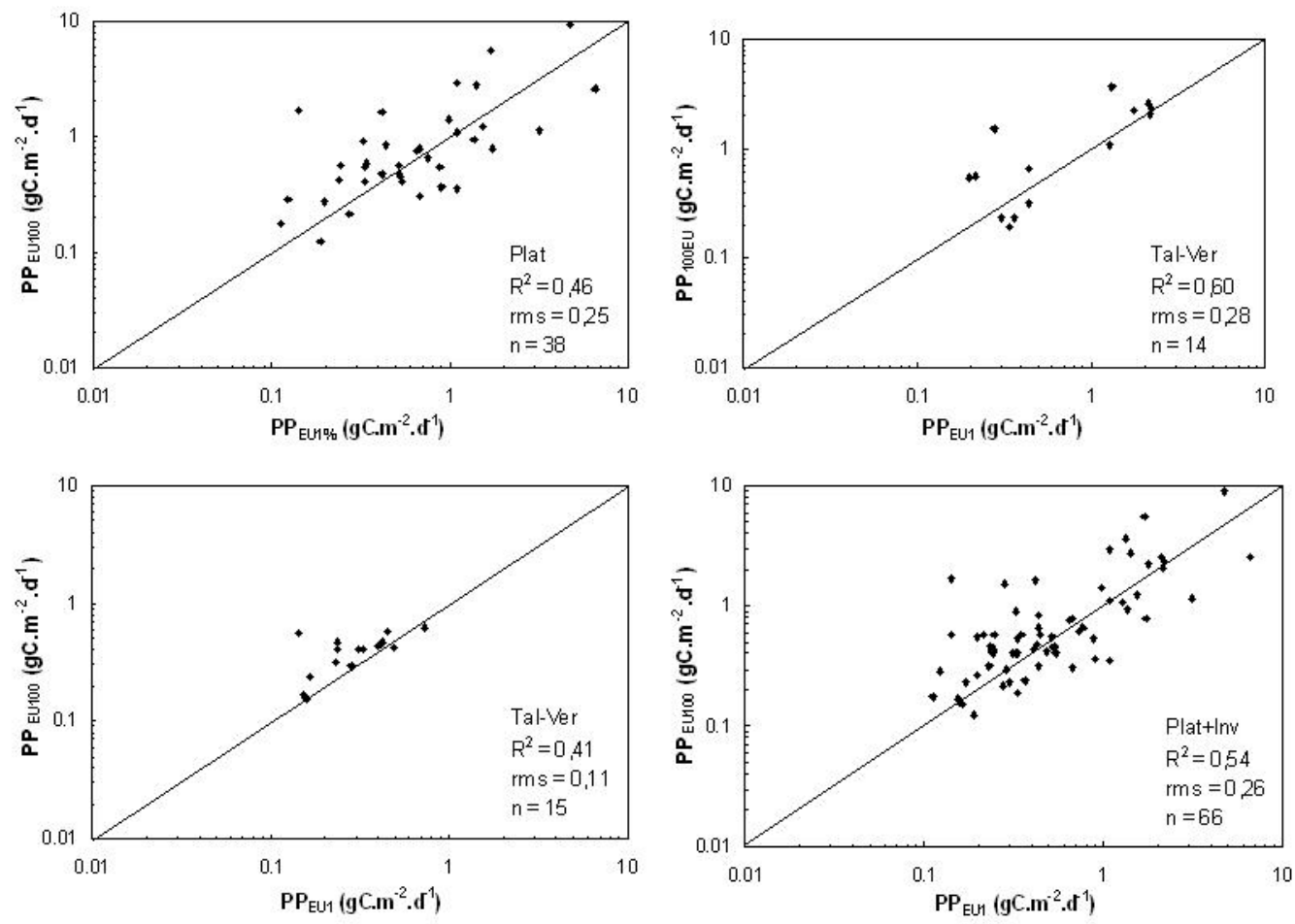

Figura 3.59 - Diagramas de dispersão entre as produções primárias diárias integradas na zona eufótica para amostras dos níveis de $100 \%\left(\mathrm{PP}_{\mathrm{EU} 100}\right)$ e $1 \%\left(\mathrm{PP}_{\mathrm{Eu} 1}\right)$ de irradiância, nos domínios de plataforma (lado esquerdo em cima), taludeverão (lado esquerdo embaixo), talude-inverno (lado direito em cima) e conjunto completo (lado direito embaixo).

\subsection{Imagens da produtividade primária oceânica (PPO)}

Como mencionado anteriormente, a produtividade primária oceânica (PPO), expressa em termos da taxa de fixação de carbono como resultado direto da fotossíntese em $\mathrm{gC} \cdot \mathrm{m}^{-2} \cdot \mathrm{d}^{-1}$ tem um papel fundamental no ciclo global do carbono. A seguir, serão apresentadas as primeiras imagens da produtividade primária oceânica da costa sudeste brasileira geradas a partir de dados orbitais da cor do oceano (SeaWiFS) e parâmetros fotossintéticos in situ adquiridos simultaneamente, referentes aos períodos dos cruzeiros de mesoescala do projeto DEPROAS (verão e inverno de 2001 e verão e inverno de 2002). Foi utilizado o modelo de produtividade de Bedford - BPM1, para o cálculo das produções primárias diárias integradas na zona eufótica em uma base pixel-a-pixel. 


\subsubsection{Fevereiro de 2001}

Apesar do cruzeiro de verão de 2001 ter sido realizado entre os dias 7 e 13 de fevereiro de 2001, serão incluídas imagens referentes a alguns dias anteriores e posteriores ao período de coletas in situ para melhor caracterizar a área de estudo. A Figura 3.60 mostra as imagens dos dias 1, 3, 13 e 14 de fevereiro de 2001. Neste conjunto de imagens foi possível observar que a região costeira entre a Ilha de São Sebastião e Cabo Frio, apresentou altas taxas de produtividade primária $\left(>7 \mathrm{gC} \cdot \mathrm{m}^{-2} \cdot \mathrm{d}^{-1}\right)$, principalmente no início do mês de fevereiro. As águas oligotróficas da Corrente do Brasil aparecem em tom azul escuro com taxas baixas de produtividade primária. Interessante notar uma mancha de alta produtividade $\left(>4,5 \mathrm{gC} \cdot \mathrm{m}^{-2} \cdot \mathrm{d}^{-1}\right)$, a NE de São Tomé, sobre a quebra de plataforma (ver imagem de 3/2/2001). Esta feição havia sido notada nas imagens de TSM (Figura 3.8) e de clorofila (Figura 3.10), porém de forma muito mais discreta. Mesmo com contrastes termal e de biomassa fitoplanctônica pouco acentuados, a produtividade primária se intensificou significativamente no local (em torno de $21,8^{\circ} \mathrm{S}-$ $\left.40,5^{\circ} \mathrm{W}\right)$. Manchas de altas produtividades foram observadas a S-SE de Vitória, São Tomé e O-SO de Cabo Frio ( $\left.>5 \mathrm{gC} . \mathrm{m}^{-2} \cdot \mathrm{d}^{-1}\right)$, associadas a eventos de ressurgências costeiras. 

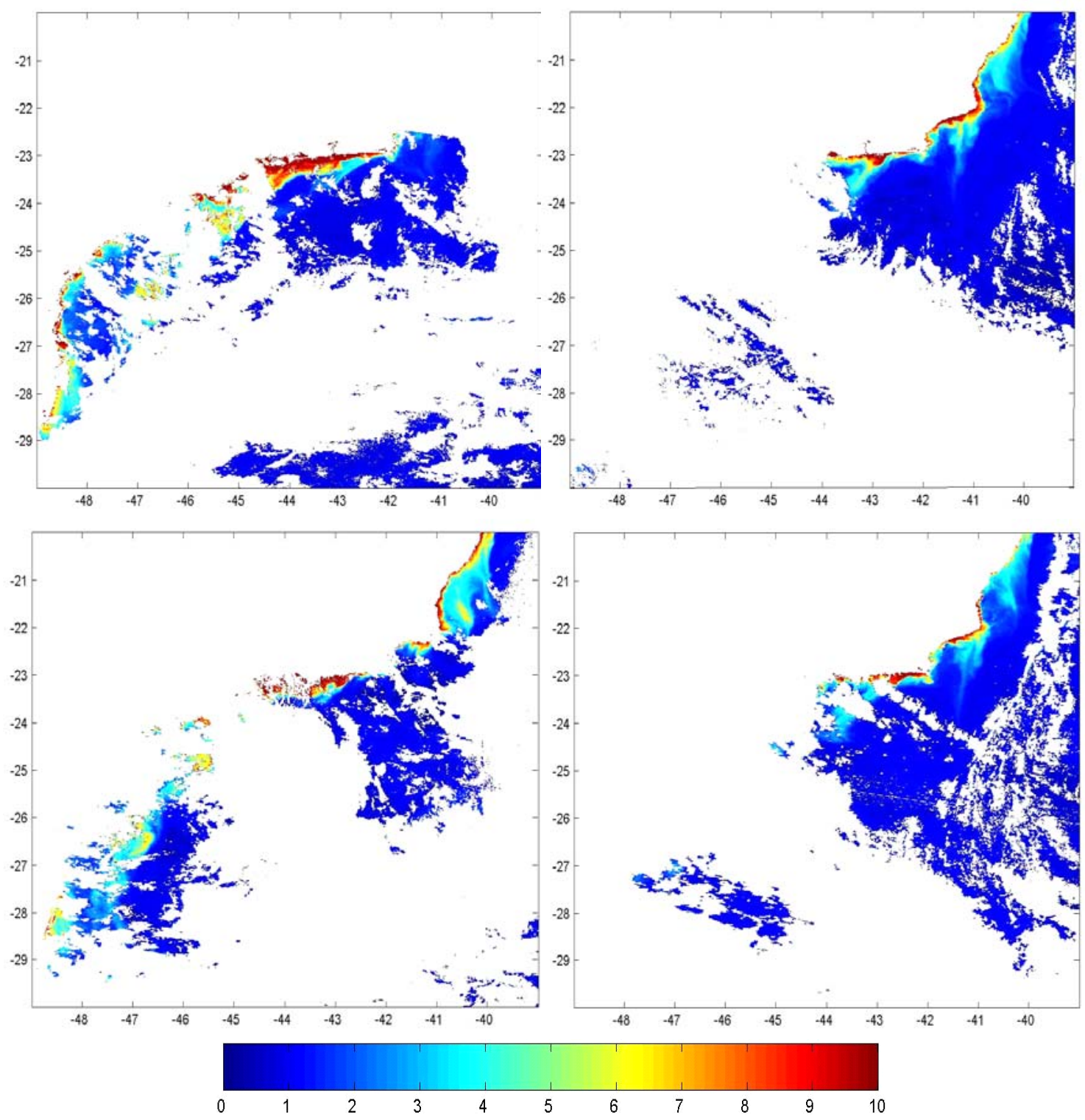

Figura 3.60 - Imagens da produção primária oceânica $\left(\mathrm{gC} \cdot \mathrm{m}^{-2} \cdot \mathrm{d}^{-1}\right)$ da costa sudeste brasileira referentes aos dias 1 (esquerda em cima), 3 (esquerda embaixo), 13 (direita em cima) e 14 (direita embaixo) de fevereiro de 2001 (continente e nuvens em branco).

A Figura 3.61 a seguir, exibe as imagens de produção primária integrada na zona eufótica $\left(\mathrm{gC} \cdot \mathrm{m}^{-2} \cdot \mathrm{d}^{-1}\right)$ calculadas nos dias 15, 16, 18 e 19 de fevereiro de 2001. Nesta seqüência de imagens pode-se observar uma pluma de alta produtividade primária $(>5$ $\left.\mathrm{gC} \cdot \mathrm{m}^{-2} \cdot \mathrm{d}^{-1}\right)$ se estendendo a partir de Cabo Frio na direção SO. 

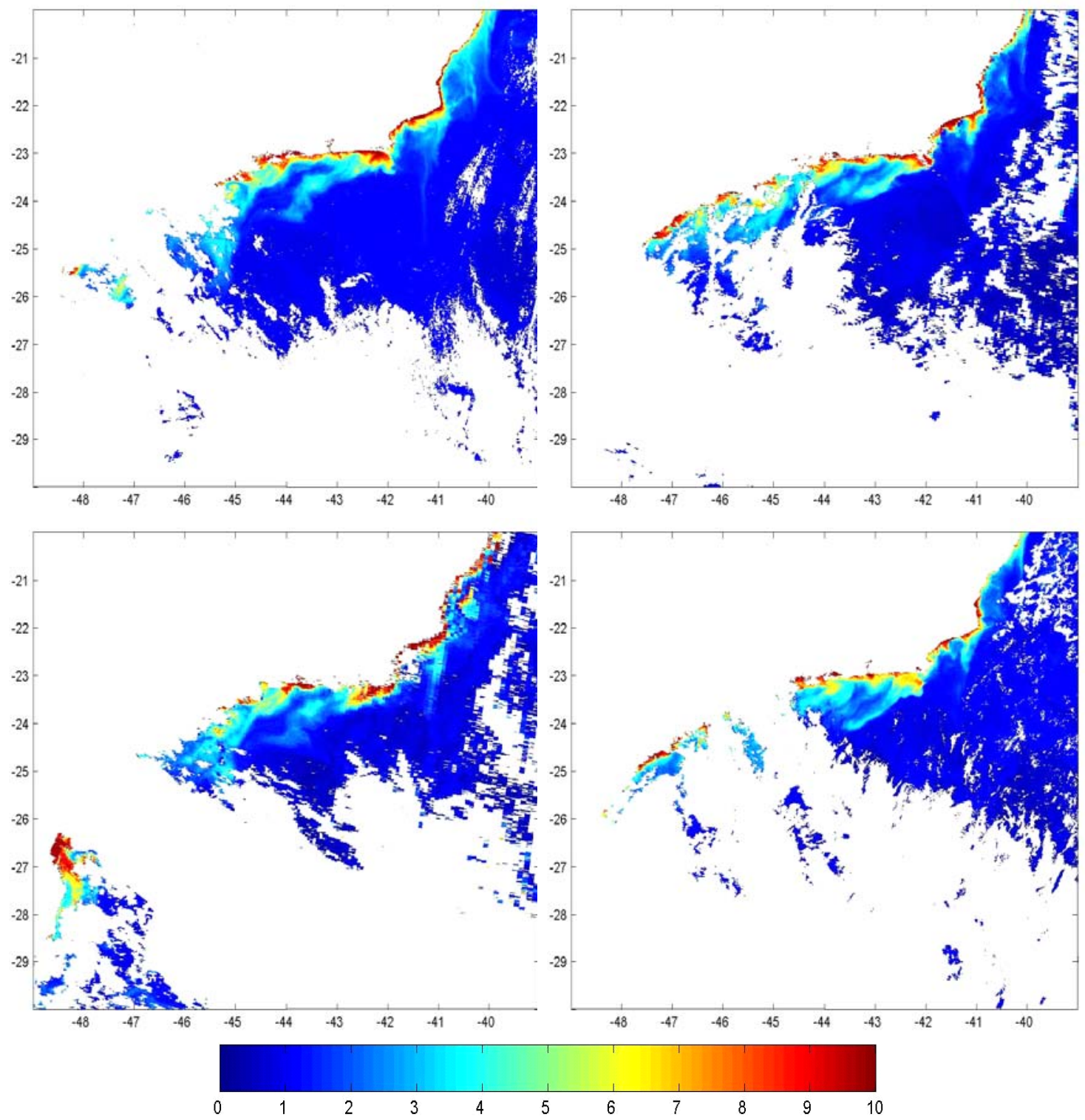

Figura 3.61 - Imagens da produção primária oceânica $\left(\mathrm{gC} \cdot \mathrm{m}^{-2} \cdot \mathrm{d}^{-1}\right)$ da costa sudeste brasileira referentes aos dias 15 (esquerda em cima), 16 (esquerda embaixo), 18 (direita em cima) e 19 (direita embaixo) de fevereiro de 2001 (continente e nuvens em branco).

No dia 15/2/2001 pode-se notar uma feição quase circular, em torno da posição $23,5^{\circ} \mathrm{S}$ $43,5^{\circ} \mathrm{W}$, um pouco destacada da pluma mencionada acima. Manchas costeiras e uma pluma em São Tomé também apresentam altas taxas de produtividade primária $\left(>6 \mathrm{gC} \cdot \mathrm{m}^{-2} \cdot \mathrm{d}^{-1}\right)$. Apesar de muitas feições terem grande correlação com estruturas também observadas nas imagens termais e dos campos de clorofila correspondentes (Figura 3.9 e Figura 3.11), parece evidente o caráter complementar dos campos de 
temperatura da superfície do mar, concentração de clorofila da superfície do mar e agora, da produtividade primária oceânica. A Figura 3.62 apresenta o campo médio de produtividade primária oceânica na costa sudeste brasileira durante o mês de fevereiro de 2001.

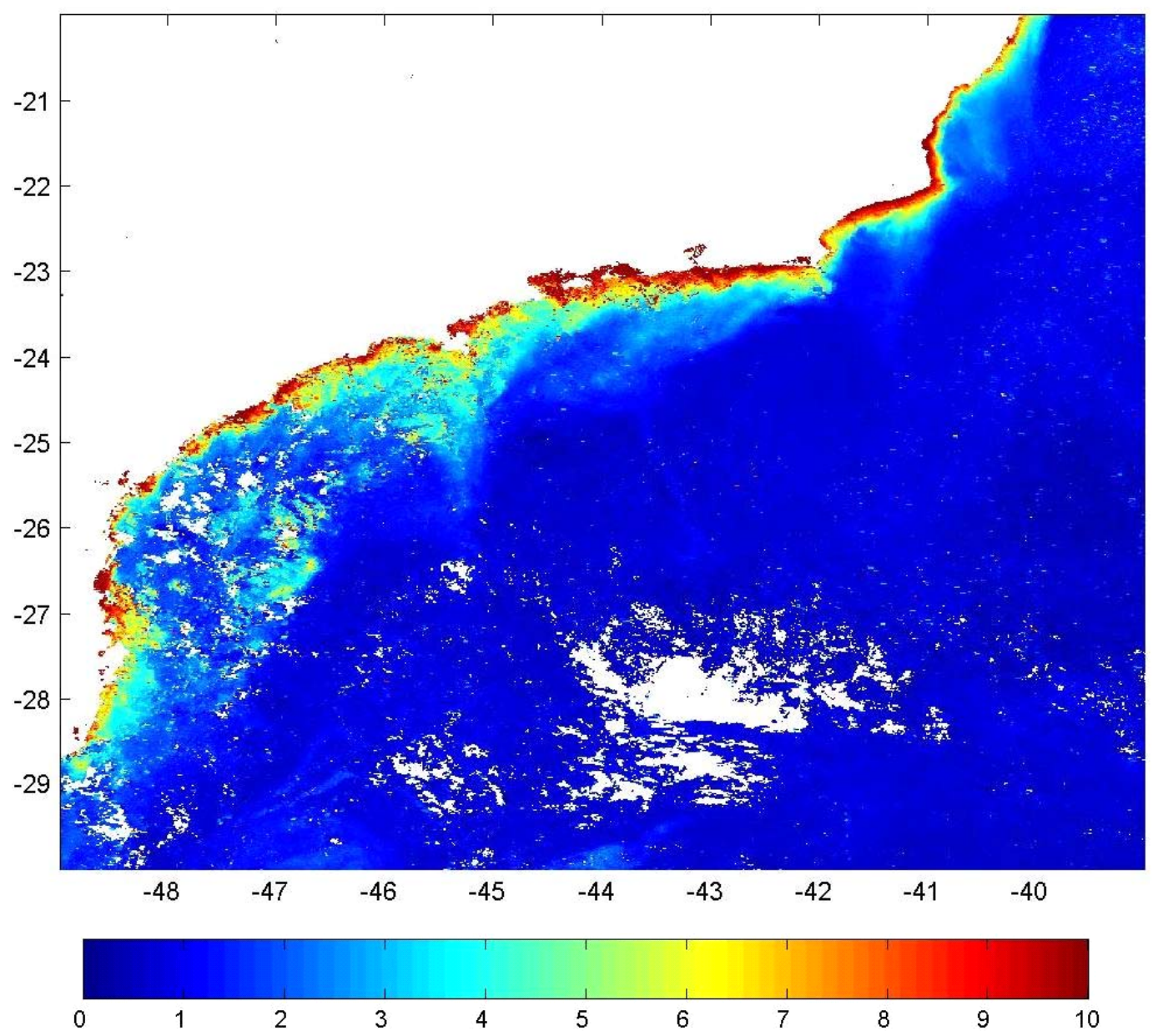

Figura 3.62 - Imagem média da produtividade primária oceânica $\left(\mathrm{gC} \cdot \mathrm{m}^{-2} \cdot \mathrm{d}^{-1}\right)$ da costa sudeste brasileira durante o mês de fevereiro de 2001 (continente e nuvens em branco).

Na Figura 3.62 é possível identificar as águas oligotróficas da CB em tons azul escuro, ao largo. Altas taxas de produtividade primária oceânica são observadas ao longo da costa, com valores acima de $5 \mathrm{gC} \cdot \mathrm{m}^{-2} \cdot \mathrm{d}^{-1}$. Mesmo sendo uma imagem média mensal, ainda é possível notar a presença de nuvens persistentes sobre a área. 


\subsubsection{Julho de 2001}

A Figura 3.63 mostra as imagens de produtividade primária oceânica dos dias 7, 8, 10 e 15 de julho de 2001. Neste conjunto de imagens, pode-se observar a intrusão de águas ricas vindas de sul pela costa, chegando até a Ilha de São Sebastião e litoral norte de São Paulo, com taxas de produtividade acima de 2,3 gC.m $\mathrm{m}^{-2} \cdot \mathrm{d}^{-1}$. No dia 15/7/2001, aparece uma mancha costeira contínua, desde a parte meridional da imagem (Cabo Santa Marta, PPO $>3 \mathrm{gC} \cdot \mathrm{m}^{-2} \cdot \mathrm{d}^{-1}$ ), até Saquarema (litoral do Rio de Janeiro, entre Cabo Frio e Baía de Guanabara,com $\left.2,0<\mathrm{PPO}<2,5 \mathrm{gC} \cdot \mathrm{m}^{-2} \cdot \mathrm{d}^{-1}\right)$. A plataforma interna e região costeira entre Vitória e São Tomé exibem uma produtividade acima de 2,5 $\mathrm{gC} \cdot \mathrm{m}^{-2} \cdot \mathrm{d}^{-1}$. Uma pluma de alta produtividade $\left(2,0\right.$ a 2,5 $\left.\mathrm{gC} . \mathrm{m}^{-2} \cdot \mathrm{d}^{-1}\right)$ pode ser notada a SE de Cabo Frio.

A Figura 3.64 a seguir, exibe as imagens de PPO referentes aos dias 16, 17, 19 e 21 de julho de 2001. Nesta seqüência de imagens, também é possível notar a presença de águas ricas vindas de sul pela costa, desde o Cabo Santa Marta (PPO $\left.>3,0 \mathrm{gC} \cdot \mathrm{m}^{-2} \cdot \mathrm{d}^{-1}\right)$ até o litoral do Rio de Janeiro. Em torno da Ilha de São Sebastião, pode-se observar a formação de uma mancha com produtividades acima de 2,3 gC.m $\mathrm{m}^{-2} \cdot \mathrm{d}^{-1}$. A SE de Cabo Frio, pode-se identificar a formação de estruturas com forma de vórtices, ciclônicos e anticiclônicos, com PPO de até $1,5 \mathrm{gC} \cdot \mathrm{m}^{-2} \cdot \mathrm{d}^{-1}$, circundados por águas pobres da $\mathrm{CB}$ $\left(\mathrm{PPO}<0,5 \mathrm{gC} \cdot \mathrm{m}^{-2} \cdot \mathrm{d}^{-1}\right)$ em tom azul escuro. A faixa costeira desde Cabo Frio até Vitória exibe uma produtividade primária maior que $3,5 \mathrm{gC} \cdot \mathrm{m}^{-2} \cdot \mathrm{d}^{-1}$, persistente por vários dias. Próximo a São Tomé, pode-se observar uma mancha com PPO maior que $2 \mathrm{gC} \cdot \mathrm{m}^{-2} \cdot \mathrm{d}^{-1}$, ocupando uma grande área sobre a plataforma $(120 \times 50 \mathrm{~km}$, aproximadamente). Um vórtice ciclônico em frente a São Tomé aparece bem visível nas imagens de 19 e $21 / 7 / 2001$, com centro em torno de $22,6^{\circ} \mathrm{S}-40,5^{\circ} \mathrm{W}$.

A Figura 3.65 apresenta a imagem média da produtividade primária oceânica integrada na zona eufótica na costa sudeste brasileira durante o mês de julho de 2001. As águas relativamente pobres da CB aparecem em tom azul escuro, com PPO menor que $0,5 \mathrm{gC} \cdot \mathrm{m}^{-2} \cdot \mathrm{d}^{-1}$. As águas ricas vindas de sul pela costa formam uma mancha de alta produtividade primária desde o Cabo Santa Marta (PPO $\left.>3,0 \mathrm{gC} \cdot \mathrm{m}^{-2} \cdot \mathrm{d}^{-1}\right)$, até Cabo Frio 
$\left(\mathrm{PPO}>2,0 \mathrm{gC} \cdot \mathrm{m}^{-2} \cdot \mathrm{d}^{-1}\right)$. Em torno da Ilha de São Sebastião, pode-se observar a formação de uma mancha com PPO maior que $2,3 \mathrm{gC} \cdot \mathrm{m}^{-2} \cdot \mathrm{d}^{-1}$.
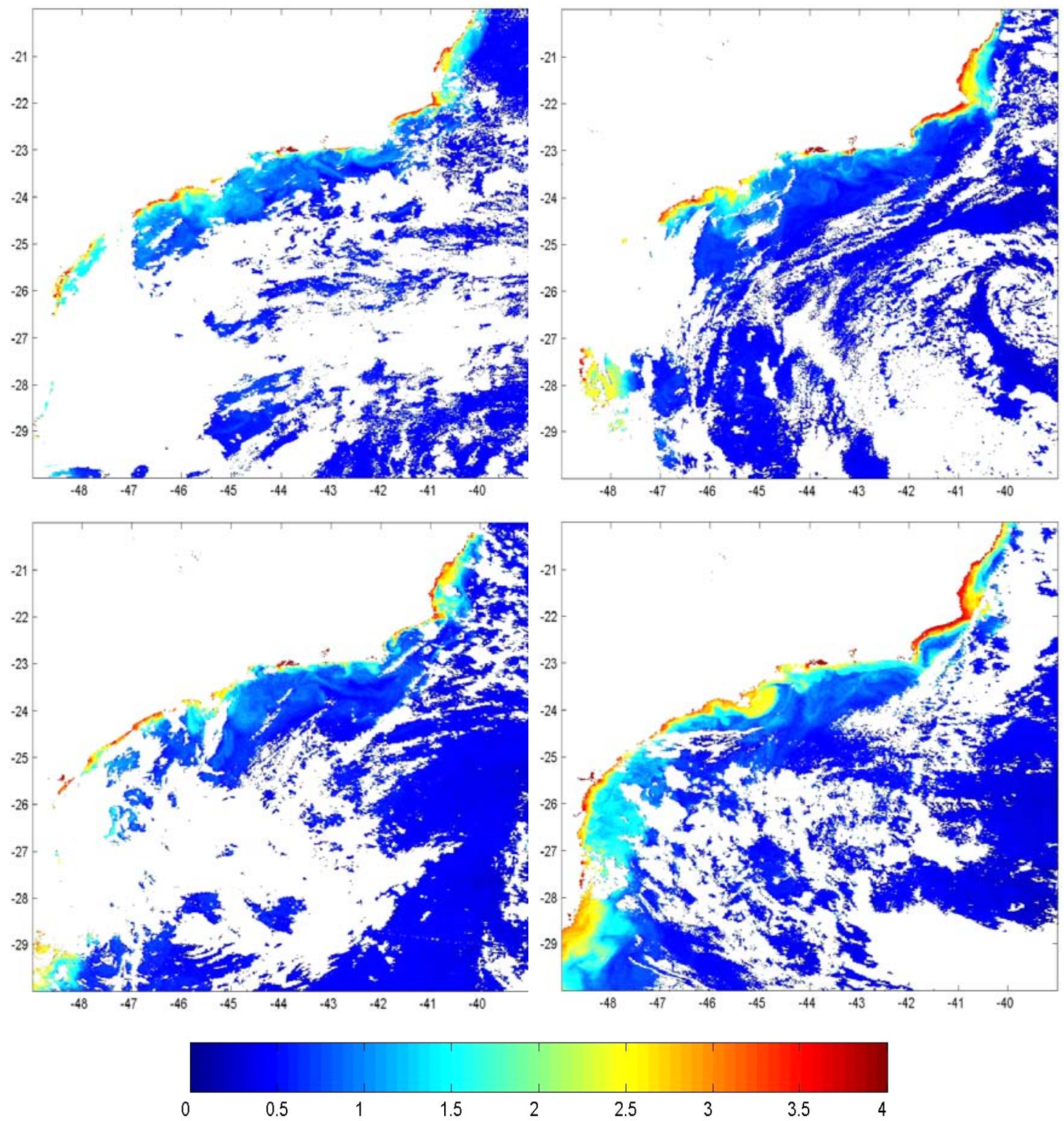

Figura 3.63 - Imagens da produção primária oceânica $\left(\mathrm{gC} \cdot \mathrm{m}^{-2} \cdot \mathrm{d}^{-1}\right)$ da costa sudeste brasileira referentes aos dias 7 (esquerda em cima), 8 (esquerda embaixo), 10 (direita em cima) e 15 (direita embaixo) de julho de 2001 (continente e nuvens em branco).

A região costeira entre Cabo Frio e Vitória exibe as maiores taxas de produtividade primária $\left(\mathrm{PPO}>3,5 \mathrm{gC} \cdot \mathrm{m}^{-2} \cdot \mathrm{d}^{-1}\right)$ na região de interesse, durante julho de 2001. Estruturas em forma de meandros e/ou vórtices ciclônicos foram identificados na região 
de São Tomé. Plumas com taxas relativamente altas de PPO $\left(>2,0 \mathrm{gC} \cdot \mathrm{m}^{-2} \cdot \mathrm{d}^{-1}\right)$ também foram notadas estendendo-se na direção SO.
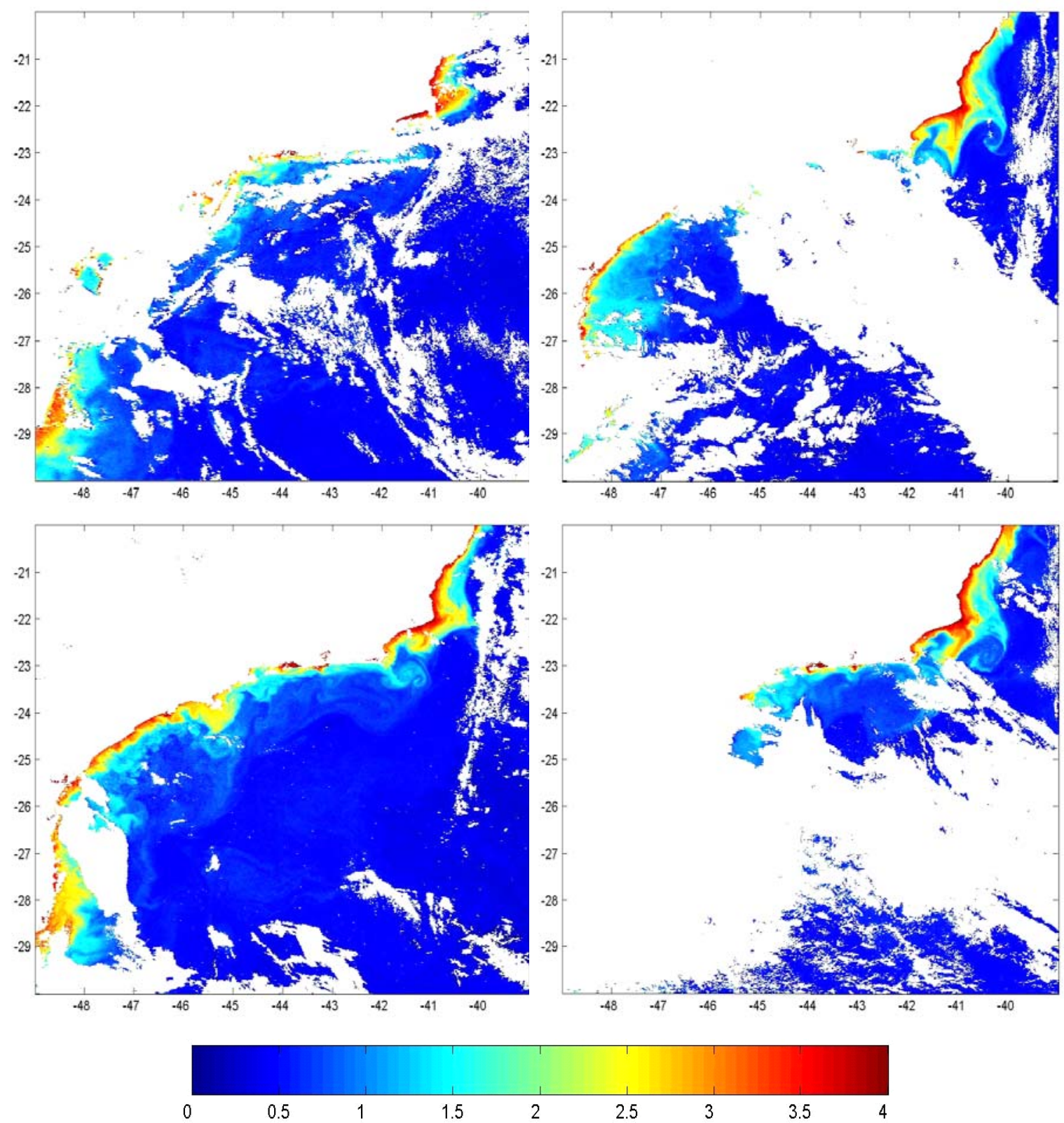

Figura 3.64 - Imagens da produção primária oceânica $\left(\mathrm{gC} \cdot \mathrm{m}^{-2} \cdot \mathrm{d}^{-1}\right)$ da costa sudeste brasileira referentes aos dias 16 (esquerda em cima), 17 (esquerda embaixo), 19 (direita em cima) e 21 (direita embaixo) de julho de 2001 (continente e nuvens em branco). 

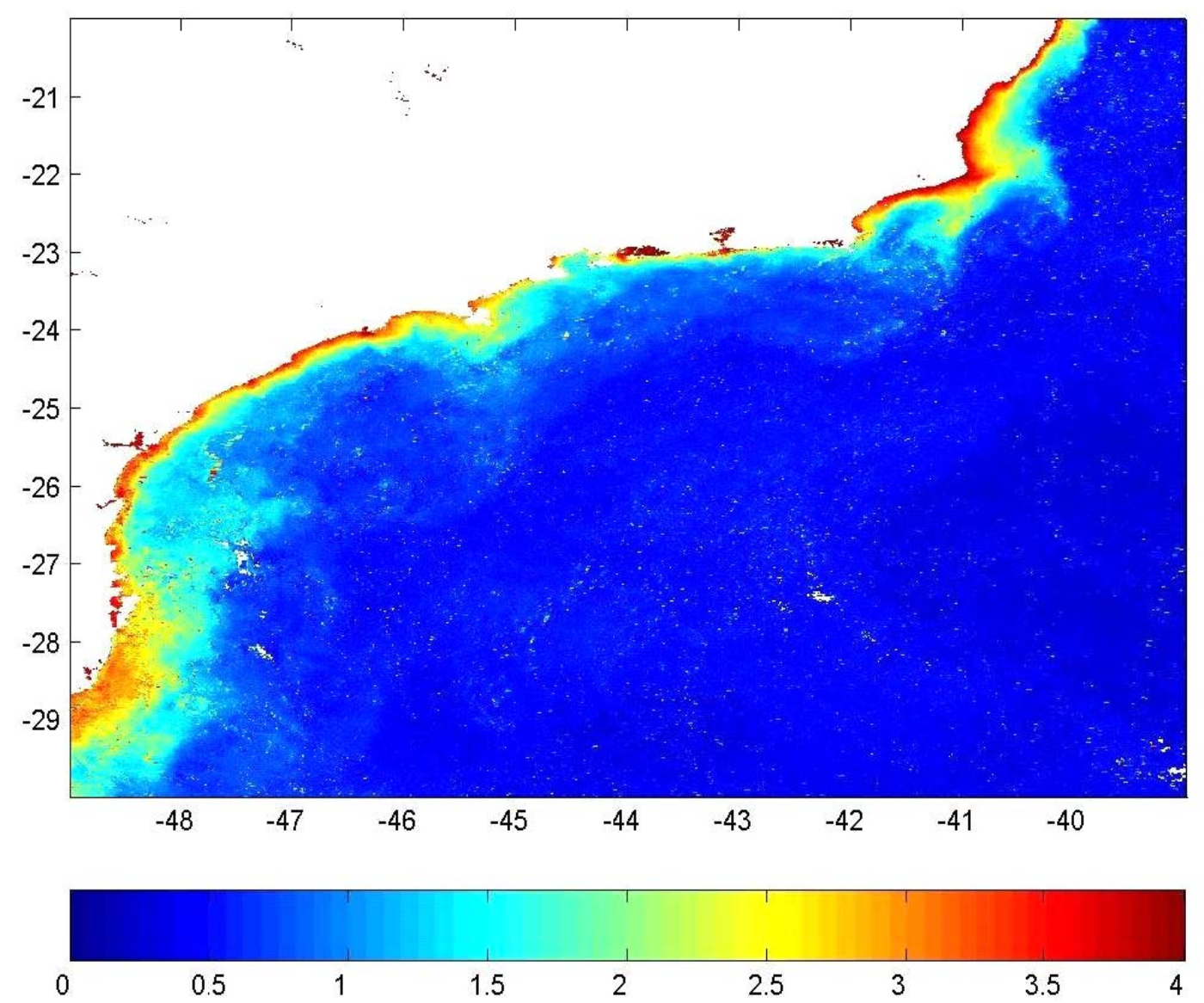

Figura 3.65 - Imagem média da produtividade primária oceânica $\left(\mathrm{gC} \cdot \mathrm{m}^{-2} \cdot \mathrm{d}^{-1}\right)$ da costa sudeste brasileira durante o mês de julho de 2001 (continente e nuvens em branco).

\subsubsection{Janeiro de 2002}

A Figura 3.66 mostras as imagens de produtividade primária oceânica dos dias 3, 4, 21 e 28 de janeiro de 2002. Neste conjunto de imagens foi possível observar altas taxas de produtividade primária $\left(>5,0 \mathrm{gC} \cdot \mathrm{m}^{-2} \cdot \mathrm{d}^{-1}\right)$ entre São Tomé e Vitória, assim como próximo a entrada da Baía de Guanabara. A CB aparece em tom azul escuro, com valores de PPO menores que $0,5 \mathrm{gC} \cdot \mathrm{m}^{-2} \cdot \mathrm{d}^{-1}$. Meandros ciclônicos foram notados principalmente em São Tomé. Na imagem do dia 21/1/2002, foi possível identificar um vórtice ciclônico a SE de Vitória, em torno de $20,1^{\circ} \mathrm{S}-39,8^{\circ} \mathrm{W}$, aproximadamente. Uma pluma a SE de Cabo Frio exibiu valores de PPO maiores que 4,0 gC. $\mathrm{m}^{-2} \cdot \mathrm{d}^{-1}$. 

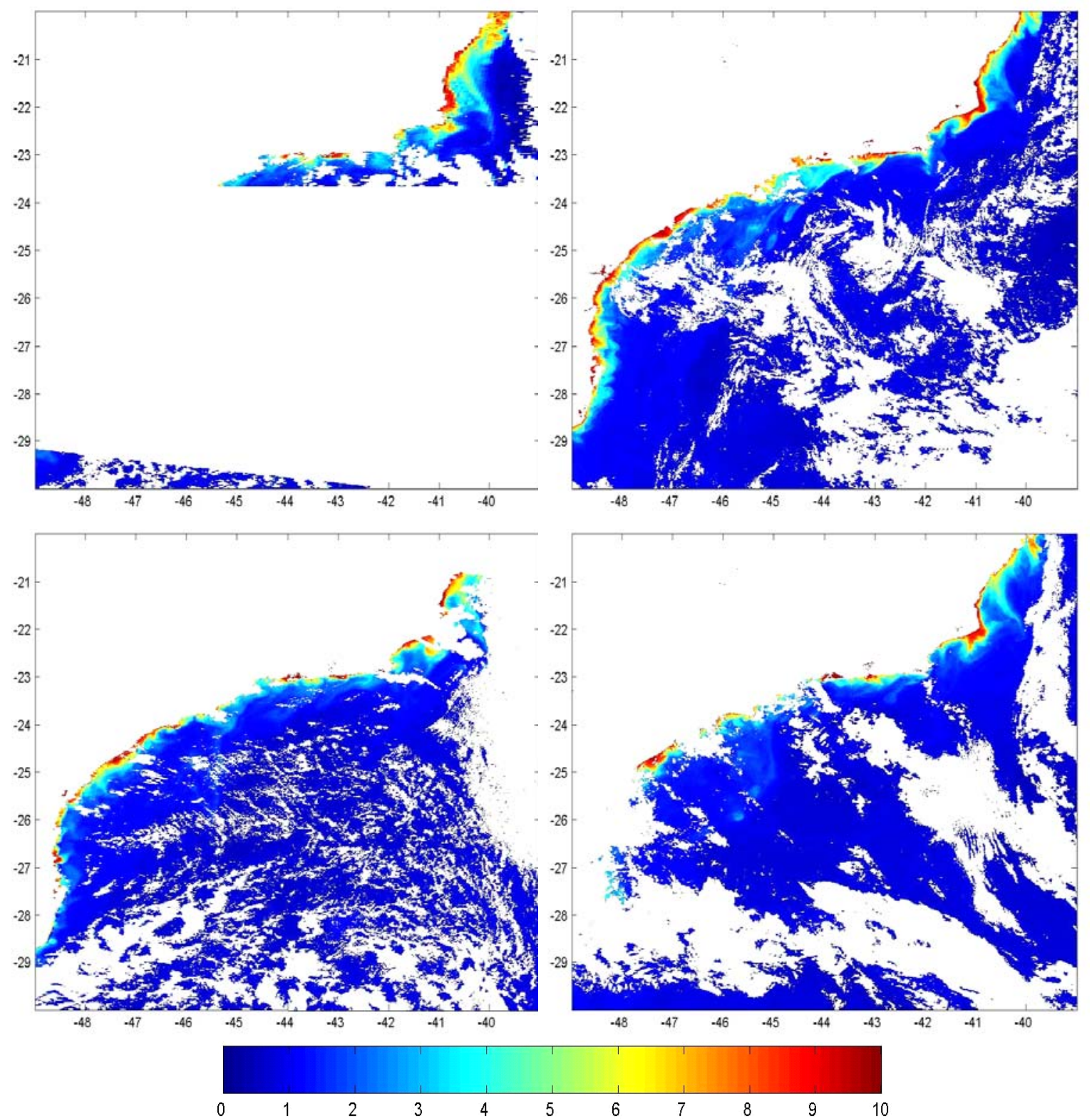

Figura 3.66 - Imagens da produção primária oceânica $\left(\mathrm{gC} \cdot \mathrm{m}^{-2} \cdot \mathrm{d}^{-1}\right)$ da costa sudeste brasileira referentes aos dias 3 (esquerda em cima), 4 (esquerda embaixo), 21 (direita em cima) e 28 (direita embaixo) de janeiro de 2002 (continente e nuvens em branco).

A Figura 3.67 apresenta a imagem média de produtividade primária oceânica integrada na zona eufótica para o mês de janeiro de 2002. Nesta imagem pode-se observar as águas pobres da $\mathrm{CB}$ ao largo, com taxas de produtividade primária menores que 0,5 $\mathrm{gC} \cdot \mathrm{m}^{-2} \cdot \mathrm{d}^{-1}$. Manchas com altas taxas de PPO $\left(>7,0 \mathrm{gC} \cdot \mathrm{m}^{-2} \cdot \mathrm{d}^{-1}\right)$ foram notadas na região costeira entre São Tomé e Vitória, próximo à Baía de Guanabara e costa sul de São 
Paulo, Paraná e norte de Santa Catarina. O meandramento ciclônico em São Tomé também pode ser identificado nesta imagem média mensal, assim como uma pluma com PPO maior que 5,0 gC.m $\mathrm{m}^{-2} \cdot \mathrm{d}^{-1}$ a S-SE de Vitória.

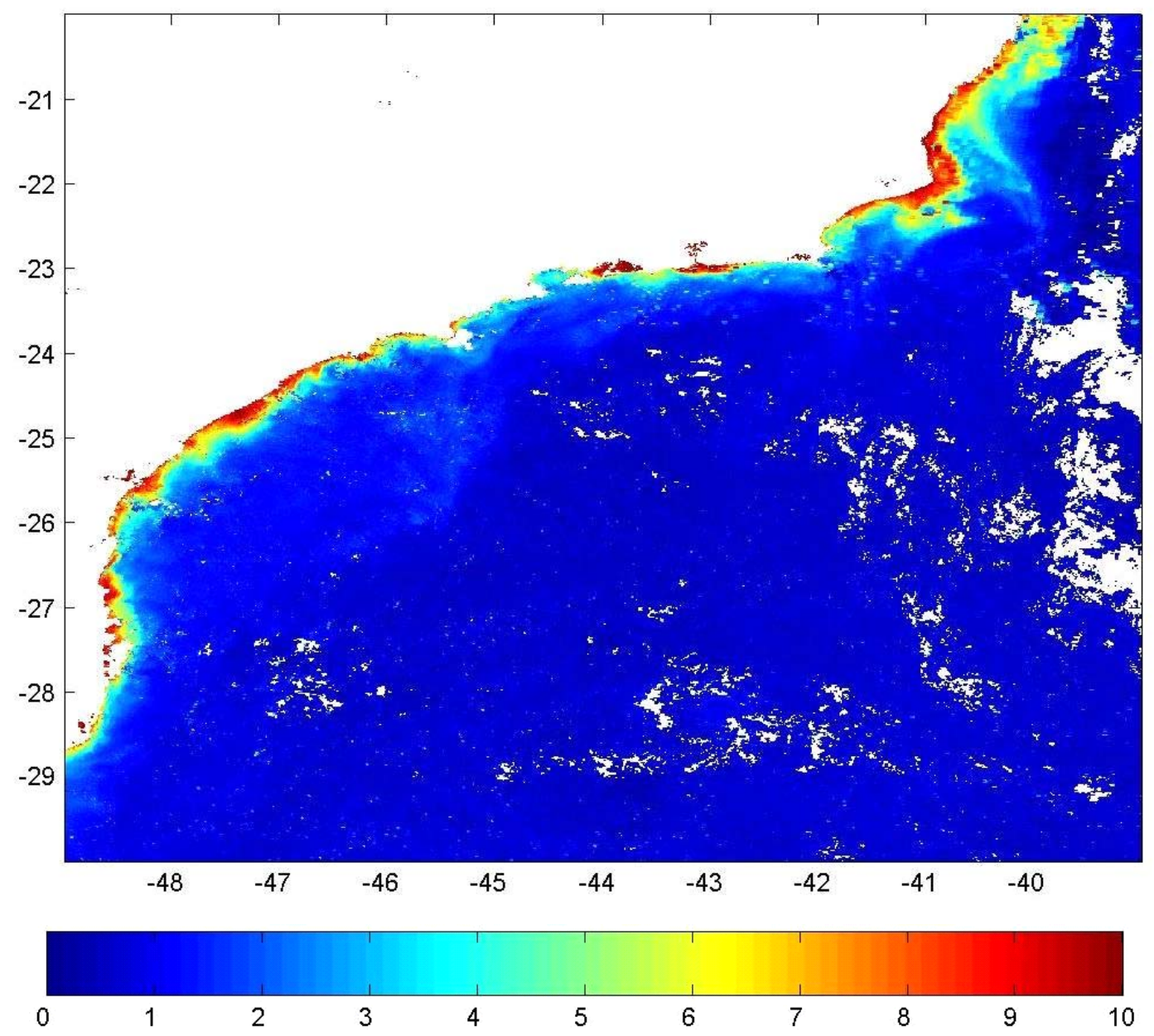

Figura 3.67 - Imagem média da produtividade primária oceânica $\left(\mathrm{gC} \cdot \mathrm{m}^{-2} \cdot \mathrm{d}^{-1}\right)$ da costa sudeste brasileira durante o mês de janeiro de 2002 (continente e nuvens em branco).

\subsubsection{Agosto de 2002}

A Figura 3.68 a seguir mostra as imagens de produtividade primária oceânica integrada na zona eufótica $\left(\mathrm{gC} \cdot \mathrm{m}^{-2} \cdot \mathrm{d}^{-1}\right)$ referentes aos dias 29 e 31 de julho, 7 e 12 de agosto de 2002. Neste conjunto de imagens pode-se observar as águas produtivas vindas de sul pela costa, desde Santa Marta até a Ilha de São Sebastião, com valores de PPO de até $3,5 \mathrm{gC} \cdot \mathrm{m}^{-2} \cdot \mathrm{d}^{-1}$. 

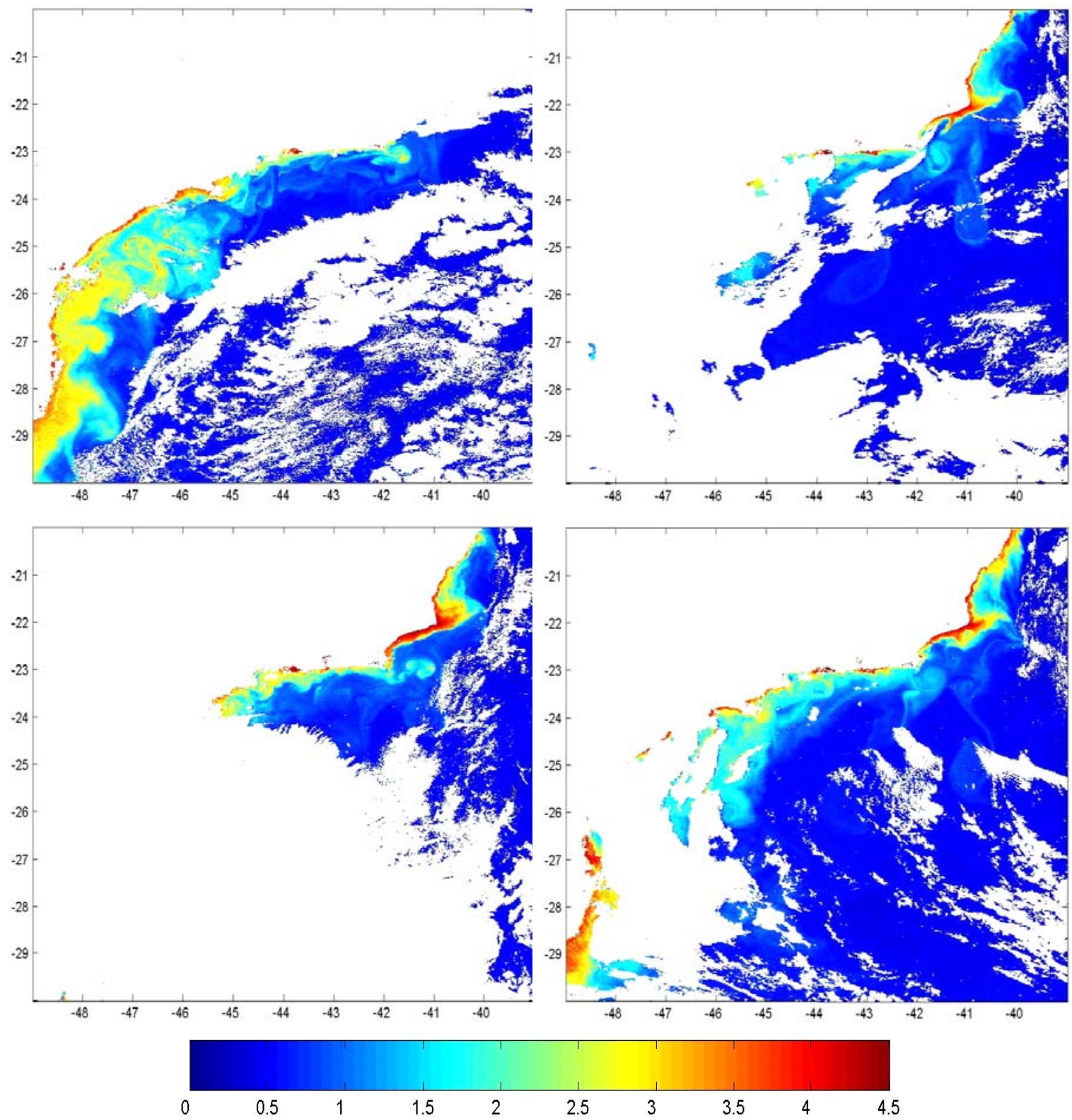

Figura 3.68 - Imagens da produção primária oceânica $\left(\mathrm{gC} \cdot \mathrm{m}^{-2} \cdot \mathrm{d}^{-1}\right)$ da costa sudeste brasileira referentes aos dias 29/7 (esquerda em cima), 31/7 (esquerda embaixo), 7/8 (direita em cima) e 12/8 (direita embaixo) de 2002 (continente e nuvens em branco).

Outra mancha quase contínua de alta produtividade costeira também pode ser notada no litoral norte de São Paulo, até quase Cabo Frio no Rio de Janeiro, com valores entre 2,0 e 3,5 gC.m $\mathrm{m}^{-2} \cdot \mathrm{d}^{-1}$. Na imagem do dia 29/7/2001 foi possível identificar um vórtice ciclônico próximo a Santa Marta, em torno de $28,9^{\circ} \mathrm{S}-47,6^{\circ} \mathrm{W}$ e com cerca de $100 \mathrm{~km}$ de diâmetro. Nesta mesma imagem, assim como nas seguintes, foi possível notar uma 
estrutura em forma de vórtice a leste de Cabo Frio, com diâmetro médio em torno de $60 \mathrm{~km}$ e PPO variando entre 1,5 e 2,5 gC. $\mathrm{m}^{-2} \cdot \mathrm{d}^{-1}$. A zona costeira entre Cabo Frio e São Tomé apresentou altas taxas de produtividade primária $\left(>3,5 \mathrm{gC} \cdot \mathrm{m}^{-2} \cdot \mathrm{d}^{-1}\right)$ durante este período. Meandramentos da $\mathrm{CB}$, ainda que sutis, também foram observados em São Tomé e no interior da corrente (mais ao largo).
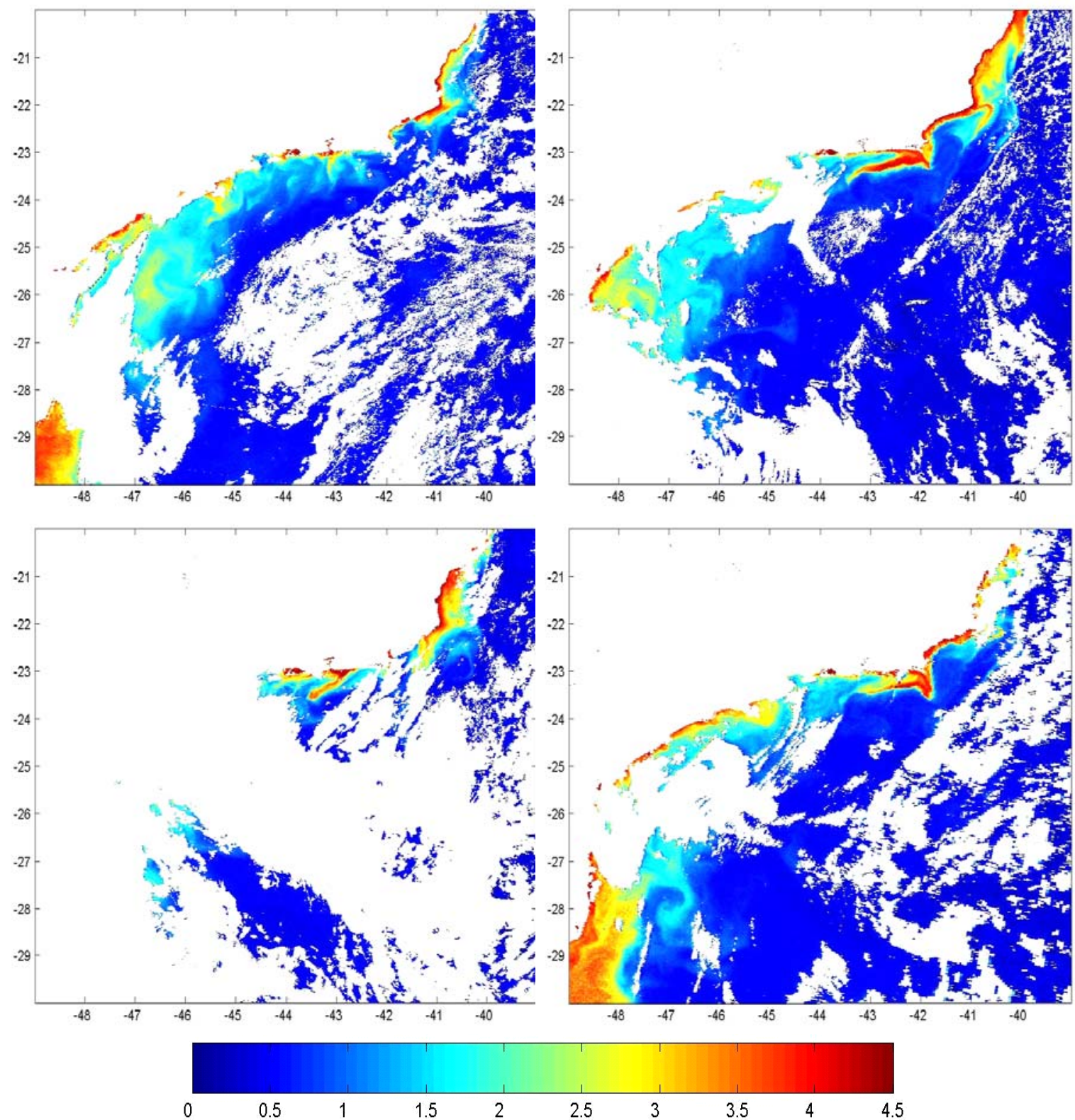

Figura 3.69 - Imagens da produção primária oceânica $\left(\mathrm{gC} \cdot \mathrm{m}^{-2} \cdot \mathrm{d}^{-1}\right)$ da costa sudeste brasileira referentes aos dias 19 (esquerda em cima), 22 (esquerda embaixo), 24 (direita em cima) e 25 (direita embaixo) de agosto 2002 (continente e nuvens em branco). 
A Figura 3.69 apresenta as imagens de produtividade primária oceânica dos dias 19, 22, 24 e 25 de agosto de 2002. Nesta seqüência de imagens, também foi possível notar a presença de águas frias vindas de sul pela costa chegando até a Ilha de São Sebastião, com valores de produtividade primária acima de $2,5 \mathrm{gC} \cdot \mathrm{m}^{-2} \cdot \mathrm{d}^{-1}$. Na imagem do dia $19 / 8 / 2002$, foi possível identificar um vórtice ciclônico em frente a Paranaguá $\left(25,6^{\circ} \mathrm{S}-\right.$ $46,2^{\circ} \mathrm{W}$, aproximadamente) com cerca de $100 \mathrm{~km}$ de diâmetro. Uma pluma de ressurgência próxima a Cabo Frio pode ser observada desde o dia 22/8/2002, se desenvolvendo para SO-O e atingindo mais de $200 \mathrm{~km}$ de extensão no dia 24/8/2002 (considerando a isolinha de $3,0 \mathrm{gC} . \mathrm{m}^{-2} \cdot \mathrm{d}^{-1}$ como seu limite). Outras plumas de alta produtividade também foram observadas em São Tomé e Vitória, associadas a meandramentos ciclônicos da CB.

A Figura 3.70 exibe a imagem média mensal da produtividade primária integrada na zona eufótica durante o mês de agosto de 2002, na costa sudeste brasileira. É possível observar a intrusão de águas produtivas vindas de sul pela costa, desde Santa Marta $\left(\mathrm{PPO}>3,0 \mathrm{gC} \cdot \mathrm{m}^{-2} \cdot \mathrm{d}^{-1}\right)$ até a Ilha de São Sebastião $\left(\mathrm{PPO}>2,5 \mathrm{gC} \cdot \mathrm{m}^{-2} \cdot \mathrm{d}^{-1}\right)$. As águas oligotróficas da $\mathrm{CB}$ podem ser notadas ao largo na imagem em tom azul escuro $\left(\mathrm{PPO}<0,5 \mathrm{gC} \cdot \mathrm{m}^{-2} \cdot \mathrm{d}^{-1}\right)$. Na região de Cabo Frio e litoral do Rio de Janeiro, aparece uma mancha com valores de produtividade relativamente altos $\left(\mathrm{PPO}>2,5 \mathrm{gC} \cdot \mathrm{m}^{-2} \cdot \mathrm{d}^{-1}\right)$ estendendo-se para O-SO. Na região do Cabo de São Tomé, as taxas de produtividade também são altas, com valores acima de $3,5 \mathrm{gC} \cdot \mathrm{m}^{-2} \cdot \mathrm{d}^{-1}$ próximo à costa. 


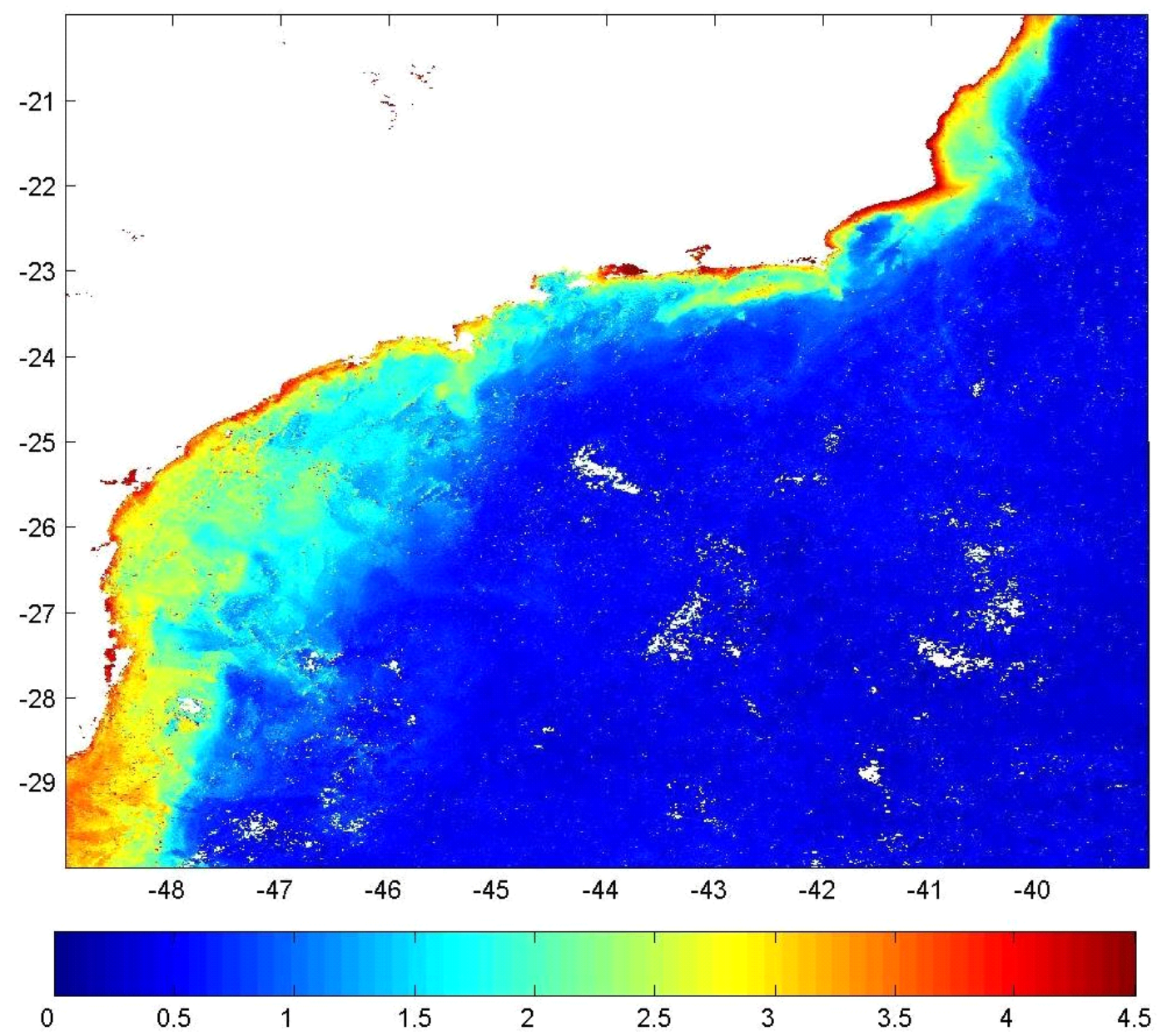

Figura 3.70 - Imagem média da produtividade primária oceânica $\left(\mathrm{gC} \cdot \mathrm{m}^{-2} \cdot \mathrm{d}^{-1}\right)$ da costa sudeste brasileira durante o mês de agosto de 2002 (continente e nuvens em branco).

\subsection{Produtividade primária anual}

Foram realizadas estimativas da produtividade primária anual $\left(\mathrm{gC} \cdot \mathrm{m}^{-2} \cdot \mathrm{ano}^{-1}\right)$ para os domínios de plataforma, talude e plataforma + talude, referentes aos anos de 2001 e 2002. Foi utilizado o modelo de produtividade de Bedford 2 (BPM2), com os parâmetros médios de $P_{\max }^{B}$ e $\alpha^{B}$ calculados para cada cruzeiro de mesoescala (Tabela 3.2 , Tabela 3.11, Tabela 3.21 e Tabela 3.28, respectivamente). Foram utilizados também, os parâmetros médios dos perfis verticais de biomassa obtidos pelo ajuste da curva de Gauss deslocada (ver Tabela 3.33). Os parâmetros médios dos cruzeiros de verão (M1 e M3) foram utilizados no cálculo da produtividade primária diária integrada na zona eufótica $\left(\mathrm{gC} . \mathrm{m}^{-2} \cdot \mathrm{d}^{-1}\right)$ referente ao dia 15 dos meses de janeiro, fevereiro, março, 
outubro, novembro e dezembro. Da mesma forma, os parâmetros médios dos cruzeiros de inverno (M2 e M4) foram utilizados no cálculo da produtividade primária diária integrada na zona eufótica referente ao dia 15 dos meses de abril, maio, junho, julho, agosto e setembro. Os valores diários obtidos foram multiplicados pelo número de dias de cada mês do ano, respectivamente. Os valores mensais encontrados foram somados obtendo-se a estimativa da produtividade primária anual $\left(\mathrm{gC} \cdot \mathrm{m}^{-2} \cdot \mathrm{ano}^{-1}\right)$. A Tabela $3.58 \mathrm{a}$ seguir apresenta os resultados obtidos para cada ano (2001 e 2002) nos domínios de plataforma, talude e plataforma + talude.

TABELA 3.58 - ESTIMATIVAS DA PRODUTIVIDADE PRIMÁRIA ANUAL PARA OS DOMÍNIOS DE PLATAFORMA E TALUDE

\begin{tabular}{c|c|c|c}
\hline & Plataforma & Talude & Plataforma + Talude \\
\hline $\mathbf{2 0 0 1}$ (M1 + M3) & 424,30 & 312,43 & 404,90 \\
\hline $\mathbf{2 0 0 2}$ (M2 + M4) & 514,81 & 219,15 & 366,25 \\
\hline Diferença & $+18 \%$ & $-30 \%$ & $-10 \%$ \\
\hline
\end{tabular}

A produtividade primária anual estimada para o domínio de plataforma em 2002 $\left(514,81 \mathrm{gC} \cdot \mathrm{m}^{-2} \cdot \mathrm{a}^{-1}\right)$ foi cerca de $18 \%$ maior que a estimada no ano de 2001 $\left(424,30 \mathrm{gC} \cdot \mathrm{m}^{-2} \cdot \mathrm{a}^{-1}\right)$. Por outro lado, o valor obtido para o domínio de talude em 2002 $\left(219,15 \mathrm{gC} \cdot \mathrm{m}^{-2} \cdot \mathrm{a}^{-1}\right)$ foi cerca de $30 \%$ menor que o valor calculado em 2001 $\left(312,43 \mathrm{gC} \cdot \mathrm{m}^{-2} \cdot \mathrm{a}^{-1}\right)$. Considerando-se a área de estudo como um todo, a produtividade primária anual foi somente 10\% maior em $2001\left(404,90 \mathrm{gC} \cdot \mathrm{m}^{-2} \cdot \mathrm{a}^{-1}\right)$ que em 2002 $\left(366,2581 \mathrm{gC} \cdot \mathrm{m}^{-2} \cdot \mathrm{a}^{-1}\right)$. 


\section{CAPÍTULO 4}

\section{DISCUSSÃO}

\subsection{Hidrografia e nitrato}

A organização e o funcionamento dos ecossistemas dependem, basicamente, de luz e elementos nutrientes (carbono, oxigênio, nitrogênio, fósforo, metais traço e vitaminas). Nas áreas tropicais e subtropicais, o desenvolvimento da comunidade planctônica depende da disponibilidade de macronutrientes inorgânicos na zona eufótica, principalmente nitrogênio, uma vez que o regime diário de luz necessária para as reações fotossintéticas é suficiente em qualquer época do ano (Brandini et al., 1997). As características hidrográficas têm implicações imediatas sobre a composição e a biomassa da comunidade planctônica, antes de serem refletidas nos estoques biológicos da teia alimentar onde está incluída a maioria dos organismos de interesse comercial.

As principais características hidrográficas da região de estudo observadas nos cruzeiros de verão (M1 e M3) e inverno (M2 e M4) foram apresentadas nas Figuras 3.1, 3.2, 3.3 (M1), 3.23, 3.24 (M3), 3.12, 3.13, 3.14 (M2), 3.30 e 3.31 (M4), respectivamente. As condições encontradas confirmam, em linhas gerais, as descrições feitas por Miranda (1982) para a mesma área geográfica, e por Castro (1996) e Gaeta (1999) para a plataforma continental norte de São Paulo. A configuração das isotermas, isohalinas e isopicnais, durante os cruzeiros de verão e no inverno de 2002, sugeriu o afloramento da termoclina e da ACAS com o estabelecimento de uma frente de ressurgência em Cabo Frio (M1, M3 e M4), São Tomé e Saquarema (M3). Durante o inverno de 2001 (M2), a presença da ACAS foi notada entre 50 e $100 \mathrm{~m}$ de profundidade na radial em frente a Cabo Frio. As distribuições de nitrato durante os cruzeiros de verão e inverno foram mostradas nas Figuras 3.5 (M1), 3.24 (M3), 3.16 (M2) e 3.31 (M4), respectivamente. De modo geral, concentrações de nitrato relativamente mais altas estiveram associadas a eventos de ressurgência costeira. Ainda que a influência da ACAS não chegue à 
superfície do mar, o incremento na concentração de nutrientes na base da zona eufótica também aumenta a produção primária total (Metzler et al., 1997).

A ressurgência é um fenômeno que ocorre em meso-escala espacial (dezenas a centenas de quilômetros) e na escala temporal de dias, semanas e meses (Smith, 1968; Hidaka, 1972). Embora sem atingir dimensões e conseqüências biológicas economicamente tão importantes como a dos limites oeste dos continentes da América do Sul, Estados Unidos e África, a ressurgência costeira de Cabo Frio despertou a atenção de vários pesquisadores (Allard, 1955; Emílsson, 1961; Moreira da Silva \& Rodrigues, 1966; Moreira da Silva, 1973; Miranda, 1982; Gonzalez-Rodriguez et al., 1992, entre outros) os quais, com base em dados observacionais, concluíram que os ventos do quadrante E-NE são a principal forçante do fenômeno. O conceito básico da ressurgência costeira gerada pelo vento está relacionado ao efeito da tensão de cisalhamento dos ventos E-NE que, ao trocarem quantidade de movimento com a superfície livre do mar, geram correntes e transporte de volume resultante na camada de Ekman para alto mar. Devido à divergência do transporte na camada superficial, massas de água de camadas subsuperficiais são transportadas para as proximidades da costa e podem ressurgir (Castro et al., 2003). A massa de água de ressurgência em Cabo Frio é a ACAS fria, menos salina e com maior concentração de sais nutrientes do que a AT do oceano adjacente, fertilizando dessa forma a zona eufótica (Valentin, 1989) com efeitos até $400 \mathrm{~km}$ a sudoeste, sobre a plataforma de São Paulo (Lorenzzetti e Gaeta, 1996).

As imagens de TSM mostradas nas Figuras 3.8, 3.9 (M1), 3.19, 3.20 (M2), 3.27, 3.28 (M3), 3.34, 3.35 e 3.36 (M4) exibem núcleos e plumas de águas frias ao sul de Vitória (sobre a quebra de plataforma), São Tomé, Cabo Frio, Saquarema e Ilha de São Sebastião. As temperaturas mínimas observadas nessas imagens, em associação com eventos de ressurgência, variaram entre $14,0^{\circ}$ e $22,5^{\circ} \mathrm{C}$. Valores relativamente mais altos de temperatura $\left(22,0^{\circ} \mathrm{C}\right)$ já foram associados a eventos de ressurgência da ACAS por outros autores uma vez que, durante o movimento ascendente ela fica sujeita aos processos de mistura e ao aquecimento. A massa de água com essas características, ou seja, concentração de sal da ACAS, mas com temperatura mais elevada, foi denominada de Massa de Água Central Aquecida (ACA) por Moreira da Silva (1973). 
Miranda (1982) mostrou a ocorrência de um núcleo frio $\left(16,0^{\circ} \mathrm{C}\right)$ em Saquarema, durante o inverno de 1970. Recentemente, imagens geradas pelo sensor AVHRR também foram submetidas a um tratamento estatístico por Kampel et al. (1997) para analisar não somente a ocorrência, como também as características espaço-temporais de plumas de água fria da região costeira SE e S do litoral brasileiro, abrangendo o período de um ano (fevereiro de 1996 a janeiro de 1997). Naquele trabalho foi demonstrada a ocorrência de valores anômalos de baixa temperatura (mínimos entre $16,0^{\circ}$ e $18,0^{\circ} \mathrm{C}$ ) em sete áreas costeiras, desde Vitória (ES) até o litoral do Rio Grande do Sul (RS), ampliando o conhecimento de regiões potencialmente importantes de ocorrência de ressurgência costeira.

Entretanto, anomalias frias da TSM podem ser confundidas com ressurgências. Por exemplo, a mistura vertical gerada por ventos fortes e o ajuste baroclínico associado à intensificação da velocidade geostrófica, diminuem a temperatura em superfície (Castro et al., 2003).

Ikeda et al. (1974) observaram um mínimo de $15,0^{\circ} \mathrm{C}$ e salinidade 35,6 ao largo da Ponta de Saquarema durante o inverno de 1971. A variação da estrutura termohalina, observada no intervalo de tempo de poucos dias, indicou conclusivamente o efeito advectivo da ressurgência costeira da ACAS, cujo núcleo estava localizado ao largo da Ponta de Saquarema, cerca de $55 \mathrm{~km}$ a oeste de Cabo Frio. Devido à divergência unilateral gerada pelo vento de NE a influência advectiva da massa de água fria e relativamente salina, propagou-se para SO. Lorenzzetti e Gaeta (1996) utilizaram imagens AVHRR e dados in situ para discutir a influência biológica e química da ressurgência costeira de Cabo Frio sobre os ecossistemas de plataforma e da bacia adjacente. Foi mostrado um evento de ressurgência para o qual a pluma fria se estendeu desde sua origem até 300-400 km em linha reta em direção à Ilha de São Sebastião. Silva Jr et al. (1997) processaram um conjunto de cinco imagens AVHRR de fevereiro de 1997 para mostrar a advecção de extensas línguas frias para sudoeste, até a região central da Bacia de Santos. Foi mostrado que a advecção horizontal de águas frias ressurgidas em Cabo Frio pode alcançar o ecossistema de plataforma em regiões distando até $386 \mathrm{~km}$ da origem. 
As distribuições de temperatura, salinidade e $\sigma_{t}$, assim como as imagens termais orbitais, também sugeriram a presença de meandros e vórtices da $\mathrm{CB}$ em diferentes regiões, como em São Tomé e Cabo Frio, entre outros. A mudança de direção das isotermas e isohalinas deixando de seguir uma orientação paralela às isobatimétricas e assumindo direções perpendiculares às mesmas, denotam um comportamento baroclínico da CB (Castro, 1996). Os movimentos ascendentes da ACAS podem ser induzidos por divergência unilateral do campo de velocidade gerado pela tensão de cisalhamento do vento ou por vórtices e na região de cisalhamento ciclônico da $\mathrm{CB}$. Em ambos os casos, a continuidade do movimento divergente na camada de superfície é estabelecida pelo movimento vertical ascendente. A CB fluindo ao longo da mudança abrupta na orientação da linha de costa em Cabo Frio (de NE - SO para E - O), pode gerar meandramentos, vórtices e ressurgência de água fria na plataforma continental SE. Um modelo conceitual desse fenômeno na costa da Califórnia foi apresentado por LaFond e LaFond (1971, citado por Castro,1996) e, recentemente, os efeitos da topografia de fundo e da geometria da linha de costa, sobre a ressurgência na costa SE brasileira, foram modelados numericamente por Rodrigues e Lorenzzetti (2001).

Estruturas na forma de vórtices ciclônicos da $\mathrm{CB}$ na quebra de plataforma são capazes de induzir movimentos ascendentes e transportar a ACAS para regiões da plataforma continental, visíveis em imagens AVHRR. Modelos conceituais da ocorrência desse fenômeno podem ser obtidos em Campos et al. (1996) e Campos et al. (2000). As distribuições de nitrato obtidas neste trabalho apresentaram máximos relativos na quebra de plataforma associados a intrusões da ACAS e a meandramentos da CB.

Silveira et al. (2000) analisaram as mesmas imagens utilizadas por Campos et al. (1996) e sugeriram que o início da atividade vortical deva estar ao largo de São Tomé $\left(22^{\circ} \mathrm{S}\right)$ por razões dinâmicas similares àquelas de Cabo Frio. Foi observado um meandro ciclônico de grande amplitude em frente ao Cabo de São Tomé e meandros ciclônicos e anticiclônicos se sucedendo em direção à Bacia de Santos. Segundo Velhote (1998), na Bacia de Santos ocorre a formação de pares vorticais, tanto de ciclones como de anticiclones, em lados opostos ao eixo da corrente, como mostrado em imagens AVHRR (ver Figura 3.19, 17/07/2001). Essas estruturas são menores em tamanho que 
as de Cabo Frio, e aparentemente não se desprendem do eixo principal da CB (Garfield III, 1990; Campos et al. , 1995; Campos et al. 1996). Hooker et al. (1997) analisaram imagens termais orbitais históricas aplicando uma paleta de cores branca-e-preta e um método de separação termal. Os resultados mostraram que treze seqüências de seis vórtices das Correntes do Golfo e da $\mathrm{CB}$, historicamente interpretados como solitários, eram dipolares. Alguns destes vórtices foram observados no oceano aberto, eliminando assim, a possibilidade de serem sustentados por interações topográficas com o talude continental.

Campos et al. (2000) seguem os argumentos de Osgood et al. (1987) para explicar como ocorreria a contribuição da CB para a ressurgência ao largo do sudeste brasileiro. Explicam que o vórtice (ou meandro) ciclônico tem núcleo de água fria e se propaga para sudoeste, com a CB. A água em seu núcleo é continuamente renovada, devido à ressurgência na parte dianteira e subsidência na parte traseira. Devido à sua circulação no sentido horário, o meandro empurraria a água ressurgida em sua parte dianteira para regiões rasas.

A partir das imagens de satélites e dados hidrográficos obtidos neste trabalho é sugerida uma explicação para os padrões observados sinopticamente nos campos de temperatura e concentração de clorofila $a$ superficiais associados aos meandramentos e vórtices frontais da CB. O meandro ciclônico se propaga para S-SO com a CB. As águas de plataforma mais frias que a AT são separadas e advectadas para regiões mais profundas, enquanto que, as águas quentes da CB são trazidas para regiões mais rasas (Figura 4.1). Esse mecanismo de trocas e mistura entre águas de plataforma e oceano aberto (entrapment) também pode ser visualizado em imagens da cor do oceano nas regiões de São Tomé e sul de Cabo Frio, por exemplo (ver Figuras 3.10, 3.11, 3.21, 3.22, 3.29, 3.37, 3.38 e 3.39 ). 

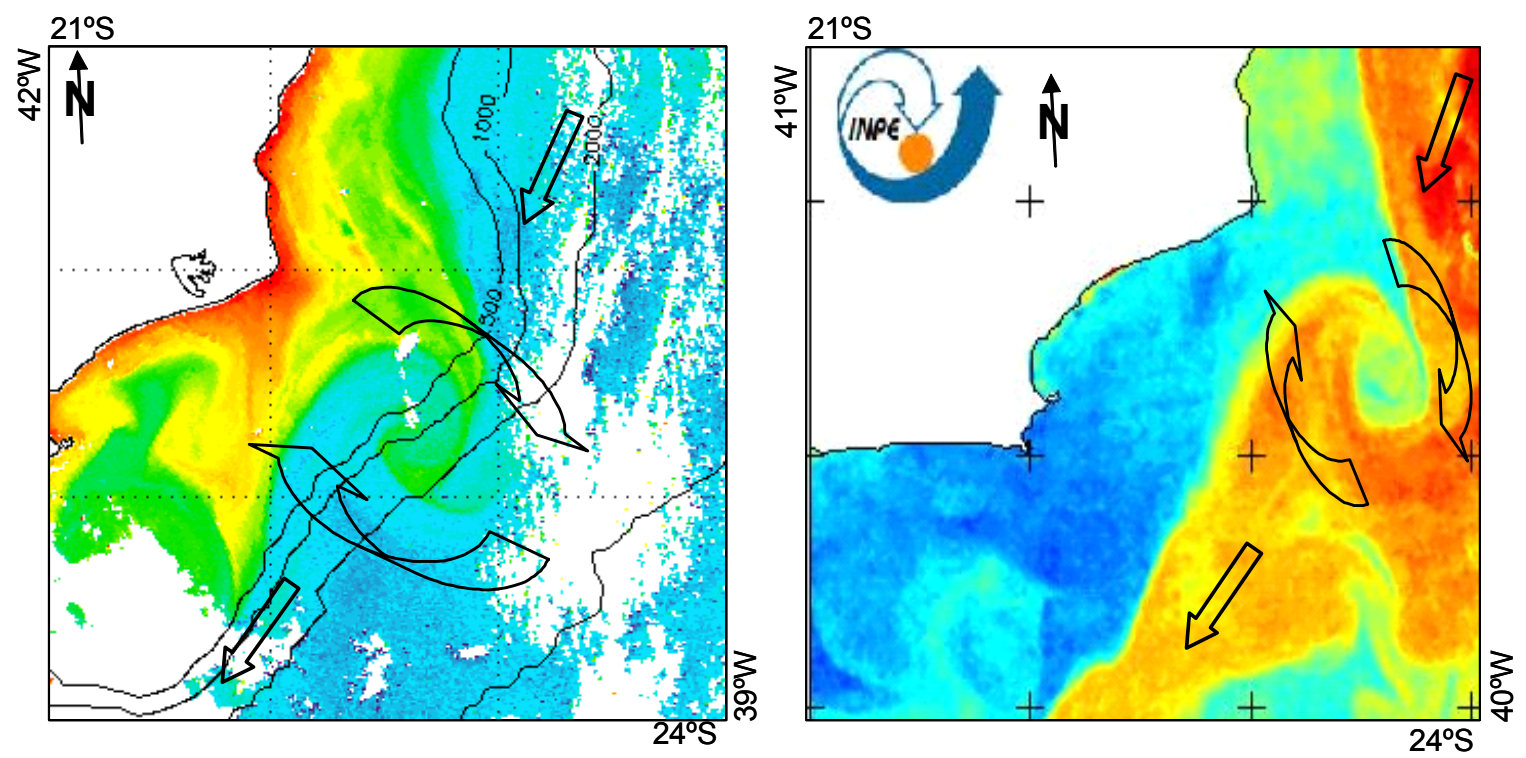

Figura 4.1 - Representação esquemática da troca e mistura (entrapment) entre águas de plataforma e águas da CB induzidas por meandro ciclônico (lado esquerdo: imagem SeaWiFS; lado direito: imagem AVHRR).

No conjunto de dados hidrográficos, nutrientes e imagens de satélites também foi possível observar a intrusão de águas frias e menos salinas sobre a plataforma continental (Figuras 3.19, 3.20, 3.34, 3.35). Estes eventos frios ocorreram nos períodos de inverno e apresentaram efeitos nos campos de massa e nitrato com conseqüente enriquecimento da zona eufótica (Figuras 3.24, 3.31).

Lino e Mascarenhas (1985) descreveram uma intrusão anômala da Corrente das Malvinas associada à presença de águas frias sobre a plataforma continental da costa sudeste do Brasil até as imediações da Ilha de São Sebastião, SP, durante o inverno de 1983. Foram feitas especulações sobre os efeitos deste fenômeno sobre a pesca comercial. Brandini (1990b) utilizou dados hidrográficos in situ para relacionar a intrusão de águas frias na plataforma interna do extremo sul do Brasil com águas subantárticas impulsionadas por ventos do quadrante S-SO. Kampel (1993) observou, a partir de imagens AVHRR de alta resolução obtidas em julho de 1993, a presença de águas frias sub-antárticas $\left(16^{\circ} \mathrm{C}\right)$, fluindo de sul sobre a plataforma continental S-SE, até a latitude de $25,6^{\circ} \mathrm{S}$. Este mesmo evento foi analisado por Campos et al. (1996a) e Campos et al. (1996b) a partir de dados hidrográficos coletados pelo projeto Circulação Oceânica de Região Oeste do Atlântico Sul (COROAS) na região sudeste do Brasil, em 
conjunto com imagens AVHRR e dados de derivadores lagrangeanos de superfície. Silva Jr e Kampel (1996) descreveram a intrusão sazonal (inverno) de águas frias sobre a plataforma continental Sul-Sudeste do Brasil a partir de um conjunto de imagens AVHRR abrangendo um período de três anos. Segundo os autores, a observação desta feição pelas imagens de satélite sugere que ela tem origem na Confluência BrasilMalvinas, ou mesmo em latitudes mais ao sul, como um ramo costeiro da Corrente das Malvinas. Stevenson et al. (1998) integraram imagens AVHRR, dados de derivadores rastreados por satélites e dados biológicos in situ para discutir a presença de foraminíferos, ostracodos e microbivalves, típicos de águas frias e menos salinas da costa sul da Argentina e região Antártica, nas águas tropicais da Baía de Sepetiba, RJ. Os autores concluíram que organismos marinhos nativos de águas mais ao Sul foram e têm sido advectados para norte ao longo da plataforma continental interna até $22^{\circ} \mathrm{S}$. Esporadicamente, parcelas de água contendo estes organismos, podem entrar na Baía de Sepetiba. A passagem de frentes meteorológicas pela região é apontada como importante mecanismo causador destes eventos esporádicos. Gaeta (1999) também observou o mesmo fenômeno de intrusão das águas frias, pouco salinas e ricas em nitrato na plataforma norte de São Paulo. Concentrações elevadas de nitrato de origem continental se comportam conservativamente devido à velocidade com que são introduzidos na região em relação ao tempo em que são absorvidos pelo fitoplâncton (Gaeta e Brandini, 2003). Recentemente, este fenômeno foi denominado como frente subtropical de plataforma do Rio La Plata (Piola et al., 2000).

\subsection{Biomassa e produtividade primária fitoplanctônica}

As distribuições de concentração de clorofila $a$ encontradas nos cruzeiros de verão e inverno foram apresentadas nas Figuras 3.4 (M1), 3.26 (M3), 3.15 (M2) e 3.33 (M4), respectivamente. As condições encontradas confirmam, em linhas gerais, as descrições feitas por Aidar et al. (1993) para o litoral norte de São Paulo, por GonzalezRodriguez et al. (1992) para Cabo Frio, e por Gaeta et al. (1993) para a região da Bacia de Campos. Aidar et al. (1993) fizeram uma primeira tentativa de avaliar a capacidade trófica das massas de água do litoral norte de São Paulo através das concentrações de clorofila. Para a Água Costeira, os valores médios variaram de 0,31 a $0,82 \mathrm{mg} \cdot \mathrm{m}^{-3}$ no 
verão e de 0,53 a $1,07 \mathrm{mg} \cdot \mathrm{m}^{-3}$ no inverno. $\mathrm{Na} \mathrm{AT}$, as médias observadas no verão foram de 0,06 a $0,25 \mathrm{mg} \cdot \mathrm{m}^{-3}$ e no inverno, de 0,31 a $0,37 \mathrm{mg} \cdot \mathrm{m}^{-3}$. No presente trabalho, os valores encontrados para os domínios de plataforma e talude correspondem, aproximadamente, aos domínios de AC e AT descritos por Aidar et al., (1993), tanto no verão como no inverno (ver Tabelas 3.1, 3.28, 3.13 e 3.35, respectivamente). A Tabela 4.1 a seguir resume as profundidades médias da camada de mistura e da zona eufótica observadas durante os quatro cruzeiros (M1, M2, M3 e M4), nos domínios de plataforma e talude, respectivamente. Do mesmo modo que em Aidar et al., (1993), durante o verão, a camada de mistura esteve menos profunda que a zona eufótica e durante o inverno foram observadas situações em que a camada de mistura foi um pouco maior ou quase igual a profundidade da zona eufótica.

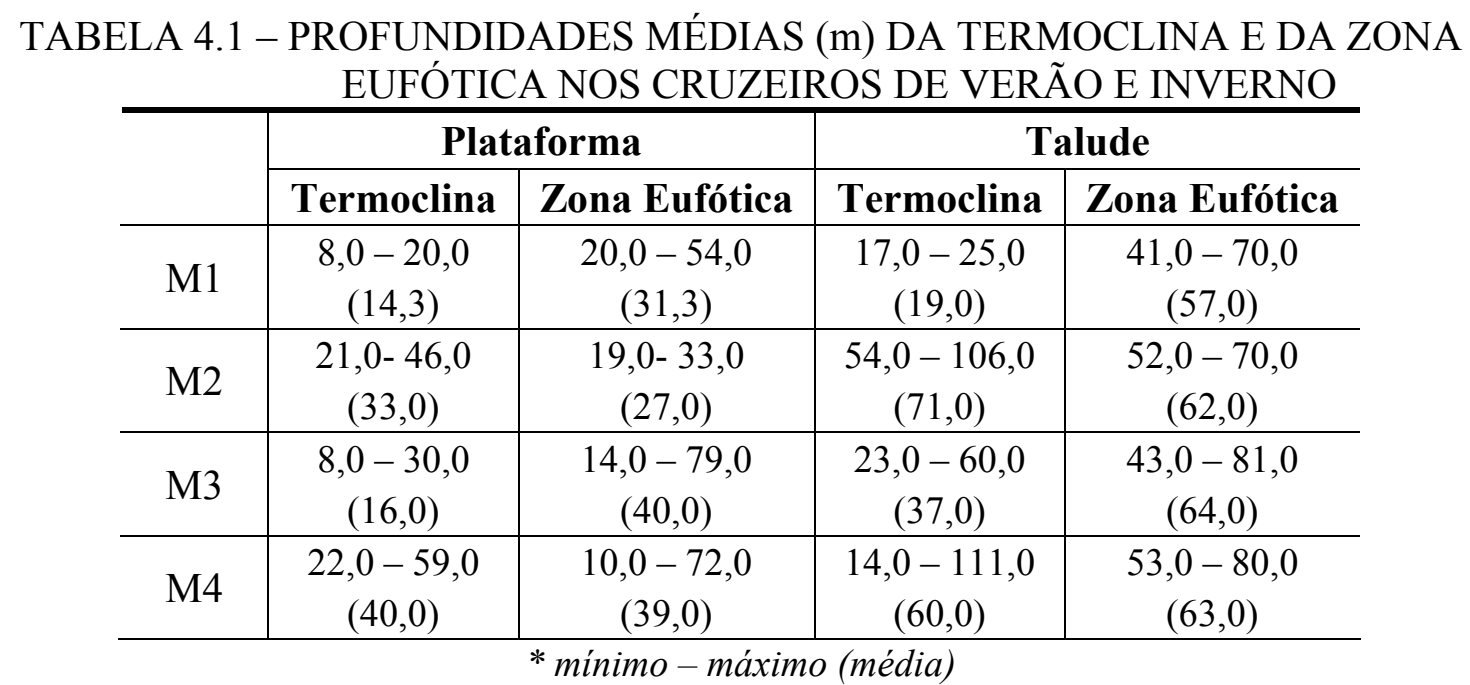

No ecossistema pelágico de Cabo Frio, Gonzalez-Rodriguez et al. (1992) descrevem uma variação das concentrações de clorofila $a$, conforme o estágio de ressurgência, entre 0,5 e $6,0 \mathrm{mg} \cdot \mathrm{m}^{-3}$, com os valores máximos perdurando por um período de 24 horas. No presente trabalho, concentrações de clorofila $a$ maiores que $11,0 \mathrm{mg} \cdot \mathrm{m}^{-3}$ foram observadas em Cabo Frio, na superfície e a $25 \mathrm{~m}$ de profundidade, durante o verão de 2002. Gaeta et al. (1993) mostraram concentrações de clorofila variando de 0,01 a 2,35 mg. $\mathrm{m}^{-3}$ em áreas costeiras e na plataforma do Rio de Janeiro no inverno, ou seja, valores similares aos observados nos cruzeiros M2 e M4. 
As distribuições horizontais de clorofila $a$ integrada na zona eufótica de verão (M3) e inverno (M4) foram mostradas nas Figuras 3.26 e 3.33, respectivamente. A correlação espacial com a clorofila $a$ superficial só foi observada no cruzeiro M3. No cruzeiro M4, foram observadas manchas com concentrações altas sobre a quebra de plataforma. Os valores de clorofila $a$ integradas na zona eufótica referentes aos quatro cruzeiros foram apresentados nas Tabelas 3.4, 3.13, 3.22 e 3.29, respectivamente. Gaeta (1999) analisando dados do projeto COROAS mostrou concentrações de clorofila $a$ integradas na zona eufótica durante o verão (1993 e 1994) maiores que no inverno (1993), na plataforma continental e talude em frente a Santos $\left(10,0\right.$ a $53,3 \mathrm{mg} \cdot \mathrm{m}^{-2}$ no verão e 3,0 a $31,0 \mathrm{mg} \cdot \mathrm{m}^{-2}$ ) . Neste trabalho, observou-se um padrão diferente, ou seja, concentrações de clorofila integradas maiores no inverno que no verão. A exceção ocorreu para o domínio de plataforma no verão de 2002, quando foi observado o valor médio máximo $\left(29,78 \mathrm{mg} \cdot \mathrm{m}^{-2}\right)$ e correlação espacial entre as concentrações de clorofila superficial e integrada na zona eufótica.

Os resultados das análises de regressão múltipla, realizadas para a variável dependente clorofila $a$ integrada na zona eufótica $\left(\mathrm{C}_{\mathrm{EU}}\right)$ nos domínios de plataforma, talude-verão e talude-inverno, foram mostrados nas Tabelas 3.46, 3.49 e 3.52, respectivamente. No domínio plataforma, a variável $\mathrm{C}_{\mathrm{EU}}$ esteve inversamente correlacionada às variáveis taxa de assimilação diária na zona eufótica $\left(\mathrm{TA}_{\mathrm{EU}}\right)$ e nitrato integrado na zona eufótica $\left(\mathrm{N}_{\mathrm{EU}}\right)$, como esperado na relação entre este nutriente e a clorofila. A clorofila $a$ integrada também esteve diretamente relacionada ao coeficiente vertical de atenuação $\left(\mathrm{K}_{\mathrm{s}}\right)$, como indicador da penetração de luz e à freqüência de Brünt-Väisäla $\left(\mathrm{N}^{2}\right)$, denotando a importância das áreas onde persistiram os processos de estratificação. No domínio talude-verão, a variável $\mathrm{C}_{\mathrm{EU}}$ também esteve diretamente correlacionada à variável $\mathrm{N}^{2}$, e inversamente correlacionada às variáveis $\mathrm{TA}_{\mathrm{EU}}, \mathrm{K}_{\mathrm{s}}$ e temperatura da superfície do mar (TSM), ou seja, associada a locais de ressurgência com assinatura no campo de TSM. No domínio talude-inverno, a $\mathrm{C}_{\mathrm{EU}}$ esteve relacionada diretamente à profundidade da termoclina $\left(\mathrm{Z}_{\mathrm{T}}\right)$ e inversamente correlacionada a profundidade da zona eufótica $\left(Z_{\mathrm{EU}}\right)$, profundidade do máximo de clorofila subsuperficial $\left(\mathrm{Z}_{\mathrm{M}}\right)$ e TSM, ou 
seja, nas regiões de presença da $\mathrm{CB}(\mathrm{AT})$, as $\mathrm{Z}_{\mathrm{M}}$ são mais profundas e com maior penetração de luz, características de águas oligotróficas.

Os valores de produção primária obtidos nos cruzeiros de verão e inverno de 2001 foram mostrados nas Tabelas 3.3 e 3.10, respectivamente. Gonzalez-Rodriguez et al. (1992) apresentaram maior amplitude de variação para a região de Cabo Frio, durante o verão de 1986 e inverno de $1987\left(0,01\right.$ a $14,28 \mathrm{mgC} \cdot \mathrm{m}^{-3} \cdot \mathrm{h}^{-1}$ e 0,37 a $4,54 \mathrm{mgC} \cdot \mathrm{m}^{-3} \cdot \mathrm{h}^{-1}$, respectivamente). Já os valores obtidos por Metzler (1991) na região de Ubatuba (1,67 e 1,82 $\mathrm{mgC} \cdot \mathrm{m}^{-3} \cdot \mathrm{h}^{-1}$ no verão e inverno, respectivamente) foram comparáveis aos encontrados neste trabalho no domínio de plataforma. Os valores de produção primária diária integrada na zona eufótica referentes aos quatro cruzeiros foram apresentados nas Tabelas 3.4 (M1), 3.13 (M2), 3.22 (M3) e 3.29 (M4). Os resultados obtidos por Gaeta (1999) para o verão de $1993\left(0,02\right.$ a $\left.1,84 \mathrm{gC} . \mathrm{m}^{-2} \cdot \mathrm{d}^{-1}\right)$ foram similares aos encontrados em M1 na plataforma, ainda que de modo geral, os valores estimados no presente trabalho tenham sido maiores que os obtidos por Gaeta (1999). Experimentos in situ e com curvas de luz realizados por Metzler (1991) na região de Ubatuba também apresentaram resultados menores que os obtidos neste trabalho. As distribuições de produção primária diária integrada na zona eufótica para o verão e inverno de 2002 foram mostradas nas Figuras 3.26 e 3.33, respectivamente. No verão, foi observada boa correlação espacial entre as manchas de alta produtividade integrada e clorofila $a$ integrada identificadas em Cabo Frio e São Tomé. No inverno, as manchas de alta produtividade coincidiram com as manchas de clorofila $a$ superficial próximas à Ilha de São Sebastião e Baía da Ilha Grande. Outro máximo relativo foi observado a sul de São Tomé. De modo geral, as produtividades integradas na zona eufótica foram maiores no verão que no inverno. Entretanto, o domínio de talude no inverno de 2001 apresentou o maior valor médio $\left(2,17 \mathrm{gC} \cdot \mathrm{m}^{-2} \cdot \mathrm{d}^{-1}\right)$, com valores associados a meandros e ressurgências de quebra de plataforma.

As ressurgências de quebra de plataforma (Mesquita et al., 1983) causadas por vórtices frontais ciclônicos da CB (Matsuura, 1990), fertilizam a base da zona eufótica com nutrientes inorgânicos modificando provisoriamente o sistema de produção regenerada, típico das áreas oceânicas oligotróficas, para o sistema de produção nova em áreas sobre 
o talude continental. Acredita-se que essas ressurgências possam ocorrer em uma faixa extensa da região SE-S e que suportam os estoques de sardinha, dourados e atuns em áreas oceânicas do talude (Matsuura, 1990; Odebrecht e Castello, 2001). Brandini (1990a) e Brandini (1988b) também comprovaram os efeitos das ressurgências da ACAS na quebra de plataforma sobre o aumento da produção primária fitoplanctônica e a composição específica em regiões afastadas da costa.

As características hidrográficas têm implicações imediatas sobre a composição e a biomassa da comunidade planctônica, antes de serem refletidas nos estoques biológicos da teia alimentar onde está incluída a maioria dos organismos de interesse comercial. Em regiões afastadas da costa, a fertilização em massa da zona eufótica ocorre apenas nas divergências equatoriais (Lalli e Parsons, 1993) ou em áreas de quebra de plataforma (Brandini, 1990a). Em regiões costeiras, ocorrem fertilizações em massa nas regiões estuarinas ou nas ressurgências costeiras como em Cabo Frio (Valentin, 1989).

$\mathrm{Na}$ área de estudo, prevalece o sistema de produção do tipo regenerativo (Metzler et al., 1996) no qual o nitrogênio inorgânico, normalmente limitante em ecossistemas marinhos (Ryther e Dunstan, 1971) está disponível sob a forma de compostos reduzidos (amônia, uréia, etc.), oriundos da excreção da comunidade planctônica e da regeneração bacteriana na coluna d'água. Sistemas de produção regenerada são pobres do ponto de vista pesqueiro, pois o acúmulo de biomassa é pequeno tendo em vista o grande número de níveis tróficos ao longo da teia alimentar pelágica (Lalli e Parsons, 1993). Eventualmente, este tipo de produção alterna-se com a produção nova, baseada em fontes externas de nitrogênio, introduzidas no sistema por ressurgências de água subsuperficial, aportes continentais e atmosféricos, difusão molecular na base da zona eufótica e ressuspensão de sedimentos em áreas rasas. Nessas condições, a produção fitoplanctônica aumenta, favorecendo o desenvolvimento larval, o recrutamento e o acúmulo de biomassa pesqueira pelágica, podendo também ser exportada sob a forma de matéria orgânica particulada para as comunidades bênticas (Brandini et al., 1997)

Do ponto de vista biológico foi possível identificar outro processo oceanográfico de grande escala que influi sobre a estrutura e dinâmica do ecossistema pelágico na 
plataforma continental da área de estudo. Os valores das produções integradas próximo à Ilha de São Sebastião foram maiores durante os cruzeiros de inverno. No inverno águas de origem subantártica são impulsionadas por ventos do quadrante S-SO, transportando águas frias na direção norte e alcançando grande parte da plataforma interna do sul do Brasil (Brandini, 1990b). Historicamente, o fenômeno foi detectado com base em dados in situ (Brandini, 1988a; Brandini, 1988b; Ambrósio Jr, 1989). Além das temperaturas mais baixas observadas na costa SE brasileira, as salinidades são igualmente baixas devido à influência da drenagem do Rio La Plata e da Lagoa dos Patos (Brandini, 1990b, 1988b). Concentrações elevadas de nutrientes de origem continental se comportam conservativamente devido à velocidade com que esses nutrientes são introduzidos na região em relação ao tempo em que são absorvidos pelo fitoplâncton (Gaeta e Brandini, 2003). Segundo estudos realizados por outros autores (Aidar-Aragão, 1980; Teixeira, 1973; Brandini,1990b; Aidar et al., 1993; Gaeta, 1999), a biomassa em termos de clorofila $a$ e as taxas de produção são comparativamente maiores no inverno do que no verão. $\mathrm{O}$ crescimento de diatomáceas é estimulado em relação aos demais grupos fitoplanctônicos (Brandini 1988b, 1990b).

As imagens de clorofila referentes aos cruzeiros de verão (Figuras 3.10, 3.11 e 3.29 ) apresentaram manchas de altas concentrações associadas a eventos de ressurgência costeira, plumas de ressurgências, meandros e vórtices da $\mathrm{CB}$ e ao aporte continental em zonas costeiras. As manchas de alta concentração de clorofila observadas nas imagens SeaWiFS de inverno (Figuras 3.21, 3.22, 3.37, 3.38 e 3.39) foram associadas à intrusão de águas frias e ricas vindas do sul pela costa, meandros e vórtices da $\mathrm{CB}$ e eventos de ressurgência costeira. A intrusão de ACAS sobre a plataforma continental tem sido apontada como o principal processo de fertilização da zona eufótica na plataforma SE durante o verão (Brandini et al., 1989; Brandini,1990a; Aidar et al., 1993; Matsuura, 1996; Lima et al., 1996; Gaeta, 1999; Gianesella, 2000), causando máximos subsuperficiais de clorofila $a$ na base da zona eufótica, entre a zona de mistura e o limite superior da nutriclina. Brandini et al., (1989) descreveram os máximos de clorofila subsuperficiais na plataforma do Paraná. Estas estruturas são comuns no verão em mares temperados devido ao crescimento de populações adaptadas às baixas 
intensidades luminosas e concentrações satisfatórias de nutrientes. Altas concentrações de oxigênio dissolvido coincidem com os máximos subsuperficiais de clorofila, sugerindo intensa atividade fotossintética. Curvas de luz - fotossíntese obtidas em diferentes níveis de profundidade comprovaram a fotoadaptação do fitoplâncton em níveis inferiores da zona eufótica, nos meses de verão com maior estratificação térmica (Brandini,1990b). Aidar et al., (1993) também associaram as altas concentrações de oxigênio dissolvido em subsuperfície aos máximos de clorofila na base da zona eufótica da plataforma de São Paulo durante o verão, sugerindo o crescimento do fitoplâncton adaptado a baixas intensidades de luz. Processo semelhante foi discutido por Odebrecht e Djurfeldt (1996) ao largo do Cabo Santa Marta. A sedimentação e acúmulo de células na termoclina sazonal ou o aumento da concentração intracelular de clorofila devido à baixa luminosidade, também poderiam ser considerados na formação desses máximos, mas ainda não foram investigados (Gaeta e Brandini, 2003). Além de sua importância ecológica, os máximos subsuperficiais de clorofila $a$ na plataforma até profundidades de 100 m são essenciais para a manutenção dos recursos pesqueiros pelágicos e demersais. Segundo Katsuragawa et al. (1993) a maior parte dos peixes de plataforma em São Paulo desovam no verão na mesma época de formação dos máximos subsuperficiais de clorofila, em conseqüência das intrusões da ACAS. Matsuura e Kitahara (1995) estudaram a distribuição horizontal e vertical da anchova (Engraulis anchoita) ao largo de Santa Marta e observaram o acúmulo de larvas em estágio avançado de desenvolvimento nas profundidades dos máximos subsuperficiais de clorofila.

O sensoriamento remoto oferece a oportunidade de comparação bi-dimensional simultânea da variabilidade biológica (pigmentos) e física (temperatura) na superfície do mar. A determinação quase simultânea da TSM é uma medida complementar excelente à medida de concentração de clorofila $a$, uma vez que os processos que contribuem para o crescimento fitoplanctônico também aparecem como anomalias de temperatura. Kampel et al. (2000) utilizaram dados de satélites (AVHRR e SeaWiFS) entre 1997 e 1998 para estudar e monitorar a costa sudeste brasileira. A caracterização das principais feições oceanográficas observadas nas imagens, como vórtices e ressurgências foram agrupados por estação do ano. Vários vórtices e meandramentos 
foram observados durante o período de estudo ao longo da frente oeste da CB. Parte destas feições coerentes eram semipermanentes (Vitória, São Tomé e Cabo Frio). Ciotti e Kampel (2001) compararam imagens termais (AVHRR) e de clorofila (SeaWiFS) da região entre São Tomé e Cabo Frio e observaram uma razoável relação entre as TSM's e campos superficiais de clorofila. As principais feições observadas foram o vórtice semipermanente de São Tomé, a ressurgência de quebra de plataforma e os meandros da frente oeste da CB. Foi observada uma resposta clara nos campos de concentração de clorofila na ressurgência de plataforma. No centro dos meandros e vórtices, a clorofila permaneceu relativamente baixa, sugerindo que as assinaturas frias também notadas nessas áreas estejam mais relacionadas com a entrada de águas de plataforma do que com ressurgências.

\subsection{Perfil vertical de biomassa fitoplanctônica}

Os parâmetros médios dos perfis verticais de biomassa estimados segundo o modelo Gaussiano - deslocado foram apresentados na Tabela 3.33, para as regiões de plataforma e talude em cada cruzeiro realizado. A proposta de Platt et al., (1988) de que a variação vertical da concentração de pigmentos fitoplanctônicos segue a forma de uma curva de Gauss, está baseada na análise de perfis obtidos em regiões tropicais oceânicas. Nessas regiões, a distribuição vertical da clorofila $a$ apresenta uma forma característica, denominada Estrutura Tropical Típica (Typical Tropical Structure, Herbland e Voituriez, 1979), onde um máximo de clorofila $a$ está normalmente associado à picnoclina. Esta estrutura deve ser estável ao longo do ano, a não ser em áreas de ressurgência. Em regiões temperadas, observa-se uma variação sazonal acentuada nas características físicas e biológicas da coluna d'água, com condições de intensa mistura vertical no inverno e de forte estabilidade no verão, ainda que fenômenos episódicos, como ventos intensos ou a presença de vórtices, possam alterar esses padrões (Mann e Lazier, 1996). Gaeta (1999) considerou a área abrangida pelos cruzeiros de grande escala do projeto COROAS (radiais com cerca de $1.100 \mathrm{~km}$ perpendiculares à costa em Santos e Rio Grande do Sul até o Canal de Vema, e uma terceira radial paralela à costa entre Santos e a plataforma do RS) com parâmetros da coluna d'água de acordo com a Estrutura Tropical Típica. As profundidades da nitraclina e dos máximos subsuperficiais 
de clorofila tenderam a ser iguais. A clorofila integrada e a produtividade primária se correlacionaram inversamente com a profundidade da nitraclina, e os máximos de atividade fotossintética ocorreram na profundidade dos máximos subsuperficiais de clorofila, em locais onde a nitraclina foi mais rasa $(60 \mathrm{~m})$. Nas estações mais oceânicas, o máximo de atividade fotossintética ocorreu em profundidades mais rasas do que o máximo subsuperficial de clorofila, uma característica comum em outras regiões do oceano (Longhurst e Harrison, 1989). Os máximos de atividade fotossintética indicaram os locais onde houve aumento da pressão de herbivoria zooplanctônica, e os máximos subsuperficiais de clorofila foram dependentes das respostas de crescimento algal com relação à nitraclina (Harrison, 1990).

Gonzalez (1994) classificou a área oceânica do litoral sul do Brasil em regiões de plataforma (profundidades até $200 \mathrm{~m}$ ), talude (entre 200 e $1.000 \mathrm{~m}$ ) e oceano (profundidades maiores que $1.000 \mathrm{~m}$ ), e apresentou parâmetros médios dos perfis gaussianos de biomassa para cada região, em diferentes épocas do ano, a partir de cruzeiros realizados entre 1987 e 1993. Os valores de $Z_{m}$ apresentados por Gonzalez (1994) para as regiões de plataforma e talude em fevereiro de 1990 foram 26,18 e $31,30 \mathrm{~m}(\mathrm{n}=9)$, respectivamente, enquanto que os valores referentes a julho de 1991 foram 0,0 e 12,26 m $(n=14)$, respectivamente. Os valores de $Z_{m}$ encontrados no presente trabalho foram mais altos, tanto na plataforma como no talude, nos períodos de verão $(n=44)$ e inverno $(n=42)$, e foram observadas diferenças entre a plataforma e o talude. Entretanto, o comportamento sazonal observado em ambos os trabalhos foi o mesmo, ou seja, $Z_{m}$ mais rasa durante o inverno. Brandini (1990b) estudando regiões de plataforma, talude e oceano aberto da região SE brasileira no inverno de 1982, observou condições de homogeneidade térmica na coluna d'água associadas a perfis de biomassa fitoplanctônica quase uniformes, principalmente no oceano aberto. Já no verão de 1983, Brandini (1988a) observou condições de estratificação térmica na coluna d'água que levaram a formação de máximos subsuperficiais de clorofila, tanto na plataforma como no oceano aberto. Os resultados do presente trabalho indicam que a forma dos perfis de biomassa é dependente da estrutura vertical do campo de massa $\left(\sigma_{t}\right)$ ou temperatura na coluna d'água. Por sua vez, essa estrutura vertical é determinada pela dinâmica das 
massas de água presentes nas regiões de plataforma e talude, variando localmente em diferentes escalas temporais.

\subsection{Comparação entre dados in situ e dados de satélites}

\subsubsection{Temperatura da superfície do mar (TSM)}

Os coeficientes utilizados nos algoritmos de TSM propostos pela NOAA são obtidos através de técnicas de regressão entre temperaturas estimadas por satélite e medidas in situ de temperatura da água coletadas por bóias e navios (McClain et al., 1985; Kidwell, 1995). Com essas regressões, as estimativas da NOAA (AVHRR) são corrigidas dos efeitos atmosféricos sobre a radiação que deixa a camada superficial molecular do oceano (skin) em direção aos satélites, mas também, perdem o sinal real da temperatura da camada de pele na interface atmosfera-oceano. De acordo com Schluessel et al. (1990), a camada de pele tem espessura menor que $1 \mathrm{~mm}$ e é geralmente, vários décimos de grau mais frias que a temperatura bulk (compreendendo um certo volume do corpo d'água) medida logo abaixo da camada de pele no oceano.

As estimativas de TSM obtidas pelos algoritmos NOAA são portanto temperaturas pseudo-bulk. Normalmente, estas temperaturas são comparadas com medidas subsuperficiais convencionais de TSM, e não com a temperatura de pele da superfície do mar. As estimativas de TSM obtidas pelos satélites NOAA são comumente utilizadas como parâmetro de entrada em modelos atmosféricos. Segundo Donlon et al. (1999), a temperatura de pele, e não a TSM bulk, é uma variável fundamental para validação de modelos acoplados oceano-atmosfera, uma vez que todas as trocas de calor e gases entre esses dois ambientes se dá através da camada de pele.

As diferenças entre as estimativas de TSM feitas através do sensor AVHRR e dados in situ podem ocorrer devido a diferentes causas. Características atmosféricas regionais possuem um importante papel neste contexto, já que os algoritmos da NOAA são globais e geralmente não consideram efeitos atmosféricos regionais nas estimativas da TSM. Strong e McClain (1984) também reportaram que estimativas globais da TSM por técnicas multicanais (Multi Channel Sea Surface Temperatures - MCSST) foram mais 
próximas de estimativas feitas com bóias de deriva (bias de $0,22^{\circ} \mathrm{C}$, dados de bóia mais quentes) do que medidas feitas por navios (bias de $0,43{ }^{\circ} \mathrm{C}$, dados de navio mais quentes). Souza (2000) obteve uma diferença $\Delta \mathrm{T}$ média entre dados Comprehensive Ocean-Atmosphere Dataset (COADS) e estimativas AVHRR igual a $-0,49{ }^{\circ} \mathrm{C}$ na área da Confluência Brasil-Malvinas, no período 1993 - 1994. Comparando dados de bóias de deriva com dados AVHRR, Souza (2000) encontrou uma diferença média $\Delta \mathrm{T}$ igual a $1,44^{\circ} \mathrm{C}$. Enquanto que navios de oportunidade ou de pesquisa tendem a seguir rotas prédeterminadas ou rede de estações oceanográficas, as bóias de deriva tendem a se concentrar em regiões de fortes gradientes termais da superfície do mar. Desta forma, as temperaturas medidas pelos derivadores ficam sujeitas a variações espaciais em relação aos dados de satélite devido a movimentos laterais das frentes.

A diferença média negativa encontrada no presente trabalho entre as temperaturas in situ e as estimadas pelo sensor AVHRR no verão $\left(\Delta \mathrm{T}=-0,32^{\circ} \mathrm{C}\right)$ indicou que as estimativas por satélite foram maiores que as obtidas com o CTD. Com relação ao período de inverno e ao conjunto completo de dados, as diferenças $\Delta \mathrm{T}$ médias foram iguais a $0,47^{\circ} \mathrm{C}$ e $0,26^{\circ} \mathrm{C}$, indicando uma subestimativa dos valores de TSM pelo AVHRR. Ainda que as correções atmosféricas aplicadas nestas imagens tenham subestimado ou superestimado os efeitos da atmosfera e da superfície de pele do oceano, a diferença média total encontrada ficou abaixo de $0,5^{\circ} \mathrm{C}$. Segundo Strong e McClain (1984) e McClain et al. (1985), a acurácia global máxima obtida pelo método multicanal varia entre $\pm 0,5^{\circ}$ e $\pm 0,6^{\circ} \mathrm{C}$, enquanto que para Barton (1995), a acurácia global dos algoritmos MCSST é de $\pm 0,7^{\circ} \mathrm{C}$. Um valor médio de $\pm 0,68^{\circ} \mathrm{C}$ foi obtido quando se comparou as temperaturas obtidas por satélite com temperaturas de bóia de deriva numa base de dados globais. Para Coll et al. (1993) o limite de acurácia que se pode obter em latitudes médias com medidas AVHRR é de $0,5^{\circ} \mathrm{C}$. Para Bernstein (1982), o nível de incerteza que caracteriza as TSMs obtidas pelo sensor AVHRR é devido a uma variedade de fontes. O próprio radiômetro possui um nível de ruído entre $0,1^{\circ}-0,2^{\circ} \mathrm{C}$. Um erro adicional de $0,1^{\circ}-0,2^{\circ} \mathrm{C}$ pode ocorrer devido à presença de pequenas nuvens não detectáveis pelo campo de visada do radiômetro, assim como por efeitos atmosféricos não modelados no método MCSST e também por aerossóis. 


\subsubsection{Concentração de clorofila da superfície do mar (CSM)}

A acurácia, precisão e utilidade dos algoritmos empíricos da cor do oceano para estimar a distribuição de clorofila $a$ superficial dependem das características desses algoritmos e das observações in situ usadas em seus respectivos desenvolvimentos. Os algoritmos empíricos para determinação de pigmentos e clorofila, amplamente utilizados no processamento global de imagens CZCS, foram desenvolvidos a partir de um conjunto de dados contendo apenas 60 radiâncias e concentrações de clorofila $a$ medidas in situ (Evans e Gordon, 1994). Desde a era CZCS, um número crescente de pesquisadores tem medido in situ a reflectância de sensoriamento remoto $\left(R_{R S}\right)$ e concentrações de clorofila $a\left(\mathrm{C}_{\text {insitu }}\right)$ em diferentes províncias oceânicas. Em 1997, o grupo SeaBAM (Firestone e Hooker, 1998) reuniu um conjunto maior de dados contendo 919 observações de $R_{R S}$ e $\mathrm{C}_{\text {insitu }}$. Esta base de dados serviu para avaliar o comportamento estatístico dos algoritmos de clorofila $a$ e para desenvolver os algoritmos de duas bandas - OC2 e de quatro bandas - OC4 (O’Reilley et al., 1998).

O algoritmo OC2 estima a $\mathrm{C}_{\text {insitu }}$ a partir da razão de bandas $R_{35}$ utilizando uma função polinomial cúbica modificada (MCP). O algoritmo OC4 também relaciona razões de bandas com a clorofila $a$ através de uma única função polinomial, mas emprega a razão de banda máxima (MBR) determinada como a maior razão entre os valores de $R_{25}, R_{35} \mathrm{e}$ $R_{45}\left(R_{\max }\right)$. O algoritmo OC2 foi empregado como padrão pelo Projeto SeaWiFS após o lançamento do satélite em setembro de 1997. Ainda que as características estatísticas de OC4 fossem superiores às do $\mathrm{OC} 2$, o grupo SeaBAM recomendou a utilização da versão mais simples OC2, logo após o lançamento. A fim de melhorar as estimativas globais em águas ricas em clorofila, o algoritmo OC2 foi revisado (versão 2) baseado em um conjunto de dados maior contendo 1.174 observações (Maritorena e O’Reilly, 2000). A revisão 2 do OC2 foi aplicada pelo Projeto SeaWiFS no segundo reprocessamento da base de dados SeaWiFS (McClain et al., 2000). Dados in situ adicionais foram sendo disponibilizados como resultado de novos programas (por exemplo, SIMBIOS) e pela continuidade e expansão de campanhas de campo em operação. Esses dados mais novos ampliaram a variedade de províncias bio-ópticas representadas na base original de dados, preenchendo regiões nos domínios de $R_{R S}$ e $\mathrm{C}_{\text {insitu }}$ que não haviam sido 
representadas até então. O'Reilly et al. (2000) apresentaram uma revisão dos algoritmos OC2 e OC4 baseados em um conjunto de dados mais amplo e mais representativo de diferentes províncias biogeoquímicas, oligotróficas e eutróficas.

Por outro lado, as propriedades bio-ópticas da água do mar nas regiões do Atlântico Sul permanecem pouco conhecidas, apesar dos esforços isolados de alguns pesquisadores (Mitchel e Holm-Hansen, 1991; Omachi e Garcia, 2000; Mitchel et al., 2001). Além dos algoritmos empíricos (OC2 e OC4), diversas outras abordagens também têm sido propostas para estimar $\mathrm{C}_{\text {insitu }}$ a partir de dados de satélite. Nas Tabela 3.35, 3.36 e 3.37 foram mostrados os coeficientes encontrados nas regressões lineares entre as concentrações de clorofila $a$ in situ e as estimativas feitas por satélite (OC4, OC2, GSM01 e NN), para os períodos de verão, inverno e conjunto completo de dados (verão + inverno). Comparações entre medidas in situ de clorofila $a$ e estimativas feitas por satélite são raras em águas brasileiras. Kahru e Mitchell (1999) obtiveram um coeficiente de determinação igual a $0,92(\mathrm{rms}=0,27$ e $\mathrm{n}=27)$ entre medidas de clorofila $a$ in situ e estimativas com o algoritmo OC2, na região da Corrente da Califórnia. Em geral, as estimativas com OC2 superestimaram a clorofila $a$ em altas concentrações e subestimaram em baixas concentrações. Omachi e Garcia (2000) analisaram algoritmos empíricos para estimativa das concentrações de clorofila $a$ para $o$ SeaWiFS na região do Atlântico SO e concluíram que uma razão de duas bandas (490 e $555 \mathrm{~nm})$ obtém melhores resultados $\left(\mathrm{R}^{2}=0,90\right)$ que uma abordagem com quatro bandas.

No presente trabalho, o algoritmo OC4 apresentou o melhor desempenho durante o verão $\left(\mathrm{R}^{2}=0,87\right)$, ainda que o rms tenha sido um pouco maior que o observado para OC2 $(0,22$ e 0,20 , respectivamente). Os outros algoritmos testados GSM01 e NN também tiveram bom desempenho. O desempenho relativo entre os algoritmos se manteve no inverno, ainda que os coeficientes de determinação tenham sido todos mais baixos que no verão (ver Tabelas 3.35 e 3.36). Em relação ao conjunto completo de dados, o algoritmo NN obteve um coeficiente de determinação maior que o GSM01. O algoritmo OC4 obteve ainda o melhor desempenho $\left(\mathrm{R}^{2}=0,71, \mathrm{rms}=0,22\right)$. De modo geral, o algoritmo OC4 subestimou as concentrações de clorofila mais baixas e 
superestimou as mais altas. É importante notar que o conjunto de dados utilizado nas análises de regressão incluía pontos localizados em águas do Caso 1 como em águas do Caso 2 (Morel, 1980; Gordon e Morel, 1983; Sathyendranath e Morel, 1983). Os algoritmos da NASA são ajustados a um conjunto heterogêneo e representativo de dados, principalmente para águas do Caso 1. Por outro lado, medidas in situ freqüentes e bem distribuídas na região do Atlântico SO são raras, o que torna o ajuste desses algoritmos uma necessidade fundamental, principalmente, para estimar a produção primária regional a partir dos campos de clorofila $a$ obtidos por satélite. Quando se comparam medidas in situ de clorofila $a$ e estimativas obtidas por satélite, outros aspectos da metodologia de processamento se tornam dominantes em relação aos algoritmos bio-ópticos propriamente ditos. Uma boa correção atmosférica dos dados orbitais é fundamental para o sucesso dos algoritmos bio-ópticos. Uma vez que a maior parte da radiância medida por um sensor orbital no topo da atmosfera é originada na própria atmosfera e não no oceano (Gordon et al., 1988), pequenos erros na correção atmosférica podem resultar em grandes erros nas propriedades ópticas marinhas assim derivadas.

O’Reilly et al. (2000) reportam que as comparações estatísticas sobre o desempenho dos algoritmos em relação a dados in situ, fornecem apenas uma informação parcial sobre suas performances quando aplicados a radiâncias derivadas por satélite. Várias razões são sugeridas para o melhor desempenho de OC4 em relação a OC2. Em águas oligotróficas, a razão sinal-ruído é maior na banda $443 \mathrm{~nm}$ que na $490 \mathrm{~nm}$. Em águas eutróficas, a forte absorção na região do azul do espectro eletromagnético resulta em uma relação sinal-ruído mais baixa nas radiâncias calculadas nas bandas $412 \mathrm{~nm}$ e $443 \mathrm{~nm}$, quando comparadas às bandas $490 \mathrm{~nm}$ e $510 \mathrm{~nm}$, respectivamente. Ainda, a influência do método de correção atmosférica sobre a acurácia das radiâncias usadas nos algoritmos de razão de bandas deve ser considerada. O algoritmo de correção atmosférica do SeaWiFS (Gordon e Wang, 1994 e Wang, 2000) utiliza as bandas do infravermelho próximo (765 e $865 \mathrm{~nm})$ para caracterizar as propriedades ópticas dos aerossóis e estimar a contribuição destes para a radiância total no espectro visível (por 
extrapolação). A banda em $510 \mathrm{~nm}$, por ser menos afastada do infravermelho próximo, é menos propensa a erros de extrapolação que as bandas em $490 \mathrm{~nm}$ e $443 \mathrm{~nm}$.

Apesar de não se dispor de medidas radiométricas in situ para efeito de validação da correção atmosférica aplicada nas imagens SeaWiFS, foi feita uma tentativa de se ajustar uma formulação para os algoritmos regionais DEP4 e DEP3, utilizando-se as radiâncias normalizadas obtidas pelo SeaWiFS. O algoritmo regional DEP4 obteve o melhor desempenho, explicando $12 \%$ a mais da variância dos dados usados para validação, que a formulação original do OC4. Já o algoritmo regional DEP3, obteve desempenho praticamente igual a OC2. Garcia e Garcia (2002) obtiveram uma equação linear empírica relacionando a concentração de clorofila $a$ e a razão de radiância em duas bandas (490 e $555 \mathrm{~nm})$ medidas in situ com $\mathrm{R}^{2}=0,82(\mathrm{rms}=0,21)$ para a região da costa S-SE brasileira (denominada pelos autores como Brazilian Coastal Waters). Foram feitas comparações com o algoritmo OC2 e, de modo geral, os resultados foram comparáveis. Estimativas mais precisas de $\mathrm{L}_{\mathrm{WN}}$ obtidas com o SeaWiFS são necessárias para melhorar ainda mais o desempenho dos algoritmos bio-ópticos e, conseqüentemente, as estimativas de concentração de clorofila $a$ por satélite.

\subsection{PNF}

A informação sobre a estrutura vertical da clorofila é importante não somente para estimar a clorofila integrada na coluna d'água, mas também, como input em modelos semi-analíticos para cálculo da produção primária através de dados de satélite. Nas estações diurnas realizadas nos quatro cruzeiros de mesoescala, foi possível avaliar a distribuição de pigmentos com a profundidade em alta freqüência, utilizando o sensor de fluorescência passiva (estimulada pelo sol) PNF-300. As Figuras 3.47, 3.48, 3.49 e 3.50 mostraram exemplos de como os dados de fluorescência foram relacionados às concentrações de clorofila $a$ medidas em profundidades discretas. As maiores limitações encontradas foram com relação ao comprimento curto do cabo do equipamento (100 m no total).

Os valores de produção primária integrada na coluna d'água obtidos pela integração das produções primárias instantâneas medidas pelo PNF foram mostrados na Tabela 3.40. 
Ainda que os valores encontrados estejam dentro de amplitudes de variação já observadas por outros autores na região de estudo (Metzler, 1991; Gonzalez-Rodriguez et al., 1992; Gaeta, 1999), não foi obtido um coeficiente de determinação significativo (95\% nível de confiança) ao se comparar os valores de produção primária integrada na coluna d'água, estimados com o PNF, com as medidas in situ $\left({ }^{14} \mathrm{C}\right)$ de produção primária integrada na zona eufótica obtidas neste trabalho. Além do problema com a profundidade limite amostrada pelo PNF (em função do comprimento do cabo), foram utilizadas as constantes empíricas sugeridas pelo fabricante do equipamento para a absorção total da água e seus constituintes sobre o espectro de emissão da clorofila $\left(0,48 \mathrm{~m}^{-1}\right)$, coeficiente de absorção específico da clorofila $\left(0,04 \mathrm{~m}^{2} \cdot \mathrm{mg}^{-1}\right)$, rendimento quântico da fluorescência $(0,045 \mu \mathrm{E}$ fluorescência por $\mu \mathrm{E}$ absorvido), valor máximo da razão entre o rendimento quântico da fotossíntese e a fluorescência $(4,0$ átomos de carbono por fóton), e irradiância na qual a razão anterior é igual a metade do valor máximo $\left(133 \mu \mathrm{E} \cdot \mathrm{m}^{-2} \cdot \mathrm{s}^{-1}\right)$.

Os valores médios, amplitudes de variação, desvios padrão e coeficientes de variação dos coeficientes de atenuação vertical obtidos pelo PNF $\left(\mathrm{K}_{\mathrm{PNF}}\right)$ nos períodos de verão e inverno, foram apresentados na Tabela 3.41. Os coeficientes encontrados pela análise de regressão linear entre os coeficientes de atenuação vertical estimados pelo disco de Secchi $\left(\mathrm{K}_{\text {Secchi }}\right)$ e com o PNF foram apresentados na Tabela 3.42. As diferenças relativas entre as duas medidas ficaram em torno de 25\% ( $\mathrm{K}_{\mathrm{PNF}}$ subestimando $\mathrm{K}_{\text {Secchi }}$ ). Omachi (1996) obteve medidas do coeficiente de atenuação difusa total no litoral do RS com o disco de Secchi $\left(0,04\right.$ a $\left.0,151 \mathrm{~m}^{-1}\right)$ que não concordaram bem com medidas realizadas com um quantum-radiômetro $\left(0,023\right.$ a $\left.0,059 \mathrm{~m}^{-1}\right)$, em abril de 1993 e janeiro de 1995. Gonzalez et al., (1997) obteve medidas de $\mathrm{K}_{\text {Secchi no litoral do RS, durante o }}$ inverno de 1991 variando entre 0,07 e $2,13 \mathrm{~m}^{-1}$, e medidas do coeficiente de atenuação total difusa com um quantum-radiômetro variando entre 0,06 e $0,51 \mathrm{~m}^{-1}$. Kirk (1994) cita como limites para corpos d'água do Caso 1 os valores de coeficiente de atenuação difusa total entre 0,03 e $0,19 \mathrm{~m}^{-1}$. Ambas as medidas feitas com o disco de Secchi ou com o PNF apresentaram valores fora desse limites, mostrando que águas do Caso 2 também foram amostradas neste trabalho. A determinação da concentração de 
clorofila $a$ por sensoriamento remoto é dificultada nessas águas, já que o material inorgânico em suspensão e a substância amarela competem pela radiação fotossinteticamente ativa com o fitoplâncton, alterando o sinal detectado pelo satélite.

\subsection{Testes estatísticos para agrupamento de dados}

No capítulo 3, foram apresentados os testes estatísticos realizados para agrupamento dos dados referentes aos cruzeiros M1, M2, M3 e M4. A partir dos resultados obtidos pela sucessão de testes $\mathrm{f}$ e $\mathrm{t}$, os dados foram agrupados em três domínios diferentes: plataforma, talude-verão e talude-inverno.

Castro (1996), sugeriu com base em dados hidrográficos e correntométricos, uma divisão da plataforma continental norte de São Paulo em três regiões: interna (PCI), média (PCM) e externa (PCE). Essas regiões possuem características físicas diferentes, conforme descrito a seguir. A PCI localiza-se entre a costa e a frente térmica profunda (FTP). A largura da PCI varia temporalmente, principalmente em escala sazonal, sendo mais estreita durante o verão, com 10 a $30 \mathrm{~km}$ de largura, e com 40 - $80 \mathrm{~km}$ no inverno. No verão, o limite externo da PCI situa-se entre as isóbatas de $20 \mathrm{~m}$ e $40 \mathrm{~m}$, enquanto que no inverno, situa-se entre as isóbatas de $50 \mathrm{~m}$ e $70 \mathrm{~m}$. A principal característica da PCI é apresentar, durante todo o ano, grande tendência à homogeneidade tridimensional das propriedades físicas. De modo geral, as águas da PCI são mais quentes, mais salinas e menos densas durante o verão do que no inverno. A tendência para a ocorrência de salinidades superficiais baixas durante inverno $(\mathrm{S}<34,0)$, também foi evidenciada por Silva e Alvarenga (1996). Salinidades mais altas medidas nas proximidades da costa durante o inverno (Castro, 1996; Miranda, 1982) indicaram a ocorrência de grandes variações intra-sazonais no campo halino. A PCM localizada entre a FTP e a Frente Halina Superficial (FHS) estende-se desde 10 - $30 \mathrm{~km}$ de distância da costa até cerca de $60-80 \mathrm{~km}$, durante o verão. Seus limites interno e externo situam-se entre as isóbatas de 20 - $40 \mathrm{~m}$ e $70-90 \mathrm{~m}$, respectivamente. No inverno, a PCM ocupa uma faixa estreita, às vezes quase inexistente, compreendida entre $40-60 \mathrm{~km}$ a $60-80 \mathrm{~km}$ de distância da costa. A característica física básica da PCM é a alta estratificação durante o verão, devido à presença de uma termoclina sazonal acentuada. A PCE prolonga-se 
desde a FHS, ou limite externo da PCM, até a quebra de plataforma. Seu limite interno fica situado a cerca de $60-80 \mathrm{~km}$ da costa, entre as isóbatas de 70 e $90 \mathrm{~m}$. A PCE também apresenta estratificação vertical acentuada, embora a termoclina seja um pouco mais difusa do que na PCM, durante o verão. Outra característica marcante da PCE é a reduzida variação sazonal das propriedades físicas. As águas da termoclina, observadas na PCM durante o verão, estão sempre presentes na PCE.

Gaeta (1999) sugeriu a divisão da região oceânica abrangida pelo projeto COROAS (entre Ubatuba e Cananéia, SP) em cinco regiões batimétricas, baseado em critérios de heterogeneidade dos gradientes horizontais de distribuição de biomassa fitoplanctônica: plataforma interna (PI: $50-100 \mathrm{~m}$ ), plataforma média (PM: > $100-150 \mathrm{~m}$ ), plataforma externa (PE: $>150-200 \mathrm{~m}$ ), talude continental e quebra de plataforma (TE: $>200-$ $2.400 \mathrm{~m}$ ) e bacia do Atlântico Sul (BA: $>3.000 \mathrm{~m}$ ). Segundo o mesmo autor, a região PI corresponderia à PCM apresentada por Castro (1996), enquanto que a PM e PE seriam subdivisões correspondentes à PCE sugerida por Castro (1996), de acordo com as principais características físicas da PI, PM, PE e TE observadas em cruzeiros de verão (1993 e 1994) e de inverno (1993).

Castro (1996) considerando os mecanismos turbulentos de mistura mais significativos que os processos termodinâmicos de troca de calor e massa entre o oceano e a atmosfera, na plataforma continental norte de São Paulo, concluiu que a estratificação observada durante o período de verão era ocasionada pela advecção de águas com densidades relativamente mais altas de origem oceânica (ACAS).

Gonzalez (2001) utilizou dados de biomassa fitoplanctônica obtidos pelo sensor CZCS (1982 a 1986) para identificar províncias biogeoquímicas entre $5^{\circ} \mathrm{N}$ e $45^{\circ} \mathrm{S}$, desde a costa até a longitude $25^{\circ} \mathrm{W}$. A região de Cabo Frio (plataforma e talude) foi identificada como uma província biogeoquímica, com concentrações de clorofila variando entre 0,05 e $0,1 \mathrm{mg} \cdot \mathrm{m}^{-3}$, com máximos de $2,5 \mathrm{mg} \cdot \mathrm{m}^{-3}$ na área de ocorrência da ressurgência. Outra região sobre a plataforma e oceano aberto foi identificada na zona de influência das águas tropicais da CB e do giro subtropical do Atlântico Sul, com concentrações de pigmentos entre 0,05 e $1,0 \mathrm{mg} \cdot \mathrm{m}^{-3}(\mathrm{R} 11)$. A região sul da costa brasileira (entre $30^{\circ} \mathrm{e}$ 
$32^{\circ}$ S) foi analisada com base em coeficientes de absorção do fitoplâncton, dados hidrográficos e de concentração de clorofila $a$. Os resultados encontrados por Gonzalez (2001) indicaram que esta área R11 podia ser dividida em duas regiões menores, uma associada às águas com influência costeira e outra de origem oceânica (característica tropical).

Os domínios obtidos no presente trabalho (baseados nas análises estatísticas das variáveis clorofila $a$ e produção primária integradas na zona eufótica) podem ser explicados pela análise conjunta dos dados hidrográficos, nutrientes, clorofila $a$, produção primária e imagens de satélites (AVHRR e SeaWiFS) apresentados anteriormente. Duas perguntas poderiam ser formuladas: i) por que o domínio taludeverão foi diferente do talude-inverno?; ii) por que no domínio plataforma não houve diferença significativa entre o verão e o inverno? A resposta para a questão (ii) pode ser resumida em um processo: intrusões da ACAS sobre a plataforma continental sudeste brasileira. Este tem sido apontado como o principal processo de fertilização da zona eufótica nas águas de plataforma da região S-SE durante o verão (Brandini et al., 1989; Brandini,1990a, 1990b; Aidar et al., 1993; Matsuura, 1996; Lima et al., 1996, Gaeta,1999; Gianesella, 2000), formando máximos subsuperficiais de clorofila $a$ na base da zona eufótica, em profundidades abaixo da camada de mistura.

A ACAS, pelo próprio ajuste baroclínico da $\mathrm{CB}$, está sempre presente na camada profunda da plataforma continental externa nas imediações do talude. É fato amplamente conhecido que a região preferencial para ressurgência costeira na costa sudeste é aquela centrada em Cabo Frio, situada aproximadamente entre o Cabo de São Tomé e a Baía da Guanabara (Castro, 1996). Entretanto, as imagens de TSM e CSM mostradas no presente trabalho e confirmadas pelos dados in situ, exibiram núcleos e plumas de ressurgência a sul de Vitória (sobre a quebra de plataforma), São Tomé, Cabo Frio, Saquarema e Ilha de São Sebastião. Outros trabalhos (Ikeda et al., 1974; Miranda, 1982, Kampel et al., 1997; Kampel et al., 2000) também mostraram a ocorrência de ressurgência costeira em períodos de inverno e em outros pontos da costa SE que não somente em Cabo Frio. Nessas regiões, os ventos, principalmente durante o verão, são favoráveis à ressurgência e, como a plataforma é relativamente estreita, a CB fica mais 
próxima da costa. Na região $\mathrm{SE}$, a ocorrência de perturbações ciclônicas da $\mathrm{CB}$ também é freqüente devido, principalmente, à mudança brusca na orientação da linha da costa (Castro, 1996). Existem trabalhos que mostram a água fria ressurgida em Cabo Frio deslocando-se na direção SO, até distâncias maiores que 100 km (Miranda, 1982; Lorenzzetti e Gaeta, 1996; Kampel et al., 1997).

Meandros ciclônicos e vórtices frontais, como os observados neste trabalho através dos dados hidrográficos, distribuições de nitrato e imagens de satélites, podem intensificar o processo de intrusão da ACAS em direção à costa. Campos (1995) mostrou evidências de ressurgência de quebra de plataforma na costa norte de São Paulo. Kampel et al., (2000) mostraram através de imagens de satélite a ocorrência e freqüência anual de meandros e vórtices de mesoescala na costa SE brasileira, entre 1997 e 1998, com predominância durante o inverno. Alguns destes meandros e vórtices mostraram-se como feições semi-permanentes. Três regiões típicas de formação dessas estruturas foram identificadas: ao largo de Vitória, São Tomé e Cabo Frio (Kampel et al., 1997). Os efeitos dos vórtices sobre o aumento da produção primária fitoplanctônica em regiões afastadas da costa foram sugeridos por Brandini (1990a; 1990b). Gaeta et al., (1999) confirmaram estas suposições através de experimentos no vórtice de Vitória. Durante a realização dos cruzeiros de verão e inverno de 2002 do projeto DEPROAS, os ventos observados a bordo do N/Oc. Prof. Besnard eram favoráveis à ressurgência. Desta forma, a ACAS pode penetrar em direção à costa também durante o inverno, como observado em M4.

\subsection{Regressão múltipla e Rede neural}

Estimativas da produção primária fitoplanctônica baseadas em modelos empíricos tem sido cada vez mais usadas na oceanografia biológica como alternativa para medidas diretas in situ que podem ser dispendiosas e levar muito tempo. Isto é particularmente relevante numa era de oceanografia por satélite já que dados orbitais da cor do oceano fornecem uma cobertura global da biomassa fitoplanctônica que pode ser utilizada como entrada em modelos de produção primária. Ainda que os modelos empíricos de produção primária sejam normalmente baseados em relações lineares simples, as 
estimativas são razoavelmente acuradas, uma vez que, a produção primária é largamente regulada por variáveis simples de serem medidas, como por exemplo, a irradiância e a biomassa fitoplanctônica. Porém, outros fatores que afetam a assimilação de carbono fotossintético estão relacionados de forma não linear com a produção, tais como, a eficiência fotossintética das células fitoplanctônicas. Um dos primeiros modelos empíricos foi o de Ryther e Yentsch (1957). A taxa fotossintética foi descrita em função da concentração de clorofila com boa concordância entre as produções previstas e observadas. Modelos mais recentes elaborados para a produção primária oceânica variam entre formulações simples, baseadas somente na concentração de clorofila (Smith et al., 1982), e mais complexas, com abordagens tipo regressões múltiplas (Eppley et al., 1985), ou uso de formulações semi-analíticas (Balch et al., 1989).

Metzler (1991) através de análise por regressão múltipla na região de Ubatuba, São Paulo, tendo como variável dependente o número de assimilação $\left(\mathrm{P}_{\max }{ }^{\mathrm{B}}\right)$, obteve $16 \%$ da variância dos dados explicada pela variável profundidade e 15\% pelo nitrato, no verão. Durante o inverno, 95\% da variância foi atribuída à razão feofitina / clorofila e $\sigma_{\mathrm{t}}$. Gaeta (1999) aplicou o método de regressão múltipla passo-a-passo para alguns parâmetros da coluna d'água tomados como variáveis dependentes, entre estes, a produção primária integrada na zona eufótica, nas regiões de plataforma e talude de São Paulo. No verão de 1993, a produção primária integrada teve $54 \%$ de sua variância explicada pelo máximo de clorofila subsuperficial e $\mathrm{N}_{\mathrm{EU}}$ (correlações diretas) e cerca de $11 \%$ pelo nitrato de superfície, razão $\mathrm{Z}_{\mathrm{EU}} / \mathrm{Z}_{\mathrm{T}}$, TSM e amônia de superfície. $\mathrm{A} \mathrm{PP}_{\mathrm{EU}}$ no inverno do mesmo ano foi diretamente correlacionada ao nitrato de superfície (17\%), razão entre feopigmentos e clorofila de superfície (16\%). No verão de 1994, a variável $\mathrm{PP}_{\mathrm{EU}}$ apresentou $27 \%$ de sua variância explicada pelo máximo de clorofila subsuperficial, razão feopigmentos / clorofila, fluxo de nitrato e TSM.

No presente trabalho, a variável dependente $\mathrm{PP}_{\mathrm{EU}}$ apresentou $83 \%$ de sua variância explicada diretamente por $\mathrm{TA}_{\mathrm{EU}}, \mathrm{C}_{\mathrm{EU}}, \mathrm{K}_{\mathrm{s}}$ e $\mathrm{Z}_{\mathrm{EU}} / \mathrm{Z}_{\mathrm{T}}$ (diretamente correlacionadas), no domínio de plataforma. No domínio talude-verão, $\mathrm{PP}_{\mathrm{EU}}$ teve $97 \%$ de sua variância atribuída a $\mathrm{TA}_{\mathrm{EU}}, \mathrm{C}_{\mathrm{EU}}$ e a profundidade (diretamente correlacionadas). No domínio talude-inverno, $\mathrm{PP}_{\mathrm{EU}}$ esteve diretamente correlacionada a $\mathrm{TA}_{\mathrm{EU}}$ e $\mathrm{C}_{\mathrm{EU}}$, que explicaram 
98\% de sua variância. Ou seja, houve uma relação direta significativa entre a produção primária integrada e a concentração de clorofila $a$ integrada na zona eufótica nos três domínios considerados.

Uma abordagem alternativa foi testada no presente trabalho com a aplicação de uma rede neural artificial para estimar empiricamente a produção primária integrada na zona eufótica (Capítulo 3, item 3.10 Rede Neural, Figuras 3.52 e 3.53). Redes neurais artificiais constituem uma ferramenta promissora para a modelagem empírica de sistemas complexos (Scardi, 1996). Redes com pelo menos uma camada oculta podem modelar sistemas não lineares mesmo que as relações causais entre as variáveis sejam desconhecidas (Scardi, 1996). O uso de redes neurais pode ter sido prejudicado por limitações computacionais no passado, uma vez que, nenhuma regra de aprendizagem estava disponível para ajustar os pesos das conexões da camada oculta até o desenvolvimento do algoritmo error-propagation (Rumelhart et al., 1986). Mesmo com a publicação do trabalho de Rumelhart e colaboradores tendo sido na revista interdisciplinar Nature, o impacto fora da comunidade de inteligência artificial e ciências da computação foi pequeno. Por outro lado, nos últimos anos, a aplicação de redes neurais tem crescido em diferentes áreas do conhecimento, inclusive na oceanografia por satélite, com o desenvolvimento dos computadores pessoais e meios de aplicação mais fáceis, mesmo para usuários não especialistas. Um dos objetivos do presente trabalho foi treinar uma rede, a mais generalizada possível, ou seja, sem considerar os domínios pré-estabelecidos, mesmo que os resultados finais não fossem os mais bem ajustados. $\mathrm{O}$ modelo final obtido explicou $53 \%$ da variância de $\mathrm{PP}_{\mathrm{EU}}$ no conjunto de dados usados para a validação. Scardi e Harding (1999) obtiveram um coeficiente de determinação $\left(\mathrm{R}^{2}\right)$ igual a 0,546 ao aplicar uma rede neural similar a testada no presente trabalho, porém, na região da Baía de Chesapeake, EUA. Naquele trabalho o desempenho da rede neural artificial foi superior ao de modelos empíricos convencionais. Como mencionado por Balch et al., (1989), um algoritmo ideal para prever a produção primária deveria explicar $100 \%$ de sua variância, provendo uma relação de 1:1 entre os valores de $\mathrm{PP}_{\mathrm{EU}}$ previstos e observados. A medida em que a base de dados disponíveis for sendo aumentada e que as relações determinísticas entre as 
variáveis de entrada e a $\mathrm{PP}_{\mathrm{EU}}$ sejam melhor definidas, os modelos empíricos baseados em redes neurais artificiais evoluirão cada vez mais (Scardi, 1986).

\subsection{Comparações entre as estimativas da produção primária diária integrada}

Os resultados das comparações feitas entre as estimativas da produção primária diária integrada na zona eufótica obtidas pelos algoritmos BPM1, BPM2 e VGPM em relação às medidas in situ pelo método do ${ }^{14} \mathrm{C}$, foram apresentados nas Tabelas 3.53, $3.54 \mathrm{e}$ 3.55. Considerando os coeficientes de determinação encontrados pelas análises de regressão linear entre $\mathrm{PP}_{\mathrm{EU}}$ e os modelos testados, observamos que a maior variância explicada (59\%) foi obtida pelo modelo BPM2, no domínio de plataforma. Este mesmo modelo também explicou 57\% no domínio talude-inverno. Já o modelo BPM1, explicou no máximo $53 \%$ da variância dos dados, no domínio talude-inverno sendo que, no domínio de plataforma o coeficiente $\mathrm{R}^{2}$ foi igual a 0,49 . Como o BPM1 considera o perfil vertical de biomassa homogêneo, este modelo não integra o máximo subsuperficial de clorofila que ocorre tipicamente, em regiões mais afastadas da costa. Entretanto, foi realizado um teste comparativo entre as integrações de BPM1 na zona eufótica e até a primeira profundidade óptica e não se observou diferença significativa nos resultados no domínio talude-inverno, ainda que no domínio de plataforma tenha ocorrido uma diferença de $15 \%$ da variância explicada. Comparando-se os conjuntos completos de dados (plataforma + talude), os modelos BPM1 e BPM2 explicaram 44\% $41 \%$, respectivamente. Com o modelo VGPM, só foi possível explicar $17 \%$ da variância dos dados no domínio de plataforma. Nenhuma outra correlação significativa foi encontrada para o VGPM (nível de confiança de 95\%). Uma possível razão para isto deve estar associada aos parâmetros utilizados pelo modelo VGPM. Da mesma forma, a profundidade da zona eufótica calculada pelo VGPM foi comparada estatisticamente com a profundidade da zona eufótica estimada pelo disco de Secchi (utilizada no cálculo da $\mathrm{PP}_{\mathrm{EU}}$ in situ $)$. $\mathrm{O}$ coeficiente de determinação foi significativo $\left(\mathrm{R}^{2}=0,47\right.$, nível de confiança de 95\%) somente para o domínio de plataforma.

Balch et al., (1989) avaliaram diferentes algoritmos para estimar a produção primária integrada na coluna d'água utilizando dados de satélite. Enquanto que os modelos 
empíricos testados (Smith et al., 1982; Brown et al., 1985; Eppley et al., 1985) explicaram de $28 \%$ a $42 \%$ da variância dos dados, um modelo semi-analítico explicou no máximo, 24\%. Balch et al., (1992) testaram diferentes algoritmos de produtividade (empíricos e semi-analíticos) que utilizam informações sobre os parâmetros fotoadaptativos, biomassa e parâmetros ópticos para estimar a produção primária integrada. Em média, os algoritmos testados explicaram menos que $50 \%$ da variância dos dados. Behrenfeld e Falkowski (1997a) usando uma compilação de medidas de produção primária realizadas pelo método do ${ }^{14} \mathrm{C}$ mostraram que com $\mathrm{P}_{\mathrm{opt}}{ }^{\mathrm{B}}$ calculado a partir da TSM, o modelo VGPM explicou 58\% da variância observada nos dados de produção primária integrada (ou 53\% quando log-transformada). Siegel et al., (2001) mostraram que diferentes modelos globais para estimativa da produção primária integrada por satélite só conseguiram explicar menos que $40 \%$ da variância dos dados obtidos em uma série temporal de 6 anos na região do Mar do Sargaço, Bermudas (Bermuda Atlantic Time Series - BATS). Os autores sugerem uma inconsistência nos modelos bio-ópticos por considerarem um estado de equilíbrio e um crescimento balanceado (Cullen, 1990), em relação aos dados observados. A maior parte da variância dos dados foi atribuída a processos de perturbação do ecossistema que simplesmente não são considerados nos modelos bio-ópticos. Os modelos empíricos ou semi-analíticos pretendem modelar fenômenos naturais através de considerações sobre os processos que regulam a produção primária. Por exemplo, a maioria dos modelos assume que a incorporação de carbono pelo fitoplâncton é balanceada pela absorção de luz e assimilação de nutrientes, sendo modificada pela saturação de luz e por processos dependentes da temperatura. Desta forma, seria possível estimar a produção primária integrada (dinâmica) a partir da abundância de um estoque (clorofila), a medida em que é modificada por fatores exógenos como a PAR e a temperatura (Siegel et al., 2001). Esses modelos devem ser ajustados a bases de dados através de funções de custo, como uma medida objetiva de seus respectivos desempenhos.

Campbell et al., (2002), sugerem que o desempenho de diferentes modelos de produção primária em relação à medidas in situ seja medido pelo erro da diferença logtransformada $(\Delta)$, como uma medida do erro relativo, ou seja: $(\Delta)=\log \left(\mathrm{PP}_{\text {sat }}\right)-$ 
$\log \left(\mathrm{PP}_{\text {insitu }}\right)$, onde $\mathrm{PP}_{\text {sat }}$ representa uma estimativa por satélite (ou modelo) e $\mathrm{PP}_{\text {insitu }}$ é a estimativa pelo método do ${ }^{14} \mathrm{C}$. Nos resultados apresentados por Campbell et al., (2002), os modelos com melhor desempenho concordaram com as estimativas baseadas no método do ${ }^{14} \mathrm{C}$ por um fator de 2. Dois dos algoritmos testados por Campbell et al., (2002) foram adaptados pela NASA para produzir mapas globais de produtividade primária a partir de dados do sensor Moderate Resolution Imaging Spectroradiometer (MODIS). Outra conclusão interessante apresentada pelos mesmos autores foi que o nível de desempenho dos algoritmos não mostrou relação aparente com suas respectivas estruturas matemáticas ou complexidades. Em alguns casos, algoritmos mais complexos baseados em modelos do tipo WRM (espectrais, integrados no tempo e em profundidade) foram altamente correlacionados com outros algoritmos mais simples integrados somente no tempo ou em profundidade. Segundo os mesmo autores, o valor rms $<0,3$ da diferença $(\Delta)$ pode ser considerado como uma referência indicativa de uma concordância dentro de um fator de 2 . O valor rms compreende um erro aleatório, indexado pelo desvio padrão e um erro sistemático (bias), indexado pela média. No presente trabalho, os valores médios, desvios padrão e rms das diferenças $(\Delta)$ para os modelos BPM1, BPM2 e VGPM foram apresentados nas Tabelas 3.53, 3.54 e 3.55 , respectivamente. Valores rms menores ou iguais a 0,3 foram encontrados para BPM1 no domínio de plataforma (integração na zona eufótica) e para BPM2 nos domínios de plataforma, talude-verão e conjunto completo de dados.

Os modelos bio-ópticos têm um grande potencial para aplicações globais. Entretanto, diversos autores não consideram totalmente esclarecido o quanto que a complexidade de determinados modelos reflete realmente no nível de entendimento sobre uma determinada variável, ou na capacidade preditiva desses modelos (Bahrenfeld e Falkowski, 1997a).

Considerando o modelo mais "complexo" utilizado no presente trabalho - BPM2, foi realizado um estudo de sensibilidade de maneira a procurar entender a influência de variações naturais na estrutura vertical da produção primária diária integrada na coluna d'água. Inicialmente, foram calculadas as médias e desvios padrão dos parâmetros da curva de Gauss-deslocada, para os períodos de verão e inverno (neste exercício, a 
abordagem foi sazonal). A partir daí, a produção primária foi estimada para o perfil "médio" e para perfis obtidos pela variação sistemática dos parâmetros de cada perfil, de acordo com seus respectivos desvios padrão. A Tabela 4.2 apresenta os parâmetros médios da curva de Gauss-deslocada e seus respectivos desvios padrão, para os períodos de verão e inverno, respectivamente.

\section{TABELA 4.2 - PARÂMETROS MÉDIOS E DESVIOS PADRÃO DA CURVA DE GAUSS-DESLOCADA PARA OS PERÍODOS DE VERÃO E INVERNO.

\begin{tabular}{c|c|c|c|c}
\hline \multirow{2}{*}{ Parâmetro } & \multicolumn{2}{|c|}{ Verão (n=97) } & \multicolumn{2}{c}{ Inverno (n= 89) } \\
\cline { 2 - 5 } & Média & $\mathbf{d p}$ & média & $\mathbf{d p}$ \\
\hline $\mathbf{h}$ & 24,9 & 19,7 & 31,7 & 25,2 \\
\hline $\boldsymbol{\sigma}$ & 18,8 & 14,4 & 23,9 & 18,7 \\
\hline $\mathbf{Z}_{\mathbf{m}}$ & 61,1 & 30,1 & 40,0 & 21,4 \\
\hline $\mathbf{B}_{\mathbf{0}}$ & 0,19 & 0,18 & 0,2 & 0,3 \\
\hline \multicolumn{2}{c}{$h\left(m g C l o . m^{-2}\right) ; \sigma(m) ; Z_{m}(m) ; B_{0}\left(m g C l o . m^{-3}\right)$}
\end{tabular}

Pode-se observar pela Tabela 4.2 que existe uma diferença sazonal entre os perfis médios. Entretanto, analisaremos a variabilidade em torno dos parâmetros médios, examinando as implicações dessas variabilidades no cálculo da produção primária integrada. Inicialmente, calcula-se a produção primária média para cada perfil sazonal, assumindo uma "estação média" localizada no centro geográfico da área de estudo. Os cálculos foram realizados para um dia hipoteticamente sem nuvens, no meio de cada estação do ano. A seguir, o valor de um dos parâmetros médios da curva de Gaussdeslocada foi acrescido ou diminuído por um desvio padrão, enquanto que os outros parâmetros eram mantidos inalterados em seus valores médios. Desta forma, uma seqüência de cálculos da produção primária foi realizada. Os resultados são apresentados nas Tabelas 4.3 e 4.4 para o verão e inverno, respectivamente. 
TABELA 4.3 - ANÁLISE DE SENSIBILIDADE DO CÁLCULO DA PRODUÇÃO PRIMÁRIA INTEGRADA E PROFUNDIDADE DA ZONA EUFÓTICA PELO MODELO BPM2 NO VERÃO.

\begin{tabular}{|c|c|c|c|c|c|c|c|c|}
\hline & h & $\Sigma$ & $\mathbf{Z}_{\mathbf{m}}$ & $\mathbf{B}_{\mathbf{0}}$ & $\mathbf{P P}_{\mathbf{E U}}$ & $\mathbf{Z}_{\mathbf{E U}}$ & $\Delta P_{\mathrm{EU}} \%$ & $\Delta \mathbf{Z}_{\mathbf{E U}}$ \\
\hline Média & 24,9 & 18,7 & 61,1 & 0,189 & 1259 & 63,4 & & \\
\hline$+d p$ & 44,63 & 18,7 & 61,1 & 0,189 & 1423 & 58,1 & 13,0 & $-8,4$ \\
\hline$-d p$ & 5,17 & 18,7 & 61,1 & 0,189 & 1014 & 78,0 & $-19,5$ & 23,0 \\
\hline$+d p$ & 24,9 & 33,13 & 61,1 & 0,189 & 1261 & 63,6 & 0,1 & 0,3 \\
\hline$-d p$ & 24,9 & 4,42 & 61,1 & 0,189 & 1368 & 65,2 & 8,6 & 2,8 \\
\hline$+d p$ & 24,9 & 18,7 & 91,2 & 0,189 & 1019 & $76,4,1$ & $-19,1$ & 20,5 \\
\hline$-d p$ & 24,9 & 18,7 & 31,1 & 0,189 & 1601 & 54,1 & 27,1 & $-14,7$ \\
\hline$+\mathrm{dp}$ & 24,9 & 18,7 & 61,1 & 0,369 & 1479 & 55,6 & 17,4 & $-12,3$ \\
\hline$-d p$ & 24,9 & 18,7 & 61,1 & 0,008 & 1050 & 78,2 & $-16,6$ & 23,3 \\
\hline Média & & & & & 1277 & 66,2 & 1,4 & 4,3 \\
\hline
\end{tabular}

TABELA 4.4 - ANÁLISE DE SENSIBILIDADE DO CÁLCULO DA PRODUÇÃO PRIMÁRIA INTEGRADA E PROFUNDIDADE DA ZONA EUFÓTICA PELO MODELO BPM2 NO INVERNO.

\begin{tabular}{|c|c|c|c|c|c|c|c|c|}
\hline & h & $\boldsymbol{\sigma}$ & $\mathbf{Z}_{\mathbf{m}}$ & $\mathbf{B}_{\mathbf{0}}$ & $\mathbf{P P}_{\mathbf{E U}}$ & $\mathbf{Z}_{\mathbf{E U}}$ & $\Delta P_{E U} \%$ & $\Delta \mathbf{Z}_{\mathbf{E U}}$ \\
\hline Média & 31,7 & 23,9 & 40,0 & 0,244 & 899 & 48,5 & & \\
\hline$+d p$ & 56,9 & 23,9 & 40,0 & 0,244 & 1078 & 43,0 & 19,9 & $-11,3$ \\
\hline$-d p$ & 6,4 & 23,9 & 40,0 & 0,244 & 666 & 63,3 & $-25,9$ & 30,5 \\
\hline$+d p$ & 31,7 & 42,6 & 40,0 & 0,244 & 833 & 52,3 & $-7,3$ & 7,8 \\
\hline$-d p$ & 31,7 & 5,2 & 40,0 & 0,244 & 972 & 48,0 & 8,2 & $-1,0$ \\
\hline$+d p$ & 31,7 & 23,9 & 61,4 & 0,244 & 748 & 54,9 & $-16,7$ & 13,2 \\
\hline$-d p$ & 31,7 & 23,9 & 18,6 & 0,244 & 1015 & 46,7 & 13,0 & $-3,7$ \\
\hline$+\mathrm{dp}$ & 31,7 & 23,9 & 18,6 & 0,545 & 1113 & 42,6 & 23,9 & $-12,2$ \\
\hline Média & & & & & 918 & 50,1 & 2,1 & 3,3 \\
\hline
\end{tabular}

Os parâmetros fotossintéticos foram mantidos constantes em seus valores sazonais médios, seguindo o protocolo sugerido por Longhurst et al., (1995). Os valores dos parâmetros fotossintéticos também são mostrados na Tabela 4.3 e Tabela 4.4. Os 
parâmetros fotossintéticos não foram alterados quando os parâmetros do perfil vertical eram modificados por seus respectivos desvios padrão. Portanto, a análise apresentada pode ser considerada como uma análise de sensibilidade do cálculo da produção primária integrada na coluna d'água, pelo modelo BPM2, em relação à variabilidade dos parâmetros do perfil vertical de biomassa somente. A sensibilidade dos resultados à variabilidade parâmetros das curvas de luz - fotossíntese, em termos sazonais, não foi examinada. Também são mostradas na Tabela 4.3 e Tabela 4.4 as diferenças percentuais entre as produções calculadas com os parâmetros médios dos perfis verticais e as calculadas com os parâmetros alterados por uma unidade de desvio padrão. Ao interpretar estes resultados, é importante compreender que as variações nos parâmetros discutidas aqui não necessariamente conservam a biomassa na coluna d'água. Algumas das mudanças nos parâmetros aumentam a biomassa na zona eufótica (refletida em uma diminuição da $Z_{\mathrm{EU}}$ ), enquanto que outras mudanças diminuem a biomassa (aumento de $\mathrm{Z}_{\mathrm{EU}}$ ), ou mesmo a conservam, ainda que a redistribuam na coluna d'água (o que pode aumentar ou diminuir a $\left.Z_{\mathrm{EU}}\right)$.

Algumas observações podem ser feitas a partir dos resultados:

- Variação em $\mathrm{B}_{0}$ : $\mathrm{O}$ incremento em $\mathrm{B}_{0}$ aumenta uniformemente a biomassa na coluna d'água em todas as profundidades, inclusive na superfície onde a iluminação é máxima. Portanto, a produção primária aumenta com o incremento de $\mathrm{B}_{0}$, e diminui também com $\mathrm{B}_{0}$;

- Variação em h: $\mathrm{O}$ incremento de $\mathrm{h}$ aumenta a biomassa total no máximo de clorofila subsuperficial. Uma vez que a espessura do pico foi mantida (determinada por $\sigma$ ), o aumento de biomassa é obtido pelo pronunciamento deste pico subsuperficial. Tipicamente, este aumento de biomassa no pico também aumenta a produção primária;

- Variação em $\mathrm{Z}_{\mathrm{m}}$ : $\mathrm{A}$ mudança em $\mathrm{Z}_{\mathrm{m}}$ não influencia a biomassa total na coluna d'água. Ocorre apenas uma oscilação vertical do máximo subsuperficial para cima ou para baixo. Portanto, uma diminuição em $\mathrm{Z}_{\mathrm{m}}$ terá o efeito de mover o 
pico em direção à superfície, isto é, em direção a profundidades mais iluminadas da coluna d'água, com resultante aumento na produção primária. Portanto, uma diminuição em $Z_{m}$ leva a um aumento na produção primária, e vice-versa.

- Variação em $\sigma:$ O efeito de $\sigma$ sobre a produção primária é mais complexo. Isto porque, mudando o valor de $\sigma$ enquanto mantém-se $\mathrm{h}$ inalterado, implica em uma mudança na amplitude do máximo subsuperficial de clorofila. A altura $\mathrm{H}$ do pico de clorofila acima da constante de fundo $\mathrm{B}_{0}$ é por definição:

$$
H=\frac{h}{\sigma \sqrt{2 \pi}}
$$

Quando $\sigma$ aumenta e $\mathrm{h}$ permanece constante, a altura $\mathrm{H}$ diminui. Ao mesmo tempo, a área de biomassa contida no máximo subsuperficial permanece constante, uma vez que h é mantido inalterado. Em outras palavras, a biomassa no pico é espalhada mais uniformemente na coluna d'água. Isto também causa um aumento de biomassa na superfície, a qual pode favorecer um aumento na produção primária. Por outro lado, deve haver um decréscimo correspondente na produção em torno de $Z_{m}$, uma vez que a altura do pico está reduzida. Portanto, o efeito líquido sobre a produção primária na coluna d'água, devido a um aumento em $\sigma$, dependerá de qual desses efeitos opostos for dominante. As Tabelas 4.3 e 4.4 de fato, mostram que um aumento em $\sigma$ pode resultar em uma diminuição ou aumento na produção primária integrada na coluna d'água.

Pode ser notado também nas Tabelas 4.3 e 4.4, que as diferenças médias não foram significativas $(<5 \%$ ), ainda que tenham excedido $25 \%$ em alguns casos individuais. Este comportamento pode justificar a utilização de parâmetros médios sazonais para estimar a produção primária em escala regional utilizando dados de biomassa fitoplanctônica obtidos por satélite (Sathyendranath et al., 1995; Longhurst et al., 1995). Neste tipo de cálculo, o objetivo principal deve ser a obtenção de uma estimativa em escala regional que não seja tendenciosa (unbiased), mais do que se estimar precisamente a produção em cada pixel individualmente. Este resultado é encorajador e serve para suportar os protocolos computacionais nos quais as estimativas da produção primária a partir de dados de satélite, em escalas regional e global, são baseadas em 
parâmetros médios sazonais e/ou por províncias (na falta de outras informações que possam ser assimiladas pela base de dados orbital).

\subsection{Imagens da produção primária oceânica (PPO)}

Segundo Gaeta e Brandini (2003), as imagens de satélite têm sido uma ferramenta valiosa na análise da distribuição espacial da produtividade potencial na região sulsudeste do Brasil, capazes de identificar processos físicos e seus efeitos na produção primária. As imagens de PPO referentes aos cruzeiros de verão e inverno de 2001 e 2002 foram mostradas nas Figuras 3.60, 3.61, 3.62 (M1), 3.63, 3.64, 3.65 (M2), 3.66, 3.67 (M3), 3.68, 3.69 e 3.70 (M4), respectivamente. Até o momento da elaboração do presente trabalho, estas são as primeiras imagens da PPO geradas para a costa brasileira, a partir de imagens orbitais da cor do oceano (SeaWiFS), utilizando-se um algoritmo semi-analítico e dados fotossintéticos in situ adquiridos simultaneamente. No conjunto de imagens da PPO mostradas, foi possível observar altas taxas de produção primária nas regiões costeiras sob influência direta do aporte continental, rios e estuários ao sul de Vitória, São Tomé, Cabo Frio, Baía de Guanabara, Baía de Sepetiba e Ilha de São Sebastião, com valores acima de 5,0 $\mathrm{gC} \cdot \mathrm{m}^{-2} \cdot \mathrm{d}^{-1}$ no verão e $3,0 \mathrm{gC} \cdot \mathrm{m}^{-2} \cdot \mathrm{d}^{-1}$ no inverno. Manchas de alta produtividade também foram notadas em áreas de ressurgência costeira e em plumas associadas a esses eventos $\left(>4,0 \mathrm{gC} \cdot \mathrm{m}^{-2} \cdot \mathrm{d}^{-1}\right.$, no verão e $>3,0 \mathrm{gC} \cdot \mathrm{m}^{-2} \cdot \mathrm{d}^{-1}$, no inverno). Meandros e vórtices ciclônicos foram identificados nas proximidades de Cabo Frio, São Tomé e SE de Vitória, tanto no verão como no inverno, com valores de PPO em torno de 2,0 $\mathrm{gC} \cdot \mathrm{m}^{-2} \cdot \mathrm{d}^{-1}$ (mas podendo chegar a 5,0 $\mathrm{gC} \cdot \mathrm{m}^{-2} \cdot \mathrm{d}^{-1}$ ). Águas relativamente férteis vindas do sul pela costa foram observadas nas imagens de inverno alcançando a latitude da Ilha de São Sebastião com produtividades acima de 2,0 $\mathrm{gC} \cdot \mathrm{m}^{-2} \cdot \mathrm{d}^{-1}$. De modo geral, a PPO máxima do verão foi maior que do inverno $(10,0$ $\mathrm{gC} \cdot \mathrm{m}^{-2} \cdot \mathrm{d}^{-1}$ e $4,5 \mathrm{gC} \cdot \mathrm{m}^{-2} \cdot \mathrm{d}^{-1}$, respectivamente).

Paiva (1997) concluiu que a plataforma continental sudeste-sul do Brasil concentra a pesca industrial de arrasto e cerco, devido à sua alta produtividade. De acordo com este autor, a variabilidade espacial e temporal dos gradientes hidrográficos horizontais e verticais nesta região, aumenta a possibilidade de fertilização da zona eufótica por 
tempo suficiente para que ocorra crescimento e acúmulo de biomassa fitoplanctônica. Segundo Falkowski et al., (1991), em áreas de ressurgência costeira ou quebra de plataforma e em feições de mesoescala com bombeamento induzido por meandros e vórtices ciclônicos, os fluxos verticais de nutrientes podem acumular temporariamente clorofila em concentrações superiores a $5 \mathrm{mg} \cdot \mathrm{m}^{-3}$. De modo geral, o nitrogênio tem sido considerado como nutriente limitante da produção primária fitoplanctônica nos oceanos (Carpenter e Capone, 1983), podendo ser suprido na forma orgânica (aminoácidos, uréia) ou inorgânica em 3 níveis de óxido-redução (nitrato, nitrito e amônia), a partir de diferentes fontes. No oceano aberto, a produção nova depende principalmente do fluxo vertical de nitrato (Eppley et al., 1973; Fogg, 1982) ainda que, contribuições de compostos nitrogenados oxidados ou reduzidos trazidos por processos advectivos, drenagem continental e interações com a atmosfera (fixação biológica do $\mathrm{N}_{2}$ molecular e precipitação), também sejam significativas (Falkowski et al., 1998).

A ACAS estoca nutrientes em concentrações relativamente altas em subsuperfície. Quando esta massa d'água aflora por movimentos ascendentes, a produtividade aumenta na zona eufótica. Ressurgências, vórtices e meandramentos ciclônicos, e ondas internas são alguns dos processos físicos que provocam a fertilização da zona eufótica com os nutrientes trazidos pela ACAS na costa SE brasileira (Gaeta e Brandini, 2003). A fertilidade potencial da ACAS foi comprovada experimentalmente por Saldanha (1993) que enriqueceu águas tropicais oligotróficas de superfície, com diferentes proporções de ACAS. O fitoplâncton se desenvolveu mais nestas águas enriquecidas do que em águas tropicais de controle mantidas sem enriquecimento pela ACAS. Yoneshigue-Braga et al., (1979) e Gonzalez-Rodriguez et al., (1992) observaram concentrações relativamente baixas de nutrientes em relação a outras áreas de ressurgência do planeta, e a falta de substâncias quelantes nas águas de ressurgência em Cabo Frio.

Apesar de muitas feições observadas nas imagens da PPO terem apresentado grande correlação com estruturas também descritas nas imagens termais (AVHRR) e de cor do oceano (SeaWiFS) correspondentes, parece evidente o caráter complementar dos campos de TSM, CSM e agora, da PPO. A dificuldade fundamental em estimar a PPO a partir de campos superficiais de pigmento (clorofila $a$ ) obtidos por satélite, é que um 
indicador do standing stock (pigmento fitoplanctônico) está sendo usado para calcular uma taxa (fixação de carbono). Uma fonte significativa de incerteza no algoritmo de produção primária utilizado (BPM1, mas também é válido para BPM2), talvez seja a variabilidade natural dos parâmetros fotossintéticos $\mathrm{P}_{\max }{ }^{\mathrm{B}}$ e $\alpha^{\mathrm{B}}$, considerados constantes neste tipo de abordagem. Fatores ambientais aos quais tem-se atribuído influência sobre estes dois parâmetros fotossintéticos incluem a temperatura, variação da irradiância, variação dos nutrientes e composição de espécies da comunidade fitoplanctônica (Platt e Jasby, 1976; Kuring et al., 1990; entre outros). A fluorescência natural do fitoplâncton, disponibilizada agora através do sensor MODIS, pode ser considerada como um indicador da eficiência quântica da fotossíntese (Neville e Gower, 1977). Desta forma, novos algoritmos podem ser desenvolvidos para utilizar a medida de fluorescência e calcular valores médios de $\alpha^{\mathrm{B}}$ na superfície do mar (Topliss e Platt, 1986; Kuring et al., 1990). Mesmo que os parâmetros obtidos por sensoriamento remoto e usados no cálculo da PPO nunca alcancem a precisão ou resolução vertical de medidas coletadas a bordo de navios, parece claro que as informações obtidas por satélite são inestimáveis para estender nosso conhecimento a partir desses pontos de amostragem superficiais para grandes áreas oceânicas (Kuring et al., 1990).

\subsection{Produtividade primária anual}

Como mencionado anteriormente, a utilização de parâmetros médios sazonais para estimar a produção primária em escala regional, utilizando dados de biomassa fitoplanctônica obtidos por satélite, pode ser considerada válida em muitos casos (Sathyendranath et al., 1995; Longhurst et al., 1995). Neste tipo de cálculo, o objetivo principal é a obtenção de uma estimativa em escala regional que não seja tendenciosa (unbiased), mais do que se estimar precisamente a produção em cada pixel individualmente. Em ecossistemas pelágicos, a variabilidade dos processos ecofisiológicos e biogeoquímicos (taxa de fotossíntese, por exemplo) é controlada por processos físicos. Essas forçantes físicas regulam as condições ambientais que por sua vez, determinam: (i) composição de espécies de uma comunidade em um determinado local, num certo tempo; (ii) magnitude do fluxo de nutrientes para a zona eufótica e o modo como esse aporte é feito; (iii) taxa de mistura vertical, capacidade de adaptação às 
condições de luz e distribuição vertical dos pigmentos fotossintéticos na coluna d'água. Levando-se isso em consideração, foi sugerido por diferentes autores que o oceano global fosse dividido em regiões com características físico-químicas comuns, denominadas como Províncias Biogeoquímicas (Platt et al., 1988, 1991; Mueller e Lange,1989; Sathyendranath et al., 1995). Os processos mencionados acima influenciam diretamente os parâmetros fotossintéticos em cada província, em função de variáveis físicas, químicas e biológicas (p.ex., temperatura, luz, nutrientes). Como a natureza e a intensidade das forçantes físicas variam sazonalmente, deve-se considerar a variação sazonal deste parâmetros (Platt et al., 1995). Como mostrado no capítulo 3, item 3.13, foram realizadas estimativas anuais da produtividade primária nos anos 2001 e 2002, para os domínios de plataforma, talude e área total (plataforma + talude). Foram utilizados os parâmetros fotossintéticos médios e os parâmetros médios do perfil vertical de biomassa modelado pela curva de Gauss deslocada, calculados para cada estação do ano amostrado (verão e inverno). As estimativas anuais foram apresentadas na Tabela 3.58. Considerando toda a área de estudo, a produtividade primária anual em 2001 foi igual a $405 \mathrm{gC} \cdot \mathrm{m}^{-2} \cdot \mathrm{a}^{-1}$, enquanto que a de 2002 foi cerca de $10 \%$ menor (366 $\left.\mathrm{gC} \cdot \mathrm{m}^{-2} \cdot \mathrm{a}^{-1}\right)$. Joint et al., (2002) estimaram a produtividade primária média da plataforma e talude na região Ibérica utilizando dados do satélite SeaWiFS com o modelo semianalítico proposto por Morel (1991), obtendo valores próximos a $300 \mathrm{gC} \cdot \mathrm{m}^{-2} \cdot \mathrm{d}^{-1}$, entre 1998 e 2000. Gaeta (1999) estimou a produtividade primária anual da região de plataforma da costa de São Paulo (em frente a Santos) a partir de dados in situ, e obteve valores mais conservativos em torno de $166 \mathrm{gC} \cdot \mathrm{m}^{-2} \cdot \mathrm{a}^{-1}$ e $141 \mathrm{gC} \cdot \mathrm{m}^{-2} \cdot \mathrm{a}^{-1}$, nos anos de 1993 e 1994 (variação de 15\% entre os dois anos). Para a região de talude, Gaeta (1999) obteve estimativas em torno de 76 e $185 \mathrm{gC} \cdot \mathrm{m}^{-2} \cdot \mathrm{a}^{-1}$, nos anos de 1993 e 1994. Porém, se tomarmos os valores de $\mathrm{PP}_{\mathrm{EU}}$ in situ médios obtidos no presente trabalho para os domínios de plataforma, talude-verão e talude-inverno (ver Tabelas 3.44, 3.47 e 3.50, respectivamente), e multiplicarmos pelos dias do ano, teríamos estimativas da produção primária anual iguais a $350 \mathrm{gC} \cdot \mathrm{m}^{-2} \cdot \mathrm{a}^{-1}$ para o domínio de plataforma, $70 \mathrm{gC} \cdot \mathrm{m}^{-2} \cdot \mathrm{d}^{-1}$ para o domínio talude-verão e $225 \mathrm{gC} \cdot \mathrm{m}^{-2} \cdot \mathrm{d}^{-1}$ no domínio talude-inverno, ou seja, mais conservativos. 
Segundo Duda e Sherman (2002), a produtividade define a capacidade de suporte que um ecossistema tem para sustentar os recursos pesqueiros. A região de estudo no presente trabalho, é conhecida por sua ressurgência costeira em Cabo Frio. Áreas de ressurgência no planeta têm sido reconhecidas por sua produtividade (Barber e Smith, 1981). Ainda que suas respectivas áreas correspondam a uma pequena fração do oceano mundial (no máximo 1\%), elas contribuem com 5\% da produção primária oceânica global e com $17 \%$ da captura pesqueira global (Pauly e Christensen, 1995). Pauly e Christensen (1995) estimaram a produção primária necessária para suportar a captura pesqueira global e concluíram que em áreas de ressurgência a captura correspondeu a $25 \%$ da produção primária estimada. De acordo com Carr (2002), a produção pesqueira pode ser estimada a partir da produção primária integrada considerando-se uma cadeia trófica simples, com uma eficiência trófica fixa e um número médio de relações tróficas (trophic links). A fórmula proposta por Pauly e Christensen (1995) para estimar a produção primária necessária para sustentar a captura observada foi usada no presente trabalho, juntamente com o valor de eficiência fornecido pelos mesmos autores $(10 \%)$, e o nível trófico médio $(2,8)$ designado aos peixes pelágicos em regiões tropicais, de modo que:

$$
F P=P P(E T)^{(N T-1)},
$$

onde FP é a produção pesqueira, $\mathrm{PP}(\mathrm{gC})$ é a produção primária multiplicada pela área da plataforma continental sudeste $\left(150 \times 10^{3} \mathrm{~km}^{2}\right)$, ET é a eficiência trófica e NT é o nível trófico médio. Nesta abordagem, considera-se que a produção primária esteja totalmente acessível ao recurso pesqueiro, tanto no tempo como no espaço. A conversão entre carbono e peso seco foi feita multiplicando-se FP por um fator igual a 8 (Carr, 2002), ou seja, a biomassa pesqueira (BP) foi calculada da seguinte forma: $\mathrm{BP}=8 *$ FP milhões de toneladas (MT). Para o ano de 2001, a biomassa pesqueira foi estimada em 7,7 MT e em 2002, 7,0 MT. Calculando-se a média dos dados de desembarque divulgados pela FAO para a produção pesqueira na nossa região (Brasil), entre os anos 1991 e 2000, obtém-se um valor de captura média em torno de 0,08 MT (apps.fao.org/cgi-bin/nph-db.pl). Como pode ser visto, a discrepância foi muito grande. 
Entretanto, cabe mencionar que a estimativa feita para BP no presente trabalho, representa apenas um limite superior máximo da biomassa pesqueira real, uma vez que nem toda a produção primária pode ser realmente utilizada pelos recursos pesqueiros. Parte da produção primária também afunda ou é transportada por processos advectivos antes de ser consumida. Shannon e Field (1985) estimam que a acessibilidade ambiental efetiva seja em torno de $12 \%$. Por outro lado, estimativas da produtividade potencial por sensoriamento remoto feitas por Carr (2002), para zonas de ressurgência em correntes de contorno leste, indicaram valores iguais a 10,0 MT para a região da Corrente da Califórnia, enquanto que os dados médios de captura divulgados pela FAO para a mesma região, no período 1990 - 1997, equivaliam a 0,07 MT. Cushing (1969) também estimou a biomassa pesqueira para a região da Corrente da Califórnia obtendo um valor igual a 7,27 MT. Segundo Bakun e Parrish (1991), a região da South Brazilian Bight (PCSE) possui um sistema de ressurgência similar ao da Southern California Bight, ou seja, região da Corrente da Califórnia. Se o estoque estimado for um limite máximo que deve ser reduzido a $10 \%$ ou $20 \%$ em função da acessibilidade ambiental, então a pesca pelágica na região sudeste parece estar limitada por alimento. Gaeta e Brandini (2003) estimaram a fixação anual de carbono orgânico na região sul e sudeste do Brasil em torno de 93 MT. Considerando uma eficiência da ordem de 10\% entre os níveis tróficos, os autores estimaram uma produção pesqueira anual de $93 \times 10^{3}$ toneladas no quarto nível trófico, que seria comparável aos níveis de captura mantidos na região sul-sudeste entre 1975 e 1993 (Haimovici, 1997, citado por Gaeta e Brandini, 2003). 


\section{CAPÍtULO 5}

\section{CONCLUSÕES}

O presente trabalho demonstrou a capacidade do sensoriamento remoto da cor do oceano para estimar a biomassa e produtividade primária fitoplanctônica da costa sudeste brasileira, de forma sinóptica e em escalas espacial e temporal impossíveis de serem obtidas por metodologias convencionais baseadas em navios. O sensoriamento remoto oferece a oportunidade de comparação bi-dimensional simultânea da variabilidade biológica (pigmentos) e física (temperatura) na superfície do mar. A determinação quase simultânea da TSM é uma medida complementar excelente à medida de concentração de clorofila $a$, uma vez que, os processos que contribuem para o crescimento fitoplanctônico, também aparecem como anomalias de temperatura na área de estudo. Apesar de muitas feições observadas nas imagens da PPO terem apresentado grande correlação com estruturas também descritas nas imagens termais (AVHRR) e da cor do oceano (SeaWiFS) correspondentes, ficou evidente o caráter complementar dos campos de TSM, CSM e agora, da PPO. No Brasil, estimativas da biomassa e produção primária fitoplanctônica na coluna d'água através de sensoriamento remoto são motivo de pesquisas muito recentes. As imagens da PPO obtidas durante a elaboração desse trabalho foram as primeiras a serem geradas para a costa brasileira a partir de imagens orbitais da cor do oceano (SeaWiFS), utilizando-se um algoritmo semi-analítico e dados fotossintéticos in situ, adquiridos simultaneamente. O avanço científico decorrente do presente trabalho é significativo, pois a estimativa da biomassa e produtividade primária fitoplanctônica através de imagens da cor do oceano e dados in situ coletados simultaneamente, ainda não haviam sido realizados em nossa Zona Econômica Exclusiva.

A diferença média total encontrada entre as medidas de temperatura da superfície do mar in situ (CTD) e obtidas por satélite (sensor AVHRR) ficou abaixo de $0,5^{\circ} \mathrm{C}$, o que pode ser considerado como ótimo. O algoritmo para estimativa da concentração de 
clorofila $a$ a partir de dados da cor do oceano, obtidos pelo sensor SeaWiFS, que apresentou melhor desempenho geral foi o OC4. De modo geral, o OC4 subestimou as concentrações de clorofila $a$ mais baixas e superestimou as mais altas. Os algoritmos de produção primária por satélite concordaram com as estimativas in situ-simuladas pelo método do ${ }^{14} \mathrm{C}$ por um fator de 2 , nos melhores casos.

Os resultados do presente trabalho indicaram que a forma dos perfis verticais de biomassa foi dependente da estrutura vertical do campo de massa ou temperatura na coluna d'água. Por sua vez, essa estrutura vertical foi determinada pela dinâmica de massas d'água presentes nas regiões de plataforma e talude, variando localmente em diferentes escalas temporais.

As características hidrográficas, distribuições de nutrientes e imagens de satélites durante os cruzeiros de verão (2001 e 2002) e inverno de 2002, sugeriram o afloramento da termoclina e da ACAS com o estabelecimento de uma frente de ressurgência costeira em Cabo Frio, São Tomé, Saquarema e Ilha de São Sebastião. Durante o inverno de 2001, a presença da ACAS foi notada entre 50 e $100 \mathrm{~m}$ de profundidade na radial em frente a Cabo Frio. As distribuições de temperatura, salinidade, $\sigma_{t}$ e nutrientes, assim como as imagens orbitais, também sugeriram a presença de meandros e vórtices da Corrente do Brasil em diferentes regiões, como em São Tomé e Cabo Frio. Estruturas na forma de meandros e vórtices ciclônicos da $\mathrm{CB}$ são capazes de induzir ressurgências da ACAS na quebra de plataforma. As ressurgências costeiras e de quebra de plataforma fertilizaram a zona eufótica com nutrientes inorgânicos. A disponibilização de nutrientes na zona eufótica deve ocorrer por tempo suficiente para que a produtividade primária aumente e a biomassa fitoplanctônica se acumule. Portanto, a ACAS se destacou em relação aos processos biológicos que ocorreram nas regiões de plataforma e quebra de plataforma, com relação à biomassa e produtividade primária fitoplanctônica.

No conjunto de dados hidrográficos, nutrientes e imagens de satélites, também foi possível observar a intrusão de águas frias vindas do sul, menos salinas e ricas em clorofila $a$ sobre a plataforma continental. Estes eventos frios ocorreram nos períodos de 
inverno e apresentaram efeitos nos campos de massa e nitrato, com conseqüente enriquecimento da zona eufótica e aumento relativo da produtividade primária.

Os domínios de plataforma, talude-verão e talude-inverno definidos nesse trabalho a partir de análises estatísticas das variáveis clorofila $a$ e produção primária integradas na zona eufótica, foram explicados pela análise conjunta dos dados hidrográficos, nutrientes, clorofila $a$, produção primária e imagens de satélites dos sensores AVHRR e SeaWiFS. Considerando-se as duas variáveis mencionadas acima, o domínio de plataforma não apresentou diferença significativa entre os períodos de verão e inverno devido ao processo de intrusão da ACAS presente na região em ambos os períodos. Durante a realização dos cruzeiros de verão e inverno de 2002, os ventos observados a bordo do N/Oc. Prof. Besnard foram favoráveis à ressurgência. Desta forma, a ACAS pôde penetrar em direção à costa também, durante o inverno de 2002. Este tem sido apontado por diversos autores como o principal processo de fertilização da zona eufótica nas águas de plataforma da região S-SE durante o verão.

As análises de regressão múltipla mostraram que houve uma significativa relação direta entre a produção primária integrada e a concentração de clorofila $a$ integrada na zona eufótica, nos três domínios considerados.

A abordagem por rede neural testada no presente trabalho para estimar a produtividade primária integrada na zona eufótica, não conseguiu superar o desempenho obtido com os modelos empíricos de regressão múltipla. Entretanto, foi possível perceber o potencial desta ferramenta para futuras aplicações, a medida em que a base de dados disponíveis for sendo aumentada e que as relações determinísticas entre as variáveis de entrada no modelo $\mathrm{NN}$ e a $\mathrm{PP}_{\mathrm{EU}}$ sejam mais bem definidas.

A utilização de parâmetros fotossintéticos e do perfil de biomassa médios sazonais para estimar a produção primária anual, a partir de dados orbitais do sensor SeaWiFS, foi considerada válida, para a área de estudo. A produtividade primária anual foi estimada em $405 \mathrm{gC} . \mathrm{m}^{2} \cdot \mathrm{a}^{-1}$ e $366 \mathrm{gC} \cdot \mathrm{m}^{-2} \cdot \mathrm{a}^{-1}$ em 2001 e 2002, respectivamente, isto é, cerca de $10 \%$ menor. Tomando os valores de $\mathrm{PP}_{\mathrm{EU}}$ médios medidos in situ $\left({ }^{14} \mathrm{C}\right)$, a produção 
anual média entre 2001 e 2002 é estimada em $323 \mathrm{gC} \cdot \mathrm{m}^{-2} \cdot \mathrm{a}^{-1}$, ou seja, cerca de $15 \%$ menor.

Com base nos dados obtidos por satélite, estimou-se a produção primária potencial na plataforma continental sudeste brasileira em torno de 0,06 Gt.C. $\mathrm{a}^{-1}$. O limite superior da produção pesqueira estimada, considerando-se uma cadeia trófica com 2,8 níveis e uma eficiência trófica média de $10 \%$, foi cerca de 90 vezes maior que a captura pesqueira média entre 1991 e 2000 . Porém, se a produção potencial estimada for apenas um limite superior que deve ser reduzido a $10 \%$ ou $20 \%$ devido a acessibilidade ambiental, o pescado estaria limitado por alimento na PCSE.

Os resultados obtidos neste trabalho serão utilizados em análises conjuntas com outros pesquisadores do projeto DEPROAS, devendo alcançar relevâncias sociais e econômicas. Hoje, o desafio do manejo pesqueiro é, antes de tudo, entender o ecossistema natural, procurando responder à questão - quanto podemos tirar do mar? A forma mais adequada para resolver essa questão é o uso apropriado do estoque de energia existente, determinando-se o standing stock, a sua produção, suas condicionantes ambientais e o coeficiente de transferência da mesma através de modelos nos quais são indicadas as inter-relações.

Além da pesca, parte dos resultados deste trabalho também pode ser aplicada a estudos climáticos, entre outros. A integração de dados orbitais com dados in situ permite a obtenção de informações interessantes, que de outra forma não seriam facilmente alcançadas, trazendo benefícios diretos para a solução de problemas brasileiros. 


\section{REFERÊNCIAS BIBLIOGRÁFICAS}

1. AIDAR, E.; GAETA, S.A.; GIANESELLA-GALVÃO, S.M.F.; M.B., KUTNER.; TEIXEIRA, C. Ecossistema costeiro subtropical: nutrientes dissolvidos, fitoplâncton e clorofila $a$ e suas relações com as condições oceanográficas na região de Ubatuba, SP. Publção. esp. Inst. oceanogr., v.10, p. 9-43, 1993.

2. AIDAR-ARAGÃO, E.; TEIXEIRA, C.; VIEIRA, A.A.H. Produção primária e concentração de clorofila $a$ na costa brasileira (Lat. $22^{\circ} 31^{\prime}$ S-Long. $41^{\circ} 52^{\prime} \mathrm{W}$ a Lat. $28^{\circ} 43^{\prime}$ S-Long. 47 $\left.57^{\prime} \mathrm{W}\right)$. Bolm. Inst. oceanogr., v.29, p. 9-14, 1980.

3. ALLARD, P. Anomalies dans les temperatures de l'eau de la mer observées au Cabo Frio au Brésil. Bull. Inf. Com. Océanogr. Études Côtes, v.7, n.2, p. 58-63, 1955.

4. AMBRÓSIO JR, O. Estudos sazonais sobre distribuição de alguns fatores físicos, químicos e da clorofila $a$ na Enseada das Palmas - Ilha Anchieta - Ubatuba - São Paulo. Tese de Doutorado. Instituto Oceanográfico. São Paulo, Universidade de São Paulo. 142p. 1989.

5. ANDRE, J.M. Ocean colour remote sensing and the subsurface vertical structure of phytoplankton pigments. Deep-Sea Res., v.39, p. 763-779, 1992.

6. ANDRE, J.M.; MOREL, A. Simulated effects of barimetric pressure and ozone content upon the estimate of marine phytoplankton from space. J. Geophys. Res., v.94, p. 1029-1039, 1989.

7. ANTOINE, D.; ANDRE, J.M.; MOREL, A. Oceanic primary production 2. Estimation at global scale from satellite (coastal zone color scanner) chlorophyll. Global Biogeochemical Cycles, v.10, p. 57-69, 1996.

8. ANTOINE, D.; MOREL, A. Oceanic primary production 1. Adaptation of a spectral light-photosynthesis model in view of application to satellite chlorophyll observations. Global Biogeochemical Cycles, v.10, p. 43-55, 1996.

9. BALCH, W.M.; BYRNE, C.F. Factors affecting the estimate of primary production from space. J. Geophys. Res., v.99, n.C4, p. 7555-7570, 1994.

10. BALCH, W.M.; EPPLEY, R.W.; ABBOTT, M.R. Remote sensing of primary production. II. A semi-analytical algortihm based on piggments, temperature and light. Deep-Sea Res. I, v.36, n.8, p. 1201-1217, 1989.

11. BALCH, W.M.; EVANS, R.; BROWN, J.; FELDMAN, G.; MCCLAIN, C.; ESAIAS, W. The remote sensing of ocean primary productivity: use of a new data compilation to test satellite algorithms. J. Geoph. Res. - Oceans, v.97, n.2, p. 2279-2293, 1992. 
12. BARBER, R.T.; SMITH, R.L. Coastal Upwelling ecosystems. In: A. R. Longhurst (ed). Analysis of Marine Ecosystems. New York, Academic Press, p.31-68, 1981.

13. BARTON, I.J. Satellite-derived sea surface temperatures: Current status. J .Geophys. Res., v.100, n.5, p. 8777-8790, 1995.

14. BEHERENFELD, M.J.; FALKOWSKI, P.G. Photosynthetic rates derived from satellite-based chlorophyll concentration. Limnol.Oceanogr, v.42, p. 1-20, $1997 \mathrm{a}$.

15. BEHERENFELD, M.J.; FALKOWSKI, P.G. A consumer's guide to phytoplankton primary productivity models. Limnol.Oceanogr, v.42, n.7, p. 1479-1491, $1997 b$.

16. BEHRENFELD, M.J.; RANDERSON, J.T.; MCCLAIN, C.R.; FELDMAN, G.C.; S.O., LOS; TUCKER, C.J.; FALKOWSKI, P.G.; FIELD, C.B.; FROUIN, R.; ESAIAS, E.W.; KOLBER, D.D.; POLLACK, N.H. Biospheric Primary Production During an ENSO transition. Science, v.291, p. 2594-2597, 2001.

17. BERGER, W.H.; SMETACEK, V.S.; WEFER, G. Ocean productivity and paleoproductivity: an overview. In: W. H. Beger e V. S. Smetacek (ed). Productivity of the ocean: presente and past, John Wiley \& Sons, p.1-34, 1989.

18. BERNSTEIN, R.L. Sea surface temperature estimation using the NOAA 6 satellite Advanced Very High Resolution Radiometer. Journal of Geophysical Research, v.87, n.12, p. 9455-9465, 1982.

19. BERTHELOT, B.; DESCHAMPS, P.Y. Evaluation of bio-optical algorithms to remotely sense marine primary production from space. J.Geophys.Res., v.99, p. 7979-7989, 1994.

20. BIGGS, D.C.; MÜLLER-KARGER, F.E. Ship and satellite observations of chlorophyll stocks in interacting cyclone-anticyclone eddy pairs in the western Gulf of Mexico. J. Geoph. Res., v.99, p. 7371-7348, 1994.

21. BIOSPHERICAL INSTRUMENTS. PNF-300 Profiling Natural Fluoremeter. San Diego, Biospherical Instruments Inc., 104 p. 1996.

22. BIRD, R.E. A simple, solar spectral model for direct-normal diffuse horizontal irradiance. Solar Energy, v.32, p. 461-471, 1984.

23. BIRD, R.E.; RIORDAN, C. Simple solar spectral model for direct and diffuse irradiance on horizontal and tilted planes at the earth's surface for cloudless atmospheres. J. Climatol. Appl. Meteorol., v.25, p. 87-97, 1986.

24. BISHOP, C.M. Neural Network for pattern recognition. Oxford, England, UK: Clarendon, 1995. $482 \mathrm{p}$.

25. BRAGA, A.P.; CARVALHO, A.P.L.; LUDEMIR, T.B. Fundamentos de Redes Neurais Artificiais. Rio de Janeiro: DCC/IM, COPPE/SIstemas NCE/UFRJ, 1998. $246 \mathrm{p}$. 
26. BRANDINI, F.P. Composição e distribuição do fitoplâncton na região Sueste do Brasil e suas relações com as massas de água (Operaçao Sueste - Julho/Agosto 1982). Ciência e Cultura, v.40, n.4, p. 334-341, 1988a.

27. BRANDINI, F.P. Hydrography, phytoplankton biomass and photosynthesis in shelf and oceanic waters off southeastern Brazil during autumn (May/June 1983).

Bolm. Inst. oceanogr., v.36, p. 63-72, 1988 b.

28. BRANDINI, F.P. Primary production and phytoplankton photosynthetic characteristics in the southeastern Brazilian coast. Bolm. Inst. oceanogr., v.38, n.2, p. 147-159, 1990a.

29. BRANDINI, F.P. Hydrography and characteristics of the phytoplankton in shelf and oceanic waters off southeastern Brazil during winter (July/August 1982) and summer (February/March 1984). Hydrobiologia, v.196, p. 111-148, 1990 b.

30. BRANDINI, F.P.; LOPES, R.M.; GUTSEIT, K.S.; SPACH, H.L.; SASSI, R. Planctologia na Plataforma Continental do Brasil: Diagnose e Revisão Bibliográfica.: MMA - CIRM - FEMAR, 1997. 196 p.

31. BRANDINI, F.P.; MORAES, C.L.B.; THAMM, C.A. Shelf break upwelling, subsurface maxima of chlorophyll and nitrite, and vertical distribution of a subtropical nano - and microplankton community off southeastern Brazil. In: III Encontro Brasileiro de Plâncton, Proceedings. Caiobá, UFPR, 1989. p.47-56.

32. BROWN, O.B.; EVANS, R.H.; GORDON, H.R.; SMITH, R. C.; BAKER, K.S. Blooming off the U.S. coast: a satellite description. Science, v.229, p. 163-167, 1985.

33. BUKATA, R.P.; JEROME, J.H.; KONDRATYEV, K.Y.; POZDNYAKOV, D.V. Optical properties and remote sensing of inland and coastal waters. Boca Raton: CRC Press, 1995.

34. CAMPBELL, J.; ANTOINE, D.; ARMSTRONG, R.; ARRIGO, K.R.; BALCH, W.; BARBER, R.; BEHERENFELD, M.J.; BIDIGARE, R.R.; BISHOP, J.; CARR, M-E; ESAIAS, E.; FALKOWSKI, P.; HOEPFFNER, N.; IVERSON, R.L.; KIEFER, D.A.; LOHRENZ, S.; MARRA, J.; MOREL, A.; RYAN, J.; VEDERNIKOV, V.; WATERS, K.; YENTSCH, C.S.; YODER, J.A.

Comparison of algorithms for estimating ocean primary production from surface chlorophyll, temperature, and irradiance. Global Biogeochemical Cycles, v.16, n.3, p. 9-1 a 9-15, 2002.

35. CAMPBELL, J.W. ; O'REILLY, J. E. Role of satellites in estimating primary productivity on the northwest Atlantic continental shelf. Continental Shelf Research, v.8, p. 179-204, 1988.

36. CAMPOS, E.D.; GONÇALVES, J.E.; IKEDA, Y. Water mass characteristics and geostrophic circulation in the South Brazil Bight - summer of 1991. J. Geophys. Res., v.100, n.C9, p. 18537-18550, 1995. 
37. CAMPOS, E.J.D. Estudos da circulação oceânica no Atlântico Tropical e região oeste do Atlântico Subtropical Sul. Tese de Livre Docência. Instituto Oceanográfico. São Paulo, Universidade de São Paulo. 114p. 1995.

38. CAMPOS, E.J.D.; IKEDA, Y.; CASTRO FILHO, B.M.; GAETA, S.A.; LORENZZETTI, J.A.; STEVENSON, M.R. Experiment studies circulation in the western South Atlantic. EOS Transactions, v.77, n.27, p. 253-259, 1996.

39. CAMPOS, E.J.D.; VELHOTE, D.; SILVEIRA, I.C.A. Shelf break upwelling driven by Brazil Current cyclonic meanders. Geoph. Res. Lett., v.27, n.6, p. 751-754, 2000.

40. CAMPOS, E.J.D.; LORENZZETTI, J.A.; STEVENSON, M.R.; STECH, J.L.; DE SOUZA, R.B. Penetration of waters from the Brazil-Malvinas confluence region along the South American continental shelf up to $23^{\circ} \mathrm{S}$. Academia Brasileira de Ciências, v.68, n.1, p. 49-58, 1996.

41. CARPENTER, E.J.; CAPONE, D.G. (ed.). Nitrogen in the marine environment. New York, Academic Press, 920p., 1983.

42. CARR, M-E. Estimation of potential productivity in Eastern Boundary Currents using remote sensing. Deep-Sea Res.II, v.49, p. 59-80, 2002.

43. CASTRO, B. M. Correntes e massas de água da plataforma continental norte de São Paulo. Tese de Livre-Docência. Instituto Oceanográfico. São Paulo, Universidade de São Paulo. 248p. 1996.

44. CASTRO, B. M.; LORENZZETTI, J. A.; SILVEIRA, I.C.A.; MIRANDA, L.B.; ARAUJO, C.E.; KAMPEL, M. Diagnóstico do conhecimento atual da estrutura termohalina e da circulação entre o Cabo de São Tomé (RJ) e o Chuí (RS). In: C. Rossi-Wongtschowski (ed). Ambiente oceanográfico de plataforma continental e talude das regiões sudeste e sul do Brasil. São Paulo, EDUSP, no prelo.

45. CASTRO, B.M.; MIRANDA, L.B. Relatório 3. Subprojeto Oceanografia Física do Projeto Oceanografia da Plataforma Interna da Região de São Sebastião. São Paulo, FAPESP/Instituo Oceanográfico da Universidade de São Paulo, 58p., 1995.

46. CASTRO, B.M.; MIRANDA, L.B. Physical Oceanography of the Western Atlantic Continental Shelf Located Between $4 \mathrm{oN}$ and $34 \mathrm{oS}$ - Coastal Segment (4,W). In: A. R. Robinson e K. H. Brink (ed). The Sea. New York, John Wiley \& Sons, Inc., p.209-251, 1998.

47. CASTRO, B.M.; MIRANDA, L.B.; MIYAO, S.Y. Condições hidrográficas na plataforma continental ao largo de Ubatuba: variações sazonais e em média escala. Bolm. Inst. oceanogr., v.35, n.2, p. 135-151, 1987.

48. CHAMBERLIN, W.S. Light absorption, natural fluorescence, and photosynthesis in the open ocean. Ph.D. dissertation. Los Angeles, California, University of Southern California. p. 1989. 
49. CHAMBERLIN, W.S.; BOOTH, C.R.; KIEFER, D.A.; MORROW, J.H.; MURPHY, R.C. Evidence for a single relationship between natural fluorescence, photosynthesis and chlorophyll in the sea. Deep-Sea Res., v.37, n.6, p. 951-973, 1990.

50. CIOTTI, A.M.; KAMPEL, M. Concurrent observations of ocean color and sea surface temperature between Cabo Frio e Cabo Sao Tome. In: X Simpósio Brasileiro de Sensoriamento Remoto, Proceedings. Foz do Iguaçu, PR, INPE, 2001. p.8:1-7.

51. CIRANO, M. Utilização de modelo numérico no estudo diagnóstico da circulação oceânica na Bacia de Santos. M.Sc.Thesis. Instituto Oceanográfico. São Paulo, Universidade de São Paulo. 112p. 1995.

52. CLARK, D.K. Phytoplankton pigment algorithm for the NIMBUS-7 CZCS. In: J. R. F. e. Gower (ed). Oceanography from Space. New York, Plenum Press, p.227237, 1981.

53. CLARK, D.K.; SHERMAN, J.W. Nimbus-7 Coastal Zone Color Scanner: ocean color applications. MTS Journal, v.20, n.2, p. 43-56, 1986.

54. COLL, C.; CASELLES, V.; VALOR, E. Atmospheric Correction and Determination of Sea Surface Temperature in Midlatitudes from NOAAAVHRR Data. Manuscrito impresso em 1993.

55. COPIN-MONTÉGUT, C.; COPIN-MONTÉGUT, G. Stoichiometry of carbon, nitrogen, and phosphorus in marine particulate matter. Deep-Sea Res., v.30, p. 31-46, 1983.

56. CULLEN, J.J. On models of growth and photosynthesis in phytoplankton. DeepSea Res., v.I, n.37, p. 667-683, 1990.

57. CUSHING, D.H. Upwelling and fish production. FAO Fisheries Technical Paper, v.84, p. 1-40, 1969.

58. DONLON, C.J.; CASTRO, S.L.; KAYE, A. Aircraft validation of ERS-1 ATSR and NOAA-14 AVHRR sea surface temperature measurements. Int. J. Remote Sensing, v.20, n.18, p. 3503-3513, 1999.

59. DRAPER, N.R.; SMITH, H. Applied Regression Analysis. New York: John Wiley, 1966.

60. DUDA, A.M.; SHERMAN, K. A new imperative for improving management of large marine ecosystems. Ocean and Coastal Management, v.45, p. 797-833, 2002.

61. DUGDALE, R. C. Nutrient limitation in the sea: Dynamics, identification and significance. Limnol. Oceanogr., v.12, p. 685-695, 1967.

62. DUGDALE, R. C.; GOERING, J.J. Uptake of new and regenerated forms of nitrogen in primary productivity. Limnol. Oceanogr., v.12, n.196-206, 1967.

63. EMÍLSSON, I. The shelf and coastal waters off southern Brazil. Bolm. Inst. oceanogr., v.11, n.2, p. 101-112, 1961. 
64. EPPLEY, R.W. Temperature and phytoplankton growth in the sea. Fisheries Bulletin, v.70, n.4, p. 1063-1085, 1972.

65. EPPLEY, R.W.; RENGER, E.H.; VENRICK, E.L.; MULLIN, M. A study of plankton dynamics and nutrient cycling in the central gyre of the North Pacific Ocean. Limnol. Oceanogr., v.18, n.4, p. 534-551, 1973.

66. EPPLEY, R.W.; STEWART, E.; ABBOTT, M.R.; HEYMAN, U. Estimating ocean primary production from satellite chlorophyll. Introduction to regional differences and statistics for the Southern California Bight. J. Plankton. Res., v.7, p. 57-70, 1985.

67. EVANS, R.H.; GORDON, H.R. Coastal zone color scanner "system calibration": A retrospective examination. J .Geophys. Res., v.99, p. 7293-7307, 1994.

68. FALKOWSKI, P.G.; BARBER, R.T.; SMETACEK, V. Biogeochemical Controls and Feedbacks on Ocean Primary Production. Science, v.281, p. 200-206, 1998a.

69. FALKOWSKI, P.G.; BEHRENFELD, M.J.; ESAIAS, E.; BALCH, W.; CAMPBELL, J.W.; IVERSON, R.L.; KIEFER, D.A.; MOREL, A.; YODER, J.A. Satellite primary productivity data and algorithm development: a science plan for mission to planet Earth. In: S. B. Hooker e E. R. Firestone (ed).

SeaWiFS Technical Report Series - NASA Technical Memorandum 104566. Washington, DC, NASA, p.36, 1998 b.

70. FALKOWSKI, P.G.; ZIEMANN, D.; KOLBER, Z.; BIENFANG, P.K. Role of eddy pumping in enhancing primary production in the ocean. Nature, v.352, p. $55,1991$.

71. FEE, E.J. Computer programs for calculating in situ phytoplankton photosynthesis, 32 p. 1990.

72. FIELD, C.B; BEHERENFELD, M.J.; RANDERSON, J.T.; FALKOWSKI, P. Primary Production of the Biosphere: Integrating Terrestrial and Oceanic Components. Science, v.281, p. 237-240, 1998.

73. FIRESTONE, E.R.; HOOKER, S.B. SeaWiFS Prelaunch Technical Report Series Final Cumulative Index. In: S. B. Hooker e E. R. Firestone (ed). NASA Tech. Memo. 1998-104566. Greenbeld, Maryland, NASA Goddard Space Flight Center, p.4-8, 1998.

74. FIRESTONE, E.R.; HOOKER, S.B. SeaWiFS Postlaunch Technical Report Series. In: S. B. Hooker e E. R. Firestone (ed). SeaWiFS Postlaunch Technical Report Series: Cumulative Index: Volumes 1-17, NASA/TM-2003-206892, 2003.

75. FOGG, G.E. Nitrogen cycling in sea waters. Phil. Trans. R. Soc. Lond, v.B296, p. 511-520, 1982.

76. GAETA, A.S. Oceanografia Biológica: Plâncton - Estado de São Paulo. In: J. L. Valentin e A. S. Gaeta (ed). Diagnóstico Ambiental Oceânico e Costeiro das Regiões Sul e Sudeste do Brasil. São Paulo, p.46-119, 1994. 
77. GAETA, S.A. Produção Primária na Região Oeste do Atlântico Sul. Tese de Livre Docência. Instituto Oceanográfico. São Paulo, Univ. São Paulo. 140p. 1999.

78. GAETA, S.A.; BRANDINI, F.P. Diagnóstico sobre o atual conhecimento da produção primária do fitoplâncton entre o Cabo de São Tomé (RJ) e o Chuí (RS). In: C. Rossi-Wongtschowski (ed). Ambiente oceanográfico de plataforma continental e talude das regiões sudeste e sul do Brasil. São Paulo, EDUSP, (no prelo).

79. GAETA, S.A.; METZLER, P.M.; LOPES, R.M. Plâncton e Produtividade Primária na plataforma da costa norte do Estado do Rio de JaneiroCampanha de Verão (dez/91-jan/92). Relatório do Projeto Monitoramento Oceânico da Bacia de Campos FUNDESPA/GEOMAP-PETROBRÁS, 1993.

80. GALVÃO, C.O.; VALENÇA, M.J.S. Sistemas inteligentes: aplicações a recursos hídricos e ciências ambientais. 1ed. Porto Alegre: Editora da Universidade/UFRGS/ABRH, 1999. 246 p.

81. GARCIA, C.A.E.; GARCIA, V.M.T. Bio-0optical measurements in the Southwestern Atlantic and Southern Oceans for chlorophyll-a concentration mapping from space. Ocean Optics, v.XVII, p. 1-8, 2002.

82. GARFIELD III, N. The Brazil Current at subtropical latitudes. Tese de doutorado. Rhode Island, University of Rhode Island. 121p. 1990.

83. GARVER, S. A.; SIEGEL, D. A. Inherent optical property inversion of ocean color spectra and its biogeochemical interpretation. I. Time series from the Saragasso Sea. J. Geoph. Res., v.102, p. 18607-18625, 1997.

84. GIANESELLA, S.M.F. Variabilidade da camada de clorofila máxima na região de quebra de plataforma continental sudeste brasileira. Tese de Livre-Docência. Instituto Oceanográfico. São Paulo, Univ. São Paulo. 92p. 2000.

85. GONZALEZ, A.F.; TRATHAN, P.N.; YAU, C.; RODHOUSE, P.G. Interactions between oceanography, ecology and fishery biology of the ommastrephid squid Martialia hyadesi in the South Atlantic. MARINE ECOLOGY-PROGRESS SERIES, v.152, n.1-3, p. 205-215, 1997.

86. GONZALEZ, A.G. Modelos semi-analiticos para determinar a produção primária fitoplanctônica através de sensoriamento remoto: uma aplicação a nível regional. M.Sc. Oceanografia Biológica. Rio Grande, Universidade do Rio Grande. 118p. 1994.

87. GONZALEZ, A.G. Identificação de regiões biogeoquímicas do Oceano Atlântico Sul Ocidental $\left(5^{\circ} \mathrm{N}\right.$ a $\left.45^{\circ} \mathrm{S}\right)$. Tese de Doutorado. Depto de Oceanografia. Fundação Universidade do Rio Grande. 166p. 2001.

88. GONZALEZ-RODRIGUEZ, E.; VALENTIN, J.L.; ANDRÉ, D.L.; JACOB, S.A. Upwelling and downwelling at Cabo Frio (Brazil): Comparison of biomass and primary production responses. J. Plank. Res., v.14, p. 289-306, 1992.

89. GORDON, H.R. Diffuse refelctance of the ocean: influence of non-uniform phytoplankton pigment profile. Applied Optics, v.31, p. 2116-2129, 1992. 
90. GORDON, H.R. Radiative transfer in the atmosphere for correction of ocean color remote sensing. In: V. Barale e P. M. Schlittenhardt (ed). Ocean colour: Theory and applications in a decade of CZCS Experience. Dordrecht, Kluwer Academic Publishers, p.33-77, 1993.

91. GORDON, H.R. Atmospheric correction of ocean color imagery in the Earth Observing System era. J. Geophys. Res., v.102, p. 17081-17106, 1997.

92. GORDON, H.R.; BROWN, J.W.; EVANS, R.H. Exact Reyleigh scattering calculations for use with the Nimbus-7 coastal zone color scanner. Appl. Optics, v.27, n.5, p. 862-871, 1988.

93. GORDON, H.R.; CASTANO, D.J. Aerosol analysis with the Coastal Zone Color Scanner: a simple method for including multiple scattering effects. Appl. Optics, v.28, p. 1320-1327, 1989.

94. GORDON, H.R.; CLARK, D.K. Clear water radiance for atmospheric correction of coastal zone color scanner imagery. Appl. Optics, v.20, n.24, p. 4175-4180, 1980.

95. GORDON, H.R.; MCCLUNEY, W.R. Estimation of the depth of sunlight penetration in the sea for remote sensing. Appl. Optics, v.140, p. 413-416, 1975.

96. GORDON, H.R.; MOREL, A. Remote assessment of ocean colour for interpretation of satellite visible imagery: a review. New York, SpringerVerlag, 114 p. 1983.

97. GORDON, H.R.; WANG, M. Retrieval of water-leaving radiance and aerosol optical Thickness over the oceans with SeaWiFS: a preliminary algorithm. Appl. Optics, v.33, p. 443-452, 1994.

98. GRASSHOFF, K. Methods of Sea Water Analysis. 2nd. ed. Weimhein: Verlag Chemie, 1983. 423 p.

99. GREGG, W.W.; CARDER, K.L. A simple spectral solar irradiance model for cloudless-maritime atmospheres. Limnol. Oceanogr., v.35, n.8, p. 1657-1675, 1990.

100. GROSS, L.; THIRIA, S.; FROUIN, R.; MITCHELL, B. G. Artificial neural networks for modeling the transfer function between marine reflectance and phytoplankton pigment concentration. J. Geophys. Res., v.105, n.2, p. 34833496, 2000.

101. HAIMOVICI, M. Recursos pesqueiros demersais da região sul-sudeste do Brasil. Documento inédito com subsídios para o levantamento do estado da arte dos recursos vivos marinhos do Brasil. Rio Grande, FURG Departamento de Oceanografia, 59 p. 1996.

102. HARRISON, W.G. Nitrogen utilization in chlorophyll and primary productivity maximum layers: an analysis based on the f-ratio. Mar. Ecol. Prog. Ser., v.60, p. 85-90, 1990. 
103. HASTENRATH, S.; MERLE, J. Annual cycle of the tropical Pacific atmosphere and ocean. Mon. Wea. Rev., v.110, p. 1863-1878, 1987.

104. HAYKIN, S. Neural networks: a comprehensive foundation: Ontario, Prentice Hall International, Inc., 1994. 696 p.

105. HERBLAND, A.; VOITURIEZ, B. Hydrological structure analysis for estimating the primary production in the tropical Atlantic Ocean. J. Mar. Res., v.37, p. 87$101,1979$.

106. HIDAKA, K. Oceanography of upwelling. Journal of Physical, Human and Regional Geosciences, Geoforum, v.11, n.72, p. 0-21, 1972.

107. HOLM-HANSEN, O.; LORENZEN, C.J.; HOLEMS, R.W.; STRICKLAND, J.D.H. Fluorimetric determination of chlorophyll. International council for the exploration of the sea, v.30, p. 3-15, 1965.

108. HOOKER, S.B.; ESAIAS, E.; FELDMAN, G.; GREGG, W.W.; MCCLAIN, C. An overview of SeaWiFS and ocean color, 22 p. 1992.

109. HOOKER, S.B.; FIRESTONE, E.R. SeaWiFS Postlaunch Technical Report Series, NASA Technical Memorandum 2000-106892, V.11, p. 2003.

110. HOOKER, S.B.; MIED, R.P.; BROWN, J.W.; KIRWAN, A.D. Remote sensing of dipole rings. IEEE TRANSACTIONS ON GEOSCIENCE AND REMOTE SENSING, v.35, n.6, p. 1394-1399, 1997.

111. HOWARD, K.L. Estimating global ocean primary production using satellitederived data. M.S. Thesis. Kingston, Univ. of Rhode Island 98p. 1995.

112. HOWARD, K.L.; YODER, J.A. Contribution of the subtropical oceans to global primary production. In: Space Remote Sensing of Subtropical Oceans, Proceedings. Taiwan, Pergamon Press, Oxford, 1997. p.157-168.

113. IKEDA, Y.; MIRANDA, L.B.; ROCK, N. Observations on stages of upwelling in the region of Cabo Frio (Brazil), as conducted by continuous surface temperature and salinity measurements. Bolm. Inst. oceanogr., v.23, p. 33-46, 1974.

114. IVERSON, R.L.; ESAIAS, E.; TURPIE, K. Ocean annual phytoplankton carbon and new production, and annual export production estimated with empirical equations and CZCS data. Global Change Biol., v.6, p. 57-72, 2000.

115. JASSBY, A.D.; PLATT, T. Mathematical formulation of the relationship between photosynthesis and light for phytoplankton. Limnol. Oceanogr., v.21, n.4, p. 540-547, 1976.

116. JOINT, I.; GROOM, S.B.; WOLLAST, R.; CHOU, L.; TILSTONE, G.H.; FIGUEIRAS, F.G.; LOIJENS, M.; SMYTH, T.J. The response of phytoplankton to periodic upwelling and relaxation events at the Iberian shelf break: estimates by the ${ }^{14} \mathrm{C}$ method and by satellite remote sensing. Journal of Marine Systems, v.32, p. 219-238, 2002. 
117. KAHRU, M.; MITCHELL, B.G. Empirical chlorophyll algorithm and preliminary SeaWiFS validation for the California Current. Int. J. Remote Sensing, v.20, n.17, p. 3423-3429, 1999.

118. KAMPEL, M. Caracterização dos modos principais de variabilidade dos campos de TSM no Atlântico utilizando dados AVHRR. Tese de Mestrado MSc (INPE5535-TDI/523). Sensoriamento Remoto. São José dos Campos, SP, Instituto Nacional de Pesquisas Espaciais. 111p. 1993.

119. KAMPEL, M. Os satélites NOAA. In: N. J. Ferreira (ed). Aplicações ambientais dos satélites NOAA. São José dos Campos, SP, INPE, em preparação.

120. KAMPEL, M.; LORENZZETTI, J. A.; SILVA JUNIOR, C. L. Observação por satélite de ressurgências na costa Sul-Sudeste brasileira. In: VII Congresso Latino-Americano sobre Ciências do Mar, Proceedings. Santos, SP, ALICMAR, 1997. p.38-40.

121. KAMPEL, M.; LORENZZETTI, J.A.; GAETA, S.A.; ARAUJO, C.E.; ASSIREU, A. Use of satellite data for studying and monitoring the southeast cost of Brazil. In: IX Simposio latinoamericano en percepcion remota y sistemas de informacion espacial, Proceedings. Puerto Iguazu, Missiones, Argentina, SELPER, 2000. p.1033-1044.

122. KAMPEL, M.; NOVO, E.M.L.M. Cor da água. In: R. B. Souza (ed). O sensoriamento remoto dos oceanos. São José dos Campos, SP, INPE, em preparação.

123. KARL, D.M.; DORE, J.; LUKAS, R.; MICHAELS, A.F.; BATES, N.; KNAP, A. Building the long-therm picture: The U.S. JGOFS Time-series programs. Oceanography, v.14, p. 6-17, 2001.

124. KATSURAGAWA, M. ; MATSUURA, Y. ; SUZUKI, K. ; DIAS, J.F.; SPACH, H.L. O ictioplâncton ao largo de Ubatuba, SP: composição, distribuição e ocorrência sazonal (1985-1988). Publ. esp. Inst. oceanogr., v.10, p. 85-121, 1993.

125. KEINER, L.E.; BROWN, C.W. Estimating oceanic chlorophyll concentrations with neural networks. Int. J. Remote Sens., v.20, p. 189-194, 1999.

126. KIDWELL, K.B. NOAA polar orbiter data users guide. Washington, D.C: NOAA /NESDIS /NCDC /SDSD, 1995. 260 p.

127. KIEFER, D.A.; CHAMBERLAIN, W.S. Natural fluorescence of chlorophyll a: relationship to photosynthesis and chlorophyll concentration in the Western South Pacific gyre. Limnol. Oceanogr., v.34, n.5, p. 868-881, 1989.

128. KIRK, J.T.O. Light and photosyntesis in aquatic ecosystems. 3 ed. Orlando, Florida: Academic Press, 1994.

129. KOBLENTZ-MISHKE, O.J.; VOLKOVINSKY, V.V.; KABANOBA, J.G. In: W. S. Wooster (ed). Scientific Exploration of the South Pacific. Washington, D.C., National Academy of Science, p.183-193, 1970. 
130. KOROLEFF, K. Determination of silicon. In: K. Grasshoff, M. Erhardt e K. Kremling (ed). Methods of seawater analysis. Weinhein, Verlag Chemie, p.125-139, 1983.

131. KOUSKY, V.E. Frontal influences on northeast Brazil. Mon. Wea. Rev., v.107, n.9, p. 1140-1153, 1979.

132. KOVÁCS, Z.L. Redes neurais artificiais: fundamentos e aplicações. 2 ed. São Paulo: Editora Collegium Cognitio, 1996. 174 p.

133. KURING, N.; LEWIS, M.R.; PLATT, T; O'REILLEY, J.E. Satellite-derived estimates of primary production of the northwest Atlantic continental shelf. Cont. Shelf Res., v.10, n.5, p. 461-484, 1990.

134. LALLI, C.M.; PARSONS, T.R. Biological oceanography: an introduction. Oxford: Pergamon-press, 1993. 301 p.

135. LAURS, R.M.; BRUCKS, J.T. Living marine resources applications. In: B. Saltzman (ed). Advances in Geophysics. New York, Academic Press, p.419$452,1985$.

136. LAWS, E.; DITULLIO, G.; BETZER, P.R.; HAWES, S. Primary production in the deep blue sea. Deep-Sea Res., v.37, p. 715-730, 1990.

137. LAWS, E.; SAKSHAUG, E.; BABIN, M.; DANDONNEAU, Y.; FALKOWSKI, P.; GEIDER, R.; LEGENDRE, L.; MOREL, A.; SONDERGAARD, M.; TAKAHASHI, M.; WILLIAMS, P.J. Photosynthesis and primary productivity in marine ecosystems: practical aspects and application of techniques. Bergen, Norway, International Council for Science / Scientific Committee on Oceanic Research, 89 p. 2002.

138. LEK, S.; DELACOSTE, M.; BARAN, P.; DOIMOPOLOUS, I.; LAUGA, J.; AULAGNIER, S. Application of neural networks to modelling nonlinear relationships in ecology. Ecol. Model., v.90, n.1, p. 39-52, 1996.

139. LEWIS, M.R. NASA Technical Memorandum 104566. Washington, DC: NASA, 1992. $24 \mathrm{p}$.

140. LEWIS, M.R. Coastal Zone Color Scanner on Nimbus and Sea-Viewing Wide Field of View sensor on Seastar. In: M. Ikeda e F. W. Dobson (ed).

Oceanographic Applications of remote sensing. EUA, CRC Press, p.167-181, 1995.

141. LEWIS, M.R.; CULLEN, J.J.; PLATT, T. Phytoplankton and thermal structure in the upper ocean: Consequences of nonuniformity in chlorophyll profile. $\mathbf{J}$. Geoph. Res., v.88, p. 2565-2570, 1983.

142. LIMA, I.S.D.; GARCIA, C.A.E.; MOLLER, O.O. Ocean surface process on the Southern Brazilian shelf: characterization and seasonal variability. Continental Shelf Research, v.16, n.10, p. 1307-1317, 1996. 
143. LINO, G.J.; MASCARENHAS, A.S. Sobre a propagação da Corrente das Malvinas ao longo da costa Sul do Brasil no período de 1980-1983. In: IV Congresso Brasileiro de Engenharia de Pesca, Proceedings. Curitiba, PR, 1985.

144. LOESCH, C.; SARI, S. Redes neurais artificiais: fundamentos e aplicações. Blumenau: Editora da FURB, 1996. 125 p.

145. LOMAS, M.W.; BATES, N.R.; KNAP, A.H.; KARL, D.M.; LUKAS, R.; LANDRY, M.R.; BIDIGARE, R.R.; STEINBERG, D.K.; CARLSON, C.A. Refining our understanding of oceanic biogeochemistry and ecosystem functioning. EOS Trans., v.83, n.48, p. 559-567, 2002.

146. LONGHURST, A.; SATHYENDRANATH, S.; PLATT, T.; CAVERHILL, C. An estimate of global Primary Production in the ocean from satellite radiometer data. J. Plankton Res., v.17, n.6, p. 1245-1271, 1995.

147. LONGHURST, A.R.; HARRISON, W.C. The biological pump: profiles of plankton production and consumption in the upper ocean. Prog. Oceanogr., v.22, n.47-123, 1989.

148. LORENZZETTI, J.A.; ARAUJO, C.E. Determinação da temperatura da superfície do mar (TSM) a partir dos canais termais do sensor AVHRR. In: N. J. Ferreira (ed). Aplicações ambientais dos satélites NOAA. São José dos Campos, São Paulo, INPE,, em preparação.

149. LORENZZETTI, J.A.; GAETA, S.A. The Cape Frio upwelling effect over the South Brazil Bight northern sector shelf waters: a study using AVHRR images. In: International Archives of Photogrammetry and Remote Sensing, Proceedings. Vienna, 1996. p.448-453.

150. MANN, K.H.; LAZIER, J.R.N. Dynamics of Marine Ecosystems. BiologicalPhysical Interactions in the Oceans. 2nd. ed. Dartmouth, Nova Scotia: Blackwell Science, 1996. 395 p.

151. MARITORENA, S.; O'REILLEY, J.E. Update on initial operational SeaWiFS chlorophyll a algorithm. In: S. B. Hooker e E. R. Firestone (ed). SeaWiFS postlaunch Calibration and Validation Analyses, Part 3 - NASA Tech. Memo. 2000-206892. Greenbelt, Maryland, NASA Goddar Space Flight Center,, 2000.

152. MATSUURA, Y. Contribuição ao estudo da estrutura oceanográfica da região sudeste entre o Cabo Frio (RJ) e o Cabo de Santa Marta Grande (SC). Ciência e Cultura, v.38, n.8, p. 1439-1450, 1986.

153. MATSUURA, Y. Rational utilization of coastal ecosystem in tropics: integrated investigation of coastal system in Ubatuba region. In: Simpósio de Ecossistemas da Costa Sul e Sudeste Brasileira, Proceedings. São Paulo, 1990. p.47-52. 
154. MATSUURA, Y. A probable cause of recruitment failure of the Brazilian sardine Sardinella aurita population during the 1974/75 spawning season. S. Afr. J. Mar. Sci., v.17, p. 29-35, 1996.

155. MATSUURA, Y.; KITHARA, E.M. Horizontal and vertical distribution of anchovy Engraulis anchoita eggs and larvae of Cape Santa Marta Grande in southern Brazil. Arch. Fish. Mar. Res., v.42, n.3, p. 239-250, 1995.

156. MCCLAIN, C.; ESAIAS, W.E.; BARNES, W.; GUENTHER, B.; ENDRES, D.; HOOKER, S.B.; MITCHELL, B.G.; BARNES, R. SeaWiFS calibration and validation Plan. In: S. B. Hooker e E. R. Firestone (ed). SeaWiFS Technical Report Series - NASA Technical Memorandum 104566. Washington, DC, NASA, p.43, 1992.

157. MCCLAIN, C.R.; BARNES, R.A.; EPLEE, R.E.; FRANZ, B.A.; HSU, N.C.; PATT, F.S.; PIETRAS, C.M.; ROBINSON, W.D.; SCHIEBER, B.D.; SCHMIDT, C.M.; WANG, M.; BAILEY, S.W.; WERDELL, P.J. SeaWiFS Postlaunch Calibration and Validation Analyses, Part 2. In: S. B. Hooker e E. R. Firestone (ed). NASA Tech. Memo. 2000-206892. Greenbelt, Md, NASA Goddard Space Flight Center, 2000.

158. MCCLAIN, E.P ; PICHEL, W.G.; WALTON, C.C. Comparative performance of AVHRR-based multichannel sea surface temperatures. J .Geophys. Res., v.90, n.11, p. 11587-11601, 1985.

159. MCMILLIN, L.M.; CROSBY, D.S. Theory and validation of multiple window sea surface temperature technique. J. Geophys. Res., v.89, p. 3655-3661, 1984.

160. MESQUITA, A.R.; PEREIRA FILHO, N.; LEITE, J.B.A.; RIZZO, R. Circulation and evidence of shelf break upwelling, Brazil, near lat. $\mathbf{2 6}^{\circ} 07^{\prime} \mathrm{S}$; long. 47039'W. São Paulo, Inst. Oceanogr. USP, 1-27 p. 1983.

161. METZLER, P.M. Estudo da produtividade primária e características fisiológicas do fitoplâncton na região de Ubatuba, São Paulo, através de curvas de luz fotossíntese. Dissertação de Mestrado. Instituto Oceanográfico. São Paulo, Universidade de São Paulo. 123p. 1991.

162. METZLER, P.M.; GILBERT, P.; GAETA, S.A.; LUDLAM, J.M. New and regenerated production in the South Atlantic off Brazil. Union Geod. Geoph. Inst. Monogr., v.10, p. 11-30, 1996.

163. METZLER, P.M.; GILBERT, P.M.; GAETA, S.A.; LUBLAN, J.M. New and regenerated production in the South Atlantic off Brazil. Deep-Sea Res., v.44, p. 363-384, 1997.

164. MIRANDA, L.B. Análise de massas de água da plataforma continental e da região oceânica adjacente: Cabo de São Tomé (RJ) à Ilha de São Sebastião (SP). Tese de Livre-Docência. Instituto Oceanográfico. São Paulo, Universidade de São Paulo. 194p. 1982. 
165. MIRANDA, L.B.; IKEDA, Y.; CASTRO, B.M.; FO., N. PEREIRA. Note on the occurrence of saline fronts in the Ilha Grande (RJ) region. Bolm Inst. oceanogr., v.26, n.2, p. 249-256, 1977.

166. MITCHEL, B.G.; KAHRU, M.; REYNOLDS, R.; WIELAND, J.; STRAMSKI, D.; HEWES, C.; HOLM-HANSEN, O. Evaluation of chlorophyll-a ocean color algorithms for the Southern Ocean. San Francisco, p. 2001.

167. MITCHELL, B. G.; HOLM-HANSEN, O. Bio-optical properties of Antartic Peninsula waters: Differentiation from temperate ocean models. Deep-Sea Res., Part A, v.38, p. 1009-1028, 1991.

168. MOBLEY, C.D. Light and water: radiative transfer in natural waters. San Diego: Academic Press, 1994. 592 p.

169. MONGER, B.; MCCLAIN, C.; MURTUGUUDE, R. Seasonal phytoplancton dynamics in the eastern tropical Atlantic. J. Geoph. Res., v.102, p. 12389$12411,1997$.

170. MOREIRA DA SILVA, P.C. Tentativas de determinação de um índice de produção primária pela avaliação de caracterização químicas da água em ressurgência. Publ. Inst. Pesq. Marinha, v.74, p. 1-46, 1973.

171. MOREIRA DA SILVA, P.C; RODRIGUES, R.F. Modificações na estrutura vertical das águas sobre a borda da plataforma continental por influência do vento. Nota Téc. Inst. Pesq. Mar., v.35, p. 1-13, 1966.

172. MOREL, A. In-water and remote measurements of ocean colour. Boundary Layer Meteorology, v.18, p. 177-201, 1980.

173. MOREL, A. Light and marine photosynthesis: a spectral model with geochemical and climatological implications. Prog. Oceanogr., v.26, p. 263-270, 1991.

174. MOREL, A.; ANTOINE, D.; BABIN, M.; DANDONNEAU, Y. Measured and modeled primary production in the northeast Atlantic (EUMELI JGOFS program): the impact of natural variations in photosynthetic parameters on model predictive skill. Deep-Sea Research, v.43, n.8, p. 1273-1304, 1996.

175. MOREL, A.; BERTHON, J.F. Surface pigments, algal biomass profile, and potential production of the euphotic layer: relationships reinvestigated in view of remote sensing applications. Limnol. Oceanogr., v.34, p. 1545-1562, 1989.

176. MOREL, A.; PRIEUR, L. Analysis of variations in ocean color. Limnol. Oceanogr., v.22, p. 709-722, 1977.

177. MUELLER, J.L.; LANGE, R.E. Bio-optical provinces of the Northeast Pacific Ocean: A provisional analysis. Limnol. Oceanogr., v.34, p. 1572-1586, 1989.

178. NEVILLE, R.A.; GOWER, J.R.F. Passive remote sensing of phytoplankton via chlorophyll $a$ fluorescence. J. Geoph. Res., v.82, p. 3487-3493, 1977.

179. ODEBRECHT, C.; CASTELLO, J.P. The Convergence Ecosystem in the Southwest Atlantic. In: U. S. a. B.Kjerfve (ed). Coastal Marine Ecosystems of Latin America. Berlim, Heidelberg, Springer-verlag, p.147-165, 2001. 
180. ODEBRECHT, C.; DJURFELDT, L. The role of newarshore mixing on the phytoplankton size structure off Cape Santa Marta grande, southern Brazil (spring 1989). Arch. Fish. Mar. Res., v.43, p. 13-26, 1996.

181. OLIVEIRA, A.S. Interações entre sistemas frontais na América do Sul e convecção na Amazônia. Dissertação de Mestrado. São José dos Campos, Instituto Nacional de Pesquisas Espaciais. p. 1986.

182. OLSON, D.B.; PODESTÁ, G.G.; EVANS, R.H.; BROWN, O.B. Temporal variations in the separation of Brazil and Malvinas currents. Deep-Sea Research, v.35, n.12, p. 1971-1990, 1988.

183. OMACHI, C.Y. Análise de algoritimos empíricos de concentração de clorofila para o sensor SeaWiFS na região sudoeste do Oceano Atlântico. Dissertação de Mestrado. Centro Estadual de Pesquisas em Sensoriamento Remoto e Meteorologia. Univ. Fed. Rio Grande do Sul. 98p. 1996.

184. OMACHI, C.Y.; GARCIA, C.A.E. Analysis of empirical algorithms of surface chlorophyll a for SeaWifs in the Southwestern Atlantic Ocean. Monaco, 1184 p. 2000.

185. ONDRUSEK, M.E.; BIDIGARE, R.R.; WATERS, K.; KARL, D.M. A predictive model for estimating rates of primary production in the subtropical North Pacific Ocean. Deep-Sea Res. II, v.48, p. 1837-1863, 2001.

186. O'REILLY, J. E.; MARITORENA, S.; MITCHELL, B. G.; SIEGEL, D. A.; CARDER, K. L.; GARVER, S. A.; MCCLAIN, C. R. Ocean color chlorophyll algorithms for SeaWIFS. J. Geophys. Res., v.103, p. 24937-24953, 1998.

187. O'REILLY, J. E.; MARITORENA, S.; O'BRIEN, M. C.; SIEGEL, D. A.; TOOLE, D.; MENZIES, D.; SMITH, R. C.; MUELLER, J. L.; MITCHELL, B. G.; KAHRU, M.; CHAVEZ, R. P.; STRUTTON, P.; COTA, G. F.; HOOKER, S.B.; MCCLAIN, C.R.; CARDER, K. L.; MUELLER-KARGER, F.; HARDING, L.; MAGNUSION, A.; PHYNNEY, D.; MOORE, G.F.; AIKEN, J.; ARRIGO, K.R.; LETELIER, R.; CULVER, M. SeaWiFS Postlaunch Calibration and Validation Analyses, Part 3, Volume 11. In: S. B. Hooker e E. R. Firestone (ed). NASA Tech. Memo. 2000-2206892. Greenbelt, Md, NASA Goddard Space Flight Center, 2000.

188. OSGOOD, K.E.; BANE, J.M.; DEWAR, W.K. Vertical velocities and dynamical balances in the Gulf Stream meanders. J. Geophys. Res., v.92, p. 13029-13040, 1987.

189. PAIVA, M. P. Recursos pesqueiros estuarinos e marinhos do Brasil. EUFC Edições, Fortaleza,1997. 278 p.

190. PALTRIDGE, G.W.; PLATT, M.R. Radiative processes in meteorology and climatology: Elsevier, 1976.

191. PARANHOS, R. Alguns métodos para análise da água. Rio de Janeiro: UFRJ, 1996. $281 \mathrm{p}$. 
192. PAULY, D.; CHRISTENSEN, V. Primary production required to sustain global fisheries. Nature, v.374, p. 255-257, 1995.

193. PELÁEZ, J.; MCGOWAN, J.A. Phytoplankton pigment patterns in the California Current as determined by satellite. Limnol. Oceanogr., v.31, n.5, p. 927-950, 1986.

194. PETERSON, R.G.; STRAMMA, L. Upper-level circulation in the South Atlantic ocean. Progress in Oceanography, v.26, p. 1-73, 1991.

195. PIOLA, A.R.; CAMPOS, E.J.D.; MOLLER O.O.; CAHRO, M.; MARTINEZ, M. Continental shelf water masses of eastern South America $-20^{\circ}$ to $40^{\circ} \mathrm{S}$. In: 10th Symposium on Global Change Studies, Proceedings. Dallas, Texas, USA, American Meteorological Society, 1999.

196. PIOLA, A.R.; CAMPOS, E.J.D.; MOLLER, O.O.; CHARO, M.; MARTINEZ, C. The subtropical shelf front off eastern South America. Journal of Geophysical Research, v.105, n.C3, p. 6565-6578, 2000.

197. PLATT, T.; BIRD, D.F.; SATHYENDRANATH, S. Critical depth and marine primary production. Proceedings of the Royal Society. London. Series B, v.246, p. 205-217, 1991.

198. PLATT, T.; GALLEGOS, C.L.; HARRISON, W.G. Photoinhibition of photosynthesis in natural assemblages of marine phytoplankton. J. Mar. Res., v.38, p. 687-701, 1980.

199. PLATT, T.; JASBY, A.D. The relationship between photosynthesis and light for natural assemblages of coastal marine phytoplankton. Jounal of Phycology, v.12, p. 412-430, 1976.

200. PLATT, T.; SATHYENDRANATH, S. Oceanic primary production: estimation by remote sensing at local and regional scales. Science, v.241, p. 1613, 1988.

201. PLATT, T.; SATHYENDRANATH, S. Biological production models as elements of coupled atmosphere-ocean models for climate research. J. Geoph. Res., v.96, p. 2585-2592, 1991.

202. PLATT, T.; SATHYENDRANATH, S. Estimators of primary production for interpretation of remotely sensed data on ocean color. J. Geophys. Res., v.98, n.C8, p. 14.561-14.576, 1993.

203. PLATT, T.; SATHYENDRANATH, S. Modelling marine primary production. Halifax, Nova Scotia, 2002. 280 p.

204. PLATT, T.; SATHYENDRANATH, S.; CAVERHILL, C.M.; LEWIS, M.R. Ocean primary production and available light: further algorithms for remote sensing. Deep-Sea Res. I, v.35, p. 855-879, 1988a.

205. PLATT, T.; SATHYENDRANATH, S.; CAVERHILL, C.M.; LEWIS, M.R. Oceanic primary production and available light: further algorithms for remote sensing. Deep-Sea Res., v.35, n.6, p. 855-879, 1988 b. 
206. PLATT, T.; SATHYENDRANATH, S.; LONGHURST, A. Remote sensing of primary production in the ocean - promise and fulfillment. Philosophical Transactions of the Royal Society of London Series B: Biological Sciences, v.348, p. 191-201, 1995.

207. PLATT, T.; SATHYENDRANATH, S.; RAVINDRAN, P. Primary production by phytoplankton: analytic solutions for daily rates per unit area of water surface.

Proc. R. Soc. Lond. Ser. B, v.B 241, p. 101-111, 1990.

208. PLATT, T.; SATHYENDRANATH, S.; WHITE III, G.N.; RAVINDRAN, P. Attenuation of visible light by phytoplankton in a vertically-structured ocean: Solutions and applications. Journal of Plankton Research, v.16, p. 1461-1487, 1994.

209. POND, S.; PICKARD, G. Introductory Dynamical Oceanography: Pergamon Press, 1983. 329 p.

210. POOLE, H.H. ; ATKINS, W.R.G. Photo-electric measurements of submarine illumination throughout the year. J. Mar. Biol. Assoc. U.K., v.16, p. 297-324, 1929.

211. PREISENDORFER, R.W. Hydrologic optics. Vol. I. Introduction. Honololu: U.S. Department of Commerce National Oceanic and Atmospheric Administration, Environmental Resarch Laboratory, 1976. 218 p.

212. REID, J.L. On the total geostrophic circulation of the South Atlantic Ocean: flow patterns, tracers and transports. Progress in Oceanography, v.23, p. 149-244, 1989.

213. RODRIGUES, R.R.; LORENZZETTI, J.A. A numerical study of the effects of bottom topography and coastline geometry on the Southeast Brazilian coastal upwelling. Cont. Shelf. Res., v.21, n.4, p. 371-394, 2001.

214. RUMELHART, D.E.; HINTON, G.E.; WILLIAMS, R.J. Learning representations by back-propagating errors. Nature, v.323, p. 533-536, 1986.

215. RYTHER, J.H.; DUNSTAN, W.M. Nitrogen, phosphorus and eutrophication in the coastal marine environment. Science, v.171, p. 1008-1013, 1971.

216. RYTHER, J.H.; YENTSCH, C.S. The estimation of phytoplankton production in the ocean from chlorophyll and light data. Limnol. Oceanogr., v.2, p. 281-286, 1957.

217. SALDANHA, F.M.P. Simulação da mistura vertical de massas d'água da região de Ubatuba (SP), efeitos sobre a produção primária e biomassa fitoplanctônica. Dissertação de Mestrado. Instituto Oceanográfico. São Paulo, Universidade de São Paulo. p. 1993.

218. SAMUELS, B. ; COX, M. Data set atlas for ocean modeling. Ocean Modeling, v.75, p. 1-3, 1987. 
219. SANTAMARIA-DEL-ANGEL, E.; ALAVAREZ-BORREGO, S.; MÜLLERKARGER, F.E. Gulf of California biogeographics regions based on coastal zone color scanner imagery. J. Geoph. Res., v.99, p. 7411-7422, 1994.

220. SATHYENDRANATH, S.; LONGHURST, A.; CAVERHILL, C.; PLATT, T. Regionally and seasonally differentiated primary production in the North Atlantic. Deep-Sea Res., v.I, n.42, p. 1773-1802, 1995.

221. SATHYENDRANATH, S.; MOREL, A. Light emerging from the sea interpretation and uses in remote sensing. In: A. P. e. Cracknell (ed). Remote sensing applications in marine science and technology. Dordrecht, D. Reidel Publishing Company, p.323-357, 1983.

222. SATHYENDRANATH, S.; PLATT, T. The spectral irradiance field at the surface and in the interior of the Ocean: a model for applications in Oceanography and Remote Sensing. J. Geoph. Res., v.93, p. 9270-9280, 1988.

223. SATHYENDRANATH, S.; PLATT, T. Remote sensing of ocean chlorophyll: consequence of nonuniform pigment profile. Appl. Optics, v.28, p. 490-495, 1989.

224. SATHYENDRANATH, S.; PLATT, T.; CAVERHILL, C.; WARNOCK, R.E.; LEWIS, M.R. Remote sensing of Oceanic production: Computations using a spectral model. Deep-Sea Res., v.36, p. 431-453, 1989.

225. SCARDI, M. Artificial neural network as empirical models of phytoplankton production. Mar. Ecol. Prog. Ser., v.139, p. 289-299, 1996.

226. SCARDI, M.; HARDING JR, L.W. Developing an empirical model of phytoplankton primary production: a neural network case study. Ecological Modelling, v.120, p. 213-223, 1999.

227. SCHILLER, H.; DOERFFER, R. Neural network for emulation of an inverse model-operational derivation of case II propertites from MERIS data. Int. J. Remote Sens., v.20, p. 1735-1746, 1998.

228. SCHLUESSEL, P.; EMERGY, W.J.; GRASSI, H.; MAMMEN, T. On the bulkskin temperature difference and its impact on satellite remote sensing of sea surface temperature. J. Geophys. Res., v.95, n.C8, p. 13341-13356, 1990.

229. SHANNON, L.V.; FIELD, J.G. Are fish stocks food-limited in the southern Benguela pelagic ecosystem? Marine Ecoogy Progress Series, v.22, p. 7-19, 1985.

230. SHOAF, W.T.; LIUM, B.W. Improved extraction of chlorophyll a and b from algae using dimethyl sulfoxide. Limnol. Oceanogr., v.21, p. 926-928, 1976.

231. SIEGEL, D. A.; WESTBERRY, T.K.; O'BRIEN, M.C.; NELSON, N.B.; MICHAELS, A.F.; MORRISSON, J.R.; SCOTT, A.; CAPORELLI, E.A.; SORENSEN, J.C.; MARITORENA, S.; GARVER, S.A.; BRODY, E.A.; UBANTE, J.; HAMMER, M.A. Bio-optical modeling of primary production on regional scales: the Bermuda BioOptics project. Deep-Sea Res.II, v.48, p. 18651896, 2001. 
232. SIGNORINI, S.R. On the circulation and volume transport of the Brazil Current between the Cape of São Tomé and Guanabara Bay. Deep-Sea Res., v.25, p. 481-490, 1978.

233. SILVA JR, C.L.; KAMPEL, M. Observação da penetração do ramo costeiro da corrente das Malvinas na costa sul-sudeste do Brasil a partir de imagens AVHRR. In: VIII Simpósio Brasileiro de Sensoriamento Remoto, Proceedings. Salvador, BA, INPE, 1996.

234. SILVA JR, C.L.; KAMPEL, M.; ARAUJO, C.E. Utilização de imagens AVHRR/NOAA na avaliação da extensão da ressurgência costeira de Cabo Frio: estudo de caso. In: VII Congresso Latino-Americano sobre Ciências do Mar, Proceedings. Santos, SP, ALICMAR, 1997. p.445-446.

235. SILVA, L.C.F.; ALVARENGA, J.B.R. Oceanografia Física - Região Sul: Levantamento do estado da arte da pesquisa dos recursos vivos marinhos do Brasil. Programa REVIZEE. São Paulo, MMA, 98 p. 1996.

236. SILVEIRA, I.C.A.; MIRANDA, L.B.; BROWN, W. S. On the origin of the North Brazil Current. J .Geophys. Res., v.99, n.C11, p. 22501-22512, 1994.

237. SILVEIRA, I.C.A.; SCHMIDT, A.C.; CAMPOS, E.D.; GODOI, S.S.; IKEDA, Y. A Corrente do Brasil ao largo da costa Leste brasileira. Revista Brasileira de Oceanografia, v.48, n.2, p. 171-183, 2000.

238. SILVERA, A.G.G. Identificação de regiões biogeoquímicas do Oc. Atlântico Sul Ocidental $\left(5^{\circ} \mathrm{N} \mathrm{a} 45^{\circ} \mathrm{S}\right)$. Doutorado. Oceanografia Biológica. Rio Grande, Fundação Universidade Federal do Rio Grande. 166p. 2001.

239. SMITH, R.C.; BAKER, K.S. The bio-optical state of ocean waters and remote sensing. Limnol. Ocenogr., v.23, n.2, p. 247-259, 1978.

240. SMITH, R.C.; EPPLEY, R.W.; BAKER, K.S. Correlation of primary production as measured aboard ship in Southern California coastal waters and as estimated from satellite chlorophyll images. Mar. Biol., v.66, p. 281-288, 1982.

241. SMITH, R.L. Upwelling Oceanogr. Mar. Biol. Ann. Ver, n.6, p. 11-46, 1968.

242. SOUZA, M.C.A. A Corrente do Brasil ao largo de Santos: medições diretas. Dissertação de Mestrado. Instituto Oceanográfico. São Paulo, Universidade de São Paulo. 169p. 2000a.

243. SOUZA, R.B. Satellite and lagrangian observations of mesoscale surface processes in the Southwestern Atlantic Ocean. Doctor of Philosophy. Faculty of Science Oceanography. Southampton, University of Southampton. 238p. 2000 b.

244. STEEMAN-NIELSEN, E. The use of radio-active carbon (14C) for measuring organic production in the sea. J. Cons. Explor. Mer., v.18, p. 117-140, 1952.

245. STEVENSON, M.R.; BRITO-DIAS, D.; STECH, J.L.; KAMPEL, M. How do cold water biota arrive in a tropical bay near Rio de Janeiro, Brazil. Continental Shelf Research, v.18, p. 1595-1612, 1998. 
246. STOMMEL, H. A survey of ocean current theory. Deep Sea Res., v.4, p. 149-184, 1957.

247. STRAMMA, L. Geostrophic transport of the South Equatorial Current in the Atlantic. J. Mar. Res., v.49, p. 281-294, 1991.

248. STRAMMA, L.; IKEDA, Y.; PETERSON, R.G. Geostrophic transport in the Brazil Current region. Deep-Sea. Res., v.37, n.12, p. 1875-1886, 1990.

249. STRAMSKI, D.; MOREL, A. Optical properties of photosynthetic phytoplankton in different physiological states as affected by growth irradiance. Deep-Sea Res., v.37, p. 245-266, 1990.

250. STRICKLAND, J.D.; PARSONS, T.R. A practical handbook of sewater analysis. J. Fish Res. Bd. Can. Bull., v.167, p. 311, 1972.

251. STRONG, A.E. ; MCCLAIN, E.P. Improved ocean surface temperatures from space - comparisons with drifting buoys. Bulletin American Meteorological Society, v.65, n.2, p. 138-142, 1984.

252. STÜRM, B. CZCS data processing algorithms. In: V. Barale e P. M. Schlliterhardt (ed). Ocean colour: theory and applications in a decade of CZCS experience. Dordrecht, Kluwer Academic Publishers, p.95-116, 1993.

253. TAKAHASHI, A.T.; BARTH, R. Estudos sobre produtividade primária em nanoplâncton por 14C na Corrente do Brasil. Notas Técnicas do Inst. Pesq. Mar., v.10, n.1-12, 1968.

254. TEIXEIRA, C. Introdução aos métodos para medir a produção primária do fitoplâncton marinho. Bolm Inst. oceanogr., v.22, p. 59-92, 1973.

255. THIRIA, S.; MEJIA, C.; BADRAN, F.; CREPON, M. A neural network approach for modeling nonlinear transfer functions: Application for wind retrieval from spaceborn scatteromer data. J .Geophys. Res., v.98, p. 22-827 a 22-841, 1993.

256. TOPLISS, B.J.; PLATT, T. Passive fluorescence and photosynthesis in the ocean: implications for remote sensing. Deep-Sea Res. I, v.33, p. 849-864, 1986.

257. UNESCO. Progress on oceanographic tables and standards: work and recommendations of the UNESCO/SCOR/ICES/IAPSO Joint Panel.: Unesco technical papers in marine science 50, 1988.

258. VALENTIN, J.L. A dinâmica do plâncton na ressurgência de Cabo Frio - RJ. In: III Encontro Brasileiro de Plâncton, Proceedings. Caiobá - PR, Fundação da Universidade Federal do Paraná, 1989. p.26-35.

259. VALENTIN, J.L. A ressurgência: fonte de vida dos oceanos. Ciência Hoje, v.18, n.102, p. 18-25, 1994.

260. VELHOTE, D. Modelagem numérica da ressurgência da quebra de plataforma induzida por vórtices ciclônicos da Corrente do Brasil na Bacia de Santos. MSc. Instituto Oceanográfico. São Paulo, Universidade de São Paulo. 134p. 1998. 
261. WANG, M. The SeaWiFS atmospheric correction algorithm updates. In: S. B. Hooker e E. R. Firestone (ed). NASA Tech. Memom. 2000-2006892.

Greenbeld, Maryland, NASA Goddard Space Flight Center, p.57-63, 2000.

262. WELSHMEYER, N.A. Fluorometric analysis of chlorophyll a in the presence of chlorophyll b and pheopigments. Limnol. Oceanogr., v.39, p. 1985-1992, 1994.

263. YODER, J.A.; MCCLAIN, C.; FELDMAN, G.C.; ESAIAS, W. Global Biogeochemical Cycles, v.7, n.181, 1983.

264. YONESHIGUE-BRAGA, Y.; MAESTRINI, S.Y.; GONZALEZ RODRIGUEZ, E. Fertilité et facteurs nutritionnels limitant la croissance des producteurs des eaux dee 1'upwelling the Cabo Frio (Brésil). Étudee préliminaire. C. R. Acad. Sc. Paris, v.288, p. 135-138, 1979.

265. ZEMBRUSKI, S.G. Geomorfologia da margem continental sul brasileira e das bacias oceânicas adjacentes. In: H. A. F. Chaves (ed). Rio de Janeiro, Petrobrás, 1979. 